\title{
The geomorphic significance of hurricanes on coral-fringed calcium carbonate coastlines: Hurricane Wilma 15-25 October 2005, northeastern Yucatan Peninsula, Mexico
}

\author{
Nicholas Paul Everett Mulcahy
}

A thesis submitted to Victoria University of Wellington as partial fulfilment of the requirements for the degree of Master of Science with Honours in Physical Geography

School of Geography, Environment and Earth Sciences

Victoria University of Wellington 


\section{Frontispiece}

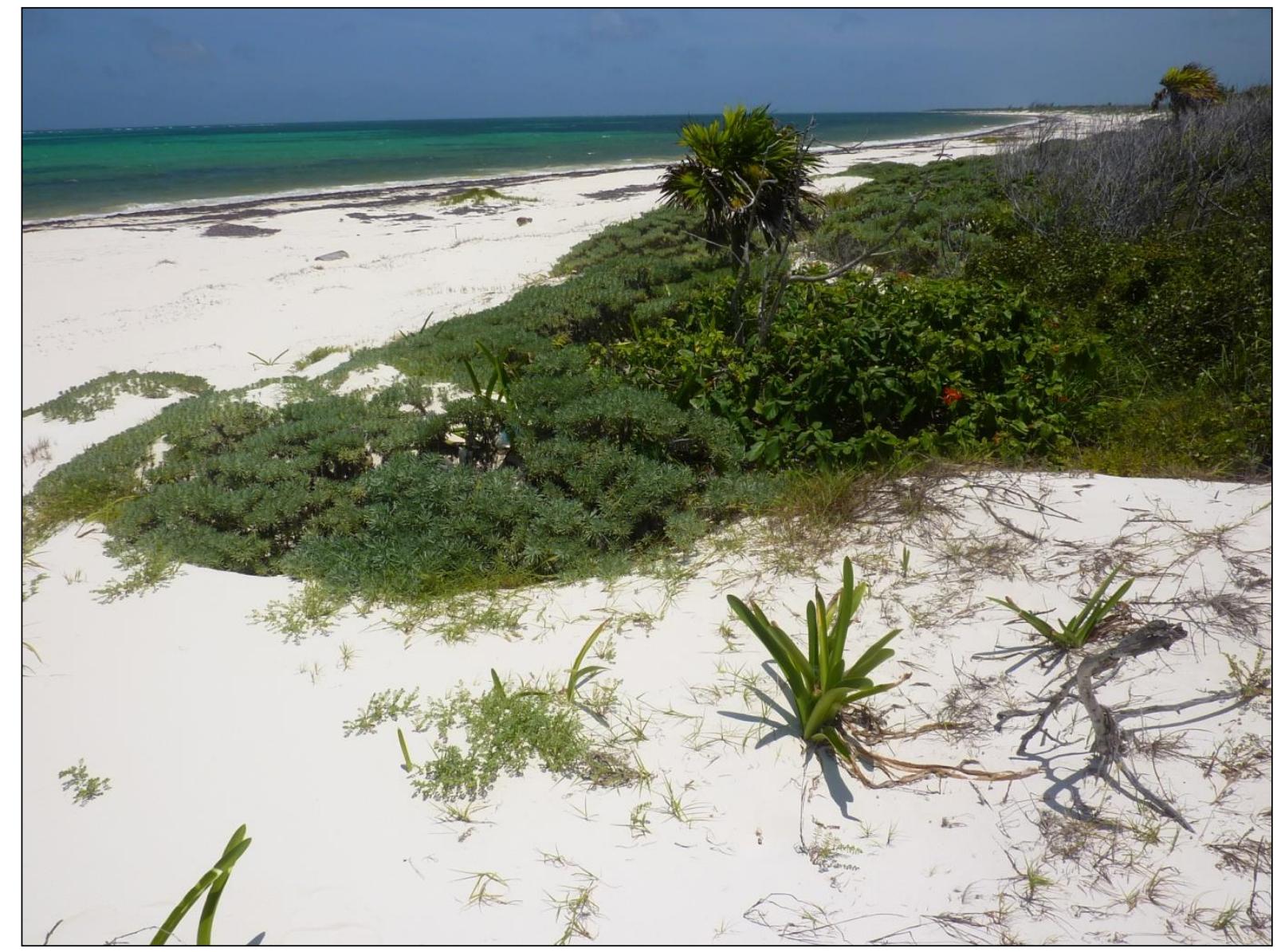

Reef-protected barrier beach, Punta Tanchacte, northeastern Yucatan Peninsula, Mexico

\section{Dedication}

This thesis is dedicated to the memories of my late grandfathers: Kevin Mulcahy and Maurice Cave, who both passed away during the course of my university studies. 


\begin{abstract}
Hurricanes and tropical storms can cause large scale morphological changes to barrier beach systems in tropical environments. Many such systems are fronted by coral reefs; however, unlike siliciclastic barrier beaches, little is known about the significance of hurricanes to barrier beach evolution on coral-fringed calcium carbonate coastlines. This study provides a detailed assessment of the impacts of Hurricane Wilma, a major hurricane, on the reefprotected and exposed barrier beaches of northeastern Yucatan Peninsula, Mexico. The study considers both the short (0-8 months) and medium term (8-56 months) response, and postulates the significance of major storm events over the longer term.

Hurricane Wilma made landfall in late October 2005 as a Category 4 hurricane, bringing sustained wind speeds of $67 \mathrm{~ms}^{-1}$, and storm waves with significant wave heights $\left(H_{s}\right) \approx 13$ $\mathrm{m}$. The storm persisted for over 20 hours, while storm waves inundated the low lying barrier beaches and rainfall flooded inland wetlands and lagoons.

To determine the impacts of Hurricane Wilma and quantify post-storm recovery of reefprotected and unprotected barrier beaches, geomorphic mapping and post-storm surveying (2006 and 2010) was completed at 49 locations between Punta Nizuc and Punta Maroma. In addition, 220 sediment samples were collected from across barrier beaches and the backreef lagoon for textural and petrographic analysis. Satellite imagery was also used to quantify immediate storm impacts and recovery of the shoreline.

Barrier beaches were found to have responded to storm waves in two broadly different ways: reef-protected beaches accreted by between 2.1 and $24.6 \mathrm{~m}$, as the beach and foredunes were reworked. In contrast, unprotected beaches underwent erosion of over 10 m. By 2006, reef-protected beaches had undergone rapid shoreface and beachface adjustment. Over the next four years, these beaches gradually transgressed landwards and aggraded subaerially as they readjusted to their pre-storm equilibrium beach profile. Exposed beaches responded much more rapidly than those protected by reefs, with shoreline adjustment occurring within eight months of the storm. Subaerial beach development was, however, much slower, requiring extended calm conditions to infill the eroded beach. The storm and post storm geomorphic responses were found to be highly
\end{abstract}


variable alongshore, and influenced by several factors, including dune height, beach width, and wave exposure.

The results indicate that under the contemporary climatic conditions hurricanes are key drivers of barrier beach evolution over the short (0-8 months) to medium terms (8-56 months), but are not so influential over longer time scales. However, an expected increase in the number of major storms (category 3-5) in the future may increase the significance of hurricanes to longer term barrier evolution, with the storm impacts likely to be greater and the recovery times longer. Understanding these responses is particularly critical as many areas continue to be developed, and as the coral reef protecting the coastline becomes threatened by the implications of climatic change. 


\section{Acknowledgements}

Firstly I would like to thank my supervisors Dr David Kennedy (School of Land and Environment, The University of Melbourne), Dr Paul Blanchon (Institute of Marine Sciences and Limnology, National Autonomous University of Mexico), and Professor Rewi Newnham (School of Geography Environment and Earth Sciences, Victoria University of Wellington). Your guidance and encouragement through this process was greatly appreciated.

Secondly, I wish to thank the Mexican Government for their support of this research through a grant received from Project 23749 of the 'Consejo Nacional de Ciencia y Technologia' (CONACYT), administered by Dr Paul Blanchon. Thank you to the staff and students at the Reef Systems Unit, Institute of Marine Sciences and Limnology, Puerto Morelos, in particular, Dr Paul Blanchon, Marian Graco, and Javier Humberto Echavarria, for their assistance in the field, and Amouri, for providing transportation to many of the field sites. Thanks must also go to Dr David Kennedy for passing on his expertise in the field, and to Felipe, Paloma and Germán, who provided great assistance in the field, as language barriers were overcome. Rene Garcia Montero provided beach access through Moon Palace Golf and Spa Resort, and also provided transportation which was much appreciated.

Dr David Kennedy, Dr Paul Blanchon, and Miguel Sócrates Ibarra Fernández are recognised for collecting the sediment samples in May 2006 following Hurricane Wilma, and Pierre Leplatois and Rejane Georgeault for conducting the initial post-storm across-shore beach profiles in June 2006.

Thank you to the staff and students in the School of Geography, Environment, and Earth Sciences, Victoria University of Wellington, in particular Dr David Kennedy, (late) Dr Nicholas Preston, Professor Michael Crozier and Dr Bethanna Jackson, for helping to develop my skills and passion as a geomorphologist. I wish to thank Stuart Bush for his assistance in the preparation of thin sections, and Ashley Pockock, Josephine Woods, Sam Mulcahy and James Brigham-Watson for their assistance in the lab. Dr David Kennedy and Hamish Mckoy provided assistance in identifying sediment constituents. Thanks must go to Meagan Lowe, Deb Maxwell, Hamish McKoy, Elyse Robert and James Mulcahy, who assisted with thesis proofing, Beth Risdon for some data entry, and to Will Reis, Katrin Sattler and Andrew Rae for assistance with geographic information systems. 
I wish to thank the School of Land and Environment, The University of Melbourne, for allowing me to use their Coastal Lab during my visits, and to the staff and postgraduate students for welcoming me. Particular thanks to Dr David Kennedy and Josephine Woods for accommodating me during my visits to Melbourne to discuss this project.

I would like to thank my colleagues at Surf Life Saving New Zealand, in particular my manager Brett Sullivan, for his support and encouragement as I completed my thesis whilst working for this organisation. I would particularly like to thank them for the opportunity to combine my understanding of coastal geomorphology with aquatic risk management, and drowning and injury prevention research.

Finally, I wish to thank all of my family and friends for their support during this testing, but immensely rewarding experience. In particular, I would like to thank my parents James and Mary Mulcahy who have supported me throughout this process and to Alex Mulcahy and Julia Burke for their support towards the end of my thesis. Lastly, thank you to my partner Meagan Lowe for her unfailing support and encouragement. 


\section{Table of Contents}

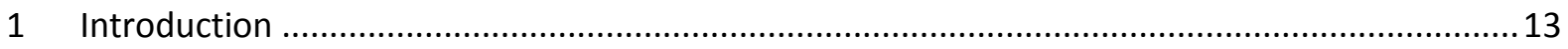

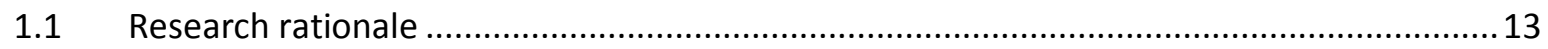

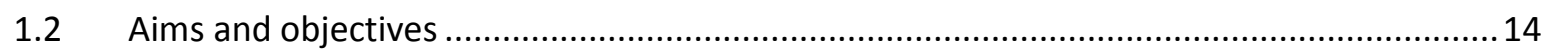

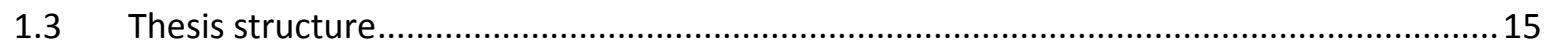

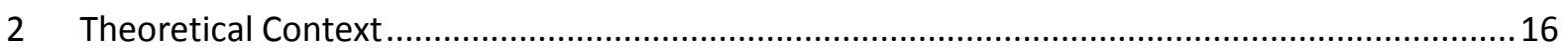

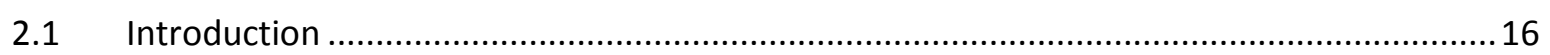

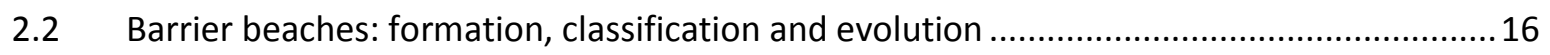

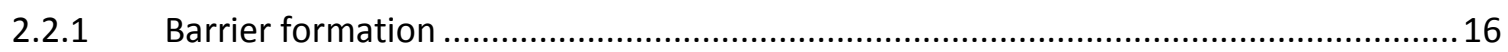

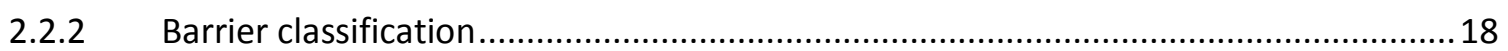

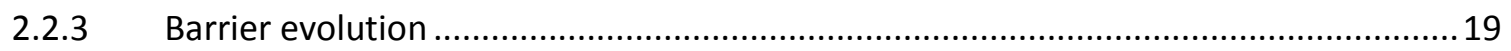

2.3 Coral fringed coasts: geomorphology \& sedimentary dynamics ........................................... 22

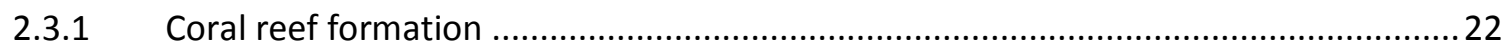

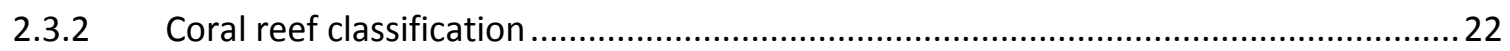

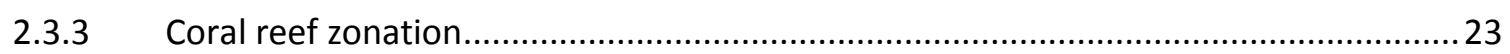

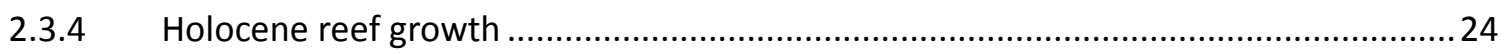

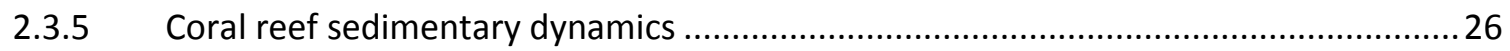

2.3.6 Chemical transformation of sediment: micritisation and cementation ........................29

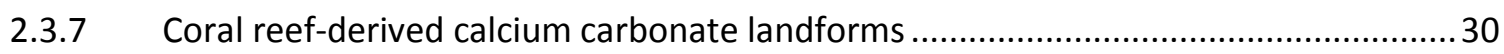

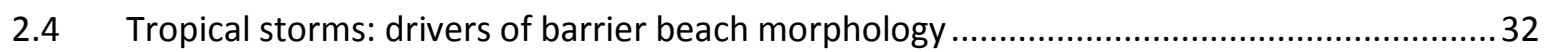

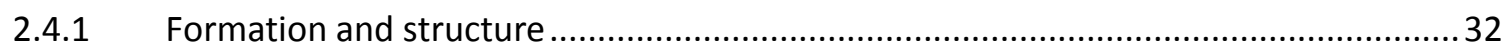

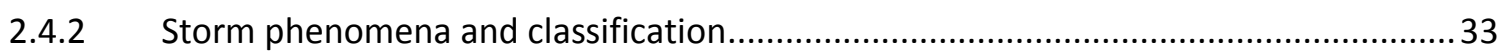

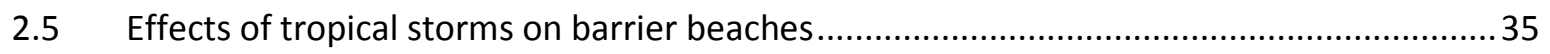

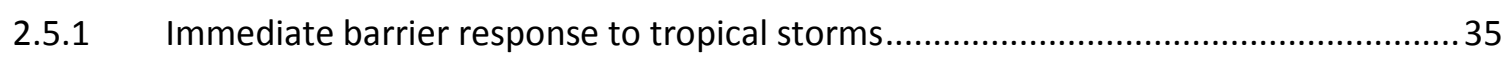

2.5.2 Determinants on barrier beach response to tropical storms ....................................... 38

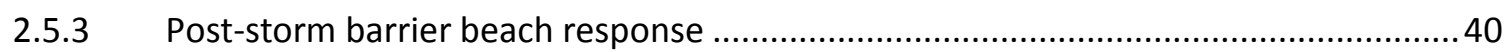

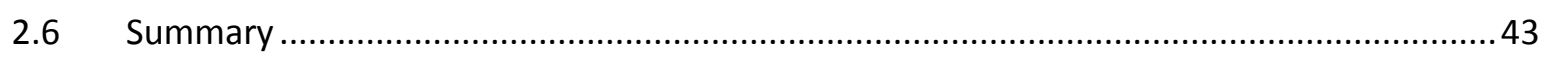

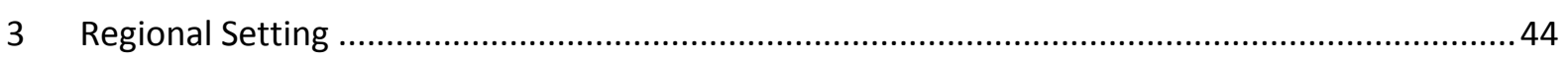

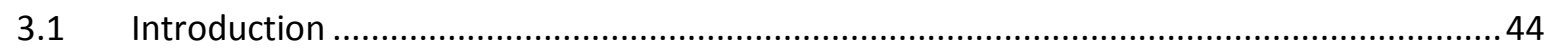

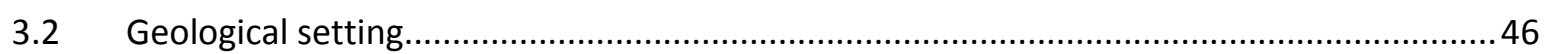

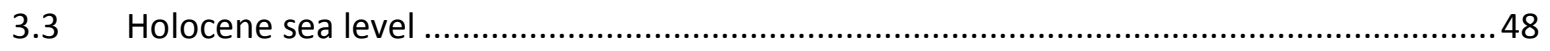

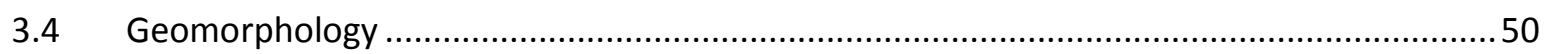

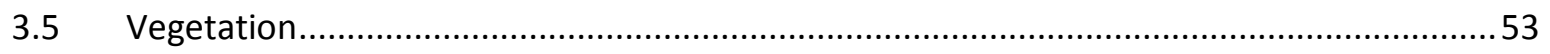

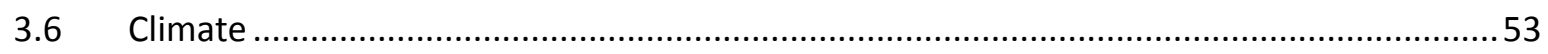




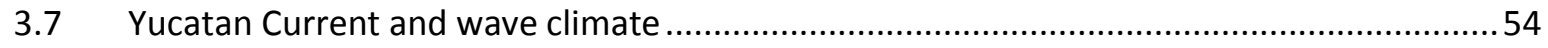

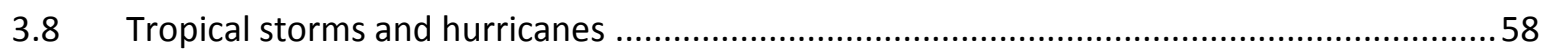

3.8.1 Northeastern Yucatan Peninsula storm profile ....................................................... 59

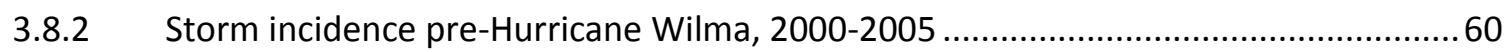

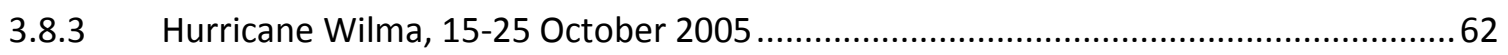

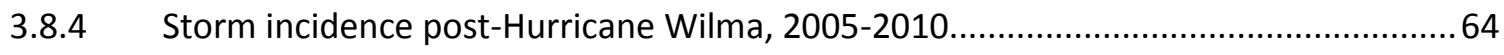

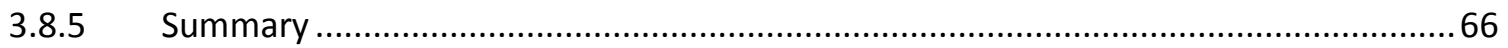

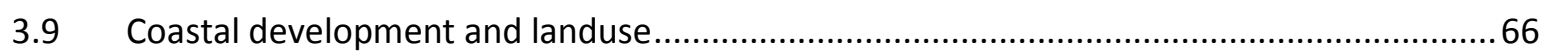

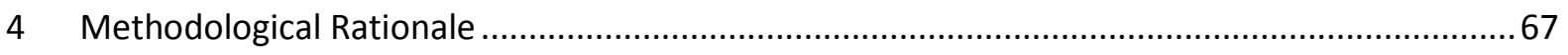

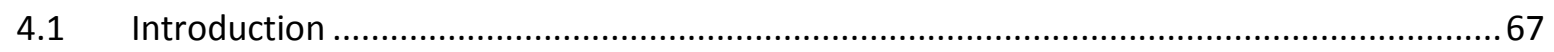

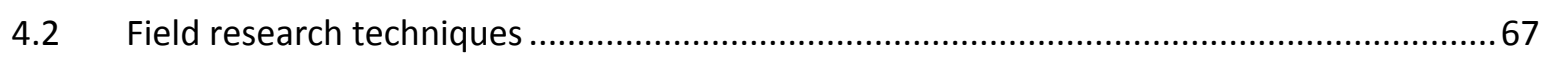

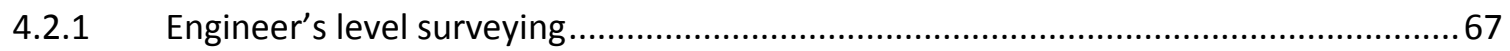

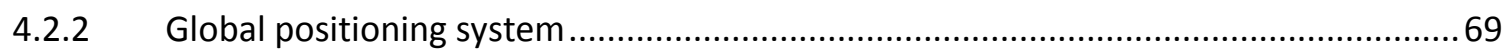

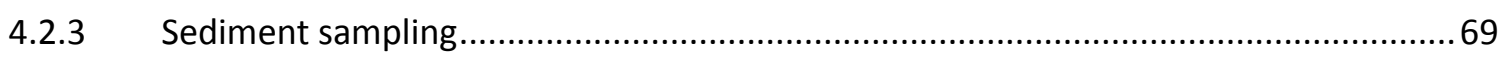

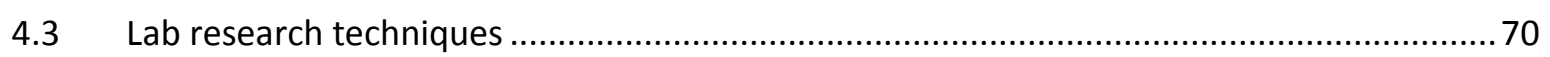

4.3.1 Engineers level survey: data processing .............................................................. 70

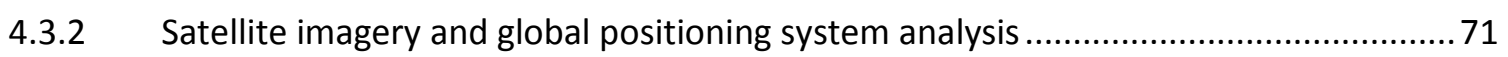

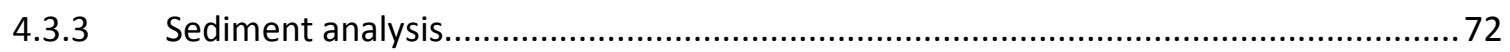

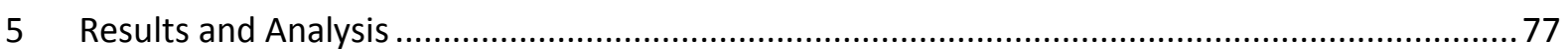

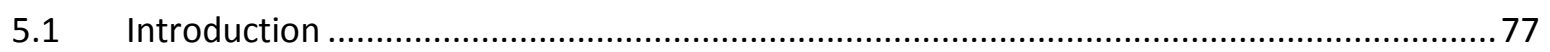

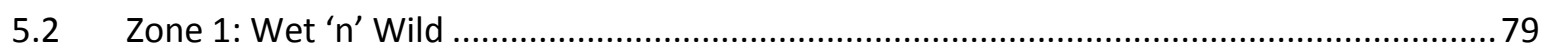

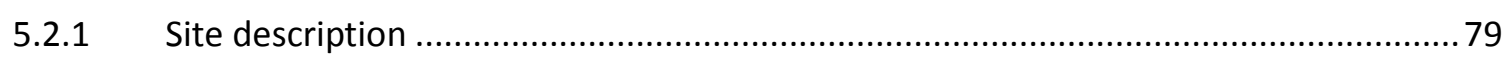

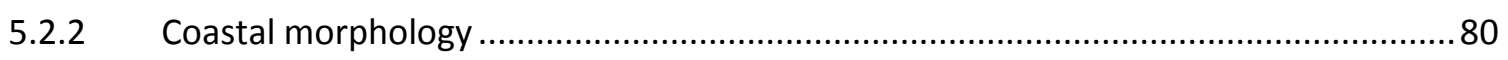

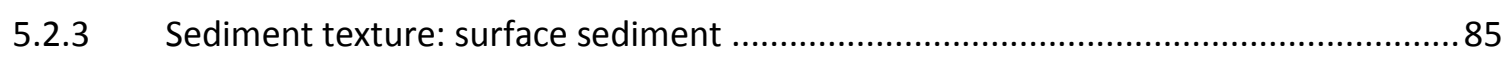

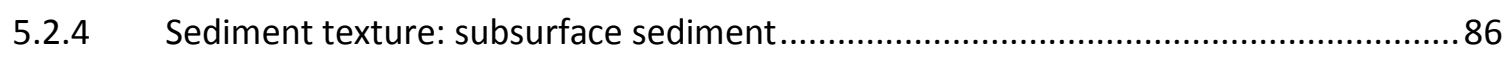

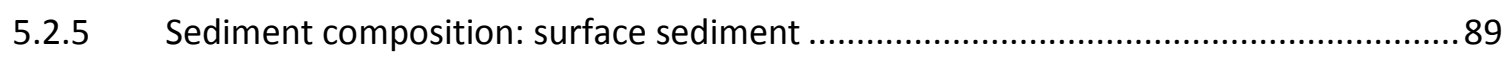

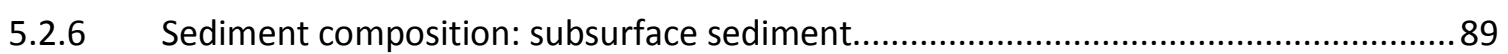

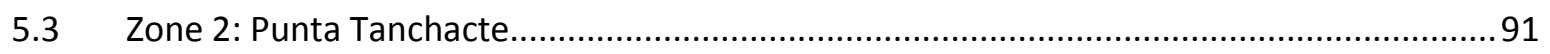

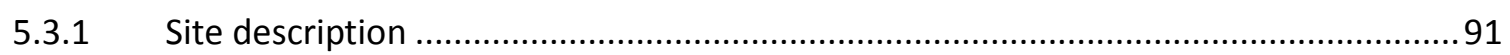

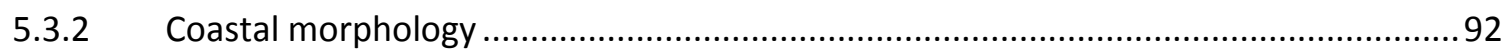

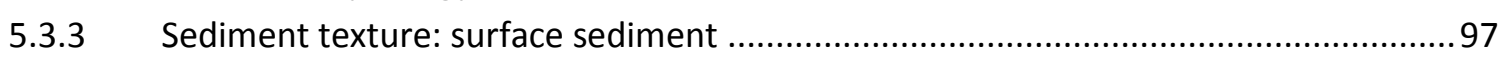

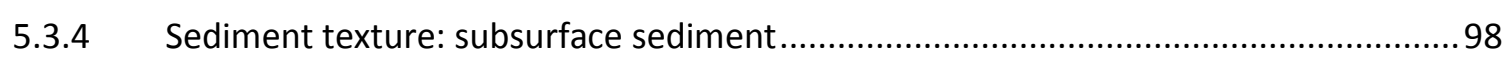

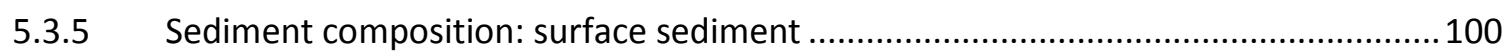

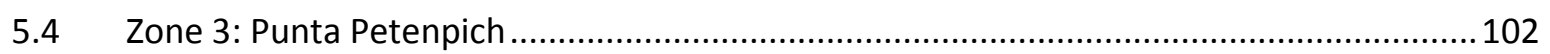

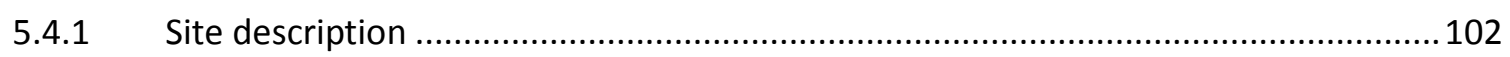

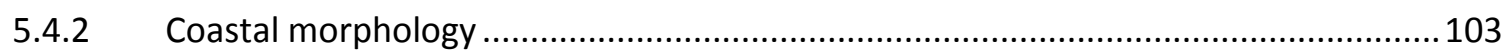

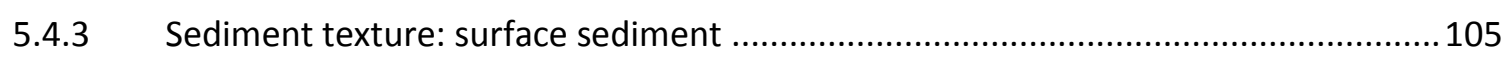

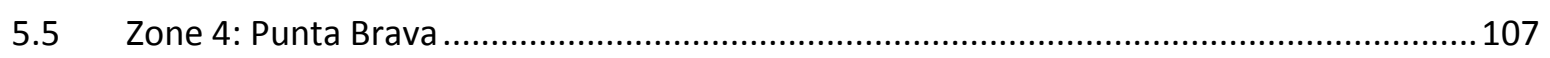

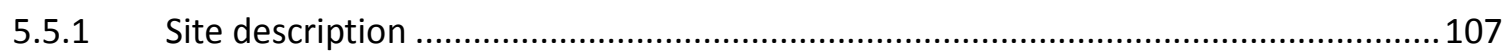

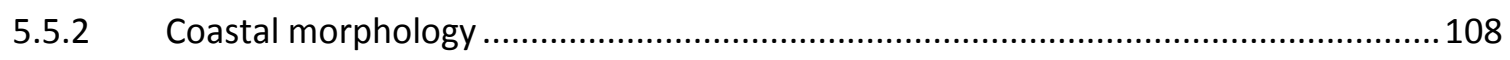

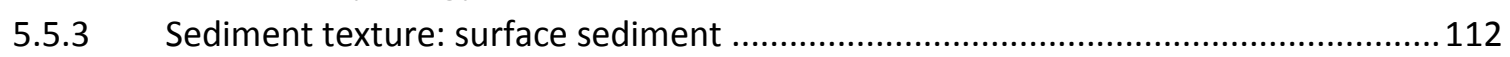

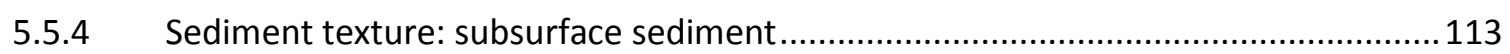

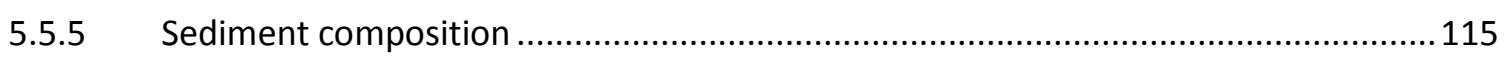

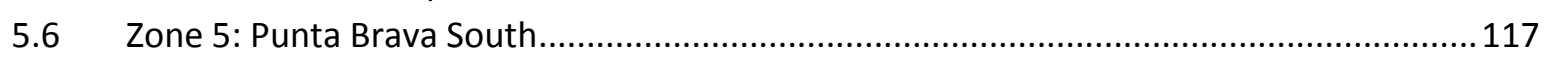

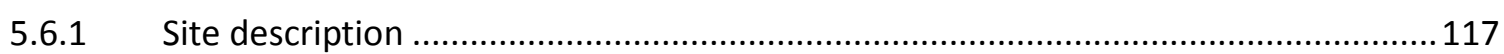




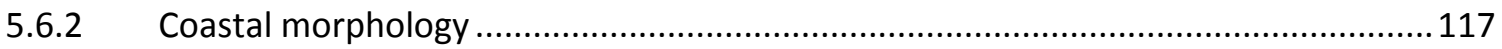

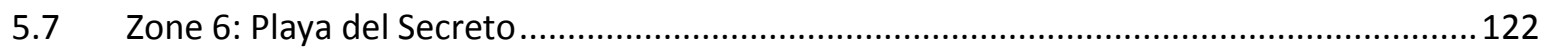

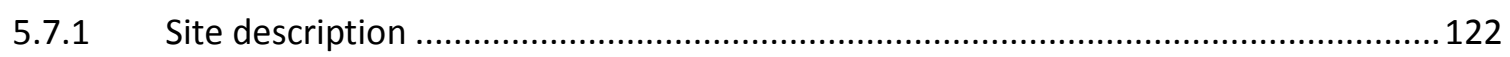

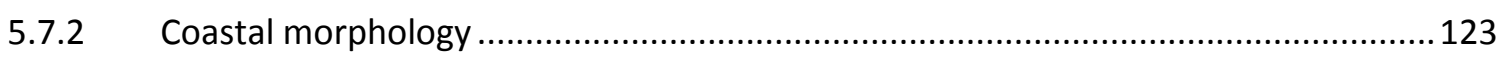

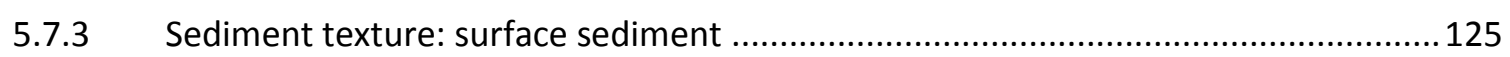

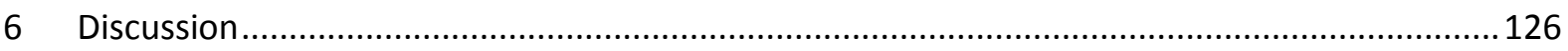

6.1 Geomorphic response of barrier beaches to Hurricane Wilma .......................................126

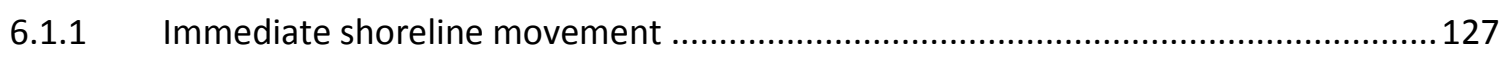

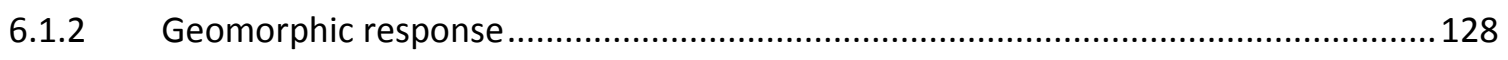

6.1.3 Responses of reef-protected and unprotected barrier beach systems ......................128

6.1.4 Other factors influencing storm response ............................................................. 131

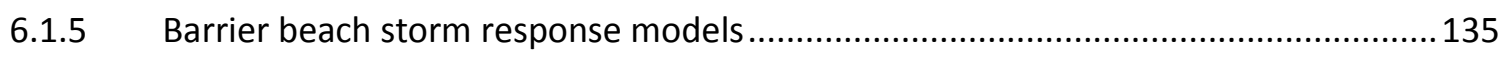

6.1.6 Type 1a: reef-protected and barred-reflective barrier beach systems .......................135

6.1.7 Type 1b: reef-protected and dissipative barrier beach systems ...............................137

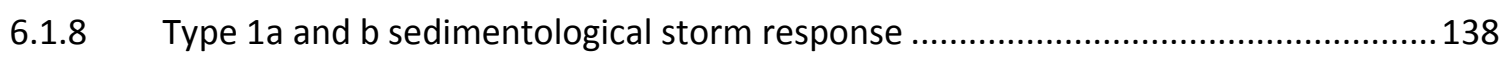

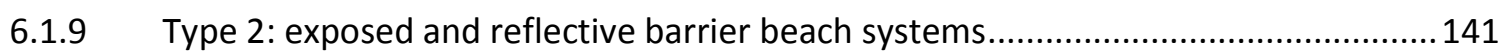

6.1.10 Type 2 sedimentological storm response ............................................................. 142

6.2 Post-storm geomorphic responses of barrier beaches.................................................... 144

6.2.1 Short-term shoreline response (8 months post-storm) .......................................... 146

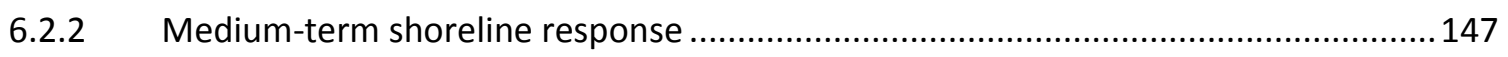

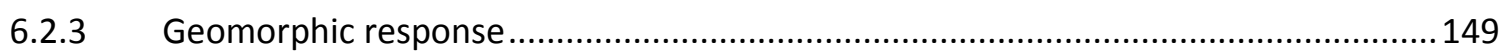

6.2.4 Factors influencing post-storm response: reef-protected barriers ............................ 150

6.2.5 Factors influencing post-storm response: exposed barriers .....................................157

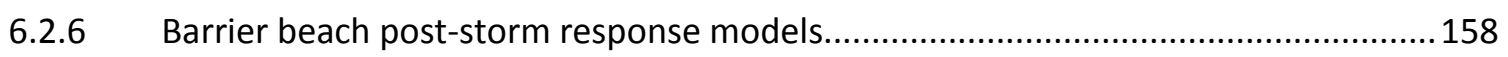

6.2.7 Type 1a: reef-protected and barred-reflective barrier beach systems .......................159

6.2.8 Type 1b: reef-protected and dissipative barrier beach systems .................................163

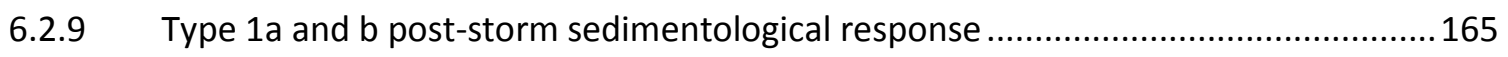

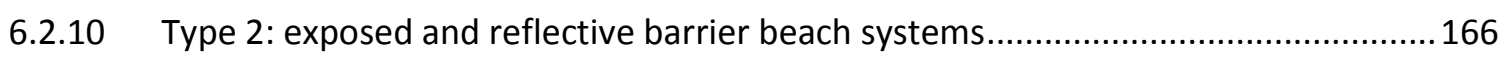

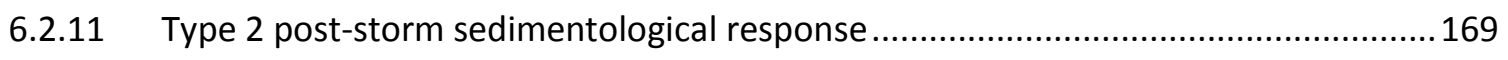

6.3 Geomorphic significance of storms to barrier beach evolution .......................................169

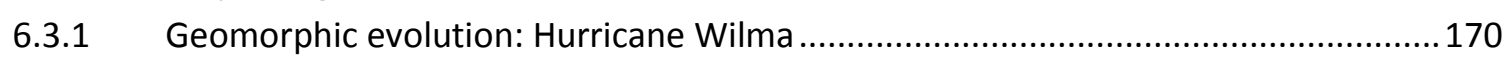

6.3.2 Climate change: increased storm intensity and sea level rise ..................................174

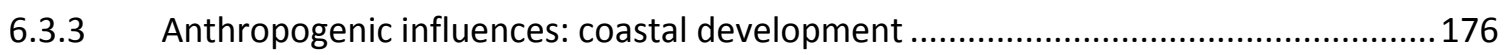

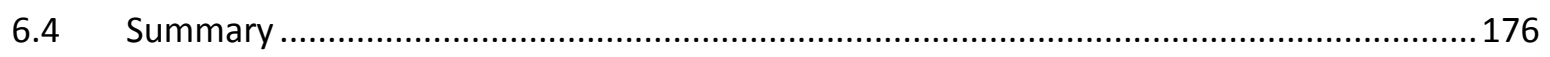

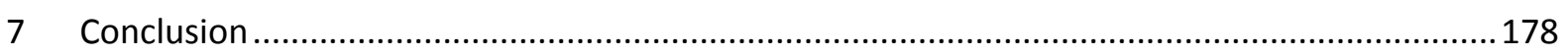

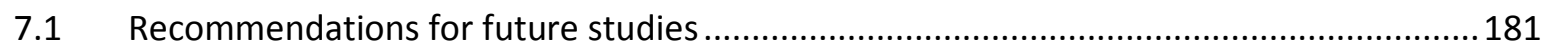

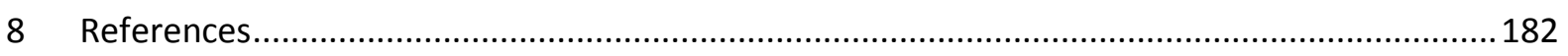

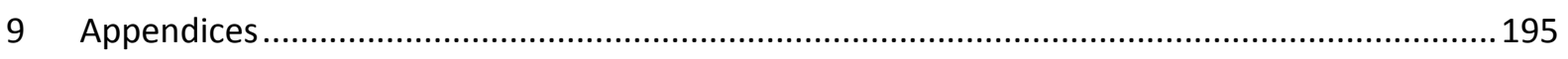

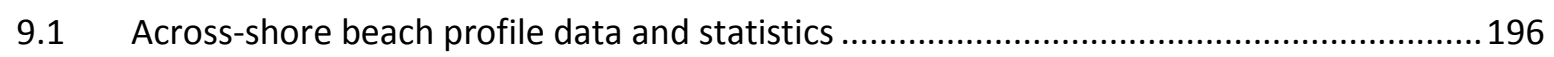

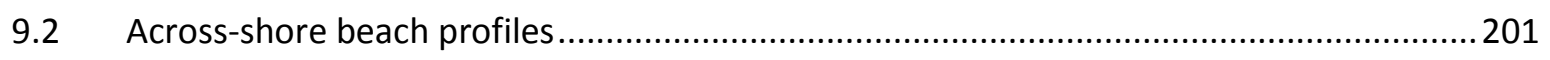

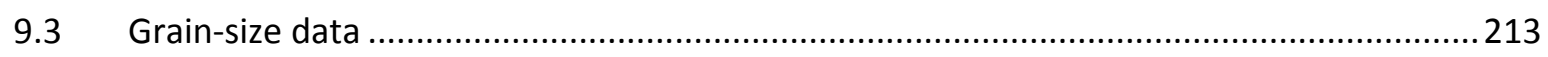

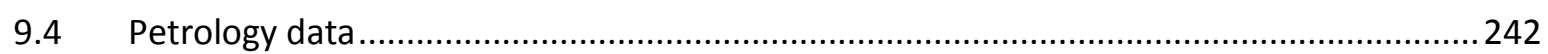

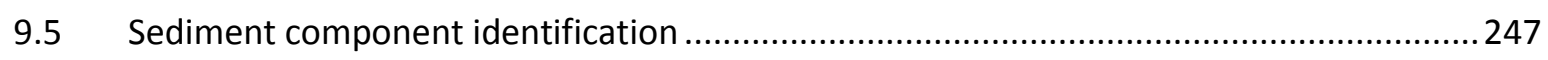




\section{List of Figures}

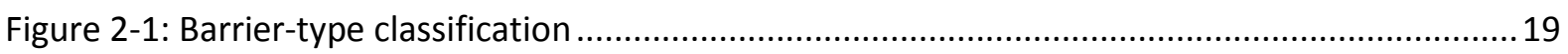

Figure 2-2: The 'Bruun Rule' of beach profile response to sea level rise ..........................................20

Figure 2-3: The growth-form distribution of sediment producing organisms on coral reefs .............. 24

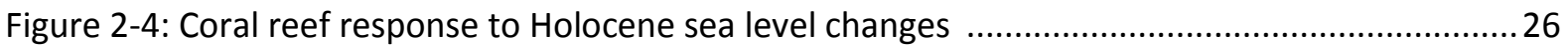

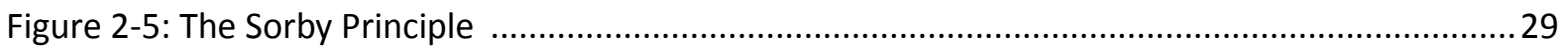

Figure 2-6: Geomorphic and sedimentological impacts of storms on reef islands .............................. 31

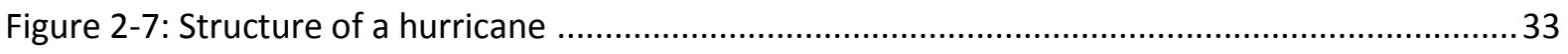

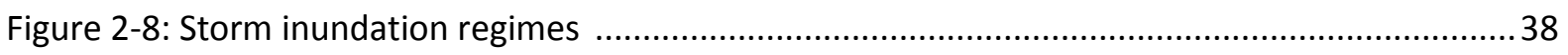

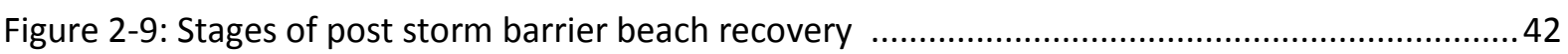

Figure 3-1: Geographic location of the study area in northeastern Yucatan Peninsula, Mexico .........44

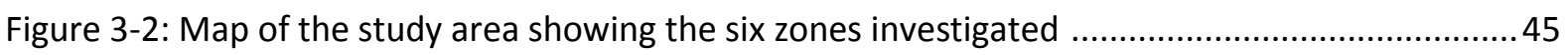

Figure 3-3: Geology and geomorphology of northeastern Yucatan Peninsula, Mexico ....................... 48

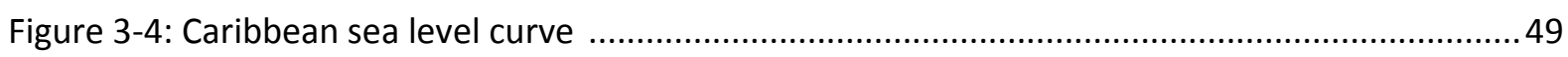

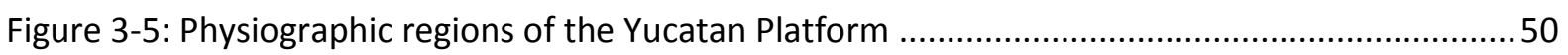

Figure 3-6: Upper Pleistocene beach ridges, northeastern Yucatan Peninsula, Mexico .......................5 52

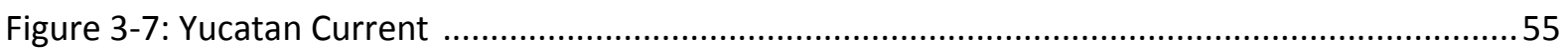

Figure 3-8: Surface currents in the Puerto Morelos backreef lagoon ..............................................57

Figure 3-9: Prevailing hurricane tracks through the North Atlantic ...................................................59

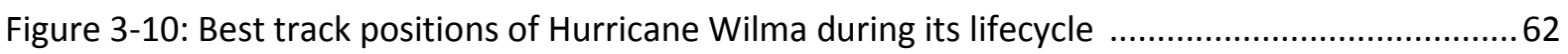

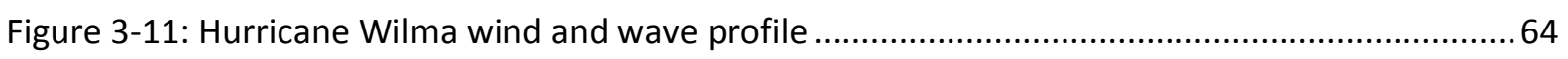

Figure 4-1: Beach profile surveying using an engineer's level ...................................................6

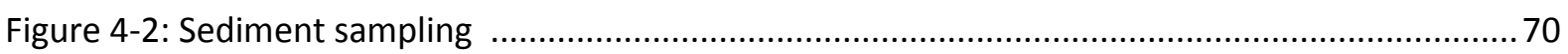

Figure 4-3: Digital Globe: Quickbird Two satellite imagery pixel size .............................................. 71

Figure 4-4: Linear regression curve of LPS and sieve grain size measurements ................................74

Figure 4-5: Post processing regression curve of LPS and sieve grain size measurements ...................75

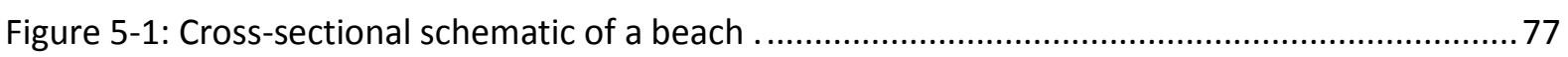

Figure 5-2: Map showing the six different zones investigated in this study ..................................... 78

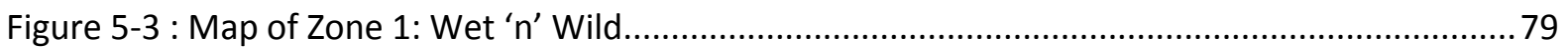

Figure 5-4: Storm and post-storm barrier beach response: Wet ' $n$ ' Wild .......................................... 81

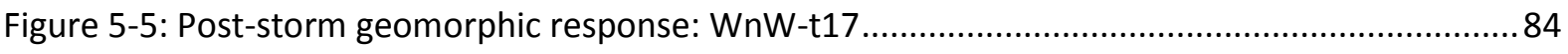

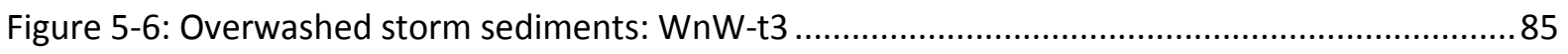

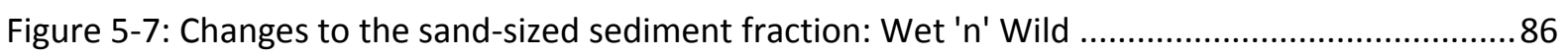

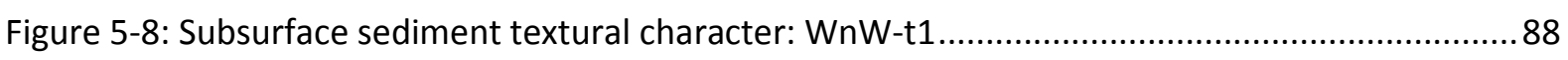

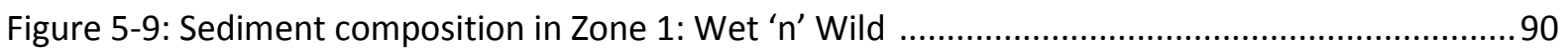

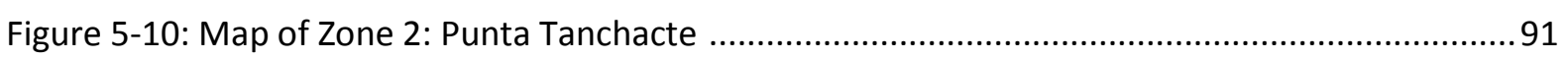

Figure 5-11: Storm and post-storm barrier beach response: Punta Tanchacte .................................93

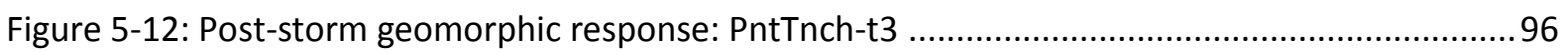

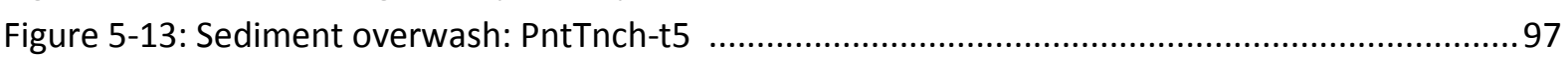

Figure 5-14: Changes to the sand-sized sediment fraction: Punta Tanchacte ..................................98 


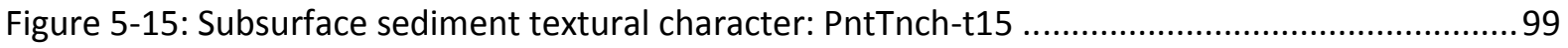

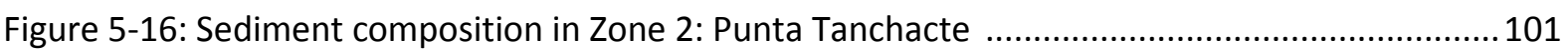

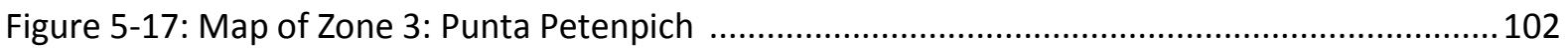

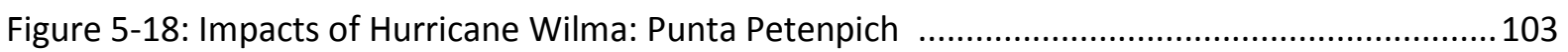

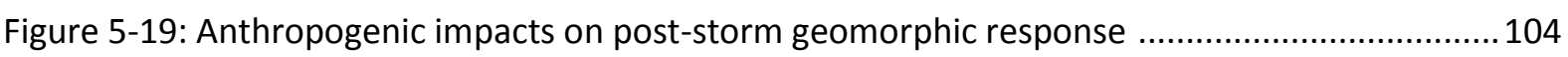

Figure 5-20: Overwashed storm sediments: Punta Petenpich ...................................................... 105

Figure 5-21: Changes to the sand-sized sediment fraction: Punta Petenpich ..................................106

Figure 5-22: Mean grain size and sorting with distance from the shoreline: Punta Petenpich ..........106

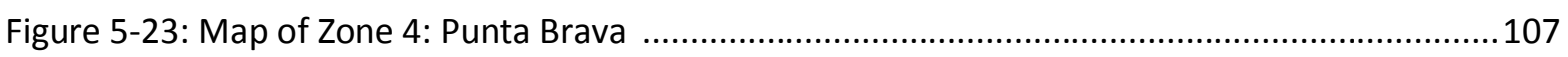

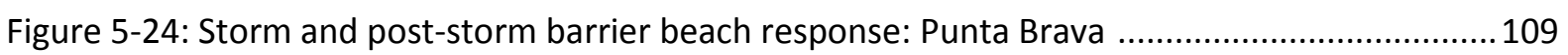

Figure 5-25: Across-shore barrier beach morphology: PntBrv-t2 ............................................... 110

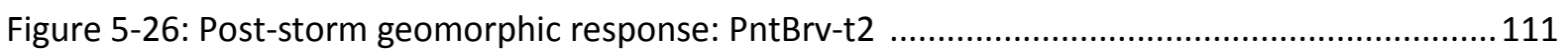

Figure 5-27: Changes to the sand-sized sediment fraction: PntBrv-t1 and PntBrv-t2 .......................113

Figure 5-28: Subsurface sediment textural character: PntBrv-t2 …............................................ 114

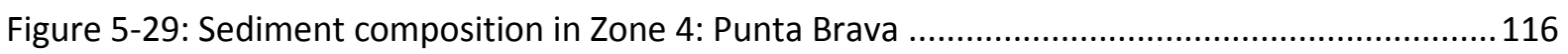

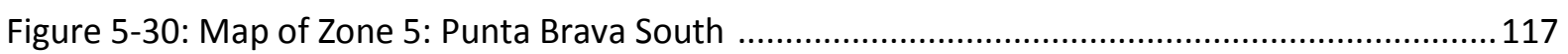

Figure 5-31: Storm and post-storm barrier beach response: Punta Brava South .............................119

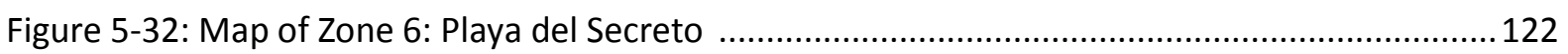

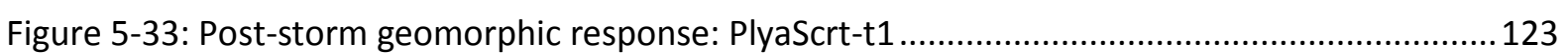

Figure 5-34: Storm and post-storm barrier beach response: Playa del Secreto................................. 124

Figure 5-35: Changes to the sand-sized sediment fraction: Playa del Secreto.................................... 125

Figure 6-1: Hurricane Wilma storm wave profile .................................................................... 127

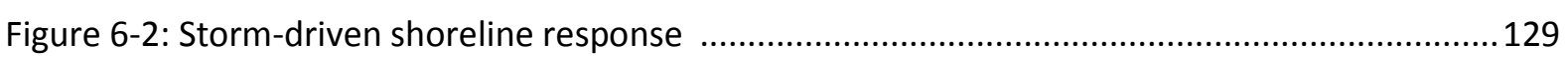

Figure 6-3: Textural character of barrier beach systems of northeastern Yucatan Peninsula ...........130

Figure 6-4: Geomorphic character and storm-driven shoreline response .....................................132

Figure 6-5: Geomorphic character and reef-protected barrier beach type ........................................ 133

Figure 6-6: Correlation between storm-driven shoreline response and foredune height .................134

Figure 6-7: Correlation between storm-driven shoreline response and pre-storm beach width ......134

Figure 6-8: Type 1a: reef-protected barrier beach system storm response ....................................137

Figure 6-9: Type 1b: reef-protected barrier beach system storm response ....................................... 138

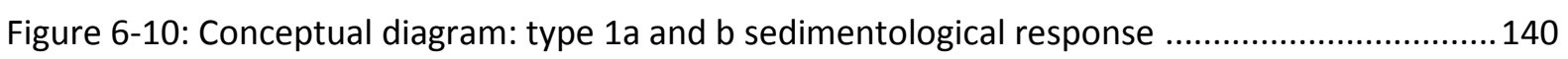

Figure 6-11: Type2: exposed and reflective barrier beach system storm response ...........................142

Figure 6-12: Conceptual diagram: type 2 sedimentological response ............................................ 143

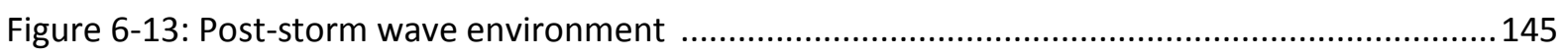

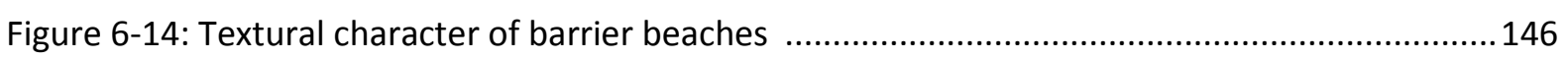

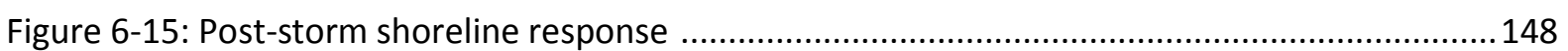

Figure 6-16: Geomorphic character and post-storm shoreline response .......................................151

Figure 6-17: Correlation between storm-driven accretion and post-storm shoreline erosion .........152

Figure 6-18: Correlation between backreef lagoon width and barrier beach width ...........................153

Figure 6-19: Seagrass deposits on the beachface and shoreface: WnW-t14 ...................................154

Figure 6-20: Beach aggradation and dune development: PntTnch-t7 ............................................... 155

Figure 6-21: Relationship between beach width and embryo dune development ............................156

Figure 6-22: Geomorphic controls and post-storm shoreline response .........................................157

Figure 6-23 Correlation between storm-driven erosion and post-storm shoreline accretion ..........158

Figure 6-24: Type 1a: reef-protected barrier beach system post-storm response ............................. 162 
Figure 6-25: Type 1b: reef-protected barrier beach system post-storm response ............................164

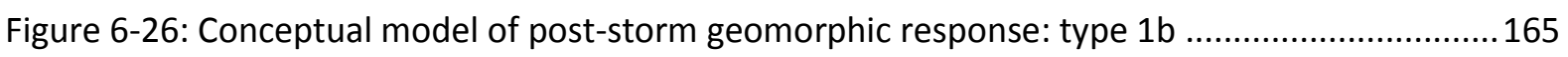

Figure 6-27: Type 2: exposed and reflective barrier beach system post-storm response ..................168

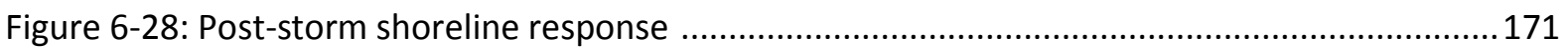

Figure 6-29: Calculated significant storm wave heights between 1948 and 2007 ............................172

Figure 6-30: Conceptual relationship between storm intensity and beach recovery time ...............173

Figure 6-31: Storm-driven changes to beach width in a dynamic equilibrium model .......................174

Figure 6-32: Storm-driven changes to beach width in a metastable equilibrium model ...................175

\section{List of tables}

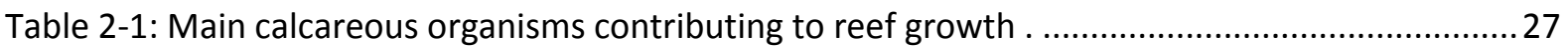

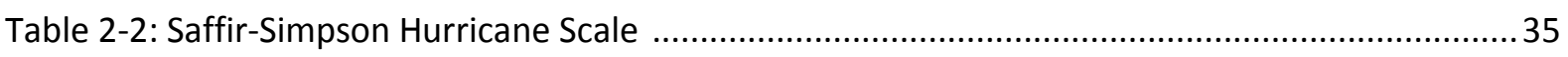

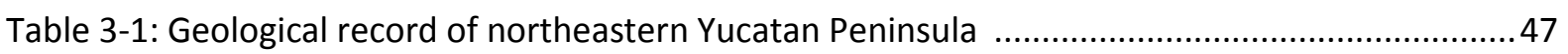

Table 3-2: Tropical storm record of northeastern Yucatan Peninsula, 2000-2005 ............................61

Table 3-3: Tropical storm record of northeastern Yucatan Peninsula, 2005-2010 .............................65

Table 5-1: Storm and post-storm barrier beach response: Playa del Secreto ...................................124

Table 6-1: Reef energy window index calculated for the northeastern Yucatan Peninsula ..............150

\section{List of equations}

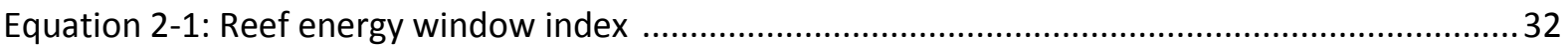

Equation 4-1: Laser particle sizer to sieve conversion factor ........................................................... 74

Abbreviations

\begin{tabular}{|c|c|}
\hline LPS & Laser particle sizer \\
\hline MHW & Mean high water \\
\hline MSL & Mean sea level \\
\hline SD & Standard deviation \\
\hline
\end{tabular}




\section{Introduction}

\subsection{Research rationale}

Barrier beaches are dynamic landforms, sensitive to changes in sediment supply, wind and wave conditions, sea level and tectonics (Hesp and Short, 1999). They are characterised by low-lying relief and typically backed by shallow lagoons or mangrove wetlands. Their distribution is limited to areas with shelf slopes of $0.05-0.80^{\circ}$, accommodation space at the coastline, supply of sediment, and input of wave energy. The nature of these factors also influences the type and morphology of the barrier which is formed.

Storms have historically been seen as important drivers of barrier beach evolution, specifically responsible for shoreline erosion. However, more recent research suggests they may only result in temporary fluctuations around long-term trends, which are driven by other factors such as sea level rise and sediment supply (Zhang et al., 2002). The response of barrier beaches to storms has been found to be highly variable, with geomorphic changes reflecting site-specific factors (Sallenger (Jr.), 2000; Morton, 2002; Wang et al., 2006). Research to date has largely focused on the immediate impacts of storms, often neglecting short (0-8 months) and medium-term (8-56 months) poststorm responses. Additionally, research into the response of barrier beaches on coral fringed coastlines is scarce, with most studies focused on the quartz-dominated barrier islands of the Gulf and East Coasts of the United States (Morton, 2002; Morton and Sallenger, 2003).

The calcium carbonate $\left(\mathrm{CaCO}_{3}\right)$ sediments of barrier beaches in reefal settings are derived from primary and secondary biological production. Primary producers contribute directly to the reef framework when broken down, such as coral; secondary producers, such as foraminifera, reside on the reef framework and are less productive (Kench, 2011). Sediment is broken down and distributed, and enables the development of coastal landforms (Woodroffe, 2002). Understanding these sediment dynamics is essential for understanding barrier beach evolution. 
Barrier beaches are further threatened by climatic change. A shift towards increasing storm intensities and an increase in the number of major (category 3-5) hurricanes is predicted (Trenberth et al., 2007). As a result, larger scale storm impacts, from which barrier beaches take longer to recover, are expected to occur more frequently in the future. In addition, sea level is expected to be $0.6 \mathrm{~m}$ higher by 2100 (IPCC, 2007) and drive landward transgression of barrier beaches, as the equilibrium beach profile readjusts to the new sea level position. Coral reefs are also threatened by warming sea surface temperatures, and are prone to coral bleaching and destruction by invasive species. This will have an effect on the rate and form of sediment supply. Along with these climatically-driven changes, rapid coastal urbanisation and settlement is also set to add continued pressure to barrier beaches around the world and alter the natural dynamics of these systems (Gornitz, 1991; Nicholls et al., 2007).

The northeastern Yucatan Peninsula, Mexico, provides an ideal location to study the significance of hurricanes to barrier beach evolution on coral-fringed coastlines. With the passage of Hurricane Wilma (15-25 October 2005, a category 4 storm on landfall), the most intense storm recorded to date in the Atlantic Basin (Pasch, 2006), the immediate geomorphic response of barrier beaches to a major hurricane can be assessed. The lack of geomorphically significant tropical storms or hurricanes since Hurricane Wilma enabled the post-storm response to also be evaluated five years later. The assessment of beach response to a hurricane of this magnitude also provides some indications of the more common barrier responses to be expected in the future, particularly in the context of increased storm intensities. Northeastern Yucatan offers a range of different coastal geomorphologies, in particular the distinction between reefprotected and exposed barrier beaches; this enables the influence of coral reefs and other local geomorphology on storm-induced barrier evolution to be assessed.

\subsection{Aims and objectives}

The primary aim of this research is to quantify the geomorphic significance of tropical storms and hurricanes on the short to medium-term evolution of shore-attached barrier beaches on coral fringed coastlines. A secondary aim is to assess the significance of coral reefs and coastal geomorphology to barrier beach evolution. This research will address the current lack of understanding of the ways in which these dynamic coastal landforms respond over the short to medium-term following the passage of tropical storms and hurricanes. Specifically, by outlining the dominant controls on carbonate barrier beach response, this study provides a framework within which these carbonate systems may be better understood, including their response to future climatic change.

To achieve this aim the thesis has the following objectives:

1. Quantify and describe the geomorphic response and sedimentological character of shore-attached barrier beaches along northeastern Yucatan 
Peninsula to Hurricane Wilma; evaluate the significance of coral reefs, landscape controls and other factors to the highly variable response alongshore.

2. Quantify and describe the post-storm geomorphic response and sedimentological character of shore-attached barrier beaches along northeastern Yucatan Peninsula up to 54 months after Hurricane Wilma; evaluate the significance of coral reefs, landscape controls, and other factors to the highly variable response alongshore.

3. Discuss the geomorphic significance of hurricanes on the evolution of shoreattached barrier beaches along northeastern Yucatan Peninsula, and the implications of predicted increased storm intensity and sea level rise in the future.

\subsection{Thesis structure}

This thesis is divided into seven chapters. Chapter 1 outlines the intentions and aims of the research. Chapter 2 provides the theoretical background to barrier beaches, wetlands and coral reefs, current understanding of the response of these systems to storms and hurricanes, and evolution of these coastal landforms. Chapter 3 outlines the regional setting of the northeastern Yucatan Peninsula where this research was undertaken. Chapter 4 outlines the methodologies used in data collection, laboratory procedures and sample analysis. Chapter 5 presents the results of this research, while Chapter 6 provides discussion on the role of hurricanes in barrier beach evolution on the northeastern Yucatan Peninsula. The conclusion is presented in Chapter 7, along with recommendations for future research. 


\section{Theoretical Context}

\subsection{Introduction}

This chapter provides background information on the type of coastal system under investigation, namely barrier beach systems on soft carbonate coastlines which are influenced by fringing-barrier reefs. It also provides details of storm-driven impacts on barrier beaches and discusses contemporary understandings of how these environments recover following these events.

The term barrier was first used by Gilbert (1885) to describe the shoreline ridges of Lake Bonneville, though it was Johnson's (1919) use that spurred its widespread use. These landforms are some of the most dynamic coastal systems, sensitive to changes in sediment supply, wind and wave conditions, sea level and tectonics (Hesp and Short, 1999). Recent advances in technology, specifically the advent of vibracoring, have enabled greater understanding of these previously ill-interpreted coastal landforms (Hesp and Short, 1999).

\subsection{Barrier beaches: formation, classification and evolution}

Barrier beaches are herein defined as unconsolidated accumulations of sand, shaped by the forcing of shore-parallel waves, tides, and winds that restrict terrestrial drainage or bind a lagoon to the mainland (Woodroffe, 2002). The morphology of these coastal landforms reflects not only contemporary processes but also those operating over geological timescales (Roy et al., 1994; Riggs et al., 1995).

\subsubsection{Barrier formation}

An explanation for the formation and evolution of barrier beaches was first provided by de Beaumont (1845) who posited that barrier islands evolved from platforms or submarine bars (Woodroffe, 2002). Gilbert (1885) later suggested that littoral drift processes were responsible for these coastal landforms, while McGee (1890) explained them as drowned coastal ridges (Woodroffe, 2002). These theories have since been refuted, and the next progression in their understanding came about when Swift (1975) 
proposed that barriers resulted from onshore sediment migration during sea level rise. This was later revised to reflect barrier formation as the result of landward transport and upward accumulation of sediment (Davis Jr, 1994; Roy et al., 1994).

Recent research indicates that the only critical requirements to barrier formation are suitable substrate gradient and accommodation space at the coastline, sufficient sediment, and input of sufficient wave energy (Hesp and Short, 1999; Woodroffe, 2002). The first of these, substrate gradient is thought to require a critical shelf slope of between $0.05^{\circ}$ and $0.8^{\circ}$, based on modelling conducted by Roy et al. (1994). Wave energy, another critical requirement, becomes insignificant due to wave shoaling on shelves shallower than $0.05^{\circ}$, while sediment on shelves steeper than $0.8^{\circ}$ tends to be transported offshore (Roy et al., 1994). Roy et al's (Roy et al., 1994) modelling also suggested an optimal shelf slope for barrier formation of $0.1^{\circ}$. Furthermore the substrate and surrounding coastal landscape also determines the accommodation space at the coastline, therefore influences the type of barrier which may or may not develop (Belknap and Kraft, 1985). Headland-bay structured coastlines, pinned by resistant lithology, tend to result in embayed barriers (Hesp and Short, 1999). In comparison, straight or curvilinear barriers tend to represent highly erodible lithologies (Hesp and Short, 1999). As such, the degree of topographic shelter afforded by headlands also influences the resulting barrier morphology (Davis and Hayes, 1984; Kochel et al., 1985).

Barrier development and morphology is also dependent on the quantity, rate of supply, and size of available sediment (Hesp and Short, 1999). Sediment may be derived from shelf deposits (Davis Jr, 1994; Roy et al., 1994), fluvial sources (Fitzgerald and Van Heteren, 1999), or erosion of alongshore headlands (Oretel and Kraft, 1994). Short (1987) also proposed that sediment may originate from in situ carbonate production (Hesp and Short, 1999).

Another essential component to barrier formation is input of energy from waves. Short (1987) related the wave energy regime and associated rate of onshore and alongshore sediment supply to the character of sand accumulation. Short proposed that chenier deposits would form where sediment was supplied at a rate of $0.1 \mathrm{~m}^{3} / \mathrm{m} / \mathrm{yr}$; progradational beaches would result where the rate of supply increased to $3 \mathrm{~m}^{3} / \mathrm{m} / \mathrm{yr}$, and retrogradational beaches would form when the rate was further accelerated to approximately $10 \mathrm{~m}^{3} / \mathrm{m} / \mathrm{yr}$ (Hesp and Short, 1999). The wave versus tidal dominance is also reflected in barrier morphology (Hayes, 1979; Davis and Hayes, 1984). With increasing tidal dominance (microtidal to mesotidal) comes an increasing tidal prism, typically resulting in an increased number of tidal inlets; therefore an increase in the number, but reduction in the length of barrier deposits (Hayes, 1979; Davis and Hayes, 1984). Wind dynamics also affect barrier morphology as they help shape subaerial barrier morphology (Hesp and Short, 1999).

In addition to the critical variables discussed above, sea level rise and tectonics play a significant role in barrier evolution, altering the boundary conditions under which these 
coastal landforms operate (Glaeser, 1978; Kraft et al., 1987; Roy et al., 1994). Barrier evolution can be considered as one of three phases of sea level fluctuation. These are the transgressive phase (sea level rise), stillstand phase (stable sea level) and regressive phase (falling sea level) (Roy et al., 1994). These phases relate not only to eustatic sea level change, but also relative sea level change (Roy et al., 1994). Up until the Holocene sea level highstand, approximately 6000-7000 years BP, eustatic sea level fluctuations predominated, driven by expansion and retreat of polar ice sheets. Since this time regionally distinctive relative sea level change has had notable impacts on barriers, resulting in regional variation in morphology (Salinas et al., 1986; Kraft et al., 1987; Roy et al., 1994).

Lastly, tectonic movement may also drive relative sea level change, but in a much more abrupt manner with barriers in tectonically active regions often pinned to the coastline and free of backbarrier environments (Hesp and Short, 1999).

\subsubsection{Barrier classification}

Several barrier-type classifications have been proposed based on either process or form, with the first provided by Johnson (1919). Zenkovich (1967) and Roy et al. (1994) have since arguably provided the most notable models. This study will discuss barrier type in relation to the classifications provided by Roy et al. (1994) and Hesp and Short (1999).

Barriers can be defined under three sea level settings; transgressive barriers, stillstand barriers, and regressive barriers (Roy, 1994). Several transgressive barrier classifications have been proposed by Hesp and Short (1999), including prograded barriers and strandplains, which periodically prograde, due to sediment transportation from the shelf being far greater than that within the beach system. Retrogradational barriers or barrier islands (Figure 2-1) are classic barrier rollover systems (Roy et al., 1994; Hesp and Short, 1999) where sediment from the shoreface is reworked landward as these barriers try to remain in equilibrium with sea level and marine processes (Kraft et al., 1987; Roy et al., 1994). Retrogradational coastal plains are those which attach to the mainland and rollover mainland deposits during landward transgression. Retrogradational attached barriers are those pinned to cliffed coastlines.

When sea level is in a stillstand phase barriers will typically reflect one of the following forms, of which some are shown in Figure 2-1: transgressive dune barrier, prograded barrier, stationary barrier, headland spit, receded barrier, mainland beach, inner shelf sand sheet, shelf ridge field, and headland attached shelf sand body (Roy et al., 1994; Hesp and Short, 1999). Transgressive dune barriers contain large mobile dune fields, which have migrated landward due to dominant aeolian processes, and become detached from the shoreline (Roy et al., 1994). Prograded barriers are characterised by multiple foredune ridges, while stationary barriers maintain their morphology, as the sediment budget is in balance with marine processes (Roy et al., 1994). Headland barriers migrate alongshore, and are aligned to the predominant littoral drift, while 
receded barriers and mainland beach barriers reflect a net deficit in the sediment budget (Roy et al., 1994). The shelf sand accumulations are stores of sediment offshore, which result from either seafloor or shoreface erosion (Roy et al., 1994).

Barriers respond to falling sea levels by building-out and typically developing an extensive strandplain lined with beach or foredune ridges (Roy et al., 1994; Hesp and Short, 1999). As with other sea level settings, barrier morphology is largely determined by regional factors, such as the texture and supply of sediment, and the nature of the processes operating at the coastline (Hesp and Short, 1999).

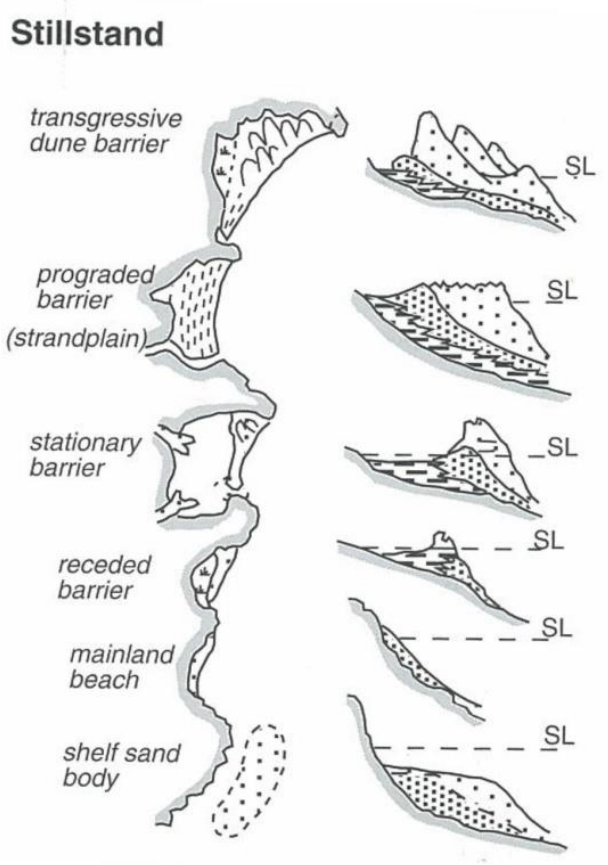

Transgressive

Figure 2-1: Barrier-type classification under transgressive, stillstand and regressive sea level phases (Woodroffe, 2002).

\subsubsection{Barrier evolution}

Barriers evolve as a result of changes in sea level, sediment supply, wave environment and tectonics (Roy et al., 1994; Hesp and Short, 1999). This section will primarily focus on the contemporary understanding of landward transgression through both shoreface reworking and barrier overstepping (Kraft, 1971).

Several theories and models have been proposed to explain shoreface reworking and landward adjustment of the coastline to sea level rise (Bruun, 1954; 1962; Kraft et al., 1987; Leatherman, 1990; Dean, 1991; Douglas and Crowell, 2000; Honeycutt et al., 2001). This research tends to suggest that sediment from the beach is removed and either deposited on the shoreface, transported offshore, driven alongshore or pushed landward. All models suggest the beach system transgresses landward as a result. Per Bruun $(1954$; 1962) developed a simplistic two dimensional empirical model to 
represent the response of the beach system to sea level rise (Figure 2-2). Termed the 'Bruun Rule' by Schwartz (1967), the model assumes that the beach stays in equilibrium with sea level and maintains an equilibrium beach profile (Bruun, 1962). With a rise in sea level, Bruun $(1954 ; 1962 ; 1983)$ proposed that sediment from the upper shoreface is eroded away and re-deposited on the nearshore subaqueous face, resulting in landward migration and vertical accretion. Bruun $(1954 ; 1962 ; 1983 ; 1988)$ also suggested that landward migration occurred at a rate 100 times that of the vertical rise in sea level. The Bruun Rule was supported by some studies, which included those conducted by Schwartz (1967) in a wave flume, Dubois (1976) on the shores of Lake Michigan (USA), and Rosen (1978) on the shores of the Virginia Chesapeake Bay (USA). However, the rule has been widely criticised by coastal scientists for being too simplistic and therefore not applicable to the real world (Pilkey et al., 1993; Cooper and Pilkey, 2004).

Criticisms of the Bruun Rule focus mainly on the assumptions embedded in the model itself, specifically, (i) beach systems establishing an equilibrium profile, (ii) inputs and outputs from littoral drift being in balance, and (iii) sediment being homogenous across the beach profile (Bruun, 1954; 1962). The Bruun Rule fails to acknowledge that beach profiles are dynamic, constantly changing with changes in wave energy (Pilkey et al., 1993), sediment budgets are rarely, if ever in perfect balance (Cooper and Pilkey, 2004), and many beaches are composed of mixed source sediment (Woodroffe, 2002). However, despite all of these assumptions and criticisms, the Bruun Rule remains widely used for modelling shoreline response to sea level rise.

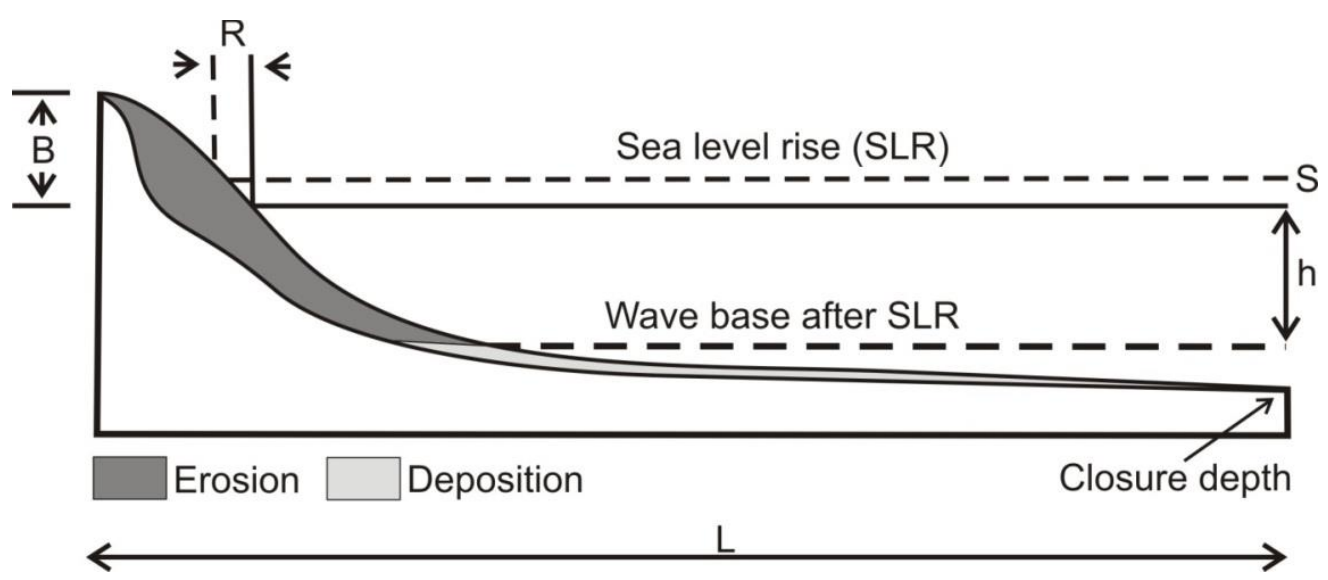

Figure 2-2: The 'Bruun Rule' of beach profile response to sea level rise (Bruun, 1954; Bruun, 1962). Adapted from (Cooper and Pilkey, 2004).

Following the Bruun Rule, numerous higher order and highly complex models were developed in an attempt to address the underlying assumptions and limitations discussed above; they also aimed to provide a predictive tool for shoreline response under rising sea level (Leatherman, 1990). Dean and Maurmeyer's (1983) dynamic equilibrium model, which introduced a scaled sediment transport parameter, and Everts (1985) three dimensional sediment budget, which accounted for sediment gains and 
losses, are two such models (Leatherman, 1990). These developments were succeeded by the linear regression models of Crowell et al. (1997) and Douglas and Crowell (2000), and the flooding principle of Brunel and Sabatier (2009), which combine the relative sea level rise with the slope of the beach profile. Cooper et al. (2010) also revised the beach profile model through the use of a weighted polynomial function, to better reflect specific beach contexts. However, increased model complexity brings additional difficulties in understanding the significance of each model parameter (Leatherman, 1990; Cooper and Pilkey, 2004). As such, none of these models are yet to provide a robust means to predict future change to beach systems under rising sea levels (Cooper and Pilkey, 2004); this problem remains largely unresolved.

In addition to shoreface reworking, which is thought to occur under moderate rates of sea level rise, barriers may also undergo overstepping whereby the barrier stratigraphy is preserved as it becomes submerged (Kraft, 1971). First proposed by Fischer (1961), it was suggested that when sea level rises rapidly the shoreface would be exposed to erosive processes for only a short period of time, and therefore would likely remain in situ (Kraft, 1971). In comparison, slow sea level rise is expected to result in no shoreface preservation (Kraft, 1971).

However, it is important to not only recognise the evolution of barriers over hundreds or thousands of years due to climatically driven sea level rise, but also to consider how they change over decadal timescales and at near-instantaneous timescales, such as those caused by storms (Regnauld et al., 1999; Keim et al., 2004; Regnauld et al., 2004; Nicholls et al., 2007). The significance of storms to barrier evolution has long been debated, and typically concerns the magnitude and frequency of processes, and their significance to long-term geomorphic change (Wolman and Miller, 1960; Zhang et al., 2002). One way to describe the influence of coastal processes to barrier evolution is to consider their impact over spatial and temporal scales, therein establishing the role of particular processes on the system's equilibrium state (Schumm and Lichty, 1965; Woodroffe, 2002). Coastal landforms are typically described as reflecting one of several equilibrium states, namely; static, stable, steady-state, metastable, or dynamic equilibrium (Woodroffe, 2002). Static, stable and steady-state equilibrium all represent stable landforms with slightly different processes or boundary conditions (Woodroffe, 2002). As such, they are not so applicable to storm prevalent coastlines, which are better reflected by metastable or dynamic equilibrium states.

Metastable equilibrium represents coastal landforms subject to irregular changes in energy inputs, temporarily changing the equilibrium position, after which it returns to a stable position (Woodroffe, 2002). Some research suggests that metastable equilibrium best represents the impacts of storms on barrier systems, that is, a temporary shift from an equilibrium position, with the size of the shift and time taken to recover dependent on the storm intensity and coastal resilience (Woodroffe, 2002; Zhang et al., 2002). In contrast, other research suggests they are better reflected by dynamic equilibrium, 
which represents continual landform change through space and time (Woodroffe, 2002). These equilibrium states typically represent changes in boundary conditions over time, such as sea level rise, or climatically driven changes to the intensity of storms (Woodroffe, 2002).

\subsection{Coral fringed coasts: geomorphology \& sedimentary dynamics}

Barriers and other coastal landforms on coral fringed coasts are highly dependent on the productivity of sediment contributing organisms residing on the reef (Kench, 2011). Coral reefs and their associated soft-carbonate environments are dynamic systems, which involve the interaction of a myriad of physical and biological processes. Together they produce, break down and distribute sediment (Woodroffe, 2002); understanding these processes is essential for recognising barrier dynamics in these environments.

\subsubsection{Coral reef formation}

Coral reefs only form under specific environmental conditions: an average sea surface temperature of 18 to $34^{\circ} \mathrm{C}$, salinity of 30 to 38 parts per thousand, low turbidity, sunlight, and a viable platform conducive to coral reef development (Ladd, 1977; Guilcher, 1988). As such, coral reefs are typically situated within the tropical regions of the western Pacific, Indian and Atlantic oceans (Guilcher, 1988; Bird, 2008).

Coral reefs grow as carbonate skeletal material derived from marine plants and animals accumulates, forming a rigid framework. This is then overlain by unconsolidated carbonate material. Scoffin (1987) proposed five stages of coral reef growth:

1. Growth of the primary reef framework, dominated by reef building scleractinian corals.

2. Growth of the secondary reef framework, dominated by encrusting calcareous organisms, such as algae and foraminifera.

3. Erosion by physical and biological processes, such as high wave energy events (including hurricanes), and grazing activities of reef dwelling organisms, such as bivalves, worms and fish.

4. Internal sedimentation, as calcareous material is excreted by those organisms grazing on the reef.

5. Marine cementation, as aragonite and $\mathrm{Mg}$ calcite are precipitated from both the reef dwelling organisms and the seawater, resulting in the coral reef framework being cemented and lithified.

Scoffin (1987)

\subsubsection{Coral reef classification}

Several different types of coral reef have been identified, including patch reefs, fringing reefs, barrier reefs, and atolls. Darwin (1842) proposed that fringing reefs were the first stage in the evolution of coral reefs, followed by barrier reefs and atolls, the second and 
third stages, as these systems matured (Smithers, 2011). As this study is concerned with fringing and barrier reef morphologies, these will be discussed in further detail.

Fringing reefs are characterised as shore-attached systems, whereby the reef platform is at or near the sea surface, and as such there is typically no lagoon between reef and shoreline (Steers and Stoddart, 1977). They develop off the coast of either continental shelves or mid-ocean islands, and are suited to either stable or tectonically active coastlines (Bird, 2008; Smithers, 2011). Fringing reef morphologies are the most common reef type, and reportedly (Hopley, 2004) comprise over half of the world's total reefal area (Smithers, 2011). In comparison, barrier reefs are defined as reefs separated from the mainland by a lagoon of at least $10 \mathrm{~m}$ depth (Steers and Stoddart, 1977; Woodroffe, 2002). They may form on small subsiding islands, such as Pohnpei in Micronesia, on moderate sized islands like New Caledonia, or along continental margins as exemplified by the Great Barrier Reef of Australia and the Mesoamerican Barrier Reef of Central America (Woodroffe, 2002).

\subsubsection{Coral reef zonation}

The surface morphology across coral reefs is highly variable, reflecting changes in light levels, wave energy, sediment flux and subaerial exposure, while driving preferential distribution of sediment producing organisms to particular parts of the reef (Chappell, 1980; Graus and Macintyre, 1989). The reef can be divided into three zones based on these morphological and biosedimentilogical characteristics (Figure 2-3), namely, forereef, reef crest (and reef flat) and backreef (Chappell, 1980; Woodroffe, 2002; Smithers, 2011).

The forereef extends from the sea floor to the reef flat and is typically very steep in gradient (Woodroffe, 2002). The lower forereef is characterised by a talus slope, formed as detrital material sourced higher on the reef is deposited on the seaward margin. Further up the reef there is a distinct change at approximately $10 \mathrm{~m}$ depth, where an abundance of scleractinian corals begin to line the slope, and continue through to the reef crest (Guilcher, 1988; Woodroffe, 2002). The upper forereef may also exhibit spur and groove morphologies. These are a series of perpendicular extrusions, usually 30 to $80 \mathrm{~m}$ long and separated by grooves of 10 to $30 \mathrm{~m}$, and typically found on West Indian and Indo-Pacific reefs (Woodroffe, 2002). The spurs dissipate wave energy, while the groves act as sediment conduits (Tracey et al., 1948).

The reef crest is the point of highest wave energy on the coral reef (Woodroffe, 2002). Shallow sloping to flat morphology persists, with encrusting scleractinian, alcyonarian and milleporoid corals, and coralline algae thriving in this higher energy environment. The backreef is typically reflected by a near-horizontal reef platform or lagoon, which extends from $10 \mathrm{~m}$ to $1 \mathrm{~km}$ towards the shoreline (Smithers, 2011). This relatively sheltered environment is typically lined with a landward thinning veneer of carbonate 
sediment, and is conducive to growth of the codiacean algae, Halimeda, and associated in situ sediment production.
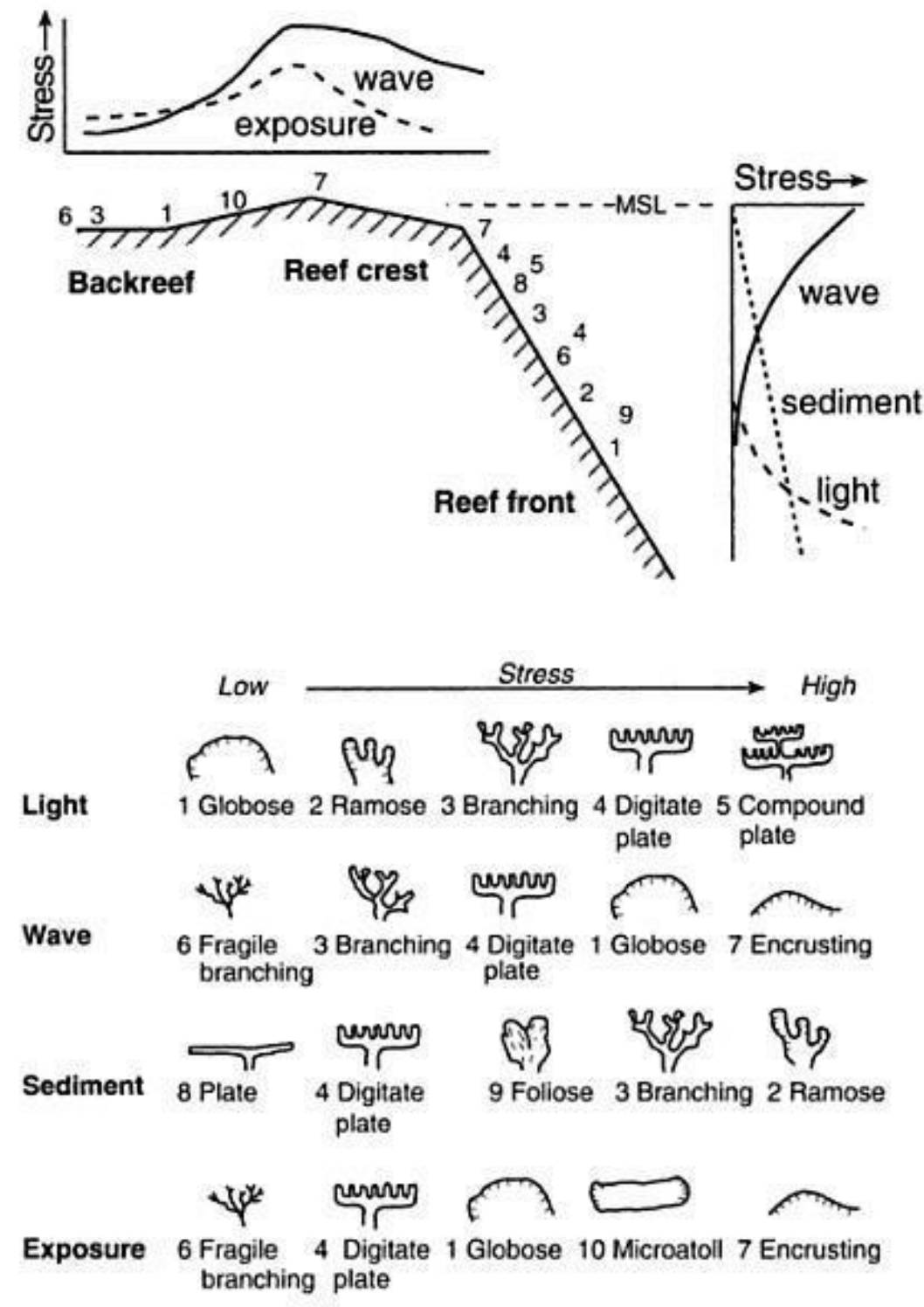

Figure 2-3: The growth-form distribution of sediment producing organisms on coral reefs (Woodroffe, 2002).

\subsubsection{Holocene reef growth}

Coral reefs are sensitive to changes in sea level and tectonics, which influence the accommodation space and drive coral reef evolution (Kennedy and Woodroffe, 2002). The rate of coral and coral reef growth is also important to this evolution. Individual corals can grow at rates of $10 \mathrm{~mm} \mathrm{a}^{-1}$ to $100 \mathrm{~mm} \mathrm{a}^{-1}$, with coral reefs typically growing at rates of $1 \mathrm{~mm} \mathrm{a}^{-1}$ to $10 \mathrm{~mm} \mathrm{a} \mathrm{a}^{-1}$ (Woodroffe, 2007). Furthermore the specific morphological change is influenced by the timing and rate of sea level rise, and the type of reef (Woodroffe, 2007). 
Coral reef morphology reflects regional variation in Holocene sea level rise. Neumann and Macintyre (1985) suggest they respond in several different ways, and identified drowned, back-stepped, catch-up, keep-up, prograded, and emergent reef morphologies (Figure 2-4). Drowned (or 'give-up') reefs (Figure 2-4a) show initial vertical growth as sea levels rise, however this cannot be maintained, and they cease growing, resulting in drowned terraces (Woodroffe, 2007). This is typical of many drowned reefs in the Caribbean and West Atlantic Ocean, which remain in situ, as terraces, at approximately $20 \mathrm{~m}$ depth. However, where there is available accommodation space then reef back-stepping (Figure 2-4b) may occur, with the reef occupying a new position further landward and at higher elevations (Blanchon, 2010; Blanchon, 2011a). Both these morphologies reflect a transgressive sea level curve, whereby sea level rise took place, as rapid rise events (Fairbanks, 1989; Blanchon and Shaw, 1995; Blanchon, 2011b) or as a more continual, but decelerating, rise over time (Toscano and Macintyre, 2003; Toscano and Macintyre, 2005). The Caribbean Sea level curve, relevant to this study, will be discussed further in Section 3.3.

Catch-up reefs (Figure 2-4c) initially grow slowly, but their growth rate soon increases to a rate faster than that of sea level rise, and continues until they fill the available accommodation space. Keep-up reefs (Figure 2-4a) grow at a similar rate to sea level rise, thus remaining at or near sea level, with limited accommodation space. Where the accommodation space becomes exhausted due to sea level stabilisation, the reef reverts to growing laterally, forming prograded reefs (Figure 2-4e). Finally, when sea level falls, much of the reef may be left as an emergent feature (Figure 2-4f) and lateral progradation may occur at lower levels. This is typical of many Indo-Pacific coral reefs which reflect initial marine transgression, whereby sea levels rose to the mid-Holocene highstand, established 5000-6000 years BP, then fell to the present position (Davies and Montaggioni, 1985). 


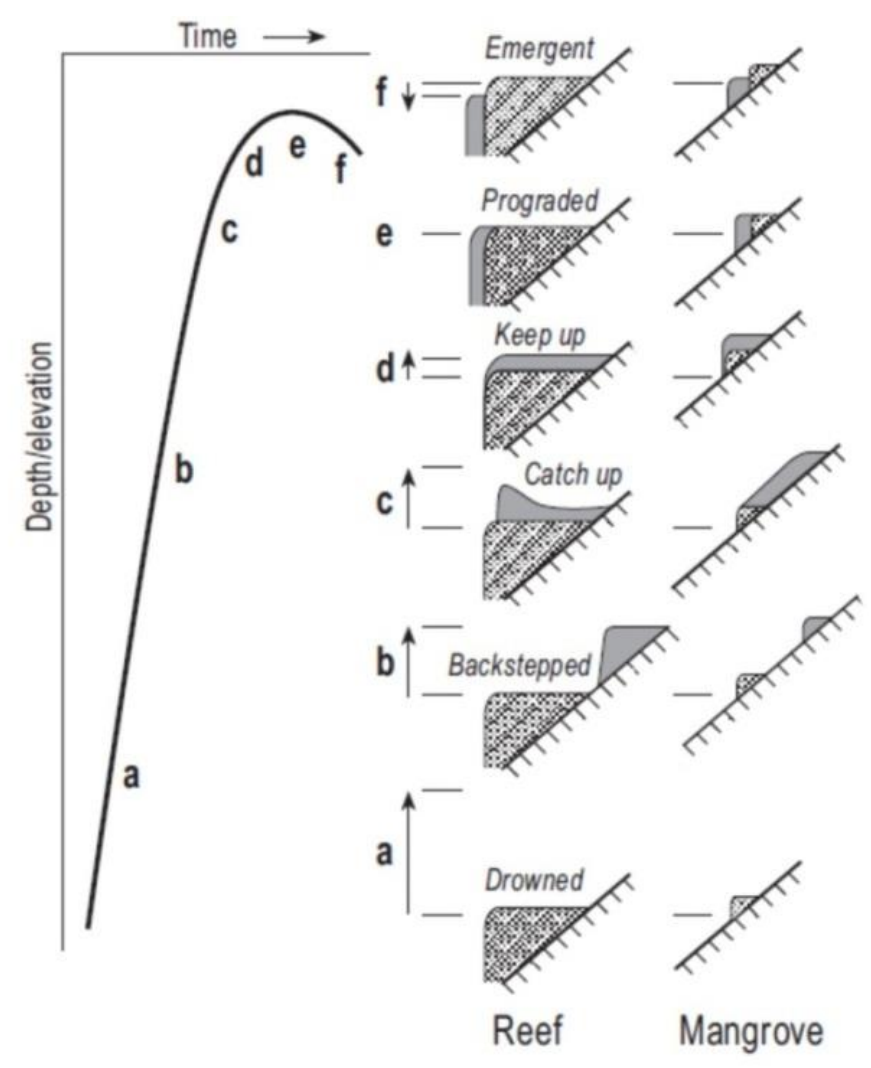

Figure 2-4: Coral reef response to Holocene sea level changes (Woodroffe, 2002).

\subsubsection{Coral reef sedimentary dynamics}

Sediment production, transportation and deposition closely relate to the organisms and processes operating over the reef. There are two types of sediment producers in coral reef environments: primary producers and secondary producers. Primary producers are those organisms which contribute directly to the reef framework, such as scleractinian corals and coralline algae, and whose skeletons add to unconsolidated reef sediment when they are broken down (Kench, 2011). Secondary producers typically reside on the reef framework and include a wide range of benthic organisms, such as foraminifera, molluscs, calcareous algae, echinoids, and crustaceans (Kench, 2011). The productivity of these sediment producing organisms varies considerably (Table 2-1). Coral tend to be the greatest contributors, followed by coralline algae, Halimeda, foraminifera, and molluscs (Kench, 2011). Productivity can also be defined by morphological zones, due to the selective distribution of these organisms throughout the reef (as discussed earlier). Research conducted by Hart and Kench (2007) returned production rates of $2.0 \mathrm{~kg}$ $\mathrm{CaCO}_{3} \mathrm{~m}^{-2} \mathrm{a}^{-1}$ on the forereef, 1.6 to $5.0 \mathrm{~kg} \mathrm{CaCO}_{3} \mathrm{~m}^{-2} \mathrm{a}^{-1}$ on the reef crest, and $0.80 \mathrm{~kg}$ $\mathrm{CaCO}_{3} \mathrm{~m}^{-2} \mathrm{a}^{-1}$ in the backreef lagoon. 
Table 2-1: Main calcareous organisms contributing to reef growth and carbonate sediment production, adapted from Woodroffe (2002).

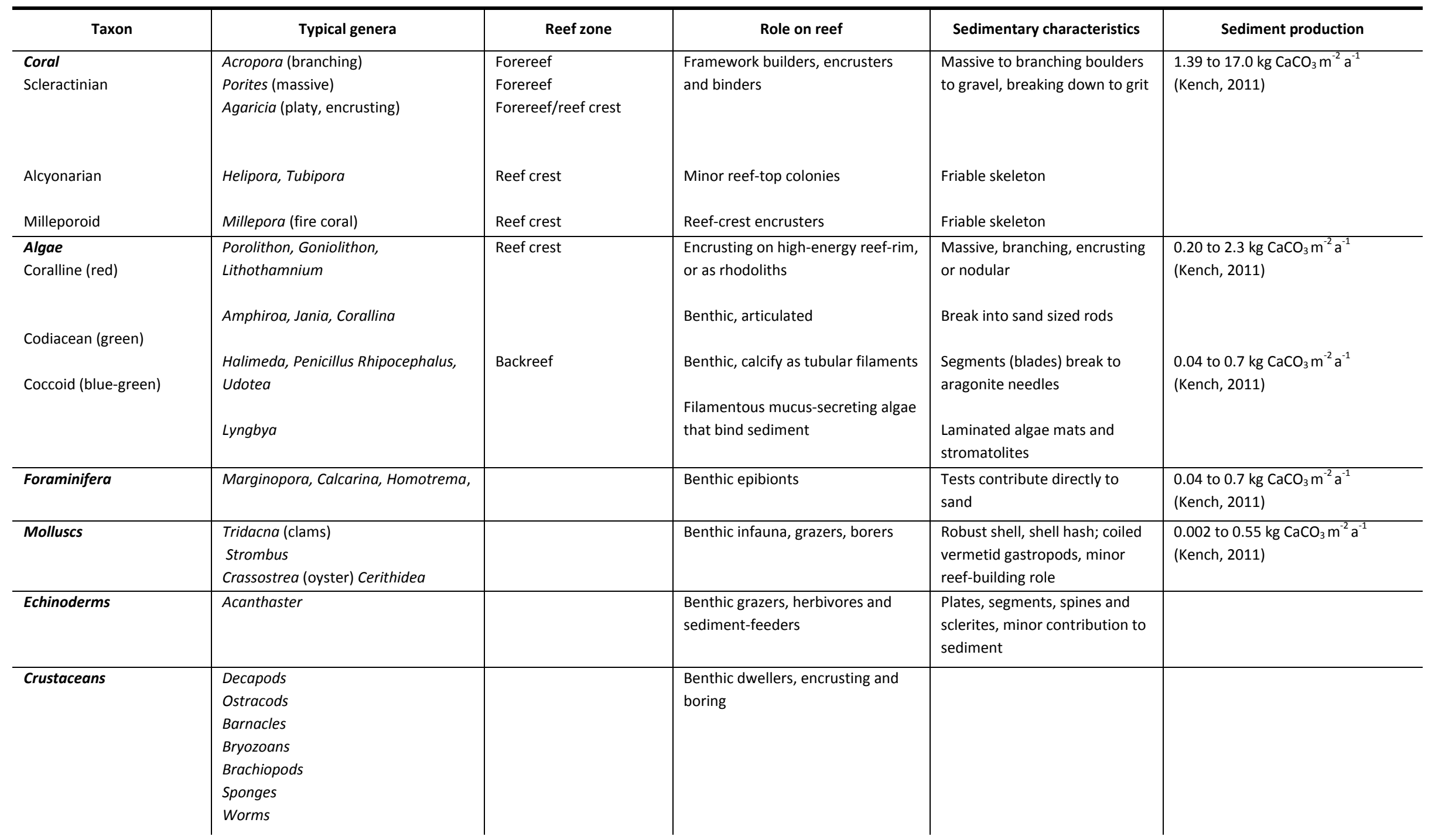


The texture and breakdown of reefal sediments is highly varied, depending on the micro architecture of the original skeletal material (Orme, 1977; Hubbard et al., 1990). The Sorby Principle (Figure 2-5) proposed by Folk and Robles (1964) relates the size and breakdown of carbonate grains to specific sediment producing organisms. For example, coral colonies typically break down from boulders to cobbles, sticks $(-6 \phi)$, and coral grit (2申); they rarely form grains of intermediate size (Folk and Robles, 1964; Woodroffe, 2002). In contrast, Halimeda colonies segment and break down into discoid pieces $(0 \phi)$, with further breakdown due to abrasion occurring relatively rapidly as they disintegrate into fine dust (10ф)(Folk and Robles, 1964). Halimeda-derived sediment can therefore range from grains of gravel to sand size, or finer (Folk and Robles, 1964; Woodroffe, 2002). Tests show that foraminifera largely break down into sediments of coarse sand size (Woodroffe, 2002); concurrent with grain size and/or constituent analysis, it is possible to deduce the primary sediment contributors of a specific coastal landform (i.e. a barrier beach). As such it is then possible to identify how the sedimentary dynamics of those landforms may respond to the loss of specific reef dwelling organisms, or environmental forcing (i.e. storms).

Skeletal material is broken down by physical, biological and chemical processes (Ford, 2011). The rate at which they are broken down depends on the constituents' durability, with those that are highly durable, such as coral, compared to those which are more susceptible to breakdown, for example Halimeda (Ford, 2011; Ford and Kench, 2012). The rate of breakdown (and sediment productivity) of constituents also influences the degree to which they are represented in sedimentary systems and the conditions under which they are predominantly transported (Kench et al., 2005; Ford, 2011; Ford and Kench, 2012). Physical (or mechanical) breakdown occurs when constituents are entrained by hydrodynamic processes, causing fragmentation and abrasion (Ford, 2011; Ford and Kench, 2012). Clast breakdown is particularly prevalent under storm conditions (Ford, 2011). Considerable sediment breakdown is also attributed to bioerosion, whereby numerous organisms including, fish, echinoid taxa, sponges, bivalves and worms, feed on the coral reef (graze, etch and bore), and excrete unconsolidated sediment (Hutchings, 1986; Perry et al., 2008). Moreover they reduce the resilience of the primary and secondary reef framework, making it less durable to mechanical and chemical breakdown (Perry et al., 2008). Finally, chemical breakdown is largely controlled by grain mineralogy and the chemistry of the surrounding water. 

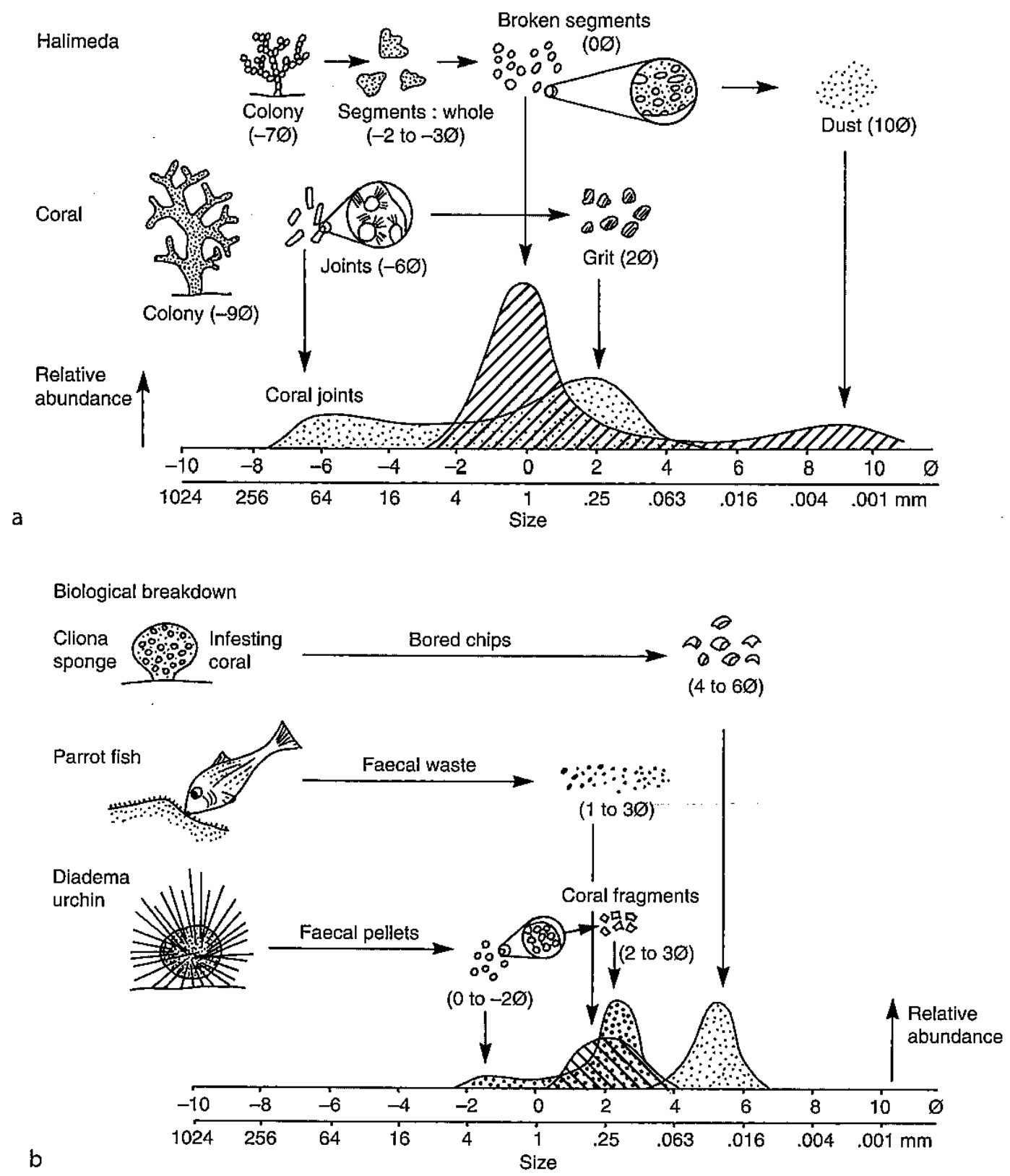

Figure 2-5: The Sorby Principle, which relates the size and breakdown of carbonate grains to specific sediment producing organisms (Folk and Robles, 1964). Taken from Scoffin (1992).

\subsubsection{Chemical transformation of sediment: micritisation and cementation}

Micritisation is the most commonly described form of sediment recrystalisation in tropical marine carbonate environments (Scoffin, 1987). This shallow-water process occurs when the calcium carbonate $\left(\mathrm{CaCO}_{3}\right)$ crystalline structure of the sediment grain is chemically altered, resulting in the loss of the internal structure of carbonate grains. It is thought the process begins when micro boring of sediments occurs, with the resulting holes conducive to $\mathrm{CaCO}_{3}$ precipitation (Scoffin, 1987). This begins in the skeletons of living organisms, but occurs more rapidly after they die. The process typically continues until the entire grain is 
micritised and unidentifiable; this can reduce the durability of the sediment further and accelerate sediment breakdown (Macintyre and Reid, 1995; Kennedy, 2003). Also of importance to coastal geomorphologists, the degree of sediment micritisation can be correlated to sediment residence time: older in situ reef-fringed beach and lagoon sediments typically contain high proportions of micritic material, whereas an influx of recently formed sediment does not.

Another prominent chemical alteration on coral-fringed coastlines is the cementation of carbonate grains, primarily in the intertidal and supra-tidal zones, which can form beach rock (Scoffin, 1987). This involves the precipitation of calcite, aragonite, micrite and Mgcalcite; however the transformation process remains unclear. It is thought to be catalysed by a rise in ionic concentration in beach sediment, due to the evaporation of drained seawater during outgoing tides, or from freshwater dissolution in the intertidal zone (Scoffin, 1987). The beach rock is cemented in situ beneath unconsolidated sediment, and is characterised by seaward-dipping layers which correspond to beach slope (Scoffin, 1987). Beach rock can also indicate former beach positions (Szabo et al., 1978; Ward and Brady, 1979).

\subsubsection{Coral reef-derived calcium carbonate landforms}

Coral reef-derived carbonate $\left(\mathrm{CaCO}_{3}\right)$ landforms are characterised by heterogeneous skeletal material which varies in size, shape, age, density, and durability (Kench, 2011). The oceanographic regime and sediment supply are the main controls on these landforms (Kench, 2011). As part of the oceanographic regime, storms and hurricanes have erosional and accretional impacts on $\mathrm{CaCO}_{3}$ landforms, with the response of a specific system dependant on the storm frequency and sediment texture.

Areas rarely affected by storms are typically composed of sand-sized sediment, the result of broken down skeletal material that has been reworked in situ for an extended period of time. These systems are susceptible to storm-driven erosion during the passage of major hurricanes; for example, some reeftop islands off Belize were severely eroded as a result of 1961's Hurricane Hattie (Kench, 2011). By contrast, areas of high storm frequency typically contain recent storm-derived rubble on their exposed margins, with sand-sized sediment predominating across the leeward margin and the fringing reef coastal plain (Kench, 2011). Gravel content has been seen to increase following storm events of higher intensity and frequency; sand content decreases in response (Figure 2-6).

Additionally, $\mathrm{CaCO}_{3}$ landforms (predominately small islands and sand cays) are vulnerable to changes in wind and wave patterns on a seasonal scale, and atmospheric circulation patterns (for example, the decadal oscillation in the Pacific Ocean) on a longer timescale. They are also affected by variations in sediment supply, including changes in net sediment generation and net littoral transport gradients (Kench, 2011). 

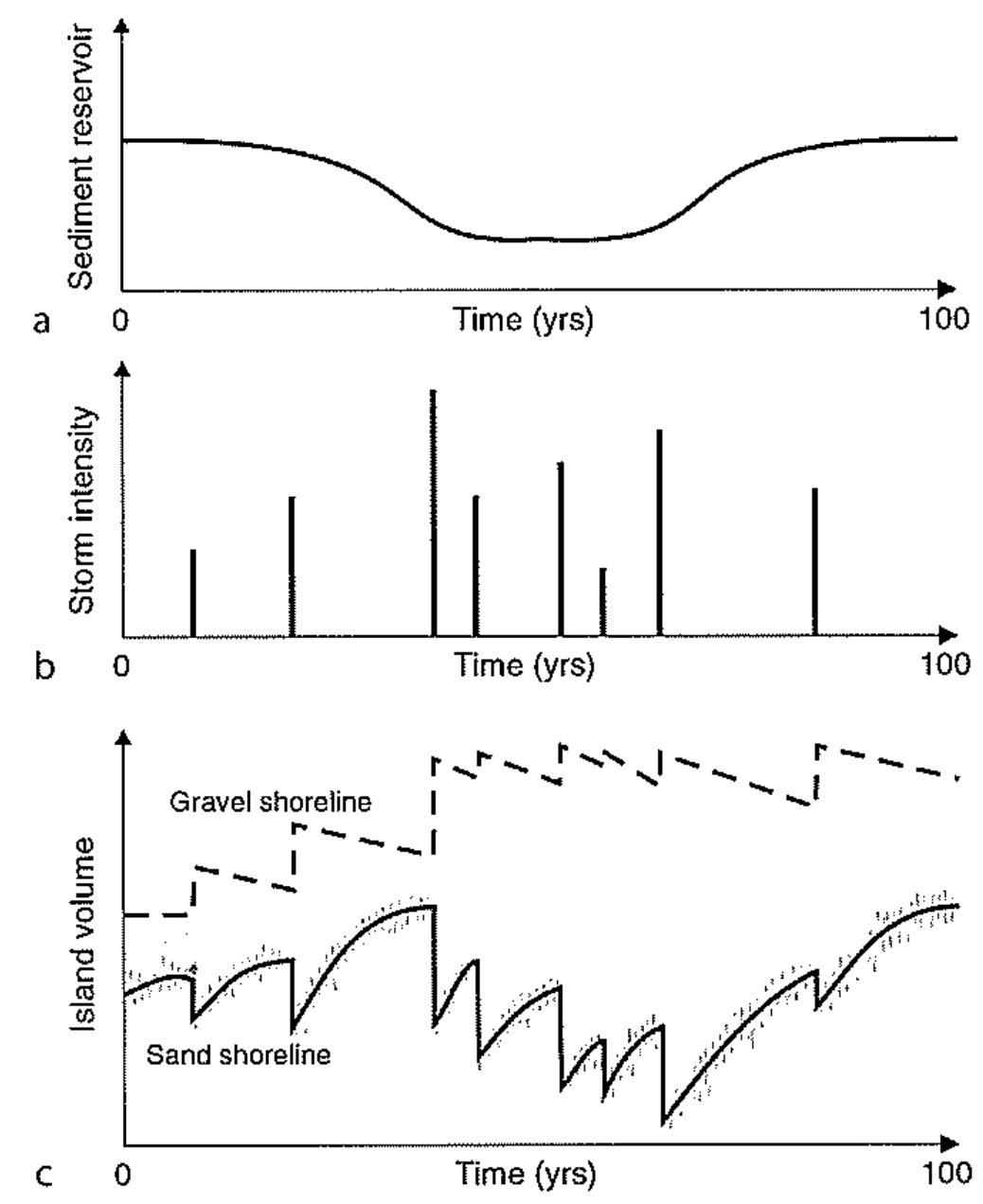

Figure 2-6: Temporal fluctuations in sediment storage and morphological change on reef islands with the incidence of tropical storms: (a) medium-term sediment fluctuations, (b) storm incidence and intensity, and (c) reef-island volumetric changes (Kench, 2011).

Waves and tidal-induced currents are the primary mechanisms of sediment transportation across coral reefs. Gravity waves (0.3-30 second wave period) dominate sediment dynamics on the reef flat, with wave energy greatest on the windward reef crest, from where it is dissipated by $70-99 \%$ by the time it reaches the shoreline (Kench, 1997; 1998). As such, the coarsest material remains on the reef crest, with sediment fining across the backreef as wave dissipation increases and sediment mobility decreases (Hopley, 1982). However, the energy flux is not constant, and wave dissipation fluctuates with changes in water depth through the tidal cycle (Kench and Brander, 2006).

The ability of waves to transport sediment is therefore dependant on the amount of energy leaked into the backreef lagoon; this may be controlled by wave height, tidal range, and the width and depth of the backreef lagoon (Kench and Brander, 2006). Kench and Brander (2006) proposed a method of calculating the 'leaked energy' using the aforementioned geomorphic and oceanographic variables, and relating it to the frequency and significance of sediment transportation; this is termed the reef energy window index ( $\Psi$ ) (Equation 2-1). 
Kench and Brander (2006) argued that wide, shallow lagoons are effective at dissipating wave energy, and as such sediment is likely to be mobile only under high energy conditions. Such lagoons are therefore geomorphically inactive under the prevailing conditions. In contrast, narrow, deep lagoons are considered geomorphically active, with sediment highly mobile under most conditions (Kench and Brander, 2006).

$$
\text { Reef energy window index }(\Psi)=\frac{\text { Backreef lagoon depth at MHWS }}{\text { Backreef lagoon width }}
$$

Equation 2-1: Reef energy window index (Kench and Brander, 2006).

\subsection{Tropical storms: drivers of barrier beach morphology}

Tropical cyclones are known by different names in different oceanic basins. When they first develop they are known as tropical depressions and have maximum sustained winds speeds of up to $17 \mathrm{~ms}^{-1}$; as wind speeds increase to between 18 and $32 \mathrm{~ms}^{-1}$ these systems are named, and are referred to as tropical storms. When wind speeds exceed $33 \mathrm{~ms}^{-1}$ they are classified as hurricanes in the Western North Atlantic and Eastern North Pacific, typhoons in the Western North Pacific, and severe tropical cyclones in the South Pacific and South Indian Ocean (Emanuel, 2003). Tropical cyclones rotate in a counter clockwise direction in the northern hemisphere, and a clockwise direction in the Southern hemisphere (Pielke, 1990). In this study the term hurricanes will be used to represent those events where maximum sustained wind speeds exceed $33 \mathrm{~ms}^{-1}$.

\subsubsection{Formation and structure}

Tropical storms and hurricanes only form under specific environmental conditions. They are largely confined between $5^{\circ}$ and $20^{\circ}$ latitude, with the notable exception of the relatively small South Atlantic basin. The critical factors necessitating storm initiation include:

1. A sea surface temperature of at least $26^{\circ} \mathrm{C}$ (to a depth of $60 \mathrm{~m}$ ), which restricts these systems to within $20^{\circ}$ latitude of the equator.

2. Atmospheric circulation driven by Coriolis force, which excludes these storms from within $5^{\circ}$ of the equator.

3. A great enough gradient of air temperature change with height such that air is saturated with water vapour as it rises and continues to follow the moist air adiabat (near the eye wall).

4. Low vertical shear, which is the gradient of horizontal wind with height near the cyclone's centre; this is important to maintain the vertical structure.

5. Sufficiently high relative humidity in the mid troposphere; this avoids the drying-out effects as air is mixed in deep convective clouds in the eyewall updraft.

6. Low altitude cyclonic vorticity.

(Gray, 1968; Gray, 1979; Pielke, 1990; Gray, 1998) 
Tropical storms and hurricanes originate as tropical disturbances, which consist of groups of disorganised thunderstorms with weak pressure gradients and little or no rotation (Pielke, 1990; Emanuel, 2003). They develop from either the migration of midlatitude troughs into the tropics, convection associated with the Intertropical Convergence Zone (ITCZ), or Easterly waves (Atlantic) or similar causing large undulations in normal trade wind patterns (Pielke, 1990; Emanuel, 2003). Under favourable atmospheric conditions tropical disturbances may develop into a tropical depression, tropical storm or hurricane (Pielke, 1990).

The largest of these storm assemblages may strengthen into a hurricane as the thunderstorms become organised and structured in a funnel formation (Figure 2-7). The thunderstorms and associated bands of thick cloud rotate around a central vortex and may extend up to 1,000 km laterally from this point (Simpson and Riehl, 1981; Emanuel, 2003). The central vortex (or eye) is characterised by descending air and low barometric pressure, which can extend 7-8 km high and 20-50 km wide (Simpson and Riehl, 1981; Emanuel, 2003). It is surrounded by the eye wall, the most intense section of the storm, which is typically 1-2 km wide (Simpson and Riehl, 1981). Rainfall decreases towards the outer reaches of the hurricane, as do wind speed and pressure gradients (Pielke, 1990). Stronger winds are experienced on the right side of the hurricane (northern hemisphere), as it tracks in a forward motion (Coch, 1994; Morton, 2002).

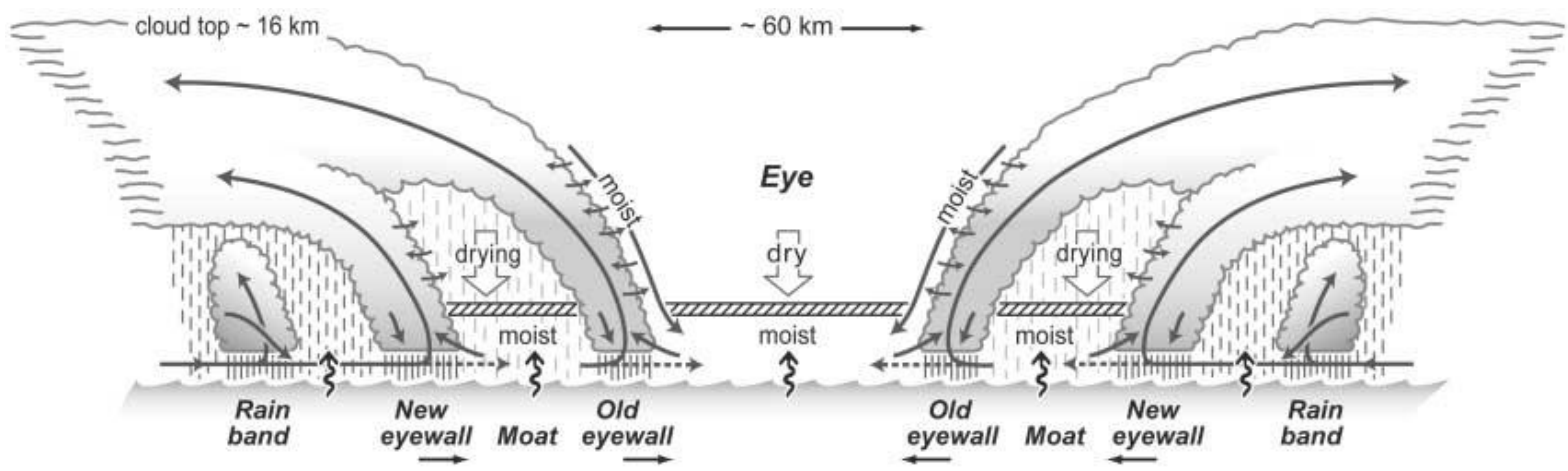

Figure 2-7: Structure of a hurricane; the direction of wind rotation is dependent on the hemisphere (Houze et al., 2007).

\subsubsection{Storm phenomena and classification}

Several atmospheric and oceanic phenomena are typically associated with tropical storms and hurricanes including storm surges, large storm generated waves, strong winds, and heavy rainfall (Simpson and Riehl, 1981; Pielke, 1990). These phenomena have been responsible for considerable geomorphic alteration of barrier beach systems (Kahn and Roberts, 1982; Phillips, 1999).

Storm surge is the temporary rise in relative sea level, as a result of low atmospheric pressure. It arguably has greatest impact on the coastal morphology of barrier beaches (Woodroffe, 2002; Irish et al., 2008). Referred to as the inverse barometric pressure effect, 
the ocean is forced up beneath the hurricane and is greatest at the eye (where pressure is the lowest) and decreases towards areas of higher pressure (Morton, 2002; Irish et al., 2008). However, due to other factors such as wind stress, the maximum storm surge may not necessarily be located at the centre of the storm (Coch, 1994). As wind forcing also generates storm surge by forcing water on to the coastline (often referred to as wave stackup), the maximum storm surge height may occur where wind forcing plays a contributory role (Coch, 1994). The storm size may also play a role in surge height (Irish et al., 2008).

Storm surges are often accompanied by large storm generated waves which alter coastal morphology further. These two phenomena are often discussed as one of the same, and are referred to as storm waves. The geomorphic impact of these phenomena has been illustrated on many occasions; for example, when 2005's Hurricane Katrina made landfall along the Gulf Coast of Florida, Alabama, Mississippi and Louisiana, it produced storm waves in excess of 10 metres. This resulted in shoreline retreat of approximately $100 \mathrm{~m}$ and vertical erosion of up to $0.7 \mathrm{~m}$ on Mississippi and Alabama barrier islands (Fritz et al., 2007).

Furthermore, strong winds produced by storms can damage vegetation, drive aeolian transportation and contribute additional energy to oceans, bays and lagoons; this further amplifies storm surge and storm waves (Hook et al., 1991; Doyle et al., 1995; Morton, 2002). For example, strong winds generated by 1992's Hurricane Andrew resulted in extensive damage to mangrove forests along the southwest coast of Florida, USA (Doyle et al., 1995). Doyle et al. found that the type and extent of damage caused by this hurricane generally decreased exponentially with distance from the eye, while greater damage was also recorded to the right of the storm. One other phenomenon associated with storms, heavy rainfall, can result in flooding of coastal water bodies, such as barrier enclosed lagoons, with sediment transported seaward (Morton, 2002).

Not all storms function in the same manner, and as a result of ever-changing atmospheric conditions the abovementioned phenomena vary considerably in their resulting behaviours. As such, storm classifications have been developed to represent the intensity of individual events and their potential impacts. The most widely used of these is the 'Saffir-Simpson Hurricane Scale' (Table 2-2). This scale categorises storms based on the maximum sustained wind speed and/or maximum surface pressure they attain (Simpson, 1974). Where winds exceed $33 \mathrm{~ms}^{-1}$ or surface pressure falls below $920 \mathrm{mb}$, tropical cyclones are classified as hurricanes, and then categorised on a scale of one to five, with ratings increasing with strengthening events (Simpson, 1974). Within each of these categories the likely storm surge height and potential damage of the storm is detailed, and is based on extensive analysis of past hurricane events (Simpson, 1974). A range of factors influence a given storm surge: depth, slope and width of the continental shelf. As such this scale is to only be used as a preliminary guide. 
Table 2-2: Saffir-Simpson Hurricane Scale showing the maximum sustained wind speed, maximum surface pressure, storm surge height, and potential damaging effects associated with each of the hurricane categories (Simpson, 1974). Adapted from Landsea (1993).

\begin{tabular}{c|c|c|c|c}
\hline $\begin{array}{c}\text { Saffir-Simpson } \\
\text { Category }\end{array}$ & $\begin{array}{c}\text { Maximum sustained wind } \\
\text { speed }\left(\mathbf{m s}^{-1}\right)\end{array}$ & $\begin{array}{c}\text { Maximum surface } \\
\text { pressure }(\mathbf{m b})\end{array}$ & Storm surge (m) & $\begin{array}{c}\text { Potential } \\
\text { damaging effects }\end{array}$ \\
\hline 1 & 33 to 42 & $\geq 980$ & 1.0 to 1.7 & Minimal \\
2 & 43 to 49 & 979 to 965 & 2.6 & Moderate \\
3 & 50 to 58 & 964 to 945 & 3.8 & Extensive \\
4 & 59 to 69 & 944 to 920 & Extreme 5.6 & $>5.6$
\end{tabular}

\subsection{Effects of tropical storms on barrier beaches}

The response of barriers to storms is highly variable, with geomorphic change found to be highly localised (Sallenger (Jr.), 2000; Morton, 2002; Wang et al., 2006). Research to date has largely focused on the immediate impact of hurricanes on barriers, and has paid little attention to the short (0-1 years), medium (1-5 years), or long-term (> 5 years) responses. To date, coastal research has primarily focussed on the effects of tropical storms on siliceous coastlines, particularly the barrier beaches and barrier islands of the Gulf and East coasts of the United States. Comparatively, little work has been done on coral-fringed calcium carbonate coastlines.

\subsubsection{Immediate barrier response to tropical storms}

Over the past three decades research into the response of barriers to storm events has largely focused on quantifying and describing shoreline migration (Kahn and Roberts, 1982; Morton and Paine, 1985; Phillips, 1999; Otvos, 2004; Robertson et al., 2007; Priestas and Fagherazzi, 2010), changes in beach and/or dune morphology, and changes to their sediment and vegetative character. More recently, the process by which these changes occur and various storm thresholds have also been proposed (Sallenger, 2000; Morton, 2002).

The response of the shoreline to storm events is highly variable both temporally, as a result of different storms, and spatially, as barriers respond in different ways alongshore. The shoreline may erode landward, accrete seaward, or maintain its position. The shoreline erodes landward as storm waves and currents remove sediment from the beach; sediment is either deposited on the upper shoreface (Komar, 1976; Lee et al., 1998; Hill et al., 2004) washed inland (Kraft et al., 1987; Morton and Sallenger, 2003), or transported alongshore (Kahn and Roberts, 1982). For example, Hurricane Frederic (1979), a category 4 event which made landfall on the Gulf Coast state of Louisiana, USA, produced a storm surge in excess of $3.5 \mathrm{~m}$ and resulted in the shoreline of the southern Chandelier Islands barrier system retreating by an average of $30 \mathrm{~m}$. However, at some sites barrier retreat was as much as 70m; an additional 50 to 100 m of mangrove marsh was also lost (Kahn and Roberts, 1982). 
In this instance, storm wave overwash flattened the barrier and sediment was transported offshore and into the littoral zone during the ebb flow, after which it was lost from the system (Kahn and Roberts, 1982).

Alternatively the shoreline may accrete seaward of the pre-storm position. This occurs as a result of reworking of the beach and dunes and subsequent redistribution of sediment seaward of the pre-storm profile, deposition of sediment transported alongshore, or deposition of material derived offshore, such as from coral reefs (Kahn and Roberts, 1982; Kench, 2011). For example, 2005's Hurricane Dennis, a category 3 storm which made landfall on St George Island (a barrier island in the Florida Panhandle, USA) produced a 2.5 $\mathrm{m}$ storm surge and resulted in up to $10 \mathrm{~m}$ of shoreline accretion as the beach and foredunes were either partially or completely reworked (Priestas and Fagherazzi, 2010). During the initial stages of the storm, wave overwash dominated and sediment was transported over the barrier and into the lagoon (Priestas and Fagherazzi, 2010). However, as the storm passed over the barrier island, the direction of wind forcing and storm surge relative to the coastline changed and sediment reverted to being transported seaward across the beach face during the ebb flow (Priestas and Fagherazzi, 2010). Lastly, where limited storm wave inundation occurs, there may be no observable change to the position of the shoreline.

Further to this, storm waves are a major driver of barrier morphology, in particular the shape and subaerial features of beaches and dunes. Field investigations suggest storm waves typically rework the beachface to either a planar seaward dipping surface or slightly upward tilting concave profile (Leatherman, 1979b; Morton and Paine, 1985; Penland et al., 1989; Birkemeier et al., 1991; FitzGerald et al., 1994). Unconsolidated dunes tend to respond to storm waves by being partially or completely eroded, or by transgressing inland (Morton, 2002). In contrast, well vegetated dunes tend to maintain a greater proportion of sediment and structure, and as such maintain some future resilience to storms (Morton and Paine, 1985; Morton, 2002). Other research has detailed the storm-driven sedimentological change of barriers (e.g. Wang et al. $(2006 ; 2007)$ ), and storm impacts on coastal vegetation, such as those described by Doyle et al. (1995) on mangrove forests in Florida (as mentioned earlier).

The response of barriers to storm events is often expressed as a number of impact and inundation stages (Ritchie and Penland, 1988; Sallenger, 2000; Morton, 2002; Morton and Sallenger, 2003; Houser et al., 2008a). Thresholds between storm waves, and beach and dune heights are typically detailed (Figure 2-8), and as such these models attempt to illustrate how these landforms would be expected to respond under measured storm wave conditions. These models typically encompass several stages as follows: 


\section{Stage 1: Swash Regime ( $\boldsymbol{R}_{\text {Low }}$ - Shoreface and beachface concentrated reworking}

This first stage of storm inundation is represented by relatively small storm waves. Wave energy is concentrated on the beach face, and wave run-up does not overtop the berm crest or reach the dune toe (Morton, 2002). The beach face is eroded and sediment is transported and deposited offshore (temporarily), often as sand bars (Houser and Hamilton, 2009). Erosion is generally short-term and sediment is transported back onshore under normal conditions, often within a few weeks or months of the storm (Sallenger, 2000). This stage is most prominent during low intensity storms, or high intensity storms which are a considerable distance from coast (Sallenger, 2000).

\section{Stage 2: Collision Regime $\left(\boldsymbol{R}_{H I G H}\right)$ - Back beach and foredune face concentrated reworking}

Under larger storm waves, wave run-up also inundates the back beach and dunes, however it does not overtop these features. Net erosion often results, as sediment is stripped and transported offshore to be deposited as submarine bars or lost either offshore or alongshore (Sallenger, 2000; Morton, 2002). In contrast to stage 1, much of the sediment displaced during this stage does not return and is lost from the system (Houser and Hamilton, 2009).

\section{Stage 3: Overwash Regime ( $D_{\text {Low }}$ ) - Foredune concentrated reworking}

With larger waves, wave run-up may overtop the dunes. Depending on the storm wave height relative to the dunes, water can flow over the dunes at speeds in excess of $2 \mathrm{~m} / \mathrm{s}$, slowing with inland penetration (Sallenger, 2000). Landward inundation may extend from tens of metres to hundreds of metres. Unvegetated dune depressions are the first to be penetrated (Wright et al., 1970; Kahn and Roberts, 1982). The back beach and dunes are eroded and sediment is transported inland. The dunes or barrier transgress landward as a result (Sallenger, 2000).

\section{Stage 4: Inundation Regime $\left(D_{H I G H}\right)$ - Entire barrier reworking}

This stage represents full inundation, when sea level is elevated to a height that the beach and dune system is completely submerged. The whole beach profile is thought to undergo surf zone type processes, though this is not clearly understood (Sallenger, 2000). Dramatic geomorphic change results, and in some cases beaches may be completely stripped of sand. Sediment is predominately transported landward and considerable coastal transgression may result (Sallenger, 2000; Morton, 2002). 

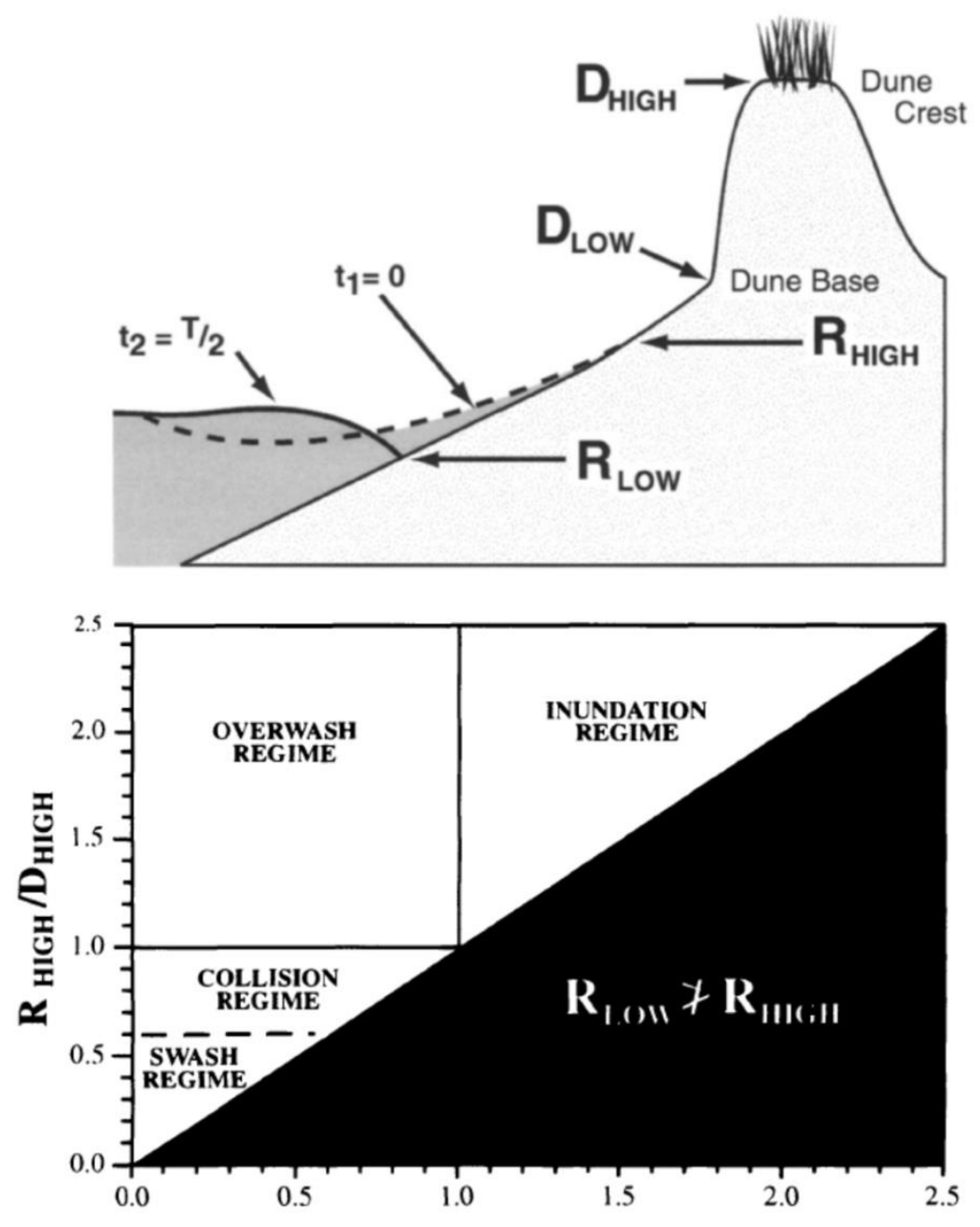

Figure 2-8: Storm inundation regimes as determined by the storm wave height relative to beach and dune height (Sallenger, 2000).

\subsubsection{Determinants on barrier beach response to tropical storms}

The response of barrier systems to storms is highly variable, and is influenced by several factors including the geomorphology and nature of the continental shelf, storm profile, event timing and duration, and storm recurrence (Morton, 2002; Morton and Sallenger, 2003; Wang et al., 2006; Claudino-Sales et al., 2008; Houser et al., 2008a; Priestas and Fagherazzi, 2010; Qi et al., 2010; Weaver and Slinn, 2010).

The continental shelf influences storm wave height on the coastline, with wider and shallower shelves typically conducive to greater storm surge, as water builds up on the coastline more effectively in comparison to narrower, steeper shelves. Similarly, coral reefs influence the storm wave profile at the coastline, specifically by forcing wave breaking and wave energy dissipation as waves pass over these structures (Gourlay, 1994; Kench and Brander, 2006; Fernando et al., 2008). The dissipation of wave energy has been modelled and measured to be in the order of $70-90 \%$ under normal sea conditions (Massel and Gourlay, 2000) and as much as $94-99.5 \%$ under low water conditions (Kench and Brander, 
2006). However, the efficacy of the coral reef under storm conditions is likely to be much less as wave energy dissipation decreases with increasing water depth due to storm surge sea level elevation. Wave dissipation is also dependent on the morphology of the coral reef and alongshore continuity (Woodroffe, 2002). In addition, some researchers also suggest that mangrove wetlands reduce storm wave energy by increasing bottom friction and limiting storm wave inundation (Halford, 1995; Loder et al., 2009). However the efficacy of these in coastal settings requires further research.

Furthermore the elevation, slope, width, and alongshore continuity of the beach and dunes is essential for determining the resilience of the barrier to storm waves and the geomorphic change which may result (Morton, 2002; Morton and Sallenger, 2003; Wang et al., 2006). Of these, the foredune is the most critical, with higher and wider dunes more resilient to storm waves (Morton, 2002; Morton and Sallenger, 2003; Wang et al., 2006). Where dunes are either undeveloped or absent the barrier becomes vulnerable to full storm wave inundation; alongshore areas of lower relief are exceeded first (Morton, 2002). Vegetation also has some influence on barrier response to storms, with the type, height, rooting depth and density the most influential vegetation characteristics (Türker et al., 2006). Vegetation can influence barrier response by reducing wind speeds and as such aeolian sediment transportation (Powell and Houston, 1996b). It also increases bottom friction, and therefore reduces storm wave overwash in a similar way to mangrove wetlands (Morton and Paine, 1985; Halford, 1995), and captures sediment (Cahoon et al., 1995b). Furthermore vegetation also stabilises sediment, reducing dune susceptibility to storm wave or aeolian erosion (Stoddart, 1964; Ritchie and Penland, 1988).

The geomorphic response of barriers to storms is also largely dependent on the nature of the storm, in particular the location and orientation of the storm relative to the coastline (Perkins and Enos, 1968; Simpson and Riehl, 1981; Morton, 2002). The trajectory of a storm relative to the coastline affects the size of the storm waves, wind direction and sediment transport directions (Perkins and Enos, 1968; Simpson and Riehl, 1981; Coch, 1994; Morton, 2002; Wang et al., 2006). In the instance of a hurricane tracking directly towards the coastline (northern hemisphere), beaches to the right of the hurricane eye are subject to compounding storm phenomena, as vortex winds and steering winds travel in the same direction, increasing wind forcing and amplifying storm waves (Pore, 1960; Perkins and Enos, 1968; Penland et al., 1989; Coch and Wolff, 1991; Coch, 1994; Morton, 2002). Storm wave overwash typically results, with sediment transported inland (Wang et al., 2006; Priestas and Fagherazzi, 2010).

In contrast, barrier beaches to the left of the eye (northern hemisphere) experience less intense storm phenomena, as vortex winds and steering winds travel in opposite directions, dampening down the wind forcing and producing a smaller storm surge (Pore, 1960; Penland et al., 1989; Coch and Wolff, 1991; Coch, 1994; Morton, 2002). In these cases dune washout may occur as wind forcing elevates coastal lagoons above dune crests and transports sediment seaward across the beach (Morton and Paine, 1985). Furthermore the 
storm intensity as measured against the Saffir-Simpson Hurricane Scale has considerable impact over barrier response.

The timing, duration and recurrence of storms can have considerable impact on barrier morphology and longer term barrier evolution. The coincidence of storms with high tides, particularly spring tides, will result in storm waves being amplified further with greater geomorphic response (Rodríguez et al., 1994; Zhang et al., 2001). Storm duration also affects the length of inundation by storm waves and strong winds, with relatively weak but slow storms having a similar impact to more intense but faster moving systems (Zhang et al., 2001; Morton, 2002). For example, the Galveston Island barrier system, Texas, USA, responded in similar ways to Hurricane Alicia (1983), a fast moving category 3 hurricane, and Tropical Storm Frances (1998), a much weaker, but slower moving system (Morton, 2002). Therefore an intense, slow moving hurricane would likely drive the most significant geomorphic change.

Finally, storm frequency affects the geomorphic response of barriers to successive events, with frequent inundation causing preferential reworking of previously eroded dunes, in a type of positive feedback (Fearnley et al., 2009; Houser and Hamilton, 2009). Where storm waves inundate and erode the beach and dunes, the barrier is left vulnerable to future events and can be more easily breached during successive events (Phillips, 1999; Fearnley et al., 2009; Houser and Hamilton, 2009). For example, the Santa Rosa Island barrier system, Northwest Florida, USA, was inundated by three hurricanes in relatively short succession: 2004's Hurricane Ivan, 2005's Hurricane Dennis, and 2005's Hurricane Katrina (Houser and Hamilton, 2009). Storm waves from Hurricane Ivan eroded dunes which were still recovering from 1995's Hurricane Opal, and washed sediment landward (Houser and Hamilton, 2009). Dunes were then breached with ease and masses of material were transported landward by Hurricanes Dennis and Katrina (Houser and Hamilton, 2009).

\subsubsection{Post-storm barrier beach response}

Research has tended to focus on the immediate response of beaches and dunes to storm events, with very few studies monitoring medium (1-5 years) or long-term ( $>5$ years) changes (Morton et al., 1994; Houser and Hamilton, 2009); this is of concern, particularly when temporally constricted studies are used to make judgements on longer-term barrier evolution. However, some such studies have quantified change over longer temporal scales, and includes the studies of Morton et al. (1994) on the Galveston Island barrier system, Texas, USA; Lee et al. (1998) at the US Army Corps of Engineers Duck Field Research Facility on the Outer Banks barrier system, North Carolina, USA; and Houser (2009) on the Santa Rosa Island barrier system, northwest Florida, USA. Despite these studies, a significant gap remains in understanding how these systems operate over longer time-scales, and the role of tropical storms to their evolution.

With relatively few longer-term studies, the medium-term (1-5 years) response of barrier beaches to tropical storms remains largely unknown (Zhang et al., 2002; Houser and 
Hamilton, 2009); moreover, even short-term (0-1 year) responses are unknown on coralfringed calcium carbonate barrier beaches. From the research that has been conducted, Morton et al. (1994) proposed four stages of post-storm beach and dune recovery (Figure 29); these were based on the results of a decade-long study at seven sites on the Galveston Island barrier system, following the passage of Hurricane Alicia (1983), and include:

\section{Stage 1: Berm reconstruction and forebeach accretion}

Berm reconstruction and forebeach accretion begin immediately after the passage of a storm, and generally last from anywhere between a few months to a year. Sand from subaqueous bars is transported onshore and deposited on the upper shore face.

\section{Stage 2: Back beach aggradation}

Back beach aggradation follows, with onshore winds and back beach wave inundation depositing sediment from the back beach through to the storm-eroded foredune scarp. This process may begin soon after the storm, or during the second summer following the storm.

\section{Stage 3: Dune formation}

Stage three is dominated by dune formation. Aeolian processes prevail and vegetation begins to re-colonise the back beach, promoting sediment accumulation and dune formation. Hummocky mounds begin to develop in the back beach, later transforming into patchy incipient dunes and a more continuous foredune ridge. The extent of dune formation is largely dependent on the pre-storm vegetative cover and the depth of beach scour. This stage can continue for several years.

\section{Stage 4: Dune expansion and re-colonisation}

The final stage, dune expansion and re-colonisation, results in increasing vegetative cover and ongoing dune development. Dunes become higher, wider and more extensive alongshore. 

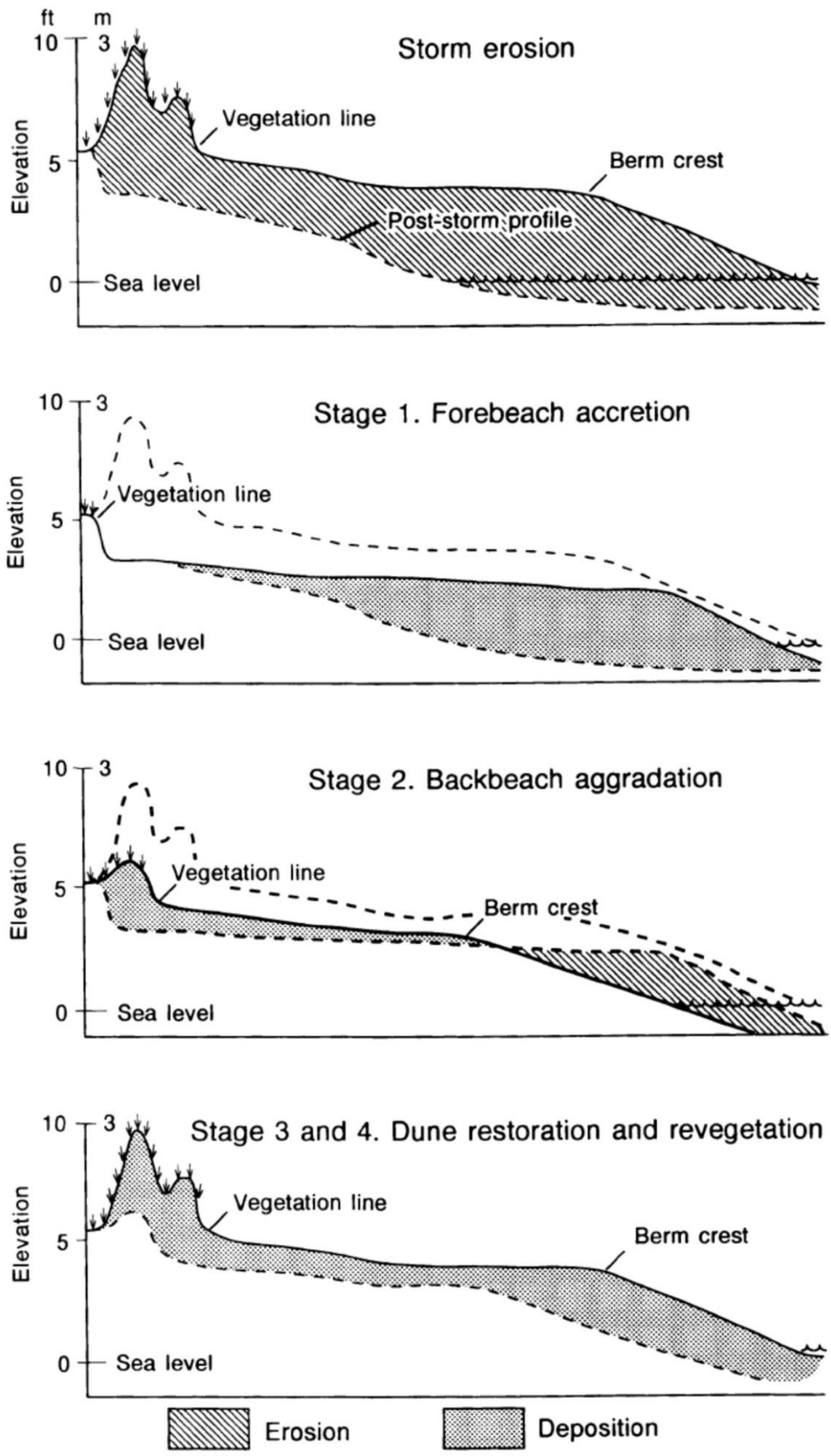

Figure 2-9: Stages of post storm barrier beach recovery, based on a decade-long study at seven sites on the Galveston Island barrier system (Morton et al., 1994). 


\subsection{Summary}

Research into the geomorphic response of barrier beach systems to tropical storms has largely focused on the immediate changes of Gulf and East Coast barrier islands in the United States, which are characterised by siliceous sediments. These studies have found the response of barriers to be highly variable and geomorphic change highly localised. In some instances the results of these studies has been used to postulate the evolution of barrier beach systems over longer temporal scales, in different geographic locations, and under future climatic scenarios. However, these extrapolations cannot be applied with confidence beyond the specific barrier settings, characteristics and temporal periods, from which the information is derived.

Studies which have been conducted on coral-fringed calcium carbonate landforms have tended to focus on the sedimentary dynamics of reef islands. This research suggests the two primary controls on these landforms are the sediment supply and oceanographic regime, with storm activity also playing a role in sediment flux. Therefore, there is a significant need for research into the short (0-1 year) to medium-term (1-5 years) response of barrier beach systems to storms in calcium carbonate settings; such research would help shape scientific understandings of these environments, and enable more robust prediction of barrier beach response to tropical storms in similar settings. 


\section{Regional Setting}

\subsection{Introduction}

This study examines shore-attached barrier beaches on predominately natural sections of the northeastern Yucatan Peninsula, Mexico (Figure 3-1). The beaches studied lie between

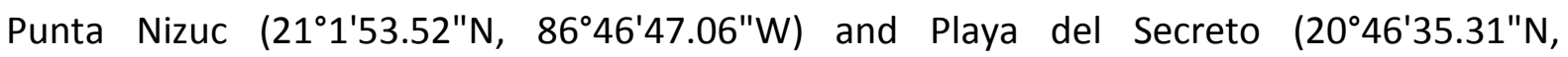
$\left.86^{\circ} 56^{\prime} 38.06^{\prime \prime} \mathrm{W}\right)$, an expanse of approximately $35 \mathrm{~km}$ (Figure 3-2).

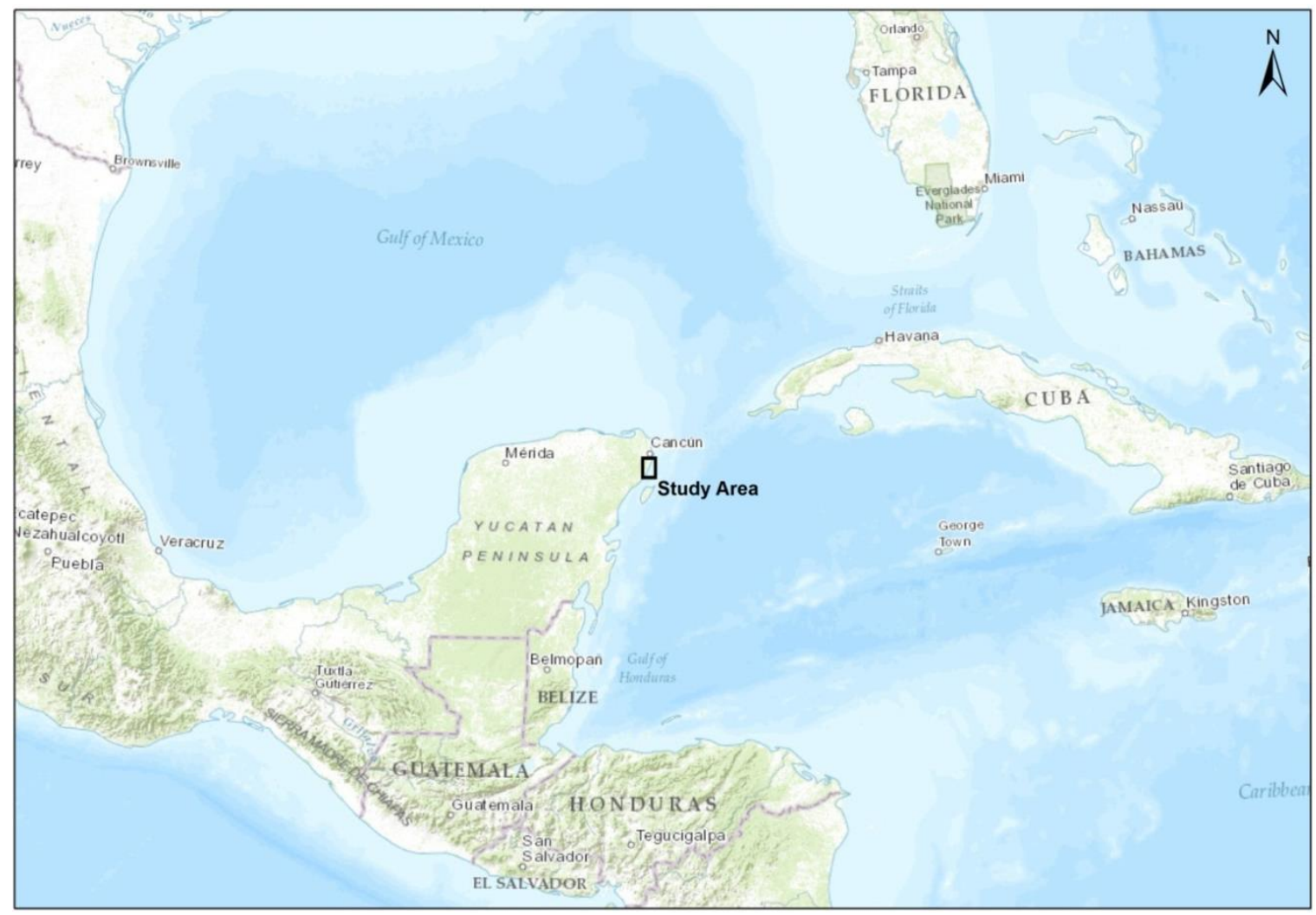

Figure 3-1: Geographic location of the study area in northeastern Yucatan Peninsula, Mexico, and within the Caribbean Sea and Atlantic Ocean. 


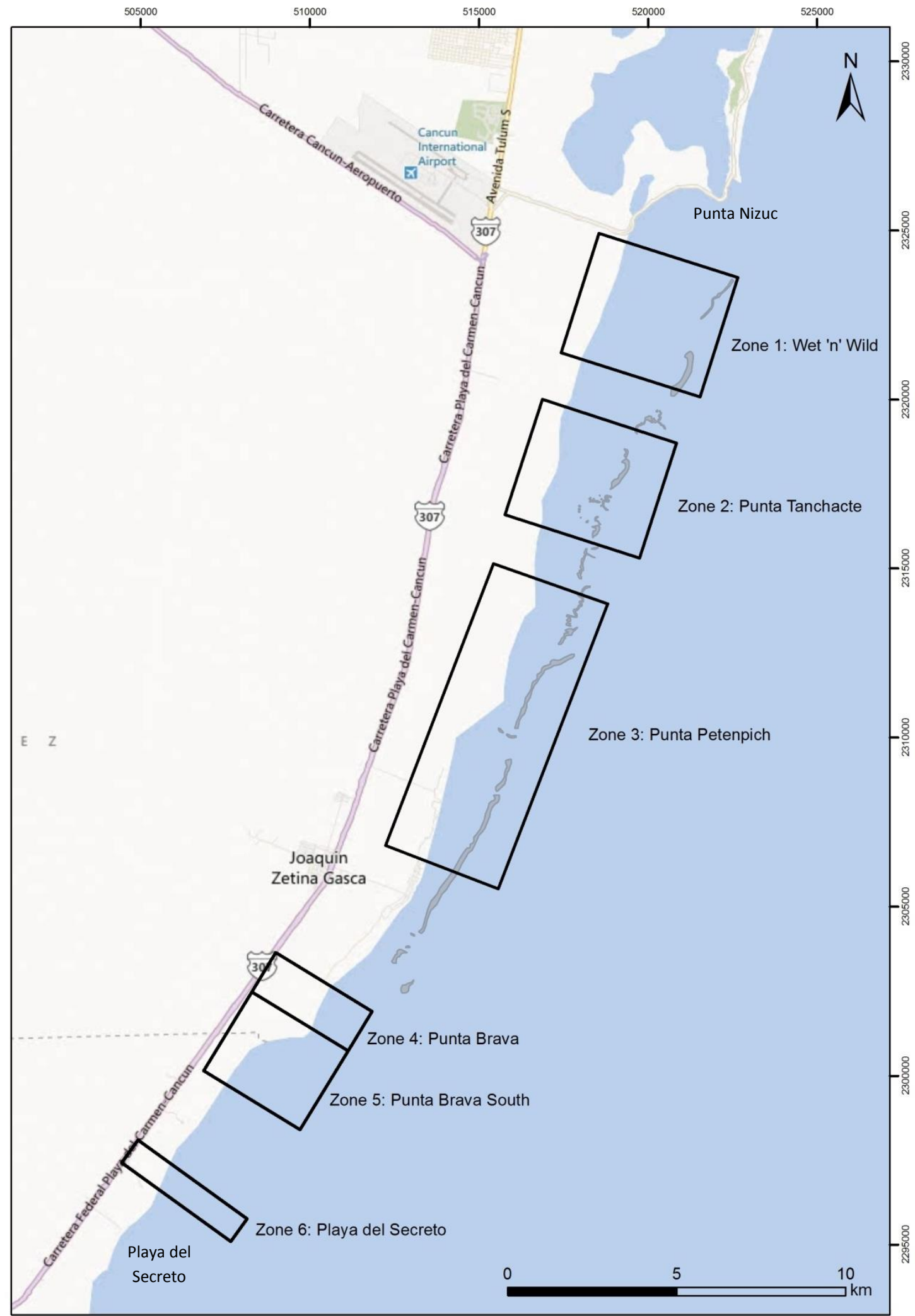

Figure 3-2: Map showing the study area outlined in Figure 3-1 on the northeastern Yucatan Peninsula, Mexico. The six zones investigated in this study are outlined. 
The barrier beaches in this study most closely resemble the 'stationary barriers' in the 'stillstand phase' (refer to Section 2.2.2), under the current climatic conditions. However, they are much more complex than the siliceous barriers of which the models of Roy et al. (1994) and Hesp and Short (1999) are based: the barriers are separated from a late Pleistocene sea cliff (Marine Isotope Stage (MIS) 5e) by mangrove wetlands (Szabo et al., 1978), which are largely cut-off from the Caribbean Sea. Together with the barrier they form a coastal plain of Holocene age (Szabo et al., 1978; Blanchon, 2010). On the seaward side, the barrier beach is fronted by the Mesoamerican Barrier Reef System (MBRS), the second largest coral reef system in the world, which runs from the Yucatan Channel in the north to Honduras in the south (Coronado et al., 2007). The section of the MBRS relevant to this study is characterised by discontinuous fringing reefs and shallow backreef lagoons; as such both reef-protected and unprotected barrier beaches can be found (Ward, 1985; Coronado et al., 2007).

Therefore, a more appropriate description of the broad barrier beach types and geomorphic forms investigated in this study could be termed type 1: shore-attached, coral-fringed, $\mathrm{CaCO}_{3}$ barrier beaches, and type 2: shore attached, open-ocean, $\mathrm{CaCO}_{3}$ barrier beaches, both which are currently in a stillstand phase, set within a longer-term erosional phase.

\subsection{Geological setting}

The Yucatan Peninsula and adjacent shelf form a limestone platform of Tertiary to Quaternary age (Weidie, 1976; Ward, 1985). Dominated by upper Pleistocene limestone, the platform is a mix of low magnesium calcite and aragonite mineralogies (Stoessell et al., 1989). Underlying the carbonates is a basal Mesozoic sequence, which is dominated by red beds (Todos Santos Formation) of Triassic to Cretaceous age (Viniegra-O, 1971; Weidie, 1976; Ward, 1985; Weidie, 1985). However basement rocks of late Palaeozoic, or older, have been found in southern parts of the peninsula, namely, Belize and Honduras (Ward, 1985; Weidie, 1985). The peninsula has been relatively stable since at least late Pleistocene time (120-130 ka), and has been largely tectonically inactive since the Eocene (55 Ma) (Szabo et al., 1978; Pindell and Barrett, 1990; Blanchon, 2010).

Surface sediments of the northeastern Yucatan Peninsula have largely been deposited during the Quaternary, and at least three Pleistocene units have been identified (Table 3-1 and Figure 3-3) (Ward, 1985). It has been suggested that the lowest of the three Pleistocene units was deposited somewhere between $200 \mathrm{ka}$ and $800 \mathrm{ka}$, based on the results of uranium-series age dates of corals (Ward, 1985). The middle unit dates back two glacial cycles (MIS 7) to approximately 200 ka (Harmon et al., 1983; Ward, 1985; Ward and Halley, 1985). The upper unit was deposited during the penultimate interglacial (MIS 5e), 120 ka to $130 \mathrm{ka}$, when the Caribbean Sea reached a highstand, approximately $6 \mathrm{~m}$ above present level (Szabo et al., 1978; Ward, 1985). However this was short-lived, lasting no more than 10 ka; as such deposition of this upper unit was limited (Steinen et al., 1973; Harmon et al., 1981; Harmon et al., 1983; Ward, 1985; Blanchon, 2010). Each of the Pleistocene units is 
capped by a caliche layer, which formed as a result of prolonged periods of subaerial exposure during glacial periods (Ward, 1985; Ward and Halley, 1985).

Table 3-1: Geological record of northeastern Yucatan Peninsula, Mexico (Ward, 1985).

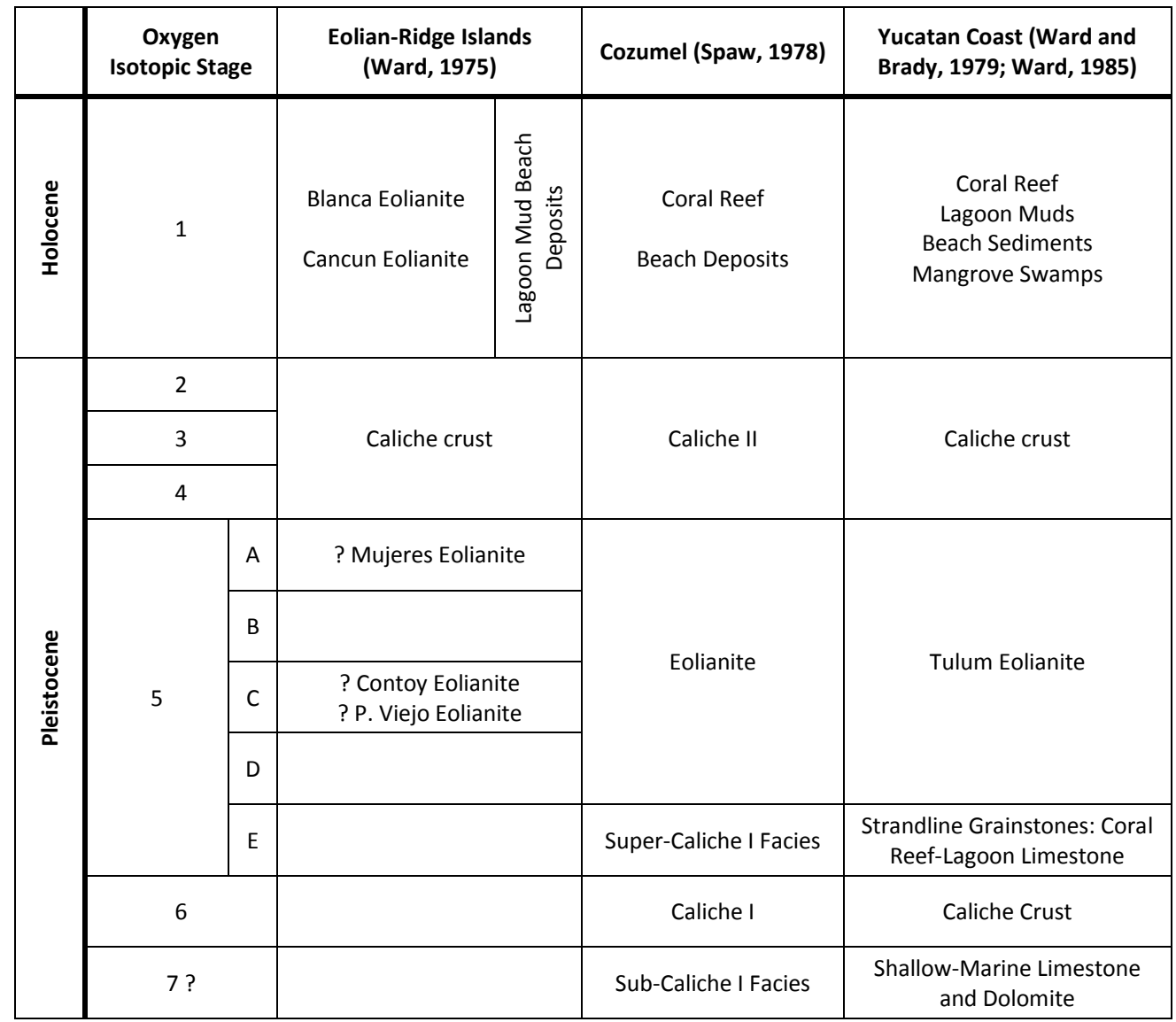

The Caribbean shelf is situated on the eastern margin of the Yucatan Peninsula and is relatively narrow at 5-10 km wide in the north and central region, and only a few kilometres wide in the south (Ward and Wilson, 1976; Ward, 1985). Further to this, there is a distinct difference in the shelf slope between the northern and southern sections of coastline relevant to this study (Ward, 1985). This is largely due to a sequence of north-northeast trending normal faults, which are also responsible for a series of northeast trending ridges and basins (Weidie, 1985; Perry et al., 2002; Perry et al., 2009). From the northeastern tip of the shelf, southwest to Puerto Morelos, the shelf slope is approximately $0.25-1^{\circ}$ between the shoreline and $183 \mathrm{~m}$ deep (Ward and Wilson, 1976; Ward, 1985). South of Puerto Morelos the shelf steepens to approximately $2^{\circ}$ (Ward, 1985). A sharp break in the shelf also occurs approximately 1-2 km from the shoreline, and drops to depths greater than $400 \mathrm{~m}$ within $10 \mathrm{~km}$ of the shoreline (Ward, 1985). 


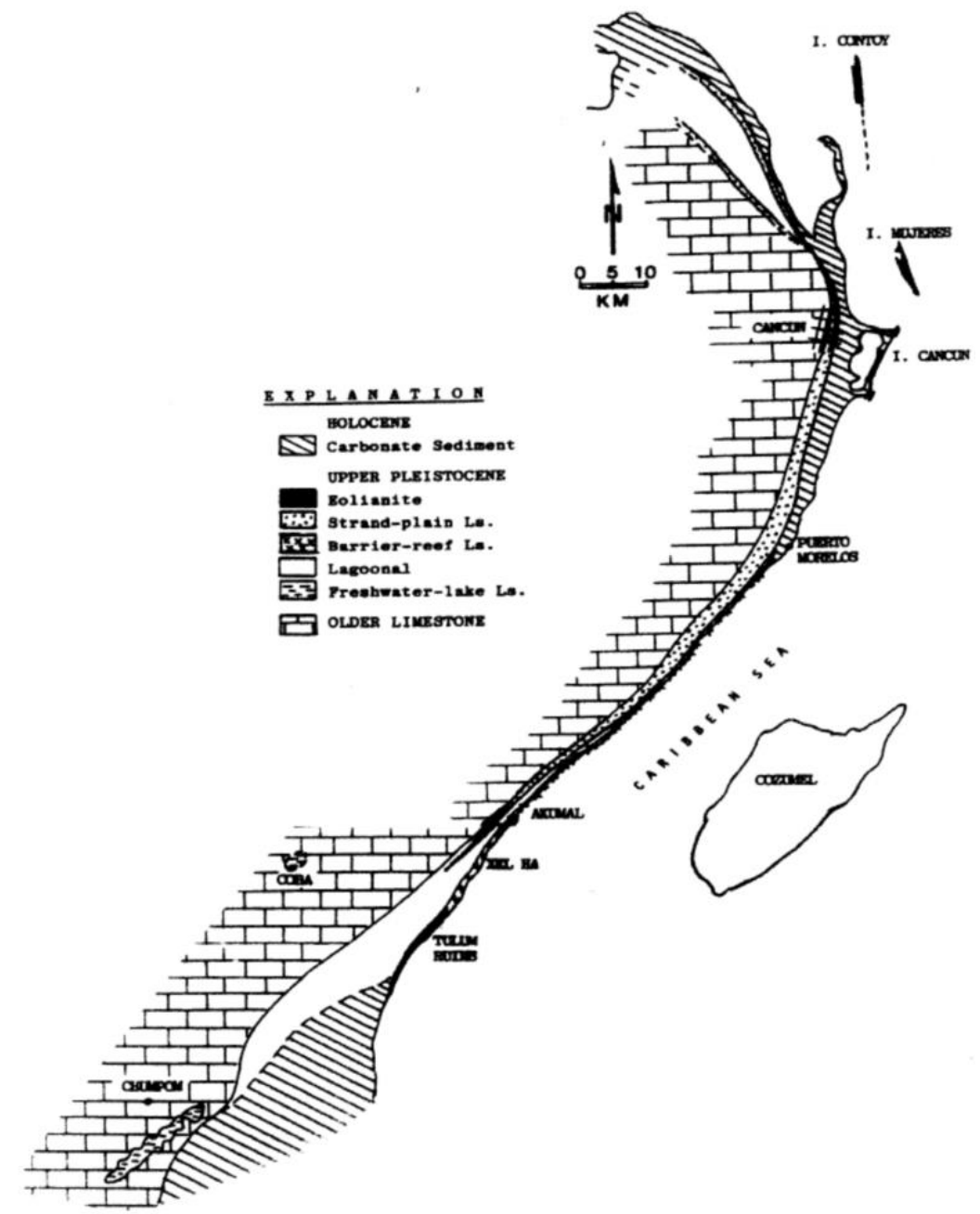

Figure 3-3: Geology and geomorphology of northeastern Yucatan Peninsula, Mexico (Ward, 1985).

\subsection{Holocene sea level}

The Caribbean sea level curve of the last deglaciation (past 17,100 years) remains the subject of considerable debate, with some researchers suggesting the curve around 10 to 8 ka reflects a series of rapid sea level rise events (Fairbanks, 1989; Blanchon and Shaw, 1995; Blanchon and Perry, 2004; Blanchon, 2010; Blanchon, 2011b; Blanchon, 2011a) and others a more continual, but decelerating rate of sea level rise (Toscano and Macintyre, 2003; Toscano and Macintyre, 2005).

The primary contention between the contrasting sea level curves concerns the data used in each instance, and the quality and interpretations of the data (Blanchon and Shaw, 1995; Toscano and Macintyre, 2003; Blanchon and Perry, 2004; Toscano and Macintyre, 2005). Blanchon and others propose three stages of rapid sea level rise, termed meltwater pulses, Mwp-1a (14.6 ka), Mwp-1b (11.4 ka), and Mwp-1c (8 ka; Figure 3-4), which result from rapid ice-loss events associated with ice sheet collapse (Blanchon, 2011b). Evidence from coral reef backstepping, in particular the analysis of drowned Acropora palmate reefs in the Caribbean-Atlantic reef province (Fairbanks, 1989; Blanchon and Shaw, 1995; Blanchon, 
2010; Blanchon, 2011a), indicates sea level rise during these rapid-rise events was between 35 and $60 \mathrm{~mm} / \mathrm{yr}$ and persisted for between 300 and 500 years (Blanchon, 2011a).

In comparison, Toscano and Macintyre (2003) propose a decelerating rate of sea level rise, with three transitional periods: $5.2 \mathrm{~mm} /$ year from 10.6 to $7.7 \mathrm{ka}, 1.47 \mathrm{~mm} / \mathrm{yr}$ from 7.7 to 2 $\mathrm{ka}$, and $0.93 \mathrm{~mm} / \mathrm{yr}$ from 2 to $0.4 \mathrm{ka}$ (Toscano and Macintyre, 2003). This curve was based on data derived from both Acropora palmate reefs and intertidal Rhizopora mangle peat (Toscano and Macintyre, 2003; Toscano and Macintyre, 2005). The nature of the Caribbean sea level curve does have implications to predicting the rate and process of sea level rise in the future, and therefore the likely response of barrier beaches. This will be revisited in Section 6 in relation to the response of barrier beaches under future climatic scenarios.

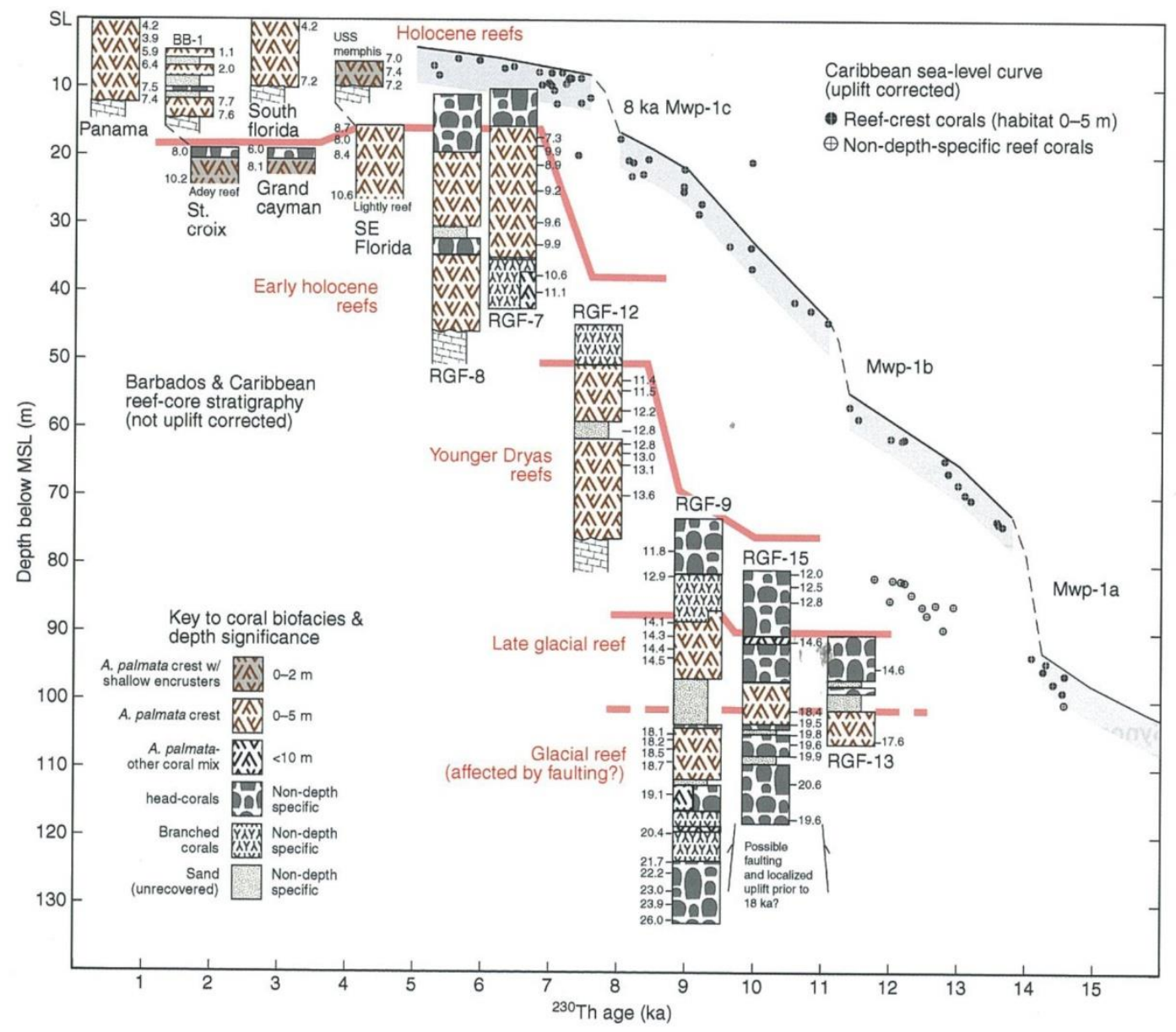

Figure 3-4: Caribbean sea level curve of the last deglaciation (past 17,100 years), showing three stages of rapid sea level rise, termed meltwater pulses: Mwp-1a (14.6 ka), Mwp-1b (11.4 ka), and Mwp-1c (8 ka)(Blanchon, 2011b). 


\subsection{Geomorphology}

The Yucatan Platform comprises four distinct physiographic regions (Figure 3-5). The barrier beach systems investigated in this study are situated in the North Pitted Karst Plain (NPKP). This plain extends from the northeast of the Sierrita de Ticul, a low mountain range, to the shorelines of the Gulf of Mexico and the Caribbean Sea, and is between $50 \mathrm{~km}$ and $275 \mathrm{~km}$ wide (Weidie, 1985). Elevation increases inland from the coast to approximately $35-40 \mathrm{~m}$ near the base of the Sierrita de Ticul, though local relief is largely constrained to within $10 \mathrm{~m}$ of mean sea level (Hanshaw and Back, 1980; Weidie, 1985).

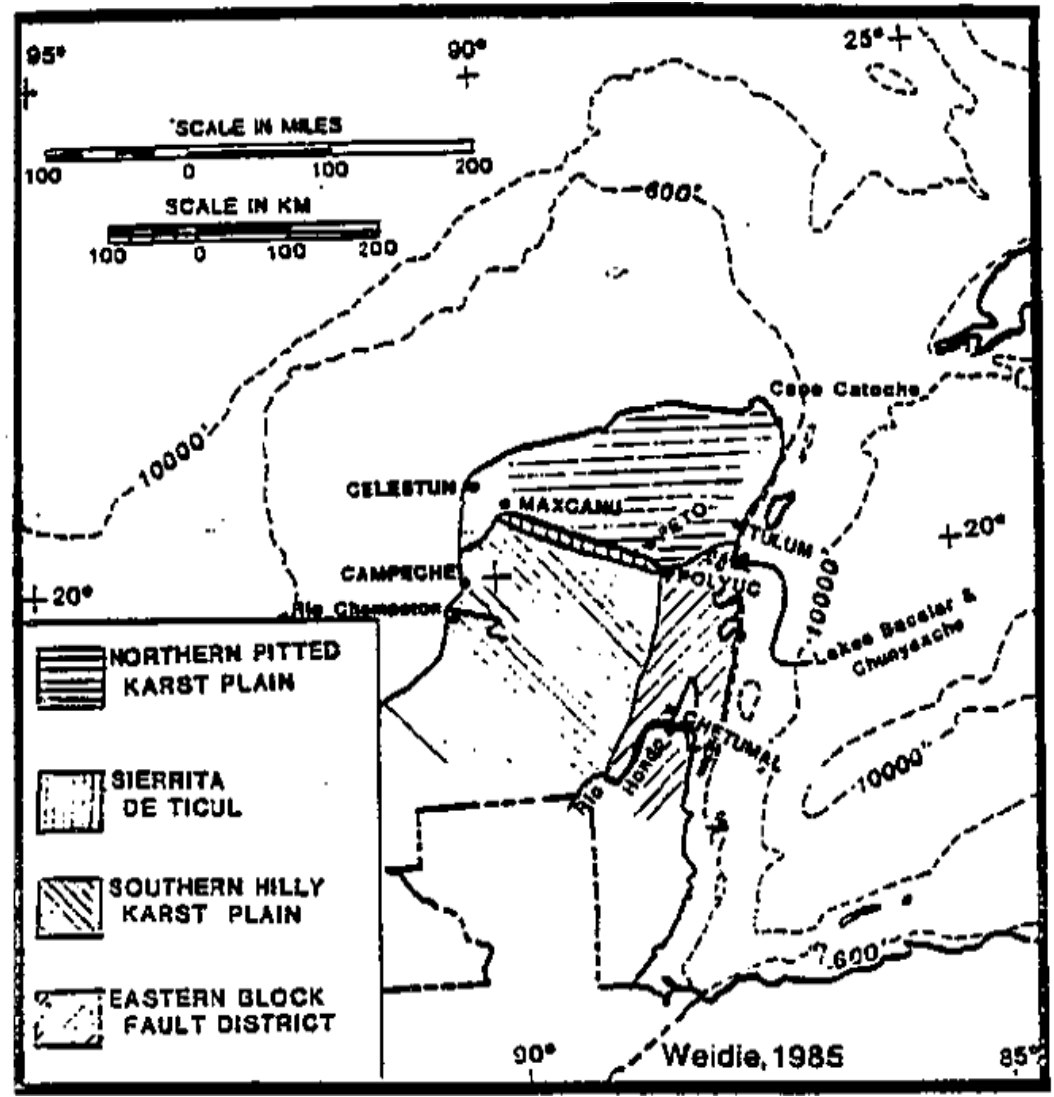

Figure 3-5: Physiographic regions of the Yucatan Platform (Weidie, 1985; Perry et al., 2009).

There are no stream channels in northeastern Yucatan due to the high permeability of the upper Pleistocene limestone, which promotes rapid and unlimited infiltration, with a mean annual groundwater recharge of 150 mm (Back et al., 1979; Hanshaw and Back, 1980; Back et al., 1986; Stoessell et al., 1989). The rate of infiltration depends on whether the water is delivered through the fracture (cavernous) system or porous-medium (intergranular) system (Moore et al., 1992; Perry et al., 2003). As such there is negligible sediment delivery to the coastline by way of surface hydrology, one of the variables important to maintaining the health of coral reefs (Hanshaw and Back, 1980; Woodroffe, 2002). However, freshwater is nonetheless transferred to the coastline via a network of aquifers which run throughout 
northeastern Yucatan and are associated with the Holbox fracture zone (Hanshaw and Back, 1980; Perry et al., 1989; Stoessell et al., 1989; Steinich and Marín, 1997).

Furthermore as water permeates through the upper unit of limestone, a chemical reaction occurs, resulting in chemical mass wasting of the surrounding calcium carbonate rock. This can result in the formation of subsurface features, such as cenotes (sinkholes) (Hanshaw and Back, 1980; Schmitter-Soto et al., 2002). Two of the most commonly occurring minerals, calcite and aragonite, dissolve into the water at solubility of approximately $2.5 \mathrm{mmol} / \mathrm{L}$, until the water is in equilibrium with the surrounding limestone (Hanshaw and Back, 1980; Back, 1985). Further dissolution occurs in the mixing zone at the coastline, where fresh groundwater and subterranean saltwater converge, with up to a further $1.2 \mathrm{mmol} / \mathrm{L}$ of calcite being dissolved. This results in the development of caves, caletas (coves) and crescent shaped beaches along much of the southern coastline of northeastern Yucatan Peninsula (Back et al., 1979; Hanshaw and Back, 1980; Back, 1985; Back et al., 1986; Stoessell et al., 1989; Moore et al., 1992; Smart et al., 2006).

The North Pitted Karst Plain also encompasses coastal plains of Pleistocene and Holocene age to the east (Szabo et al., 1978; Ward and Brady, 1979; Ward, 1985; Weidie, 1985). The Pleistocene coastal plain extends approximately $150 \mathrm{~km}$ along the northeastern margin of the peninsula, from the tip of the peninsula to Xel Ha (Ward and Brady, 1979). This plain is 0.5 to $4 \mathrm{~km}$ wide, with sediments 3 to $10 \mathrm{~m}$ thick, and is largely restricted to within $10 \mathrm{~km}$ of the coastline (Szabo et al., 1978; Ward and Brady, 1979). The plain lies between $5 \mathrm{~m}$ and 10 $\mathrm{m}$ above mean sea level, and is characterised by a beach ridge and swale sequence, which runs parallel to the present coastline, and contains between 1 and 20 ridges (Figure 36)(Ward and Brady, 1979; Blanchon, 2010). These ridges lie between 1 and $5 \mathrm{~m}$ above the swales, and are spaced between $50 \mathrm{~m}$ and $200 \mathrm{~m}$ apart (Ward and Brady, 1979). This ridgeswale complex reflects a progradational shoreline sequence from the last interglacial highstand (MIS 5e), when sea level was $6 \mathrm{~m}$ above present (Szabo et al., 1978; Blanchon, 2010). 


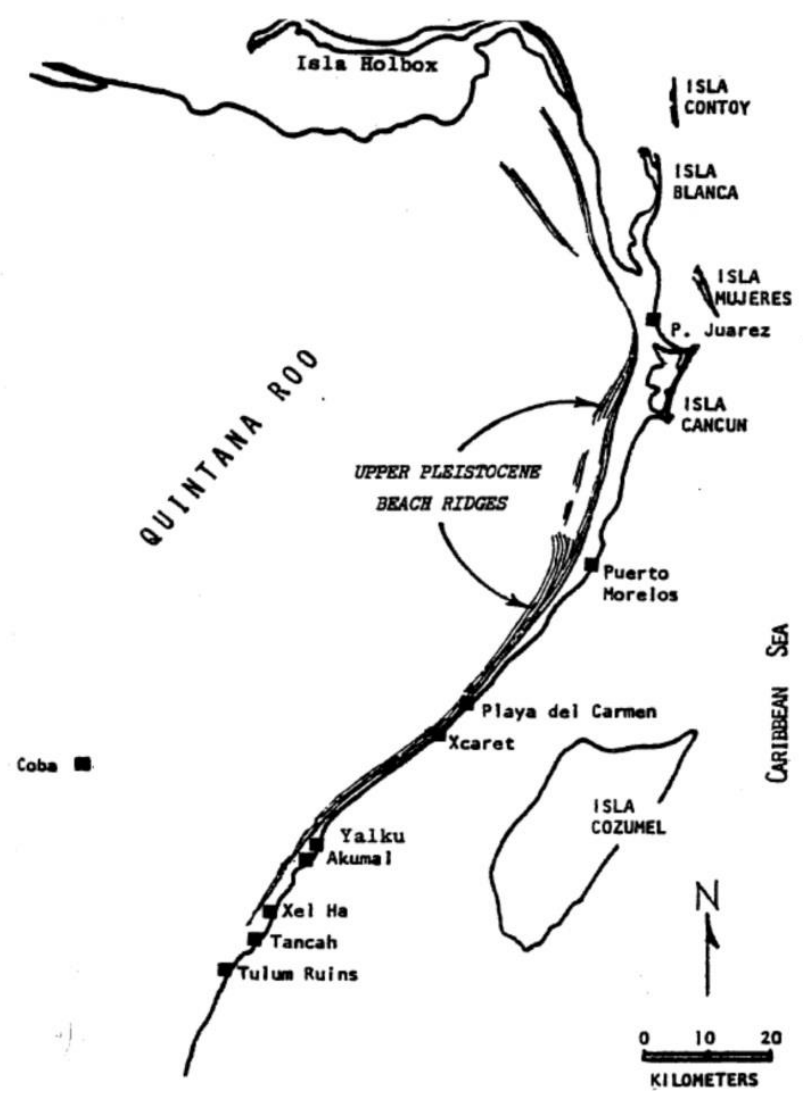

Figure 3-6: Upper Pleistocene beach ridges, northeastern Yucatan Peninsula, Mexico (Ward and Brady, 1979).

Further to the east lies a Holocene coastal plain, which covers a similar distance, but is at its greatest width between Cancun and Puerto Morelos. This more recent plain is characterised by narrow, dune-backed, shore-attached barrier beaches, with dunes of 2-4 $\mathrm{m}$ in height and 100-300 m wide. The barriers typically enclose mangrove wetlands (Rodríguez-Martínez et al., 2010), and are fronted by a discontinuous coral reef (Weidie, 1985). This reef can be classified as a model F fringing reef, according to Kennedy and Woodroffe (2002); as such, storms are thought to have played a contributory role in their barrier-like morphology, and ongoing geomorphic evolution. The reef typically lies between $1.35 \mathrm{~km}$ and $3.5 \mathrm{~km}$ off the present shoreline in the north of the study site, $0.55 \mathrm{~km}$ and $1.5 \mathrm{~km}$ around Puerto Morelos (Coronado et al., 2007), and within $300 \mathrm{~m}$ at Punta Maroma. A shallow lagoon occupies the backreef zone and has an average depth of 3-4 $\mathrm{m}$, with a maximum depth of $8 \mathrm{~m}$, as measured at Puerto Morelos (Ruíz-Rentería et al., 1998; Coronado et al., 2007). Barrier beaches in the north (Punta Nizuc to Puerto Morelos) and far south (Punta Maroma) of the study site are protected by coral reefs, while barrier beaches between Punta Brava and Playa del Secreto are exposed to the Caribbean Sea. 


\subsection{Vegetation}

The vegetation of northeastern Yucatan Peninsula is characterised by semi-evergreen (selva subperennifolia) or semi-deciduous (selva subcaducifolia) forests, which are typically classified as tropical dry or very dry under the Holdridge life zone system (Holdridge et al., 1971; Whigham et al., 1991; Harmon et al., 1995). Forests typically have a canopy height of $10 \mathrm{~m}$ to $25 \mathrm{~m}$, with the dominant species including Manilkara zapota, Talisia olivaeformis, Gymnanthes lucida, Brosimum alicastrum, Drypetes lateriflora, Sapindus saponaria, Coccoloba diversifolia, Beaucarnea pliabilis, Bursera simaruba, and Mycrianthes fragrans (Whigham et al., 1991; Harmon et al., 1995). The vegetation occupies shallow soils, classified as lithosol-redzina (Whigham et al., 1990).

The wetlands of the Holocene plain are largely dominated by Rhizophora mangle, also known as red mangroves, which are concentrated in narrow belts along the inner fringe of the wetlands, and as small accumulations through the centre (Ruíz-Rentería et al., 1998). Seagrass meadows are in abundance in the backreef lagoon, and reflect three main zones (based on an assessment by Ruiz-Renteria (1998) at Puerto Morelos): the coastal fringe, mid-lagoon zone and backreef zone. The coastal fringe is a $20-50 \mathrm{~m}$ wide zone adjacent to the shoreline and largely comprises Syringodium filiforme and Thalassia testudinum; the 200-1000 m mid-lagoon zone is dominated by Thalassia testudinum, in addition to some low density algae. The backreef zone of $100-400 \mathrm{~m}$ is characterised by short $(9-10 \mathrm{~cm})$ Thalassia testudinum and long (13-15 cm) Thalassia testudinum (Ruíz-Rentería et al., 1998).

\subsection{Climate}

The northeastern Yucatan Peninsula is situated within a tropical maritime climate, which broadly reflects two seasons, summer (May to October), and winter (November to April), based on wind patterns and air temperature (Coronado et al., 2007). Summer air flow is dominated by easterly trade winds, with average wind speeds of 3-9 $\mathrm{ms}^{-1}$ (Coronado et al., 2007). This is periodically interrupted by tropical storms and hurricanes, which bring sustained strong winds; these reached in excess of $59 \mathrm{~ms}^{-1}$ during Hurricane Wilma, 2005 (Simpson, 1974; Pasch et al., 2006a; Coronado et al., 2007). The winter sees a shift in the prevailing wind, tending to blow from the northeast (October to February). However this changes with the passage of cold fronts, or 'Nortes', when winds initially approach from the southeast, then later veer to the north as the location of the front relative to the coastline changes (Coronado et al., 2007). Nortes typically last several days and produce wind speeds of approximately $10 \mathrm{~ms}^{-1}$ (Coronado et al., 2007).

Air temperatures, as measured at Puerto Morelos, are typically between $24.7^{\circ} \mathrm{C}$ and $30.4^{\circ} \mathrm{C}$ during summer and $20.7^{\circ} \mathrm{C}$ to $28.2^{\circ} \mathrm{C}$ during winter. January (mean $20.7^{\circ} \mathrm{C} \pm 0.3^{\circ} \mathrm{C}$ ) is the coolest month, while August $\left(30.4^{\circ} \mathrm{C} \pm 0.1^{\circ} \mathrm{C}\right)$ and September $\left(30.4^{\circ} \mathrm{C} \pm 0.2^{\circ} \mathrm{C}\right)$ tend to be the warmest. The sea surface temperature reflects a similar pattern, with winter temperatures between $25.1^{\circ} \mathrm{C}$ and $26.8^{\circ} \mathrm{C}$, including a January low of $25.1^{\circ} \mathrm{C} \pm 0.1^{\circ} \mathrm{C}$, and summer temperatures of $28.2^{\circ} \mathrm{C}$ to $29.9^{\circ} \mathrm{C}$, peaking in August at $29.9^{\circ} \mathrm{C} \pm 0.1^{\circ} \mathrm{C}$. 
Finally, rainfall tends to be highest towards the end of summer (September and October), and beginning of winter (November), with the exception of early summer rainfall in June. These months will typically receive between $111.9 \mathrm{~mm}$ and $161.4 \mathrm{~mm}$ of rain, peaking in October at $161.4 \pm 22.1 \mathrm{~mm}$. For the rest of the year between $21.1 \mathrm{~mm}$ and $72.4 \mathrm{~mm}$ tends to fall per month, with April the driest, receiving only $21.1 \pm 5.1 \mathrm{~mm}$ of rainfall on average. Rainfall also varies spatially, with the precipitation gradient increasing to the south (Ward, 1985). Notably, Xel Ha receives approximately 50\% more rainfall than Cancun (Ward, 1985).

\subsection{Yucatan Current and wave climate}

The northeastern Yucatan Peninsula is characterised by a microtidal regime, the unidirectional Yucatan Current and a highly variable wave regime (Ward, 1985; Coronado et al., 2007). The mean tidal range, as measured at Puerto Morelos is approximately $0.17 \mathrm{~m}$ (and a maximal range of $0.32 \mathrm{~m}$, as recorded at Isla de Cozumel), with a neap tide of just below $0.07 \mathrm{~m}$ and a maximal spring tide of $0.32 \mathrm{~m}$ (Coronado et al., 2007). The prevailing flow direction of the Yucatan Current is to the northeast (Figure 3-7), flowing at an average rate of $1.5 \mathrm{~ms}^{-1}$, based on measurements recorded $12 \mathrm{~km}$ off Puerto Morelos by an acoustic Doppler current profiler (Coronado et al., 2007).

The strength of the current varies seasonally, with flow velocity increasing to approximately $2 \mathrm{~ms}^{-1}$ in summer, due to the prevailing easterly trade winds, and decreasing to a minimum rate of $0.9 \mathrm{~ms}^{-1}$ during winter as the prevailing northeasterly winds work against the current (Coronado et al., 2007). 


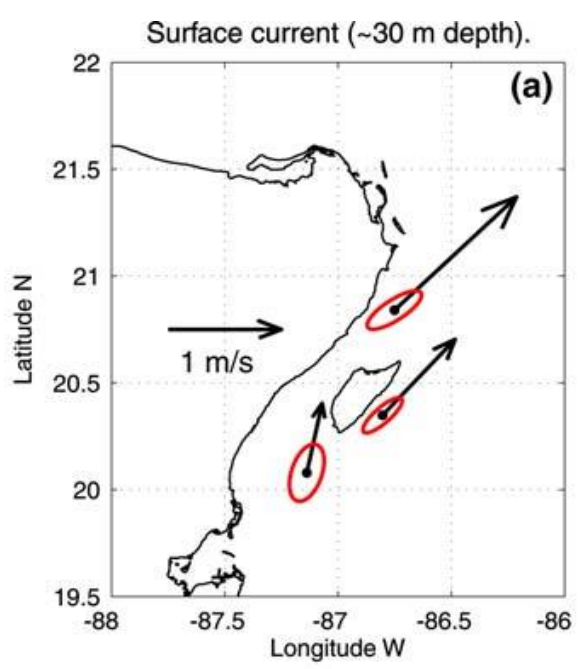

(b)

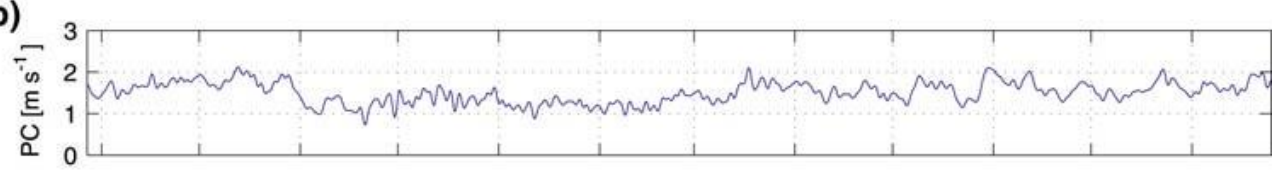

(c)

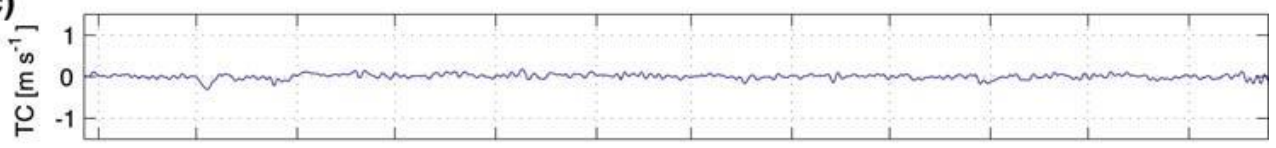

(d)

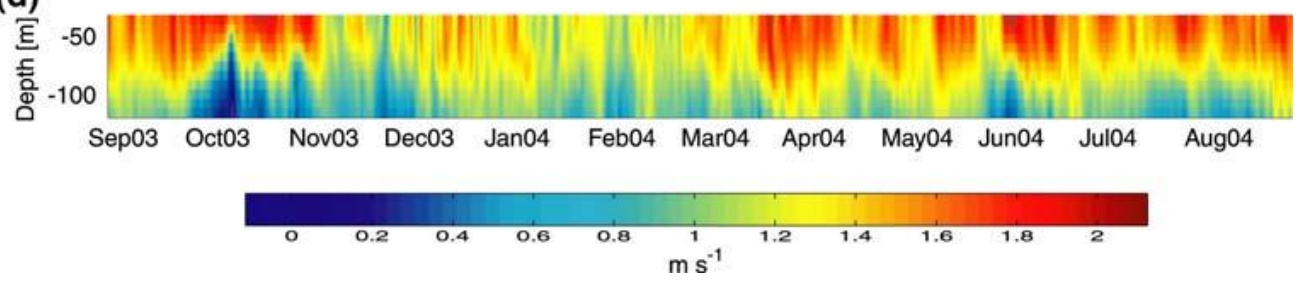

Figure 3-7: (a) Prevailing direction and flow velocity of the Yucatan Current, northeastern Yucatan Peninsula; temporal fluctuation of flow velocity, as measured at $30 \mathrm{~m}$ water depth, (b) along, and (c) across the principle current axis; and (d) temporal fluctuation of flow velocity with depth (Coronado et al., 2007).

Similar to the wind regime discussed in Section 3.6, the wave climate of northeastern Yucatan Peninsula is characterised by relatively long periods of low wave conditions, which are periodically interrupted by high energy events and large waves, with the passage of cold fronts, tropical storms, and hurricanes (Coronado et al., 2007; Silva-Casarín et al., 2009; Whelan lii et al., 2011). In summer the prevailing swell approaches from the east, driven by the easterly trade winds. This produces a mean significant wave height $\left(\mathrm{H}_{\mathrm{s}}\right)$ of $<0.3 \mathrm{~m}$ (though $\mathrm{H}_{\mathrm{S}}<0.1 \mathrm{~m}$ can ensue for weeks at a time), and wave period ( $\mathrm{T}_{\mathrm{P}}$ ) of 5 to 8 seconds (Coronado et al., 2007). $\mathrm{H}_{\mathrm{s}}$ increases to $\approx 0.8 \mathrm{~m}$ during winter, though it fluctuates between $\mathrm{H}_{\mathrm{s}} \approx 0.5 \mathrm{~m}$ and $1.5 \mathrm{~m}$ (Coronado et al., 2007). High energy wave events (defined as those where $\mathrm{H}_{\mathrm{S}}>1.75 \mathrm{~m}$ ) occur 6-8 times per year, and are associated with the passage of cold fronts during the winter, and tropical storms or hurricanes in the summer (Coronado et al., 2007). Cold fronts typically produce $H_{s} \approx 1.5 \mathrm{~m}$ to $2.5 \mathrm{~m}$, and $T_{p} \approx 4 \mathrm{~s}$ to $8 \mathrm{~s}$, with waves initially approaching from the southeast (Coronado et al., 2007). As cold fronts progress alongshore waves begin to approach from the northeast as winds change direction relative 
to the coastline (Coronado et al., 2007). Tropical storms and hurricanes produce even larger waves. For instance, Hurricane Ivan, 2004, produced maximum wave heights $\left(\mathrm{H}_{\max }\right)$ of $5.7 \mathrm{~m}$ and $T_{P}>12 \mathrm{~s}$, and Hurricane Wilma, 2005, produced $H_{S}>12.5 \mathrm{~m}$ (Coronado et al., 2007; Blanchon et al., 2010). These events can also produce a considerable storm surge.

As discussed in Section 3.4, the coastline contains sections of both reef-protected and unprotected barrier beaches; therefore the wave energy reaching the barrier beach system differs alongshore. The most extensive investigation of wave variability across the reef platform, and circulation of water within the fringing reefs of northeastern Yucatan Peninsula, was conducted by Coronado et al. (2007) off Puerto Morelos. They installed four current profilers across the reef for a period of 22 months to measure wave parameters (Figure 3-8a). The following measurements were attained: the forereef profiler, LPM3 $(22 \mathrm{~m}$ deep), measured mean $\mathrm{H}_{\mathrm{S}} \approx 0.83 \mathrm{~m}$ and $\mathrm{H}_{\max } \approx 5.7 \mathrm{~m}$; the northern inlet profiler, LPM2 $(6 \mathrm{~m}$ deep), recorded mean $\mathrm{H}_{\mathrm{S}} \approx 0.63 \mathrm{~m}$ and $\mathrm{H}_{\max } \approx 2.5 \mathrm{~m}$; the backreef profiler, LPM1 $(3.5 \mathrm{~m}$ deep), measured $\mathrm{H}_{\mathrm{S}} \approx 0.30 \mathrm{~m}$ and $\mathrm{H}_{\max } \approx 1.33 \mathrm{~m}$; and the southern inlet profiler, LPMO (8 $\mathrm{m}$ deep), recorded mean $\mathrm{H}_{\mathrm{S}} \approx 0.15 \mathrm{~m}$ and $\mathrm{H}_{\max } \approx 0.69 \mathrm{~m}$ (Coronado et al., 2007). Computation of the measurements, in relation to LPM3, produces the following statistics with regards to wave transformation over the coral reef (proportional reduction of $\mathrm{H}_{\mathrm{S}}$ and $\mathrm{H}_{\max }$ ): $\mathrm{H}_{\mathrm{S}} \leq 24.1 \%$ and $H_{\max } \leq 56.14 \%$, LPM2; $H_{\mathrm{S}} \leq 63.86 \%$ and $\mathrm{H}_{\max } \leq 76.67 \%$, LPM1; and $\mathrm{H}_{\mathrm{S}} \leq 81.93 \%$ and $\mathrm{H}_{\max }$ $\leq 87.89 \%$, LPMO. These results indicate coral reefs significantly reduce wave heights and induce considerably different wave climates on reef-protected and unprotected barrier beaches.

Further to this, and important to this study, the instruments deployed by Coronado et al. (2007) also recorded sea levels which were up to $0.55 \mathrm{~m}$ higher in the backreef lagoon than the adjacent Caribbean Sea during the passage of (category 5) Hurricane Ivan, 2004. This difference was less in the northern and southern inlets (Coronado et al., 2007). This suggests the shallow semi-enclosed backreef lagoon amplifies storm surge when situated to the left of the hurricanes eye (Stewart, 2005), as discussed in Section 2.5.2. These differences in storm surge and wave parameters are important considerations when analysing the evolution of barrier beaches.

Finally, coral reef morphology can also alter circulation patterns in the nearshore zone (Figure 3-8b), with the orientation of the longitudinal axis of the backreef lagoon controlling the direction of surface currents at a reef scale, and reef inlets influencing currents on a smaller scale (Coronado et al., 2007). In the Puerto Morelos backreef lagoon, LPM1 recorded a prevailing northerly flow at a rate of $10 \mathrm{~cm} \mathrm{~s}^{-1}$; in contrast the reef inlets tended to flush the lagoon and flow into the Caribbean Sea at rates of approximately $20 \mathrm{~cm} \mathrm{~s}^{-1}$, while the average flow at the forereef was onshore at $2-3 \mathrm{~cm} \mathrm{~s}^{-1}$ and highly variable (Coronado et al., 2007). These flow variations may have significance to nearshore sediment transportation. 
(a)

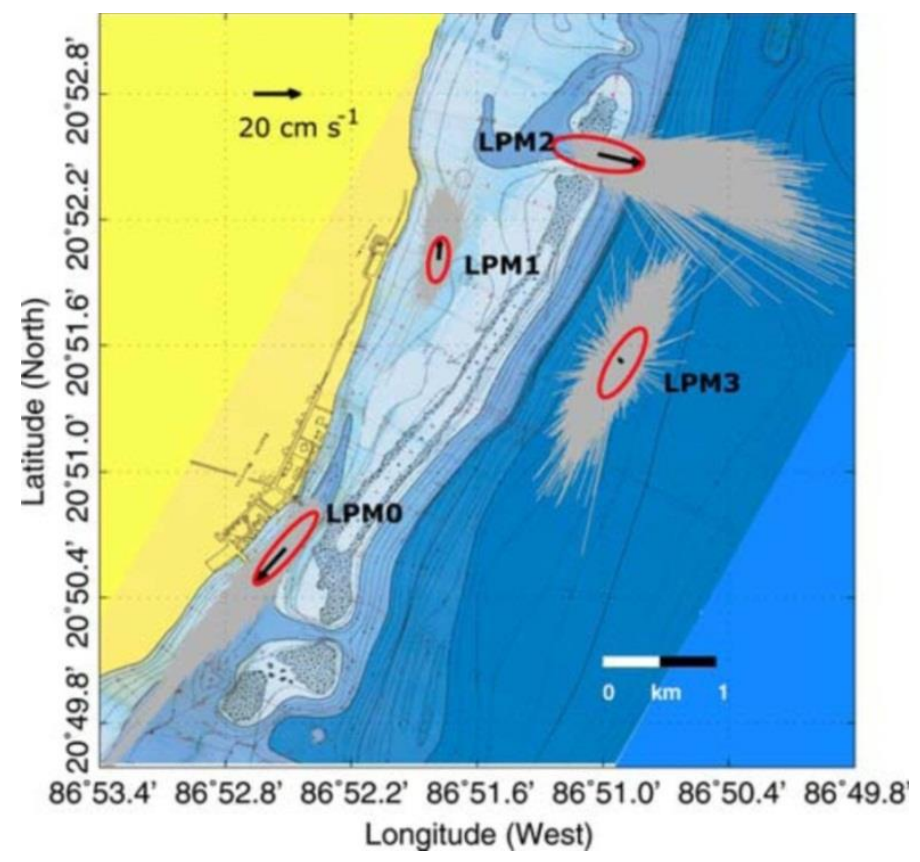

(b)

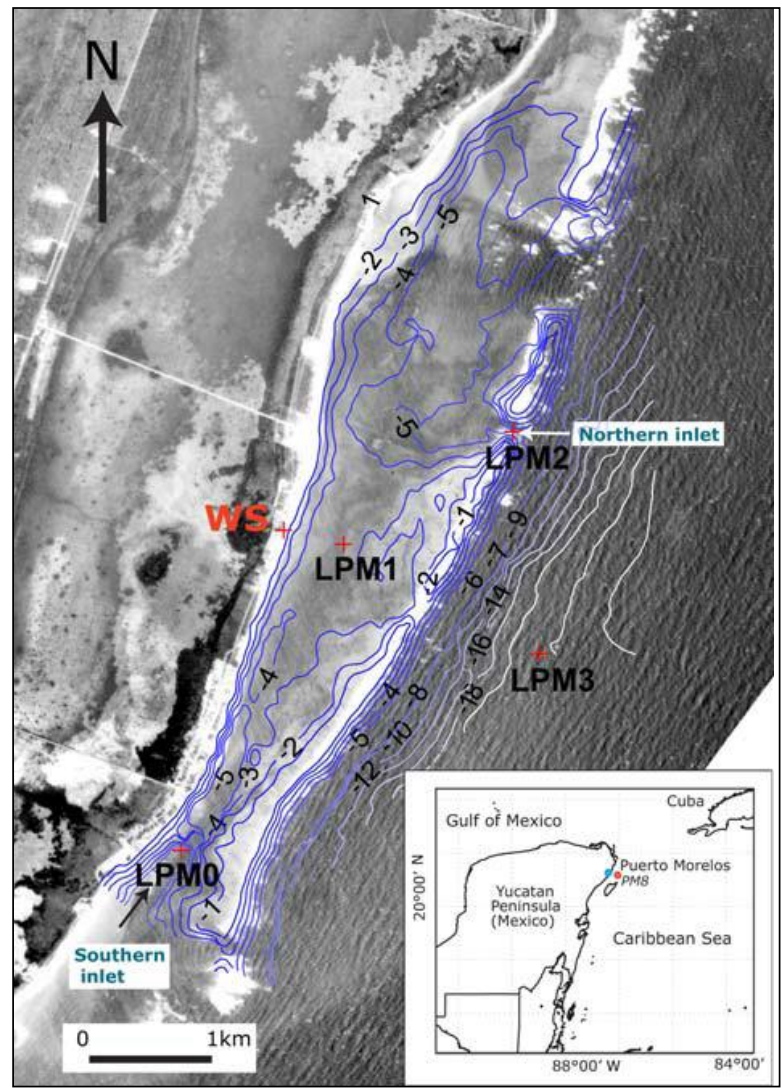

Figure 3-8: (a) Map showing the location and depth of a series of Nortek 1,000 KHz acoustic profilers across the fringing reef at Puerto Morelos; the location of the deepwater acoustic Doppler current profiler ADCP RDI WorkHorse $300 \mathrm{KHz}$ used to measure the Yucatan Current is represented by the red dot on the inset map, and (b) directions of the 1-hour averaged mean surface currents across the fringing reef at Puerto Morelos (Coronado et al., 2007). 


\subsection{Tropical storms and hurricanes}

The North Atlantic is prone to tropical storms and hurricanes, which in recent years have been becoming more intense (Webster et al., 2005) and more frequent (Goldenberg et al., 2001). From 1995 to 2005 there were on average 13.6 tropical storms, 7.8 hurricanes and 3.8 major hurricanes (category 3 to 5) each year, while the preceding period, 1970 to 1994, recorded on average 8.6 tropical storms, 5 hurricanes and 1.5 major hurricanes, each year (Trenberth et al., 2007). Furthermore, 2005 was a record breaking hurricane season and included 28 named storms (sustained wind speeds $\geq 17 \mathrm{~ms}^{-1}$ ), of which 15 were hurricane strength (sustained wind speeds $\geq 33 \mathrm{~ms}^{-1}$ ), and four were category 5 hurricanes (sustained wind speeds $\geq 69 \mathrm{~ms}^{-1}$ ) (Trenberth and Shea, 2006; Trenberth et al., 2007). This included Hurricane Wilma, which is investigated as part of this study.

However, questions remain regarding the drivers of this increased activity in the North Atlantic. Some researchers suggest it is a temporary increase linked to climatic fluctuations, including the Atlantic Multi-decadal Oscillation (increased activity during positive phase), and El Nino-Southern Oscillation (increased activity during the La Nina phase). This is based on the premise that increased basin-wide sea surface temperatures and decreased vertical wind shear are responsible for greater storm activity (Shapiro and Goldenberg, 1998; Elsner et al., 1999; Landsea et al., 1999; Pielke and Landsea, 1999; Goldenberg et al., 2001; Webster et al., 2005; Trenberth et al., 2007).

Others suggest increased storm activity may also be linked to increases in eustatic sea surface temperatures, associated with longer-term climatic change (Trenberth and Shea, 2006). However, this is not widely accepted among scientists (Pielke et al., 2005), with some even suggesting storm frequency may decrease if this were the case (Knutson et al., 2008). It is more widely accepted that future climatic warming will likely increase the intensity and duration of storms in the North Atlantic (Emanuel, 1993; Emanuel, 2005; Kossin et al., 2007; Trenberth et al., 2007). Greater understanding of storm drivers and longer storm records are required to predict how storm magnitude and frequency may change under increased atmospheric $\mathrm{CO}_{2}$, and to distinguish decadal to multi-decadal climatic oscillations from longer-term climatic change (Pielke et al., 2005; Webster et al., 2005).

In the Caribbean (and North Atlantic) tropical storms and hurricanes typically occur between June 1 and November 30, with most activity from August 1 to October 31, peaking in September (Landsea, 1993; Wang and Lee, 2007). This corresponds to the most widespread warming of sea surface temperatures in the Atlantic and the reduced vertical wind shear (Landsea, 1993). The prevailing storm tracks also migrate during the course of the season, shifting across the Western Atlantic (Landsea, 1993). The prevailing tracks come within relatively close proximity, or cross, the northeastern Yucatan Peninsula between June and October; this path is most likely followed in September (Figure 3-9). 


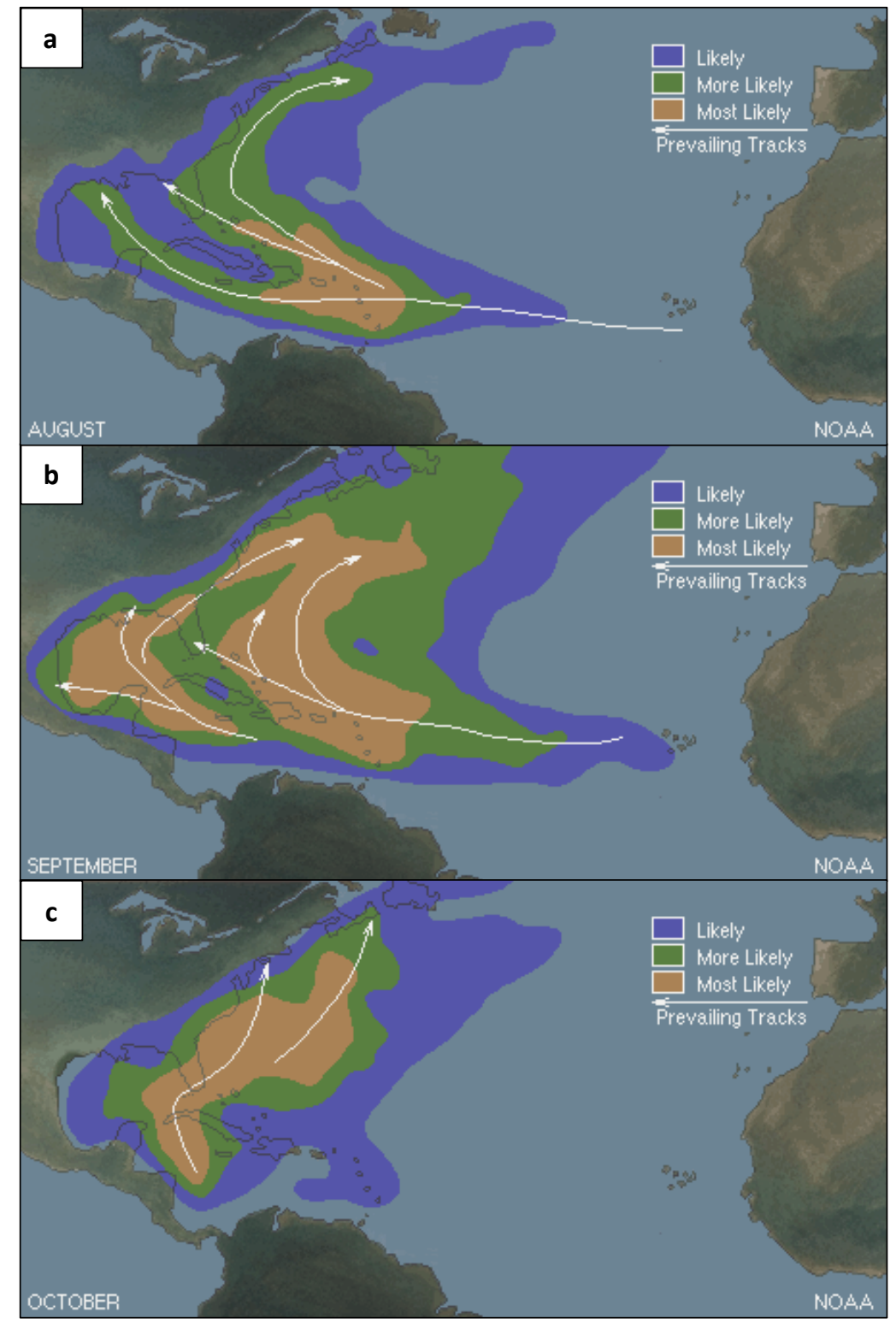

Figure 3-9: Prevailing hurricane tracks through the North Atlantic during (a) August, (b) September, and (c) October, based on data from 1851-2009 (retrieved from http://www.nhc.noaa.gov/climo/\#ori).

\subsubsection{Northeastern Yucatan Peninsula storm profile}

This study sets out to investigate the geomorphic significance of tropical storms and hurricanes on the barrier beaches of northeastern Yucatan Peninsula, Mexico. In particular, the short to medium-term response of reef-protected and unprotected barriers to Hurricane Wilma is to be quantified. As such the incidence and character of storms prior to and following Hurricane Wilma will be evaluated, in addition to the impact of Hurricane Wilma itself. 


\subsubsection{Storm incidence pre-Hurricane Wilma, 2000-2005}

In order to quantify and describe the geomorphic significance of Hurricane Wilma on the barrier beaches and wetlands of northeastern Yucatan Peninsula, the intensity and track of tropical storms and hurricanes in the preceding years must first be examined. This is intended to provide some evidence on the state of the system (for example, dune stability, vegetative cover, and sedimentary dynamics) prior to the passage of Hurricane Wilma, as recently inundated barrier beaches can respond in different ways during subsequent storm events (Perkins and Enos, 1968; Phillips, 1999; Claudino-Sales et al., 2008).

Tropical storms and hurricanes can have far reaching geomorphic impacts on the coastline, well beyond the atmospheric bounds of the storm; considerable sediment transportation and changes to surface elevation can be recorded up to $130 \mathrm{~km}$ from the storm track (Cahoon et al., 1995b). There have even been instances where beach erosion and washover has occurred $500 \mathrm{~km}$ from the storm centre (Morton, 2002).

Since the beginning of 2000, six storms events, ranging from tropical depressions to category 4 hurricanes, have tracked within $130 \mathrm{~km}$ of the study site, and 21 have come within $500 \mathrm{~km}$ (Table 3-2). Of these events, Hurricane Emily 2005 was the most significant, due to its intensity and timing. It passed over the Yucatan Peninsula just three months prior to Hurricane Wilma. Unofficial reports indicate a storm surge of up to one metre, and maximum wave heights of $4 \mathrm{~m}$. There were reports of some coastal erosion however it is not known how widespread this was.

Beach reworking prior to Hurricane Wilma could have had two very different impacts on the resistance of the barrier beach systems to further change: the beach may have become more resistant, with greater energy required to remove additional sediment during future events (Morton, 2002), or it could have become less resistant and more vulnerable (Phillips, 1999). For example, Phillips (1999) recorded little change to the shoreline bluffs along the Neuse River estuary, North Carolina following the passage of Hurricane Bertha, a category 3 storm, in July 1996. However, 55 days later Hurricane Fran, also a category 3 hurricane, drove bluff retreat of between 3 and $12 \mathrm{~m}$ (Phillips, 1999). The different responses is attributed to Hurricane Fran removing the toeslope sediment and woody debris, both of which acted as wave buffers, therefore making the bluffs vulnerable to further events (Phillips, 1999). The relationship between storm frequency and landform recovery time is important to the geomorphic response caused by a single event. This will be examined further in Section 6. 
Table 3-2: Details of storms, ranging in intensity from tropical depressions to hurricanes, tracking within $130 \mathrm{~km}$ and $500 \mathrm{~km}$ of the study site in the northeastern Yucatan Peninsula, between the beginning of 2000 and the passage of Hurricane Wilma 15-25 October 2005. Storms were selected and analysed using the 'Historical Hurricane Tracks' database, provided by the National Oceanic and Atmospheric Administration (http://www.csc.noaa.gov/hurricanes).

\begin{tabular}{|c|c|c|c|c|c|}
\hline Year & Storm name (maximum intensity) & $\begin{array}{l}\text { Maximum intensity within } 500 \text { km (130 } \\
\text { km) of the study site, Punta Nizuc to } \\
\text { Playa del Secreto }\end{array}$ & $\begin{array}{l}\text { Study site orientation relative } \\
\text { to the hurricane, during forward } \\
\text { motion: typically storm surge } \\
\text { amplified on the right side, } \\
\text { dampened on the left-side }\end{array}$ & $\begin{array}{l}\text { Storm surge height }(\mathrm{m}) \text { at the } \\
\text { eye of the hurricane, as } \\
\text { suggested by the Saffir- } \\
\text { Simpson Scale: within } 500 \\
\mathrm{~km}(130 \mathrm{~km}) \text { of the study site }\end{array}$ & $\begin{array}{l}\text { Tropical cyclone report: } \\
\text { specific report for those } \\
\text { which tracked within } 130 \\
\text { km of the study site; } \\
\text { annual summary report } \\
\text { for all others }\end{array}$ \\
\hline 2005 & $\begin{array}{l}\text { Hurricane Emily (H5) } \\
\text { Hurricane Stan (H1) } \\
\text { Hurricane Rita (H5) } \\
\text { Hurricane Katrina (H5) } \\
\text { Hurricane Cindy (H1) } \\
\text { Tropical Storm Arlene (TS) }\end{array}$ & $\begin{array}{l}\text { Category } 5 \text { hurricane (category } 4 \\
\text { hurricane) } \\
\text { Tropical storm (n/a) } \\
\text { Category } 5 \text { hurricane (n/a) } \\
\text { Category } 4-5 \text { hurricane }(\mathrm{n} / \mathrm{a}) \\
\text { Tropical depression (n/a) } \\
\text { Tropical storm (n/a) } \\
\end{array}$ & $\begin{array}{l}\text { Right-side } \\
\text { Right-side } \\
\text { Left-side } \\
\text { Left-side } \\
\text { Right-side } \\
\text { Left-side }\end{array}$ & $\begin{array}{l}>5.6 \mathrm{~m}(3.9-5.6 \mathrm{~m}) \\
-(-) \\
>5.6 \mathrm{~m}(-) \\
3.9-5.6 \mathrm{~m}(-) \\
-(-) \\
-(-)\end{array}$ & $\begin{array}{l}\text { Franklin and Brown } \\
(2006)\end{array}$ \\
\hline 2004 & $\begin{array}{l}\text { Tropical Storm Bonnie (TS) } \\
\text { Hurricane Ivan (H5) } \\
\text { Hurricane Charley (H4) }\end{array}$ & $\begin{array}{l}\text { Tropical storm (tropical depression) } \\
\text { Category } 5 \text { hurricane }(\mathrm{n} / \mathrm{a}) \\
\text { Category } 3 \text { hurricane }(\mathrm{n} / \mathrm{a})\end{array}$ & $\begin{array}{l}\text { Left-side } \\
\text { Left-side } \\
\text { Left-side }\end{array}$ & $\begin{array}{l}-(-) \\
>5.6 \mathrm{~m}(-) \\
2.7-3.8 \mathrm{~m}(-)\end{array}$ & Avila (2004) \\
\hline 2003 & $\begin{array}{l}\text { Tropical Storm Larry (TS) } \\
\text { Hurricane Claudette (H1) } \\
\text { Tropical Storm Bill (TS) }\end{array}$ & $\begin{array}{l}\text { Tropical storm (extratropical storm) } \\
\text { Category } 1 \text { hurricane (tropical storm) } \\
\text { Tropical storm (n/a) }\end{array}$ & $\begin{array}{l}\text { Right-side } \\
\text { Right-side } \\
\text { Right-side }\end{array}$ & $\begin{array}{l}-(-) \\
1-1.7 \mathrm{~m}(-) \\
-(-)\end{array}$ & $\begin{array}{l}\text { Stewart (2003) } \\
\text { Beven (2003) }\end{array}$ \\
\hline 2002 & $\begin{array}{l}\text { Hurricane Isidore (H3) } \\
\text { Hurricane Lili }(\mathrm{H} 3)\end{array}$ & $\begin{array}{l}\text { Category } 3 \text { hurricane (category } 3 \\
\text { hurricane) } \\
\text { Category } 3 \text { hurricane }(\mathrm{n} / \mathrm{a})\end{array}$ & $\begin{array}{l}\text { Left-side } \\
\text { Left-side }\end{array}$ & $\begin{array}{l}2.7-3.8 \mathrm{~m}(2.7-3.8 \mathrm{~m}) \\
2.7-3.8 \mathrm{~m}(-)\end{array}$ & Avila (2002) \\
\hline 2001 & $\begin{array}{l}\text { Tropical Storm Chantal (TS) } \\
\text { Hurricane Michelle (H4) } \\
\text { Tropical Depression Gabrielle (TD) } \\
\text { Hurricane Iris (H4) } \\
\end{array}$ & $\begin{array}{l}\text { Tropical storm (n/a) } \\
\text { Category } 4 \text { hurricane }(n / a) \\
\text { Tropical depression }(n / a) \\
\text { Category } 4 \text { hurricane }(n / a)\end{array}$ & $\begin{array}{l}\text { Right-side } \\
\text { Right-side } \\
\text { Left-side } \\
\text { Right-side }\end{array}$ & $\begin{array}{l}-(-) \\
3.9-5.6 \mathrm{~m}(-) \\
-(-) \\
3.9-5.6 \mathrm{~m}(-)\end{array}$ & \\
\hline 2000 & $\begin{array}{l}\text { Hurricane Gordon (H1) } \\
\text { Hurricane Keith }(\mathrm{H} 4)\end{array}$ & $\begin{array}{l}\text { Category } 1 \text { hurricane (tropical } \\
\text { depression) } \\
\text { Category } 4 \text { hurricane }(n / a)\end{array}$ & $\begin{array}{l}\text { Left-side } \\
\text { Right-side }\end{array}$ & $\begin{array}{l}1-1.7 \mathrm{~m}(-) \\
3.9-5.6 \mathrm{~m}(-)\end{array}$ & Stewart (2001) \\
\hline
\end{tabular}




\subsubsection{Hurricane Wilma, 15-25 October 2005}

Hurricane Wilma originated as a tropical depression at approximately 1800 UTC on 15 October 2005 (Figure 3-10), centred 352 km east-southeast of Grand Cayman (Pasch et al., 2006a). The depression initially moved west-southwest, then south-southwest for the following two days, slowly strengthening into a tropical storm by 0600 UTC on 17 October (Pasch et al., 2006a). By 18 October the system had strengthened further into a hurricane, and it changed track, heading west-northwest (Pasch et al., 2006a). Over the next 24 hours the system strengthened to a category 5 hurricane, with sustained winds reaching $77 \mathrm{~ms}^{-1}$ by 0600 UTC on 19 October, and peaking at $82 \mathrm{~ms}^{-1}$ at approximately 1200 UTC later that day (Pasch et al., 2006a).

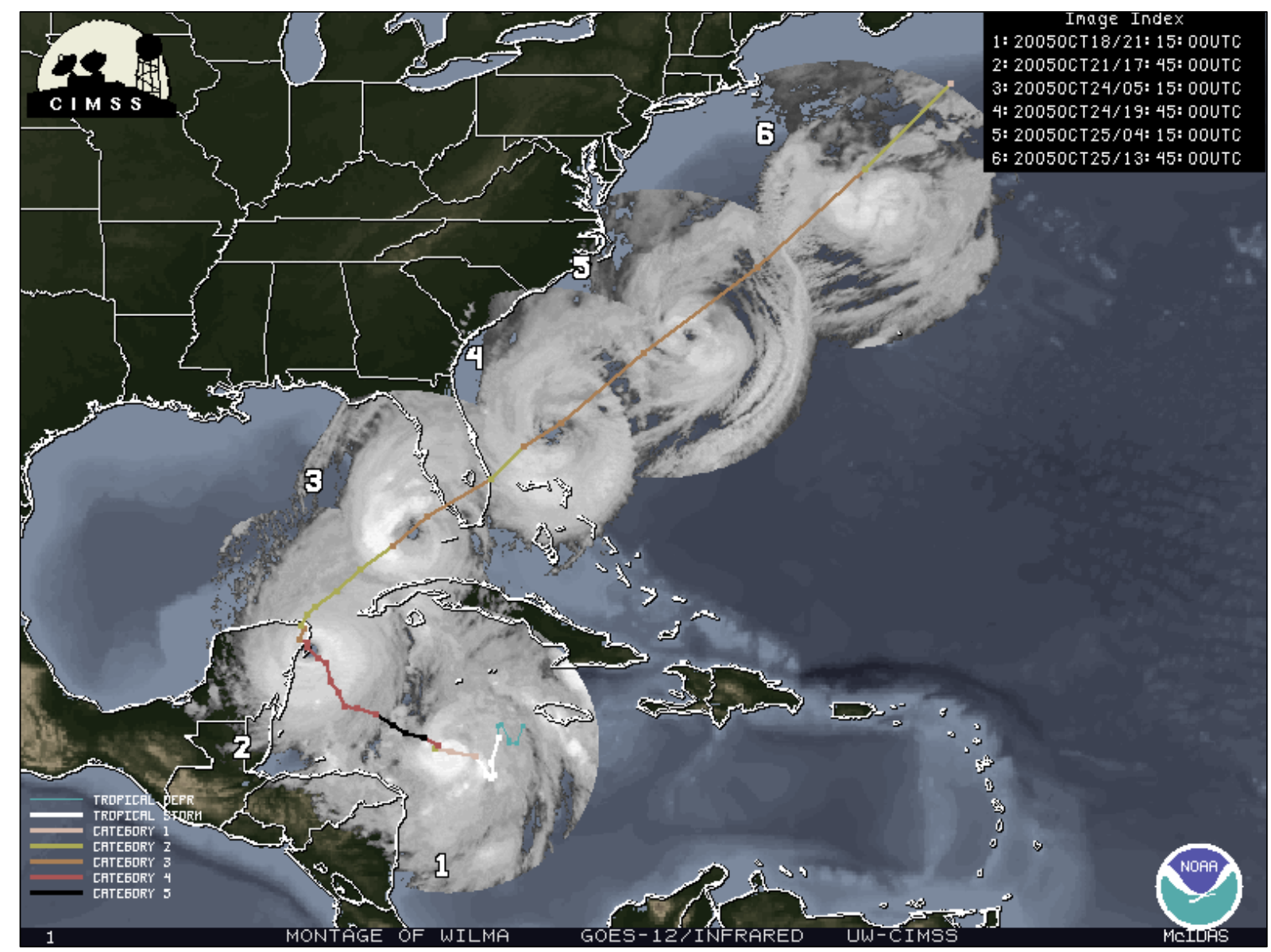

Figure 3-10: Best track positions of Hurricane Wilma during its lifecycle, 15-25 October 2005 (retrieved from http://cherrylogisticsmarketing.blogspot.co.nz/2011/09/2005-hurricane-season.html).

The eye increased to $74 \mathrm{~km}$ in width on 20 October, as the hurricane weakened slightly to category 4. Sustained wind speeds dropped to $67 \mathrm{~ms}^{-1}$, weakening further over the next day, and the storm changed direction, tracking towards the northwest and north-northwest (Pasch et al., 2006a). This was directly towards the northeastern Yucatan Peninsula, where it first made landfall on the island of Cozumel, at approximately 2145 UTC on 21 October, as a category 4 hurricane (Pasch et al., 2006b). Six hours later it crossed the channel onto the mainland, and tracked slowly north along the coast for the next 20 hours, finally crossing the 
northeastern limit of the peninsula, and into the Gulf of Mexico at approximately 0000 UTC 23 October, as a category 2 hurricane (Pasch et al., 2006b). It then tracked northeast to Florida, increased in strength and made landfall in southwestern Florida on 24 October. After this it dissipated to an extratropical storm, and was absorbed into another system on 27 October, over eastern Nova Scotia (Pasch et al., 2006a).

Hurricane Wilma recorded unprecedented rates of deepening (strengthening), as it developed into a category 5 hurricane on 18 and 19 October. The pressure dropped $54 \mathrm{mb}$ over 6 hours, $83 \mathrm{mb}$ over 12 hours, $97 \mathrm{mb}$ over 24 hours, and eventually to an estimated low of $882 \mathrm{mb}$, the lowest recorded in the Atlantic Basin (Pasch et al., 2006b). Over northeastern Yucatan Peninsula the atmospheric pressure was as low as $930 \mathrm{mb}$, with sustained wind speeds of up to $62 \mathrm{~ms}-1$ (Pasch et al., 2006b). Upon initial landfall storm waves reached significant wave heights $(H S) \approx 13 \mathrm{~m}$, which approached from the southeast (Figure 3-11a and b). However, as the storm tracked north, along the coast, the winds swung relative to the coastline, and began approaching from the northeast quarter; this wind shift generated waves, which approached from the northeast (Figure 3-11a).

The storm continued through several tidal cycles; however, due to the small tidal range this would not have amounted to significant changes in sea level. Torrential rain also persisted during the passage of the storm (Pasch et al., 2006b). Storm waves inundated the low lying barrier beaches of northeastern Yucatan Peninsula and rainfall flooded inland wetlands and lagoons, resulting in considerable geomorphic change. These changes and the post-storm response of the barrier beaches were investigated in this study; the mechanisms of change are discussed, and later put in the context of barrier beach evolution. 
(a)
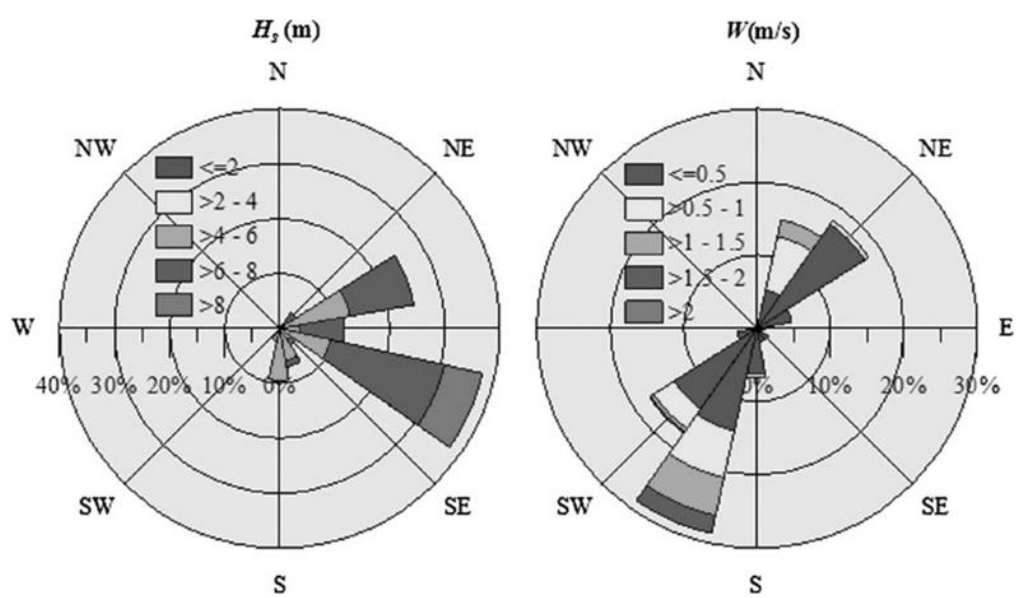

(b)

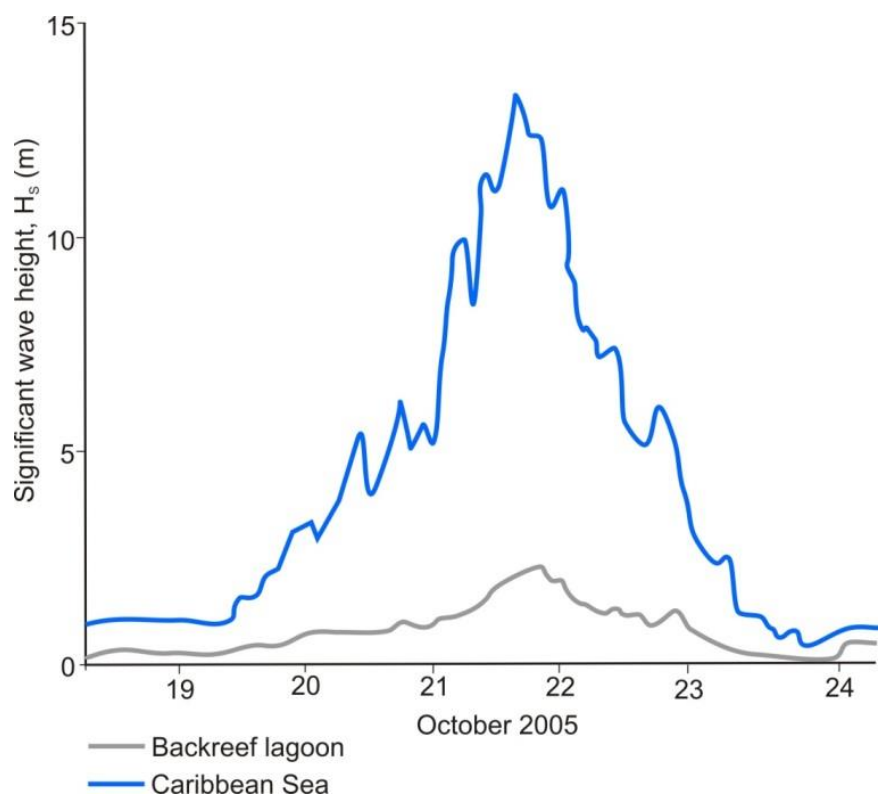

Figure 3-11: (a) Wave and wind roses of measured conditions off northeastern Yucatan Peninsula during Hurricane Wilma (Casarin et al., 2012), and (b) peak significant wave height outside and inside the backreef lagoon off Puerto Morelos, northeastern Yucatan Peninsula during Hurricane Wilma. Adapted from Blanchon et al. (2010).

\subsubsection{Storm incidence post-Hurricane Wilma, 2005-2010}

To investigate the geomorphic significance of an individual storm, Hurricane Wilma, over the short to medium-term first requires a number of criteria to be met: the barrier beach systems must not undergo considerable geomorphic change from subsequent storms (Cahoon et al., 1995b), and it should be largely free of direct (for example, hotels and seawalls) and indirect (for example, groynes alongshore) anthropogenic impacts. There have been four storms, ranging in intensity from extratropical storms to category 2 hurricanes, between Hurricane Wilma and the final field excursion in early to mid-2010 (Table 3-3). 
Table 3-3: Details of storms, ranging in intensity from extra-tropical storms to hurricanes, tracking within $130 \mathrm{~km}$ and $500 \mathrm{~km}$ of the study site in the northeastern Yucatan Peninsula, between 26 October 2005 (after the passage of Hurricane Wilma 15-25 October 2005) and the end of June 2010. Storms were selected using the 'Historical Hurricane Tracks' database, provided by the National Oceanic and Atmospheric Administration (http://www.csc.noaa.gov/hurricanes).

\begin{tabular}{|c|c|c|c|c|c|}
\hline Year & $\begin{array}{l}\text { Storm name (maximum } \\
\text { intensity) }\end{array}$ & $\begin{array}{l}\text { Maximum intensity within } 500 \mathrm{~km} \text { (130 } \\
\mathrm{km} \text { ) of the study site, Punta Nizuc to } \\
\text { Playa del Secreto }\end{array}$ & $\begin{array}{l}\text { Study site orientation } \\
\text { relative to the hurricane, } \\
\text { during forward motion: } \\
\text { typically storm surge } \\
\text { amplified on the right } \\
\text { side, dampened on the } \\
\text { left-side }\end{array}$ & $\begin{array}{l}\text { Storm surge height }(\mathrm{m}) \\
\text { at the eye of the } \\
\text { hurricane, as } \\
\text { suggested by the } \\
\text { Saffir-Simpson Scale: } \\
\text { within } 500 \mathrm{~km}(130 \\
\mathrm{km}) \text { of the study site }\end{array}$ & $\begin{array}{l}\text { Tropical cyclone report: } \\
\text { specific report for } \\
\text { those which tracked } \\
\text { within } 130 \mathrm{~km} \text { of the } \\
\text { study site; annual } \\
\text { summary report for all } \\
\text { others }\end{array}$ \\
\hline 2010 & Hurricane Paula (H2) & Category 2 hurricane (n/a) & Left-side & $1.8-2.6 \mathrm{~m}(-)$ & \\
\hline 2009 & Hurricane Ida (H2) & $\begin{array}{l}\text { Category } 2 \text { hurricane (category 1-2 } \\
\text { hurricane) }\end{array}$ & Left-side & $1.8-2.6 \mathrm{~m}(1-1.7 \mathrm{~m})$ & $\begin{array}{l}\text { Avila and Cangialosi } \\
\text { (2010) }\end{array}$ \\
\hline 2008 & $\begin{array}{l}\text { Hurricane Dolly (H2) } \\
\text { Tropical Storm Arthur (TS) }\end{array}$ & $\begin{array}{l}\text { Tropical storm (tropical storm) } \\
\text { Tropical storm (n/a) }\end{array}$ & $\begin{array}{l}\text { Right-side (tracked 1km } \\
\text { south of PntMrma-t2) } \\
\text { Right-side }\end{array}$ & $\begin{array}{l}-(-) \\
-(-)\end{array}$ & $\begin{array}{l}\text { Pasch and Kimberlain } \\
\text { (2009) }\end{array}$ \\
\hline 2007 & $\begin{array}{l}\text { Tropical storm Olga (TS) } \\
\text { Tropical storm Barry (TS) } \\
\text { Hurricane Dean (H5) }\end{array}$ & $\begin{array}{l}\text { Extra-tropical storm (extra-tropical } \\
\text { storm) } \\
\text { Tropical storm (extra-tropical storm) } \\
\text { Category } 5 \text { hurricane }(\mathrm{n} / \mathrm{a})\end{array}$ & $\begin{array}{l}\text { Mainly left-side (tracked } \\
\text { over WnW-t15) } \\
\text { Left-side } \\
\text { Right-side }\end{array}$ & $\begin{array}{l}-(-) \\
-(-) \\
>5.6 \mathrm{~m}(-)\end{array}$ & $\begin{array}{l}\text { Mainelli (2008) } \\
\text { Avila (2007) }\end{array}$ \\
\hline 2006 & Tropical Storm Alberto & Tropical storm (n/a) & Left-side & $-(-)$ & \\
\hline
\end{tabular}




\subsubsection{Summary}

It has been shown that storms in the years prior to Hurricane Wilma were likely of little geomorphic significance, with the exception of Hurricane Emily. Similarly tropical storms and hurricanes affecting northeastern Yucatan Peninsula after Hurricane Wilma also had little significance. Therefore, the study site investigated presents itself as an ideal location to study the short (0-8 months) to medium-term (8-56 months) significance of hurricanes on barrier beaches.

\subsection{Coastal development and land use}

The Caribbean coast of northeastern Yucatan Peninsula has undergone extensive development, as part of a targeted tourism strategy by the Mexican government aimed at boosting the economy (Murray, 2007; Smith, 2009). Cancun, directly north of the area investigated by this study, was the first of five 'mega resorts' planned and developed by the Fondo Nacional de Fomento al Turismo (National Fund for the Development of Tourism). This followed extensive computer tourism research, as part of Mexico's so called 'second generation resorts' (Collins, 1979; Smith, 2009). Development began in the early 1970s, with the area quickly becoming popular. International arrivals grew at an average annual rate of $38 \%$, and resulted in Cancun becoming the most popular Mexican tourist destination among foreigners by 1989 (Clancy, 2001). In the early to mid-1990s the development explosion spread south along the Riviera Maya, a $120 \mathrm{~km}$ coastal expanse between Cancun and Talum (Murray, 2007). The construction of hotels, condominium apartments, and housing took place rapidly; 4,918 hotel rooms in 1998 increased to over 19,800 by 2002 (Murray, 2007). These were concentrated along the narrow shore attached barrier beaches, between the mangrove wetlands and backreef lagoon. By 2005, Cancun boasted over 26,560 hotel rooms and received approximately 6 million visitors a year, accounting for over 30\% of Mexico's tourism-associated revenue (Smith, 2009).

However this rapid growth has resulted in considerable environmental degradation: the loss of vegetation and ecosystems, particularly mangrove wetlands, infilled in order to provide further space to develop hotels and coastal roads. Coral reef degradation as a result of increased sediment run-off and discharge of untreated sewage and pollution of the water, air, soil and biota as a result of numerous contaminant sources have become significant issues (Murray, 2007). Despite these problems tourism development continues, and is projected to expand further. These land use changes have resulted in considerable alterations to the dynamics and evolution of the barrier beaches, particularly under tropical storm and hurricane conditions. This will be discussed in more detail later in this study. 


\section{Methodological Rationale}

\subsection{Introduction}

The northeastern coast of the Yucatan Peninsula, Mexico, was selected as the location to study the geomorphic significance of hurricanes on coral-fringed calcium carbonate barrier beach systems, using the impacts of Hurricane Wilma (2005) as the case study. This area contains long stretches of coastline which are relatively free of anthropogenic influences, enabling quantification of the natural dynamics and post-storm responses of these systems.

Numerous research techniques have been employed in this project, including: surveying with an engineer's level to measure the cross-sectional geomorphic change of the barrier beaches; sediment sampling and textural analysis using a laser particle sizer (LPS), sieve stack and thin section petrology to characterise the sedimentological response; and satellite imagery analysis to measure overall shoreline changes. Two temporal sets of field data were collected to represent different stages of barrier beach evolution: the first set of sediment data was collected in May 2006, seven months after Hurricane Wilma, and the first acrossshore beach surveys a month later, in June. The data were then compared with further sediment and across-shore profile data collected between April and June 2010, up to 56 months after Hurricane Wilma. In this study the data collected in May-June 2006 will be considered to represent the short-term (0-8 months) response, and measurements taken from April-June 2010 will be considered to represent the medium-term (8-56 months) response.

\subsection{Field research techniques}

\subsubsection{Engineer's level surveying}

To measure the cross-sectional profile of the beach and foredune system, a set square was employed during fieldwork in 2006 and a Sokkia B20 Automatic engineer's level was used in 2010. In total, 29 comparative transects were measured between Punta Nizuc and Playa del Secreto. These instruments were chosen due to their measurement accuracy and durability in tropical environments (Kennedy, 2012 In Press). Surveying was spaced at $200 \mathrm{~m}$ intervals 
along sections of continuous natural coastline, enabling robust analysis of alongshore geomorphic change. This spacing also reduced the influence of local geomorphic variation. Large expanses of coastline were not surveyed due to significant anthropogenic impacts.

Profiles conducted in June 2006 were marked using a handheld GPS, with a positional accuracy of $\pm 10 \mathrm{~m}$. These coordinates enabled the same sites to be surveyed between April and June 2010 (identified using a Trimble GEO XT handheld GPS, positional accuracy \pm 10 $\mathrm{m})$. A number of the sites measured in 2006 had since been developed, and as such were largely dismissed from comparative analysis, with the exception of two sites which were used to assess anthropogenic influences on barrier beach response (outlined in Section 5.4). Where a small degree of anthropogenic influence was evident, but not considered significant enough to affect coastal morphology (for example, construction of wire fences on the beach or foredune), cross-shore surveying still proceeded.

Cross-shore surveying spanned from the backdune swale across the barrier beach to 1.0-1.5 $m$ water depth (Figure 4-1). The seaward limit of the cross-shore profiles was largely controlled by the shoreface slope and the wave conditions at the time of survey. The landward limit was restricted by dense vegetation or mangrove wetlands. To enable temporal and spatial comparisons, barrier beach widths reported in this study were determined by the distance between the foredune crest and mean high water (MHW).

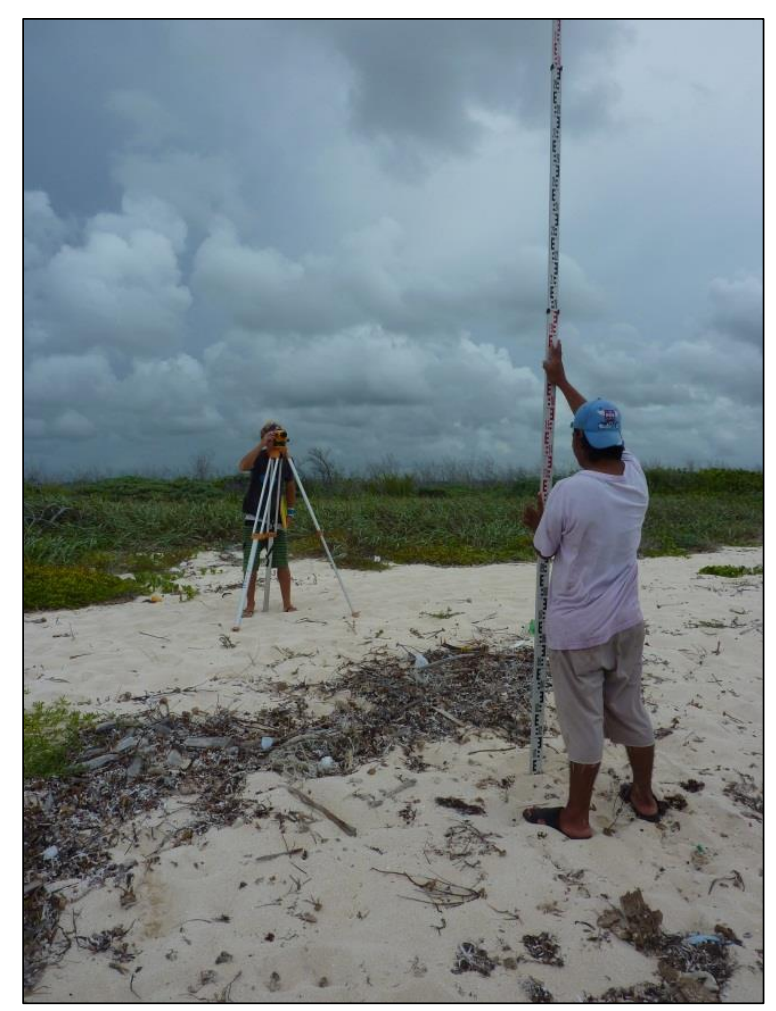

Figure 4-1: Across-shore beach profile surveying using a Sokkia B20 Automatic engineer's level. 


\subsubsection{Global positioning system}

A handheld Global Positioning System ((GPS) Trimble GEO XT) with a $10 \mathrm{~m}$ positional accuracy was used from April-June 2010 to locate geomorphic features within the coastal zone. These were: beach toe, berm crest, foredune toe, and foredune crest. In some instances, additional features were recorded, such as subaqueous sand bars, the toe of the backdune swale and transgressive dune features. These were largely recorded as point features and imported into ArcGIS version 10.1, a Geographic Information System (GIS). These data were used to identify barrier beach features, in particular the foredune crest for use in beach width measurement, on satellite images. The GPS was used to support other research techniques, including providing geographic positions for the engineers level surveys and sediment pits.

\subsubsection{Sediment sampling}

Sediment sampling was conducted over the two periods, May 2006 and April-June 2010. Subsurface samples and some of the surface samples (in particular foredune and backdune sediments) collected in May 2006 were considered representative of the storm deposit left in situ following Hurricane Wilma; surface samples were largely considered to represent the post-storm sedimentological response. A total of 14 sites were sampled alongshore, with between three and five across-shore sediment pits excavated at each site.

Surface sediments collected in 2010 are considered to be representative of the prevailing energy regime, whereas subsurface sediments represented the sedimentological change since Hurricane Wilma. In total sediment was taken from 12 sites between Punta Nizuc and Playa del Secreto, between April-June 2010. A cross-shore profile was conducted at all sampled sites. Similar to the cross-shore surveying, a number of sites sampled in 2006 had since been developed, and had to be dismissed.

All sediment transects were excavated manually with a spade (Figure 4-2a). The sediment pits ranged from 0.2-1.2 $\mathrm{m}$ deep, and were located in the beachface, back beach, foredune, and backdune swale. The depth of each sediment pit varied depending on the thickness of the post-storm beach deposit above the water table, calcarenite dune or dense root networks. Layers were identified and a minimum of $150 \mathrm{~g}$ of sediment was taken from each; where no apparent layering was observed sampling was taken at $0.15 \mathrm{~m}$ intervals.

In June 2010, sediment sampling in the backreef lagoon was conducted across five transects between Punta Nizuc and Playa del Secreto, with a total of 28 surface samples collected using a surface scooping sampling device (Figure 4-2b). Of the five sites, three were reefprotected (Wet ' $n$ ' Wild, Punta Tanchacte and Punta Petenpich) with the remaining two on exposed coasts (Punta Brava and Playa del Secreto). The backreef lagoon sediment transects extended perpendicular from the beach to either the reef crest or approximately $10 \mathrm{~m}$ water depth on exposed coastlines. Samples were taken at similar intervals across each transect and their geographic location was recorded using a handheld GPS unit. Five to ten 
samples were generally taken across each transect, depending on backreef lagoon width and/or water depth. Samples were typically $200 \mathrm{~g}$.

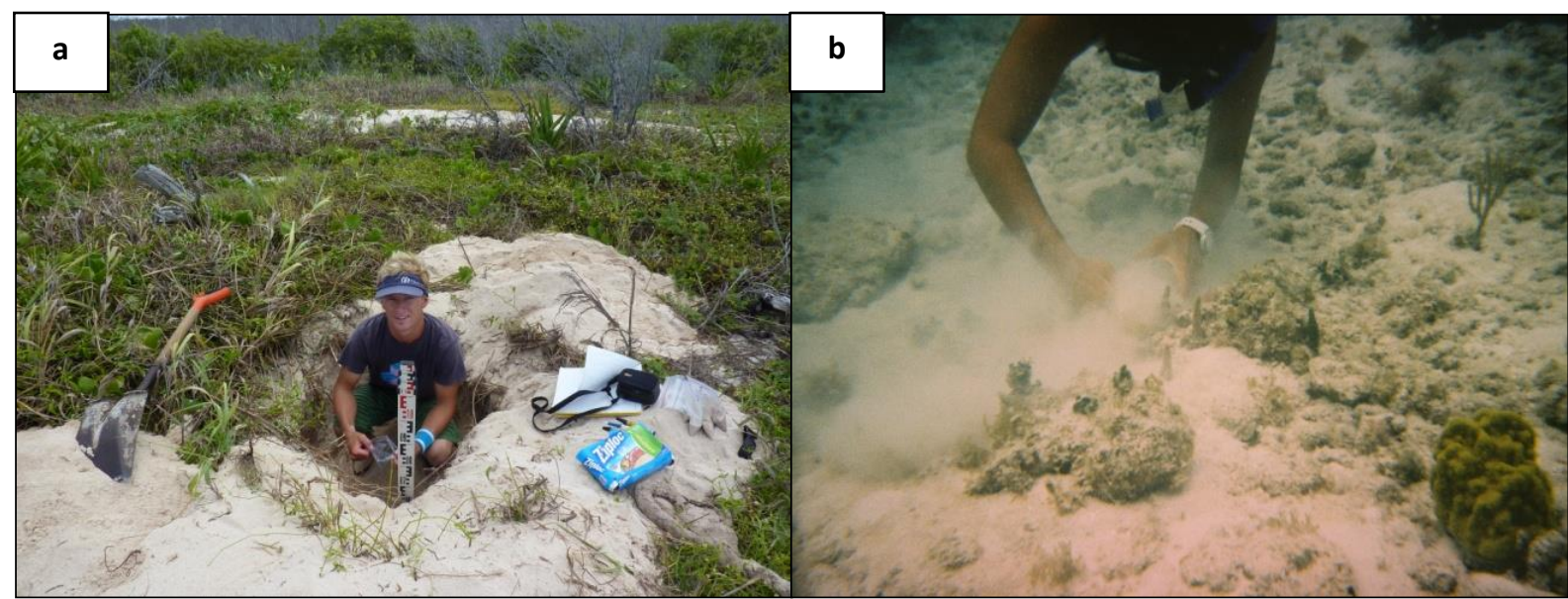

Figure 4-2: (a) Extracting and bagging sediment samples from identified stratigraphic sequences, Zone 5: Punta Brava South and (b) extracting sediment samples from the lagoon floor, using a surface scoop device, Zone 2: Punta Tanchacte.

\subsection{Lab research techniques}

\subsubsection{Engineers level survey: data processing}

All profiles were corrected to mean high water ( $\mathrm{MHW}$ ) using the hindcast tide correction model sourced from the Australian Bureau of Meteorology (2010); this utilised the measured water level at the time of survey and made a correction using preceding and proceeding tide times and heights. Results obtained through this method were compared to a centrally located benchmark at the Institute of Marine Sciences and Limnology, National Autonomous University of Mexico (UNAM) in Puerto Morelos. The comparison indicates an error in the range of $0.2 \mathrm{~m}$; however this does not have a significant impact on this study, as the heights all relate to the one datum and as such are comparative alongshore. This datum was found to correspond to the seagrass debris line, therefore enabling comparison with satellite imagery.

Across-shore profiles were corrected to MHW, as it is one of the most commonly used indicators of shoreline position in satellite imagery (Boak and Turner, 2005). This is essential to this study, as it enables measurements from across-shore beach profiles to be compared with those measured using satellite imagery. It was necessary to combine these two methods, due to the limited temporal coverage of cross-shore surveying, and lack of prestorm shoreline data. Satellite imagery was used to measure pre-storm (4 September 2004 and 14 August 2005), immediately post-storm (25 October 2005), and short term post-storm (June 2006) barrier beach widths. Cross-shore beach profiling was used to measure short term (June 2006) and medium term (April-June 2010) post-storm beach widths. Where the beach measurements in June 2006 showed little difference $(<2 \mathrm{~m})$ to measurements derived from satellite images from the same period, both datasets were used in the analysis. 
Where the difference was greater than $2 \mathrm{~m}$, only satellite imagery data was used. This was done in order to be comparable with the pre-storm satellite-derived beach width measurements. In total, 20 cross-shore survey measurements were used and 14 satellite imagery measurements.

Profiles were analysed for changes in beach slopes, widths and volume between June 2006 and April-June 2010. Changes in beach morphology were also noted, and the influences of local environmental factors, for example the presence of coral reef, dune vegetation and other factors, were considered.

\subsubsection{Satellite imagery and global positioning system analysis}

No profile data were available immediately prior too, or immediately following Hurricane Wilma, therefore satellite imagery was used to map shoreline change resulting from the storm. This satellite imagery was then used in conjunction with beach profile data to measure post-storm readjustment. Aerial photos purchased from Digital Globe were used.

The Digital Globe imagery was taken from the Quickbird Two Satellite, which has a horizontal positional accuracy of $23 \mathrm{~m}$, according to the specifications which came with the data. However, the exact accuracy of each image varies, but the supplier was unable to provide further details. The imagery had a pixel size of $0.6 \mathrm{~m} \times 0.6 \mathrm{~m}$, as such there is there was a maximum pixel size of $0.85 \mathrm{~m}$ (Figure 4-3).

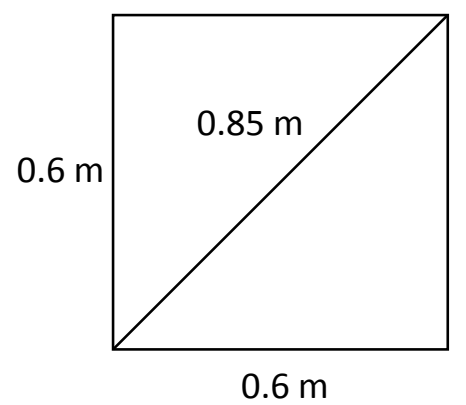

Figure 4-3: Digital Globe: Quickbird Two satellite imagery pixel size.

Satellite imagery was projected in WGS_84_UTM_Zone_16N, and all other data were converted to this projection. Cloud cover within the satellite imagery was less than $10 \%$ enabling unobstructed measurements. The images were georeferenced and georectified in ArcGIS version 10.1 to a Bing basemap. The images taken on 25 October 2005 and 14 June 2006 showed a highly accurate ( $<1 \mathrm{~m}$ horizontal error) match with the Bing basemap and one another. The images taken on 4 September 2004 and 14 August 2005 contained greater error, and were displaced approximately $9 \mathrm{~m}$ to the southeast; these images were repositioned during georectification. During this process four control points, placed as square as possible, were used to align the images; greater points could have increased the image stretch and distortion. Roads and other permanent features were used as control points. Care was taken to avoid buildings and other elevated structures, as the apparent 
position of elevated structures is affected by the angle from which the satellite image is taken. The root mean square error calculated during this process was less than 0.4 .

Dune crest data, captured using the GPS, was used as the baseline position from which all satellite imagery measurements of beach width were taken. The measurements were taken across-shore to mean high water (MHW), marked by the line of seagrass debris during calm periods (4 September 2004, 14 August 2005, and 14 June 2006) and the wetted line following Hurricane Wilma (25 October 2005). The across-shore beach profiles were also corrected to this position to enable comparison. MHW is often used as a shoreline indicator when measuring shoreline change (Moore, 2000; Boak and Turner, 2005). Under normal conditions this provides an accurate point of comparison, however, under storm conditions there is greater error (Boak and Turner, 2005).

The beach was subject to the prevailing energy regime in all satellite images, except 25 October 2005; this image was taken immediately following Hurricane Wilma to capture the coastal damage and extent of geomorphic work, and was essential to quantifying the full impacts of the storm. However, the water level may have still been above mean sea level (MSL). Furthermore, due to the barrier beach being reworked, it was not possible to use seagrass debris lines. As an alternative, the most recent wetted line was used as an indicator; this was situated just beyond sea level at the time. Image colour bands were highlighted in ArcGIS 10.1 to help identify this wetted line. Measurement error is likely to be slightly greater on reef-protected barrier beaches, due to the lower beachface gradient.

\subsubsection{Sediment analysis}

All sediment samples were initially dried at the National University of Mexico field station, Puerto Morelos, prior to processing at Victoria University of Wellington, New Zealand. As the sand was of marine origin, all samples were washed in fresh water to remove salt, a common agent of particle flocculation (Gale and Hoare, 1991). Prior to decanting, samples were left to settle until all material had fallen out of suspension. Samples were then dried at $50^{\circ} \mathrm{C}$ for at least 72 hours. Once dry, beach and lagoon sediment samples from three different areas (Zones 1, 2 and 4; Chapter 5) were split using a riffle box splitter; half of the sample was used for grain size analysis and half for composition analysis. The remaining beach samples were only subject to grain size analysis.

\section{Grain size analysis: Laser Particle Sizer (LPS) and Sieve}

An extremely varied range of densities and grain morphologies occur within carbonate environments. Methods for measuring this sediment include Laser Particle Sizer (LPS), sediment sieving and settling velocity analysis. Some authors have suggested that size measurements based on the settling velocity of grains are most relevant to these environments (Orme 1977, Scoffin 1987, Kench and McLean 1997). However, the main aim of this project was to broadly characterise the general sediment population of the surface and at depth on the beach and within the lagoon. As a detailed reconstruction of the energies of deposition based solely on the grain size results was not attempted, LPS and 
sieving were considered adequate to categorize the sediment. This is consistent with the work of many other authors (e.g. McKee et al. 1959, Folk and Robles 1964, Colby and Boardman 1989, Smithers 1994, Chevillon 1996).

LPS analysis was chosen as the principle method of grain size measurement for this project, due to its proven accuracy and efficiency (Blott et al., 2004). The LPS measures the diffraction of waterborne particles as they are introduced into the laser unit, which is then correlated to particle size; this is based on the Fraunhofer diffraction theory (Blott et al., 2004). The laser particle sizer can be utilized for measuring particles between 0.4-2000 $\mu \mathrm{m}$ in diameter. A total of 220 samples were analysed using the Coulter LS 13320 Laser Diffraction Particle Size Analyzer (LPS) at Victoria University of Wellington. Prior to particle size analysis, samples were weighed and dry sieved at $2 \mathrm{~mm}(-1.0 \phi)$, with the fraction < 2 $\mathrm{mm}$ subsequently run through the laser particle sizer (LPS). Circa $10 \mathrm{~g}$ was run through the LPS for each sample. Glass calibration beads were run through the LPS prior to the first sample run and after the last sample run in order to verify the accuracy of the laser diffraction instrument. This confirmed the accuracy of the laser during operation.

There are, however, some limitations associated with this method. Firstly, particle size, particularly platy particles, can be overestimated. The LPS measures particle volume based on the grain's optical properties, which are then related to an assumed spheroid shape using an optical model (Blott et al., 2004). Despite this, standard use and calibration of the instrument ensured the consistency of the measurements, enabling comparative analysis. Secondly, data from the LPS is not reliable when more than $5 \%$ of a sample (by weight) is over $2 \mathrm{~mm}(-1.0 \phi)$ in size. Therefore, it was necessary to also run some samples using a standard sediment sieve method (Komar and Cui, 1984). A set of sieve stacks ranging from 4 $\phi(63 \mu \mathrm{m})$ to $-4.5 \phi(22,627 \mu \mathrm{m})$ was employed; 20 samples, with $>5 \%$ of the sample by weight, larger than $2 \mathrm{~mm}$ were sieved.

LPS and sieve data is not directly comparable due to the different ways in which these methods measure the sediment. The LPS measures the volume of particles, by relating their optical properties to a predetermined model (Blott et al., 2004; Blott and Pye, 2006). In comparison, the sediment sieve method measures the intermediate (caliper) diameter of individual particles and is recorded as weight within each sieve size class (Blott et al., 2004; Blott and Pye, 2006). Sieved material is also affected by the density of specific particles. Due to these different forms of measurement, analysis of the same sediment often provides different results (Blott et al., 2004; Blott and Pye, 2006). The difference between the techniques tends to increase with increasing grain size and decreasing sphericity (Blott et al., 2004; Blott and Pye, 2006).

Due to these differences, a mathematical correlation was calculated based on 12 samples that were both sieved and run through the LPS. A linear regression curve was found to account for the aforementioned difference between the two methods, which increases with larger grain size $\left(r^{2}=0.79\right.$; Figure 4-4). 


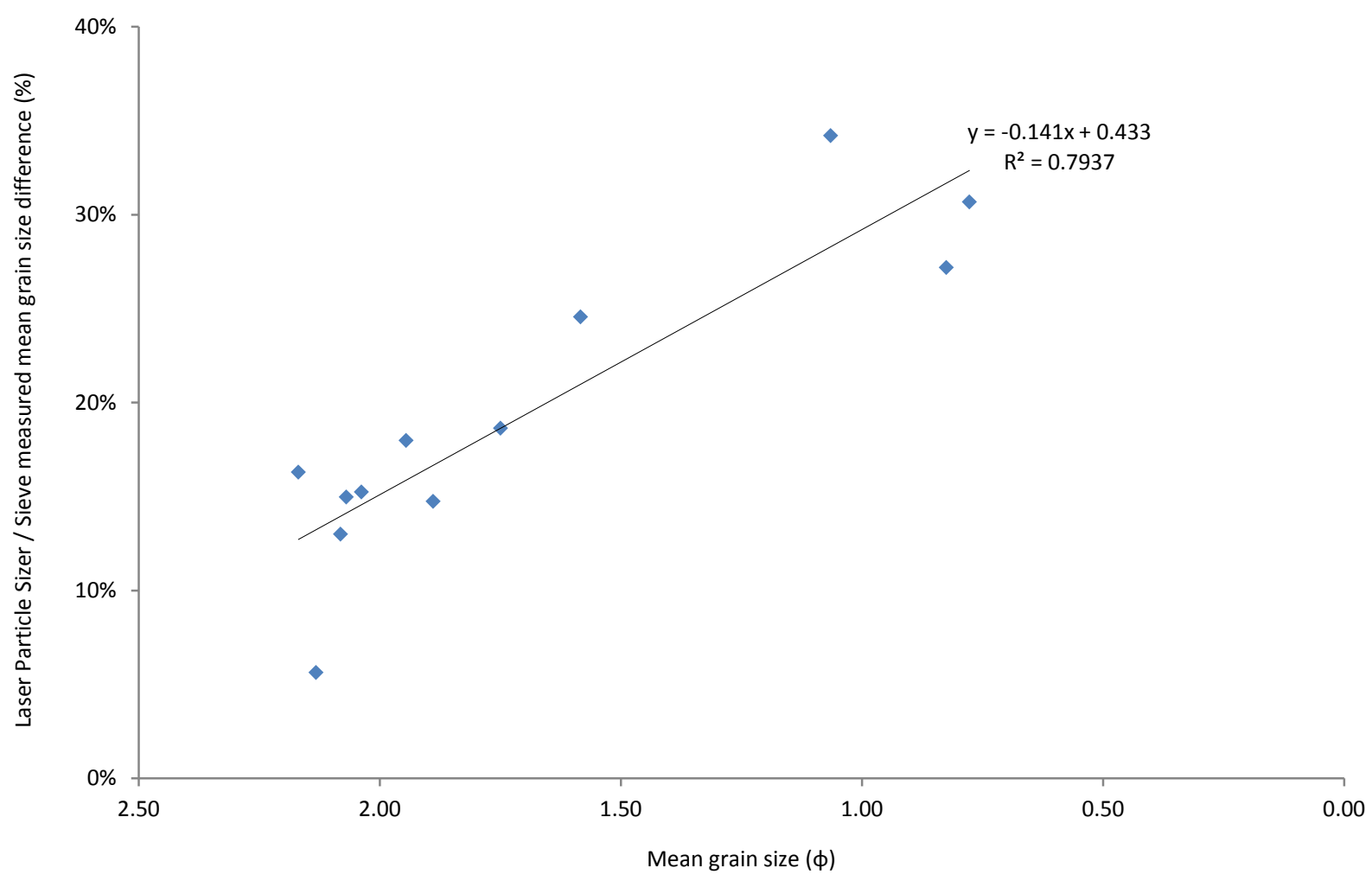

Figure 4-4: Linear regression curve showing increasing difference in mean grain size of sediment measured using a Laser Particle Sizer and sieve, with increasing grain size.

The calculated equation (Equation 4-1) was then applied to the raw sieved data of samples that contained $>5 \%$ (by weight) sediment larger than $2 \mathrm{~mm}(-1.0 \phi)$. It was used to change the 'pan-size' or categories of which the grain-size data is placed. The results showed both over and under-representation of grain-size, when the LPS and sieve measurements were compared post-processing (Figure 4-5); however the measurements were much more closely aligned than the pre-processed data. This equation was used to process sediment within the calculated range of the regression curve (Figure 4-4). Some of the data processed for this study fell outside of this range; as such the error involved in the LPS to sieve grainsize conversion is likely to be greater.

$$
y=-0.141 x+0.433
$$

Equation 4-1: Laser Particle Sizer to sieve conversion factor. 


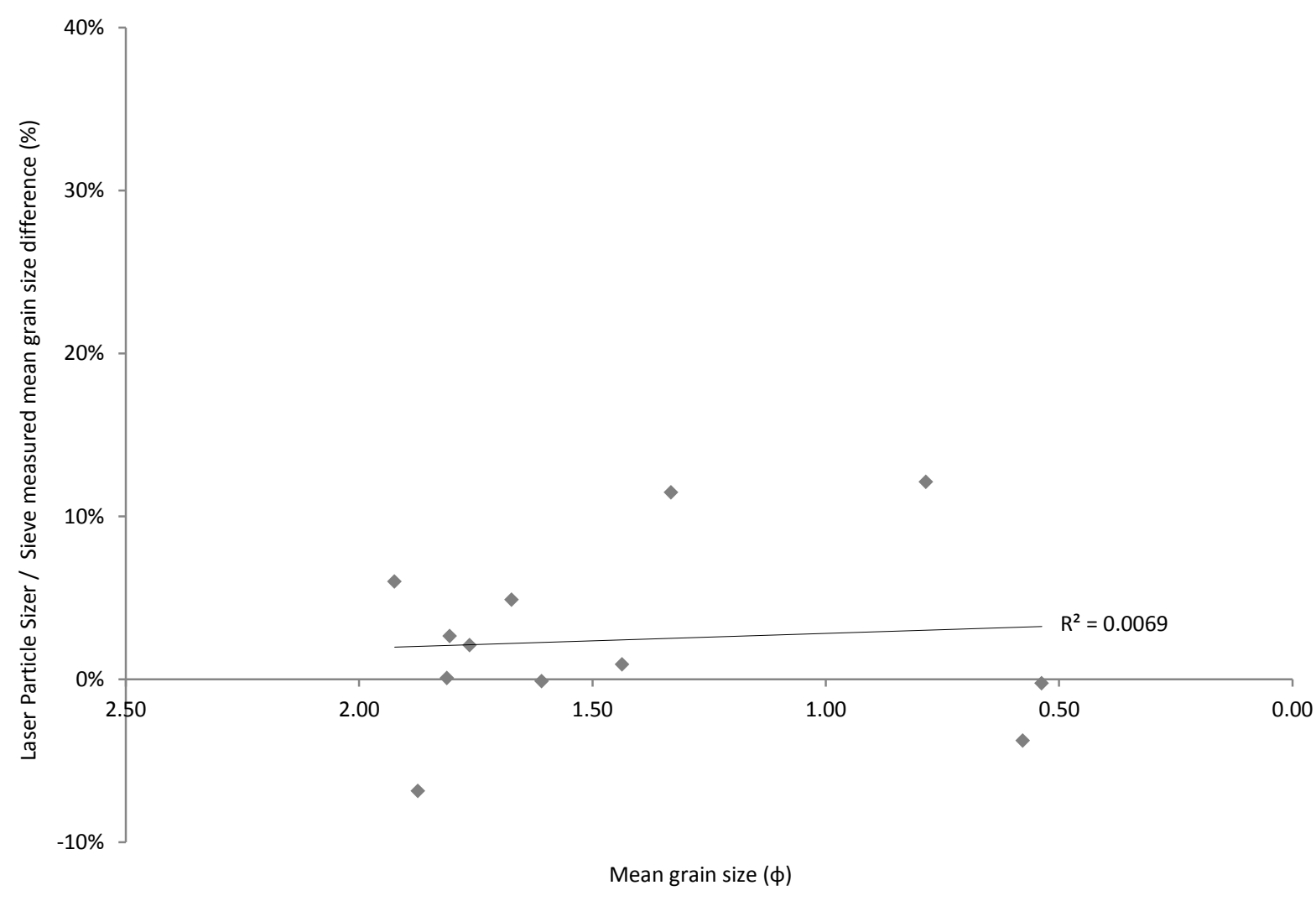

Figure 4-5: Post processing regression curve showing the difference between the measured mean grain-size of the LPS and sieve methods after the conversion factor had been applied (Equation 4-1).

Data from the LPS and sediment sieving was then imported into GRADISTAT version 7.0 for processing, using the Folk and Ward method of calculation and grain size distribution (Blott and Pye, 2001; Blott and Pye, 2008). The output data was used for final sediment characterisation and comparison across-shore and alongshore, between May 2006 and April-June 2010.

\section{Composition analysis}

Sieved sub-samples used for composition analysis were dry sieved between $2 \phi$ and $-1 \phi$ in a sieve shaker for 10 minutes to remove the coarse and very fine sand fractions. These intervals were selected for two reasons: particles finer than $2 \phi$ are inherently difficult to identify and classify due to their degree of abrasion and fracture (Flugel, 1982), and particles coarser than $-1 \phi$ are proportionally large for thin section analysis, making counting a large number of particles difficult ( $\approx 400$ particles per thin section are required). The standard procedure used to produce these thin sections was followed, including (1) mounting the samples in epoxy resin, and (2) grinding to a thickness of $40 \mu \mathrm{m}$.

A total of 87 samples were analysed using the Leitz petrographic binocular microscope and Swift Model F counter at Victoria University of Wellington. Approximately 400 grains on each slide were classified into one of eight categories: coral, coralline algae, mollusc, Halimeda, foraminifera, micrite, echinoid and other. Each grid point overlying a grain was 
counted regardless of whether the grain was large enough that it was counted twice, as this is gives the most accurate representation of grain composition (Fluegel, 1982). The expected standard error associated with this method is $0.5-0.6 \%$ for components with a composition of $<1 \%$ of the sample and $2.2-2.5 \%$ for grains with a composition of over $75 \%$ of the sample (Bayly, 1960; Bayly, 1965). The grain classifications of Milliman (1974), Scoffin (1987), and Adams and McKenzie (1998) were employed to identify and classify the grains in this study. Sediment composition was used to determine the source of storm deposition that occurred as a result of Hurricane Wilma, and the pattern of subsequent reworking to April-June 2010. 


\section{Results and Analysis}

\subsection{Introduction}

Hurricane Wilma had a dramatic impact on the low-lying barrier beach systems of northeastern Yucatan Peninsula, driving considerable geomorphic and sedimentological change. To quantify the significance of Hurricane Wilma on coastal evolution, this change was evaluated over both the short (0-8 months) and medium-terms (8-56 months). This was achieved through the use of satellite imagery, across-shore beach profile analysis and sediment characterisation. The across-shore beach profile in this study is subdivided into five sections from the seaward shoreface to the beachface, back beach, foredune and landward backdune (Figure 5-1). The study area has been broken into six zones based on the exposure to waves, barrier beach geomorphology (barrier beach width and foredune height) and the extent of development. The zones are named: Wet ' $n$ ' Wild, Punta Tanchacte, Punta Petenpich, Punta Brava, Punta Brava South, and Playa del Secreto (Figure 5-2).

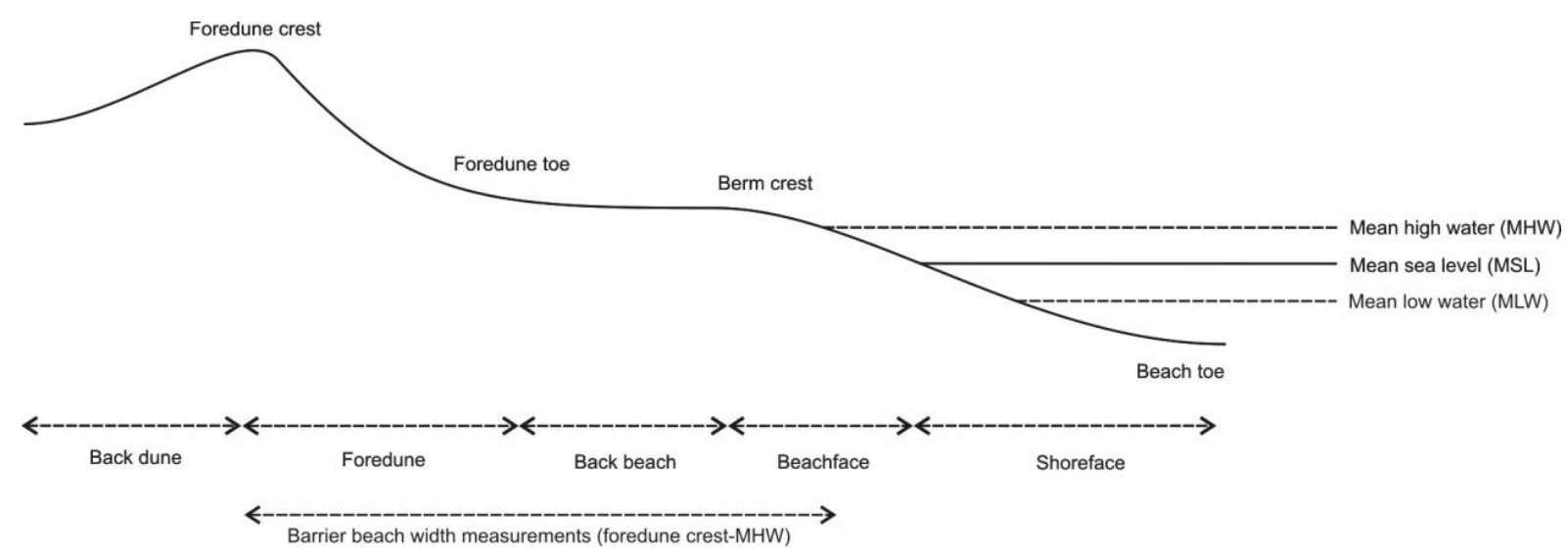

Figure 5-1: Cross-sectional schematic of a beach, with the terms used to describe beach sections in this study. 


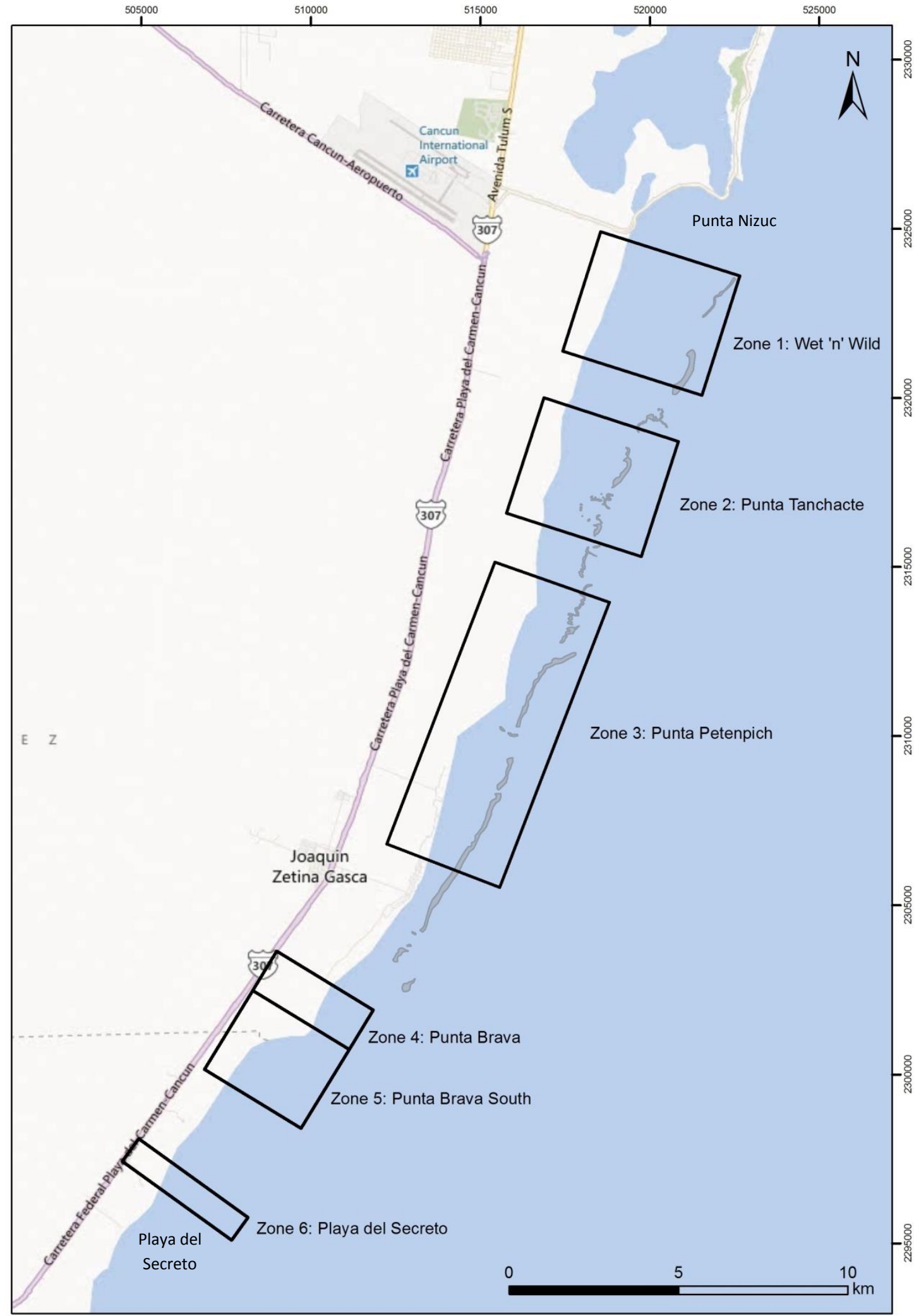

Figure 5-2: Map showing the six different zones investigated in this study, namely: Zone 1: Wet ' $n$ ' Wild, Zone 2: Punta Tanchacte, Zone 3: Punta Petenpich, Zone 4: Punta Brava, Zone 5: Punta Brava South, and Zone 6: Playa del Secreto. Note the distribution of coral reef (grey outline) along the coastline. 


\subsection{Zone 1: Wet 'n' Wild}

\subsubsection{Site description}

Wet ' $n$ ' Wild (WnW) is situated at the northern end of the study area, and covers an alongshore distance of $3.4 \mathrm{~km}$ (Figure 5-3). This zone is situated behind a fringing reef which encloses a lagoon 2.6-3.5 km wide and 3-4 m deep, dominated by Halimeda, Syringodium filiforme and Thalassia testudinum seagrasses. The back beach and foredune are well vegetated by trees and shrubs, with a mangrove wetland situated behind the backdune. The foredune is typically 1.5-3 m above mean high water (MHW), and there has been little development on this feature. 17 sites were surveyed in this zone and sediment samples taken from four of these (WnW-t1, 3, 12 and 17). One sediment transect was also taken across the lagoon (Figure 5-3).

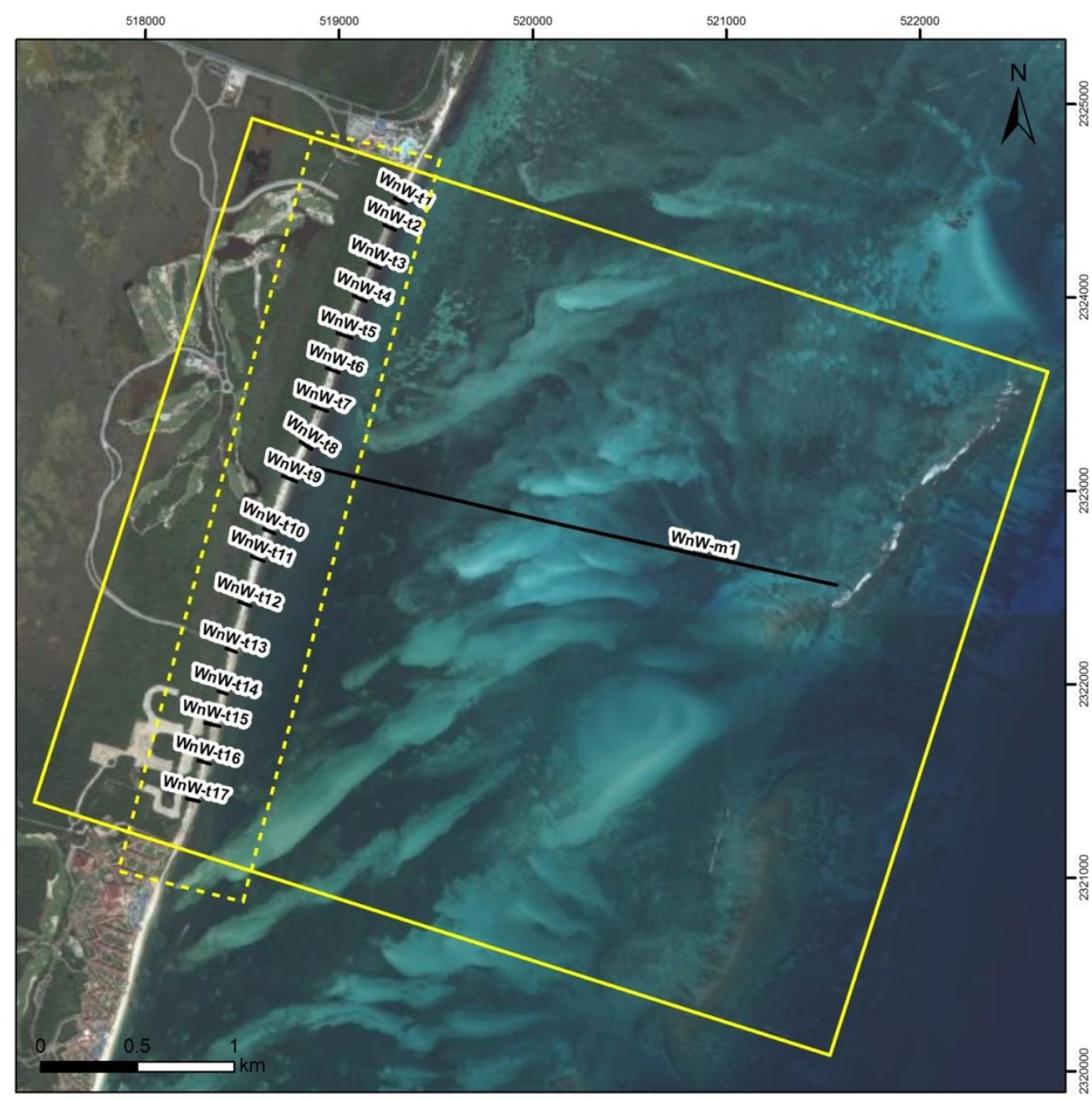

Figure 5-3: Map of Zone 1: Wet ' $n$ ' Wild, showing the locations of the 17 surveyed transects and the backreef lagoon sediment transect. Note the reef crest and sediment shoals. 


\subsubsection{Coastal morphology}

Approximately two months prior to Hurricane Wilma (14 August 2005), the barrier beaches of Wet ' $n$ ' Wild were on average $34.5 \pm 5.1$ (1 SD) $m$ wide, as measured from the foredune crest to mean high water (MHW), and characterised by a well vegetated foredune (Figure 54c). Storm waves from Hurricane Wilma reworked the beach and foredune, and caused the beach to widen significantly, immediately following the storm to $49.5 \pm 5.2 \mathrm{~m}$ (significantly different $(t=12.51)$ at $95 \%$ confidence interval $\left(t_{0.05(2) 15}=2.1314\right)$ of students $t$-test). This showed an average increase in beach width of $15.0 \pm 4.8 \mathrm{~m}$. The northern part of the zone experienced the greatest increases in width (up to $22.1 \mathrm{~m}$ ), compared to the southern end which increased by $3.1 \mathrm{~m}$ (Figures 5-4b, $d$ and g). Sediment was washed inland (Figure 5-4a), the barrier was stripped of vegetation, and the calcarenite dune beneath the beach was left exposed.

By June 2006, eight months after Hurricane Wilma, the barrier beaches in Zone 1 had undergone some post-storm re-adjustment (Figure 5-4e). The beach had narrowed significantly to $45.3 \pm 4.9 \mathrm{~m}\left(\mathrm{t}=5.07, \mathrm{t}_{0.05(2) 15}=2.1314\right)$, which represented an average loss of $4.1 \pm 3.2 \mathrm{~m}$. Beaches in the northern part of the zone, which showed the greatest accretion immediately following Hurricane Wilma, then tended to experience the greatest erosion (up to $8.64 \mathrm{~m}, \mathrm{WnW}$-t1). Sites further south showed considerably less change, and in some instances underwent continued beach accretion (WnW-t14; Figure 5-4h). Fortyeight months later, in April 2010, the barrier beaches showed signs of continued erosion. The barrier was significantly narrower at $35.9 \pm 5.7 \mathrm{~m}\left(\mathrm{t}=8.66, \mathrm{t}_{0.05(2) 16}=2.1314\right)$, representing erosion of $9.4 \pm 4.5 \mathrm{~m}$ since June 2006 and $13.9 \pm 6.2 \mathrm{~m}$ since Hurricane Wilma. The greatest erosion continued to occur in the northern part of the zone between June 2006 and April 2010 (Figure 5-4f). Central parts (except WnW-t9) also experienced erosion; this was also represented by the overall erosional trend since Hurricane Wilma (Figure 5-4h). Following this post-storm readjustment, the barrier beach was left only $1.1 \pm 3.9 \mathrm{~m}$ wider than the pre-storm (14 August 2005) width, indicating the beach had almost completely readjusted 54 months after Hurricane Wilma. The greatest readjustment was seen in the northern and central parts of the zone, with the least change at the southern end (Figure 54i). By April 2010 terrestrial vegetation had also migrated onto the back beach and foredune, aiding sediment accumulation and beach stability in these sections. 

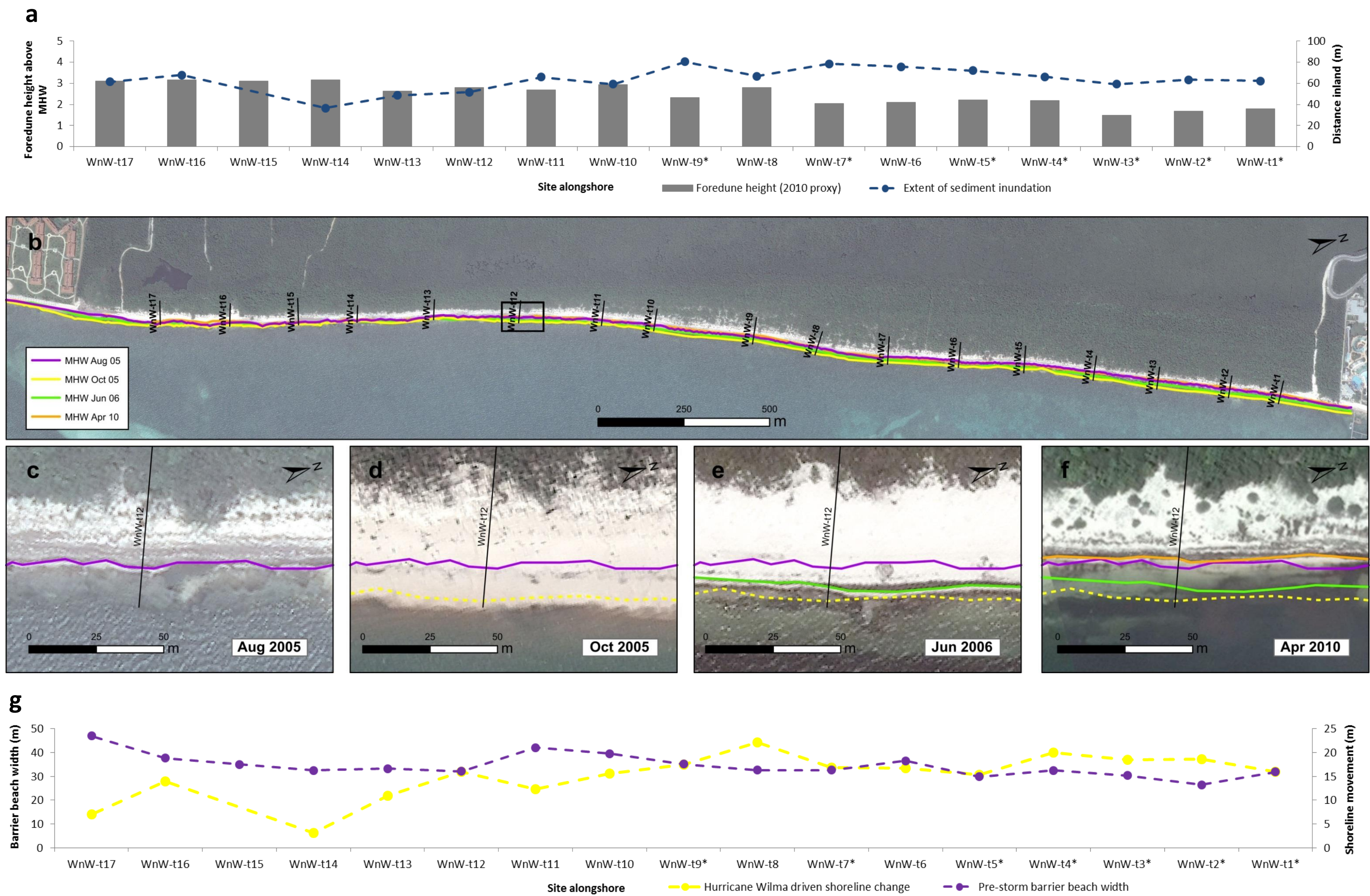

Figure 5-4: Storm and post-storm shoreline movement, profile adjustment and volumetric change along Wet ' $n$ ' Wild: (a) sediment inundation and foredune height (using the 2010 foredune height as a proxy), (b) shoreline movement both as a result of Hurricane Wilma and in the 54 months following the storm to April 2010, (c, d, e, and f) time-stepped shoreline response of the barrier beach at site WnW-t12, and (g) measured shoreline change resulting from Hurricane Wilma. 


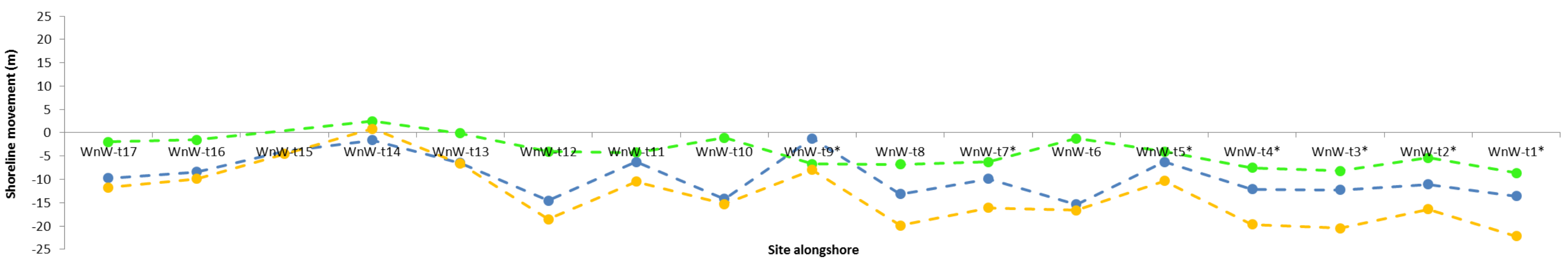

- c- Shoreline movement to June 2006 (0-8 months) - - Shoreline movement June 2006 to April 2010 (8-54 months) - c- Total post-storm shoreline movement to April 2010 (0-54 months)
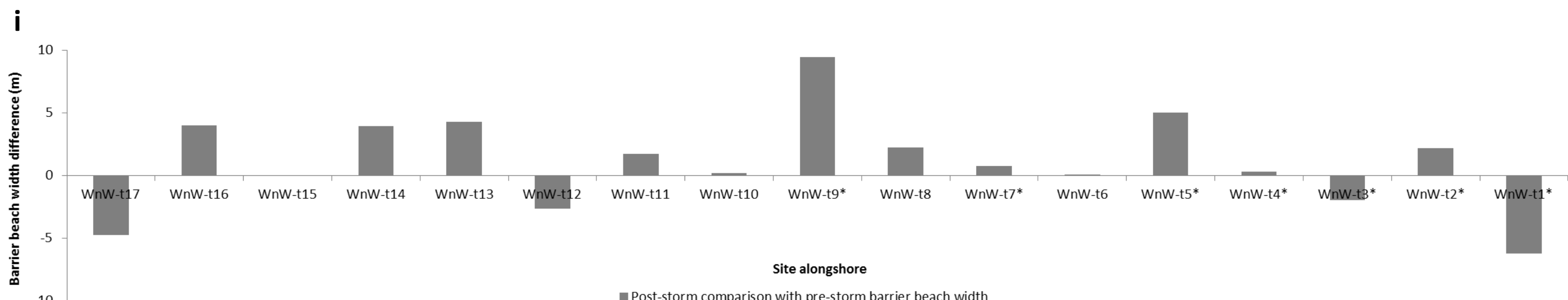

- Post-storm comparison with pre-storm barrier beach width
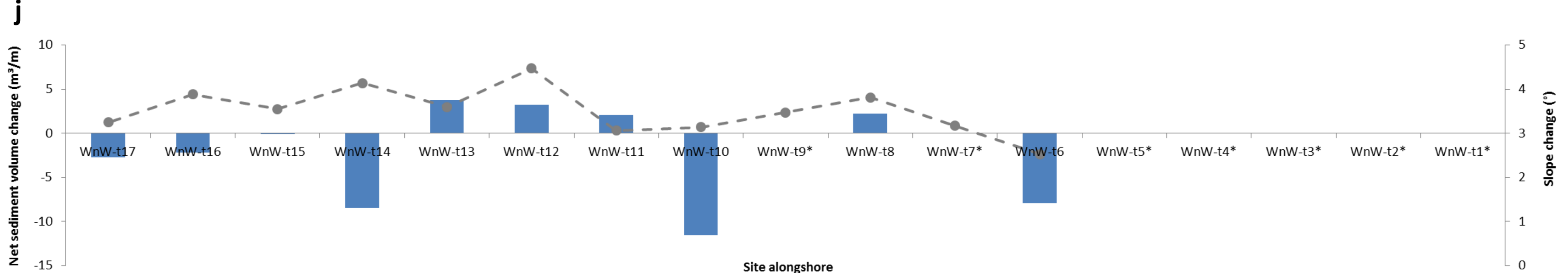

Barrier beach net voume change June 2006 to April 2010 (8-54 months) - - B Barrier beach slope change June 2006 to April 2010 (8-54 months)

Figure 5-4 (continued): (h) measured shoreline movement eight months(June 2006) and 54 months (April 2010) after Hurricane Wilma, (i) difference between the barrier beach width in April 2010 and August 142005 (two months prior to Hurricane Wilma), and (j) barrier beach slope and volumetric changes at selected sites between June 2006 and April 2010. *Denotes sites where satellite image measurements were used, as such only shoreline movement was measured (not profile changes). 
The barrier beaches also underwent considerable post-storm profile change. By April 2010 the barrier had a mean beach slope (based on measurements at WnW-t6, 8, 10-17: Figure 5$4 \mathrm{j})$ which was $0.8 \pm 0.6^{\circ}$ steeper than previous measurements from June 2006 . Net beach volume showed sediment gains of up to $3.8 \mathrm{~m}^{3} / \mathrm{m}$ in some areas (WnW-t13) and losses amounting to $11.6 \mathrm{~m}^{3} / \mathrm{m}$ in others (WnW-t10). The greatest loss occurred in the centre of the zone (Figure $5-4 \mathrm{j}$ ).

The beachface profile is similar in both June 2006 and April 2010, indicating this beach section responds relatively quickly to the prevailing energy regime. In contrast, the results suggest that the geomorphic changes were concentrated in the back beach and foredune: the back beach experienced significant erosion of $4.2 \pm 4.3 \mathrm{~m}\left(\mathrm{t}=3.06, \mathrm{t}_{0.05(2) 9}=2.2621\right)$ and similarly significant profile steepening of $1.5 \pm 1.9^{\circ}\left(t=2.39, t_{0.05(2) 9}=2.2621\right)$ since June 2006. The back beach underwent sediment losses amounting to $5.07 \mathrm{~m}^{3} / \mathrm{m}$ (WnW-t14), compared to gains of up to $11.7 \mathrm{~m}^{3} / \mathrm{m}$ at other sites (WnW-t10). All of the beach changes were found to be highly variable alongshore, with few apparent patterns to these responses (Appendix 9.1 and 9.2). Overall, with the shoreline readjusting landward, sediment was found to accumulate vertically in the back beach and the profile reverted from a concaveupward shape in June 2006 to a more convex shape by April 2010 (Figure 5-5). Sediment accumulation was further aided by the growth of vegetation in the back beach (Figure 5-5d), and previously exposed calcarenite dune remained evident only in the centre of the zone.

By April 2010 the foredune was on average $20.7 \pm 6.1 \mathrm{~m}$ wide with a slope of $5.0 \pm 1.6^{\circ}$, and as such was both narrower and steeper than in June 2006. Reduction in foredune width averaged $5.3 \pm 6.1 \mathrm{~m}$, but was highly variable with the greatest change in the centre of the zone. Changes to the slope and sediment volume also occurred, although these varied considerably alongshore $\left(0.91^{\circ}\right.$ flatter to $3.8^{\circ}$ steeper, and $24.2 \mathrm{~m}^{3} / \mathrm{m}$ less sediment to 5.2 $\mathrm{m}^{3} / \mathrm{m}$ more sediment). Once again, the greatest changes occurred in the centre of the zone (Appendix 9.1). Vegetation had become widespread across the foredune and led to greater beach stability. Overall, over the period June 2006 to April 2010, the barrier beach matured, and the subaerial morphology developed as sediment migrated landward and accreted vertically, and was stabilised by recolonizing vegetation. 

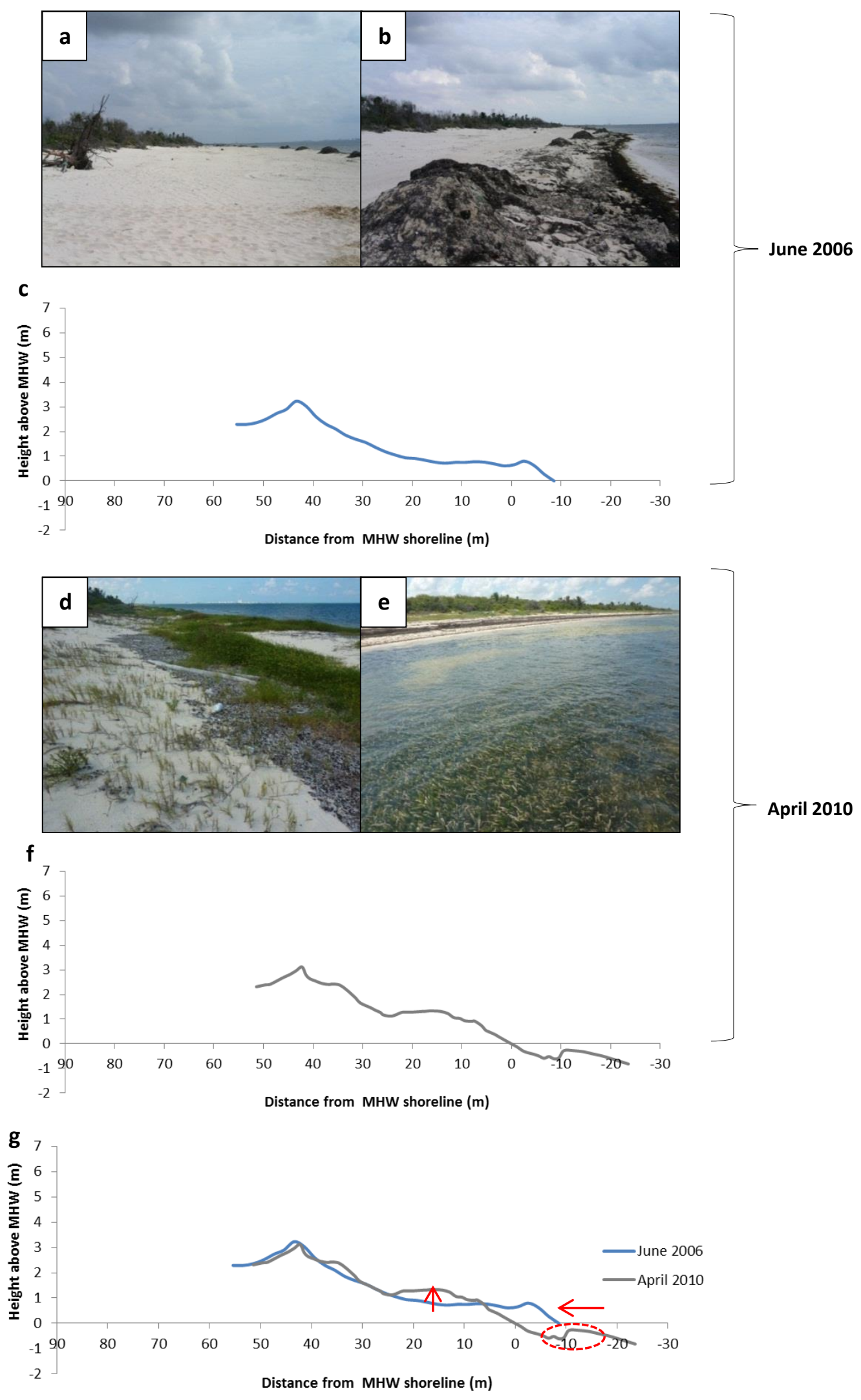

Figure 5-5: Post-storm geomorphic response (WnW-t17): (a-c) across-shore images and profile of the barrier beach in June 2006, (d-f) across-shore images and profile of the revegetated and aggrading barrier beach, and shore-attached sandbar (stabilised by Thalassia testudinum) in April 2010, and (g) comparison of the respective post-storm beach profiles, showing shoreline transgression and subaerial aggradation (arrowed); the subaqueous sand bar is also evident (red circle). 


\subsubsection{Sediment texture: surface sediment}

Hurricane Wilma drove considerable sedimentological change along the barrier beaches of Zone 1. Storm waves reworked sediment and transported it over the foredune and into the backdune swale where it was deposited on top of in situ organic soils (Figure 5-6a and b). These overwashed sediments were visible over $80 \mathrm{~m}$ inland in the centre of this zone where there is a break in the reef crest (Figure 5-4a). The storm deposit in Zone 1 (based on subsurface sediment samples collected in May 2006) was dominated by moderately sorted $(0.76 \phi)$ medium grained sand $(99.80 \pm 0.13 \%)$, with only trace amounts of gravel $(0.10 \pm$ $0.08 \%)$ and mud $(0.10 \pm 0.08 \%)$.

The storm deposit showed small variation alongshore; the northernmost site (WnW-t1) contained coarser sediment $(1.10 \phi)$ than sites further south $(1.45-1.56 \phi)$, and WnW-t12, adjacent to the reef inlet, contained the most poorly sorted sediment $(0.94 \phi)$. The largest $(1.08 \phi)$ and most poorly sorted $(0.79 \phi)$ across-shore sediment was found the the of the foredune, and represented the deposition of coarse sediment during wave uprush, and winnowing of fine sediment during wave backrush. Sediment fined towards the front of the beach, as larger material would have fallen out of suspension first.

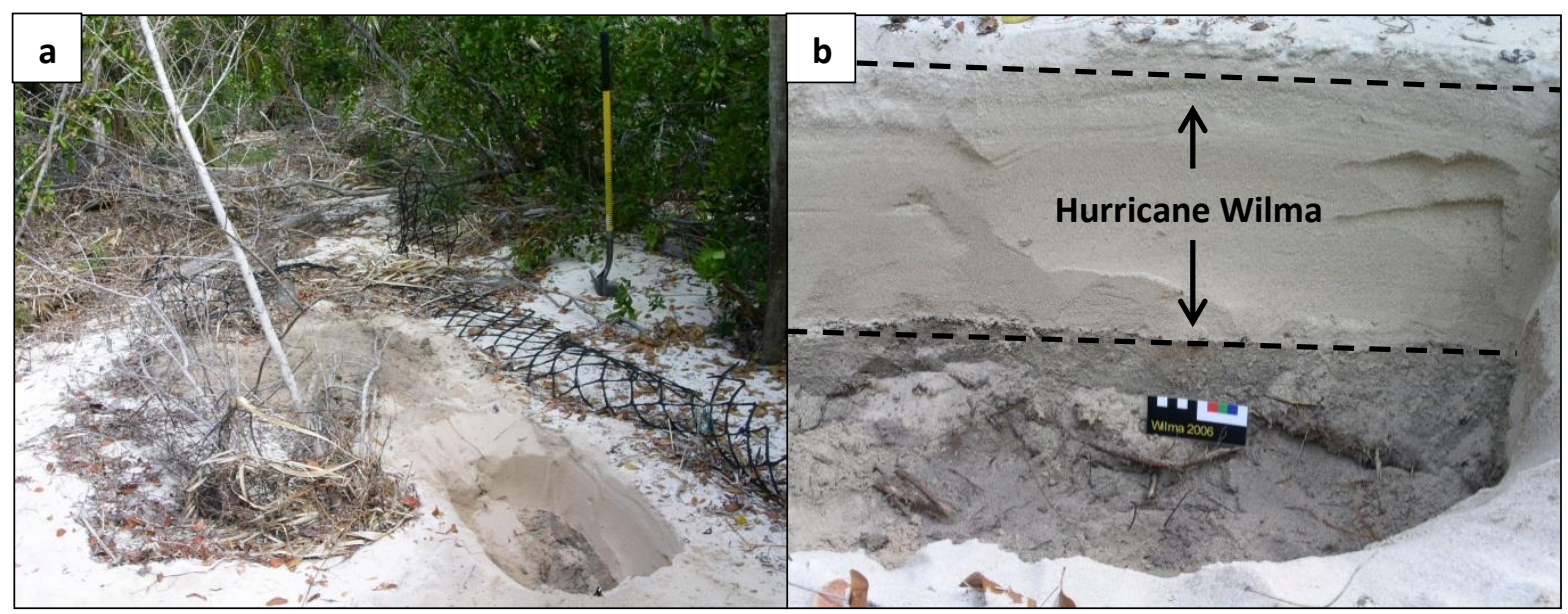

Figure 5-6: Overwashed storm sediments: (a) sediment washed over the top of the foredune crest, and (b) storm layer deposited on top of in situ organic soil and lined by a thin aeolian cap (split by dashed black lines), WnW-t3, May 2006 (Images: David Kennedy).

By May 2006, seven months after Hurricane Wilma, the subaqueous sand bar and beach face had been reworked, as the beach transgressed landward. A post-storm layer was evident in the back beach, and a thin aeolian cap covered the storm deposit in the backdune (Figure 5-6a and b). Overall the post-storm layer was marginally finer (0.21ф) and better sorted $(0.16 \phi)$ than the storm deposit (see also Figure 5-7). Grain-size became more evenly distributed alongshore, and the across-shore grain size pattern reversed (Appendix 9.3); sediment fined towards the back of the beach (1.52-1.74ф), as low-energy wave swash and aeolian sediment transportation predominated. Coarser material was found on the upper foredune $(1.37 \phi)$ and in the backdune, and represented the mixture of storm-derived sediment, with a thin aeolian cap (1.43ф). 
Forty-seven months later, in April 2010, the beach had continued to erode and the storm deposit had been reworked; several layers were evident in the back beach, representing this process. Overall surface sediment, which reflects the prevailing energy regime, was similar in size and sorting to May 2006 (Figure 5-7). However, the northern-most site, WnW10-t1 $(1.08 \phi)$, underwent further sediment coarsening, and had a similar grain-size to the storm deposit. Sediment coarsening was further highlighted by analysis of the sand-sized fraction, with a significant reduction in the proportion of medium sand $\left(13.33 \%, t=5.1, t_{0.05(2) 3}=\right.$ $3.18)$ and significant increase in very coarse sand $(158.41 \%, t=3.79, t 0.05(2) 3=3.18)$ during the medium-term (8-54 months) post-storm period.

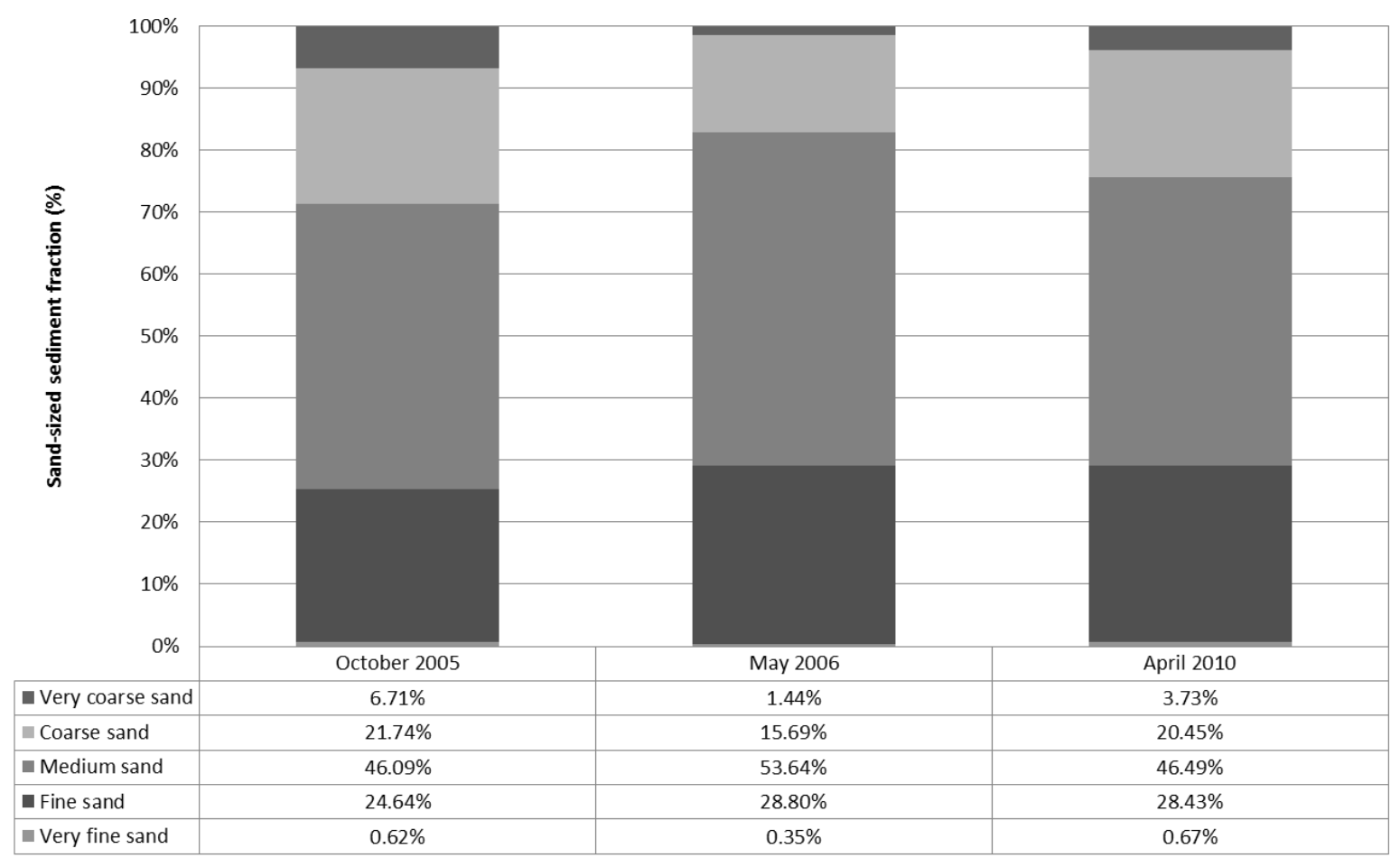

Figure 5-7: Changes to the sand-sized fraction, averaged across the four sampled sites (WnW-t1, 3, 12, and 17) following Hurricane Wilma.

The pattern of sediment coarsening across-shore also changed between May 2006 and April 2010: by 2010 the previously fine-grained back beach contained the coarsest (1.25 $\phi)$ and most poorly sorted $(0.77 \phi)$ sediment; this may have been the result of coarser-grained sediment deposition during minor storm wave inundation. The beachface, foredune and backdune sediments were all finer, and of a similar size (1.59-1.71ф) and sorting (0.61$0.64 \phi)$. Foredune sediments were dominated by aeolian-entrained sediment, while beachface sediment represents low-energy wave swash.

\subsubsection{Sediment texture: subsurface sediment}

As the surface sediment only reflects the prevailing energy regime, subsurface pits were excavated across the beach to investigate the process of post-storm sedimentological change (Appendix 9.3); layers were identified, and textural characteristics were found to 
vary with depth in some instances. However, there was difficulty in linking these layers alongshore and across-shore, due to considerable geomorphic variability. As such one site was chosen to be representative of subsurface changes, WnW10-t1 (Figure 5-8).

Several layers were identified and sampled, with some of these layers showing a discernible difference in grain-size: distinct coarser-grained layers were found to occur at $0.09 \mathrm{~m}$ $(1.05 \phi)$ and $0.13 \mathrm{~m}(0.84 \phi)$ depth in beachface sediments (Figure 5-8d), representative of higher energy depositional events. Back beach sediment tended to coarsen with depth (Figure 5-8c), indicative of finer-grained sediment deposition, which followed a secondary (post-storm) pulse of coarser-grained material. Backdune sediment size was found to be relatively constant with depth (Figure 5-8b); as such it appears to have remained inactive, with the exception of an aeolian cap. All grain size fluctuations tended to be relatively small, suggesting most sediment deposition and beach aggradation was comprised of reworked beach sediment, transported landwards as the shoreline eroded. 


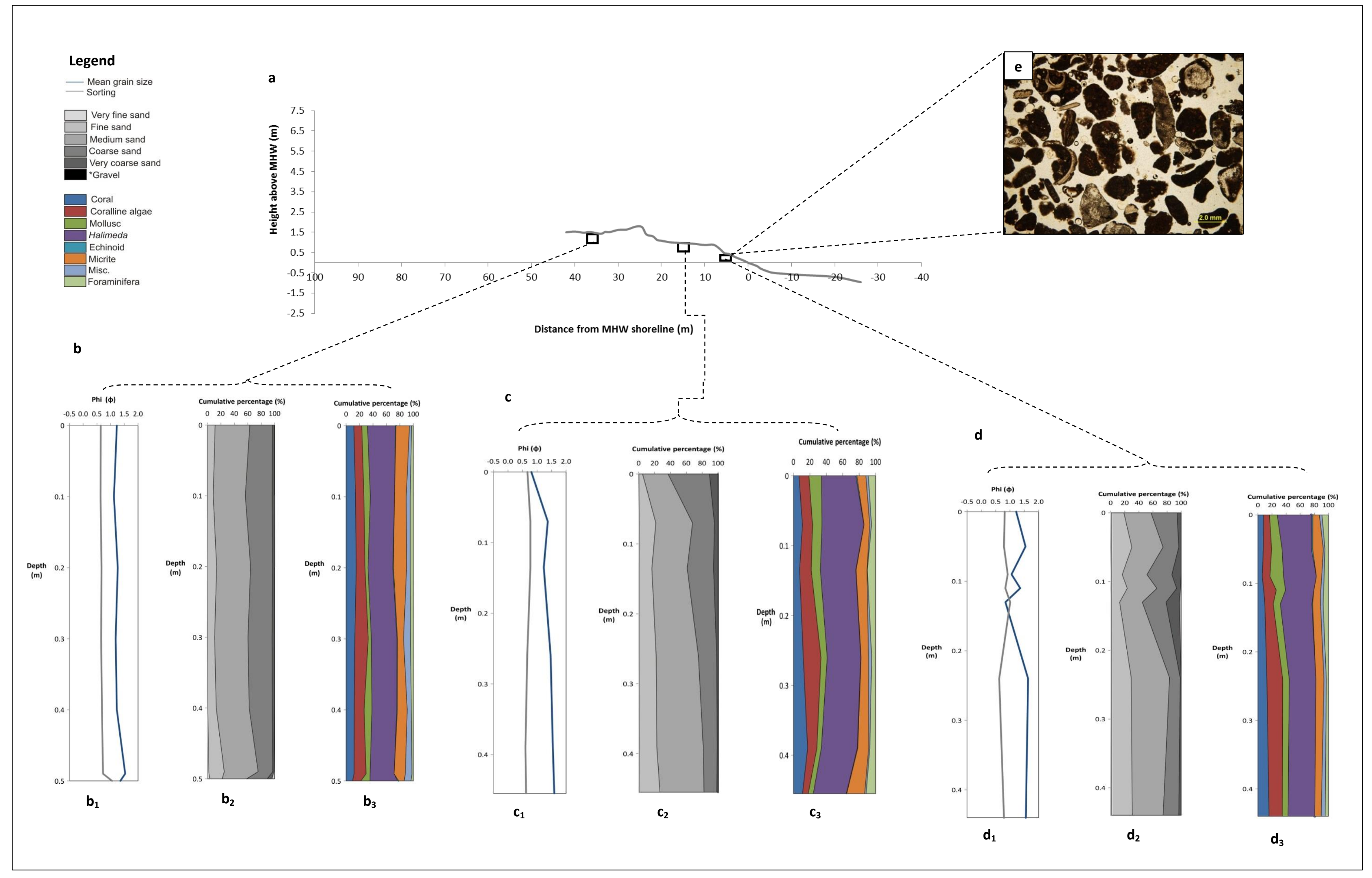

Figure 5-8: Subsurface sediment textural character: (a) Across-shore profile of WnW-t1 in April 2010 outlining the location of sediment pits b, c and d; mean grain size and sorting $\left(b_{1} / c_{1} / d_{1}\right)$, sand-sized sediment fraction ( $\left.b_{2} / c_{2} / d_{2}\right)$, and sediment composition $\left(b_{3} / c_{3} / d_{3}\right)$ are presented from these pits. (e) Thin section of the surface sediment from the beachface (WnW-t1-a) showing the primary skeletal constituents (Halimeda, coralline algae, mollusc, coral, foraminifera and micrite). 


\subsubsection{Sediment composition: surface sediment}

Halimeda $(41.23 \pm 2.89 \%)$ was found to be the dominant constituent within the storm deposit, with smaller proportions of coral $(10.29 \pm 3.27 \%)$, coralline algae $(9.27 \pm 2.56 \%)$, foraminifera $(9.09 \pm 3.01 \%)$, and molluscs $(7.00 \pm 3.14 \%)$. Sediment was highly micritic $(20.24 \pm 5.81 \%)$, indicating the predominance of beach and foredune reworking and/or material from the backreef lagoon (see Section 2.3.6). The small coral component indicates only a relatively small proportion of material was derived from the reef crest; moreover, some of these constituents had undergone micritisation, therefore may have already been in situ in the barrier beach or backreef lagoon. These results indicate that even under storm conditions sedimentological response is predominately characterised by in situ barrier beach and/or backreef lagoon reworking, with the reef crest relatively disconnected from the beach; this may be due to the wide backreef lagoon.

By May 2006, the storm deposit had shown little change: the Halimeda content was marginally smaller, and there were slight increases in the coral, coralline algae and mollusc contents. However changes to the composition did vary across-shore (Figure 5-9).

A further 47 months later, in April 2010, surface sediment contained similar Halimeda and coralline algae contents (10.82 $\pm 2.06 \%$ and $43.94 \pm 3.86 \%$, respectively), a higher mollusc proportion $(11.5 \pm 3.52 \%)$ and slightly lower coral content $(8.67 \pm 2.47 \%)$; micritisation remained high. These results indicate storm driven sedimentology is not too dissimilar to the prevailing conditions (see Figure 5-9), and likely comprises largely reworked barrier beach sediment, originally sourced from the lagoon.

Across-lagoon sediment was also analysed and, similar to grain-size, found to be highly variable (Figure 5-9b). Halimeda content fluctuated around $40 \%$, and was the dominant sand-sized fraction to within a few hundred metres of the reef crest, at which point it transitioned to coral co-dominance (Figure 5-9b). Coralline algae and molluscs tended to constitute approximately $15-20 \%$ of the sand-sized fraction across the lagoon (Figure 5-9b). It is therefore apparent Halimeda is highly productive within the backreef lagoon.

\subsubsection{Sediment composition: subsurface sediment}

Fluctuations in mean grain size (with depth) on the barrier beach, tended to follow changes in constituent contents; increases in grain size tended to correspond to increases in coralline algae (Figure 5-8); this relationship was most apparent in the beachface. Constituent micritisation was high throughout the sediment pit stratigraphy, further supporting the notion of barrier beach sediment largely being comprised of reworked beach material, and backreef lagoon sediment. 


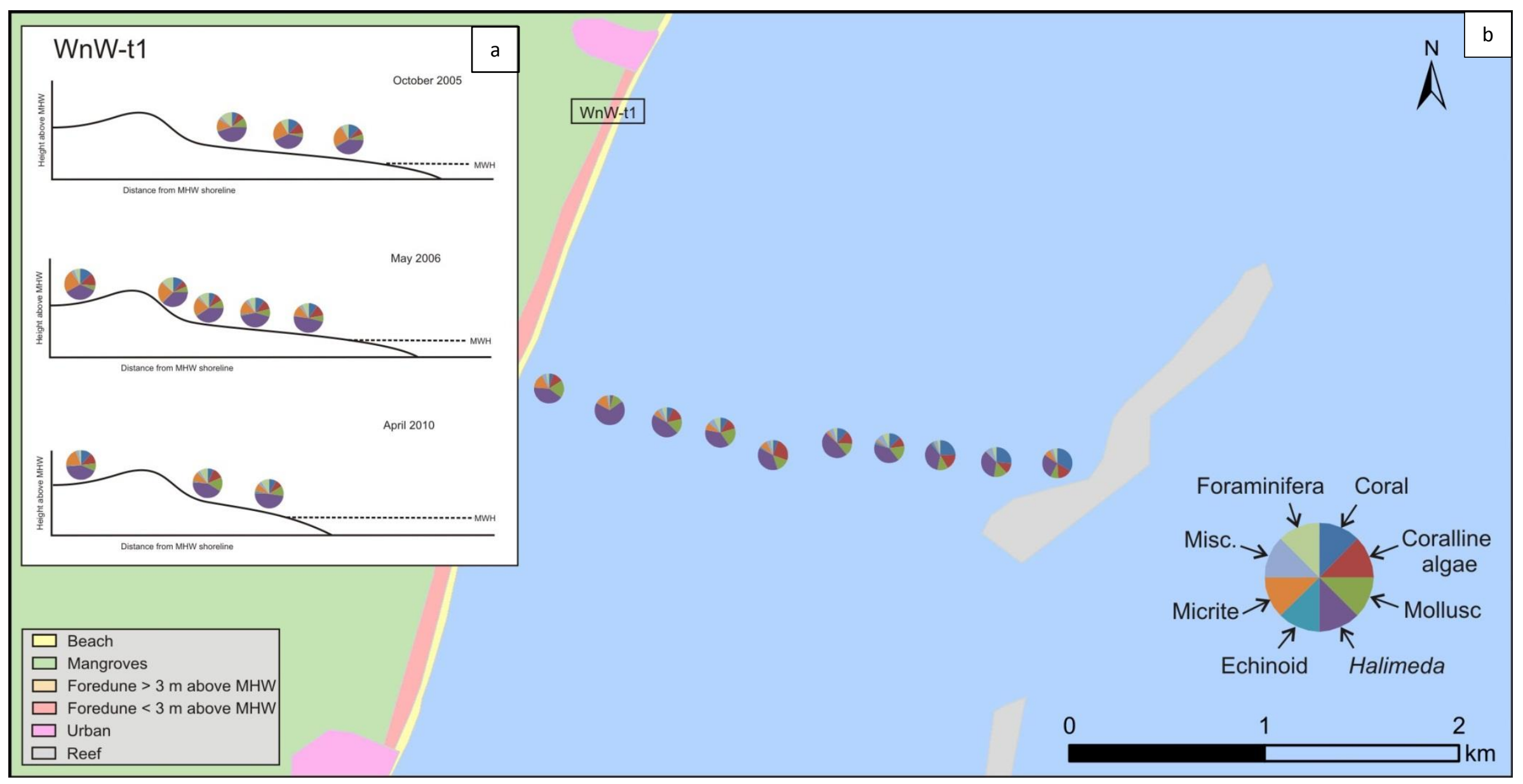

Figure 5-9: Sediment composition in Zone 1: Wet ' $n$ ' Wild: (a) Changes in sediment composition following Hurricane Wilma, and (b) sediment composition across the backreef lagoon in April 2010. 


\subsection{Zone 2: Punta Tanchacte}

\subsubsection{Site description}

Punta Tanchacte (PntTnch) is situated south of Wet ' $n$ ' Wild and covers an alongshore distance of $2.65 \mathrm{~km}$ (Figure 5-10). This zone is situated behind a fringing reef which encloses a lagoon 1.35-1.80 km wide and 3-4 $\mathrm{m}$ deep, and is dominated by Halimeda, Syringodium filiforme and Thalassia testudinum seagrasses. Punta Tanchacte is characterised by the highest foredunes in this study, which range from 3-3.5 m above MHW in the centre-north, to 5.5-6.5 $\mathrm{m}$ at the northern and southern ends. A calcarenite beach ridge is exposed near the foredune crest at some sites, and a transgressive ridge adjoins the foredune at the northern end of the site. The back beach and foredunes are well vegetated by trees and shrubs, and mangrove wetlands dominate the backdune. Sixteen sites were surveyed in this zone and sediment samples taken from three of these (PntTnch-t3, 5, and 12). One sediment transect was taken across the lagoon (Figure 5-10).

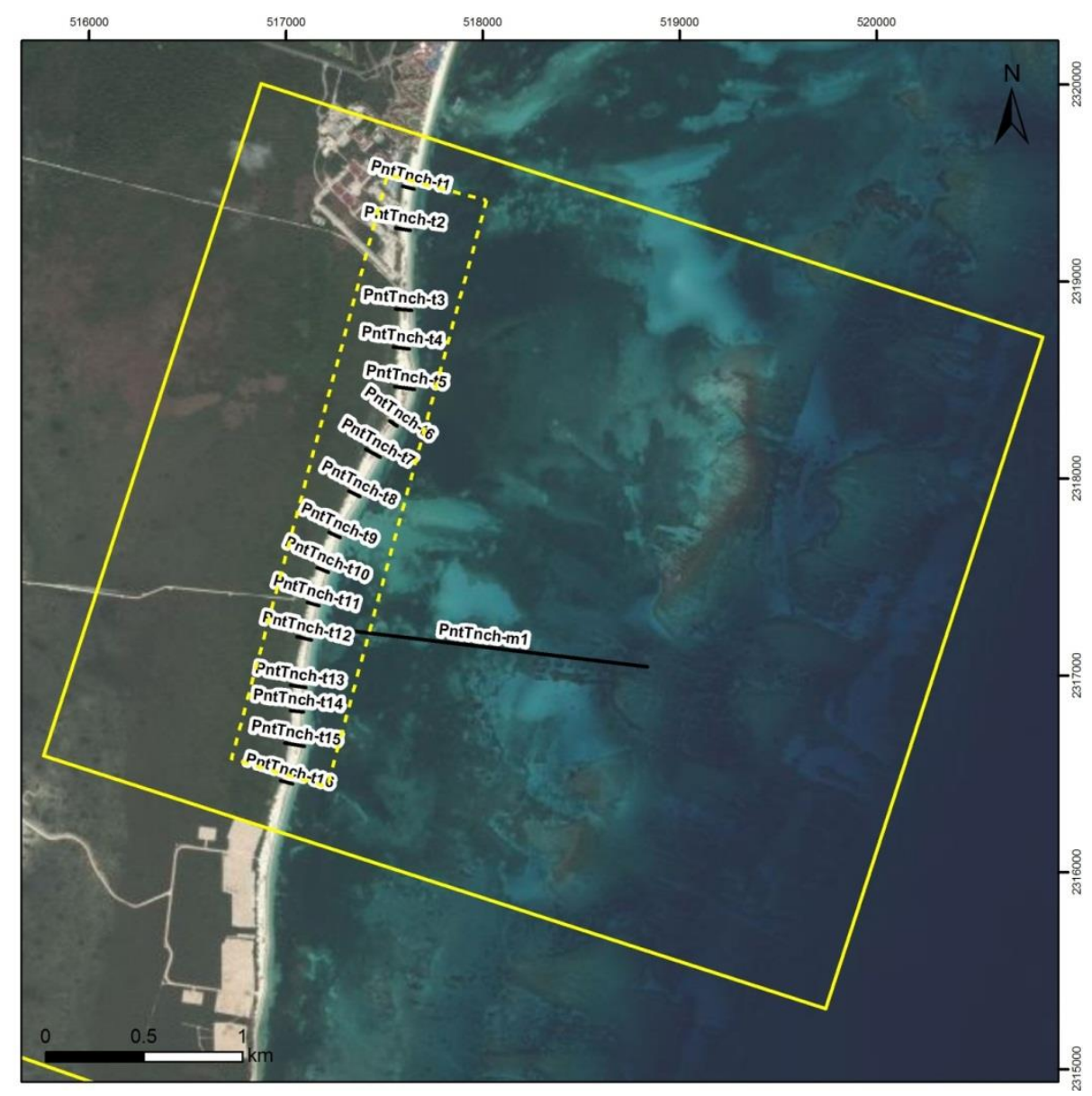

Figure 5-10: Map of Zone 2: Punta Tanchacte showing the locations of the 16 surveyed transects and backreef lagoon sediment transect. Note the reef crest and cuspate foreland. 


\subsubsection{Coastal morphology}

Two months prior to Hurricane Wilma, on 14 August 2005, the barrier beaches of Punta Tanchacte were on average $61.9 \pm 9.0 \mathrm{~m}$ wide, with a well vegetated foredune (Figure 511c). Storm waves from Hurricane Wilma reworked the beach and part of the foredune, overtopping only those foredunes less than $3 \mathrm{~m}$ above $\mathrm{MHW}$, and caused the beach to significantly widen to $78.2 \pm 8.6 \mathrm{~m}\left(\mathrm{t}=16.42, \mathrm{t}_{0.05(2) 14}=2.1448\right)$, an average increase of 16.3 $\pm 3.9 \mathrm{~m}$ (Figure 5-11). Shoreline accretion was relatively similar alongshore, however beach widening of up to $24.6 \mathrm{~m}$ was experienced at the southern end and shoreline accretion as little as $7.7 \mathrm{~m}$ was experienced at the northern end. The lower foredune and beach were stripped of vegetation.

By June 2006, 8 months after Hurricane Wilma, the barrier beaches of Punta Tanchacte had undergone some post-storm re-adjustment, as the beaches responded to the prevailing energy regime; the easily workable shoreface and beachface were the first to respond. The beach had undergone significant narrowing to $74.7 \pm 8.3 \mathrm{~m}\left(\mathrm{t}=3.33, \mathrm{t}_{0.05(2) 14}=2.1448\right)$, and represented average erosion of $3.4 \pm 4.0 \mathrm{~m}$ (Figure 5-11); this was however highly variable, with the greatest erosion experienced at the southern end $(9.7 \mathrm{~m})$, no change in the centre of the zone, and a site in the north underwent shoreline accretion ( $2.7 \mathrm{~m}$, PntTnch-t4) (Figure 5-11h). By April 2010, a further 48 months later the barrier beaches had undergone continued erosion at all sites alongshore $\left(t=12.29, t_{0.05(2) 14}=2.1448\right)$, with the barrier eroding by on average $11.8 \pm 5.7 \mathrm{~m}$ since June 2006 , and amounting to $15.5 \pm 4.9 \mathrm{~m}$ since Hurricane Wilma. The greatest erosion tended to occur where the beach had undergone the least post-storm change to June 2006 (up to $19.4 \mathrm{~m}$ ), with the shoreline erosion since Hurricane Wilma greatest at sites in the central $(27.6 \mathrm{~m})$ and southern ends $(19.4 \mathrm{~m})$ of the zone. Considerably less change was typically experienced on the cuspate foreland, in the lee of the reef crest, at the northern end of the zone (9.0-15.4 m). Furthermore, the total shoreline erosion to June 2010 positioned the beach width only $0.8 \pm 4.8 \mathrm{~m}$ wider than the pre-storm position of 14 September 2005 (Figure 5-11j).

The post-storm shoreline changes took place at a normalized rate of approximately $0.5 \pm$ $0.42 \mathrm{~m} / \mathrm{month}$, during the first eight months, but later slowed to $0.25 \pm 0.12 \mathrm{~m} / \mathrm{month}$ over the period 8-56 months after Hurricane Wilma (Figure 5-11h). This indicates that easily reworkable beach features, such as the low-lying beachface, respond relatively quickly, after which the rate of shoreline loss slows; greater energy over a longer duration is required to make further changes. 

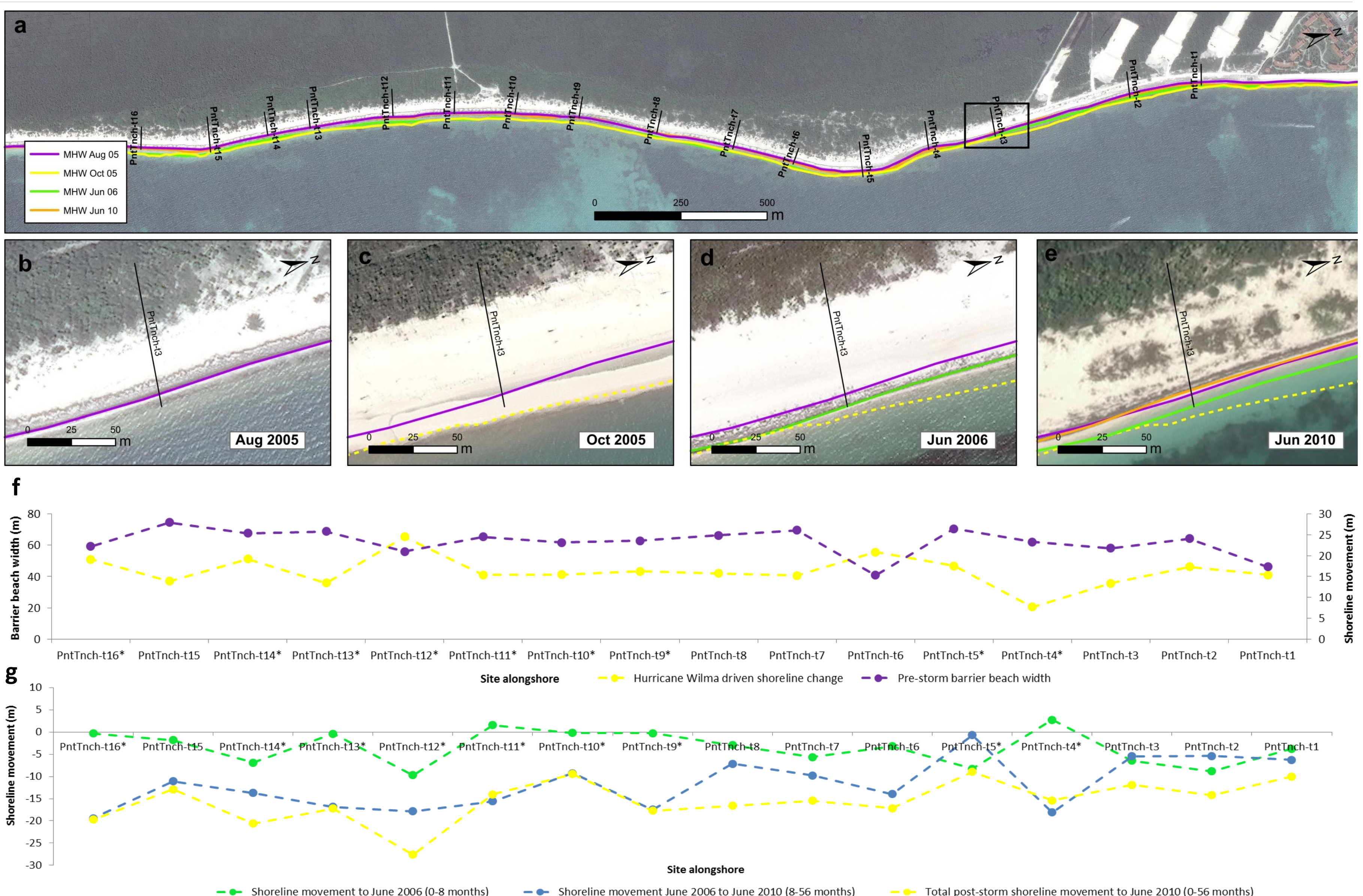

Figure 5-11: Storm and post-storm shoreline movement, profile adjustment and volumetric change along Punta Tanchacte: (a) shoreline movement both as a result of Hurricane Wilma and in the 56 months following the storm to June 2010 , (b, c, d, and e) time-stepped shoreline response of the barrier beach at site PntTnch-t3, (f) storm-driven shoreline movement with pre-storm barrier beach width, and (f) post-storm shoreline. movements 


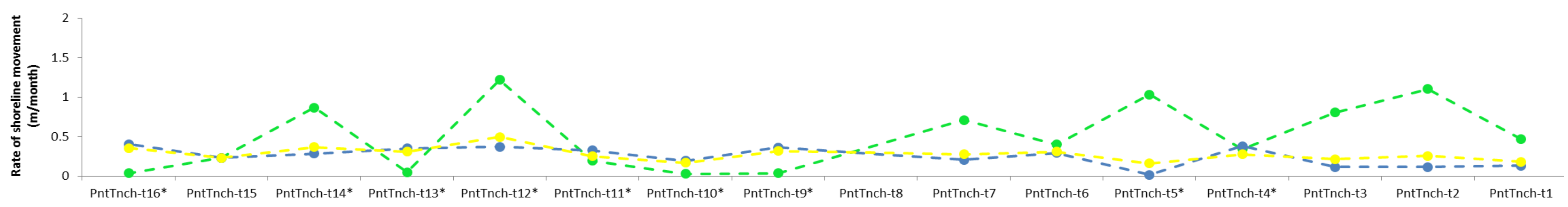

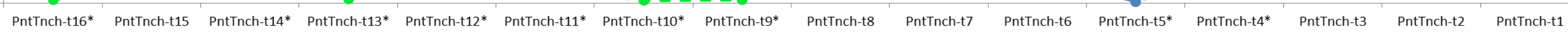

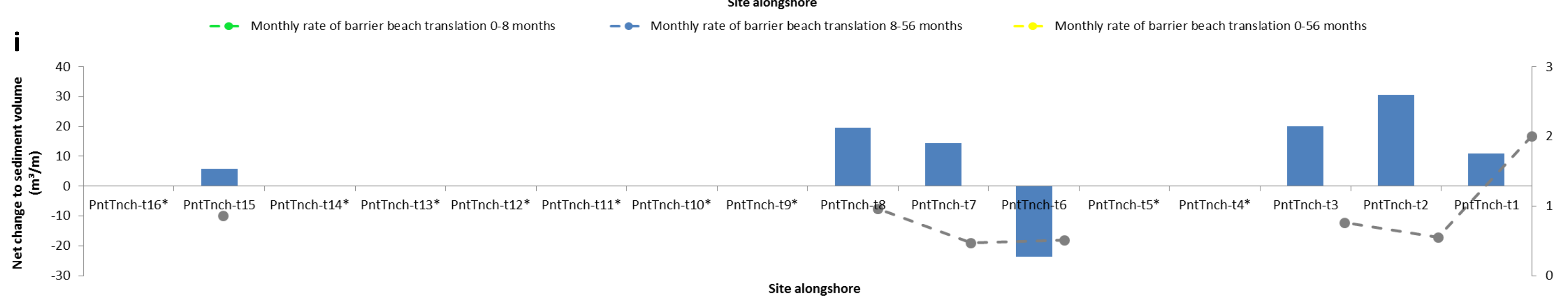

Barrier beach net volume change June 2006 to June 2010 (8-56 months)

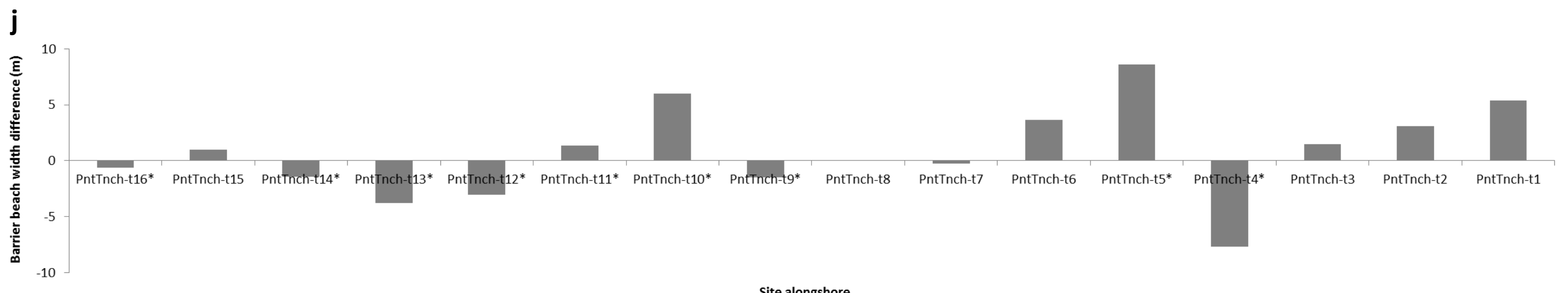

Site alongshore

- Post-storm comparison with pre-storm barrier beach width

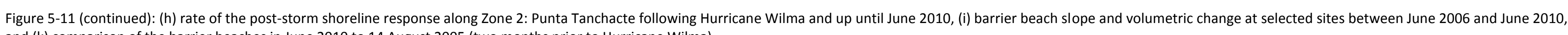
and (k) comparison of the barrier beaches in June 2010 to 14 August 2005 (two months prior to Hurricane Wilma). 
Post-storm profile changes were also evident along the barrier beaches of Punta Tanchacte, although they were not as prominent as in Zone 1. By June 2010 the barrier beaches had a mean beach slope of $3.3 \pm 0.9^{\circ}$ (based on PntTnch-t1-3, 6-8, and 15: Figure 5-11i). This was $0.9 \pm 0.5^{\circ}$ steeper than June 2006 , but was found to be both steeper and flatter at different sites. Changes to net sediment volume were also recorded with net sediment gains of up to $30.6 \mathrm{~m}^{3} / \mathrm{m}$ in at the northern end of the zone, contrasting sediment losses of $23.8 \mathrm{~m}^{3} / \mathrm{m}$ further south.

Post-storm barrier beach response saw dramatic changes focused in the back beach (Figure $5-12$ ). This beach section was compressed between the foredune and the eroding shoreline, and was $20.8 \pm 7.8 \mathrm{~m}$ wide and $0.7 \pm 0.5^{\circ}$ steep in June 2010 ; this was on average $8.9 \pm 1.9$ $\mathrm{m}$ narrower and $0.9 \pm 0.4^{\circ}$ steeper than 48 months earlier. The greatest changes were experienced just south of the cuspate foreland (PntTnch-t6). This indicated that littoral drift and backreef circulation processes predominated under the prevailing conditions. The back beach also underwent vertical accumulation and the profile reverted from a concaveupward shape in June 2006 to a convex shape, dominated by incipient dune development 48 months later (Figure 5-12f).

Unlike the back beach, the foredune underwent only minor landward movement (on average $2.3 \pm 5.9 \mathrm{~m}$ ). However changes to net sediment volume were more significant $(\mathrm{t}=$ $\left.4.4, \mathrm{t}_{0.01(2) 6}=3.7074\right)$, with an average sediment gain of $69.5 \pm 41.8 \mathrm{~m}^{3} / \mathrm{m}$ as the foredune accreted and became more convex due to post-storm aeolian deposition (Figure 5-12f). Grasses and shrubs recolonised the foredune and brought greater stability, particularly to those overtopped by storm waves. 

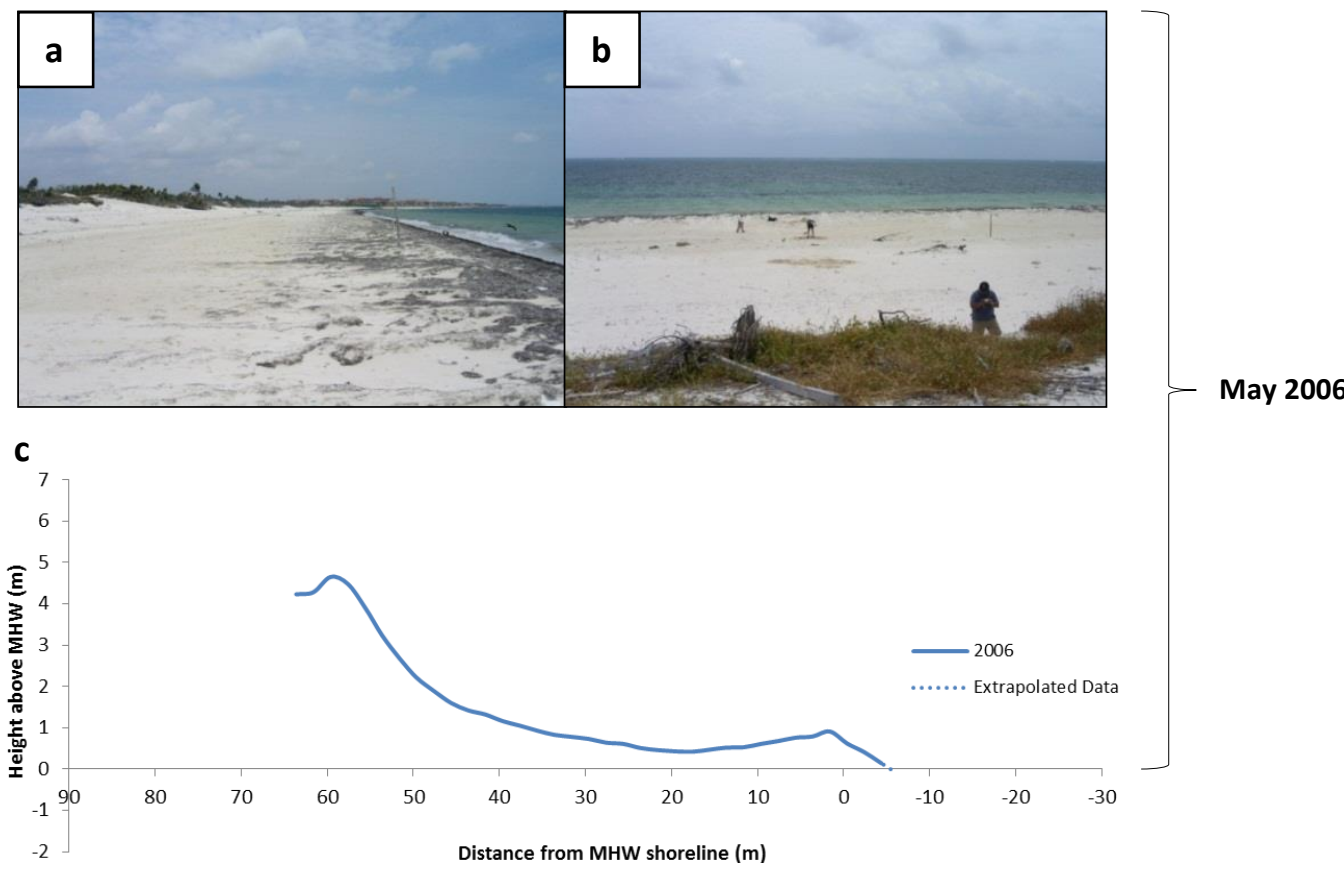

June 2010

f
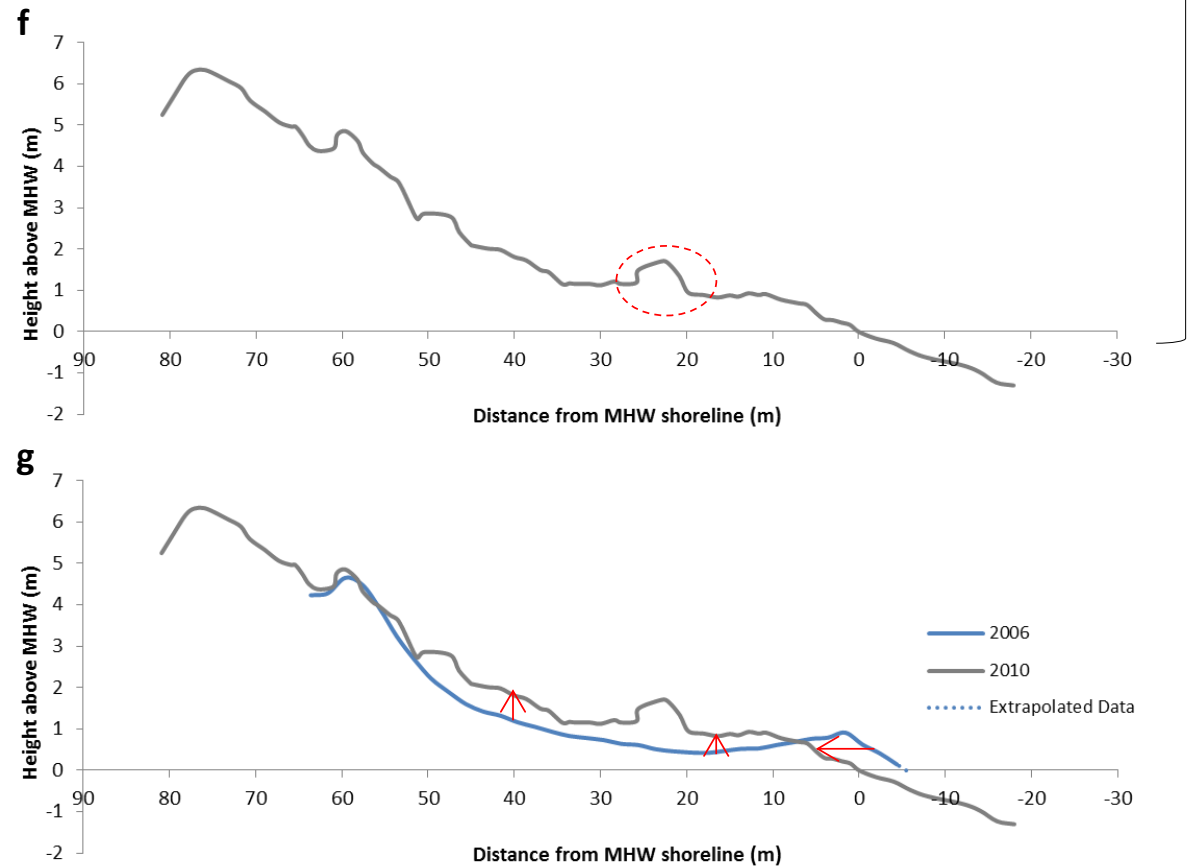

Figure 5-12: Post-storm geomorphic response (PntTnch-t3): (a-c) Images and profile across the barrier beach in May 2006, (d-f) across-shore images and profile of aggrading beach, and embryo dune development (red circle) in June 2010 and (g) comparison of the respective poststorm beach profiles, showing shoreline transgression and subaerial aggradation (arrowed). 


\subsubsection{Sediment texture: surface sediment}

Punta Tanchacte showed a similar sedimentological response to Zone 1, and was characterised by a thick and largely homogeneous storm deposit. However, the foredunes were considerably higher than Zone 1 (typically 3.5-6.5 m above MHW); this restricted storm wave inundation to the foredune face and beach, with only the lowest foredunes $(<3$ $\mathrm{m}$ above MHW), concentrated in the centre of the zone, overtopped (Figure 5-13a and b). Overwashed sediment at these sites was visible a short distance beyond the foredune. The storm deposit in Punta Tanchacte (based on subsurface sediments sampled in May 2006) was characterised by moderately well sorted $(0.67 \phi)$ medium sand $(1.52 \phi)$. The storm deposit was of similar sediment size and sorting alongshore (Appendix 9.3), indicating barrier beaches underwent relatively uniform sediment deposition, regardless of geomorphic variability.

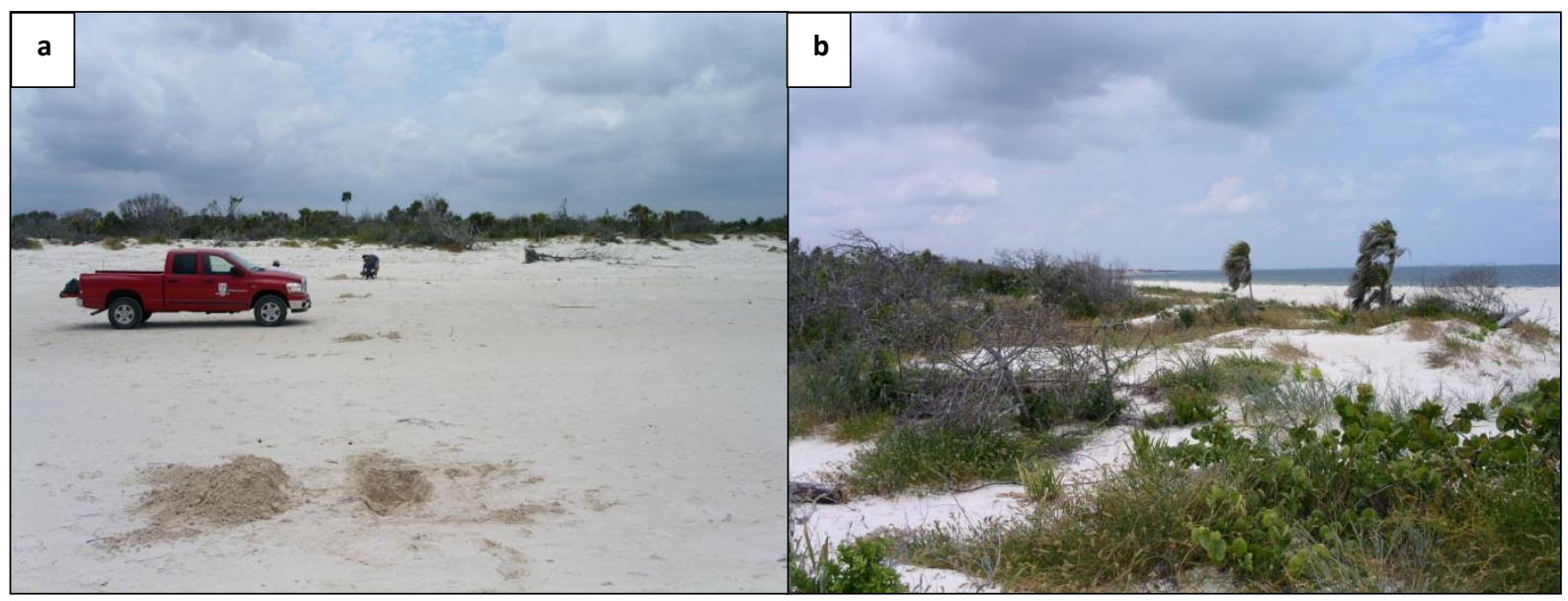

Figure 5-13: (a/b) Sediment was washed over lower-lying foredunes at PntTnch-t5, during Hurricane Wilma (Images: David Kennedy).

By May 2006, a slightly finer $(0.19 \phi)$ and better sorted $(0.09 \phi)$ sediment layer had been deposited on top of the storm-derived material in the back beach (see also Figure 5-14); the sediment was not too dissimilar due to being comprised of largely reworked shoreface and beachface material. Sediment at the northern (PntTnch-t3) and southern (PntTnch-t15) ends tended to fine, whereas PntTnch-t5, which was in the direct lee of the reef crest, remained largely unchanged. There was also some preferential sediment distribution across-shore: sediment became coarser $(1.78 \phi-1.56 \phi)$ and more poorly sorted $(0.55 \phi-0.64 \phi)$ from the beachface to the foredune. Similar to Zone 1 this likely represents minor storm wave inundation towards the back of the beach, and the low-energy swash gradient on the beachface.

The beach continued to erode and the storm deposit reworked to June 2010. As with Zone 1 , sediment reworking occurred in stages, and was evidenced by the subsurface sediment layers. Surface sediment was found to be slightly coarser $(0.19 \phi)$ and more poorly sorted $(0.15 \phi)$ than May 2006 and was of similar texture to the storm deposit; these changes were most evident in changes in the sand-sized sediment fraction (Figure 5-14). Sediment 
distribution across-shore was largely unchanged; however, sediment size had increased, with greater proportions of coarse and very coarse sand (Appendix 9.3).

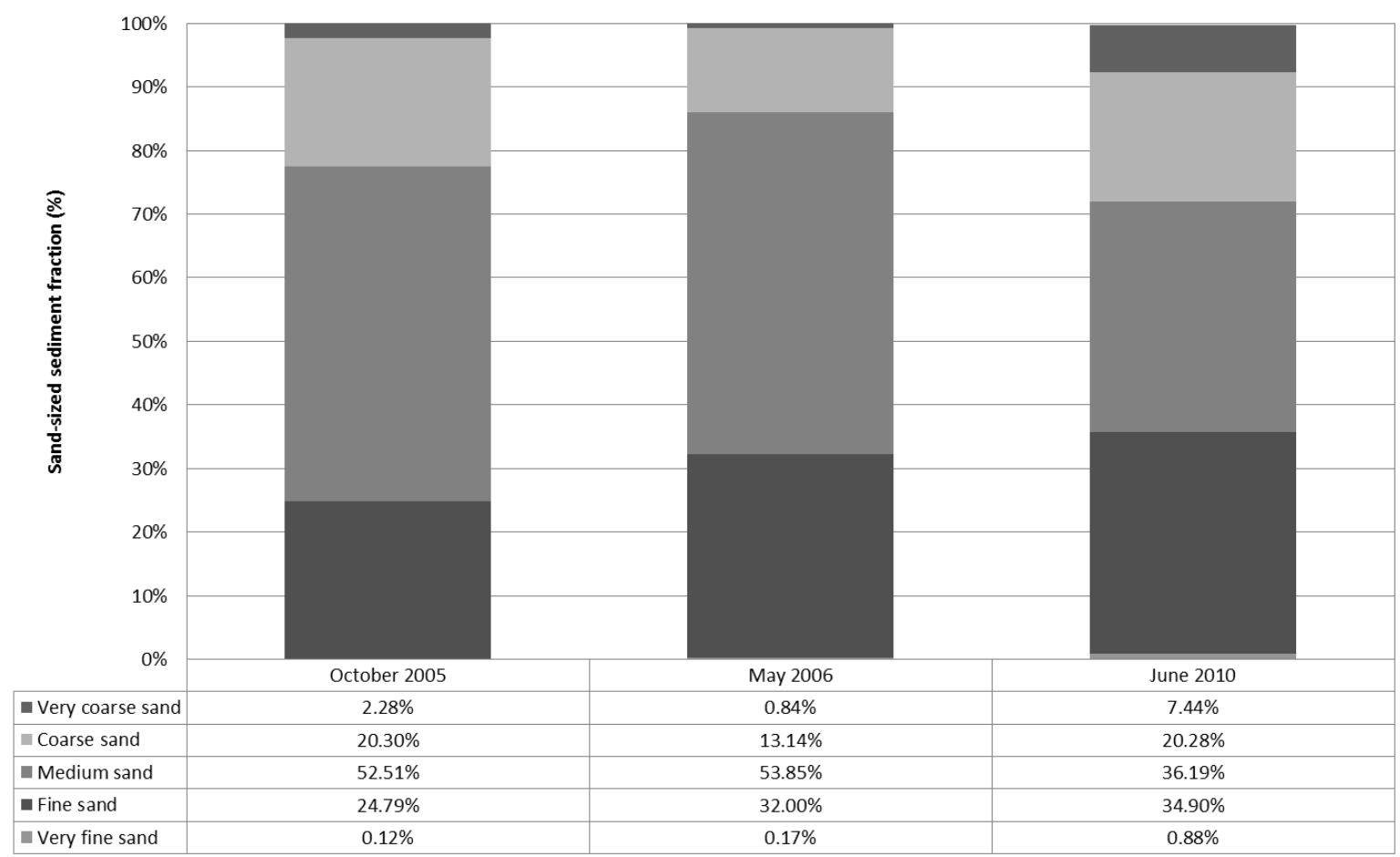

Figure 5-14: Changes to the sand-sized fraction, averaged across the three sampled sites (PntTnch-t3, 5, and 15) following Hurricane Wilma.

\subsubsection{Sediment texture: subsurface sediment}

As the surface sediment only represents the prevailing energy regime, subsurface pits were also excavated across all the sampled sites, and grain size analysed (Appendix 9.3). Several layers were identified and, though similar to Zone 1, only some of these layers showed any discernable difference in grain-size (Appendix 9.3). There appeared to be no correlation between the layers alongshore, which would be expected, due to inherent variability in geomorphic and sedimentological response alongshore. As such one site was chosen to be representative of subsurface changes in Zone 2; PntTnch-15 (Figure 5-15).

The subsurface sediment pits of PntTnch-t15 showed distinct coarser layers in both the back beach and lower foredune; these layers were situated at approximately $0.15 \mathrm{~m}$ deep in the back beach and $0.22 \mathrm{~m}$ deep in the foredune (Figure 5-15). The back beach layers remained relatively uniform with depth, in contrast to the foredune, which experienced sediment fining with depth (Figure 5-15). These layers were probably representative of higher-energy conditions, such as the passage of a tropical storm. However, overall the textural character of the sediment was relatively similar; this indicates the material is predominately comprised of reworked beach sediment, which was transported landward, as the shoreline eroded. 


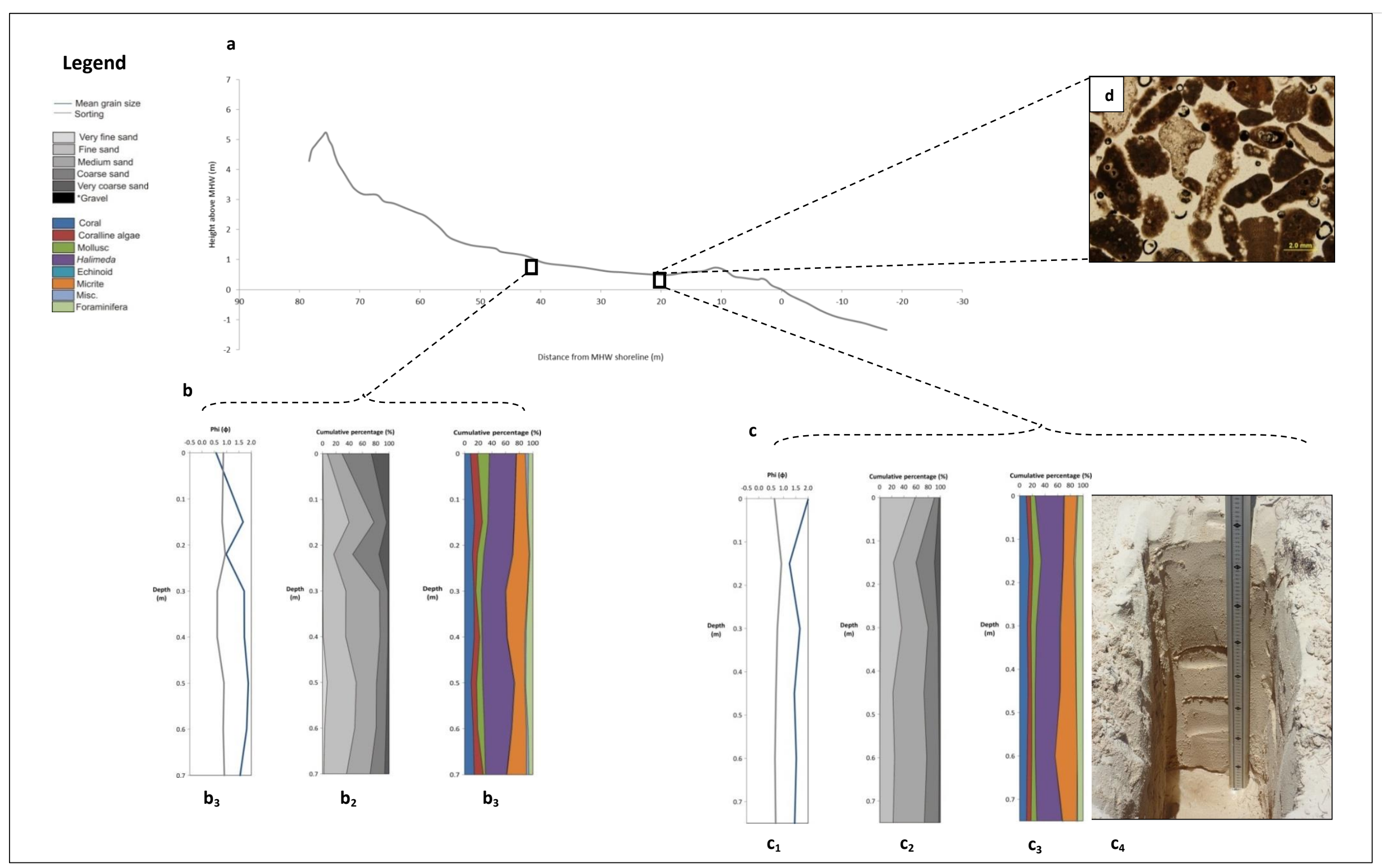

Figure 5-15: Subsurface sediment textural character: (a) Across-shore profile of PntTnch-t15 in June 2010 outlining the location of sediment pits b and c; mean grain size and sorting $\left(b_{1} / c_{1}\right)$, sand-sized sediment fraction $\left(b_{2} / c_{2}\right)$, and sediment composition $\left(b_{3} / c_{3}\right)$ are presented from these pits, and $c_{4}$ shows the nature of the sediment pit. $(d)$ Thin section of the surface sediment from the beachface (PntTnch-t15-a) showing the primary skeletal constituents (Halimeda, coralline algae, mollusc, coral and micrite). 


\subsubsection{Sediment composition: surface sediment}

The storm deposit was of similar composition to Zone 1: Wet ' $n$ ' Wild, and dominated by Halimeda (44.76\%). There were small proportions of coral (12.57\%), foraminifera (11.67\%) and coralline algae (8.38\%); sediments were also found to be highly micritic (16.75\%). As with Zone 1, these results suggest sediment was largely derived from barrier beach reworking and the backreef lagoon. However, sediment in the backreef lagoon is likely to be larger than the barrier beach; as such, if this sediment was to dominate the storm deposit you would expect the grain size to be relatively coarse. This was not the case at this site (Figure 5-14).

Seven months after Hurricane Wilma, in May 2006, the composition had undergone no discernable change. However there was some small variation across-shore (Figure 5-16). By June 2010, and despite shoreline transgression and back beach aggradation, the composition remained largely unchanged: Halimeda (42.15 $\pm 4.03 \%)$ remained the dominant constituent, with similar proportions of coral, coralline algae and foraminifera. Similar to Zone 1 , there was a small increase in the mollusc content $(12.46 \pm 7.01 \%)$ and micritisation of skeletal constituents remained high. Across-shore character varied slightly to previous results (Figure 5-16).

Back reef lagoon sediments were also analysed, and were found to be dominated by Halimeda, which comprised approximately $40 \%$ of the sediment. Molluscs (15-20\%), coral and coralline algae (both 10-20\%) constituted most of the remaining sand-sized sediment. The predominance of these constituents increased near the reef crest, and coincided with decreases in Halimeda (Figure 5-16); these changes were sometimes represented by increases in mean grain size. 


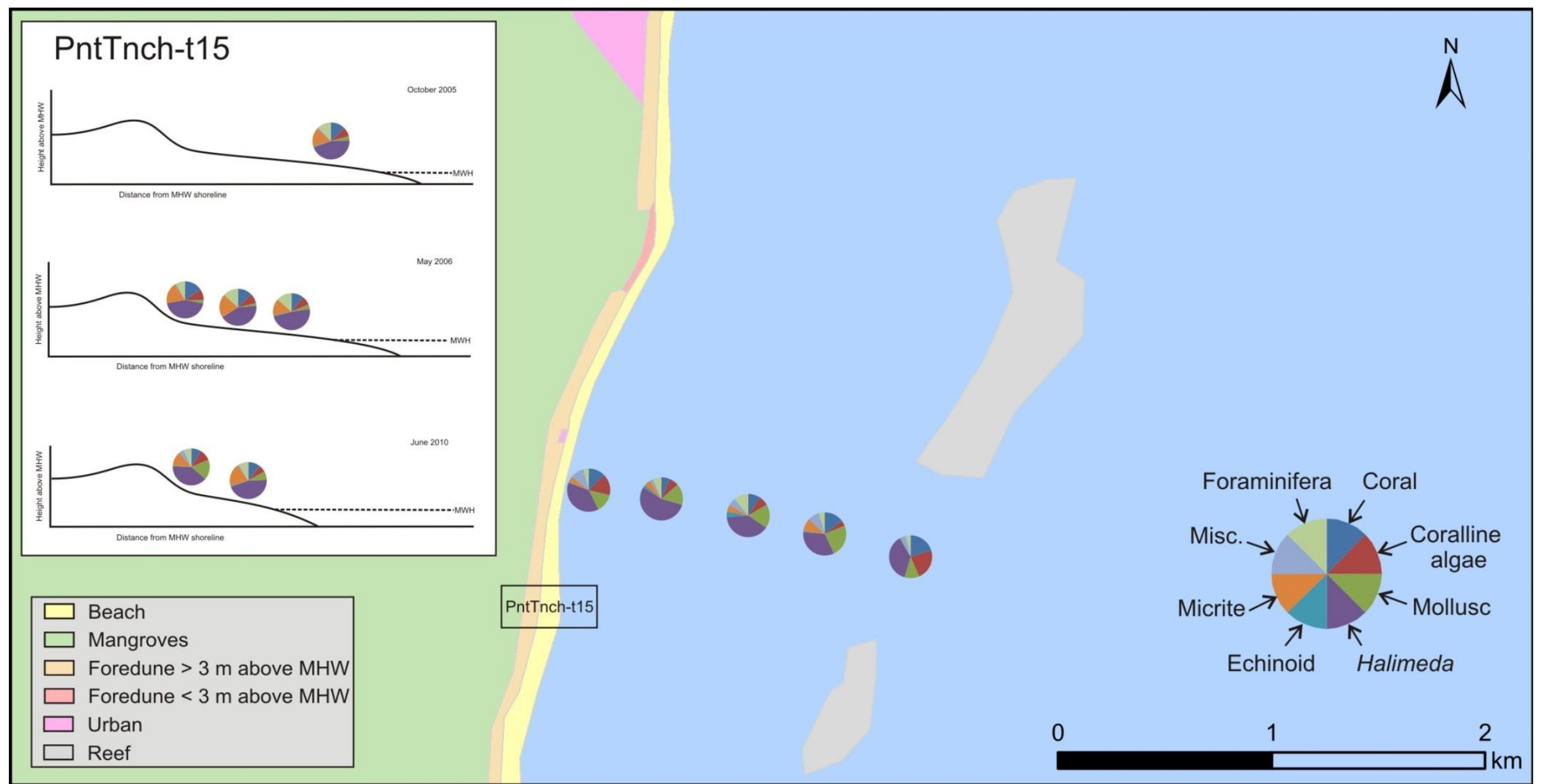

Figure 5-16: Sediment composition in Zone 2: Punta Tanchacte: (a) Changes in sediment composition following Hurricane Wilma, and (b) sediment composition across the backreef lagoon in June 2010. 


\subsection{Zone 3: Punta Petenpich}

\subsubsection{Site description}

Punta Petenpich (PntPtnpch) is situated south of Punta Tanchacte and covers an alongshore distance of $9 \mathrm{~km}$ (Figure 5-17). This zone is situated behind a fringing reef which encloses a lagoon 0.6-1.6 km wide and 3-4 m deep, stabilised by Halimeda, Syringodium filiforme and Thalassia testudinum seagrasses. Unlike Zones 1 and 2, Punta Petenpich is largely developed, with apartments and hotels built on the foredune or back beach. The barrier is backed by mangrove wetlands. Four sites were surveyed in this zone and sediment samples were taken from several sites (Figure 5-17).

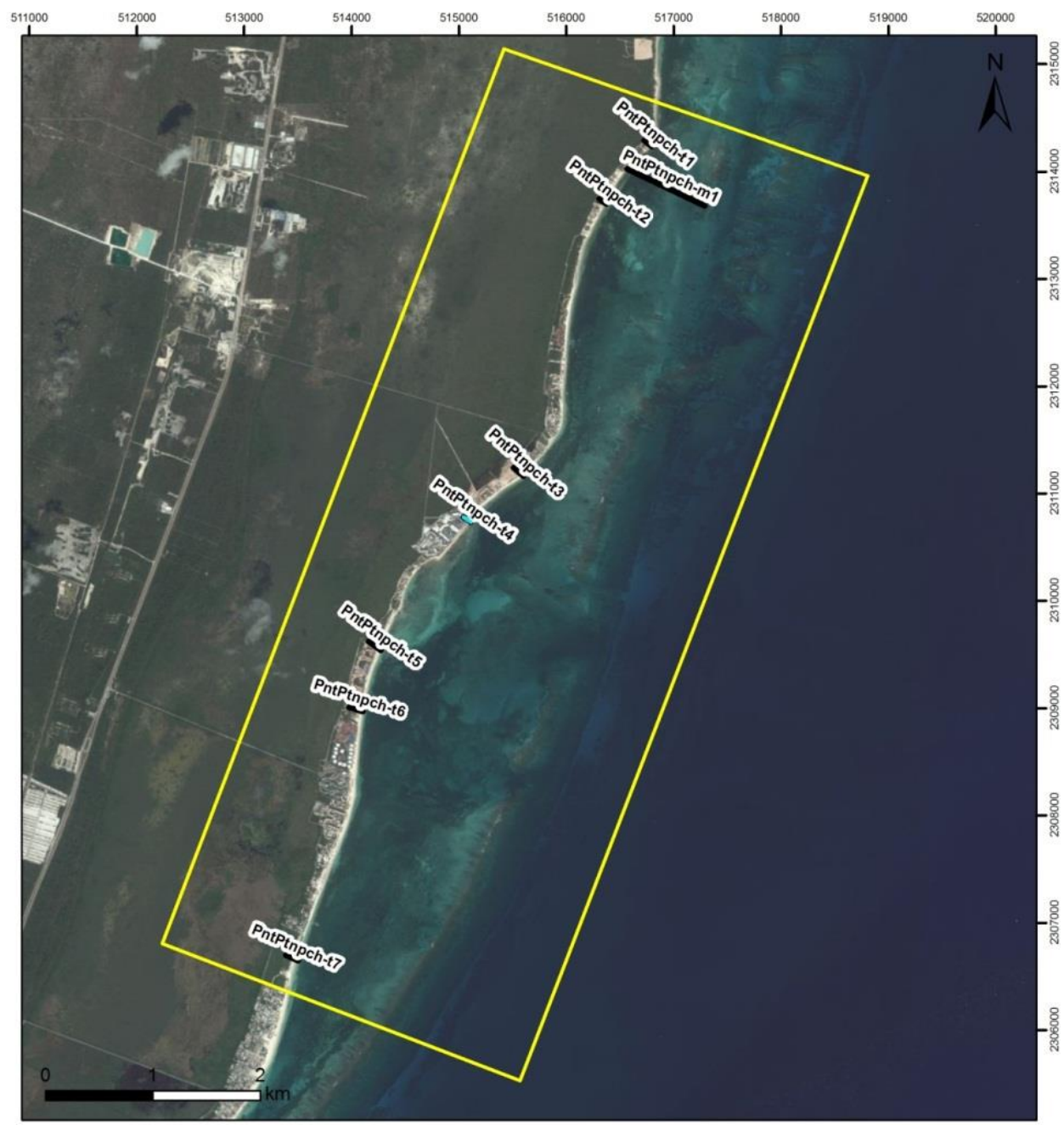

Figure 5-17: Map of Zone 3: Punta Petenpich showing the seven sites investigated. PntPtnpch-t2, 3, 4, and 5 are comparative beach profiles; PntPtnpch-t3, 5, 6, and 7 are sediment samples collecting in May 2006; PntPtnpch-t1 and 2 are sediment samples collected in June 2010; and Pntptnpch-m1 is the backreef lagoon sediment transect. 


\subsubsection{Coastal morphology}

The barrier beaches of Punta Petenpich were reworked (Figure 5-18a), stripped of vegetation, and underwent considerable shoreline accretion in response to Hurricane Wilma. In addition, beachfront apartments and hotels were destroyed, and large coral boulders were thrown up onto the beach (Figure 5-18b, c and d).

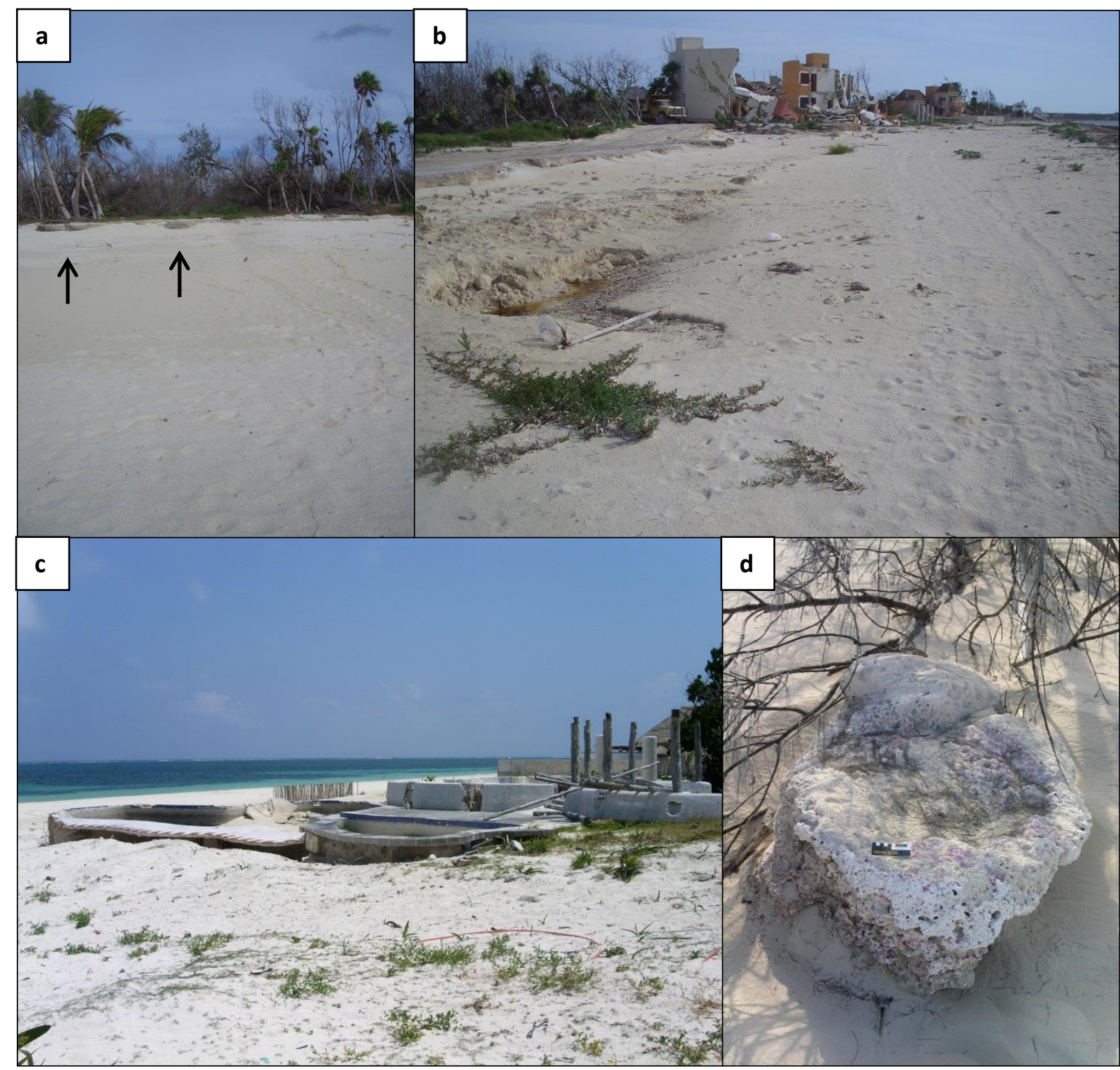

Figure 5-18: Impacts of Hurricane Wilma: (a) Exposed soil (indicated by black arrows) at the northern end of the zone after the beach was reworked, ( $b$ and $c$ ) the remains of apartments built in the foredune at the northern and southern ends of the zone, and (d) a large coral boulder covered by the encrusting foraminifera Homotrema rubrum thrown up on the beach (Images: David Kennedy). 
In June 2010 the barrier beaches of Punta Petenpich were on average $37.5 \pm 17.3 \mathrm{~m}$ wide with a slope of $3.7 \pm 1.5^{\circ}$, reflecting $7.5 \pm 8.4 \mathrm{~m}$ of shoreline erosion and $2.4 \pm 1.9^{\circ}$ of profile steepening since June 2006; however these changes were found to be highly variable alongshore with no discernible pattern to the response (Appendix 9.1).

On the undeveloped section of this zone, the beachface migrated landward with the eroding shoreline, compressing the back beach and driving vertical accretion. Along with vegetation migration, this promoted the development of incipient dunes in the back beach and transitioned this beach section from a concave storm profile to a more convex post-storm shape. In contrast, developed barrier beaches were unable to adjust landward naturally, as the beach profile was confined between a seawall and the eroding shoreline. Instead the profile responded by forming a relatively steep and continuous slope from the beachface to seawall, thus moulding the beachface, back beach and foredune together (Figure 5-19). This is the result of wave up-rush and wave reflection off the seawall, as well as beach grooming.
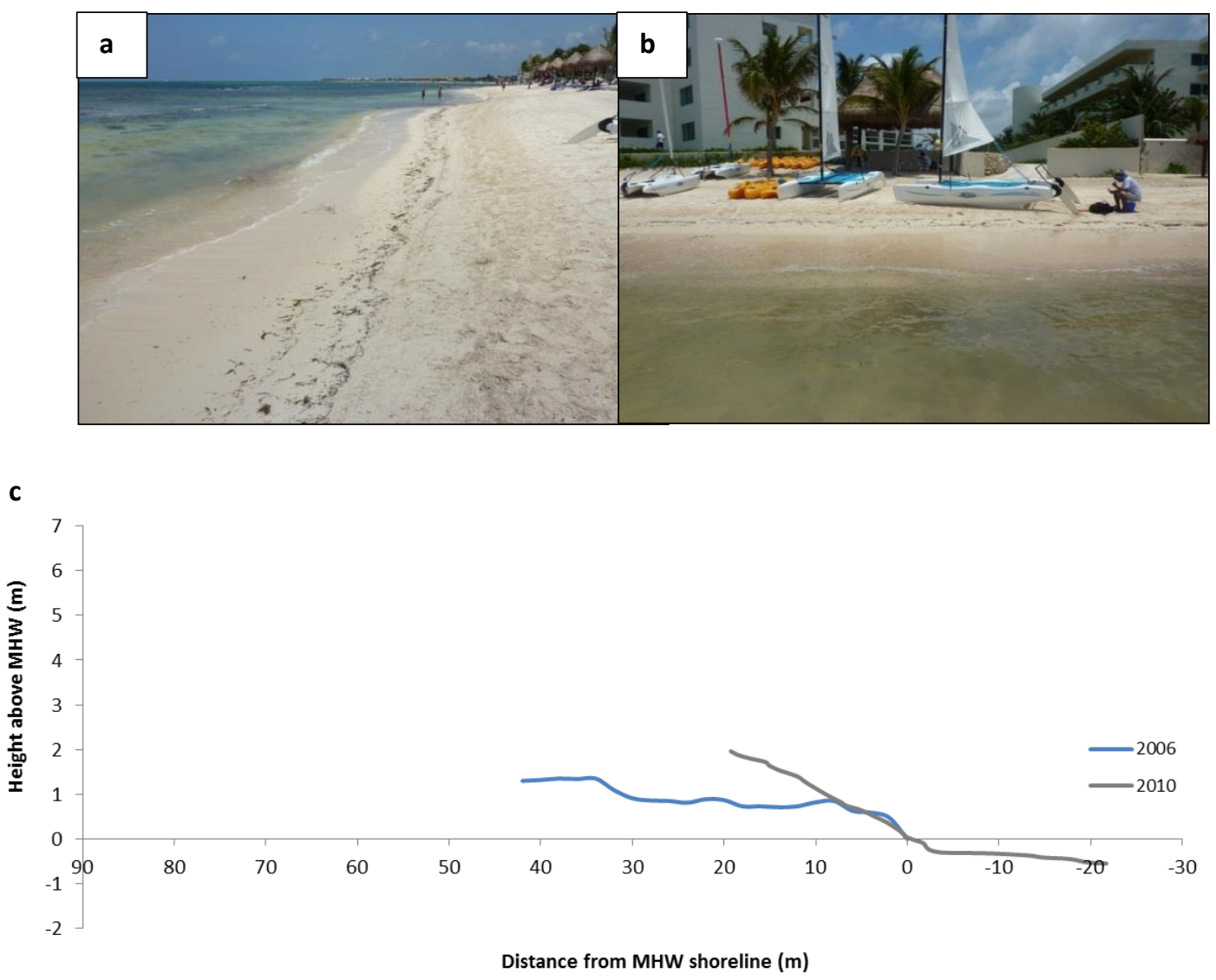

Figure 5-19: Anthropogenic impacts on post-storm geomorphic response: (a and b) images of developed barrier beach, and (c) profile changes as a result of anthropogenic impacts at PtnPtnpch-t4. 


\subsubsection{Sediment texture: surface sediment}

Punta Petenpich underwent complete storm wave inundation in some areas, due to the absence of a foredune, or foredune of sufficient height ( $>3 \mathrm{~m}$ above MHW). Sediment was washed a considerable distance inland as overwash flowed into the mangrove wetlands behind the barrier beach (Figure 5-20a and b). The storm deposit was coarser than Zones 1 and 2 , but still represented moderately sorted $(0.81 \phi)$ medium sand $(1.30 \phi)$. Gravel content remained below $1 \%$ with only a trace mud fraction.

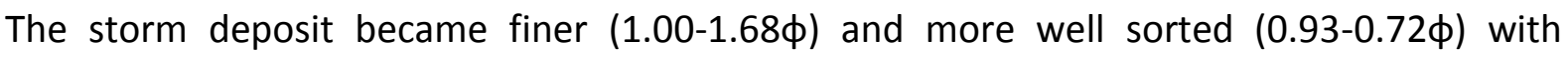
distance south, and as the width of the backreef lagoon increased. This may represent different depositional energies, due to differences in wave dissipation across the reef and backreef lagoon. Across-shore sediment distribution was similar to those detailed in Zones 1 and 2, with sediment typically getting coarser (1.41-0.85 $\phi)$ and more poorly sorted (0.73$0.96 \phi)$, and the back of the beach containing a distinct coarse deposit.

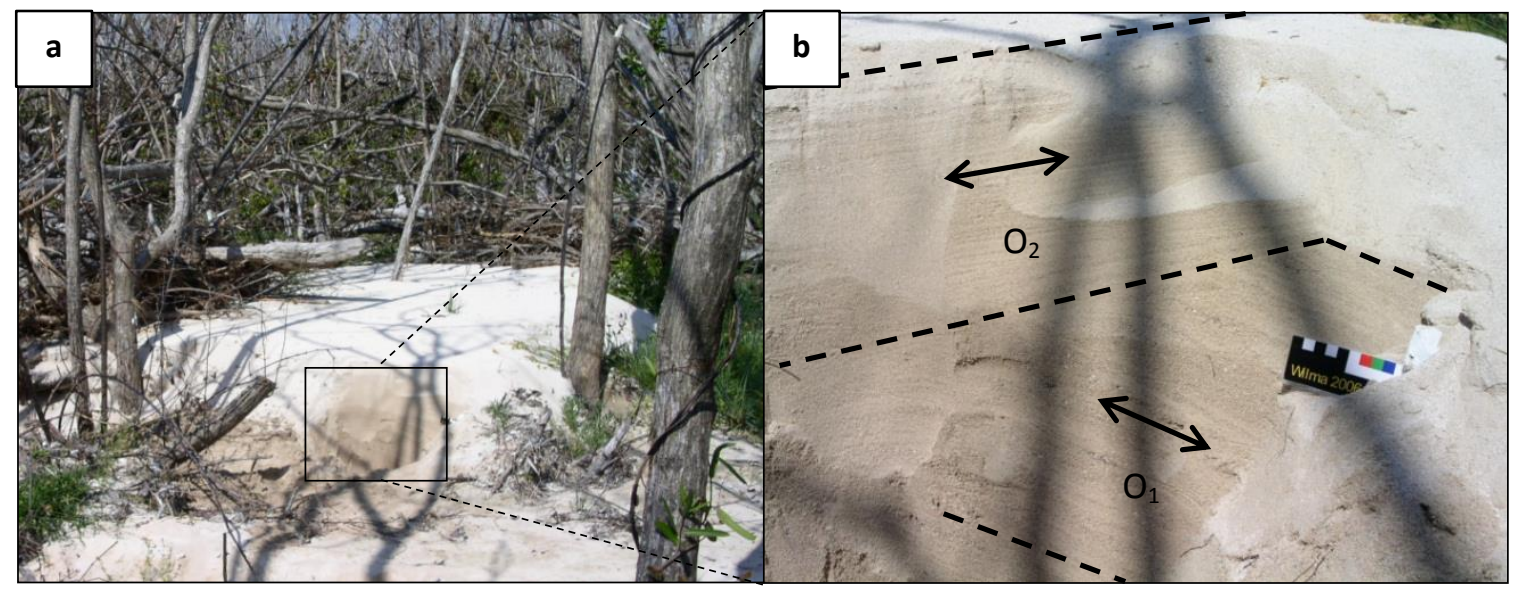

Figure 5-20: (a) Sediment overwash layer, inset in (b) which shows two distinct overwash flow layers driven by storm waves from Hurricane Wilma. $\mathrm{O}_{1}$ was deposited first, during the peak of inundation, while $\mathrm{O}_{2}$ reflects return flow, after Hurricane Wilma had passed over the coastline.

Punta Petenpich underwent shoreline erosion over the next seven months, and by May 2006, a finer post-storm layer had been deposited on top of the in situ storm sediment (Figure 5-21). Particular change was experienced in the back beach, which transformed from moderately sorted coarse sand to moderately-well sorted medium sand; this represents the predominance of aeolian deposition in the months after Hurricane Wilma. Under the prevailing conditions sediment-size became more evenly distributed alongshore, although southern sites were still marginally finer-grained (Figure 5-21). 


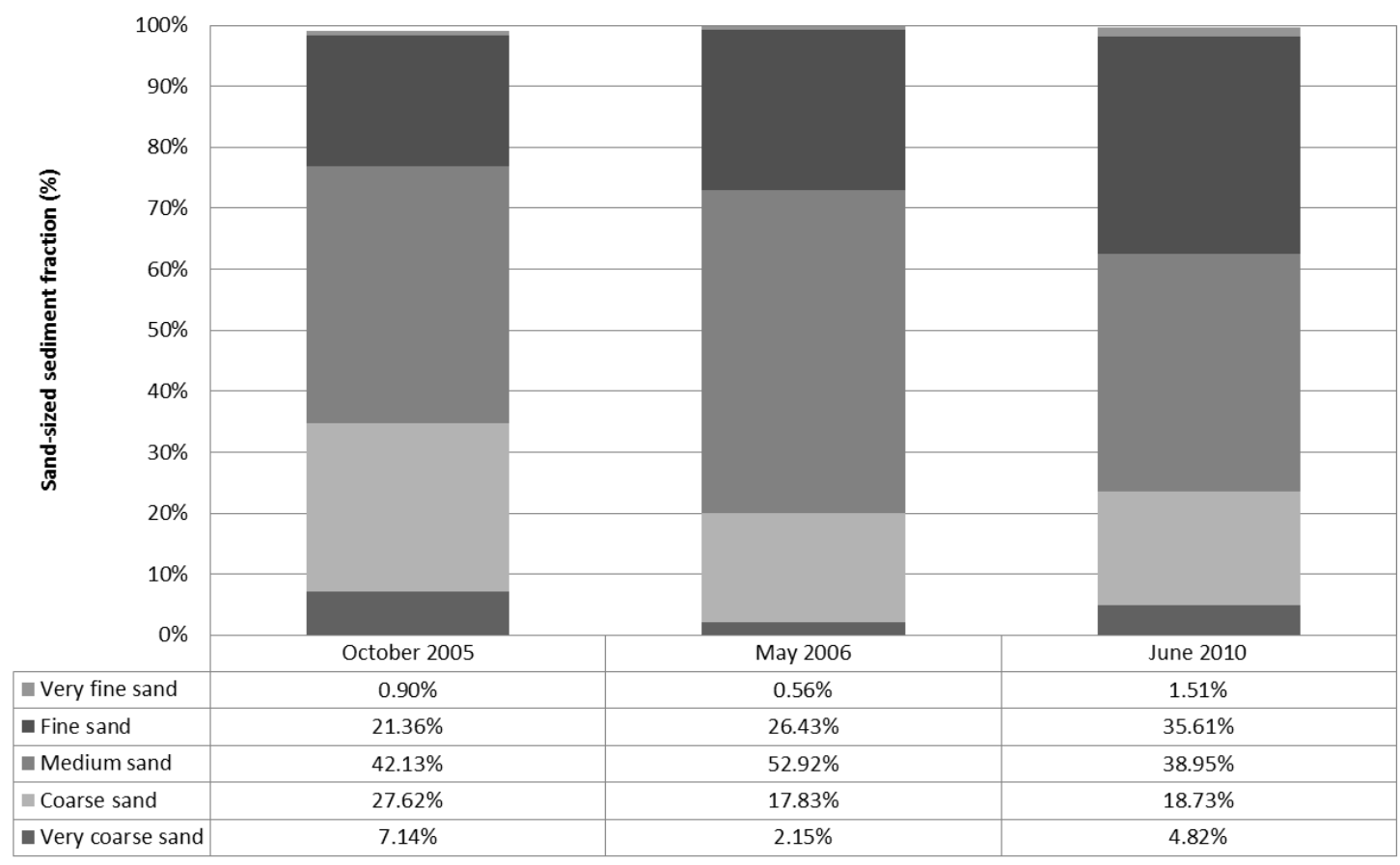

Figure 5-21: Changes to the sand-sized fraction following Hurricane Wilma. Sediment was averaged across four sampled sites in May 2006 (PntPtnch-t3, 5, 6, and 7) and two sample sites in June 2010 (PntPtnpch-1 and 2).

By June 2010, many of the sites previously investigated had since been developed. As such two sites were assessed at the northern end of the zone. However they do not allow direct comparison. The textural characteristics of the surface sediment were similar to those of Zones 1 and 2: moderately well sorted $(0.78 \phi)$ medium sand $(1.62 \phi)$. This was further confirmed by analysis of the sand-sized sediment fractions, shown in Figure 5-21, which indicates sediment distribution is similar along reef-protected beaches under the prevailing wind and wave conditions. Moreover, across-lagoon sampling revealed sediment to be coarsest in the mid-lagoon area, and fine towards both the shoreline and reef crest (Figure 5-22). This represents the predominance of in situ calcium-carbonate production in the backreef lagoon, and is likely to be an important long-term sediment source of the barrier beaches.

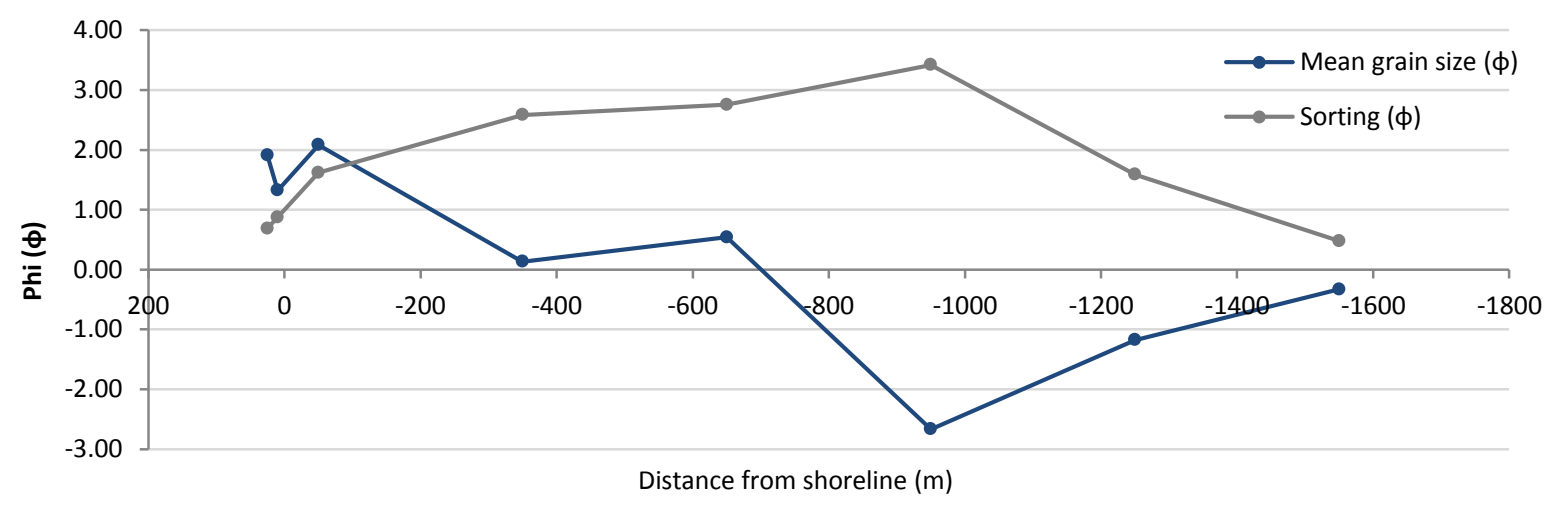

Figure 5-22: Mean grain size and sorting with distance from the shoreline, Zone 3: Punta Petenpich, June 2010. 


\subsection{Zone 4: Punta Brava}

\subsubsection{Site description}

Punta Brava (PntBrv) is situated south of Punta Petenpich and extends for an alongshore distance of $1.29 \mathrm{~km}$ (Figure 5-23). The zone is exposed to waves from the Caribbean Sea due to its location within a gap in the Mesoamerican Barrier Reef. The coastline has a relatively steep shoreface which reaches a depth of $5 \mathrm{~m}$ within $200 \mathrm{~m}$ of the shoreline. The barrier beach is approximately $100 \mathrm{~m}$ wide, up to $3 \mathrm{~m}$ above mean high water (MHW), and backed by mangrove wetlands. Three sites were surveyed at Punta Brava and sediment analysis was undertaken for two of these (PntBrv-t1 and 2).

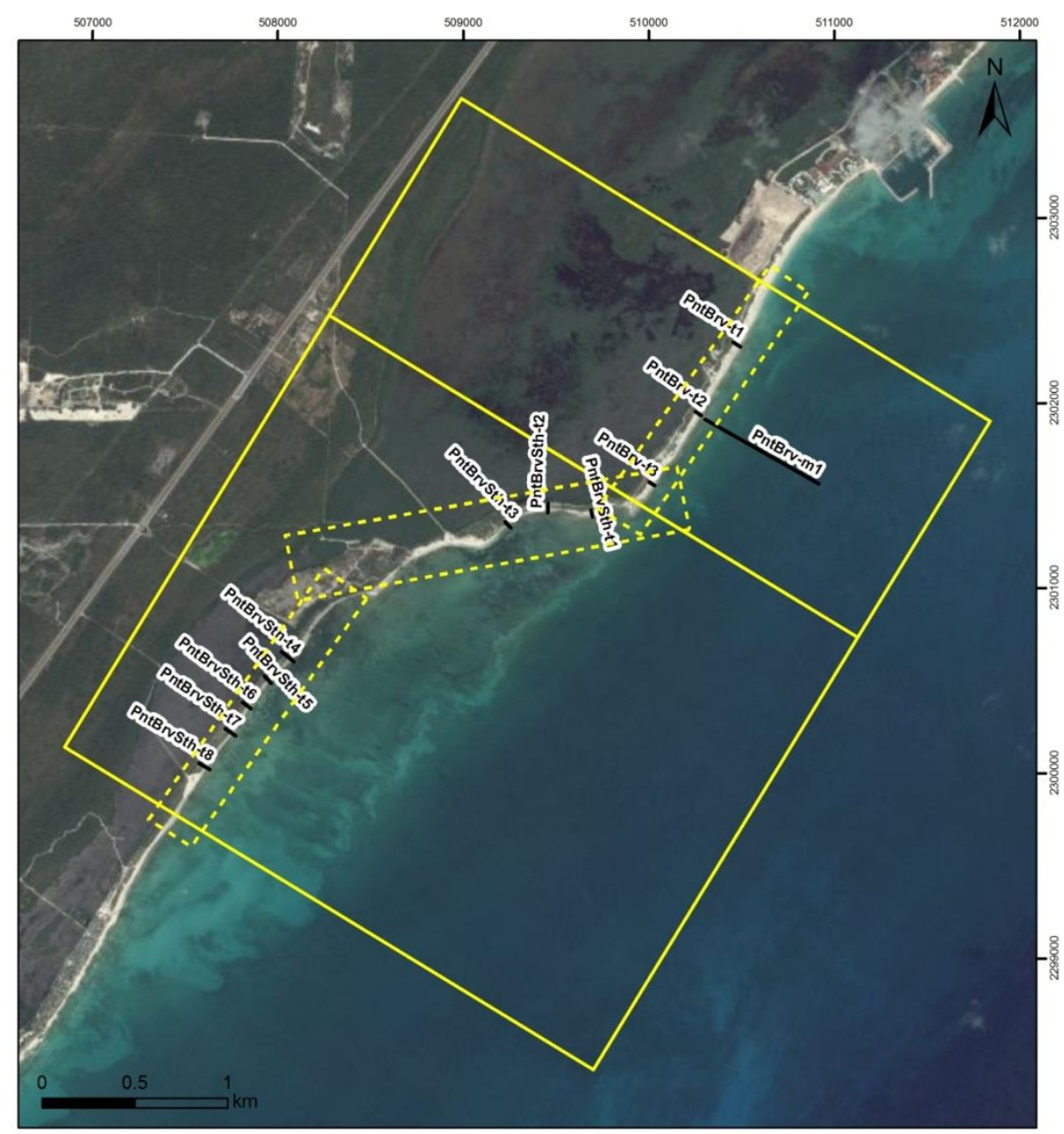

Figure 5-23: Map of Zone 4: Punta Brava (top box) showing the locations of the three surveyed transects and the backreef lagoon sediment transect. 


\subsubsection{Coastal morphology}

On 4 September 2004 the barrier beaches of Punta Brava were on average $29.3 \pm 1.4 \mathrm{~m}$ wide, with a well vegetated foredune crest (Figure 5-24c). Storm waves inundated the exposed barrier beaches during Hurricane Wilma, reworking the beach and foredune and driving sediment overwash. Considerable volumes of sediment, including large coral boulders, were transferred into the backdune and mangrove wetlands. As a result the barrier beaches eroded by on average $5.3 \pm 4.8 \mathrm{~m}$ (Figure 5-24). However, shoreline response varied considerably with the greatest erosion at the southern-most site PntBrv-t3, which lost over $10 \mathrm{~m}$ of beach (Figure 5-24f).

By June 2006, eight months after Hurricane Wilma the barrier beach had undergone some shoreline recovery, with on average $6.3 \pm 6.7 \mathrm{~m}$ of horizontal accretion. Most accretion $(13.8 \mathrm{~m})$ was seen at the southern-most site, which had earlier undergone the greatest erosion as a result of Hurricane Wilma. The barrier beach was therefore $1.1 \pm 2.0 \mathrm{~m}$ wider than the pre-storm beach width, indicating the shoreline had recovered (Figure 5-24e). This rapid recovery suggests that exposed, high energy beaches may respond considerably faster to prevailing conditions following major storms than low-energy barrier systems. By June 2010, a further 48 months later the shoreline had shifted once again, with shoreline transgression at the northern (1.8 m, PntBrv-t1) and southern (4.4 m, PntBrv-t3) ends of the zone, contrasting beach accretion of $2.8 \mathrm{~m}$ in the centre of the zone (PntBrv-t2). This indicates that the prevailing energy regime is a major control on shoreline position at Punta Brava. 

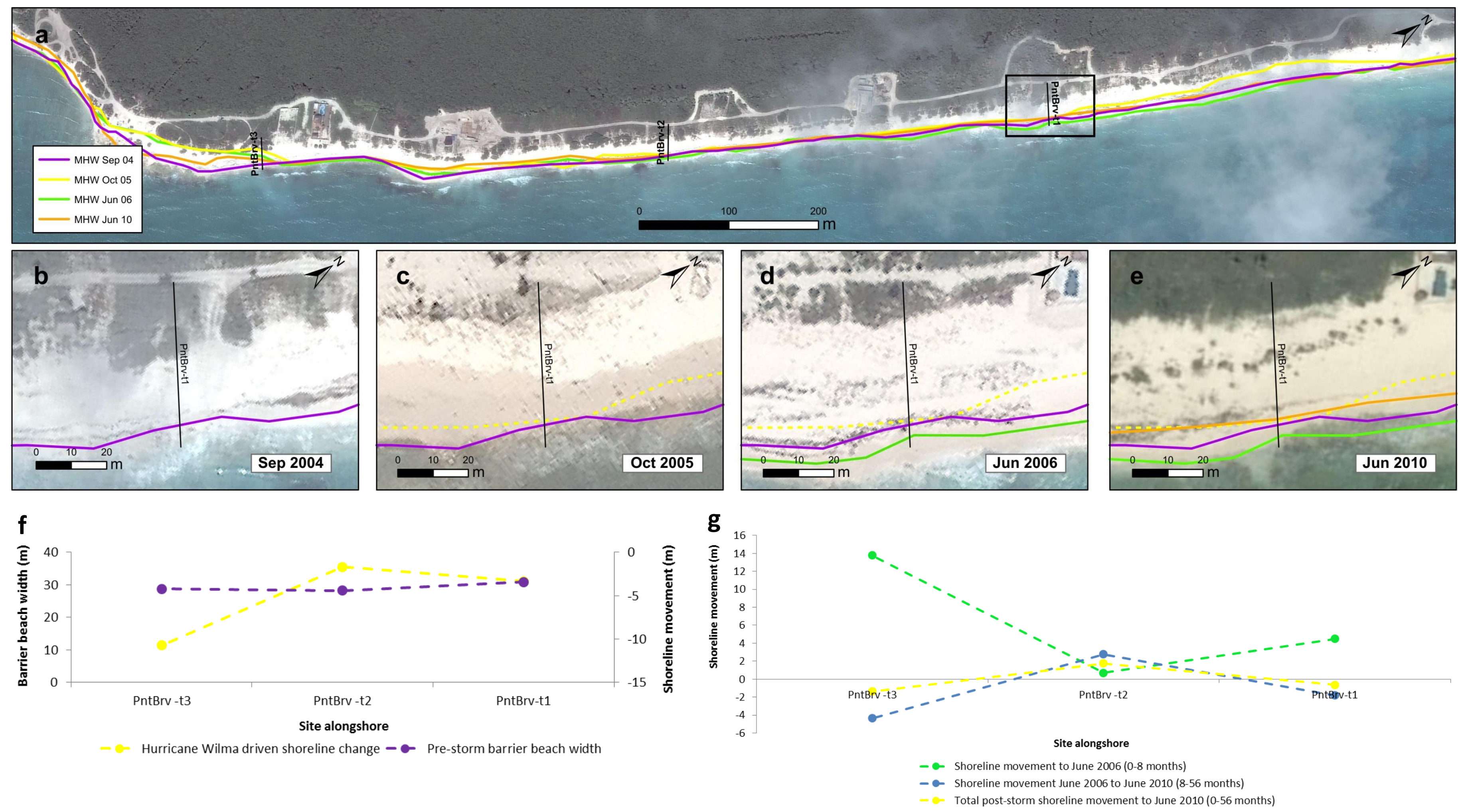

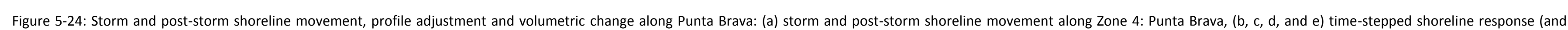
geomorphic evolution) of PntBrv-t1, (f) storm-driven shoreline change in relation to pre-storm barrier beach width, and (g) post-storm shoreline change. 
The barrier beach also underwent considerable profile change. By June 2010 the barrier had a mean slope of $4.5 \pm 0.5^{\circ}$, representing beach steepening of $1.7 \pm 0.7^{\circ}$ since June 2006 . Net sediment volume was also found to increase over this period and varied between increases of $5.3 \mathrm{~m}^{3} / \mathrm{m}$ at the southern-most site to $14.3 \mathrm{~m}^{3} / \mathrm{m}$ in the centre of the zone (Appendix 9.1 and 9.2). Volumetric changes were predominately concentrated in the back beach and represented sediment infill of this beach section, as the profile recovered following Hurricane Wilma. The beach profile transitioned from a concave-up shape, with an abrupt back beach depression, to a more sloping profile (Figure 5-25 and 5-26). The foredune underwent smaller changes as it adjusted with the shoreline, and the beachface tended to respond relatively quickly to the prevailing energy regime (Appendix 9.1). Surface morphology also matured as grasses and shrubs re-established the back beach, promoting sediment accumulation and the formation of small subaerial features (Figure 5-26).

These results indicate that the beach profile and sediment volume recovers considerably slower than the shoreline position. In June 2006, a time at which the shoreline appeared to have recovered, the barrier profile and sediment volume represented a system which still showed storm erosion. Beach volume was found to have recovered by June 2010, and subaerial development was ongoing.

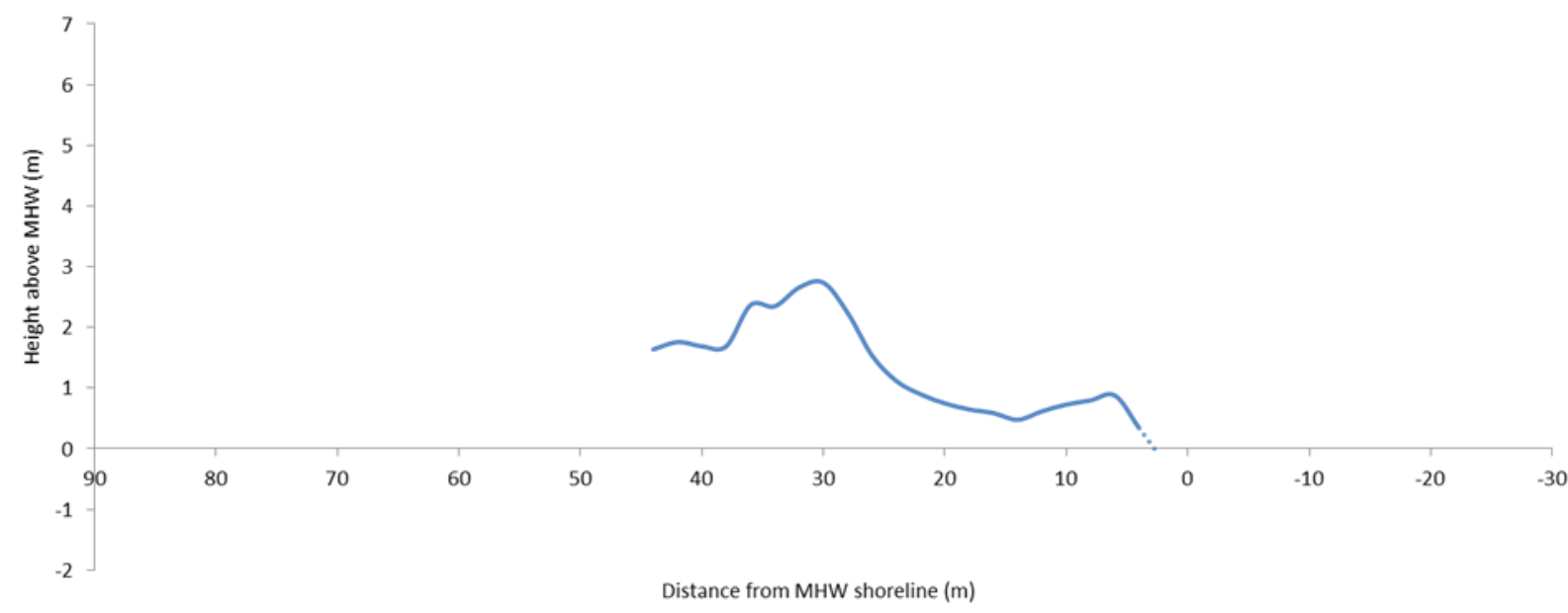

Figure 5-25: Across-shore morphology of the barrier beach at PntBrv-t2 in June 2006 showing a landward dipping back beach depression, with an abrupt change in slope to the foredune ridge. 

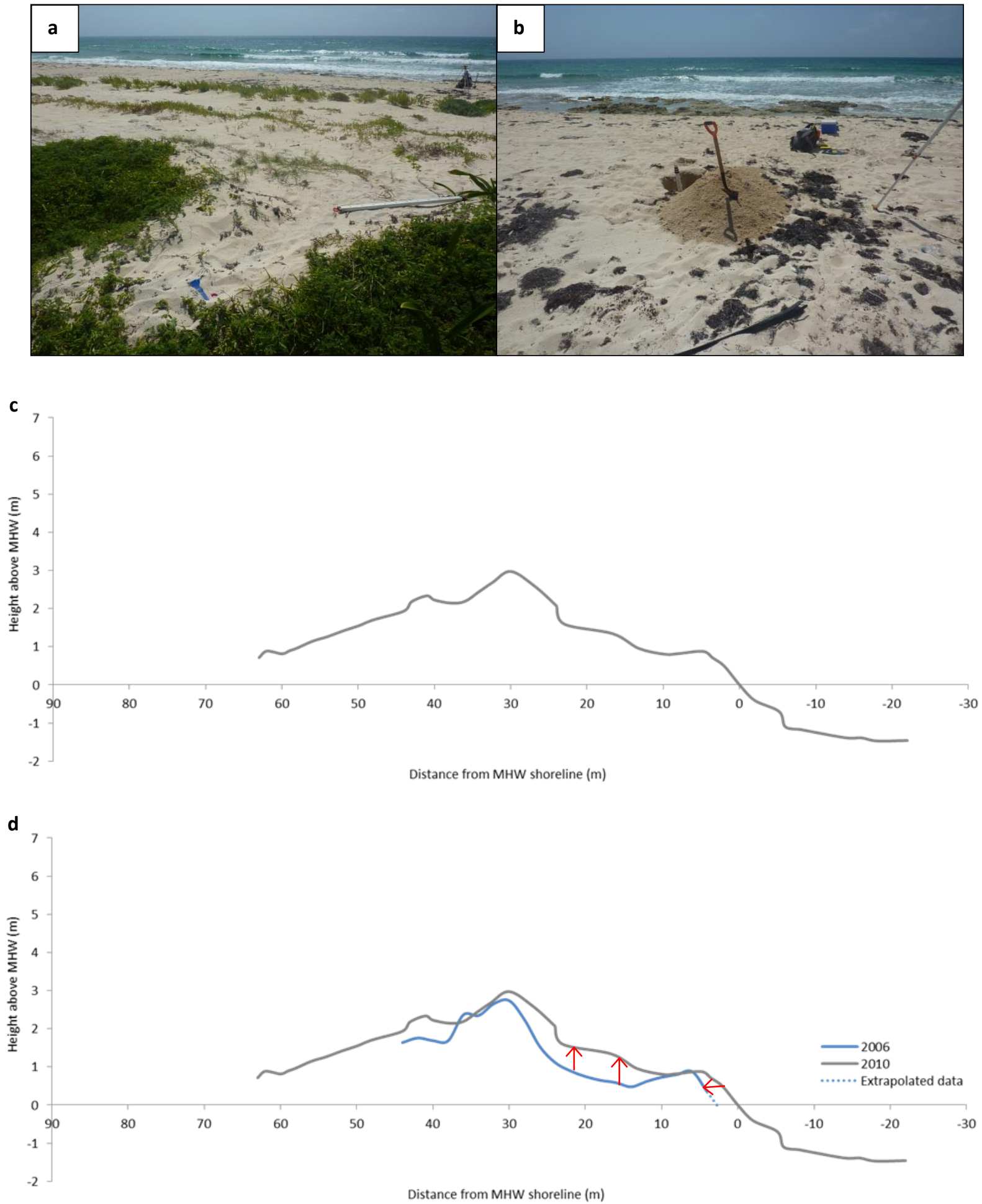

Figure 5-26: Post-storm geomorphic response of PntBrv-t2 between June 2006 and June 2010. (a-d) Images and profiles showing landward migration and back beach aggradation, of the increasingly vegetated beach. 


\subsubsection{Sediment texture: surface sediment}

Punta Brava underwent considerable sedimentological changes as storm waves eroded the beach and foredune, washing sediment over the foredune crest into the backdune swale and mangrove wetlands. The storm deposit was almost entirely dominated by sand (97.88\%), but was of variable size and sorting: the northern-most site (PntBrv-t1) was characterized by moderately well sorted $(0.53 \phi)$ medium sand $(1.20 \phi)$, transitioning to moderately sorted $(0.83 \phi)$ coarse sand $(0.61 \phi)$ further south (PntBrv-t2). The textural characteristics of PntBrv-t2 were similar to reef-protected barrier beaches. This may be a result of the site experiencing lower wave energy during Hurricane Wilma, due to protection afforded by a marina and patch reefs to the north and northeast.

Over the next seven months the shoreline accreted and back beach sediment aggradation occurred. However there remained a textural difference alongshore (Figure 5-27); PntBrv-t1 underwent post-storm fining and sorting, while PntBrv-t2 experienced sediment coarsening. This represents the onshore migration of coarser-grained material contained within the shoreface further south; it also shows that barrier beaches may undergo a secondary pulse of storm-derived sedimentological change, even under 'normal conditions'. However, under the prevailing conditions sediment did typically become finer-grained across-shore (0.66$1.79 \phi)$; this contrasted previously landward coarsening (1.32-0.48 $\phi)$. These results represent a transition from foredune focused barrier beach reworking to beachface concentrated wave swash, with lower energy wave swash and saltation processes predominating in the back beach.

By June 2010 the storm deposit had been well covered as back beach and foredune aggradation continued. Surface sediment coarsened at the northern-most site, PntBrv-t2, with increasing proportions of coarse and very coarse sand (Figure 5-27). These changes created greater alongshore homogeneity, as the barrier beaches transitioned to the sedimentological regime of the prevailing conditions. Surface sediment showed greater fining landwards, and represented the increased prevalence of saltation. Sediment offshore was typically found to be coarser, with the exception of a finer unit on the shoreface. 


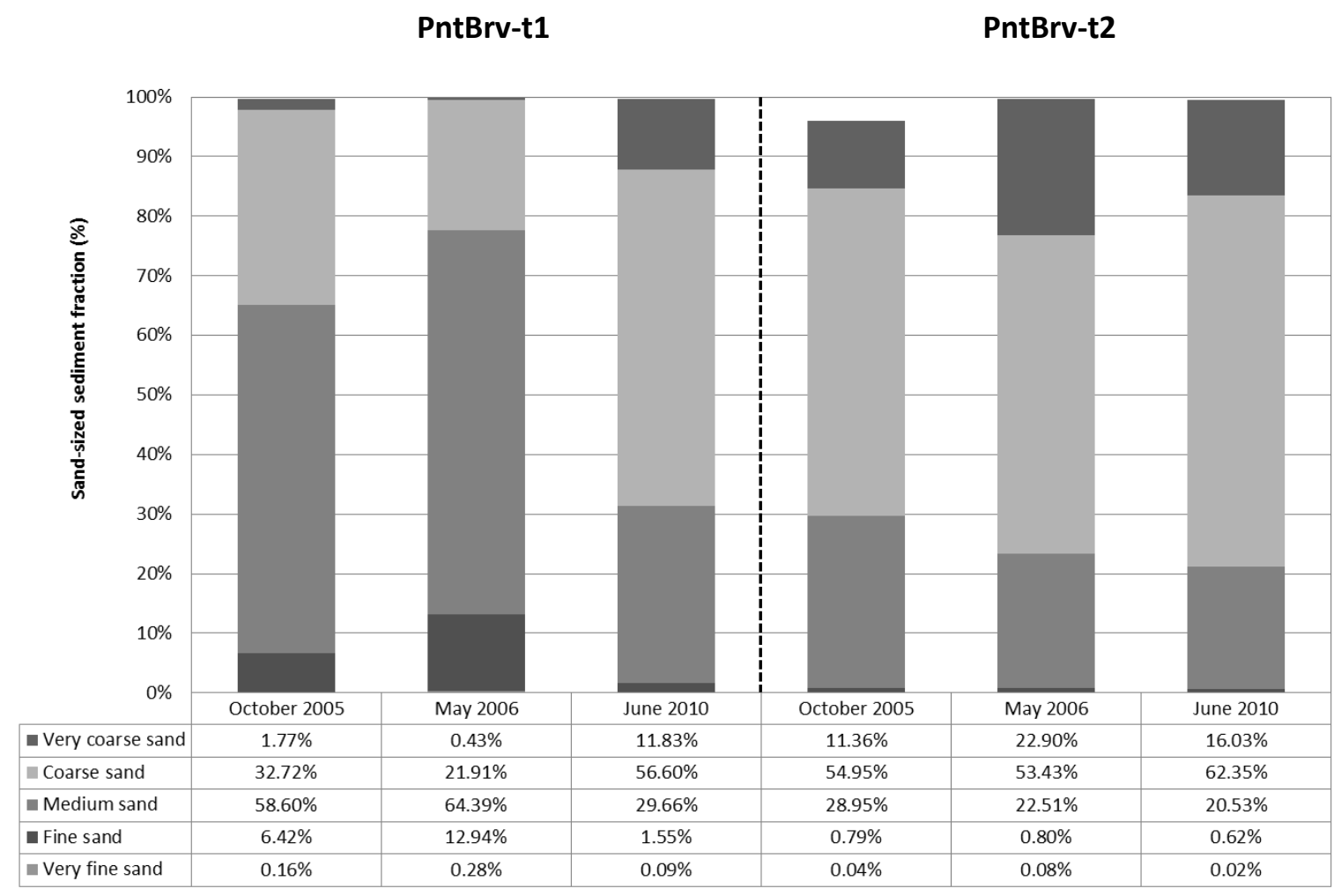

Figure 5-27: Changes to the sand-sized sediment fraction at PntBrv-t1 and PntBrv-t2 following Hurricane Wilma.

\subsubsection{Sediment texture: subsurface sediment}

Subsurface sediment pits were excavated across both sites at Punta Brava (Appendix 9.3). This sediment represented the material which aggraded in the back beach in the months to years following Hurricane Wilma (Figure 5-26); this section will focus on the results at PntBrv-t2 (Figure 5-28).

Several textural layers were identified in the back beach of PntBrv-t2 (Figure 5-28); the most distinct of these was a coarse layer at approximately $0.55 \mathrm{~m}$ depth, and was most likely the Hurricane Wilma storm deposit (Figure 5-28c and e); therefore approximately $0.55 \mathrm{~m}$ of back beach aggradation has occurred since Hurricane Wilma. The sediment aggraded since this point shows coarser and finer fluctuations, representing pulses of coarser sediment with higher-energy events (Figure 5-28). This indicates a mix of higher and lower energy in beach response. These changes are correlated with only small fluctuations in sediment composition. The backdune sediment pit is largely homogeneous, in both grain size and composition, representing an in situ storm deposit, covered with a thin aeolian cap. 


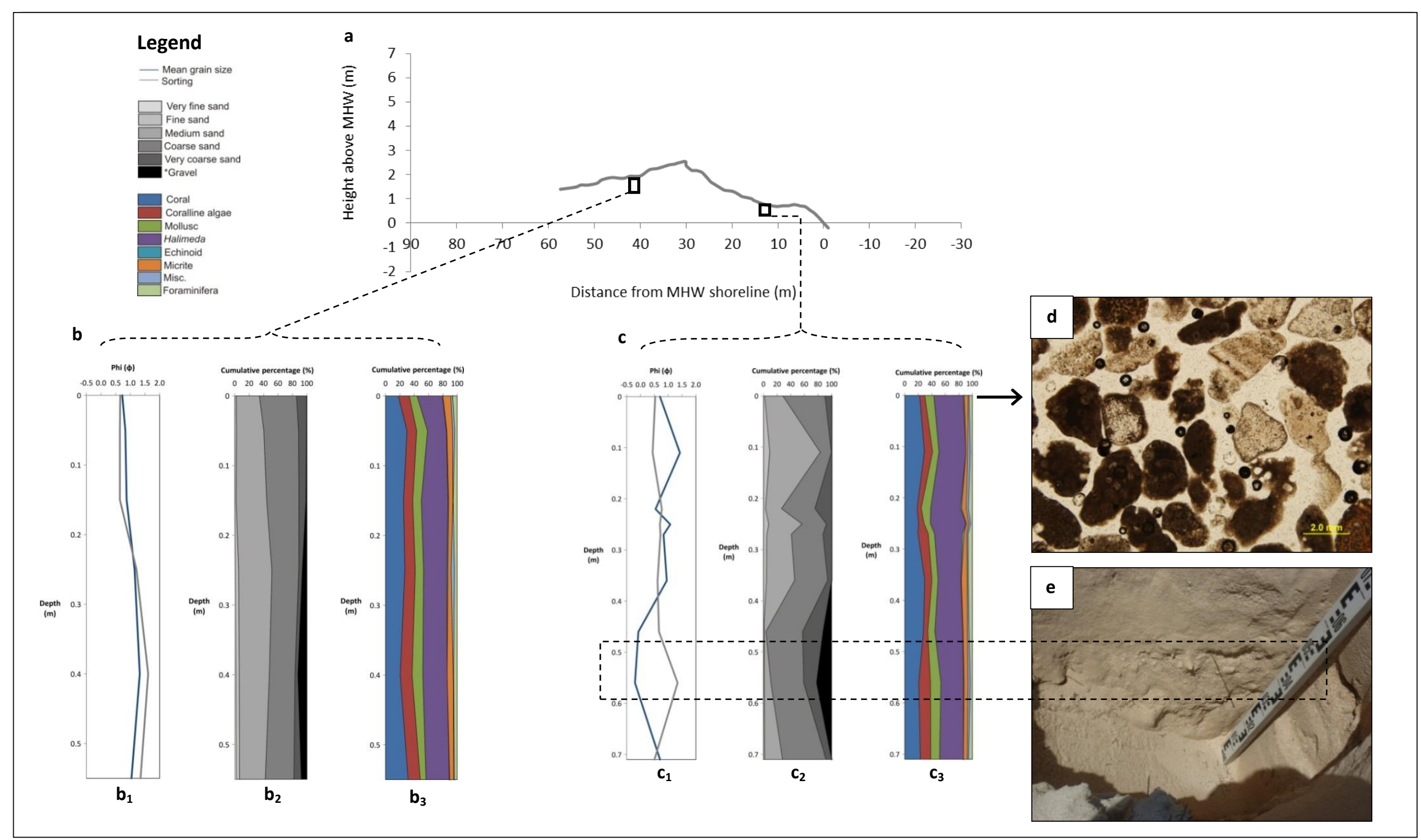

Figure 5-28: Subsurface sediment textural character: (a) Across-shore profile of PntBrv-t2 in June 2010 outlining the location of sediment pits b and c; mean grain size and sorting $\left(b_{1} / c_{1}\right)$, sand-sized sediment fraction $\left(b_{2} / c_{2}\right)$, and sediment composition $\left(b_{3} / c_{3}\right)$ are presented from these pits. (d) Thin section of the surface sediment from the beachface (PntBrv10-t2-a) showing the primary skeletal constituents (coral, Halimeda and coralline algae) and (e) the sediment pit in the beachface showing the gravel unit situated at approximately $0.55 \mathrm{~m}$ depth. 


\subsubsection{Sediment composition}

The storm deposit along Punta Brava was characterised by co-dominant Halimeda (41.31 \pm $5.10 \%)$ and coral $(36.05 \pm 1.15 \%)$ constituents. There was a small proportion of coralline algae $(7.16 \pm 2.40 \%)$ and only relatively minor micritisation $(5.02 \pm 2.19 \%)$. These results indicate that exposed barrier beaches receive a considerable proportion of material from coral reefs during storm events, with the increase in energy; this is similar to the findings of Kench (2011) on reef islands. However, as with reef-protected beaches, these barriers also have a dependence on Halimeda; both fresh and in situ Halimeda were seen in the sediments.

By May 2006, seven months after Hurricane Wilma, some compositional change had occurred; most significantly there was a decrease in the coral content and increase in Halimeda (Appendix 9.4; also see Figure 5-29). These changes represented the transition towards a more Halimeda-dominated system. A further 47 months later the proportions of coral $(20.07 \pm 2.93 \%)$ had continue to decline, and Halimeda (39.27 $\pm 6.03 \%$ ) became the dominant constituent (Appendix 9.4; also see Figure 5-29). The prevailing conditions also saw greater constituent diversity, with the proportions of coralline algae (11.23 $\pm 5.33 \%)$, molluscs $(12.22 \pm 1.72 \%)$ and foraminifera $(5.74 \pm 1.08 \%)$ increasing. These results indicate that exposed barrier beaches are highly connected to reef systems under storm conditions, despite being situated alongshore. They also suggest that the barriers are connected to mixed-source sediment under the prevailing conditions.

Sediment composition varied with distance offshore, and saw decreases in the Halimeda content. In contrast the proportions of coral and coralline algae increased (Figure 5-29). 


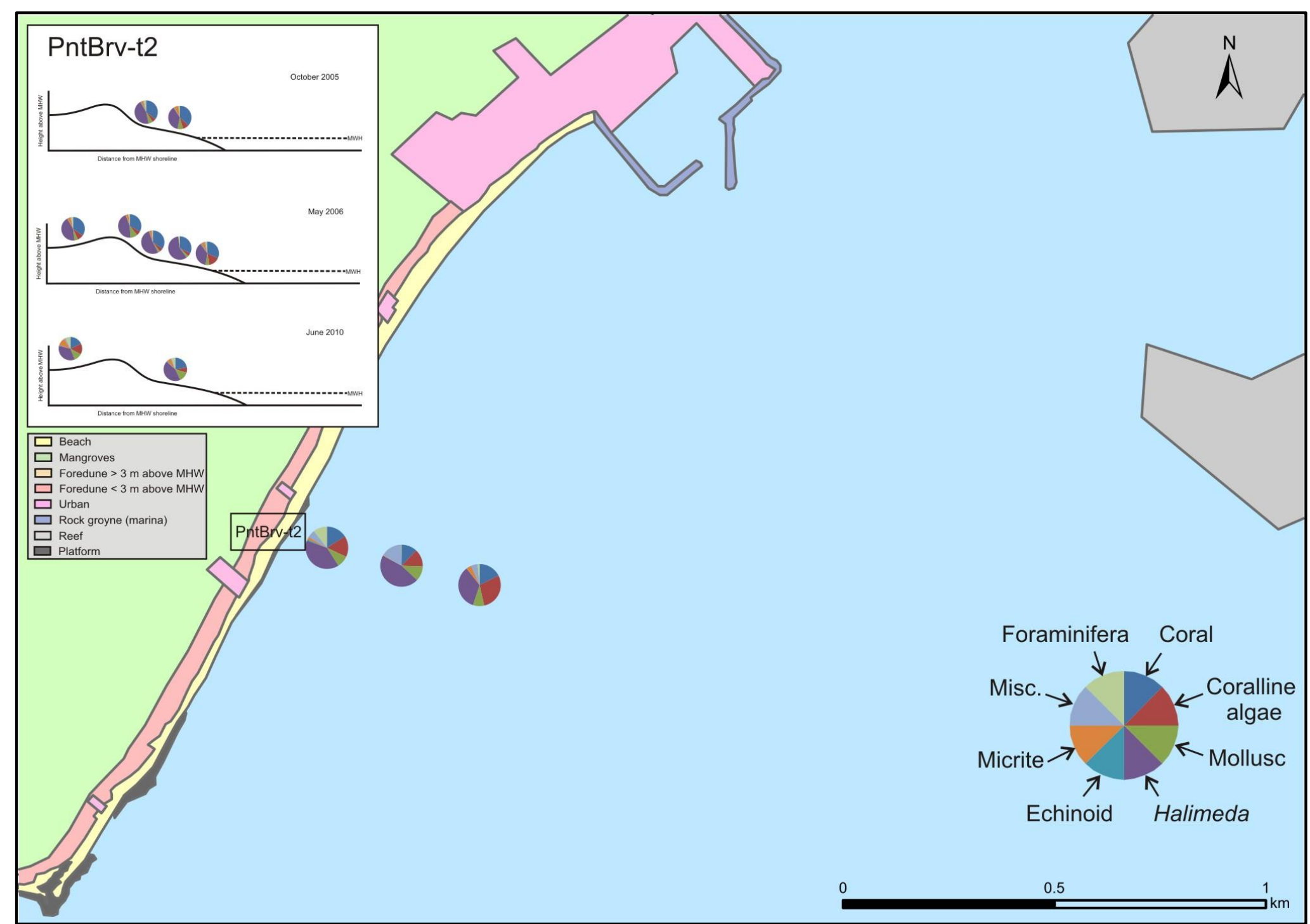

Figure 5-29: Sediment composition in Zone 4: Punta Brava: (a) Changes in sediment composition following Hurricane Wilma, and (b) sediment composition across the shelf in June 2010. 


\subsection{Zone 5: Punta Brava South}

\subsubsection{Site description}

Punta Brava South (PntBrvSth) extends $2.69 \mathrm{~km}$ south of the platform marking the southern boundary of Zone 4 (Figure 5-30). Punta Brava South is situated within a gap of the modern reef. At the northern end of the zone the barrier beaches are orientated towards the south (Zone 5a); further along this reverts back towards the southeast (Zone 5b), similar to other zones. A platform protrudes from the coastline and, in combination with patch reef, forces some wave dissipation, particularly to the north. The barrier beaches are very narrow, at less than $50 \mathrm{~m}$ wide at some points in the north, and are backed by mangrove wetlands. Vegetation is in abundance across the foredune, and is slowly migrating seaward.

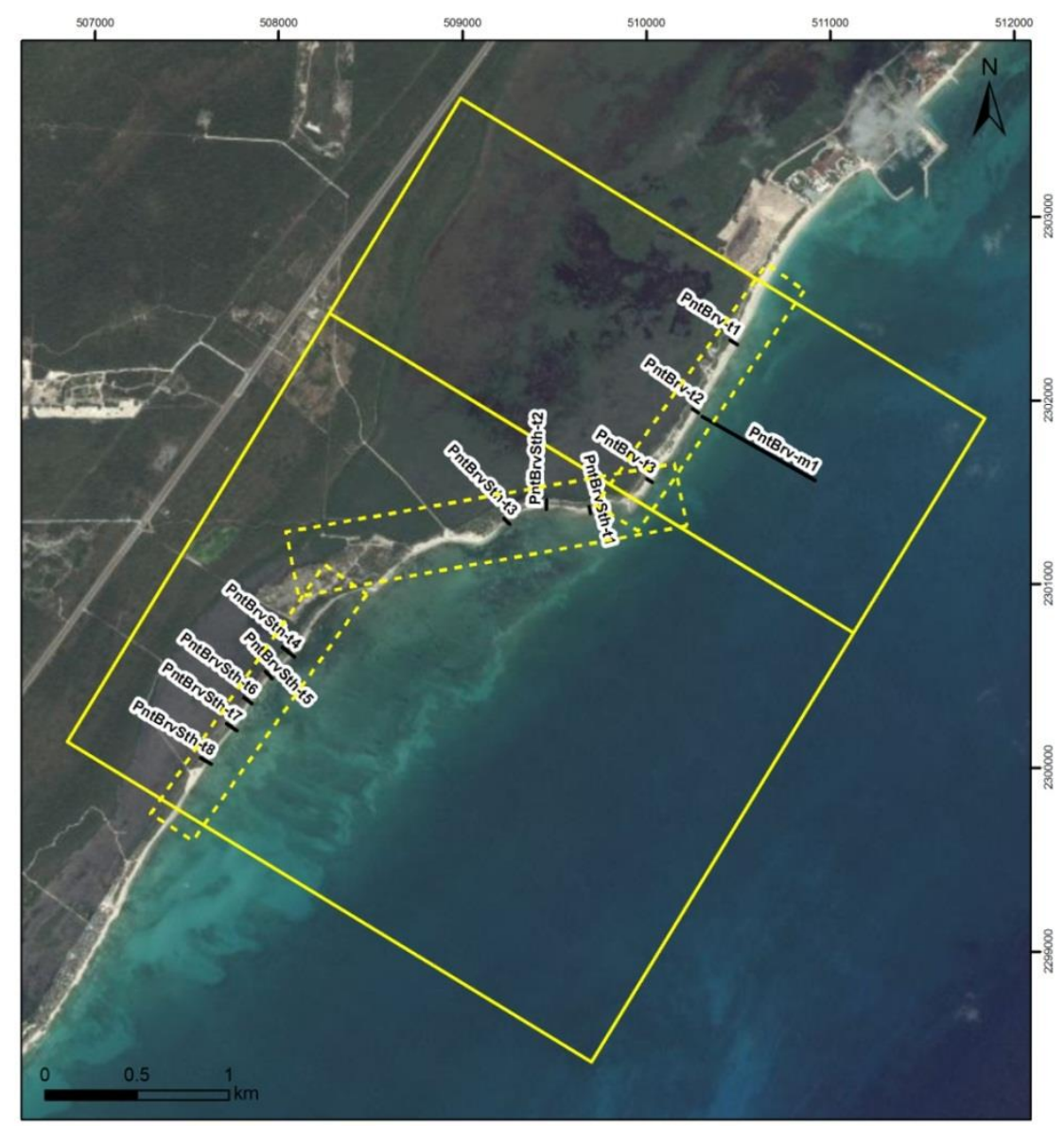

Figure 5-30: Map showing Zone 5a (middle box) and b (bottom box). The locations of the three transect in Zone $5 \mathrm{a}$, and eight transects in Zone $5 \mathrm{~b}$ are marked on the map. Note the orientation of the beaches in $5 \mathrm{a}$.

\subsubsection{Coastal morphology}

Hurricane Wilma drove landward translation of the barrier beaches of Zone 4 (Figure 5-31). Storm waves inundated the narrow, low-lying ( $<3 \mathrm{~m}$ above $\mathrm{MHW}$ ) beaches and washed sediment landward into the mangrove wetlands. The barrier beaches eroded from a pre- 
storm width of $26.1 \pm 3.6 \mathrm{~m}$ (using 4 September 2004 as the shoreline proxy) to $21.6 \pm 1.4$ $\mathrm{m}$. As with the other zones, this response was highly variable (Figure 5-31).

In the eight months which followed the barrier underwent highly variable response: some sites underwent accretion (18.5 m, PntrvSth-t1) while others continued to erode $(9.4 \mathrm{~m}$, PntBrvSth-t6). There was no significant difference in shoreline movement due to this high variability (Appendix 9.1). The northern-most beaches of Zone 5a likely captured sediment delivered alongshore by the north-moving littoral current, with some of the sediment possibly derived from the eroded beaches further south. In June 2006 beaches were on average $22.8 \pm 8.8 \mathrm{~m}$ wide. Sites in Zone 5 a ranged from relatively wide and flat back beach morphologies, with moderately sloping foredune (PntBrvSth06-t1), to sites with a very compressed back beach, largely absorbed into a steeper foredune (PntBrvSth06-t3). Sites further south (Zone $5 \mathrm{~b}$ ) were characterised as narrow arc-shaped barrier ridges with a landward dipping back beach cut directly into the ridge. In addition, most sites were characterised by a concave-up profile between the berm crest and foredune crest.

A further 48 months later, in June 2010, the barrier beaches had eroded at every site alongshore by $5.7 \pm 3.9 \mathrm{~m}$ on average, though this varied between 0.8 and $10.6 \mathrm{~m}$ (Figure 531). At this time the barriers had a mean beach width and slope of $17.1 \pm 6.9 \mathrm{~m}$, and as such were $4.5 \pm 7.3 \mathrm{~m}$ narrower than immediately following Hurricane Wilma, and $9.04 \pm 6.5 \mathrm{~m}$ narrower than the pre-storm profile of 14 September 2004 (Figure 5-31). These changes were seen across the beach with the narrowing and steepening of both the back beach and foredune as the barrier re-adjusted landwards (Appendix 9.1 and 9.2). The back beach depression was filled and the previously concave-up shape between the berm crest and foredune/barrier ridge started to reflect a more convex shape (Appendix 9.2).

In addition, the barriers had steepened by $3.1 \pm 3.2^{\circ}$ on average and lost $2.2 \pm 7.0 \mathrm{~m}^{3} / \mathrm{m}$ of sediment since June 2006. Both the landward translation and beach steepening were statistically significant (Appendix 9.1). 

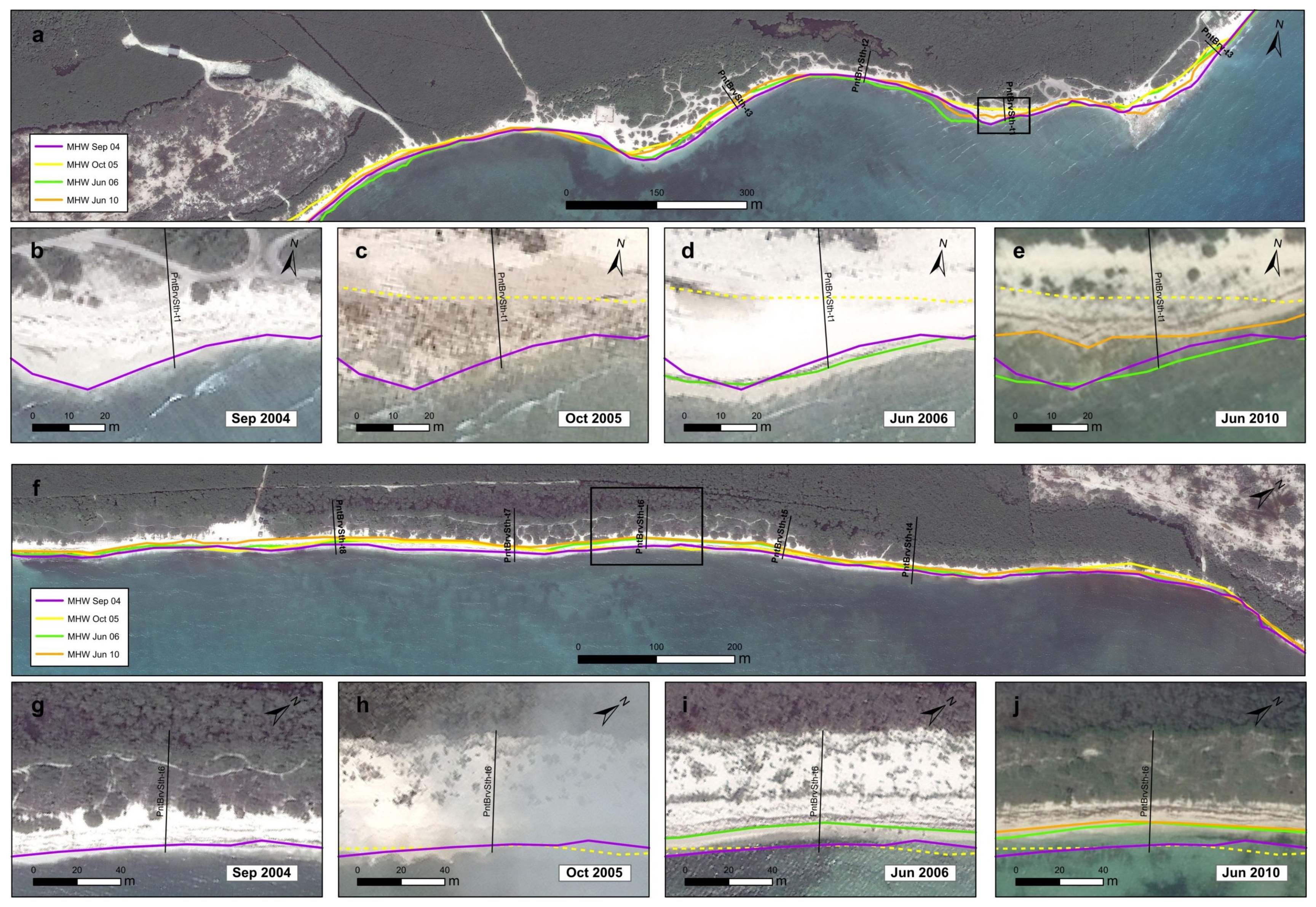

Figure 5-31: Storm and post-storm shoreline movement, profile adjustment and volumetric change along Punta Brava South: (a) storm and post-storm shoreline movement along Zone 5a, (b-e) shoreline movement and geomorphic change along PntBrvSth-t1, (f) storm and post-storm shoreline movement along Zone 5b, and (g-j) shoreline movement and geomorphic change along PntBrvSth-t6. 


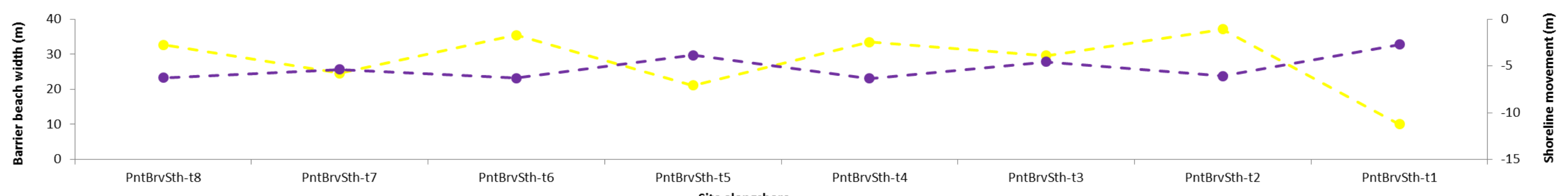

- $=$ Hurricane Wilma driven shoreline change _o Pre-storm barrier beach width

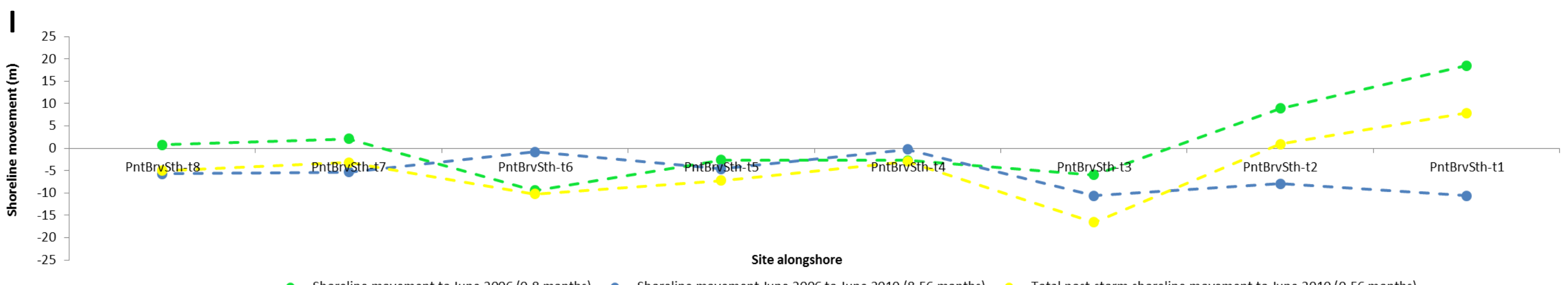

Figure 5-31 (continued): (k) Shoreline change resulting from Hurricane Wilma, (I) nature of the post-storm shoreline response along Zones 5a and b: Punta Brava South following Hurricane Wilma and up until June 2010. 
m

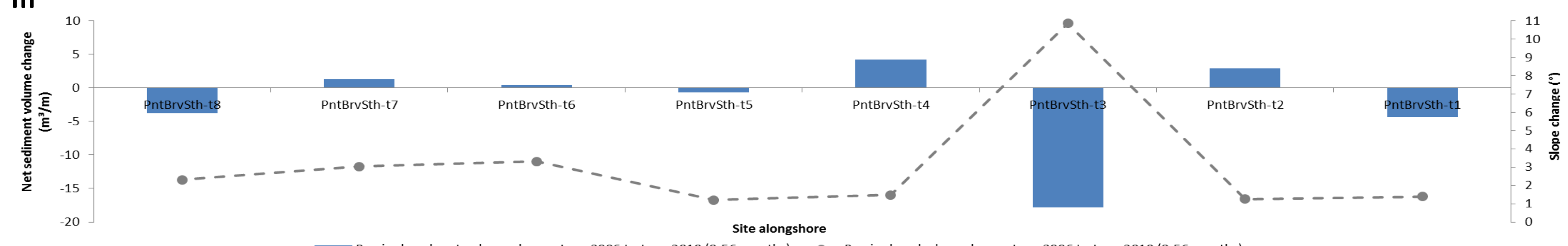

Barrier beach net volume change June 2006 to June 2010 (8-56 months) - - Barrier beach slope change June 2006 to June 2010 (8-56 months)

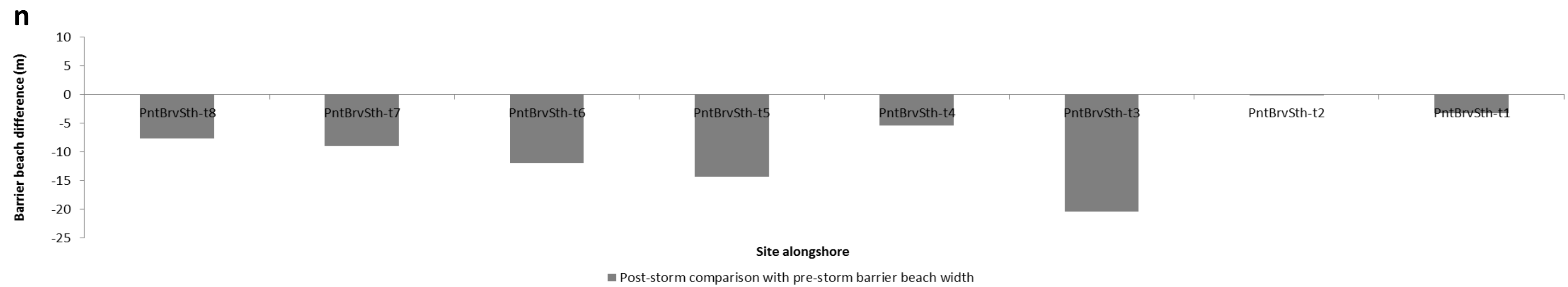

Figure 5-31 (continued): (m) Barrier beach slope and volumetric change between June 2006 and June 2010, and (n) comparison of the barrier beaches in June 2010 to 4 September 2004 (shoreline proxy prior to Hurricane Wilma). 


\subsection{Zone 6: Playa del Secreto}

\subsubsection{Site description}

Zone 6, Playa del Secreto (PlyaScrt), is the southernmost site studied and covers an alongshore distance of $0.54 \mathrm{~km}$ (Figure 5-32). Situated within a gap of the modern Mesoamerican Barrier Reef, Zone 6 is open to the full force of waves from the Caribbean Sea. There is minimal vegetation across the back beach, but the foredune is covered in shrubs and small trees. Several houses have been built at the back of the beach and a hotel, the Valentin Imperial Maya, is situated at the southern end of the zone.

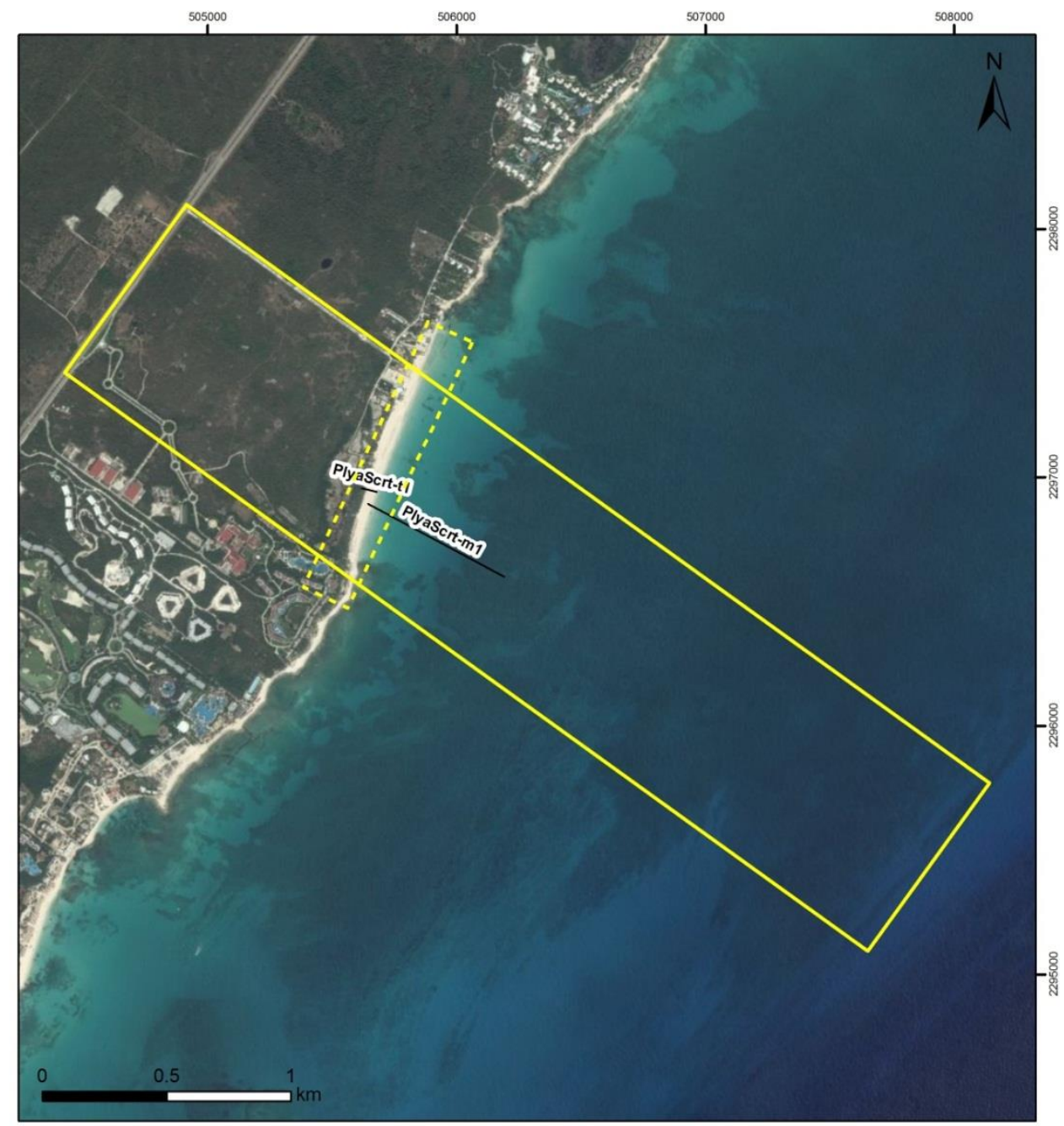

Figure 5-32: Map of Zone 6: Playa del Secreto showing the location of the barrier beach and offshore sites assessed. 


\subsubsection{Coastal morphology}

Similar to Punta Brava, the barrier beaches of Playa del Secreto eroded in response to the storm-driven waves and storm surge of Hurricane Wilma. The beach transgressed landwards from $36.1 \mathrm{~m}$ (using 4 September 2004 as the pre-storm shoreline proxy) to $27.6 \mathrm{~m}$. Eight months after Hurricane Wilma, Playa del Secreto had a measured beach width of $35.2 \pm 7.6$ $\mathrm{m}$, indicating considerable post-storm barrier recovery. At this time, the barrier contained a landward-dipping depression in the back beach, with an abrupt change at the foredune, and a flat barrier crest (Figure 5-33). Forty-eight months later the barrier had eroded once again, transgressing $6.2 \mathrm{~m}$ landward (Figure 5-33 and 5-34). These beach width changes under the post-storm energy regime indicate shoreline movement of these barriers may be controlled by the prevailing energy regime.

Post-storm geomorphic changes were characterized by profile steepening $\left(2.3^{\circ}\right)$ and net sediment gains $\left(5.4 \mathrm{~m}^{3} / \mathrm{m}\right)$, as the back beach infilled and moulded into the foredune (Figure 5-33).

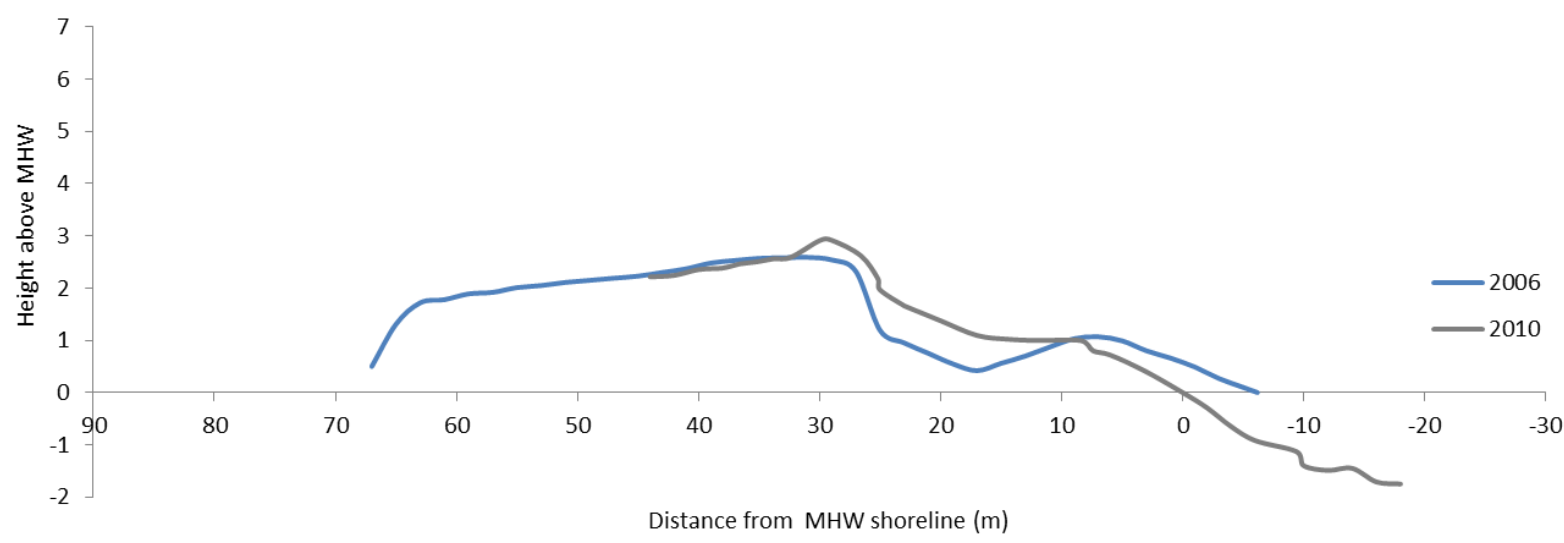

Figure 5-33: Post-storm geomorphic response of PlyaScrt-t1 between June 2006 and June 2010. 
Table 5-1: Shoreline movement, profile adjustment and volumetric change at PlyaScrt-t1

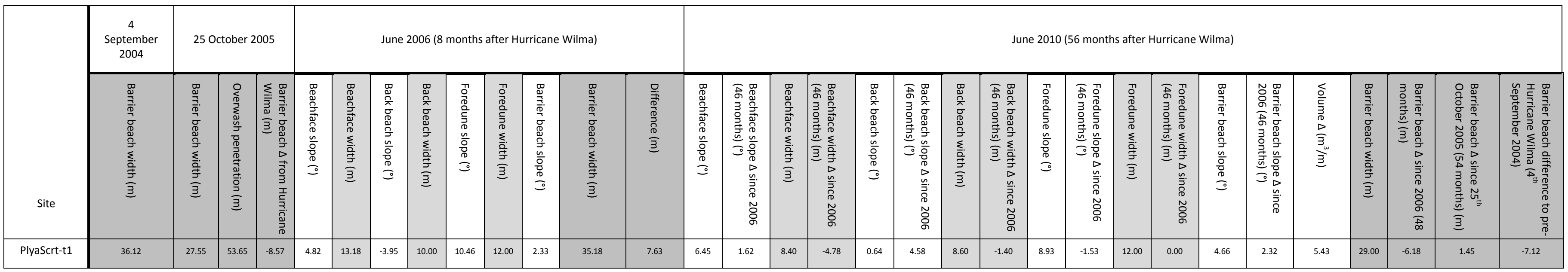
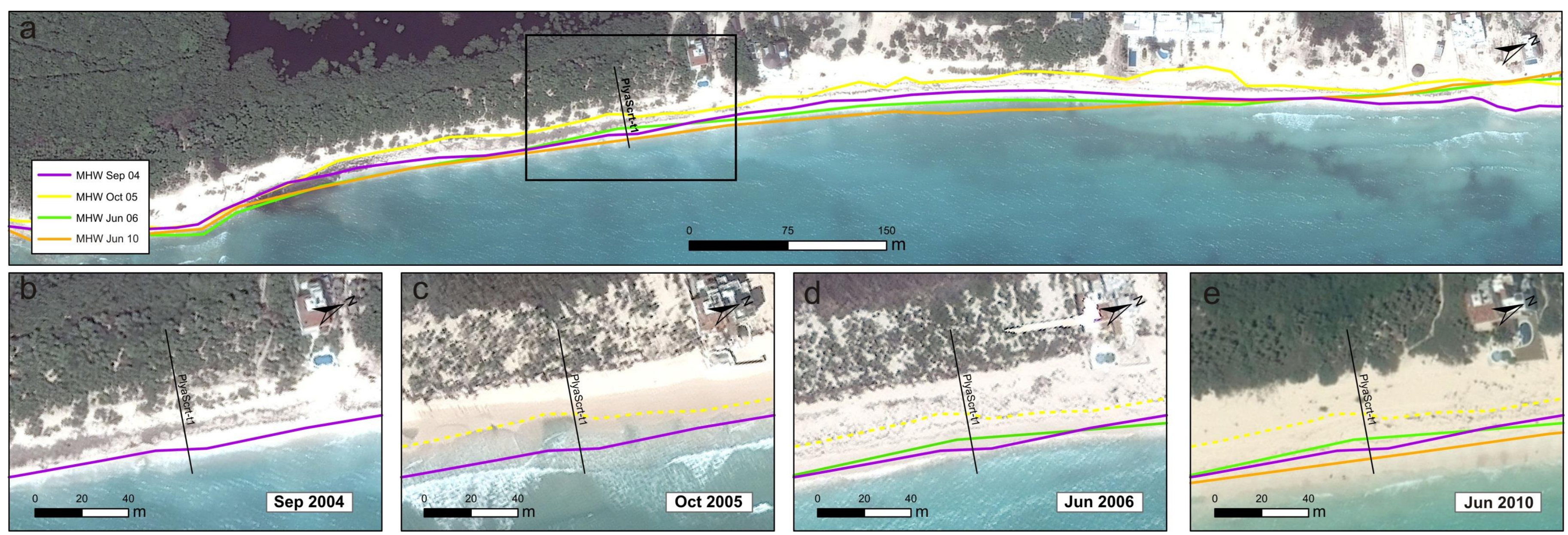

Figure 5-34: (a-e) Shoreline movement, profile adjustment and volumetric change at site PlyaScrt-t1, both as a direct result of Hurricane Wilma, and in the months to years following the storm. 


\subsubsection{Sediment texture: surface sediment}

During Hurricane Wilma storm waves transported sediment over the foredune crest and into the mangrove wetlands behind the beach; this extended over $50 \mathrm{~m}$ inland. The sedimentological character of Playa del Secreto was similar to that of Punta Brava; the storm deposit was dominated by sand-sized sediment $(98.30 \%)$, and on average coarsegrained $(0.87 \phi)$ moderately well sorted $(0.63 \phi)$ sand.

Seven months after Hurricane Wilma the beach still showed the sedimentological impacts of the storm. Coarse-grained sediment continued to predominate across-shore, with the largest material towards the back of the beach $(-1.9 \phi)$. Averaged sediment over the site reflected co-dominant coarse and medium sands, with small fractions of very coarse and fine sands (Figure 5-35).

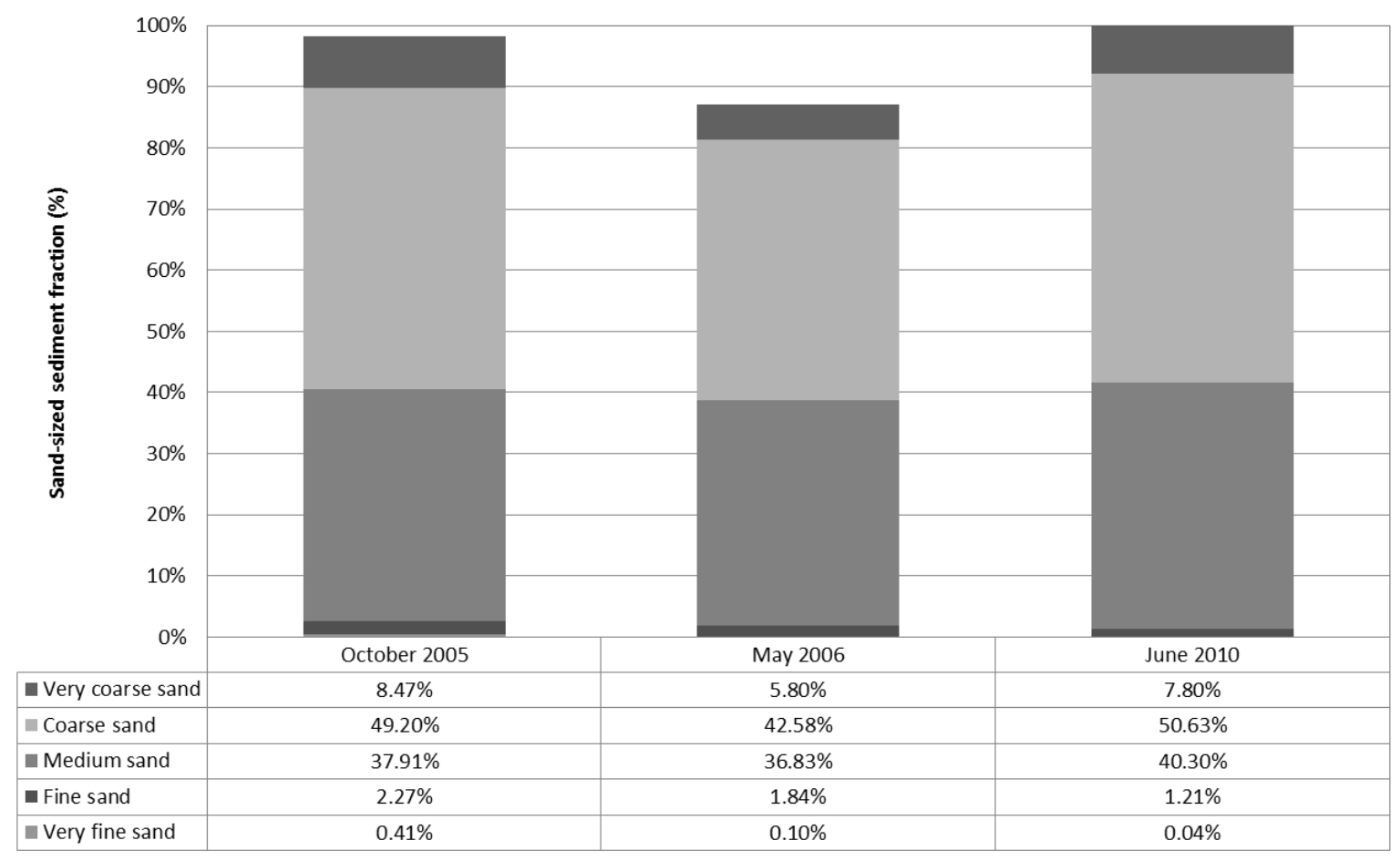

Figure 5-35: Changes to the sand-sized sediment fraction in Zone 6 (PlyaScrt-t1) following Hurricane Wilma.

By June 2010 surface sediment in the back beach had become considerably finer $(0.25 \phi$ $0.74 \phi)$ and better sorted $(1.12 \phi-0.63 \phi)$. In contrast, sediment in the backdune remained largely unchanged, with the surface layer only slightly finer and better sorted (Appendix 9.3). Similarly, coarse and medium sand remained co-dominant (Figure 5-35). Sediments tended to become more heterogeneous with distance from the shoreline (Figure 5-35). 


\section{Discussion}

\subsection{Geomorphic response of barrier beaches to Hurricane Wilma}

Tropical storms and hurricanes can drive considerable geomorphic changes to barrier beaches in a short period of time. Storm surge, combined with large storm-generated waves, can remove large quantities of sand from the beach and dune system and transport it offshore, alongshore, or if the inundation is great enough, wash sediment inland (Kraft et al., 1987; Morton and Sallenger, 2003). These impacts, however, are not the same in all locations: some stretches of barrier may accrete seaward, while others undergo rapid shoreline erosion (Morton, 2002; Morton and Sallenger, 2003; Wang et al., 2006; ClaudinoSales et al., 2008; Houser et al., 2008a; Priestas and Fagherazzi, 2010; Qi et al., 2010; Weaver and Slinn, 2010).

Waves and currents play a fundamental role in the distribution of sediments; sufficient energy input is required to overcome inertia and transport sediment (Komar, 1976). Local environmental factors and conditions, including the presence of dissipative structures (such as reefs), pre-storm beach morphology and storm duration and intensity, influence the distribution of wave energy at the shoreline, and therefore determine the way sediment is redistributed across the system (Sallenger, 2000; Morton, 2002).

During Hurricane Wilma sustained wind speeds exceeded $67 \mathrm{~ms}^{-1}$ and storm waves with significant wave heights $\left(H_{s}\right) \approx 13 \mathrm{~m}$ were experienced (Figure 6-1). Wave conditions of this nature were calculated to represent a one in one hundred year event (Silva-Casarín et al., 2009). Additionally, the slow movement of the storm along the coastline greatly increased the scale of geomorphic change. The storm persisted for over 20 hours, initially as a category 4 hurricane, and later eased slightly to category 3 (Pasch et al., 2006b). Wave heights inundating the barrier beaches varied considerably along the coast, and coral reefs were found to dissipate wave energy by over $80 \%$; as such, reef-protected beaches were inundated by storm waves of up to only $\mathrm{H}_{\mathrm{S}} \approx 2.4 \mathrm{~m}$ (Figure 6-1)(Blanchon et al., 2010). 


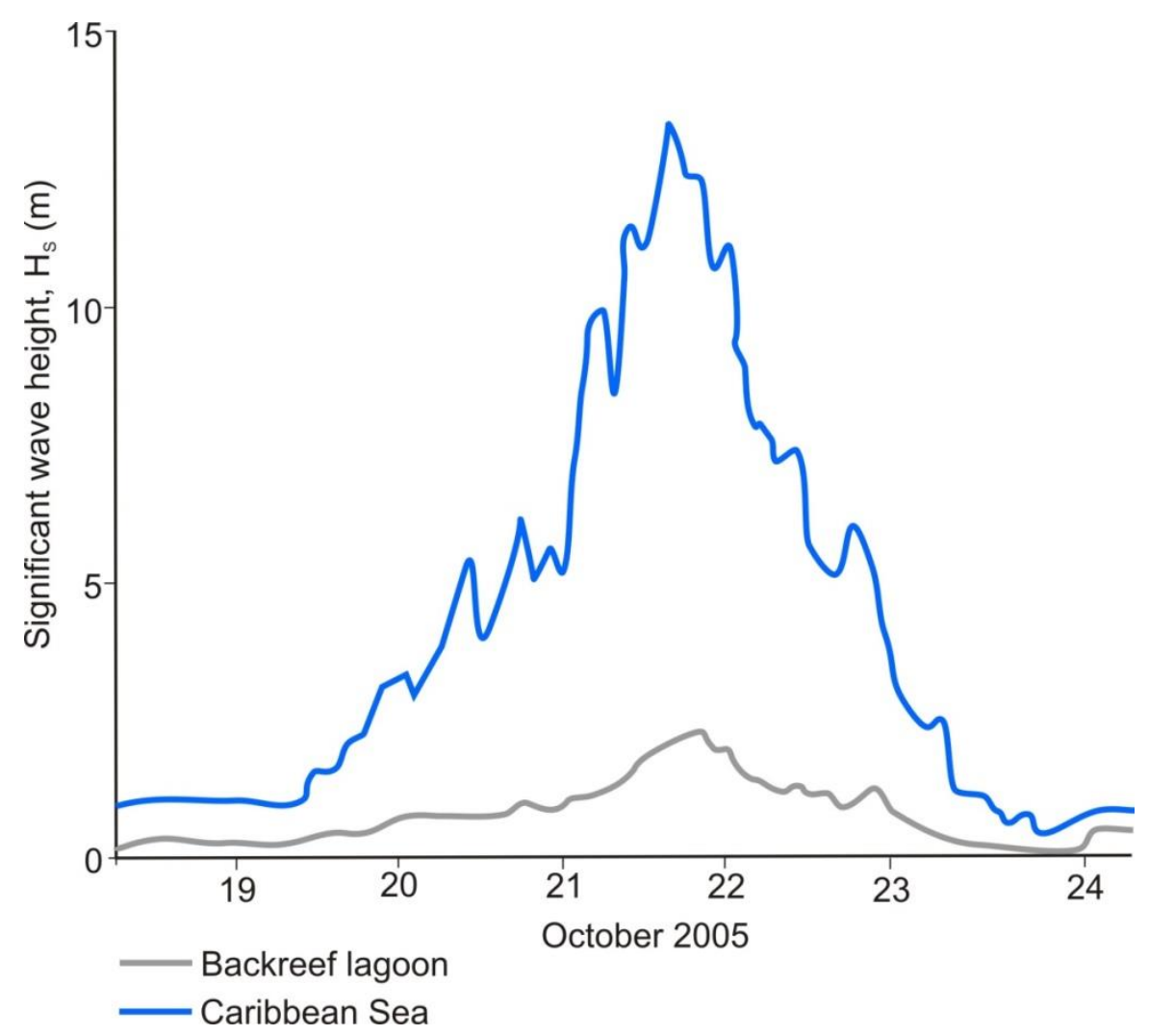

Figure 6-1: Peak significant wave height measured outside and inside the backreef lagoon off Puerto Morelos during Hurricane Wilma. Adapted from Blanchon et al. (2010).

Storm waves generated by Hurricane Wilma drove near-instantaneous shoreline movement, geomorphic destruction, and sediment redistribution. These responses, however, were found to be highly variable alongshore and influenced by a multitude of factors. The following sections discuss these responses and geomorphic drivers of storm-driven change. A conceptual beach model for each beach type is then presented.

\subsubsection{Immediate shoreline movement}

The barrier beaches of northeastern Yucatan Peninsula showed a highly variable response to Hurricane Wilma. Some eroded by up to $11.3 \mathrm{~m}$; this was measured towards the southern end of the study area in Zone 5: Punta Brava South (PntBrvSth-t1), and represents a loss of over $35 \%$ of the barrier beach width. Other stretches of shoreline accreted, with the northern beaches in Zone 2: Punta Tanchacte (PntTnch-t12) increasing in beach width by $24.6 \mathrm{~m}$ (43\%). These near-instantaneous changes could equate to many years of shoreline movement under 'normal' conditions. Of the 43 sites measured in this study, 31 sites underwent beach accretion, which was confined to Zones 1-3, the northern half of the study area, with the 12 eroded sites further south in Zones 4-6.

The shoreline response varied within these clusters, with accretion in Zones 1-3 ranging between $3.1 \mathrm{~m}$ at the southern end of Zone 1: Wet ' $n$ ' Wild (WnW-t14) to a maximum 24.6 $\mathrm{m}$ at PntTnch-t12; the proportional beach width changes varied from $9 \%$ at $\mathrm{WnW}$-t14 to 
over $70 \%$ at $\mathrm{WnW}$-t2. Shoreline erosion ranged between $1.1 \mathrm{~m}$ at PntBrvSth-t2 and a maximum of $11.3 \mathrm{~m}$ at PntBrvSth-t1, $200 \mathrm{~m}$ to the northeast. These results further illustrate the alongshore variability in shoreline response, similar to many other studies (Morton and Paine, 1985; Lee et al., 1998; Morton, 2002; Otvos, 2004; Robertson et al., 2007; Priestas and Fagherazzi, 2010), which may be the result of multiple variables.

\subsubsection{Geomorphic response}

The storm waves inundated the barrier beaches to varying extents alongshore, causing large-scale changes to beach morphology. In particular, storm waves reworked the well vegetated back beach and foredunes. A critical inundation height of approximately $3 \mathrm{~m}$ in reef-protected beaches in Zones 1-3 was observed, with foredunes below this height undergoing stages 3-4 of the 'storm inundation scale' (refer to Section 2.5.1). In these cases, sediment both washed inland and pulled out across the beach. Inundation was, however, slowed by dense vegetation (Zone 1) and mangrove wetlands (Zones 4-6), similar to other studies (Morton, 2002). Also in some instances, beach rock underlying the beach was left exposed. Barriers containing foredunes higher than $3 \mathrm{~m}$ above MHW underwent stage 3 inundation, with barrier reworking concentrated on the foredune and not behind. The beach profile was ironed out to a wide-gently sloping surface, free of vegetation. Unprotected barrier beaches in Zones 4-6 all underwent stage 4 inundation, due to all foredunes being below $3 \mathrm{~m}$ and the storm waves considerably higher.

\subsubsection{Responses of reef-protected and unprotected barrier beach systems}

Based on the large difference in wave energy reaching reef-protected and unprotected sections of coastlines, it would be expected that different patterns of storm-driven sediment redistribution would result from Hurricane Wilma. Indeed, as earlier mentioned, a distinction was clearly observed between stretches of reef-protected and unprotected barrier beaches in this study (Figure 6-2). Other factors appear to have had a lesser influence on the magnitude of beach change. Additionally, sedimentological response varied between these barrier beach types, with reef-protected systems characterised by moderately well sorted medium sand, and exposed beaches consisting of moderately well sorted coarse sand (Figure 6-3). The post-storm geomorphology of these barriers can further be explained by examining the patterns of inundation, waves and currents that reworked sediment during the storm. 


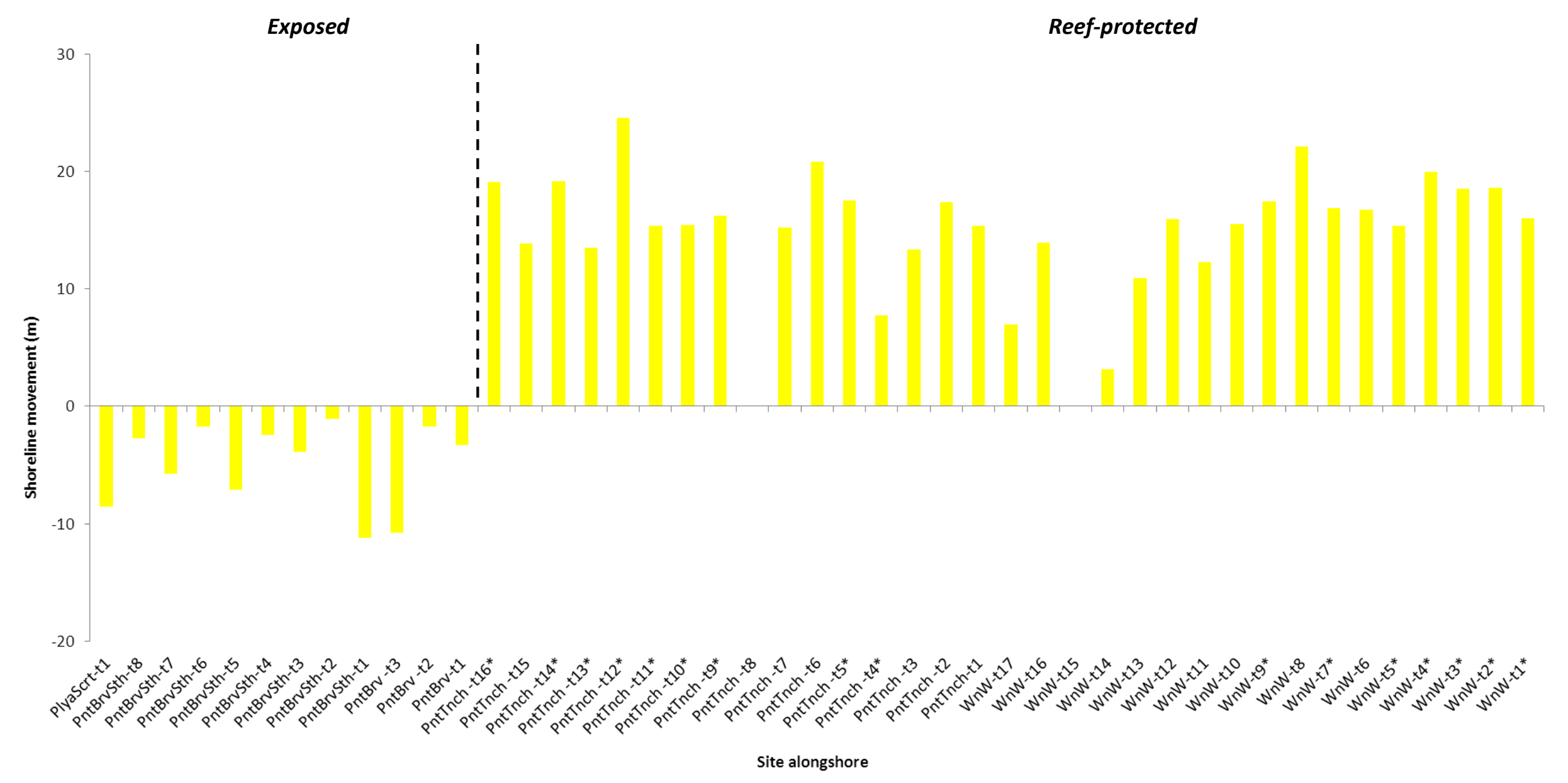

Figure 6-2: Graphical display of the shoreline response driven by Hurricane Wilma. The most distinct differences can be seen between reef-protected barrier beaches which accreted and exposed barrier beaches which eroded. 


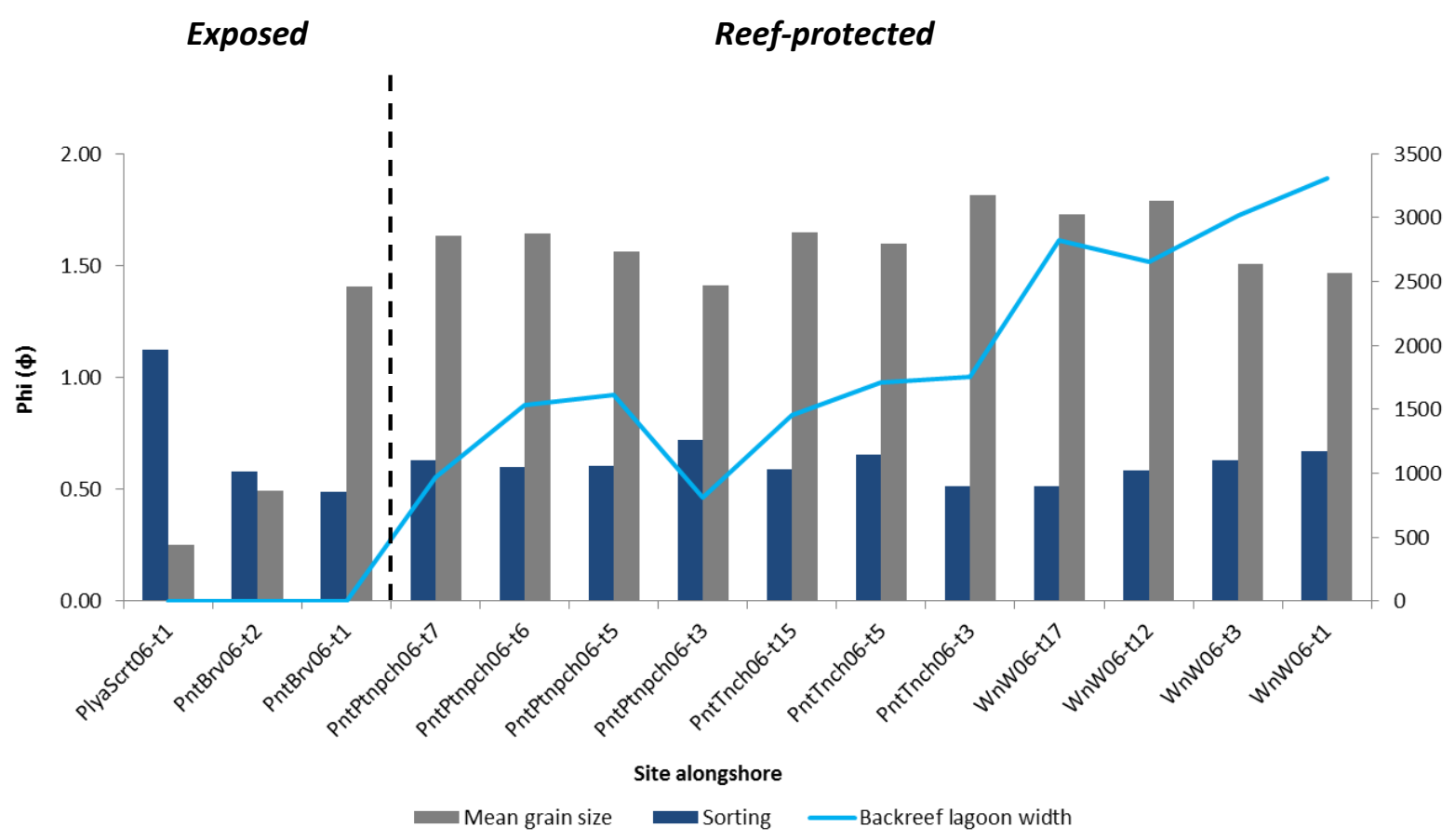

Figure 6-3: Textural character of barrier beach systems of northeastern Yucatan Peninsula as defined by the mean grain size, sorting, and backreef lagoon width.

For reef-protected barrier beaches (Zones 1-3), the increased water level $\left(H_{S} \approx 2.4 \mathrm{~m}\right)$ enabled the waves to inundate the entire beach and reach the dunes. Sediment was cut from the beach and pulled seaward as large waves were reflected back offshore, with the finest sediment preferentially suspended first and transported the farthest. Some sediment was deposited on the shoreface, which resulted in the widening of the beach. This deposition was aided by the gentle slope of the backreef lagoon. At the northern end of Zone 1 , the foredunes were overtopped by waves and sediment was also pushed inland.

The process of sediment reworking differed significantly on the exposed barrier beaches of Zones 4-6. These barriers were closer to the eye of the storm, and as such may have experienced higher storm waves, particularly during the initial landfall of the storm. Sediment overwash processes predominated, forming a large storm deposit in the backdune swale, and some sediment was transported offshore and alongshore; this was aided by the steeper offshore gradient. These results suggest that in the absence of a reef, exposed calcium carbonate barrier beach systems tend to erode, similarly to most siliceous barrier islands.

These results fit within contemporary scientific understandings of barrier beach systems, as sediment may be transported seaward as material is removed from the beach and deposited on the upper shoreface, resulting in a concave-up beach morphology (Komar, 1976; Lee et al., 1998; Hill et al., 2004; Priestas and Fagherazzi, 2010). Additionally, sediment may be washed inland, with material removed from the beach and deposited on top of in situ sediment and vegetation in the backdune swale, if waves are high enough (Morton and Sallenger, 2003). Sediment may also be lost alongshore (Kahn and Roberts, 
1982) or offshore. In this study, the sediment redistribution resulted in shoreline accretion along all reef-protected barrier beaches; this response is similar to that found by Priestas and Fagherazzi (2010) on St George Island, Florida (USA) in response to Hurricane Dennis (2005). Exposed beaches all experienced sediment overwash and shoreline erosion, similar to the findings of Sallenger (2000) and Morton (2002).

\subsubsection{Other factors influencing storm response}

While coral reefs appear to have the greatest significance to shoreline response, the prestorm barrier beach morphology (foredune height and beach width) and shoreline orientation also had some influence on site-specific change. These results are comparable with other studies, which have found barrier beach response can be influenced by several factors including the geomorphology of the coastline, nature of the storm, event timing and duration, and storm recurrence (Phillips, 1999). Figure 6-4 compares the magnitude of shoreline change at different cross-shore transect locations with several of these variables, which are each discussed further below. 
Exposed

Reef-protected

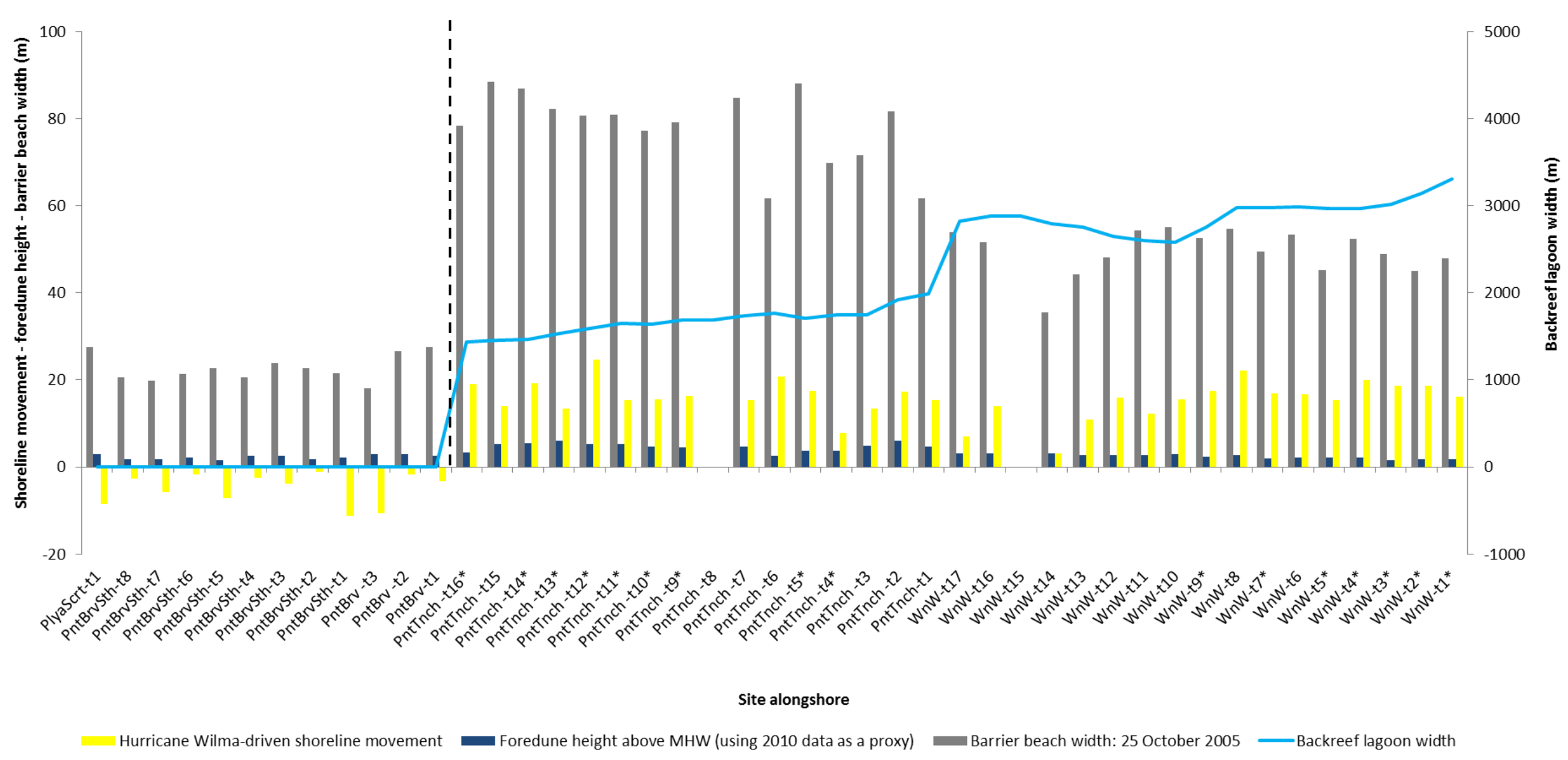

Figure 6-4: Graphical display of the highly variable shoreline response as a result of Hurricane Wilma, compared alongside foredune height, barrier beach width, and backreef lagoon width. 
Firstly, the influences of the backreef lagoon width, and proximity to reef inlets, on shoreline response were statistically investigated, but no significant relationships found. This indicates that under storm conditions these features of coral reef morphology appear to have no discernible impact. However, a wider backreef lagoon was correlated with a narrower pre-storm beach width. Further to this, and as shown in Figure 6-5, the reefprotected coastline can be further divided into two beach types. This is based on differing foredune height, barrier beach width, and backreef lagoon width. Where the backreef lagoon is relatively wide, with a narrow beach and small foredunes, reflective beaches with subaqueous sand bars predominate. Dissipative beaches tend to form where there are narrower backreef lagoons, higher foredunes and wider beaches.

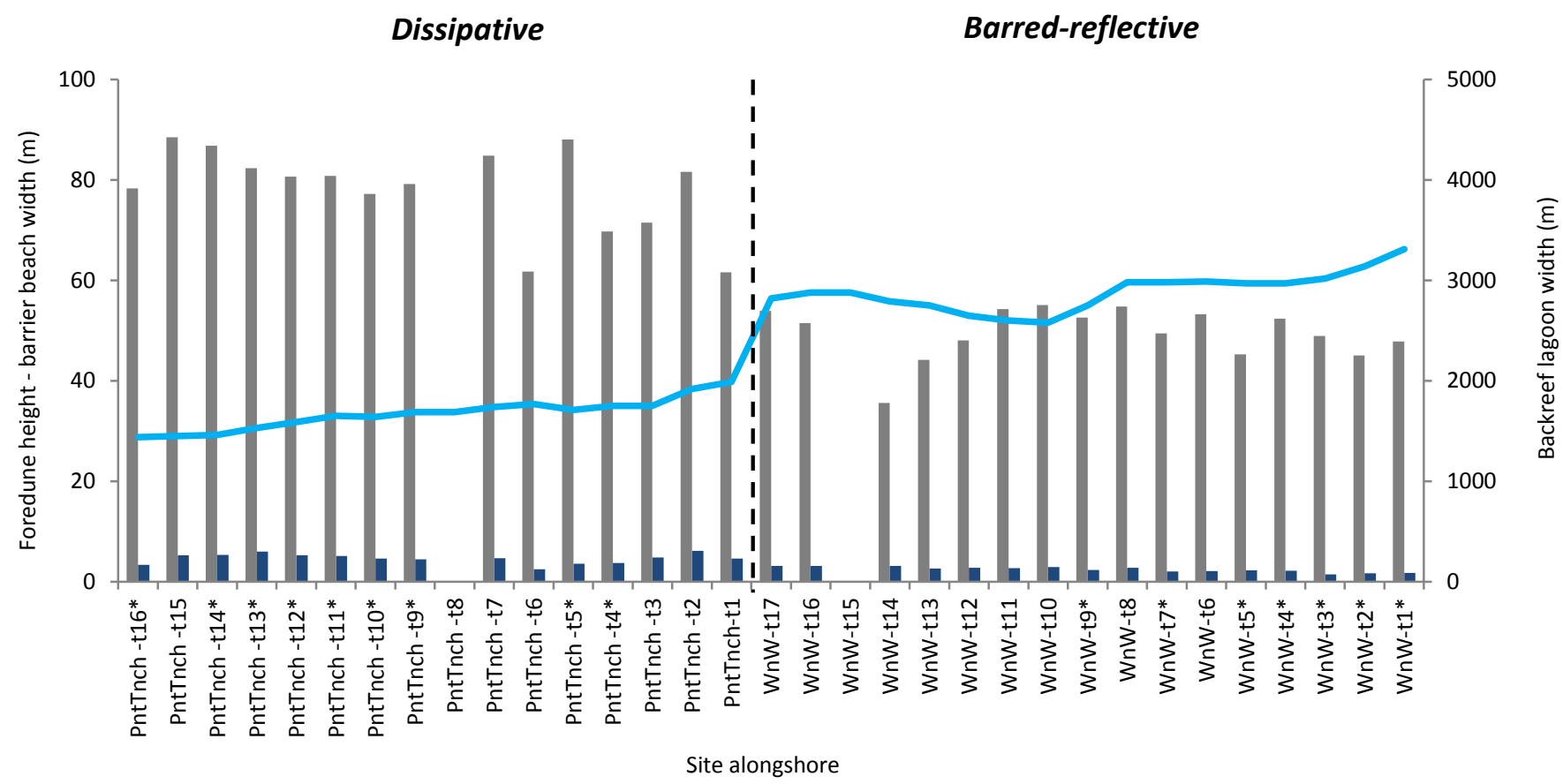

Foredune height above MHW (using 2010 data as a proxy)

Barrier beach width: 25 October 2005

Backreef lagoon width

Figure 6-5: Graphical display showing the relationship of reef-protected beach shape with foredune height, barrier beach width and backreef lagoon width.

Secondly, the height of the foredune and the beach width have been described in scientific literature as having some influence over beach response to storms (Morton, 2002; Morton and Sallenger, 2003; Wang et al., 2006; Claudino-Sales et al., 2008; Houser et al., 2008a). However, unlike the results of Priestas and Fagherazzi (2010), storm-driven barrier beach movement showed no relationship with foredune height, indicating that the extent of wave overtopping and inundation was not important to beach widening in this study (indicated by no significant correlation in Figure 6-6). 


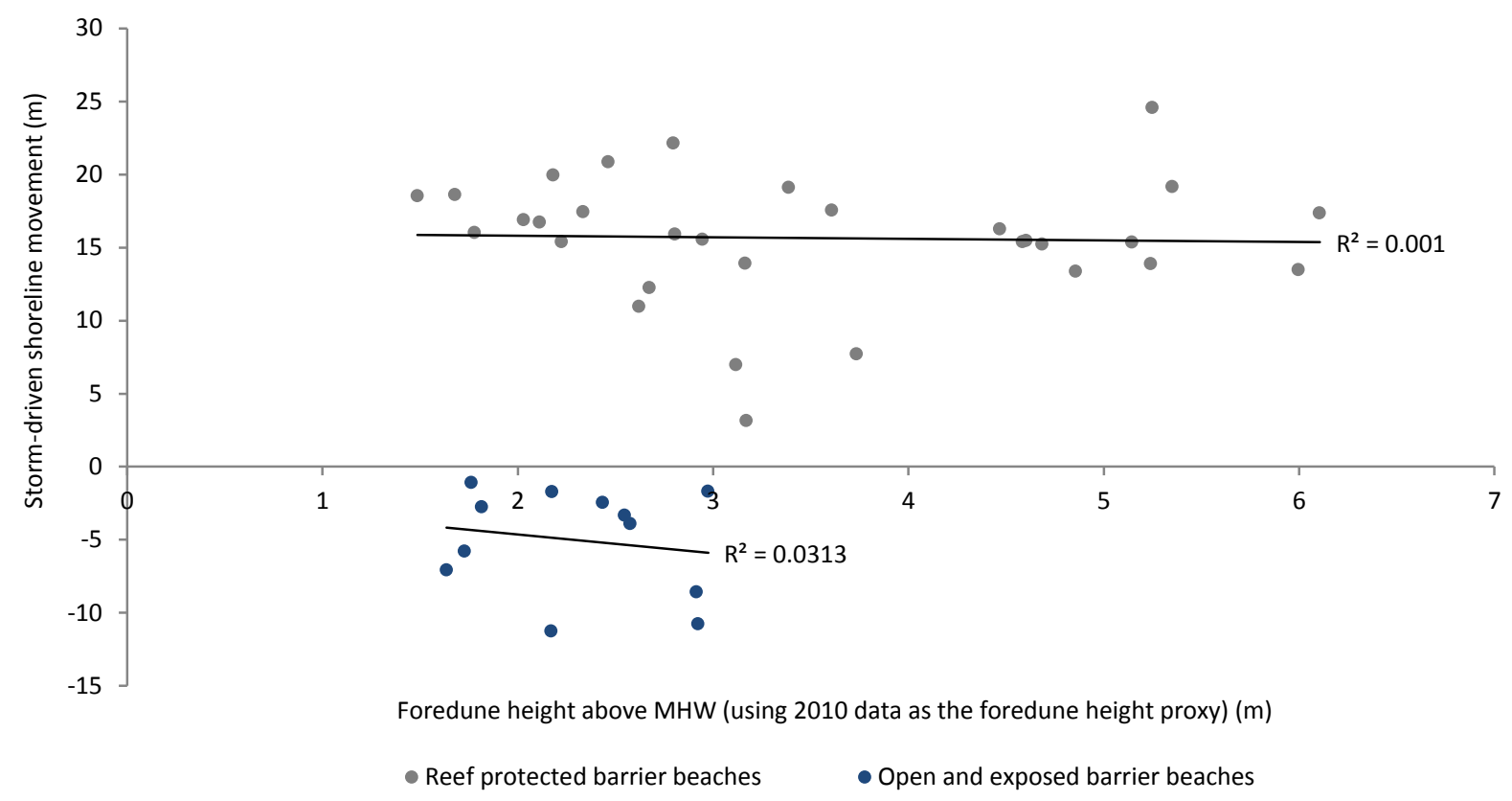

Figure 6-6: Bivariate plot showing no correlation between storm-driven shoreline movement and foredune height on reef-protected and open and exposed barrier beaches.

Pre-storm barrier beach width was also found to have no influence on the shoreline response of reef-protected barrier beaches. In comparison, on exposed coastlines, the extent of shoreline erosion was found to be related to pre-storm barrier beach width, with relatively wide barrier beaches showing a trend towards greater shoreline erosion (Figure 67).

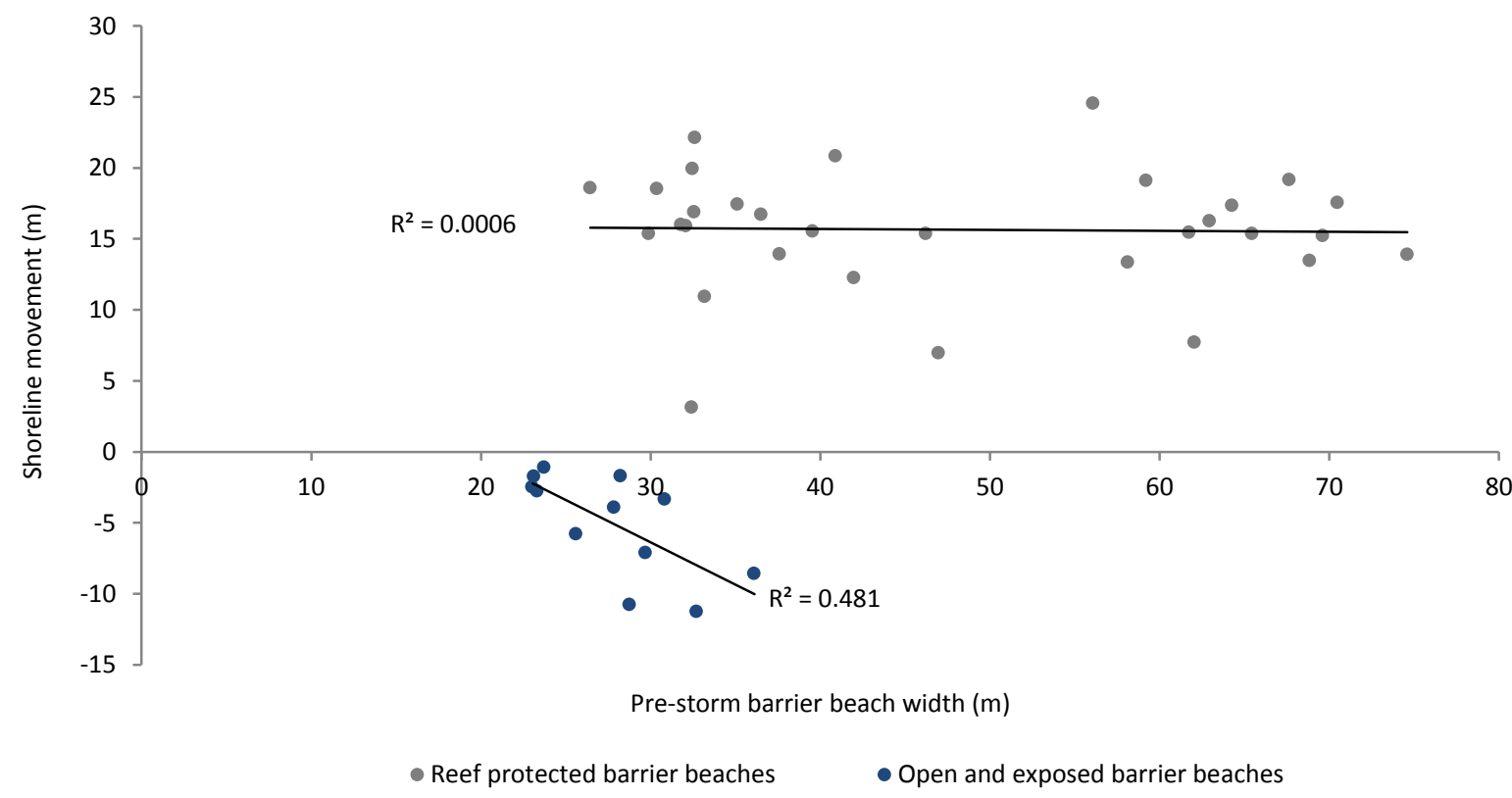

Figure 6-7: Bivariate plot showing the relationship between storm-driven shoreline erosion and pre-storm barrier beach width on exposed coastlines; there is no relationship on reefprotected coastlines. 
Finally, the characteristics of a storm, including event timing and duration, have been found to have considerable influence over barrier beach response (Phillips, 1999). During Hurricane Wilma, storm waves inundated exposed sites for a longer period of time than protected sites, due to their increased wave exposure; however, these effects could not be differentiated from other factors applicable to this study. On a storm scale, Hurricane Wilma produced comparatively large storm waves, which drove greater geomorphic change to the barrier beaches of northeastern Yucatan peninsula than other events of similar size upon landfall (see Sections 3.8.2 and 3.8.4). Hurricane Wilma differed from these previous storms in the region as it stalled over northeastern Yucatan Peninsula for over 20 hours, greatly increasing the time for storm waves to drive sediment transport (Pasch et al., 2006b). This indicates that the duration of a storm is an important factor controlling the magnitude of geomorphic change to the coastline; this agrees with the results found by Phillips (1999).

\subsubsection{Barrier beach storm response models}

Shoreline movement of barrier beaches in response to Hurricane Wilma was primarily determined by the presence or absence of a dissipative coral reef and backreef lagoon. Secondarily, local factors such as the pre-storm barrier beach width had some effect on the magnitude of change experienced. Based on these factors, barrier beach response can be described as three different systems, based on their geomorphology and sedimentology. Reef-protected beaches are divided into the two types described above (see Figure 6-5): type 1a: reef-protected and barred-reflective barrier beach systems and type $1 b$ : reefprotected and dissipative barrier beach systems. Unprotected beaches are classed as type 2: exposed and reflective barrier beaches systems. In the sections below, conceptual models are proposed to describe the storm response of each beach type, drawing on the results of this study, the logic presented above, and wider literature.

\subsubsection{Type 1a: reef-protected and barred-reflective barrier beach systems}

Type 1a barrier beach systems were characterised by beaches $40-55 \mathrm{~m}$ wide (as measured from the foredune crest to $\mathrm{MHW}$ ) and foredunes which rarely exceeded $3 \mathrm{~m}$ above MHW, following reworking by Hurricane Wilma. The backreef lagoon was typically $2-3 \mathrm{~km}$ wide and 3-4 m deep, dominated by Halimeda, Syringodium filiforme, and Thalassia testudinum seagrasses.

Storm wave inundation reworked the beach and foredunes, both through direct inundation and by wave swash. Foredunes less than $3 \mathrm{~m}$ above MHW were overtopped by waves, and sediment was transported into the backdune swale. The predominant sediment flow direction was seaward, with wave run-up removing in situ sediment from the back beach, followed by the foredune, and transporting material across the beach, depositing it on the upper shoreface. The subaqueous sand bar was infilled, with barrier beaches undergoing considerable accretion at all sites alongshore. As a result, a more dissipative beach profile was achieved (Figure 6-8, also see Section 5.2). Finer material was preferentially removed 
and transported seaward with wave backrush; this is reflected by the landward coarsening of the storm deposit.

Type 1a barrier beach width increased by $14.6 \mathrm{~m} \pm 4.8 \mathrm{~m}$ on average, representing a proportional increase of approximately $45 \%$. This response is comparable with the shoreline changes measured by Priestas and Fagherazzi (2010) on St George Island, Florida (USA) in response to Hurricane Dennis (2005). In addition, the process of sediment removal and deposition is similar to the cut and fill process conceptualised by Komar (1976). Vegetation beyond the foredune crest was largely retained, and acted to stabilise the foredune and slow inland sediment penetration. If the foredune had not been well vegetated, it is likely that complete foredune erosion or landward transgression would have resulted (Morton, 2002).

Type 1a barrier beach systems underwent stage 2: back beach and foredune face concentrated reworking (where foredune height exceeded $3 \mathrm{~m}$ above $\mathrm{MHW}$ ) and stage 3: foredune concentrated reworking (foredunes less than $3 \mathrm{~m}$ above MHW), from the impact and inundation scale conceptualised by Sallenger (2000)(see Section 2.5.1). However, the response of the beaches in this study contrasts to the typical response reported by Sallenger (2000), with the beaches in this study undergoing shoreline accretion, not erosion as he proposed. This is largely due to the relatively wide and shallow backreef lagoon, which tends to promote the formation of a gentle sloping shoreface. As a result, the upper shoreface is easily filled during sediment deposition, following beach and foredune reworking, and enables shoreline accretion. In addition, the dissipative nature of the backreef lagoon, as well as the reef crest, restricts sediment movement offshore; therefore most sediment is retained within the barrier-backreef lagoon system. Had type 1a barrier systems not been protected by coral reefs with shallow backreef morphology, erosion by large storm waves would likely have led to stage 4: entire barrier reworking (Sallenger, 2000). This would have most likely resulted in net erosion, with the barrier transgressing landward as wave overwash processes predominating. 

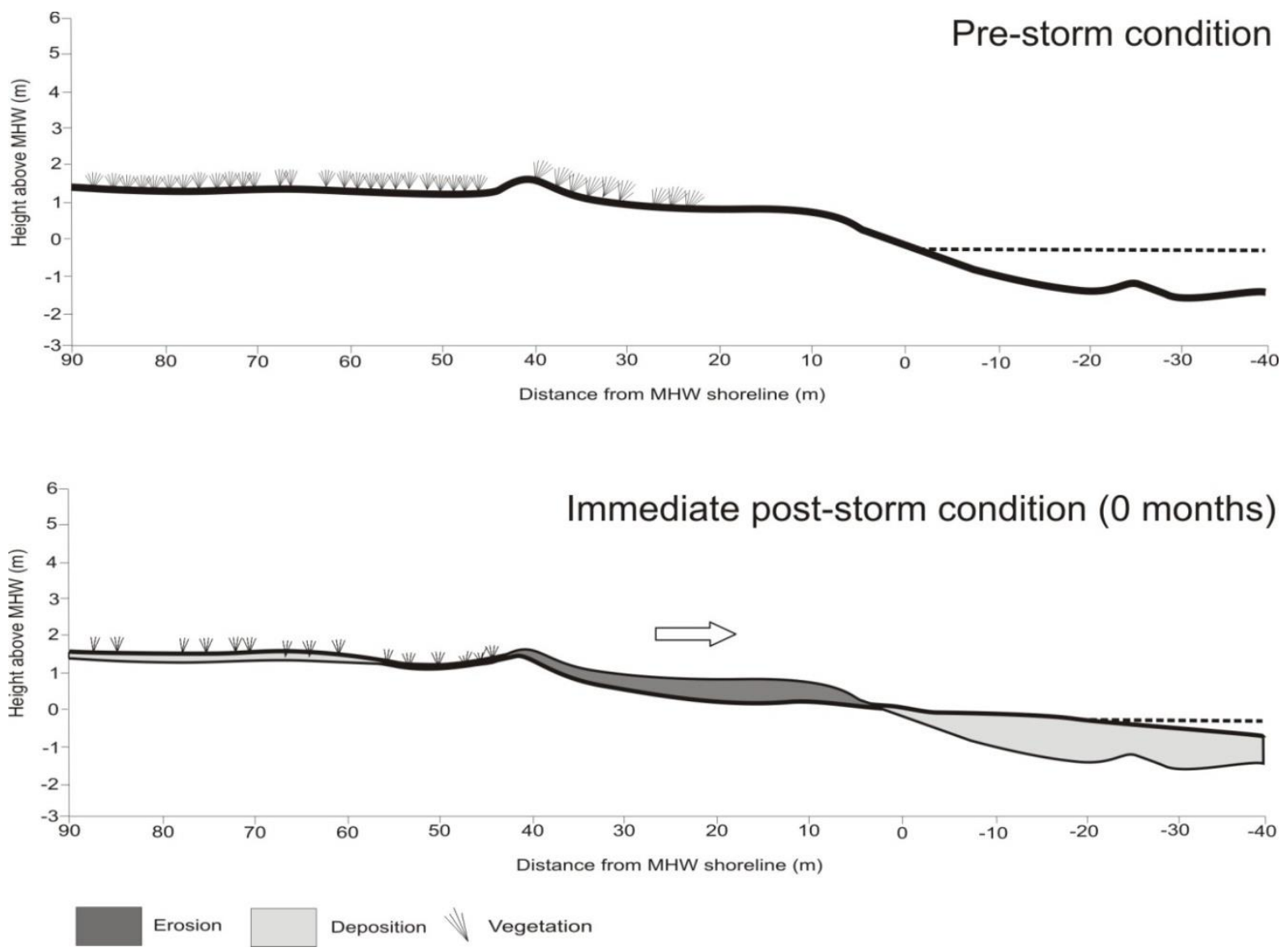

Figure 6-8: Model of the geomorphology of type 1a: reef-protected barrier beach systems, pre and post-Hurricane Wilma.

\subsubsection{Type 1b: reef-protected and dissipative barrier beach systems}

Type $1 \mathrm{~b}$ barrier beaches were exposed to higher wave energy than type 1a systems, due to a narrower backreef lagoon which dissipates less energy under normal conditions. These barriers were characterised by higher foredunes, typically 3.5-6.5 m above MHW, with wider beaches (60-90 $\mathrm{m}$ wide) following beach and foredune reworking during Hurricane Wilma (Figure 6-9).

Type 1b barriers underwent a similar geomorphic response to type 1a systems; however sediment overwash only occurred in one or two locations, owing to the higher foredunes. On average, the beaches underwent slightly greater shoreline accretion than type 1a barrier systems, though this was found to be considerably less when compared proportionally. This may be the result of either the wider pre-storm barrier beach forcing greater wave dissipation, less extensive wave backrush, and as such less sediment transportation, or smaller subaerial stores of sediment (relative to beach width) limiting the availability of material for accretion. As reported in the results, these barriers accreted by $16.3 \mathrm{~m} \pm 3.9 \mathrm{~m}$ on average, representing a proportional increase in beach width (and shift from the prestorm beach profile) of over $27 \%$. Type $1 \mathrm{~b}$ barriers predominately underwent stage 2: back beach and foredune face concentrated reworking (Sallenger, 2000). The difference between these two systems becomes more apparent during the post-storm response. 

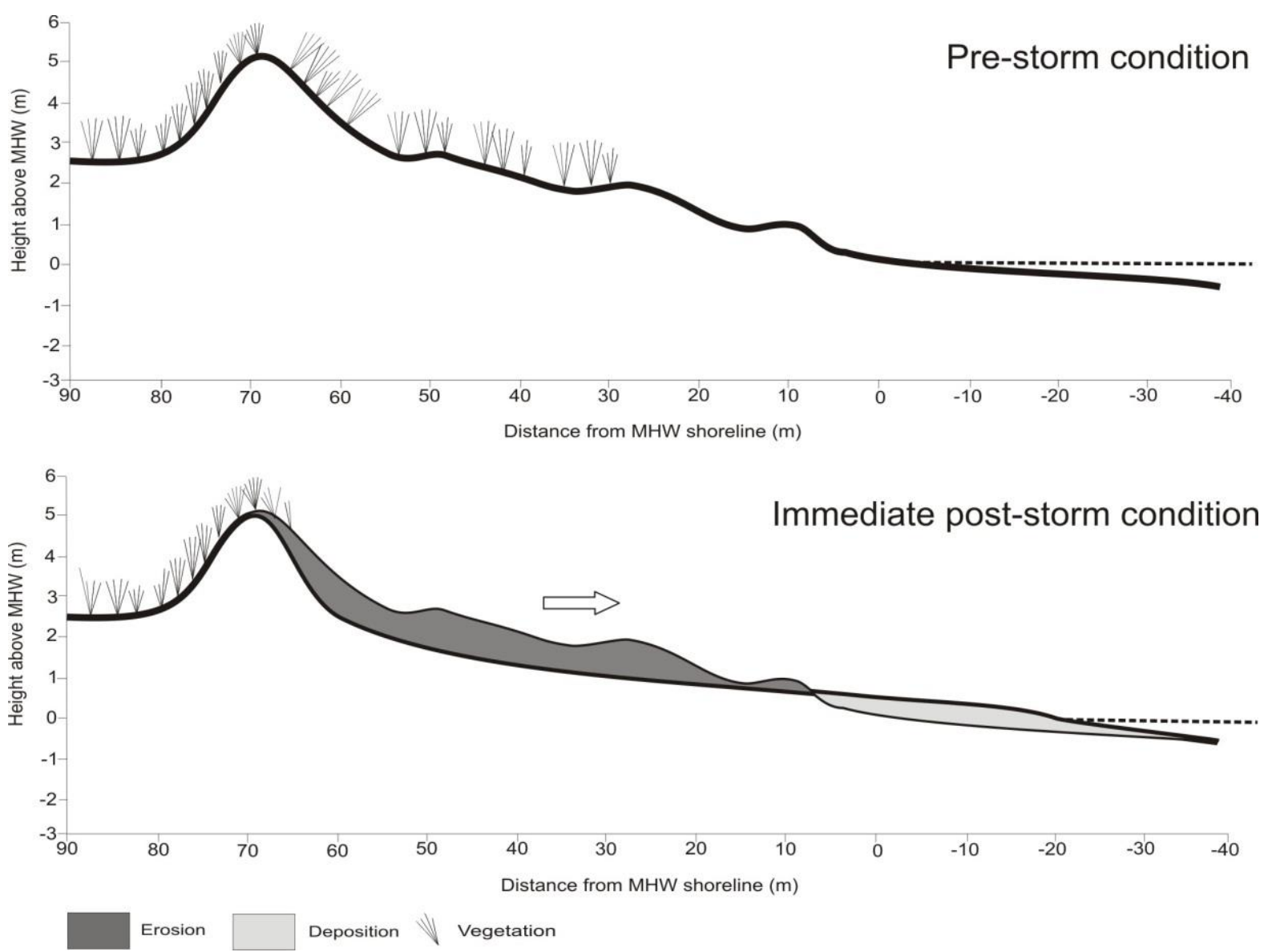

Figure 6-9: Model of the geomorphology of type $1 \mathrm{~b}$ : reef-protected barrier beach systems pre and post-Hurricane Wilma.

\subsubsection{Type 1a and $b$ sedimentological storm response}

The textural character of storm deposits indicates type $1 \mathrm{a}$ and $\mathrm{b}$ barriers were largely sedimentologically disconnected from the reef and backreef lagoon under storm conditions (Figure 6-10). The predominance of medium sand throughout the storm deposit suggests sediment was instead sourced locally, either from the barrier beach, or within the backreef lagoon; had sediment been sourced from the reef crest or forereef it would have been larger, due to a lack of reworking. This confirms that beach accretion was primarily the result of in situ beach and foredune reworking. This is further supported by analysis of sediment composition, which found only small proportions of coral and coralline algae in the storm deposit. In addition, some of this sediment was highly abraded and had undergone micritisation, indicating it was already within the barrier beach or backreef lagoon at the time of the storm. It is likely that a greater amount of storm-derived debris (from the forereef and reef crest) would have been evident in the outer limits of the backreef lagoon.

Sediment was found to be dominated by Halimeda, a species of green algae which predominates in the backreef lagoon (see Section 2.3.3, coral reef zonation); this corresponds well with the measured grain size, and aligns with the Sorby Principle (Figure 2- 
5; Section 2.3.5). In addition, constituents had also been exposed to pedogenic processes, driving micritisation and representing in situ deposition on the barrier beach or backreef lagoon (Macintyre et al., 1987; Macintyre and Reid, 1995; Kennedy, 2003). However, the influx of large volumes of sediment from the backreef lagoon during Hurricane Wilma was ruled out as van Tussenbroek et al. (2008) reported Halimeda and Thalassia testudinum seagrass beds remained intact during Hurricane Wilma, and only minor sediment deposition occurred on top of these grasses. Therefore, it can be deduced that the storm deposit was predominately derived of reworked beach and foredune sediment.

The sedimentological response found in this study contrasts to that of Kench (2011) who found storm deposits on sand cays and small islands in coral reef settings were related to the destruction of coral reefs. This was not the case for the barrier beaches in type $1 a$ and $b$ systems on the northeastern Yucatan Peninsula, and indicates that even under storm conditions these systems are largely disconnected from the coral reef. The primary barrier to sedimentological exchange appears to be the wide expanse of the backreef lagoon, much wider than those investigated by Kench (2011). This is further amplified by the inactive nature of backreef lagoon sediment, due to the stability provided by highly resistant seagrasses. Furthermore, the sedimentological response in this study is not considered a pulse, rather a reworking of existing in situ sediment, with minor reef and backreef lagoon sediment exchange (Figure 6-10). These results further support barrier beach accretion from beach and foredune reworking. 


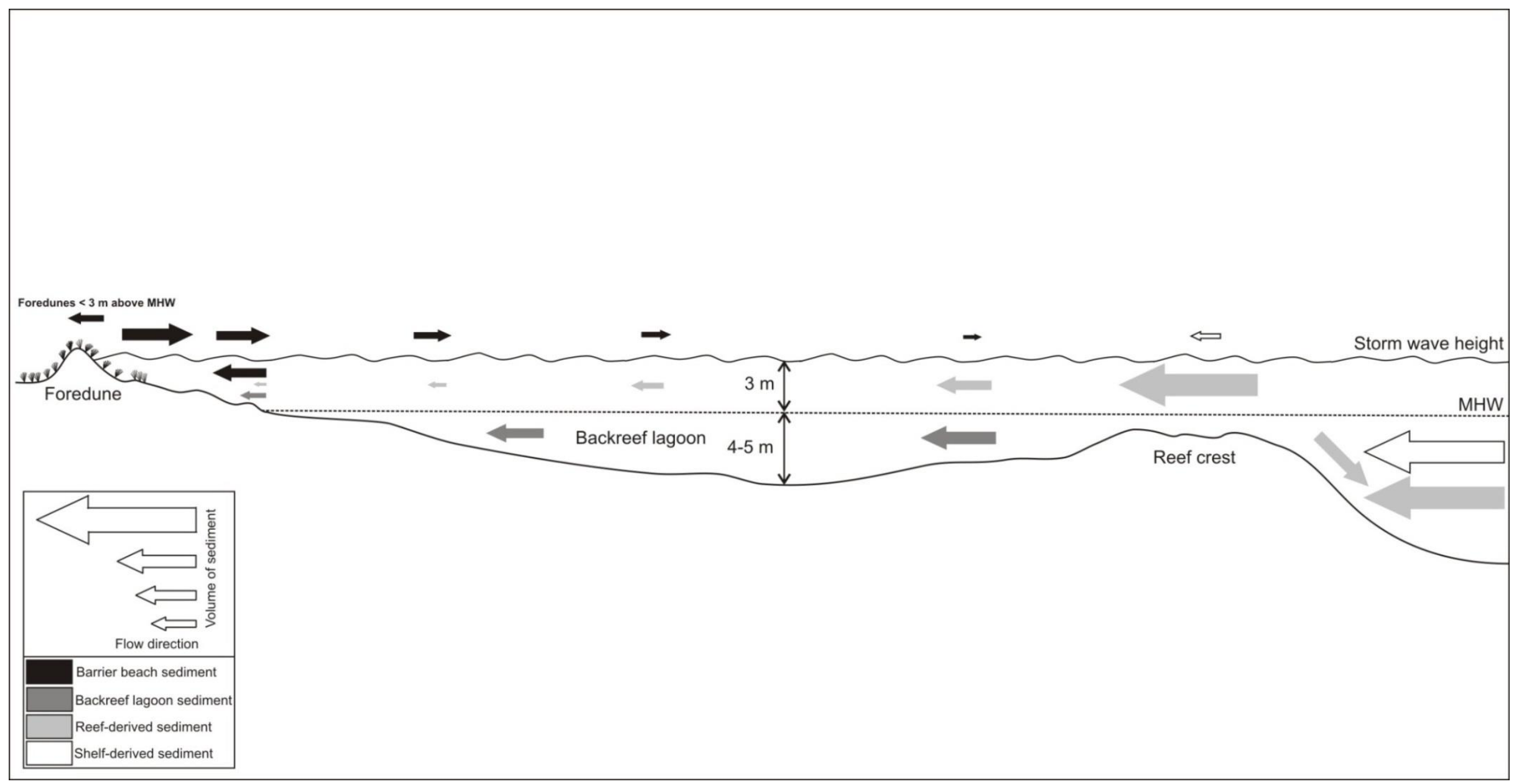

Figure 6-10: Conceptual diagram of the sedimentological response of type $1 \mathrm{a}$ and $\mathrm{b}$ barrier beach systems during Hurricane Wilma. Type $1 \mathrm{a}$ and $\mathrm{b}$ systems represent reef-protected Zones 1, 2 and 3. 


\subsubsection{Type 2: exposed and reflective barrier beach systems}

Following reworking by Hurricane Wilma, type 2 barrier beach systems were 20-27 m wide (as measured from the foredune crest to $\mathrm{MHW}$ ), with foredunes which rarely exceeded $3 \mathrm{~m}$ above MHW. These systems are exposed to significant wave heights $\left(H_{s}\right) \approx 0.3 \mathrm{~m}$ during the summer and $\mathrm{H}_{\mathrm{S}} \approx 0.8 \mathrm{~m}$ in the winter (Coronado et al., 2007). Unlike type $1 \mathrm{a}$ and $1 \mathrm{~b}$ systems, the continental shelf steepens offshore of these barriers, and the barriers are open to full sediment exchange with the Caribbean Sea (Figure 6-11).

Type 2 barrier systems underwent storm wave inundation over a longer period of time compared to reef-protected barrier beaches, due to their increased exposure. The beach and foredunes were reworked as they underwent stage 3: foredune concentrated reworking (see Section 2.5.1), and, in some locations stage 4: entire barrier reworking, as the low-lying barriers ( $<3 \mathrm{~m}$ above $\mathrm{MHW}$ ) were inundated and the shoreline eroded. Large volumes of sediment were washed over the foredune crest and into the backdune swale and mangrove wetlands (Figure 6-11), leaving the calcarenite platform, on which the barrier beach was formed, completely exposed in some areas. Material was also deposited on the upper shoreface and into subaqueous sand bars (Figure 6-11). Some of the sediment was lost alongshore, transported north by infragravity waves and south by gravity waves. Sediment was also transported onshore from the continental shelf, represented by fresh Halimeda present in the storm deposits. This shoreline eroded by $5.0 \pm 3.6 \mathrm{~m}$ on average, representing a proportional beach width loss of over $17 \%$. These responses were comparable with the typical storm responses reported by Sallenger (2000) and Morton and Sallenger (2003).

In the later stages of the storm, when Hurricane Wilma had tracked further north, the direction of wind forcing changed, generating waves from the northeast (Figure 3-12a). Coral was removed from patch reefs in the northeast and transported on to the barrier beaches. This is represented by fresh coral content in the storm deposit. In addition, some narrow south facing barrier beaches in Zone 5: Punta Brava South underwent considerable shoreline accretion during this late stage as low-pressure, offshore winds, and high rainfall combined to raise water levels in the mangrove wetlands and result in an ebb flow. During this stage, a considerable proportion of sediment was washed across the beach and deposited on the upper shoreface. This is similar to storm responses reported by Priestas and Fagherazzi (2010).

Type 2 barrier beaches underwent considerable, but variable, profile changes: at the northern end of Zone 4: Punta Brava, a large sand bar was formed. However, bars were less prominent further south, perhaps due to a slight steepening of the shelf slope, and represented by more reflective beach morphologies. In addition, the post-storm barrier beach profile reflected a concave-upward shape, with an abrupt back beach depression. This is indicative of beach scour, and is similar to the findings of many other studies (Perkins and Enos, 1968; Morton and Paine, 1985; Phillips, 1999; Morton and Sallenger, 2003). The foredune was eroded, but maintained some structure, as it was well vegetated (Morton, 2002). 

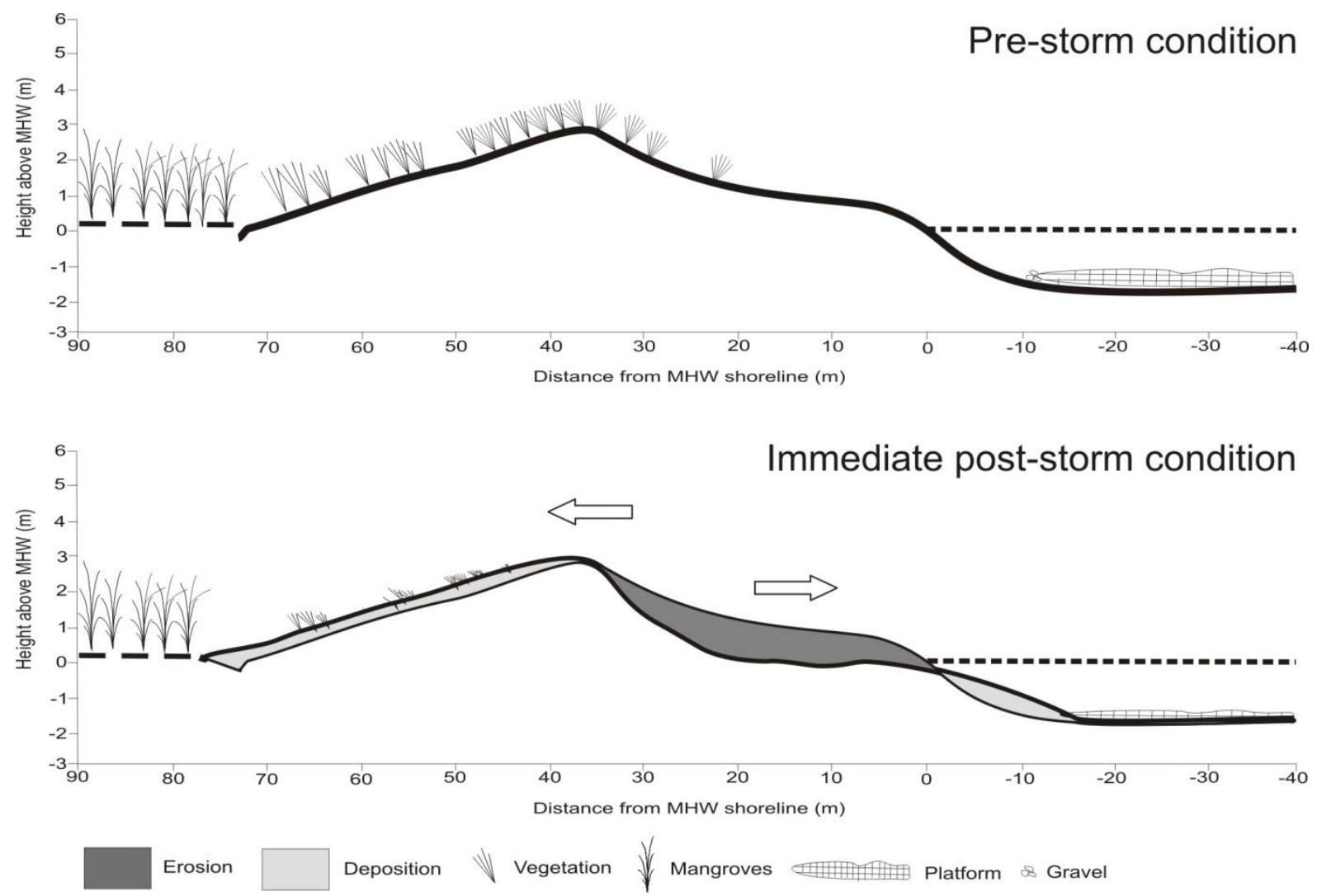

Figure 6-11: Model of the geomorphology of type 2: exposed and reflective barrier beaches pre and post-Hurricane Wilma.

\subsubsection{Type 2 sedimentological storm response}

Type 2 barrier beaches were found to be connected systems under storm conditions, with open sediment exchange between the continental shelf and barrier beach. The textural character of type 2 beaches is therefore representative of mixed sources: highly abraded Halimeda represents in situ reworked beach and foredune material, further supported by constituent micritisation (Figure 6-12). Fresh coral, coralline algae and mollusc constituents, sourced from the continental shelf and nearby reefs, are representative of onshore sediment transport during Hurricane Wilma (Figure 6-12). These results show that storm destruction of coral reefs can provide an influx of sediment to soft-carbonate coastlines, as found by Kench (2011), despite an overall pattern of erosion. This is in clear contrast to the disconnected reef-protected systems, which, despite accreting, do not do so as a result of reef-derived sediment flux, as might have been expected. 


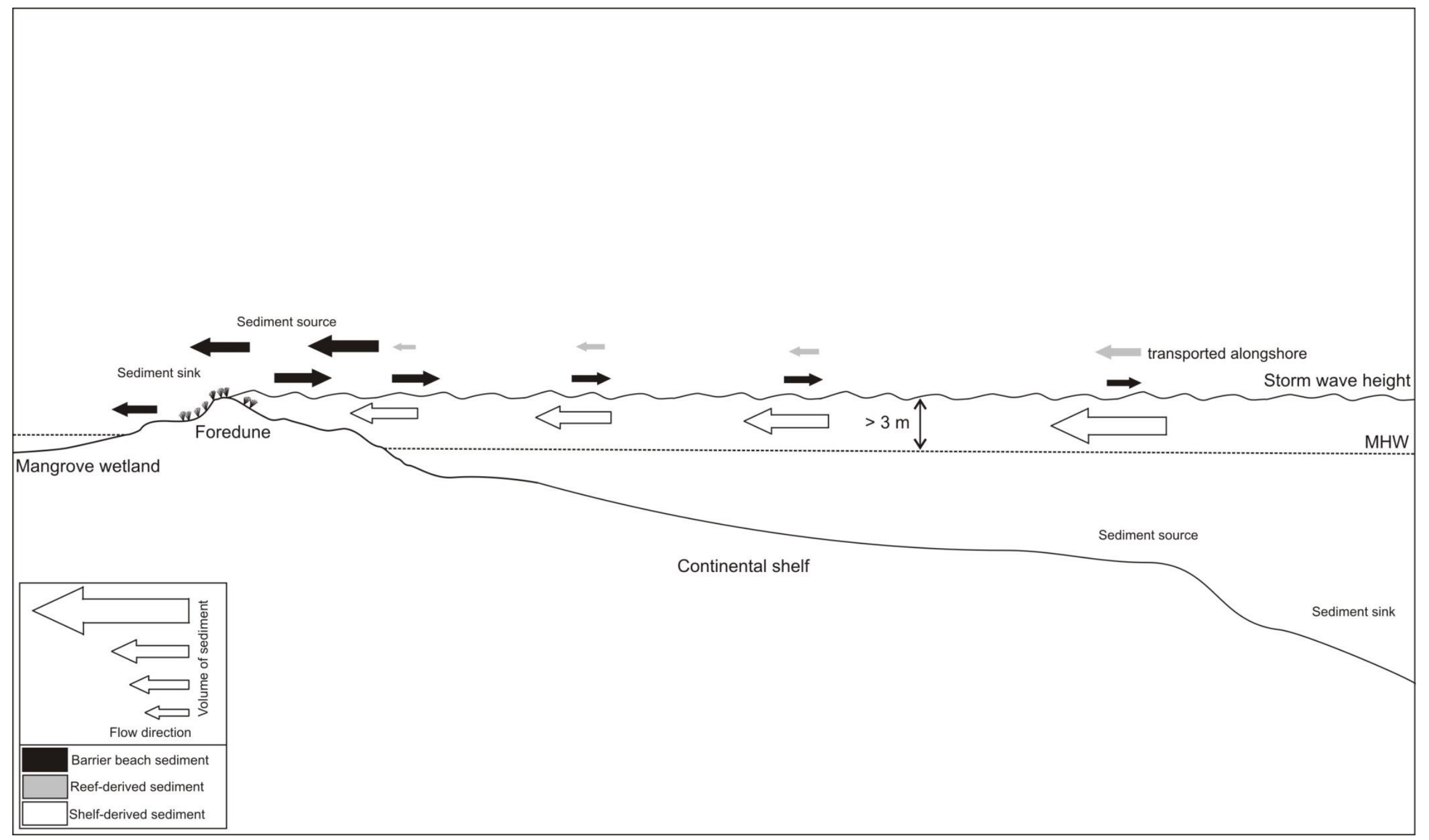

Figure 6-12: Conceptual diagram of the sedimentological response of type 2 barrier beach systems during Hurricane Wilma. Type 2 systems represent exposed Zones 4,5 and 6 . 


\subsection{Post-storm geomorphic responses of barrier beaches}

Barrier beaches tend to recover towards their pre-storm conditions following tropical storms and hurricanes. In general, eroded sediment migrates back onshore during lowerwave energy conditions as material is deposited onto the back beach and into the foredune (Morton et al., 1994; McLean and Shen, 2006; Houser and Hamilton, 2009). Beach response does however tend to vary alongshore, with some sites experiencing rapid recovery, others seeing little change and other sites continuing to erode (Morton et al., 1994; Lee et al., 1998). Furthermore, the post-storm beach response may be influenced by several factors, including: the scale of geomorphic change, subsequent storm incidence, the time of year, availability and mobility of sediment, sea level trend, and anthropogenic changes (Morton et al., 1994; Lee et al., 1998).

During the recovery phase of this study, the wave energy regime of northeastern Yucatan Peninsula was characterised by relatively low energy conditions (Figure 6-13). At times, these conditions were interrupted by intermittent high-energy events, with the passage of cold fronts (locally referred to as 'Nortes'), tropical storms and hurricanes (refer to Table 33). However, none of these weather systems were considered geomorphically significant (Blanchon, pers comms). 

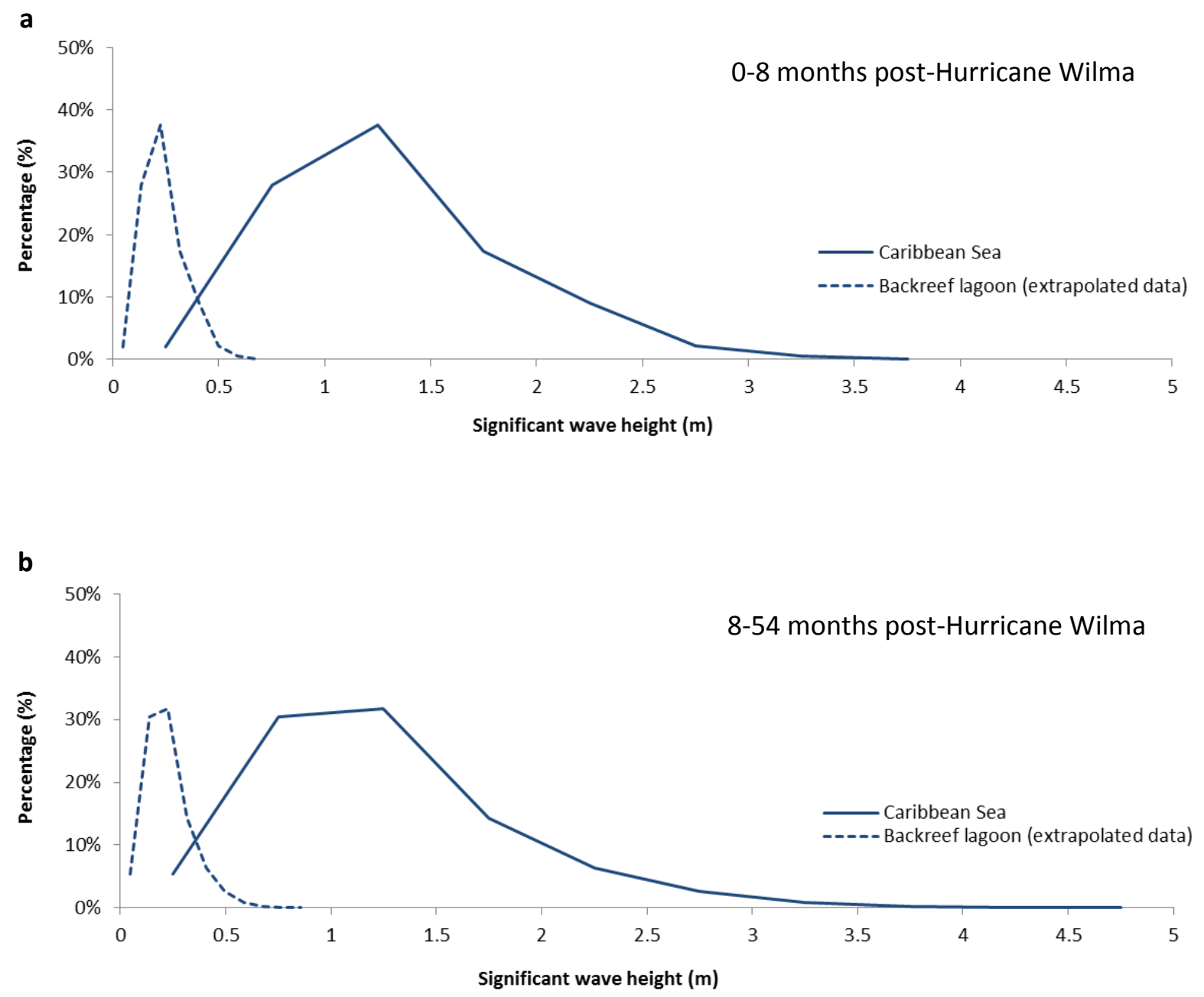

Figure 6-13: Mean significant wave height over the period (a) November 2005 to May 2006, and (b) June 2006 to March 2010. Data derived from Buoy 42046, National Data Buoy Centre National Oceanic and Atmospheric Administration, situated $\approx 241 \mathrm{~km}$ ESE of Puerto Morelos. Therefore this data only provides an indication of wave height at the shoreline.

Post-storm beach recovery in the months to years following Hurricane Wilma involved shoreline movement, geomorphic maturing, and sedimentological alignment. These responses, however, were found to be highly variable alongshore and influenced by a multitude of factors. The following sections discuss these responses, the geomorphic drivers and the controls on post-storm barrier recovery. A conceptual beach model for each beach type, as identified in Section 6.1, is then presented. These responses have again been separated into those on reef-protected and exposed coastlines, due to the contrasting impacts following Hurricane Wilma, as detailed in Section 6.1. Additionally, grain size shows a clear distinction between reef-protected and exposed barrier beaches under the prevailing post-storm conditions (Figure 6-14). 


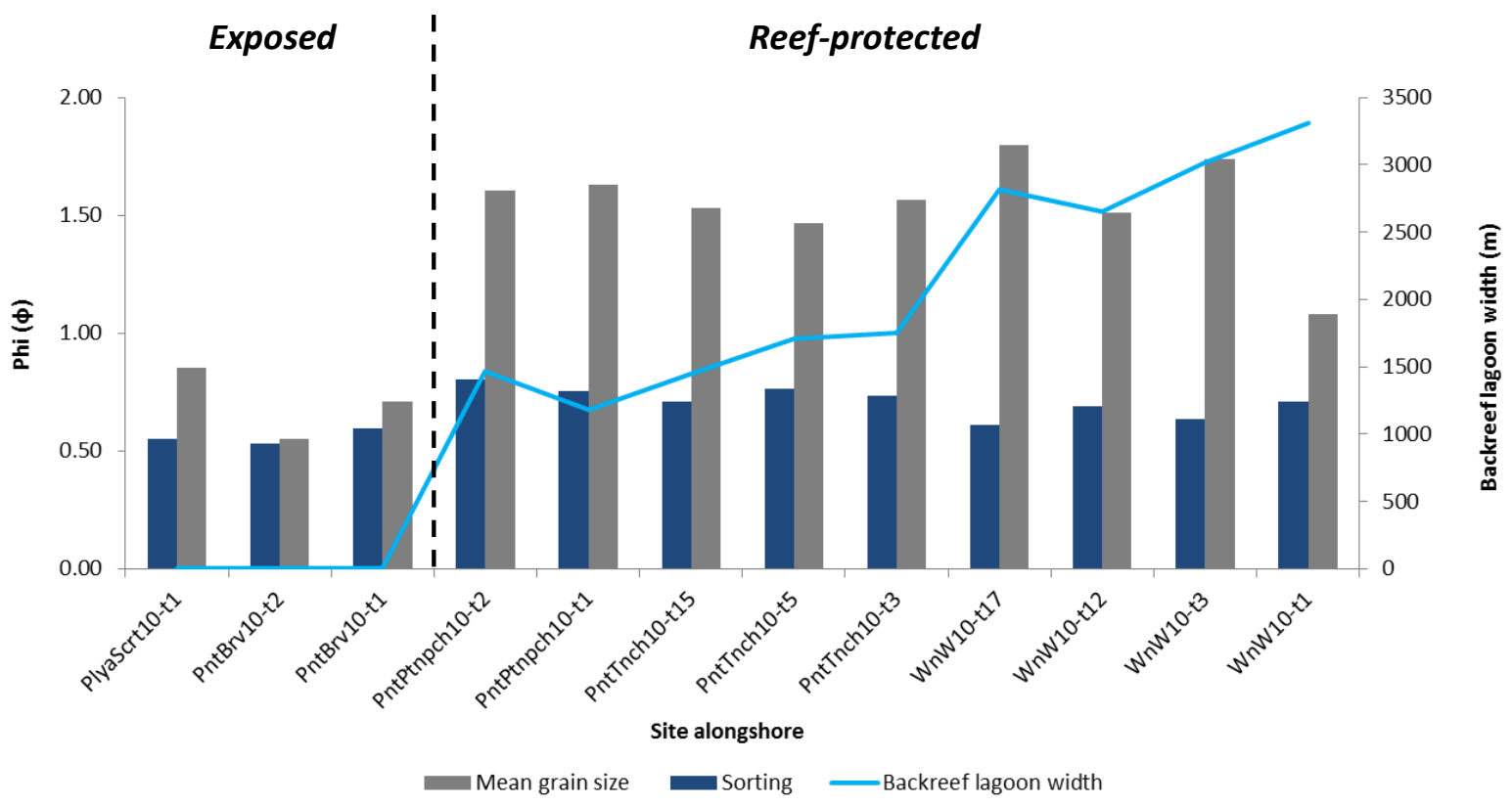

Figure 6-14: Textural character of barrier beach systems of northeastern Yucatan Peninsula as defined by the mean grain size, sorting, and wave exposure (backreef lagoon width) April-June 2010.

\subsubsection{Short-term shoreline response ( 8 months post-storm)}

The post-storm shoreline response was highly variable alongshore, with reef-protected barrier beaches, which had previously accreted, reverting to an erosional phase as the beaches readjusted landward. In 2006, shoreline movement varied from erosion of $9.7 \mathrm{~m}$, recorded at the southern end of Zone 2: Punta Tanchacte (PntTnch-t12) (this site had previously undergone the greatest beach accretion), to accretion of $2.7 \mathrm{~m}$ (PntTnch-t4). Erosion, however, was the more common response, with accretion only recorded at two of the 31 reef-protected sites measured (Figures 5-4 and 5-11). These results illustrate the tendency of the shoreline to readjust rapidly, even under low-energy conditions, and are comparable with the results of Houser and Hamilton (2009). On average, approximately a quarter $(24 \%)$ of the accreted shoreline eroded within the initial eight months. Due to the low wave energy translating across the lagoon during this period, fetch-limited waves generated within the backreef lagoon are also likely to have been drivers of this erosion. Despite the low-energy conditions, the shoreline saw considerable change due to the most easily worked beaches features being realigned (such as the sand bars) with wave swash. The shoreline response, however, was highly variable alongshore, with proportional losses amounting as much as 54\%; the factors influencing this response will be discussed further in Section 6.2.4.

Unprotected barrier beaches underwent episodes of accretion (up to $18.5 \mathrm{~m}$, PntBrvSth-t1) and erosion (up to $9.4 \mathrm{~m}$, PntBrvSth-t6) during the post-storm recovery phase. The shorelines along Zones 4 and 6 , and south-facing beaches of Zone 5, had largely recovered to the pre-storm shoreline position by 2006 , with the beach at some sites even wider than the pre-storm width (PntBrv-t1 and 3 and PntBrvSth-t1 and 2). Erosion occurred along most 
southeast facing beaches of Zone 5 (Figures 5-31). These responses may represent differences in sediment movement alongshore during the prevailing conditions, with those in Zones 4 and 6 open to slightly higher wave energy than Zone 5, which is more sheltered by a relatively shallow-lying platform and patch reef (Figure 5-30); these features are likely to reduce energy and wave swash on the coastline. Due to reduced wave energy, finer sediment may have been entrained across the platform, and any available material was likely pushed north by the prevailing Yucatan Current and deposited on the south-facing beaches at the northern end of the zone.

\subsubsection{Medium-term shoreline response}

Medium-term (8-54 months) shoreline response was typically characterised by a continuation of the short-term trend along reef-protected barrier beaches (Figure 6-15). After 54 months the greatest shoreline erosion was recorded in Zone 2: Punta Tanchacte (PntTnch-t12); $17.9 \mathrm{~m}$ had been lost since 2006, and a total of $27.6 \mathrm{~m}$ since the storm. This erosion amounted to more than the hurricane-driven shoreline accretion. A similar response occurred along many other reef-protected barrier beach sites, indicating the shoreline had largely recovered over the medium-term. This is similar to the results of Morton et al. (1994), and will be discussed further in Section 6.3. This was not the case for all sites however, with others undergoing considerably less post-storm readjustment (Figure 6-15); one site, WnW-t14, experienced a small amount of accretion since Hurricane Wilma (Figure 6-15). These results further support the findings of Morton et al. (1994) and others, in that post-storm 'recovery' is highly variable and dependant on many factors, of which many remain unknown.

Exposed barrier beaches which had accreted and eroded over the initial eight months following Hurricane Wilma almost all experienced erosion during the medium-term; the shoreline eroded on average $4.6 \mathrm{~m}$ along Zones 4-6, with PntBrv-t2 the only site experiencing accretion (Figures 5-24, 5-31, and 5-34). PntBrvSth-t1, which had previously accreted $18.5 \mathrm{~m}$ in the short-term, underwent $10.6 \mathrm{~m}$ of erosion, similar to the reefprotected sites which had transitioned to an erosive phase. This may have been the result of both higher wave energy events, and the occasional reversal of the alongshore current with the passage of 'Nortes'. Overall results indicate exposed barrier beach width shifts regularly with changes in wave energy.

These results show that the post-storm shoreline response is highly variable both spatially and temporally; in some instances the beaches return to their pre-storm positions, though at varying rates. In other instances, longer-term processes, such as a deficit in the sediment budget, may have a greater influence on shoreline response. 


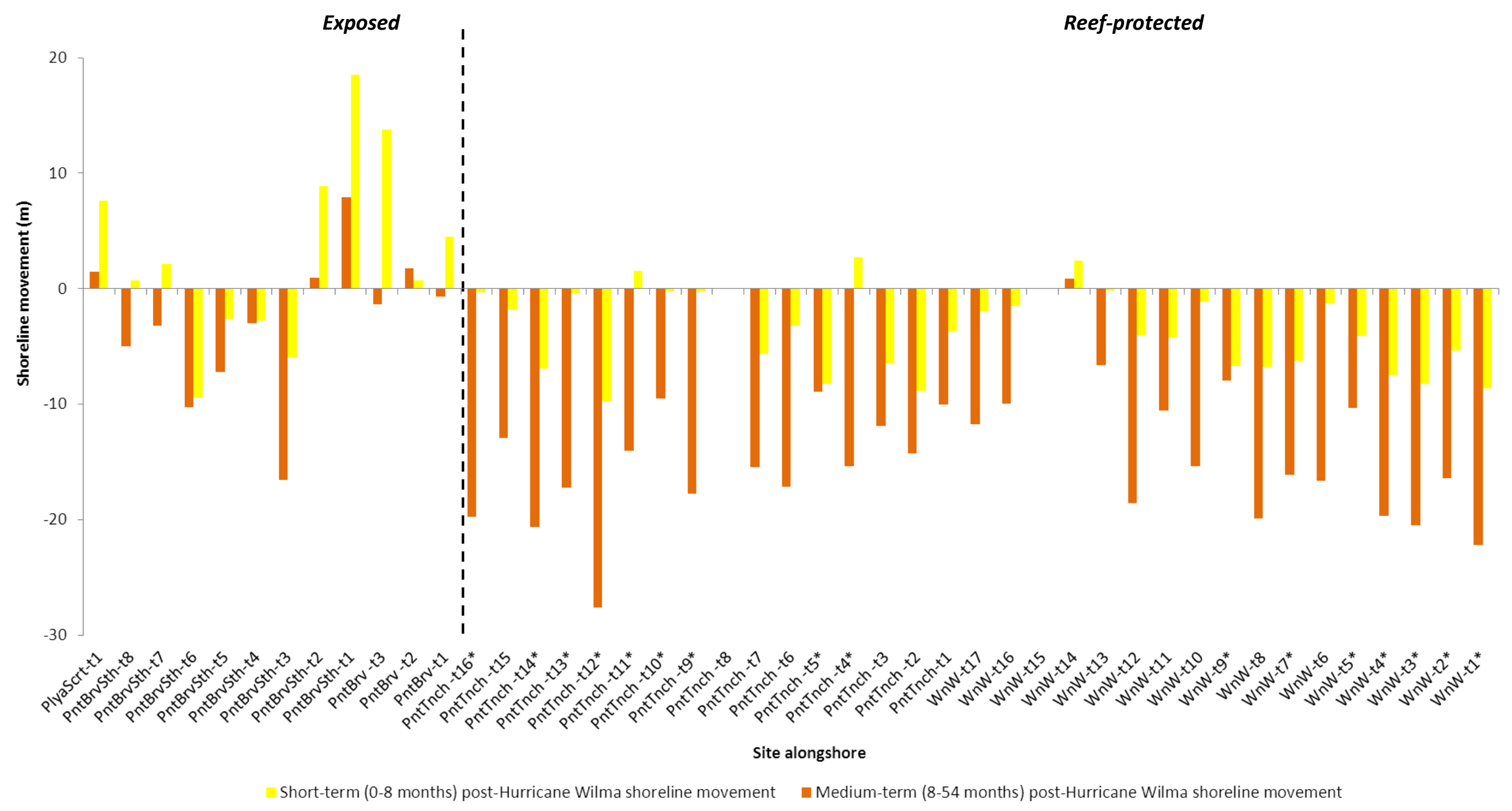

Figure 6-15: Graphical display of the post-storm shoreline movement. The most distinct differences can be seen between reef-protected barrier beaches which typically eroded and exposed barrier beaches which showed varied responses. 


\subsubsection{Geomorphic response}

Post-storm geomorphic responses were represented by subaerial accumulations of sediment in all areas alongshore, regardless of the shoreline being in an erosion or accretion phase. In general, sediment was built up in the back beach as material was washed up the beach face and transported up the beach by saltation. The foredune was also developed and became increasingly vegetated, starting in the backdune and moving seaward. Back beach vegetation growth followed, and promoted sediment accumulation and the development of embryo and incipient dunes at some sites (see Section 6.2.4). At the same time, the acrossshore profile transformed from an erosional concave-up shape, similar to those described by Morton et al. (1994) and Lee et al. (1998), to an accretional convex shape. These changes, however, occurred gradually throughout the post-storm recovery period, and at a much slower rate than shoreline movement. These changes are important indicators of post-storm beach recovery, as the shoreline may reach its pre-storm position in the short to medium-term, which some might classify as recovered; however considerable time is still required for the subaerial sediment stores to be fully restored. 


\subsubsection{Factors influencing post-storm response: reef-protected barriers}

The presence of a coral reef and backreef lagoon has already been shown to influence geomorphic response to storms. Under prevailing conditions, the effect of the reef on sediment entrainment can be estimated by calculating the reef energy window index $(\Psi)$. This statistic was proposed by Kench and Brander (2006) to indicate the extent of wave dissipation in a backreef lagoon, and was earlier described in Section 2.3.7. Wide, shallow lagoons are represented by low values of $\Psi$, where wave energy is dissipated such that there is little sediment movement from the reef crest, across the backreef lagoon to the barrier beach. For the beaches in this study, under prevailing conditions all values of $\Psi$ were very low (Table 6-1), indicating limited sediment movement was likely across the backreef lagoon. This supports the finding that post-storm beach recovery predominately involved in situ beach sediment redistribution.

Table 6-1: Reef energy window index $(\Psi)$ values for (sediment) sampled sites. Where values $<0.01$ the backreef lagoon is regarded as being effective at dissipating wave energy and considered geomorphically inert under normal conditions; values $>0.05$ are regarded geomorphically active systems.

\begin{tabular}{|c|c|c|c|c|c|c|c|c|c|}
\hline Site & $\begin{array}{l}\text { F } \\
0 \\
0 \\
3 \\
\vdots \\
3\end{array}$ & $\begin{array}{l}\stackrel{m}{+} \\
0 \\
\sum_{1}^{1} \\
\vdots \\
3\end{array}$ & \begin{tabular}{l} 
I \\
\multirow{1}{1}{} \\
0 \\
3 \\
3 \\
3
\end{tabular} & 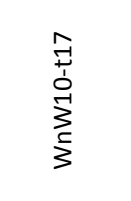 & 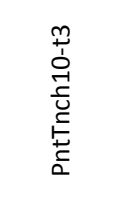 & 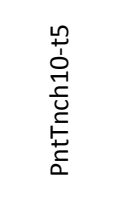 & 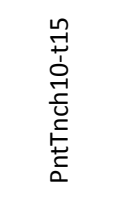 & 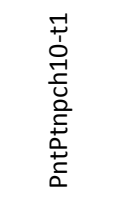 & 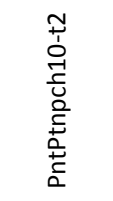 \\
\hline $\begin{array}{r}\text { Backreef lagoon } \\
\text { depth at MHWS }(m)\end{array}$ & 4 & 4 & 4 & 4.5 & 4 & 4 & 4 & 5 & 5 \\
\hline $\begin{array}{r}\text { Backreef lagoon } \\
\text { width }(\mathrm{m})\end{array}$ & 3310 & 3020 & 2650 & 2820 & 1750 & 1710 & 1450 & 1180 & 1470 \\
\hline $\begin{array}{r}\text { Reef energy window } \\
\text { index ( } \Psi)\end{array}$ & 0.001208 & 0.001325 & 0.001509 & 0.001698 & 0.002286 & 0.002339 & 0.002759 & 0.004237 & 0.003401 \\
\hline
\end{tabular}

The responses of reef-protected barrier beaches varied substantially alongshore. The main differences included: the extent of post-storm shoreline erosion, pattern of subaerial development, and degree of readjustment to the pre-storm beach profile. Each of these responses is discussed in detail below. Many differences were observed between the two different reef-protected beach types: reflective beaches with subaqueous sand bars, and dissipative beaches (Figure 6-16). These beach types differ as described in Section 6.1. 


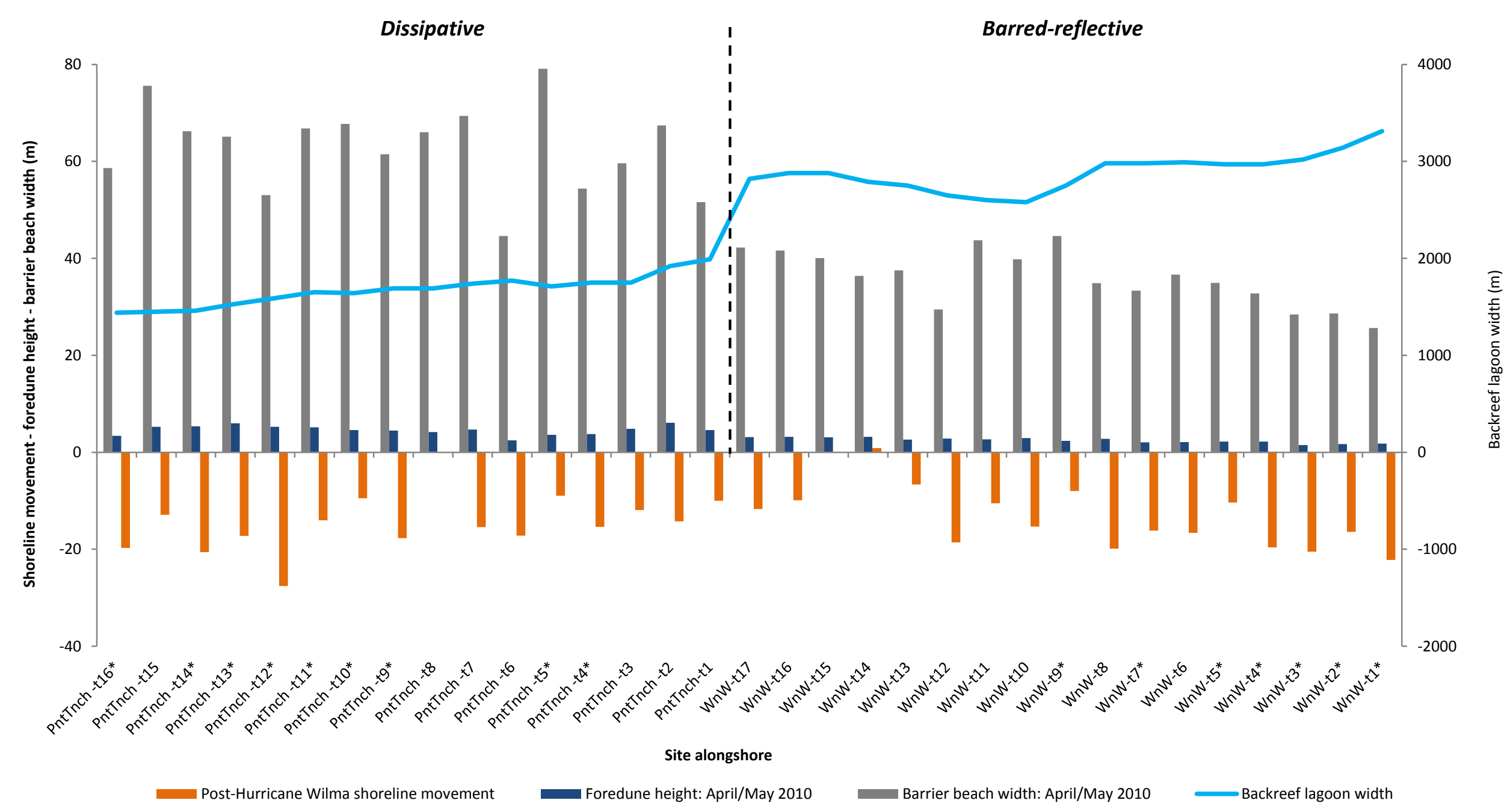

Figure 6-16: Graphical display of the shoreline movement post-Hurricane Wilma, and the correlation to foredune height, barrier beach width, and backreef lagoon width. 


\section{Shoreline readjustment factor}

Barrier beach shoreline response over the 54-56 months following Hurricane Wilma showed variance amongst both of the reef-protected barrier types (see Sections 5.2 and 5.3). However, in general, areas which experienced the greatest storm accretion were found to undergo the greatest post-storm erosion $\left(r^{2}=0.48\right.$, Figure $\left.6-17\right)$. This indicates that beaches which undergo the most accretion during a storm subsequently become the most unstable, and therefore experience the largest and most rapid changes in returning to their pre-storm position. These changes are proportionally similar alongshore, and can be conceptualised as a beach equilibrium system operating under a 'cut and fill' storm response regime, similar to that described by Thom and Hall (1991).

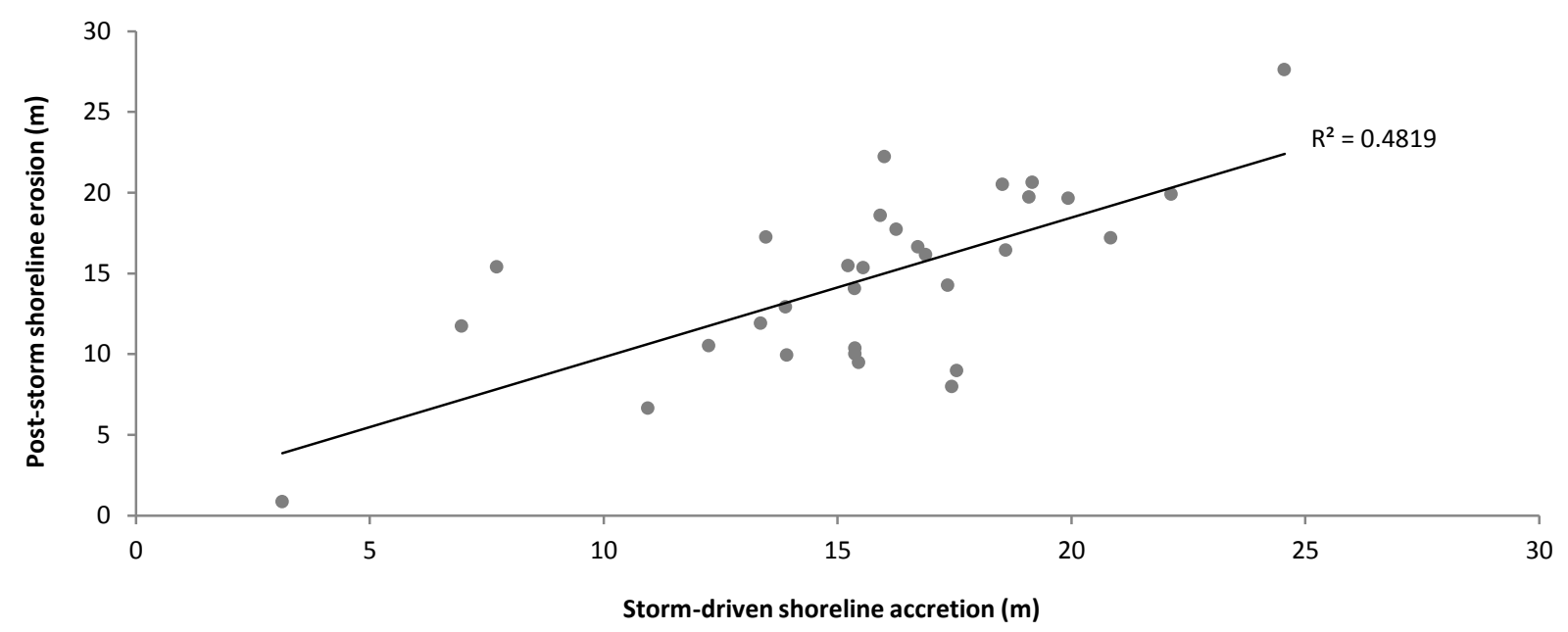

Figure 6-17: Moderate relationship $\left(r^{2}=0.48\right)$ between the storm-driven shoreline accretion and the post-storm shoreline erosion on reef-protected barrier beach systems.

\section{Backreef lagoon width}

The width of the backreef lagoon appears to play a role in determining the equilibrium shoreline position and beach profile of reef-protected barrier beaches. In April-June 2010, 54-56 months after Hurricane Wilma, and at a time when the barrier beaches were nearing their pre-storm shoreline position, the width of the barrier beach was negatively correlated with the width of the backreef lagoon; there was a moderate relationship $\left(r^{2}=0.46\right.$, Figure $6-18)$ on barred-reflective beaches, and a very weak relationship $\left(r^{2}=0.09\right.$, Figure 6-18) for dissipative beaches. Therefore, as the width of the backreef lagoon increased, the width of the barrier beach typically decreased. These results indicate that the equilibrium shoreline position and barrier beach morphology is correlated to the wave environment, with wider barrier beaches exposed to greater wave energy during the passage of storms. As such, they establish a wider and flatter profile compared to steeper and narrower profiles of lower energy beaches.

Reef-protected barrier beaches plot in two distinct groups: $>2500 \mathrm{~m}$ and $<2000 \mathrm{~m}$ (Figure 618) due to a lack of intermediary data. Barred-reflective barrier beaches were closely 
aligned to the linear regression line, showing a moderate relationship between barrier beach width and backreef lagoon width. Dissipative barrier beaches showed greater spread (Figure 6-18), representing the increased influence of other factors in determining beach width, as wave energy increased. Therefore, the backreef lagoon width appears to have more significance to barrier beach width when it exceeds approximately $2500 \mathrm{~m}$.

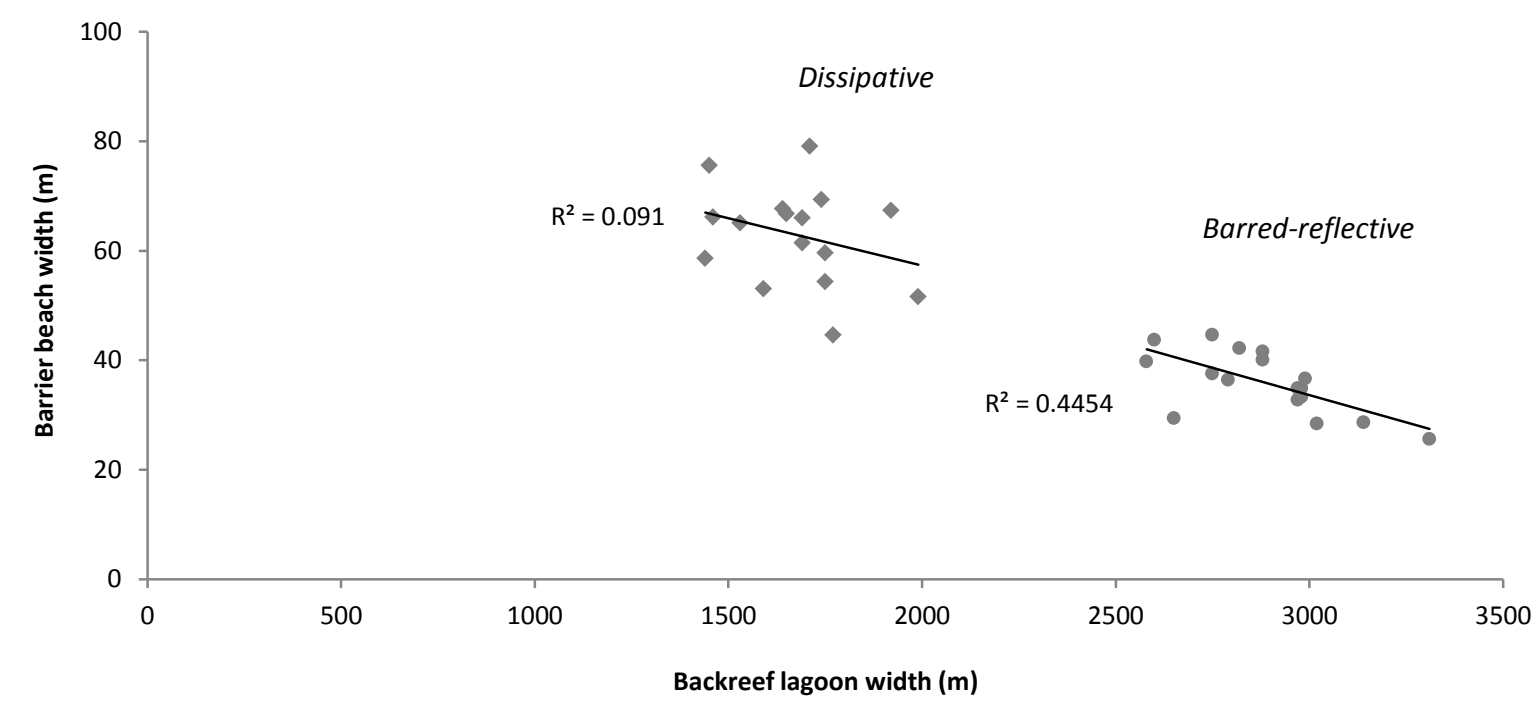

Figure 6-18: Moderate relationship $\left(r^{2}=0.46\right)$ between backreef lagoon width and barrier beach width on barred-reflective barrier beach systems. A weak relationship $\left(r^{2}=0.09\right)$ is seen on dissipative barrier beach systems.

\section{Biological controls}

Biological controls also appear to have some influence on the shoreline response of barrier beaches. Syringodium filiforme seagrasses, derived from the backreef lagoon, are typically deposited on the beachface and back beach by waves and tides, forming between one and three debris lines. However, a site at the southern end of Zone 1: Wet ' $n$ ' Wild, WnW-t14 (Figure 6-19a and b) received considerably greater volumes of seagrass, measuring $0.22 \mathrm{~m}$ thick on the beachface and also covering the shoreface. The seagrass may be deposited in this location due to backreef lagoon circulation patterns, driven by tides and determined by the location of reef inlets; Coronado et al. (2007) found them to have pronounced patterns in Puerto Morelos (Figure 3-8). Site assessment in the field and by use of satellite imagery at three times since Hurricane Wilma (June 2006, June 2009, April 2010) indicates that this seagrass may have remained in situ during much of the post-storm period. The seagrass at this site appears to protect the beach from wave energy and limit sediment mobilisation. Storm-driven barrier beach accretion at WnW-t14 totalled $3.1 \mathrm{~m}$, compared with an average of over $15 \mathrm{~m}$ for other reef-protected beaches; conversely the barrier underwent $0.84 \mathrm{~m}$ of post-storm accretion compared with erosion of over $13 \mathrm{~m}$ in other areas. These results indicate the beach has largely remained stable throughout the storm and post-storm period. 


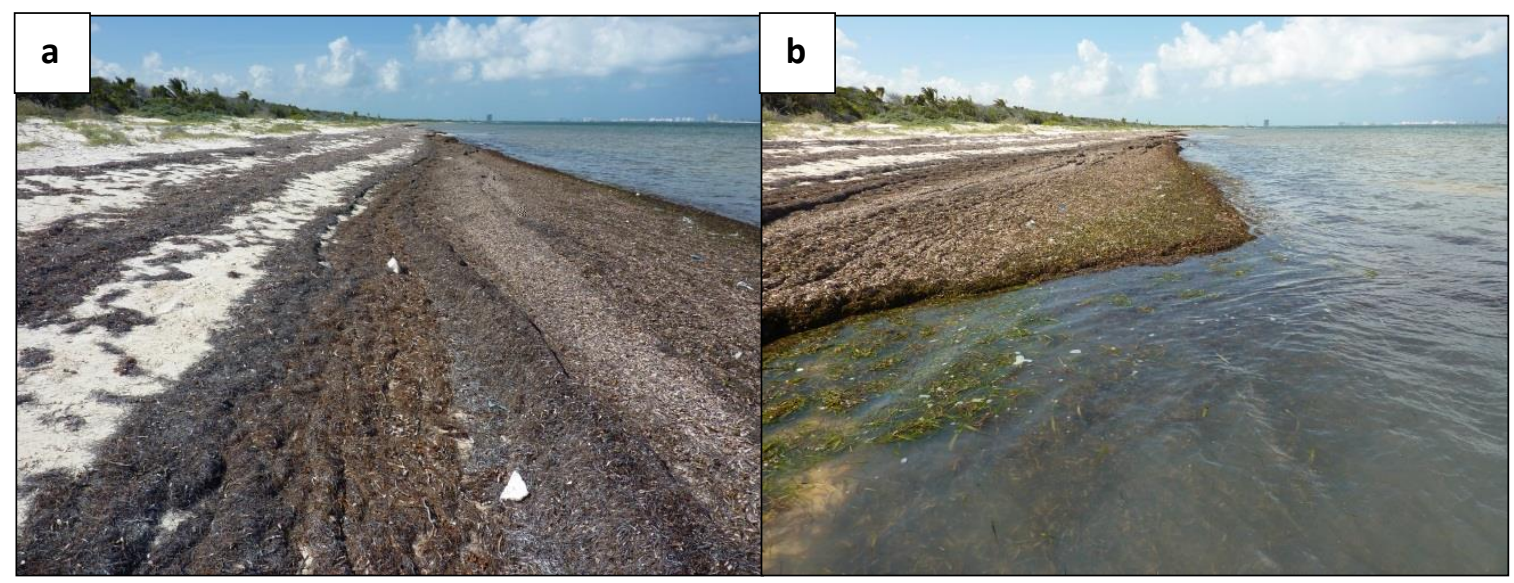

Figure 6-19: (a/b) Thick deposits of Syringodium filiforme seagrasses on the beachface and shoreface at WnW-t14, April 2010.

\section{Critical beach width}

The development of subaerial beach features in the post-storm recovery period was most evident in areas where there was a large width of 'dry' beach (landward of the berm crest), and where vegetation had rapidly re-colonised the foredune and back beach. On barredreflective reef-protected barriers, back beach and foredune aggradation predominated; the beach was typically well vegetated and the profile reflected a convex shape, with incipient dune growth at the base of the foredune. Embryo dune growth (Figure 6-20) also occurred in the back beach of one barred-reflective site (Figure 6-21). This site (WnW-t11) had a dry beach width of $44 \mathrm{~m}$ in June 2006 and $35.2 \mathrm{~m}$ in April 2010, and represents the second widest measured beach during the latter period. This width is likely to reflect a theoretical critical beach width threshold for embryo dune formation. On these beach types narrow 'dry' beach widths appeared to be a limiting factor for the development of such features. Regular wave inundation is a limiting factor for sediment accumulation and dune growth, as are sediment availability and vegetation.

Dissipative barriers underwent considerably less beach aggradation, and vegetation distribution was patchy across-shore and alongshore. On these barriers the dry beach was considerably wider, but also of lower elevation, than barred-reflective barriers. As such, waves typically inundated further inland. Embryo dune development (Figure 6-20) was found to be limited to beaches wider than $58 \mathrm{~m}$ in June 2006, and $39.8 \mathrm{~m}$ in May 2010 (Figure 6-21), which may represent critical thresholds. However, not all barriers exceeding this threshold developed embryo dunes (Figure 6-21); such sites tended to lack substantial vegetation, highlighting the significance of these plants in accumulating and stabilising sediment, and aiding subaerial beach development. 


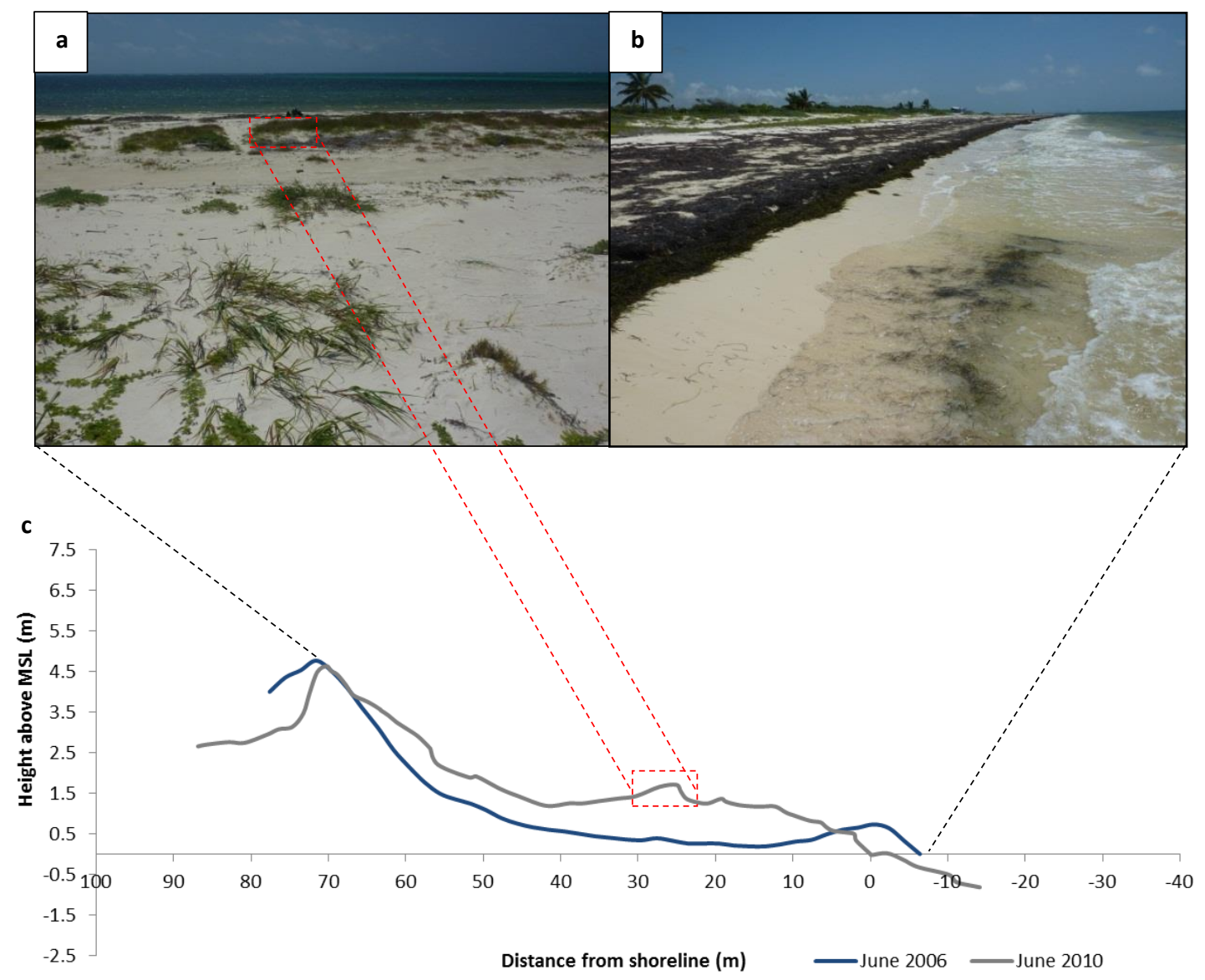

Figure 6-20: Embryo dune (dashed red box) which developed at PntTnch-t7 between June 2006 and May 2010. (a/b) Images of the site in May 2010 and (c) across-shore beach profile showing subaerial development and dune formation between June 2006 and May 2010. 


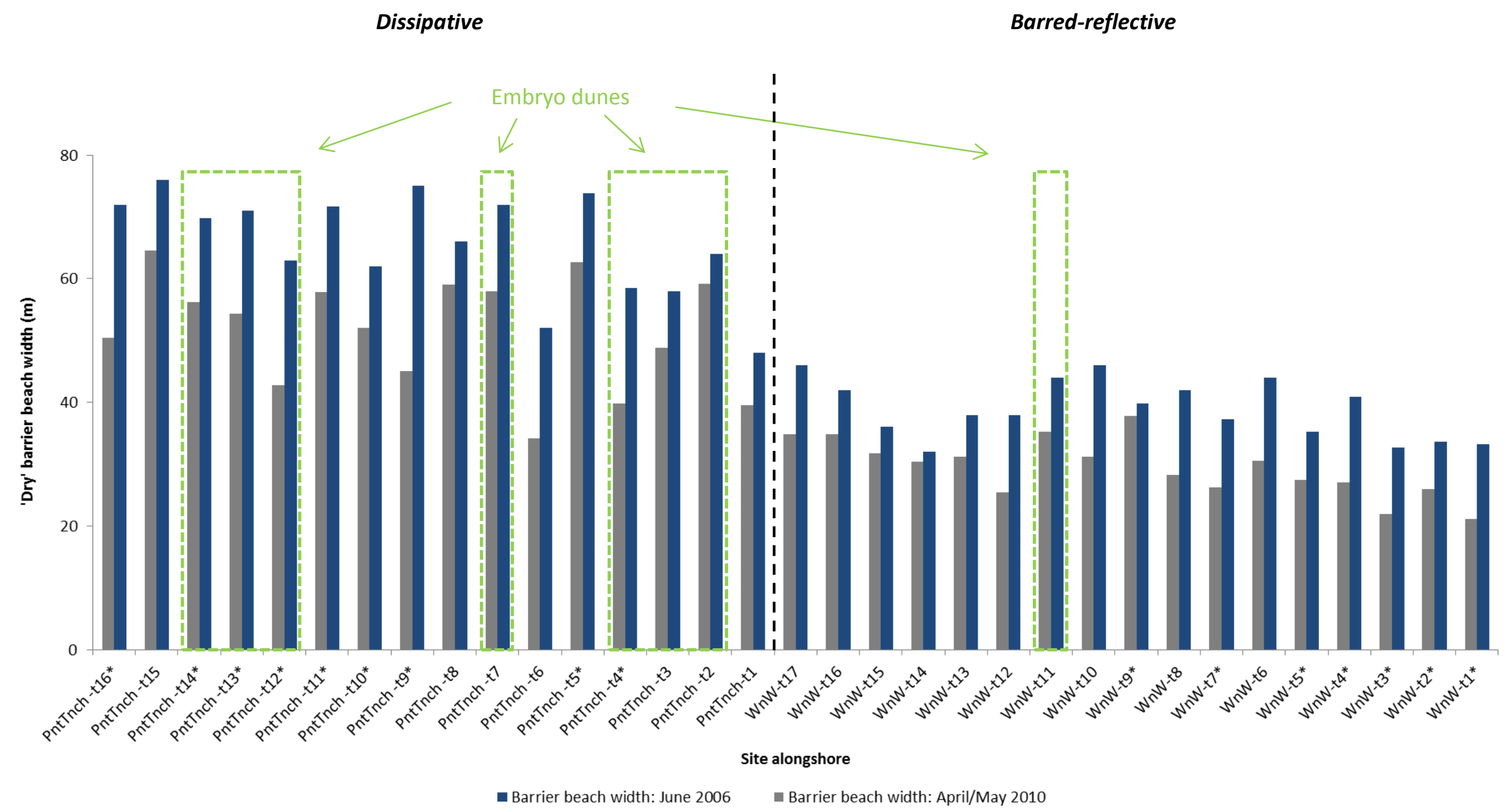

Figure 6-21: 'Dry' (landward of berm crest) beach widths of reef-protected barrier beaches in June 2006 and April/May 2010, and their relationship with embryo dune development (outlined and arrowed). 


\subsubsection{Factors influencing post-storm response: exposed barriers}

Barrier beaches open to the Caribbean Sea were exposed to considerably higher energy than reef-protected barrier beaches, and had greater sediment mobility; this is reflected by the faster rate at which these beaches tended to respond following Hurricane Wilma. However, as with reef-protected beaches, these changes were highly variable alongshore, as was the beach morphology (Figure 6-22).

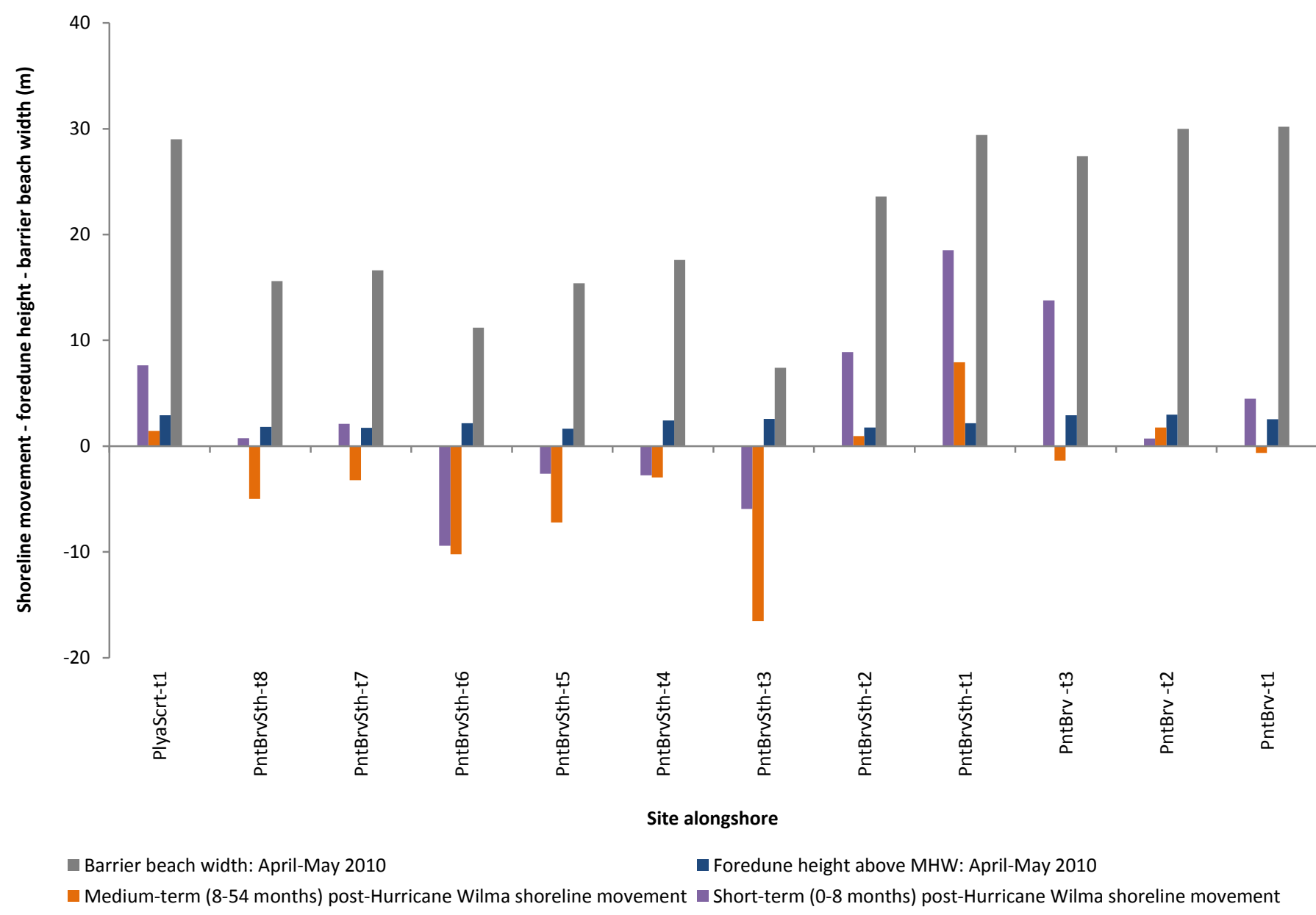

Figure 6-22: Graphical display of the shoreline movement post-Hurricane Wilma, and the relationship to foredune height and barrier beach width.

Similar to reef-protected beaches, the extent of shoreline response or 'recovery' had some correlation with the extent of storm-driven change. However, in unprotected areas this relationship was only apparent on those beaches which underwent post-storm accretion (Figure 6-23). This return towards the pre-storm position occurred over the short-term (0-8 months), with the beaches reverting towards erosion over the longer-term. This indicates these sites tend to return to an equilibrium position, though at a much faster rate than reefprotected sites. This is perhaps the result of a higher energy environment and subsequently greater sediment entrainment, and therefore more rapid post-storm sediment redistribution. 


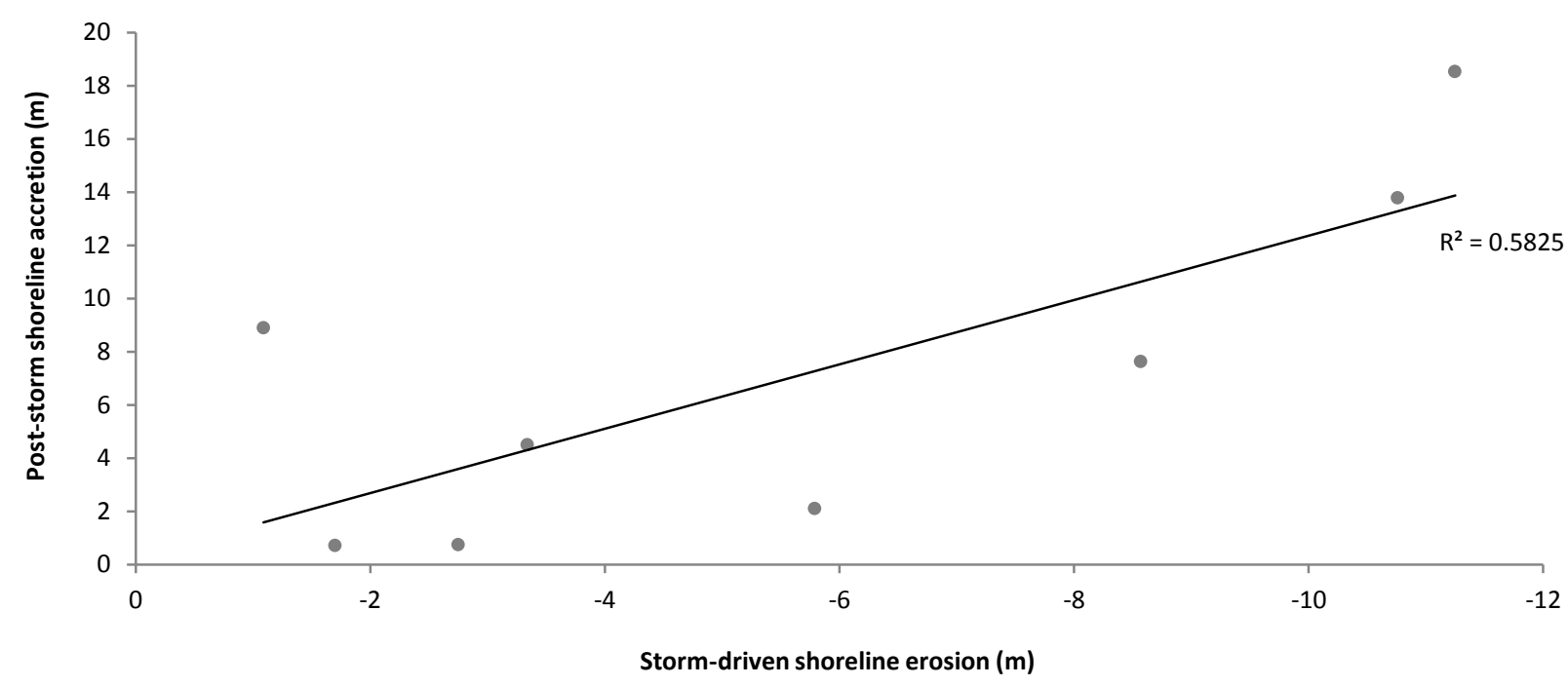

Figure 6-23: Moderate relationship $\left(r^{2}=0.58\right)$ between the storm-driven shoreline erosion and the post-storm shoreline accretion on exposed barrier beach systems, which underwent accretion (Zones 4, 6 and south facing beaches of Zone 5).

Not all exposed sites accreted following Hurricane Wilma, with sites in the centre of Zone 5 experiencing continued erosion (Figure 6-22). Beaches along Zones 4 and 6 were exposed to higher wave energy than those in Zone 5 during the first eight months following Hurricane Wilma; Zone 5 was partially sheltered by a platform, patch reef and shallower shelf slope. This period was characterised by low-energy conditions (Figure 6-13a), therefore the wave dissipation provided by these features may have reduced sediment mobility. As such, the rate of shoreline readjustment was reduced, with the energy too low to transport shoreface and shelf sediment onshore. In contrast, the south facing beaches of this zone tended to accrete. This may have been as a result of the prevailing north moving Yucatan Current depositing fine sediment at these beaches as it was pushed along the coastline. This would indicate that beach orientation and shoreline configuration also has an influence over poststorm beach response.

\subsubsection{Barrier beach post-storm response models}

Barrier beach changes will be discussed in three different beach types, based on their geomorphology and sedimentology, and matching those of the previous section, namely: type 1a: reef-protected and barred-reflective barrier beach systems, type $1 b$ : reef-protected and dissipative barrier beach systems, and type 2: exposed and reflective barrier beaches systems. Type $1 \mathrm{a}$ and $\mathrm{b}$ barrier response was dominated by landward transgression and subaerial aggradation. These systems remained largely disconnected from the reef crest and were regarded as geomorphically inert under the prevailing conditions which ensued. Some post-storm sedimentological responses can be traced through the subsurface stratigraphy of these barriers, showing the higher and lower-energy periods in the years following Hurricane Wilma. Type 2 barrier beaches underwent periods of shoreline accretion and erosion. These systems were open to sediment exchange in the months to years following 
Hurricane Wilma. The post-storm sedimentological changes on exposed coastlines are typified by deposition and reworking on a regular basis.

\subsubsection{Type 1a: reef-protected and barred-reflective barrier beach systems}

By April 2010, the foredunes of type 1a barrier beaches remained of similar height to postHurricane Wilma profiles, but the beach width was considerably narrower at 25-40 m wide, with a slope of $2.5-4.5^{\circ}$. This closely resembles the theoretical equilibrium beach profile (assumed to be the pre-Hurricane Wilma profile). Type 1a barrier beach systems underwent several stages of change as they readjusted to the prevailing energy regime in the 54 months following Hurricane Wilma. These changes and the drivers of change are discussed as stages of post-storm response below, and supported by the type 1a post-storm response model (Figure 6-24). The potential length of each stage has also been outlined.

Immediate post-storm condition: The beach and foredunes of type 1a barrier beaches were left wide and gently sloping, with a concave upward profile following Hurricane Wilma. The beach was free of vegetation and therefore sediment was highly mobile.

Stage 1 ( 0-6 months): shoreline readjustment, berm development: Immediately following Hurricane Wilma, and during a time in which relatively low energy conditions prevailed (Figure 6-13a), the shoreface and beachface responded: mobile sediment from the infilled sand bar was transported landwards as low-energy waves washed across the beachface and formed a new berm inland of the immediate post-storm shoreline. As such, the shoreline showed rapid erosion of a few meters. These changes most likely took place within a few months of Hurricane Wilma, but no later than eight months following the storm. This nature of berm development was similar to the findings of Morton et al. (1994), however the shoreline response differed. They reported on an eroded system undergoing immediate post-storm accretion; in contrast, this study details an accreted system undergoing poststorm erosion.

Stage 2 ( 6-18 months): shoreline transgression, back beach aggradation, and vegetation migration: Once the beachface had adjusted to the prevailing conditions, (aeolian) saltation processes became significant, with the wide and unconsolidated beach highly mobile. Sediment beyond the berm crest was transported into the back beach, onto the foredune and into the backdune swale, driving beach aggradation. Vegetation began to migrate on to the foredune ( $10 \%$ coverage) and back beach ( $5 \%$ coverage), further aiding sediment accumulation. Low wave energy conditions were interrupted by intermittent higher energy events, with the passage of 'Nortes', tropical storms and hurricanes (Table 3-3). These higher energy events were geomorphically significant in reworking the barrier beach, but not at entraining sediment within the backreef lagoon. The beachface was reworked and sediment transported on to the upper shoreface and into subaqueous sand bars. However, unlike during the passage of Hurricane Wilma, the barrier beaches at this time only had a small subaerial store of sediment available for sand bar development; therefore, the shoreline eroded. 
The back beach was also inundated during these higher energy events, with Syringodium filiforme seagrasses washed ashore and surface sediment winnowed, leaving coarser sediment in situ. Some sediment was lost alongshore and offshore into the backreef lagoon. Under lower wave energy conditions, sediment was transported back onshore and the berm reformed on the beachface, but closer towards the dunes. Some sediment remained in the sand bar and was later stabilised by seagrasses. Aeolian processes were reactivated following berm development, and sediment was deposited on top of the coarser winnowed surface layer. Seagrass debris was also buried in situ in some instances. This process is evidenced in the stratigraphic profiles (Section 5.2) and corresponds to the storm record. However, only some events are maintained in the record, as successively larger events within short succession would have washed the previously coarse winnowed and finer deposited layers away; these layers would only be preserved in the back of the beach, with the beachface showing more recent lower-energy events. This stage continued until considerable vegetation occupied the foredune and back beach.

Stage 3 ( 18-48 months): storm berm development, back beach and foredune aggradation, profile steepening and vegetation spread: Stage three was characterised by the spread of vegetation, which sprouted in patches across the foredune and back beach, promoting greater sediment accumulation. Aeolian processes dominated and sediment largely accumulated in the back beach and, to a lesser extent, the foredune. The backdune received only a small proportion of sediment due to sand trapping by increasingly dense foredune vegetation. Small mounds and hummocks began to form at the toe of the foredune. This is the first stage of incipient foredune growth (Hesp, 2002), and subsequently these beach sections started to reflect a more aggradational convex shape. The previously exposed calcarenite dune was also covered in many areas. The passage of minor hurricanes, tropical storms and 'Nortes' (Table 3-3) periodically reworked the beachface, inundated the back beach (though to a lesser extent due to subaerial aggradation), and removed sediment from the bare seaward portion of the back beach. Sediment was transported on to the shoreface and added to the stabilised sand bar, which dissipated some wave energy; some sediment was also lost offshore or alongshore. A storm berm formed further seaward on the aggrading beach, and the back beach narrowed and steepened as it was compressed between the eroding shoreline and the foredune.

Stage 4 ( $>48$ months): subaerial beach development ('beach maturing'), continued vegetation expansion, fluctuating beach adjustment: The final stage in post-storm response sees the barrier beach largely come into balance with the prevailing (and periodically high) energy regime. The shoreline re-establishes near the pre-Hurricane Wilma shoreline position; this is the assumed theoretical equilibrium beach profile position (Bruun, 1954; Bruun, 1962). Vegetation continued to expand across the foredune ( $80 \%$ coverage) and back beach ( $70 \%$ coverage), and the mounds and hummocks developed into small incipient foredunes. The back beach and foredune began to reflect convex profiles, and the beach continued to steepen. The seagrass-stabilised sand bars provided some protection to 
the barrier beach, and further subaerial aggradation, driven by saltation, ensued. With beach aggradation, only relatively high wave energy events were able to inundate the back beach. The barrier may adjust a few metres further landward, and subaerial maturing is likely to continue, until the barrier is reworked by another major storm. These changes reflect the shoreline transgression and beach aggradation measured to April 2010, 54 months after Hurricane Wilma (Section 5.2). 

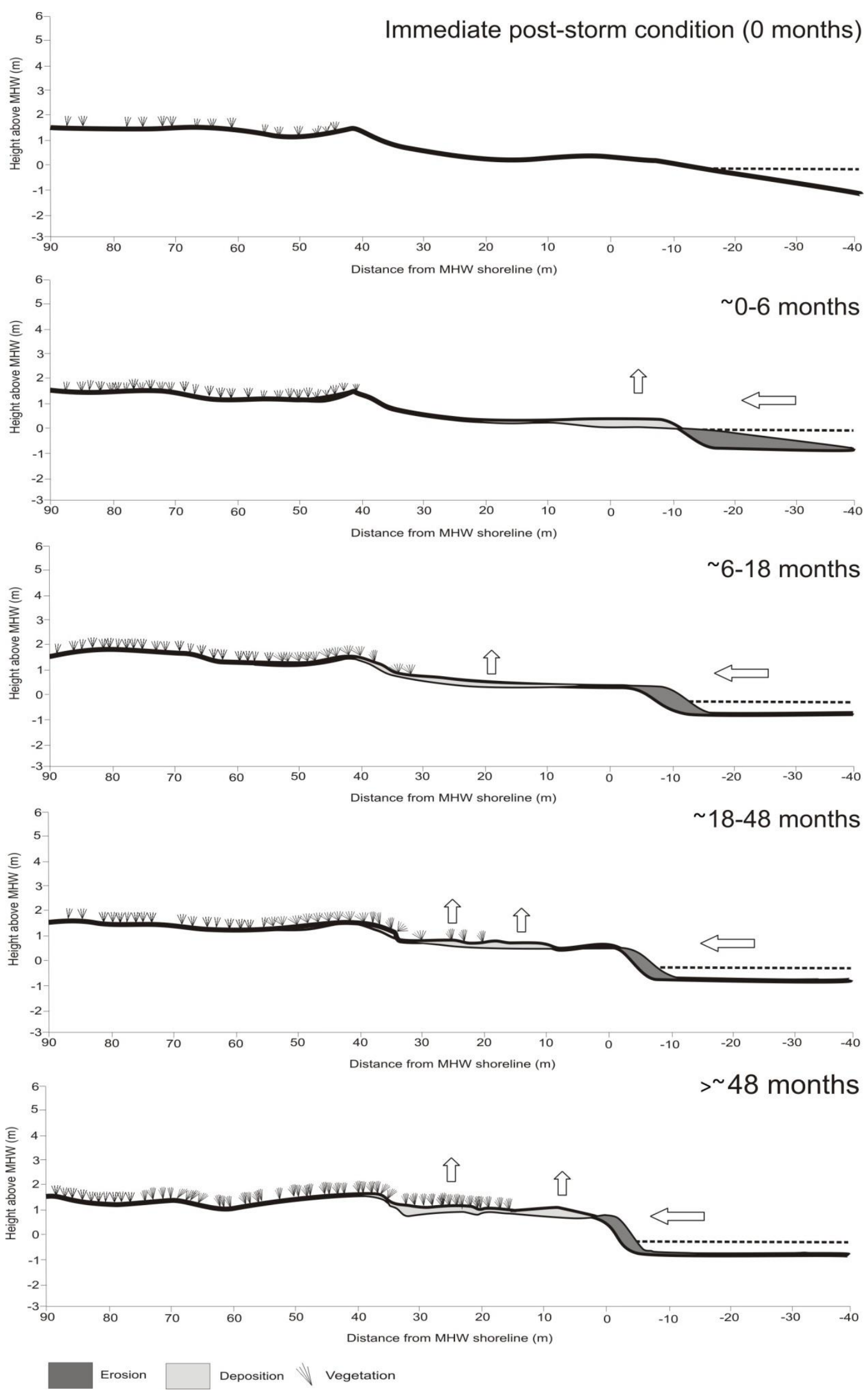

Figure 6-24: Post-storm beach response model for type 1a: reef-protected and barredreflective barrier beach systems, northeastern Yucatan Peninsula, Mexico. 


\subsubsection{Type 1b: reef-protected and dissipative barrier beach systems}

By May 2010, and following a period of post-storm recovery, the foredune height remained largely unchanged along type $1 \mathrm{~b}$ barrier beaches. The beaches had, however, narrowed to 50-70 m wide, and adopted a slope of $2.5-4^{\circ}$ (Figure $6-25$ ). This response is detailed below and has also been conceptualised in Figure 6-26.

Immediate post-storm condition: Type $1 \mathrm{~b}$ barrier beaches were left wide and flat. Vegetation was stripped from the lower reaches of the partially reworked foredune, and the beach was left unstable and highly mobile.

Stage 1 ( 0-6 months): shoreline adjustment, berm development: This stage was similar to type 1a barrier beaches with the shoreline adjusting landward as the berm developed, formed by wave swash. Beach readjustment was highly variable however, and the shoreline remained stable in some areas. Unlike type 1a barriers, aeolian transport occurred during this initial stage, as wider beach widths promoted early activation of saltation processes.

Stage 2 ( 6-18 months): shoreline transgression and back beach aggradation: During this stage the beach underwent a similar response to type 1a barrier beaches, with continued shoreline transgression. However, unlike type 1a barrier beaches, vegetation remained sparse on the foredune, and none was evident in the back beach. With the passage of storms the beach tended to respond by flattening across its profile, and some sediment was transferred onto the shoreface. Wave swash continued to inundate a considerable distance into the back beach due to the low, flat profile.

Stage 3 ( 18-48 months): storm berm development, back beach and foredune aggradation, profile steepening and vegetation migration: The process of storm response once again reflected type $1 \mathrm{a}$ barrier beaches in many aspects. However, type $1 \mathrm{~b}$ beaches underwent considerably less back beach aggradation, and as such wave run-up under higher energy conditions still inundated much of the back beach. The storm berm formed a considerable distance inland, though it may not have been identifiable if wave run-up reached the foredune toe; vegetation also remained scarce. As with type 1a barriers, coarse sediment layers and seagrass deposits were also evident in the back beach.

Stage 4 ( >48 months): subaerial beach development ('beach maturing'), vegetation spread, and continued shoreline erosion: Similarly to type 1a barriers, subaerial development continues and incipient foredunes develop. Embryo dunes also form in the back beach where wide 'dry' beach widths and vegetation predominate. The shoreline is likely to continue to erode landward another four or five metres, until it reaches the (assumed) theoretical equilibrium beach profile (Bruun, 1954; Bruun, 1962). The geomorphic change will be predominately concentrated in the back beach; this beach section will continue to narrow as it is compressed between the eroding shoreline and the foredune. Beach aggradation will continue, particularly in areas of embryo dune development, until such time that another severe storm makes landfall, and reworks the barrier. 

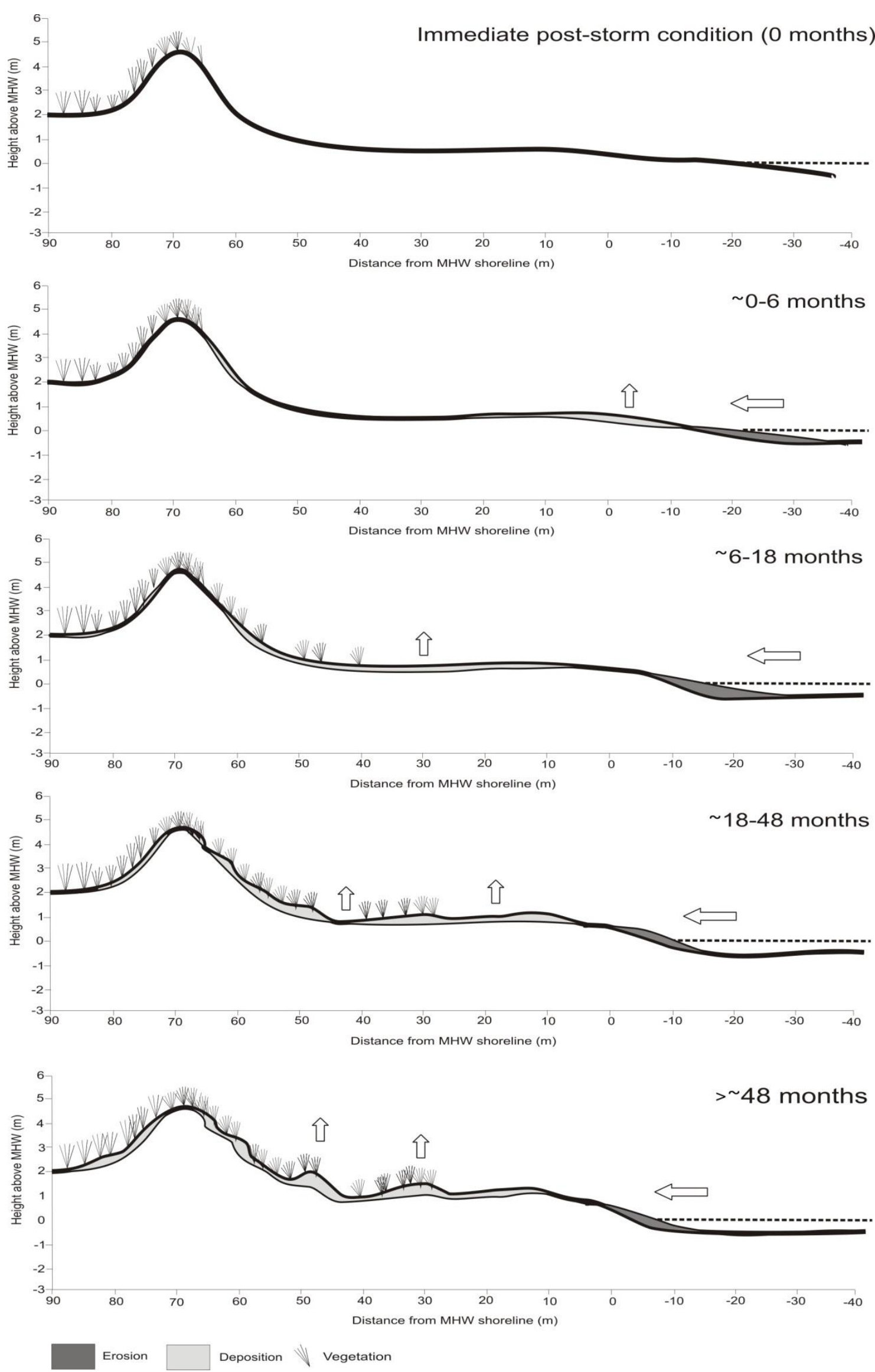

Figure 6-25: Post-storm beach response model for type $1 \mathrm{~b}$ : reef-protected and dissipative barrier beach systems, northeastern Yucatan Peninsula, Mexico. 


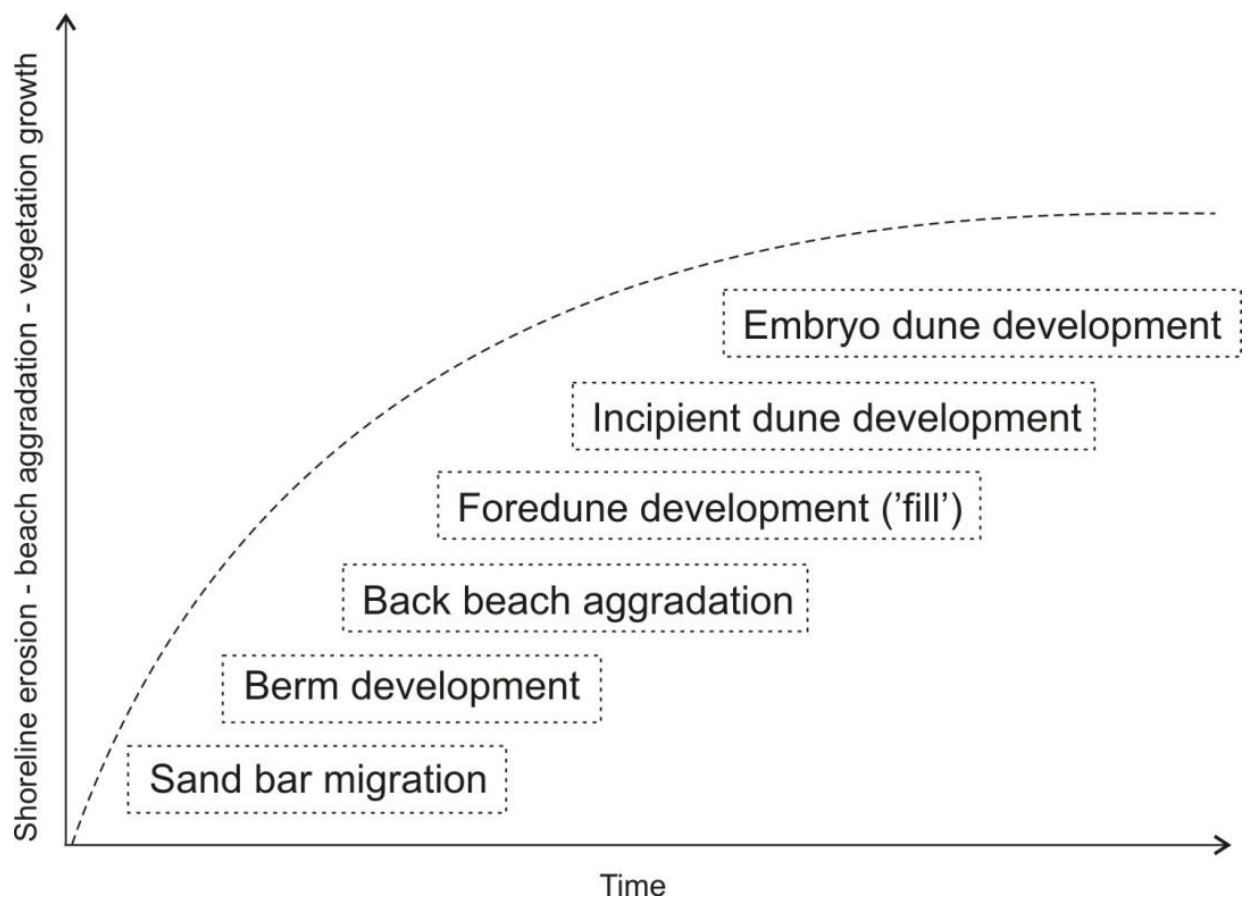

Figure 6-26: Conceptual model of the geomorphic response of type $1 \mathrm{~b}$ reefprotected barrier beaches following Hurricane Wilma.

\subsubsection{Type 1a and b post-storm sedimentological response}

The textural characteristics of type $1 \mathrm{a}$ and $\mathrm{b}$ barrier beaches were found to be not too dissimilar to the storm deposit as sampled in 2006. Surface sediment was dominated by medium-grained sand, comprised of a dominant Halimeda component, and high in micrite (Figures 5-9 and 5-16), an indication the sediment was derived from the barrier beach or backreef lagoon. Due to the prevalence of relatively calm conditions for an extended period of time prior to fieldwork, the surface sediment likely represents deposition during the prevailing conditions, and as such the material is likely derived from wave swash and aeolian-transported material from the shoreface and beachface. Sediment from the backreef lagoon is less likely a source under these low energy conditions as the lagoon surface sediment was found to be considerably larger (Figures 5-9 and 5-16), thus requiring greater energy to entrain material (Komar, 1976). These results further support the poststorm responses conceptualised in Figures 6-24 and 6-25.

There were, however, differences in the grain-size alongshore, with the northernmost site of Zone 1: Wet ' $n$ ' Wild (WnW-t1) considerably coarser than the other sites. This difference may represent the sediment circulation patterns under the prevailing conditions, in a similar manner to the surface current flow directions measured by Coronado et al. (2007), off Puerto Morelos (Figure 3-8). The flow patterns are controlled by the orientation of the longitudinal axis of the backreef lagoon and the location of the reef inlets. This may result in some sites alongshore representing areas dominated by currents of removal, where sediment is winnowed, leaving coarser-grained sediment; other sites may represent currents of deposition, depositing finer-grained material (Kench, 1998). 
The post-storm sedimentological response of reef-protected barrier beaches was also preserved as several sediment layers in the subsurface beach stratigraphy (Figures 5-8 and 5-15). These layers' textural characteristics were relatively similar through much of the profile, indicating the subaerially deposited sediment was predominately comprised of reworked shoreface and beachface sediment. However, the deposits also contained some slightly coarser material, likely transported onshore during one of the seven higher-energy storm events since Hurricane Wilma. Many of the sediment layers are separated by seagrass debris deposited in the back beach during the passage of higher-energy events and subsequently buried following aeolian deposition during lower wave conditions. The thicker sediment layers likely represent longer periods of relatively calm conditions. A layer is not preserved for every event, as some events were likely removed by subsequent storm wave inundation into the back beach. For example, the early events, prior to considerable vertical sediment accumulation, were likely removed, as the back beach was still easily inundated. Later storm events, following subaerial accumulation, would not have inundated the beach to the same extent. This assumes the same size waves, as such the layers preserved are likely those which occurred as the beach aggraded vertically.

\subsubsection{Type 2: exposed and reflective barrier beach systems}

By May 2010, the foredune height of type 2 barrier beaches remained largely unchanged, and beach widths of $15-30 \mathrm{~m}$ with slopes of $4-8^{\circ}$ predominated. During this post-storm recovery, type 2 barrier beach systems underwent several stages of change: the shoreline responded rapidly, however subaerial recovery was considerably slower. These changes and the drivers of change are discussed as stages of post-storm response below, and supported by the type 2 post-storm response model (Figure 6-27):

Immediate post-storm condition: Unlike reef-protected barriers, type 2 barrier beaches were left narrow and stripped of sand following Hurricane Wilma. The calcarenite platform was exposed in some areas and the shoreline was eroded. The beach was stripped of vegetation, and coral gravel was thrown up on the beach. A subaqueous sand bar formed.

Stage 1 ( 0-6 months): shoreline recovery, berm development: The response of exposed barrier beaches followed a similar pattern to those described by Morton et al. (1994), whereby shoreline recovery occurred rapidly as sediment from offshore sand bars migrated onshore. Relatively low energy wave swash ensued (Figure 6-13a) and a berm developed. The shoreline returned to its pre-storm position within six months of Hurricane Wilma. However, little subaerial development occurred over this period, evidenced by the erosional concave-upward storm profile and back beach depression which remained.

Stage 2 ( 6-12 months): sediment redistribution, vegetation migration: Following berm development, aeolian processes began to transport sediment into the back beach. However, as the material was considerably larger and the beach considerably narrower than reefprotected barrier beaches, sediment was not so mobile. Sediment deposition was concentrated in the back beach, with some sediment also deposited on the foredune. In 
addition, a thin aeolian cap was deposited in the backdune. At this time vegetation began to migrate on to the foredune.

Stage 3 ( 12-36 months): beachface reworking, back beach aggradation, and vegetation spread: The prevailing conditions were interrupted by the passage of the first major hurricane since Hurricane Wilma. Storm waves reworked the beachface and inundated the back beach. Some sediment migrated to the shoreface as the shoreline was eroded. These changes were, however, temporary, and under lower energy conditions sediment migrated onshore and the beachface reformed in a similar position. Vegetation migrated across the foredune and parts of the back beach, further promoting sediment accumulation. The back beach was progressively infilled, though it experienced temporary losses with the passage of subsequent storms. The subaerial aggradation in the back beach is evidenced by the accumulation of finer sediment on top of the coarse gravel layer left in situ following Hurricane Wilma (Figure 5-29).

Stage 4 ( >36 months): subaerial beach development ('beach maturing') and shoreline

fluctuation: The barrier beach continues to mature as vegetation spreads and the beach becomes more stable. Small hummocks, the first stage of incipient foredunes (Hesp, 2002), are developing in some areas (Figure 5-26). The beach profile adopts a more convex shape in some locations, and the beachface, back beach and foredune are welded together. Type 2 barrier beaches are expected to continue to mature subaerially until such time as another major hurricane drives large-scale geomorphic change. During this final stage of post-storm readjustment the beachface migrates frequently with fluctuations in wave energy; this drives shoreline erosion of a few meters. The back beach is also inundated by wave swash on occasion. The shoreline position will generally recover to a similar position a short time afterwards, and this is regarded as the equilibrium beach profile position. 

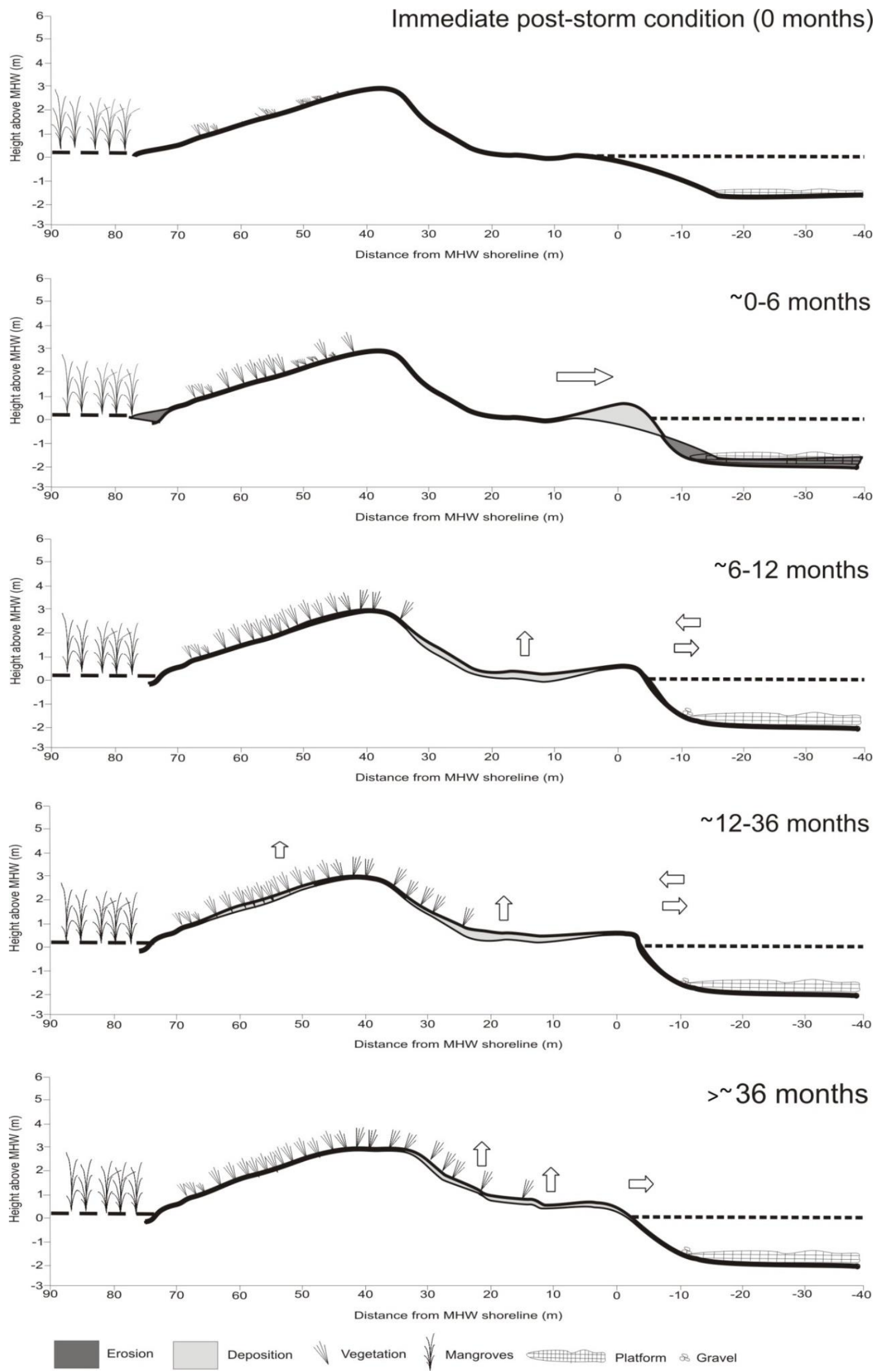

Figure 6-27: Post-storm beach response model for type 2: exposed and reflective barrier beach systems, northeastern Yucatan Peninsula, Mexico. 


\subsubsection{Type 2 post-storm sedimentological response}

The textural characteristics of post-storm sediments in type 2 systems differed to the storm deposits, representing more locally sourced sediment under the prevailing conditions. Surface sediment of unprotected barrier beaches typically fined and the sediment composition shifted towards those which were sourced on the shelf, such as molluscs and coralline algae, with a decrease in content broken off coral reefs (Section 5.5.3). The Halimeda content remained high due to the abundance of this constituent offshore, highlighting its importance as a key constituent in barrier beach stability both of reefprotected and exposed barrier beaches. Unlike type 1 barrier beaches, sediment exchange with the shelf is on-going on unprotected coastlines under the prevailing energy regime, due to greater wave energy.

In addition, the northernmost site (PntBrv-t2) in Zone 4: Punta Brava, which was considerably finer than the other sites following Hurricane Wilma, underwent post-storm coarsening, while the other sites further south fined. This represents the homogenisation of barrier beach sedimentology post-storm, as the prevailing energy regime and sediment distribution processes ensue.

The process of post-storm sedimentological response is characterised by continual beach sediment reworking and redeposition as sediment is progressively infilled, and then some material eroded. This is represented by the series of coarser and finer layers in the subsurface beach stratigraphy, and by the shoreline and subaerial movements measured during repeat field excursions and analysis of satellite imagery. These results illustrate the dynamic nature of the unprotected beaches during the passage of successive tropical storms and hurricanes, and the considerably faster rate at which these beaches respond to progressive events.

\subsection{Geomorphic significance of storms to barrier beach evolution}

Storm events were historically seen as important drivers of barrier beach evolution, specifically responsible for shoreline erosion. However, more recent research suggests they may only result in temporary shoreline movement, with long-term movement determined by other factors such as sea level rise and sediment supply (Zhang et al., 2002). The barrier beaches of northeastern Yucatan Peninsula appear to follow such a pattern: reef-protected and unprotected barrier beaches underwent considerable geomorphic change as a result of Hurricane Wilma, a major slow-moving storm; however, 54 months after Hurricane Wilma they were found to have readjusted to near pre-storm beach position. Barrier beach recovery is predicted to take approximately 4-7 years, based on field evidence and future postulations, for reef-protected barrier beaches, and considerably less for those exposed to high wave energy on a more frequent basis. 


\subsubsection{Geomorphic evolution: Hurricane Wilma}

The shoreline of reef-protected (type $1 a$ and b) barrier beaches on northeastern Yucatan Peninsula readjusted by $75-95 \%$ within approximately five years (54-56 months) of Hurricane Wilma. Type 1 a barriers were on average $1.2 \pm 3.9 \mathrm{~m}$ wider than pre-Hurricane Wilma, and type $1 \mathrm{~b}$ barriers $4.1 \pm 0.8 \mathrm{~m}$ wider. In comparison, type 2 barriers on open and exposed coastlines were found to respond much faster, with the shoreline position recovering within the first eight months of the storm; however, subaerial geomorphic features were found to respond at a much slower rate. These results indicate that major storms have a significant impact on reef-protected barrier beaches over the short (0-8 months) to medium-terms (8-54 months). Hurricane Wilma can be considered one on the primary controls of barrier beach evolution over this period, a finding comparable with those of Morton et al. (1994). Results also indicate that the shorelines of sites exposed to higher wave energy on a more regular basis recover relatively quickly; therefore storms are not significant drivers of short to medium-term change in shoreline position and barrier evolution. This is however not the case for their subaerial recovery, which is considerably slower. Inter-barrier response was also found to be highly variable (Figure 6-28), highlighting the influence of other factors on geomorphic change. 


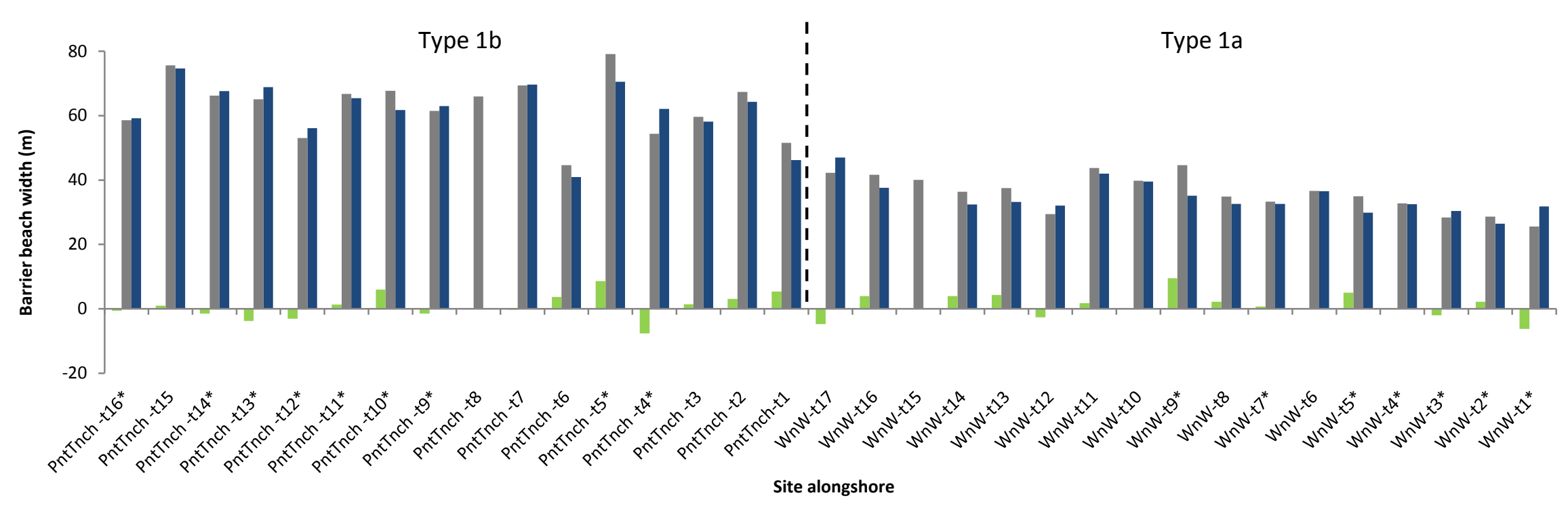

— Pre-Hurricane Wilma barrier beach width: August 2005 — Post-Hurricane Wilma barrier beach width: April/May 2010 — Pre to post-Hurricane Wilma barrier beach difference

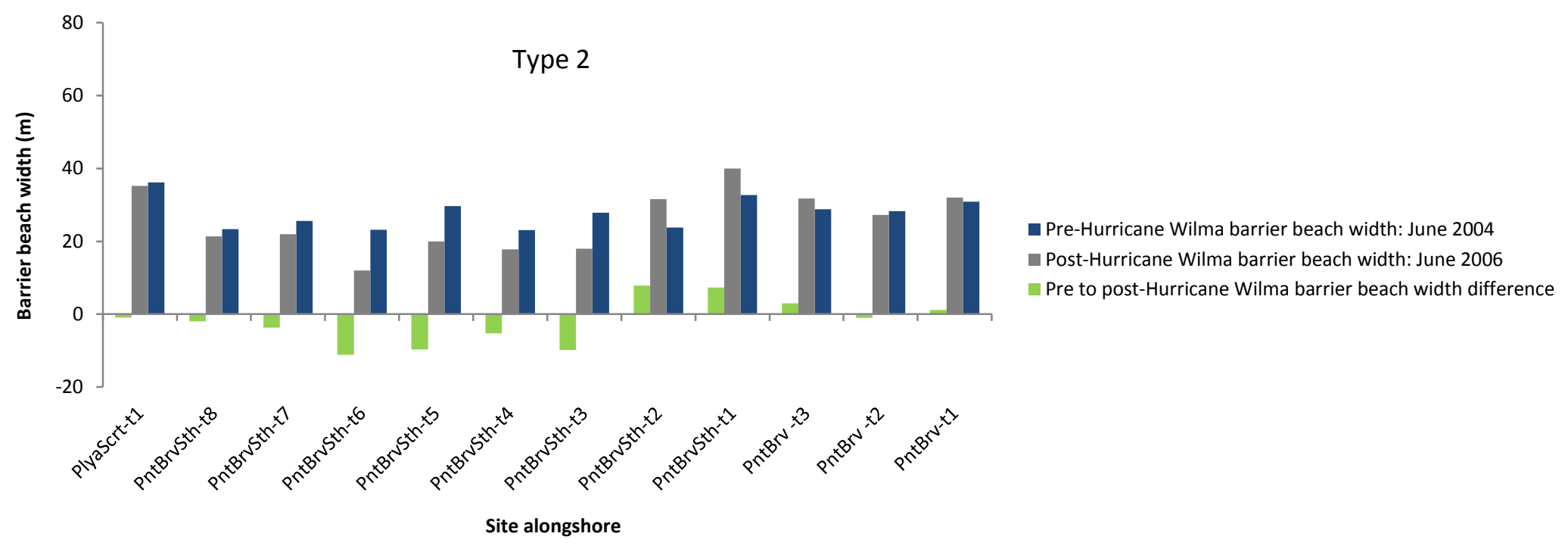

Figure 6-28: Post-storm shoreline response on type $1 a, 1 b$, and 2 barrier beaches following Hurricane Wilma. Readjustment of type 1 a and b barriers occurred over a 54-55 month period, whereas type 2 responses occurred over eight months. 
To quantify the geomorphic significance of hurricanes beyond an event scale requires the geomorphic impacts and post-storm recovery time to be put into the context of the storm record (Figure 6-29). By doing so, the magnitude and frequency of geomorphically destructive tropical storms and hurricanes can be assessed, and the contribution of these high-energy events to longer-term change can be evaluated. The storm record on the northeastern Yucatan Peninsula has been investigated by Silva-Casarin et al. (2009) who analysed wind and wave data from major hurricanes between 1948 and 2007 using the WAM-HURAC model. Most hurricanes were found to produce significant wave heights $\left(\mathrm{H}_{\mathrm{s}}\right)$ of up to eight metres. However, they also found four events that likely produced $\mathrm{H}_{\mathrm{S}}>12 \mathrm{~m}$, similar to Hurricane Wilma, and persisted for on average 7 hours. The return period of these storms was calculated to be 100 years (Silva-Casarín et al., 2009). Storms producing waves of $\mathrm{H}_{\mathrm{s}} \approx 8-10 \mathrm{~m}$ had a return period of 5-10 years.

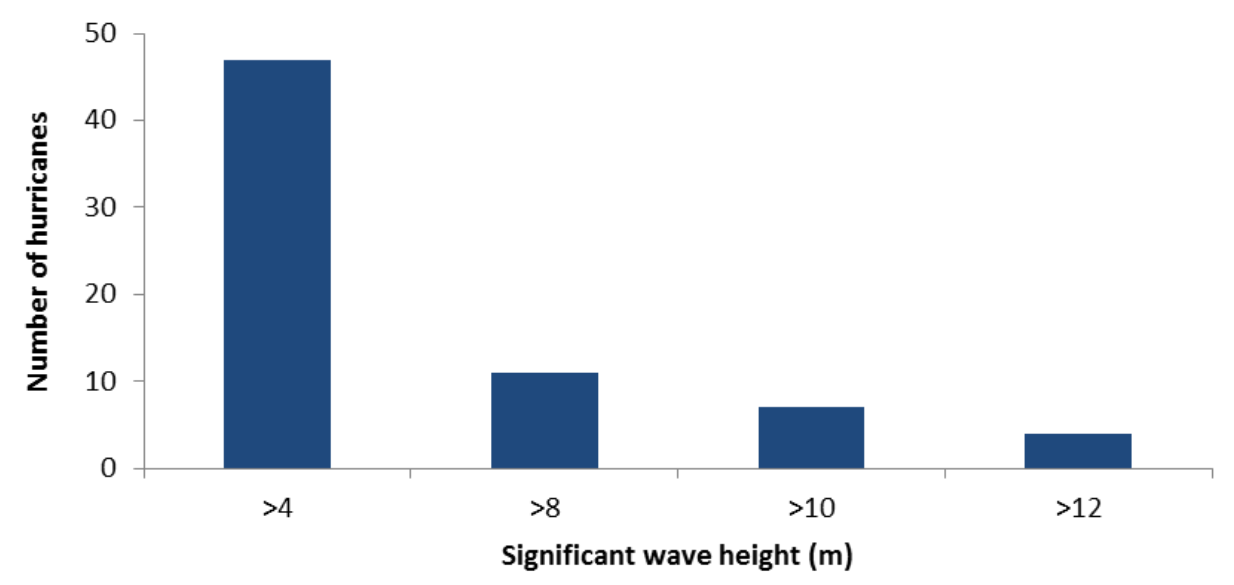

Figure 6-29: Significant wave heights generated by all major hurricanes which have tracked past northeastern Yucatan Peninsula between 1948 and 2007. Wave heights were calculated using a WAM-HURAC wave model. Data sourced from Silva-Casarin et al. (2009).

The lengthy return period for events on the scale of Hurricane Wilma indicate that the barrier beaches of northeastern Yucatan would likely have sufficient time to readjust poststorm, prior to the strike of another storm on a similar scale. Under lower energy conditions, experienced during more regular storms $\left(\mathrm{H}_{\mathrm{S}} \approx 8-10 \mathrm{~m}\right)$, dissipation across the lagoon would result in smaller waves reaching the shoreline $\left(\mathrm{H}_{\mathrm{S}} \approx 1.45-1.81 \mathrm{~m}\right.$, calculated using a wave dissipation factor of $82 \%$, based on the data of Coronado (2007)). As a result, less geomorphic work would occur than was seen with Hurricane Wilma (Figure 6-30). The beach would then likely recover within a shorter period and readjust to the pre-storm profile, a timeframe that still falls well within the return period of storms of this magnitude. 


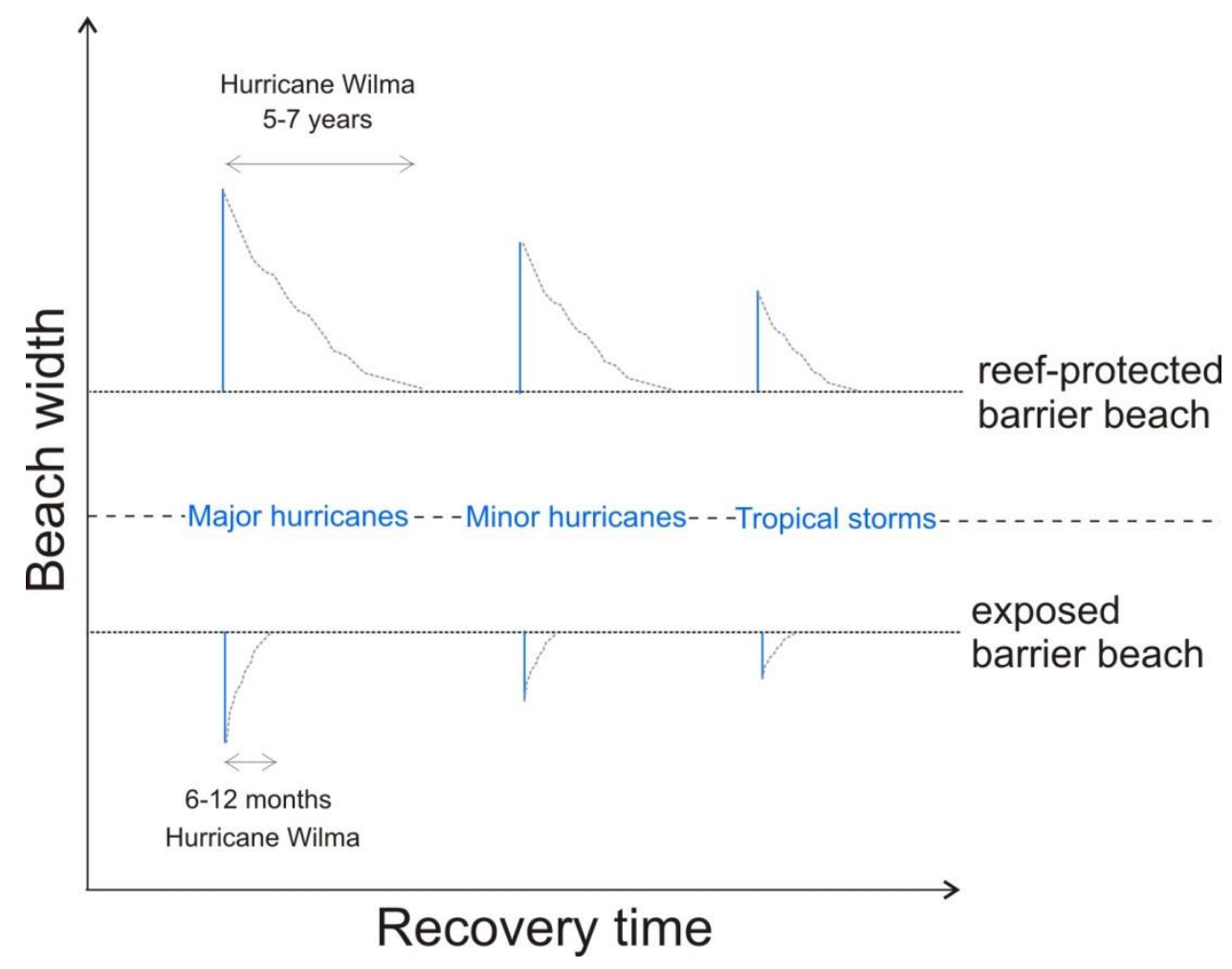

Figure 6-30: Conceptual model of barrier beach (beach) width change and poststorm recovery time, with respect to the storm intensity.

Under the current climatic conditions, tropical storms and hurricanes can be considered the primary drivers of barrier beach evolution over the short (0-8 months) to medium-terms (856 months) on the northeastern Yucatan Peninsula; this is similar to the results of Zhang et al. (2002). However, tropical storms and hurricanes appear to be less influential over the longer-term. These storms can therefore be considered the primary drivers of fluctuations within a dynamic equilibrium, without influencing longer term directional trends (Figure 631). Longer-term trends are more likely to be controlled by boundary conditions such as sea level rise and sediment supply. 


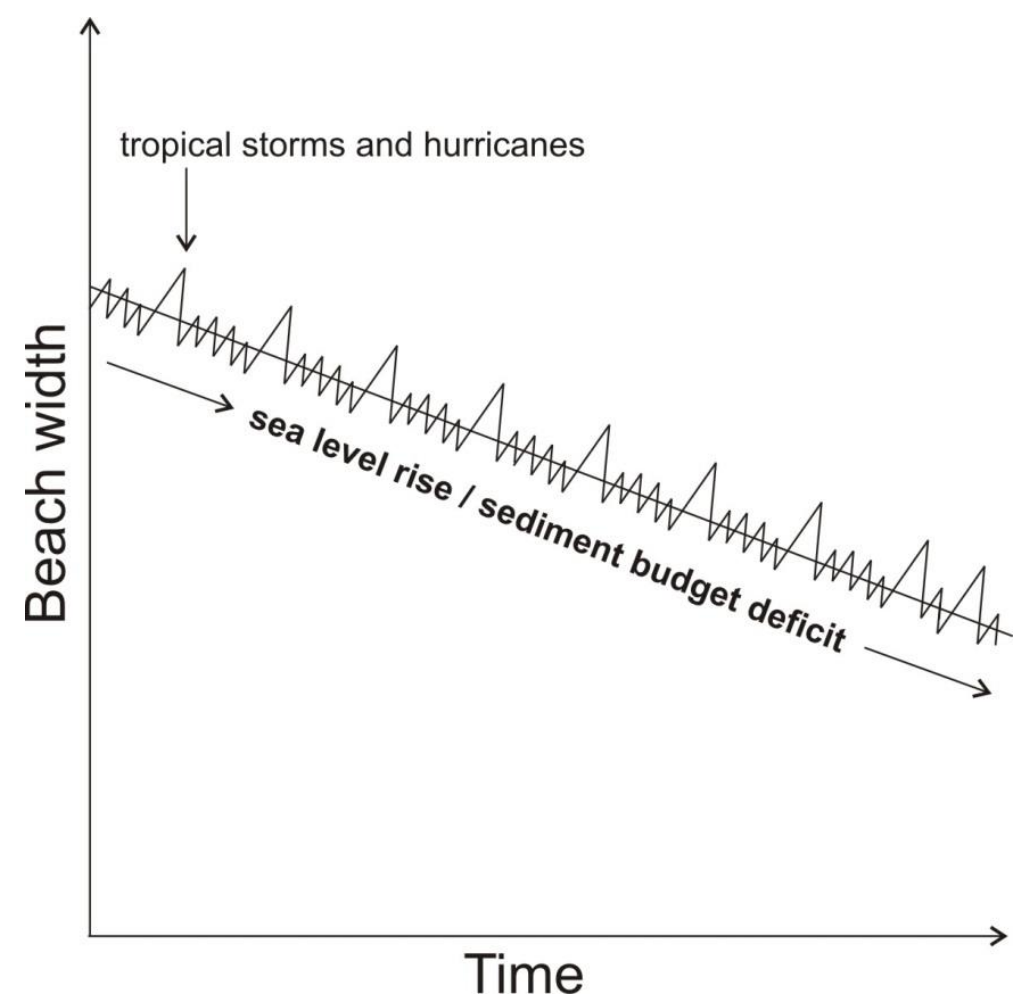

Figure 6-31: Storm-driven changes to the beach width equilibrium in a dynamic equilibrium model.

\subsubsection{Climate change: increased storm intensity and sea level rise}

One of the predicted results of climatic change is an increase in the intensity of major tropical storms and hurricanes, and subsequently an increase in the scale of their geomorphic impacts. As a result, the barrier beaches of northeastern Yucatan Peninsula may be more frequently inundated by waves greater than $8 \mathrm{~m}$ or even $12 \mathrm{~m}$, with the return period of the most intense storms likely to reduce. If this were to occur, the difference between the beach recovery time and storm recurrence interval would become smaller. Over time, these high energy events may start to have a greater influence over the longerterm evolution of barrier beaches under climate change, with successive catastrophic storms potentially making landfall prior to full beach recovery. This could result in a landward shift of the (theoretical) equilibrium shoreline position, which would represent a metastable equilibrium system (assuming constant sea level and sediment supply) (Figure 632). 

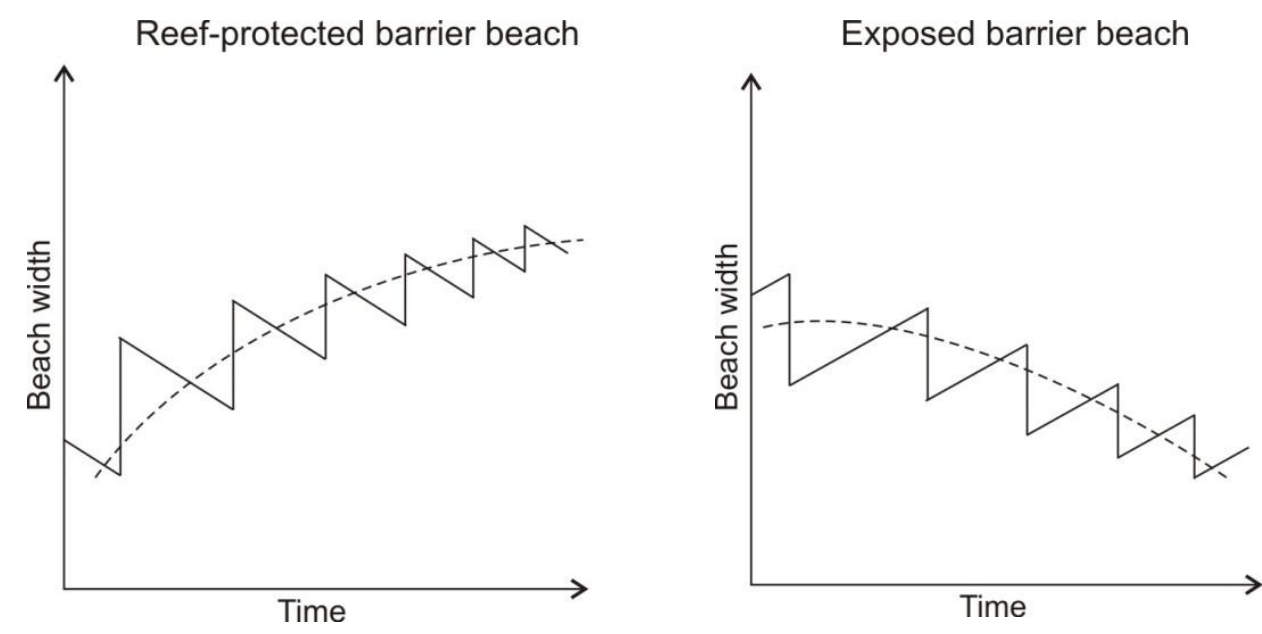

Figure 6-32: Metastable equilibrium model where storm-driven changes to the beach width equilibrium are amplified by increased storm intensity.

Future climatic change is also predicted to drive increases in sea level, with current projections indicating a sea level rise of $0.6 \mathrm{~m}$ by 2100 (IPCC, 2007). This is likely to result in the equilibrium beach profile shifting landward and upward, as the barrier beach readjusts to a new sea level position (Bruun, 1954; Bruun, 1962). The extent of this landward shift is, however, unclear, with the method of beach transformation proposed by Bruun (1954; 1962), and the notion of a beach equilibrium widely criticised (Cooper and Pilkey, 2004). Furthermore, the process of barrier beach change is likely to depend on the rate at which the sea level rise occurs (Kraft et al., 1987).

In the coastal environments investigated in this study, coral reef growth and production will also be affected, adding greater complexity to the response of coral-fringed barrier beach systems (see Section 2.3.4). During a slow rise, coral grows vertically with the sea level; however, if a rapid change occurs, coral may either shift laterally (backstep) or drown, as has previously occurred within the Caribbean region (Blanchon and Shaw, 1995; Blanchon, 2010; 2011a). This would have catastrophic impacts on the barriers by removing a key sediment supply (as sediment is slowly broken down between the reef crest and the barrier beach) and result in shoreline erosion and inland barrier migration. Higher energy waves, particularly during major hurricanes, may compound these effects.

The supply of sediment is another important contributing factor to barrier beach evolution (Hesp and Short, 1999). The barrier beaches of northeastern Yucatan Peninsula have an overwhelming reliance on Halimeda for input of new sediment to the system, with coral, coralline algae, molluscs and foraminifera also important to barrier stability. Therefore, a decline in the production of these organisms (due to adverse environmental conditions or other factors) would likely have a severe impact on barrier beach morphology and may result in shoreline erosion if there was a sediment budget deficit. Such biological factors add further complexity to barrier beaches in coral-fringed settings, particularly as reefs are vulnerable to the impacts of climate change, including coral bleaching (Brown, 1997) and the migration of invasive and destructive species (Goldberg and Wilkinson, 2004). Added to 
this are direct anthropogenic impacts such as the discharge of sewage (Pastorok and Bilyard, 1985). In addition, an increase in storm intensity is likely to increase coral damage and removal (Scoffin, 1993).

\subsubsection{Anthropogenic influences: coastal development}

Coastal development has taken place at a rapid rate along the study area since Hurricane Wilma. Hotels were developed on top of the foredune, and in some instances within the active back beach. Coastal development took advantage of the wide beaches immediately following the storm. However, as was detailed in Section 5.4 the beaches have transgressed landwards in the years following the storm, with many hotel beachfronts characterised by narrow, sloping beaches by June 2010. This is largely the result of seawall construction, which restricts natural beach readjustment. These sites were found to lose more sediment offshore as a result of wave reflection and beach scour under higher-energy events. Little sediment remained within the system, and as such these sites were left more vulnerable to future hurricanes of comparable size to Hurricane Wilma. These beaches would be eroded (unlike the accretion experienced by natural systems), and hotels would experience considerable infrastructure damage.

Such anthropogenic influences have completely altered the natural dynamic fluctuation of barrier beaches on the reef-protected coastline. The shoreline movement and across-shore sediment exchange has been restricted, with waves unable to remove sediment from the foredune for sand bar development during storm inundation. Developed barrier beaches will ultimately require sediment renourishment in order to maintain the beach. However, due to many sites being developed seaward of the pre-storm shoreline position, sediment would continually be lost under the prevailing conditions, with the largest losses occurring during the passage of storms. Current indications suggest that development is likely to continue; during fieldwork for this study several natural plots along Zone 2: Punta Tanchacte were fenced-off in preparation for construction. It is likely that most, if not all, of the study area will be developed in the coming decades.

\subsection{Summary}

Hurricane Wilma had a significant geomorphic impact on the barrier beaches of northeastern Yucatan Peninsula. Barrier beaches underwent highly contrasting storm and post-storm changes; the primary control on this response was found to be coral reefs. Beaches protected by coral reefs underwent considerable shoreline accretion, which exceeded $20 \mathrm{~m}$ in some areas, while sites exposed to the Caribbean Sea eroded by over 10 m. Post-storm barrier beach response was characterised by most sites shifting towards their pre-storm position. This supports the notion that beaches respond in a way which brings them into balance with the sediment supply, sea level and wave energy, as they readjust to a theoretical equilibrium beach profile.

Based on field evidence and future postulations, it appears that reef-protected barrier beaches recover to the pre-storm barrier beach profile over a period of 4-7 years; this 
indicates major hurricanes to be important drivers of barrier beach evolution over the short (0-8 months) to medium-terms (8-54 months). Exposed barrier beaches responded much faster; as such, storms are less significant to their medium-term evolution. Furthermore, under contemporary climatic conditions, storms do not appear to be drivers of longer-term barrier beach evolution. Rather, this is more likely controlled by changes in boundary conditions such as sea level and sediment supply. 


\section{Conclusion}

Compared to siliceous-dominated barriers, less is known about the significance of hurricanes to barrier beach evolution on coral-fringed coastlines. This study provides a detailed assessment of the impacts of Hurricane Wilma, a major hurricane, on the reefprotected and exposed barrier beaches of northeastern Yucatan Peninsula, Mexico, over the short (0-8 months) and medium-terms (8-54 months), and postulates the significance of these events over the longer-term.

Prior to Hurricane Wilma, reef-protected barrier beaches were characterised by $30-70 \mathrm{~m}$ wide subaerial profiles and well vegetated foredunes, typically reaching 2.0-6.5 m above $\mathrm{MHW}$. The beaches were fronted by a lagoon which was 0.6-3.5 km wide, 3-4 m deep and dominated by Halimeda, Syringodium filiforme and Thalassia testudinum seagrasses. Exposed beaches, by contrast, were 20-35 m wide with foredunes less than $3 \mathrm{~m}$ above MHW. The shelf slope also steepened offshore of these exposed barriers (Ward, 1985).

The storm investigated in this study, Hurricane Wilma, passed slowly along this coastline for more than 20 hours, bringing wind speeds of up to $67 \mathrm{~ms}^{-1}$, and storm waves with significant wave heights $\left(H_{s}\right) \approx 13 \mathrm{~m}$. While exposed beaches experienced the full force of these waves, wave dissipation over the reef and backreef lagoon resulted in reef-protected sites being inundated by waves reaching only $\mathrm{H}_{\mathrm{S}} \approx 2.4 \mathrm{~m}$ (Blanchon et al., 2010).

Objective 1: Quantify and describe the geomorphic response and sedimentological character of shore-attached barrier beaches along northeastern Yucatan Peninsula to Hurricane Wilma; evaluate the significance of coral reefs, landscape controls and other factors to the highly variable response alongshore.

In order to determine the geomorphic changes and sedimentological response of barrier beaches to Hurricane Wilma, and the factors important to the varied responses, beach width changes were measured at 45 sites along northeastern Yucatan Peninsula using satellite imagery. Sediment was also sampled from 14 sites following the storm, with the textural characteristics analysed (grain size measurement and petrographic analyses). These analyses revealed contrasting changes in beach response alongshore. Reef-protected barrier beaches accreted by between 2.1 - $24.6 \mathrm{~m}$, while exposed barrier beaches eroded by more 
than $10 \mathrm{~m}$ in some locations. Beach and foredune reworking predominated on protected coastlines, and sediment was transported onto the upper shoreface. Sediment overwash also occurred at sites with foredunes less than $3 \mathrm{~m}$ above MHW. Protected beaches were left wide, flat and unconsolidated. These results are comparable with those of Priestas and Fagherazzi (2010) and the shoreline accretion experienced on St George Island, Florida (USA) in response to Hurricane Dennis (2005).

Beach and foredune sediment on exposed beaches was washed over the foredune crest and into the backdune swale and mangrove wetlands, as considerably larger waves inundated these sections of coastline. A small volume of material was also transported onto the upper shoreface as subaqueous sand bars formed, aiding wave dissipation; sediment was also lost alongshore and offshore. This was a more typical storm response and similar to those reported by Perkins and Enos (1968), Morton and Paine (1985), Phillips (1999), and Morton and Sallenger (2003).

The storm deposit on reef-protected beaches was found to be dominated by Halimeda, and constituents had undergone diagenetic processes (micritisation). This indicates the sediment was largely composed of reworked in situ beach and foredune material, or derived from the backreef lagoon. Van Tussenbroek et al. (2008) reported that Hurricane Wilma had little effect on Halimeda and Thalassia testudinum seagrass beds. As such, this lagoon is unlikely to be a source for the storm deposits. Similarly, there was only a small proportion of reef crest and forereef material present in beach sediment (coral and coralline algae), and much of this had undergone micritisation. Therefore, it was determined that reef-protected barrier beaches are disconnected from the reef crest, even under storm conditions. In contrast, exposed barrier beaches contained storm deposits high in fresh Halimeda and coral constituents, reflecting the material sourced from the shelf and coral broken off the nearby reefs during the storm. These results indicate that exposed sites are highly connected during storms. Protected beaches were found to undergo uniform storm deposition alongshore; exposed sites showed a coarsening to the south.

Objective 2: Quantify and describe the post-storm geomorphic response and sedimentological character of shore-attached barrier beaches along northeastern Yucatan Peninsula up to 54 months after Hurricane Wilma; evaluate the significance of coral reefs, landscape controls, and other factors to the highly variable response alongshore.

The nature of post-storm geomorphic response was quantified and described by comparing the results of cross-shore beach surveying in June 2006 and April-June 2010 with satellite imagery from June 2006, and the measurements taken immediately after Hurricane Wilma (25 October 2005). Results indicate that beaches tend to readjust to their pre-storm barrier beach morphology, but at different rates. Reef-protected beaches initially underwent rapid shoreface and beachface adjustment. Following this, the shoreline gradually transgressed landwards and aggraded subaerially. The migration of vegetation back on to the beach 
further aided subaerial development, and it is proposed that these systems will readjust to their pre-storm beach profile 4-7 years after major storms such as Hurricane Wilma.

Beach response was, however, found to be highly variable alongshore, and the greatest shoreline erosion occurred at sites that had undergone the greatest accretion during the storm; this supports the theory of a beach equilibrium profile. Subaerial development was dependant on the influx of vegetation, and beach morphology was influenced by the width of the backreef lagoon and its efficacy in wave dissipation. Exposed sites responded much faster than those protected by reefs, with shoreline adjustment occurring within eight months of the storm. Subaerial beach development was, however, much slower, requiring extended calm conditions to infill the eroded beach. Shoreline migration was frequent, due to the higher wave energy these sites experience.

Barrier beach sedimentology was assessed under the prevailing energy regime in April-June 2010, with the exception of some developed sites. The results showed the same two distinct systems: reef-protected and exposed barrier beaches. Reef-protected systems showed greater variability in alongshore sedimentology. The backreef lagoons were found to be 'geomorphically inert' under normal conditions according to the reef energy window index of Kench and Brander (2006). However, the barrier still appeared to undergo small wave and aeolian driven-changes at these times. Beaches are largely disconnected from the reef crest under the prevailing conditions, with sediment predominately sourced from beach reworking, and a small amount from the backreef lagoon. In contrast, exposed barriers remain connected systems under the prevailing energy regime. Sediment is largely sourced from the shoreface, shelf, or alongshore under lower energy conditions, with smaller proportions of storm-activated coral.

Objective 3: Discuss the geomorphic significance of hurricanes on the evolution of shoreattached barrier beaches along northeastern Yucatan Peninsula, and the implications of predicted increased storm intensity and sea level rise in the future.

In the context of the storm record and predicted future climatic changes, storms were found to influence geomorphic evolution over different temporal scales. The results indicate that under the contemporary climatic conditions hurricanes are key drivers of barrier evolution over the short (0-8 months) to medium-terms (8-54 months), but are not so influential over longer time scales. The region has been tectonically inactive since approximately the Eocene (55 Ma) (Szabo et al., 1978; Pindell and Barrett, 1990; Blanchon, 2010); as such, longer term evolution is likely controlled by sediment supply or sea level change.

However, an expected increase in the number of major storms (category 3-5) in the future may increase the significance of hurricanes to longer-term barrier evolution, with the storm impacts likely to be greater and the recovery times longer. Sea level is also expected to rise, and is predicted to be at least $0.6 \mathrm{~m}$ higher by 2100 (IPCC, 2007). In addition, increasing ocean temperatures are likely to result in coral bleaching and the migration of invasive reefdestroying species, affecting sediment supply. At the same time, northeastern Yucatan 
Peninsula is being rapidly developed as a tourist destination, and the entire study area is likely to be urbanised by 2020 or soon thereafter. As such, the dynamics of these natural systems will undergo direct anthropogenic change; in the end this may have the most significant impact of all on barrier beach morphology.

\subsection{Recommendations for future studies}

Collection and analysis of further data on the offshore coastal morphology is required to improve the scientific understanding of hurricane significance to barrier beach evolution. Particular factors that should be investigated include the shelf slope and morphology, the backreef lagoon bathymetry, reef crest morphology, and the location and orientation of the crest and adjacent inlets in relation to the barrier beaches. Using this information, hydrodynamic models could be run to gain a greater understanding of the geomorphic factors influencing sediment redistribution and barrier beach response.

In addition, geomorphic analyses of the impacts of other hurricanes would be highly valuable. Extensive analysis of historical aerial photography and satellite imagery would enable greater understanding of the impacts of past storms on the barrier beaches of northeastern Yucatan Peninsula, including their significance to barrier beach evolution over the longer-term. This would also enable the specific storm characteristics most important to beach response to be investigated. 


\section{References}

Adams, A.E., McKenzie, W.S., 1998. A colour atlas of carbonate sediments and rocks under the microscope. Mason Publishing Ltd, London.

Avila, L.A., 2002. Tropical Cyclone Report, Hurricane Isidore 14-27 September 2002, National Oceanic and Atmospheric Administration, Miami, Florida.

Avila, L.A., 2004. Tropical Cyclone Report, Tropical Storm Bonnie 3-13 August 2004, National Oceanic and Atmospheric Administration, Miami, Florida.

Avila, L.A., 2007. Tropical Cyclone Report, Tropical Storm Barry (AL022007) 1-2 June 2007, National Oceanic and Atmospheric Administration, Miami, Florida.

Avila, L.A., Cangialosi, J., 2010. Tropical Cyclone Report, Hurricane Ida (AL112009) 4-10 November 2009, National Oceanic and Atmospheric Administration, Miami, Florida.

Back, W., 1985. Hydrogeology of the Yucatan. In: W.C. Ward, A.E. Weidie, W. Back (Eds.), Geology and hydrogeology of the Yucatan and quaternary geology of northeastern Yucatan Peninsula. New Orleans Geological Society, New Orleans, LA, pp. 99-124.

Back, W., Hanshaw, B.B., Herman, J.S., Van Driel, J.N., 1986. Differential dissolution of a Pleistocene reef in the ground-water mixing zone of coastal Yucatan, Mexico. Geology, 14(2), 137-140.

Back, W., Hanshaw, B.B., Pyle, T.E., Plummer, L.N., Weidie, A.E., 1979. Geochemical significance of groundwater discharge and carbonate solution to the formation of Caleta Xel Ha, Quintana Roo, Mexico. Water Resources., 15(6), 1521-1535.

Bayly, M.B., 1960. Errors in point-counter analysis. The American Mineralogist, 45, 447-449.

Bayly, M.B., 1965. The sampling error in modal analysis. The American Mineralogist, 50, 196211.

Belknap, D.F., Kraft, J.C., 1985. Influence of antecedent geology on stratigraphic preservation potential and evolution of Delaware's barrier systems. Marine Geology, 63(14), 235-262.

Beven, J., 2003. Tropical Cyclone Report, Hurricane Claudette 8-17 July 2003, National Oceanic and Atmospheric Administration, Miami, Florida.

Bird, E.C.F., 2008. Coastal Geomorphology: An Introduction. John Wiley \& Sons, Chichester. Birkemeier, W.A., Bichner, E.W., Scarborough, B.L., McConathy, M.A., Eiser, W.C., 1991. Nearshore Profile Response Caused by Hurricane Hugo. Journal of Coastal Research, 113127. 
Blanchon, P., 2010. Reef demise and back-stepping during the last interglacial, northeast Yucatan. Coral Reefs, 29(2), 481-498.

Blanchon, P., 2011a. Back-Stepping. In: D. Hopley (Ed.), Encyclopedia of Modern Coral Reefs: Structure, Form and Process. Springer, Dordrecht, pp. 77-84.

Blanchon, P., 2011b. Meltwater Pulses. In: D. Hopley (Ed.), Encyclopedia of Modern Coral Reefs: Structure, Form and Process. Springer, Dordrecht, pp. 683-690.

Blanchon, P., Iglesias-Prieto, R., Jordán Dahlgren, E., Richards, S., 2010. Arrecifes de coral y cambio climático: vulnerabilidad de la zona costera del estado de Quintana Roo. In: A.V. Botello, S. Villanueva-Fragoso, J. Gutiérrez, J.L. Rojas Galaviz (Eds.), Vulnerabilidad de las zonas costeras mexicanas ante el cambio climático. Semarnat-INE, UNAM-ICMyL, Universidad Autónoma de Campeche, pp. 229-248.

Blanchon, P., Perry, C.T., 2004. Taphonomic differentiation of Acropora palmata facies in cores from Campeche Bank Reefs, Gulf of México. Sedimentology, 51(1), 53-76.

Blanchon, P., Shaw, J., 1995. Reef drowning during the last deglaciation: Evidence for catastrophic sea-level rise and ice-sheet collapse. Geology, 23(1), 4-8.

Blott, S.J., Croft, D.J., Pye, K., Saye, S.E., Wilson, H.E., 2004. Particle size analysis by laser diffraction. Geological Society, London, Special Publications, 232(1), 63-73.

Blott, S.J., Pye, K., 2001. GRADISTAT: a grain size distribution and statistics package for the analysis of unconsolidated sediments. Earth Surface Processes and Landforms, 26(11), 12371248.

Blott, S.J., Pye, K., 2006. Particle size distribution analysis of sand-sized particles by laser diffraction: an experimental investigation of instrument sensitivity and the effects of particle shape. Sedimentology, 53(3), 671-685.

Blott, S.J., Pye, K., 2008. Particle shape: a review and new methods of characterization and classification. Sedimentology, 55(1), 31-63.

Boak, E.H., Turner, I.L., 2005. Shoreline Definition and Detection: A Review. Journal of Coastal Research, 688-703.

Brown, B.E., 1997. Coral bleaching: causes and consequences. Coral Reefs, 16(1), S129-S138.

Brunel, C., Sabatier, F., 2009. Potential influence of sea-level rise in controlling shoreline position on the French Mediterranean Coast. Geomorphology, 107(1-2), 47-57.

Bruun, P., 1954. Coast erosion and the development of beach profiles. In: B.E. Board (Ed.), Technical Memorandum. United States Army Corps of Engineers, Washington, DC, pp. 82.

Bruun, P., 1962. Sea-level rise as a cause of shore erosion. Proceedings of the American Society of Civil Engineers, Journal of the Waterways and Harbors Division 88(WW1), 117130.

Bruun, P., 1983. Review of conditions for uses of the Bruun rule of erosion. Coastal Engineering, 7(1), 77-89.

Bruun, P., 1988. The Bruun Rule of Erosion by Sea-Level Rise: A Discussion on Large-Scale Two- and Three-Dimensional Usages. Journal of Coastal Research, 4(4), 627-648.

Cahoon, D.R., Reed, D.J., Day, J.W., Jr., Steyer, G.D., Roelof, M.B., Lynch, J.C., McNally, D., Latif, N., 1995b. The Influence of Hurricane Andrew on Sediment Distribution in Louisiana Coastal Marshes. J. Coast. Res.(Special Issue 21), 280-294. 
Casarin, R.S., Martinez, G.R., Mariño-Tapia, I., Vanegas, G.P., Baldwin, E.M., Mancera, E.E., 2012. Manmade Vulnerability of the Cancun Beach System: The Case of Hurricane Wilma. CLEAN - Soil, Air, Water, 40(9), 911-919.

Chappell, J., 1980. Coral morphology, diversity and reef growth. Nature, 286(5770), 249-252.

Clancy, M., 2001. Mexican Tourism: Export Growth and Structural Change since 1970. Latin American Research Review, 36(1), 128-150.

Claudino-Sales, V., Wang, P., Horwitz, M.H., 2008. Factors controlling the survival of coastal dunes during multiple hurricane impacts in 2004 and 2005: Santa Rosa barrier island, Florida. Geomorphology, 95(3-4), 295-315.

Coch, N.K., 1994. Geologic effects of hurricanes. Geomorphology, 10(1-4), 37-63.

Coch, N.K., Wolff, M.P., 1991. Effects of Hurricane Hugo Storm Surge in Coastal South Carolina. Journal of Coastal Research, 201-226.

Collins, C.O., 1979. Site and situation strategy in tourism planning: A Mexican case study. Annals of Tourism Research, 6(3), 351-366.

Cooper, J.A.G., Huang, J., Jackson, D.W.T., 2010. Piecewise polynomial expression of beach profiles. Journal of Coastal Research, 26(5), 851-859.

Cooper, J.A.G., Pilkey, O.H., 2004. Sea-level rise and shoreline retreat: time to abandon the Bruun Rule. Global and Planetary Change, 43(3-4), 157-171.

Coronado, C., Candela, J., Iglesias-Prieto, R., Sheinbaum, J., López, M., Ocampo-Torres, F., 2007. On the circulation in the Puerto Morelos fringing reef lagoon. Coral Reefs, 26(1), 149163.

Crowell, M., Douglas, B.C., Leatherman, S.P., 1997. On Forecasting Future U.S. Shoreline Positions: A Test of Algorithms. Journal of Coastal Research, 13(4), 1245-1255.

Darwin, C.R., 1842. The Structure and Distribution of Coral Reefs. Smith, Elder and Co., London.

Davies, P.J., Montaggioni, L.F., 1985. Reef growth and sea-level change: the environmental signature, Proceedings of the Fifth International Coral Reef Congress, Tahiti, pp. 477-515.

Davis Jr, R.A., 1994. Barrier island systems - a geologic overview. In: R.A. Davis Jr (Ed.), Geology of Holocene Barrier Island Systems. Springer-Verlag, New York, pp. 1-46.

Davis, R.A., Hayes, M.O., 1984. What is a wave-dominated coast? Mar. Geol., 60, 313-329.

de Beaumont, L.E., 1845. Lecons de geologie practique. Septieme lecon, 221-252.

Dean, R.G., 1991. Equilibrium Beach Profiles: Characteristics and Applications. J. Coast. Res., 7(1), 53-84.

Dean, R.G., Maurmeyer, E.M., 1983. Models for beach profile response. In: P.D. Komar (Ed.), CRC Handbook of Coastal Processes and Erosion. CRC Press, Boca Raton, FL, pp. 151-165.

Douglas, B.C., Crowell, M., 2000. Long-Term Shoreline Position Prediction and Error Propagation. Journal of Coastal Research, 16(1), 145-152.

Doyle, T.W., Smith, T.J., III, Robblee, M.B., 1995. Wind Damage Effects of Hurricane Andrew on Mangrove Communities Along the Southwest Coast of Florida, USA. Journal of Coastal Research, 159-168.

Dubois, R.N., 1976. Nearshore Evidence in Support of the Bruun Rule on Shore Erosion. The Journal of Geology, 84(4), 485-491. 
Elsner, J.B., Kara, A.B., Owens, M.A., 1999. Fluctuations in North Atlantic hurricane frequency. Journal Climatology, 12(2), 427-437.

Emanuel, K., 2003. Tropical cyclones. Annual Review Earth Planetary Sciences, 31, 75-104.

Emanuel, K., 2005. Increasing destructiveness of tropical cyclones over the past 30 years. Nature, 436(7051), 686-688.

Emanuel, K.A., 1993. The dependence of hurricane intensity on climate (Reprinted from Nature, vol 326, pg 483, 1987). In: R. Bras (Ed.), World at Risk : Natural Hazards and Climate Change. Aip Conference Proceedings. Aip Press, Woodbury, pp. 25-33.

Everts, C., 1985. Sea level rise effects on shoreline position. Journal of Waterway, Port, Coastal and Ocean Engineering, 111(6), 985-999.

Fairbanks, R.G., 1989. A 17,000-year glacio-eustatic sea level record: influence of glacial melting rates on the Younger Dryas event and deep-ocean circulation. Nature, 342(6250), 637-642.

Fearnley, S., Miner, M., Kulp, M., Bohling, C., Penland, S., 2009. Hurricane impact and recovery shoreline change analysis of the Chandeleur Islands, Louisiana, USA: 1855 to 2005. Geo-Mar Lett, 29(6), 455-466.

Fernando, H.J.S., Samarawickrama, S.P., Balasubramanian, S., Hettiarachchi, S.S.L., Voropayev, S., 2008. Effects of porous barriers such as coral reefs on coastal wave propagation. Journal of Hydro-environment Research, 1(3-4), 187-194.

Fischer, A.G., 1961. Stratigraphic record of transgressing seas in light of sedimentation on Atlantic coast of New Jersey. American Association of Petroleum Geologists Bulletin, 45(10), 1656-1667.

FitzGerald, D.M., Heteren, S.v., Montello, T.M., 1994. Shoreline Processes and Damage Resulting from the Halloween Eve Storm of 1991 along the North and South Shores of Massachusetts Bay, U.S.A. Journal of Coastal Research, 10(1), 113-132.

Fitzgerald, D.M., Van Heteren, S., 1999. Classification of paraglacial barrier systems: coastal New England, USA. Sedimentology, 46(6), 1083-1108.

Fluegel, E., 1982. Microfacies analysis of limestones. Springer-Verlag, Berlin.

Folk, R.L., Robles, R., 1964. Carbonate Sands of Isla Perez, Alacran Reef Complex, Yucatán. The Journal of Geology, 72(3), 255-292.

Ford, M., 2011. Sediment Durability. In: D. Hopley (Ed.), Encyclopedia of Modern Coral Reefs: Structure, Form and Process. Springer, Dordrecht, pp. 992-994.

Ford, M.R., Kench, P.S., 2012. The durability of bioclastic sediments and implications for coral reef deposit formation. Sedimentology, 59(3), 830-842.

Franklin, J.L., Brown, D.P., 2006. Tropical Cyclone Report, Hurricane Emily 11-21 July 2005, National Oceanic and Atmospheric Administration, Miami, Florida.

Fritz, H.M., Blount, C., Sokoloski, R., Singleton, J., Fuggle, A., McAdoo, B.G., Moore, A., Grass, C., Tate, B., 2007. Hurricane Katrina storm surge distribution and field observations on the Mississippi Barrier Islands. Estuarine, Coastal and Shelf Science, 74(1-2), 12-20.

Gale, S.J., Hoare, P.G., 1991. Quaternary sediments. Belhaven Press New York.

Gilbert, G.K., 1885. The topographic features of lake shores. United States Geological Survey Annual Report, 75-123. 
Glaeser, J.D., 1978. Global Distribution of Barrier Islands in Terms of Tectonic Setting. The Journal of Geology, 86(3), 283-297.

Goldberg, J., Wilkinson, C., 2004. Global threats to coral reefs: coral bleaching, global climate change, disease, predator plagues, and invasive species. Status of coral reefs of the world, 1, 67-92.

Goldenberg, S.B., Landsea, C.W., Mestas-Nuñez, A.M., Gray, W.M., 2001. The Recent Increase in Atlantic Hurricane Activity: Causes and Implications. Science, 293(5529), 474479.

Gornitz, V., 1991. Global coastal hazards from future sea level rise. Global and Planetary Change, 3(4), 379-398.

Gourlay, M.R., 1994. Wave transformation on a coral reef. Coastal Engineering, 23(1-2), 1742.

Graus, R.R., Macintyre, I.G., 1989. The zonation patterns of Caribbean coral reefs as controlled by wave and light energy input, bathymetric setting and reef morphology: computer simulation experiments. Coral Reefs, 8(1), 9-18.

Gray, W.M., 1968. Global view of origin of tropical disturbances and storms. Mon. Weather Rev., 96(10), 669-700.

Gray, W.M., 1979. Hurricanes: Their formation, structure and likely role in the tropical circulation. Meteorology over the Tropical Oceans., 155-218.

Gray, W.M., 1998. The formation of tropical cyclones. Meteorol. Atmos. Phys., 67(1-4), 3769.

Guilcher, A., 1988. Coral Reef Geomorphology. John Wiley \& Sons, Chichester.

Halford, K.J., 1995. Estimating the Dynamic Water-Level Surfaces Associated with Hurricane Andrew Crossing the Louisiana Coast. Journal of Coastal Research, 265-279.

Hanshaw, B.B., Back, W., 1980. Chemical mass-wasting of the northern Yucatan Peninsula by groundwater dissolution. Geology, 8(5), 222-224.

Harmon, M.E., Whigham, D.F., Sexton, J., Olmsted, I., 1995. Decomposition and Mass of Woody Detritus in the Dry Tropical Forests of the Northeastern Yucatan Peninsula, Mexico. Biotropica, 27(3), 305-316.

Harmon, R.S., Land, L.S., Mitterer, R.M., Garrett, P., Schwarcz, H.P., Larson, G.J., 1981. Bermuda sea level during the last interglacial. Nature, 289(5797), 481-483.

Harmon, R.S., Mitterer, R.M., Kriausakul, N., Land, L.S., Schwarcz, H.P., Garrett, P., Larson, G.J., Leonard Vacher, H., Rowe, M., 1983. U-series and amino-acid racemization geochronology of Bermuda: Implications for eustatic sea-level fluctuation over the past 250,000 years. Palaeogeography, Palaeoclimatology, Palaeoecology, 44(1-2), 41-70.

Hart, D., Kench, P., 2007. Carbonate production of an emergent reef platform, Warraber Island, Torres Strait, Australia. Coral Reefs, 26(1), 53-68.

Hayes, M.O., 1979. Barrier island morphology as a function of tidal and wave regime. In: S.P. Leatherman (Ed.), Barrier islands from the Gulf of St Lawrence to the Gulf of Mexico. Academic Press, New York, pp. 1-27.

Hesp, P., 2002. Foredunes and blowouts: initiation, geomorphology and dynamics. Geomorphology, 48(1-3), 245-268. 
Hesp, P.A., Short, A.D., 1999. Barrier morphodynamics. In: A.D. Short (Ed.), Handbook of Beach and Shoreface Morphodynamics. John Wiley \& Sons, Chichester, pp. 307-333.

Hill, H.W., Kelley, J.T., Belknap, D.F., Dickson, S.M., 2004. The effects of storms and stormgenerated currents on sand beaches in Southern Maine, USA. Mar. Geol., 210(1-4), 149-168.

Holdridge, L.R., Grenke, W.C., Hatheway, W.H., Liang, T., Tosi, J.A., 1971. Forest environments in tropical life zones: a pilot study. Pergamon Press, New York.

Honeycutt, M.G., Crowell, M., Douglas, B.C., 2001. Shoreline-Position Forecasting: Impact of Storms, Rate-Calculation Methodologies, and Temporal Scales. J. Coast. Res., 17(3), 721-730. Hook, D.D., Buford, M.A., Williams, T.M., 1991. Impact of Hurricane Hugo on the South Carolina Coastal Plain Forest. Journal of Coastal Research, 291-300.

Hopley, D., 2004. Coral Reefs. In: M.L. Schwartz (Ed.), Encyclopedia of Coastal Science. Springer, Berlin, pp. 343-349.

Houser, C., Hamilton, S., 2009. Sensitivity of post-hurricane beach and dune recovery to event frequency. Earth Surface Processes and Landforms, 34, 613-628.

Houser, C., Hapke, C., Hamilton, S., 2008a. Controls on coastal dune morphology, shoreline erosion and barrier island response to extreme storms. Geomorphology, 100(3-4), 223-240.

Houze, R.A., Chen, S.S., Smull, B.F., Lee, W.-C., Bell, M.M., 2007. Hurricane Intensity and Eyewall Replacement. Science, 315(5816), 1235-1239.

Hubbard, D.K., Miller, A.I., Scaturo, D., 1990. Production and cycling of calcium carbonate in a shelf-edge reef system (St. Croix, U.S. Virgin Islands): Applications to the nature of reef systems in the fossil record. Journal of Sedimentary Research, 60(3), 335-360.

Hutchings, P.A., 1986. Biological destruction of coral reefs. Coral Reefs, 4(4), 239-252.

IPCC, 2007. Climate Change 2007: Synthesis Report. Contribution of Working Groups I, II and III to the Fourth Assessment Report of the Intergovernmental Panel on Climate Change, IPCC, Geneva, Switzerland.

Irish, J.L., Resio, D.T., Ratcliff, J.J., 2008. The Influence of Storm Size on Hurricane Surge. Journal of Physical Oceanography, 38(9), 2003-2013.

Johnson, D.W., 1919. Shore processes and shoreline development Prentice Hall, New York.

Kahn, J.H., Roberts, H.H., 1982. Variations in storm response along a microtidal transgressive barrier-island arc. Sediment. Geol., 33(2), 129-146.

Keim, B.D., Muller, R.A., Stone, G.W., 2004. Spatial and temporal variability of coastal storms in the North Atlantic Basin. Marine Geology, 210(1-4), 7-15.

Kench, P., 2011. Sediment Dynamics. In: D. Hopley (Ed.), Encyclopedia of Modern Coral Reefs: Structure, Form and Process. Springer, Dordrecht, pp. 994-1005.

Kench, P.S., Brander, R.W., 2006. Wave Processes on Coral Reef Flats: Implications for Reef Geomorphology Using Australian Case Studies. J. Coast. Res., 209-223.

Kench, P.S., McLean, R.F., Nichol, S.L., 2005. New model of reef-island evolution: Maldives, Indian Ocean. Geology, 33(2), 145-148.

Kennedy, D.M., 2003. Surface Lagoonal Sediments on Lord Howe Island, Tasman Sea. J. Coast. Res., 19(1), 57-63.

Kennedy, D.M. (Ed.), 2012 In Press. Topographic field surveying in geomorphology. Treatise on Geomorphology, 14. Academic Press. 
Kennedy, D.M., Woodroffe, C.D., 2002. Fringing reef growth and morphology: a review. Earth-Science Reviews, 57(3-4), 255-277.

Knutson, T.R., Sirutis, J.J., Garner, S.T., Vecchi, G.A., Held, I.M., 2008. Simulated reduction in Atlantic hurricane frequency under twenty-first-century warming conditions. Nat. Geosci., 1(6), 359-364.

Kochel, R.C., Kahn, J.H., Dolan, R., Hayden, B.P., May, P.F., 1985. US mid-Atlantic barrier island geomorphology. J. Coast. Res., 1, 1-9.

Komar, P.D., 1976. Beach Processes and Sedimentation. Prentice Hall.

Komar, P.D., Cui, B., 1984. The analysis of grain-size measurements by sieving and settlingtube techniques. Journal of sedimentary research, 54(2).

Kossin, J.P., Knapp, K.R., Vimont, D.J., Murnane, R.J., Harper, B.A., 2007. A globally consistent reanalysis of hurricane variability and trends. Geophys. Res. Lett., 34(4).

Kraft, J.C., 1971. Sedimentary Facies Patterns and Geologic History of a Holocene Marine Transgression. Geological Society of America Bulletin, 82(8), 2131-2158.

Kraft, J.C., Chrzastowski, M.J., Belknap, D.F., Toscano, M.A., Fletcher, C.H., 1987. The Transgressive Barrier-Lagoon Coast of Delaware: Morphostratigraphy, Sedimentary Sequences and Responses to Relative Rise in Sea Level. The Society of Economic Paleontologists and Mineralogists 129-144.

Ladd, H.S., 1977. Types of coral reefs and their distribution Biology and Geology of Coral Reefs, 4. Academic Press, New York.

Landsea, C.W., 1993. A climatology of intense (or major) Atlantic hurricanes Mon. Weather Rev., 121(6), 1703-1713.

Landsea, C.W., Pielke, R.A., Mestas-Nunez, A., Knaff, J.A., 1999. Atlantic basin hurricanes: Indices of climatic changes. Climate Change, 42(1), 89-129.

Leatherman, S.P., 1979b. Beach and dune interactions during storm conditions. Quarterly Journal of Engineering Geology and Hydrogeology, 12(4), 281-290.

Leatherman, S.P., 1990. Modelling shore response to sea-level rise on sedimentary coasts. Progress in Physical Geography, 14(4), 447-464.

Lee, G.-h., Nicholls, R.J., Birkemeier, W.A., 1998. Storm-driven variability of the beachnearshore profile at Duck, North Carolina, USA, 1981-1991. Mar. Geol., 148(3-4), 163-177.

Loder, N.M., Irish, J.L., Cialone, M.A., Wamsley, T.V., 2009. Sensitivity of hurricane surge to morphological parameters of coastal wetlands. Estuarine, Coastal and Shelf Science, 84(4), 625-636.

Macintyre, I., Graus, R., Reinthal, P., Littler, M., Littler, D., 1987. The Barrier Reef sediment apron: Tobacco Reef, Belize. Coral Reefs, 6(1), 1-12.

Macintyre, I.G., Reid, R.P., 1995. Crystal alteration in a living calvareous alga (Halimeda): Implications for studies in skeletal diagenesis. Journal of Sedimentary Research, 65(1), 143153.

Mainelli, M., 2008. Tropical Cyclone Report, Tropical Storm Olga (AL172007) 11-12 December 2007, National Oceanic and Atmospheric Administration, Miami, Florida.

Massel, S.R., Gourlay, M.R., 2000. On the modelling of wave breaking and set-up on coral reefs. Coastal Engineering, 39(1), 1-27.

McGee, W.J., 1890. Encroachment of the sea. Forum, 9, 437-449. 
McLean, R., Shen, J.-S., 2006. From Foreshore to Foredune: Foredune Development Over the Last 30 Years at Moruya Beach, New South Wales, Australia. J. Coast. Res., 28-36.

Milliman, J.D., 1974. Marine Carbonates. Springer-Verlag, Berlin.

Moore, L.J., 2000. Shoreline Mapping Techniques. Journal of Coastal Research, 16(1), 111124.

Moore, Y.H., Stoessell, R.K., Easley, D.H., 1992. Fresh-Water/Sea-Water Relationship Within a Ground-Water Flow System, Northeastern Coast of the Yucatan Peninsula. Ground Water, 30(3), 343-350.

Morton, R.A., 2002. Factors Controlling Storm Impacts on Coastal Barriers and Beaches - A Preliminary Basis for Near-Time Forecasting. Journal of Coastal Research, 18(3), 486-501.

Morton, R.A., Paine, J.G., 1985. Beach and vegetation-line changes at Galveston Island, Texas: erosion, deposition and recovery from Hurricane Alicia, Geological Circular, The University of Texas at Austin, Bureau of Economic Geology.

Morton, R.A., Paine, J.G., Gibeaut, J.C., 1994. Stages and Durations of Post-Storm Beach Recovery, Southeastern Texas Coast, U.S.A. Journal of Coastal Research, 10(4), 884-908.

Morton, R.A., Sallenger, A.H., 2003. Morphological impacts of extreme storms on sandy beaches and barriers. Journal of Coastal Research, 19(3), 560-573.

Murray, G., 2007. Constructing Paradise: The Impacts of Big Tourism in the Mexican Coastal Zone. Coastal Management, 35(2-3), 339-355.

Neumann, A.C., Macintyre, I.G., 1985. Reef response to sea level rise: keep-up, catch-up or give-up, Proceedings of the Fifth International Coral Reef Congress, Tahiti.

Nicholls, R.J., Wong, P.P., Burkett, V.R., Codignotto, J.O., Hay, J.E., McLean, R.F., Ragoonaden, S., Woodroffe, C.D., 2007. Coastal systems and low-lying areas, Cambridge University Press, Cambridge, UK.

Oretel, G.F., Kraft, J.C., 1994. New Jersey and Delmarva barrier islands. In: R.A. Davis Jr (Ed.), Geology of Holocene Barrier Island Systems. Springer-Verlag, New York, pp. 207-232.

Orme, G.R., 1977. Aspects of sedimentation in the coral reef environment. In: O.A. Jones, R. Endean (Eds.), Biology and Geology of Coral Reefs. Academic Press, pp. 129-182.

Otvos, E.G., 2004. Beach Aggradation Following Hurricane Landfall: Impact Comparisons from Two Contrasting Hurricanes, Northern Gulf of Mexico. Journal of Coastal Research, 20(1), 326-339.

Pasch, R.J., Blake, E.S., Cobb III, H.D., Roberts, D.P., 2006a. Tropical Cyclone Report Hurricane Wilma 15-25 October 2005 National Hurricane Center.

Pasch, R.J., Blake, E.S., Cobb III, H.D., Roberts, D.P., 2006b. Tropical Cyclone Report, Hurricane Wilma 15-25 October 2005, National Oceanic and Atmospheric Administration, Miami, Florida.

Pasch, R.J., Kimberlain, T.B., 2009. Tropical Cyclone Report, Hurricane Dolly (AL042008) 2025 July 2008, National Oceanic and Atmospheric Administration, Miami, Florida.

Pastorok, R.A., Bilyard, G.R., 1985. Effects of sewage pollution on coral-reef communities. Marine ecology progress series. Oldendorf, 21(1), 175-189. 
Penland, S.P., Suter, J.R., Sallenger, A.H., Williams, S.J., McBride, R.A., Westphal, K.E., Reimer, P.D., Jaffe, B.E., 1989. Morphodynamic signature of the 1985 hurricane impacts on the Northern Gulf of Mexico, Sixth Symposium on Coastal and Ocean Management, Charleston, South Carolina, pp. 420-433.

Perkins, R.D., Enos, P., 1968. Hurricane Betsy in the Florida-Bahama Area: Geologic effects and comparison with Hurricane Donna The Journal of Geology, 76(6), 710-717.

Perry, C.T., Spencer, T., Kench, P.S., 2008. Carbonate budgets and reef production states: a geomorphic perspective on the ecological phase-shift concept. Coral Reefs, 27(4), 853-866.

Perry, E., Paytan, A., Pedersen, B., Velazquez-Oliman, G., 2009. Groundwater geochemistry of the Yucatan Peninsula, Mexico: Constraints on stratigraphy and hydrogeology. Journal of Hydrology, 367(1-2), 27-40.

Perry, E., Swift, J., Gamboa, J., Reeve, A., Sanborn, R., Marin, L., Villasuso, M., 1989. Geologic and environmental aspects of surface cementation, north coast, Yucatan, Mexico. Geology, 17(9), 818-821.

Perry, E., Velazquez-Oliman, G., Marin, L., 2002. The Hydrogeochemistry of the Karst Aquifer System of the Northern Yucatan Peninsula, Mexico. International Geology Review, 44(3), 191-221.

Perry, E., Velazquez-Oliman, G., Socki, R.A., 2003. Hydrogeology of the Yucatan Peninsula. In: A. Gomez-Pompa, M.F. Allen, S.L. Fedick, J.J. Jimenez-Osornio (Eds.), The Lowland Maya Area: Three Millennia at the Human-Wildland Interface Food Products Press, an imprint of The Haworth Press, Binghamton, New York, pp. 115-138.

Phillips, J.D., 1999. Event Timing and Sequence in Coastal Shoreline Erosion: Hurricanes Bertha and Fran and the Neuse Estuary. Journal of Coastal Research, 15(3), 616-623.

Pielke, R.A., 1990. The hurricane. Routledge, London.

Pielke, R.A., Landsea, C., Mayfield, M., Laver, J., Pasch, R., 2005. Hurricanes and Global Warming. American Meteorological Society, 1571-1575.

Pielke, R.A., Landsea, C.N., 1999. La Nina, El Nino and Atlantic hurricane damages in the United States. Bull. Amer. Meteorol. Soc., 80(10), 2027.

Pilkey, O.H., Young, R.S., Riggs, S.R., Smith, A.W.S., Wu, H., Pilkey, W.D., 1993. The Concept of Shoreface Profile of Equilibrium: A Critical Review. Journal of Coastal Research, 9(1), 255278.

Pindell, J.L., Barrett, S.F. (Eds.), 1990. Geological evolution of the Caribbean region: a plate tectonic perspective The Caribbean region: the geology of North America. The Geological Society of America.

Pore, A., 1960. Chesapeake Bay hurricane surges. Chesapeake Science, 1(3-4), 178-186.

Powell, M.D., Houston, S.H., 1996b. Hurricane Andrew's landfall in south Florida. Part II: Surface wind fields and potential real-time applications. Weather Forecast., 11, 329-349.

Priestas, A.M., Fagherazzi, S., 2010. Morphological barrier island changes and recovery of dunes after Hurricane Dennis, St. George Island, Florida. Geomorphology, 114(4), 614-626.

Qi, H., Cai, F., Lei, G., Cao, H., Shi, F., 2010. The response of three main beach types to tropical storms in South China. Mar. Geol., 275(1-4), 244-254.

Regnauld, H., Binois, S., Fouqué, C., Lemasson, L., 1999. Micro- to mesoscale evolution of beaches in response to climatic shift: Observation and conceptual modelling (Brittany, France). Geologie en Mijnbouw, 77(3-4), 323-332. 
Regnauld, H., Pirazzoli, P.A., Morvan, G., Ruz, M., 2004. Impacts of storms and evolution of the coastline in western France. Mar. Geol., 210(1-4), 325-337.

Riggs, S.R., Cleary, W.J., Snyder, S.W., 1995. Influence of inherited geologic framework on barrier shoreface morphology and dynamics. Marine Geology, 126(1-4), 213-234.

Ritchie, W., Penland, S., 1988. Rapid dune changes associated with overwash processes on the deltaic coast of South Louisiana. Mar. Geol., 81(1-4), 97-122.

Robertson, W., Zhang, K., Whitman, D., 2007. Hurricane-induced beach change derived from airborne laser measurements near Panama City, Florida. Marine Geology, 237(3-4), 191-205.

Rodríguez-Martínez, R.E., Ruíz-Rentería, F., Tussenbroek, B.v., Barba-Santos, G., EscalanteMancera, E., Jordán-Garza, G., Jordán-Dahlgren, E., 2010. Environmental state and tendencies of the Puerto Morelos CARICOMP site, Mexico. Revista de Biología Tropical, 58, 23-43.

Rodríguez, R.W., Webb, R.M.T., Bush, D.M., 1994. Another Look at the Impact of Hurricane Hugo on the Shelf and Coastal Resources of Puerto Rico, U.S.A. Journal of Coastal Research, 10(2), 278-296.

Rosen, P.S., 1978. A regional test of the Bruun Rule on shoreline erosion. Marine Geology, 26(1-2), M7-M16.

Roy, P.S. (Ed.), 1994. Holocene estuary evolution - stratigraphic studies from southeastern Australia. Incised-Valley Systems: Origin and Sedimentary Sequences, Special Publication. Society of Economic Palaeontologists and Minerologists.

Roy, P.S., Cowell, P.J., Ferland, M.A., Thom, B.G., 1994. Wave dominated coasts. In: R.W.G. Carter, C.D. Woodroffe (Eds.), Coastal Evolution, Late Quaternary Shoreline Morphodynamics Cambridge University Press, Cambridge, pp. 121-186.

Ruíz-Rentería, F., Van Tussenbroek, B.I., Jordán-Dahlgren, E., 1998. Puerto Morelos, Quintana Roo, Mexico. In: B. Kjerfve (Ed.), CARICOMP: Caribbean Coral Reef, Seagrass and Mangrove Sites. UNESCO, Paris, pp. 57-66.

Salinas, L.M., DeLaune, R.D., Jr, W.H.P., 1986. Changes Occurring along a Rapidly Submerging Coastal Area: Louisiana, USA. J. Coast. Res., 2(3), 269-284.

Sallenger (Jr.), A.H., 2000. Storm Impact Scale for Barrier Islands. Journal of Coastal Research, 16(3), 890-895.

Sallenger, A.H., 2000. Storm Impact Scale for Barrier Islands. Journal of Coastal Research, 16(3), 890-895.

Schmitter-Soto, J.J., Comín, F.A., Escobar-Briones, E., Herrera-Silveira, J., Alcocer, J., SuárezMorales, E., Elías-Gutiérrez, M., Díaz-Arce, V., Marín, L.E., Steinich, B., 2002. Hydrogeochemical and biological characteristics of cenotes in the Yucatan Peninsula (SE Mexico). Hydrobiologia, 467(1-3), 215-228.

Schumm, S.A., Lichty, R.W., 1965. Time space and causality in geomorphology. Am. J. Sci., 263(2), 110-\&.

Schwartz, M.L., 1967. The Bruun Theory of Sea-Level Rise as a Cause of Shore Erosion. The Journal of Geology, 75(1), 76-92.

Scoffin, T.P., 1987. Introduction to carbonate sediments and rocks. Blackie, London.

Scoffin, T.P., 1992. Taphonomy of coral reefs: a review. Coral Reefs, 11(2), 57-77. 
Scoffin, T.P., 1993. The geological effects of hurricanes on coral reefs and the interpretation of storm deposits. Coral Reefs, 12(3-4), 203-221.

Shapiro, L.J., Goldenberg, S.B., 1998. Atlantic sea surface temperatures and tropical cyclone formation. J. Clim., 11(4), 578-590.

Short, A.D., 1987. Modes, timing and volume of Holocene cross-shore and aeolian sediment transport, southern Australia, Coastal Sediments '87. American Society of Civil Engineers, New Orleans, pp. 1925-1937.

Silva-Casarín, R., Mendoza-Baldwin, E., Escalante-Mancera, E., Mariño-Tapia, I., RuizRentería, F., 2009. Wind waves induced by hurricane Wilma in Puerto Morelos, Quintana Roo, Mexico. Ingenieria Hidraulica en Mexico, 24(2), 93-109.

Simpson, R.H., 1974. The hurricane disaster-potential scale. Weatherwise, 27(4), 169-186.

Simpson, R.H., Riehl, H., 1981. The hurricane and its impact. The hurricane and its impact. Louisiana State University Press.

Smart, P.L., Beddows, P.A., Coke, J., Doerr, S., Smith, S., Whitaker, F.F., 2006. Cave development on the Caribbean coast of the Yucatan Peninsula, Quintana Roo, Mexico. Geological Society of America Special Papers, 404, 105-128.

Smith, J.S., 2009. Three generations of international tourist resorts in Mexico. Geographische Rundschau International Edition, 5(1), 4-10.

Smithers, S., 2011. Fringing Reefs. In: D. Hopley (Ed.), Encyclopedia of Modern Coral Reefs: Structure, Form and Process. Springer, Dordrecht, pp. 430-446.

Steers, J.A., Stoddart, D.R., 1977. The origin of fringing reefs, barrier reefs, and atolls. In: O.A. Jones, R. Endean (Eds.), Biology and Geology of Coral Reefs. Academic Press, pp. 21-55.

Steinen, R.P., Harrison, R.S., Matthews, R.K., 1973. Eustatic low stand of sea level between 125,000 and 105,000 B.P.: Evidence from the subsurface of Barbados, West Indies. Geological Society of America Bulletin, 84, 63-70.

Steinich, B., Marín, L.E., 1997. Determination of flow characteristics in the aquifer of the Northwestern Peninsula of Yucatan, Mexico. Journal of Hydrology, 191(1-4), 315-331.

Stewart, S.R., 2001. Tropical Cyclone Report, Hurricane Gordon 14-18 September 2000, National Oceanic and Atmospheric Administration, Miami, Florida.

Stewart, S.R., 2003. Tropical Cyclone Report, Tropical Storm Larry 1-6 October 2003, National Oceanic and Atmospheric Administration, Miami, Florida.

Stewart, S.R., 2005. Tropical Cyclone Report, Hurricane Ivan 2-24 September 2004 National Oceanic and Atmospheric Administration, Miami, Florida.

Stoddart, D.R., 1964. Storm conditions and vegetation in equilibrium of reef islands 9th International Conference on Coastal Engineering, Lisbon, Portugal, pp. 893-906.

Stoessell, R.K., Ward, W.C., Ford, B.H., Schuffert, J.D., 1989. Water chemistry and CaCO3 dissolution in the saline part of an open-flow mixing zone, coastal Yucatan Peninsula, Mexico. Geological Society of America Bulletin, 101(2), 159-169.

Swift, D.J.P., 1975. Barrier-island genesis: evidence from the central atlantic shelf, eastern U.S.A. Sediment. Geol., 14(1), 1-43.

Szabo, B.J., Ward, W.C., Weidie, A.E., Brady, M.J., 1978. Age and magnitude of the late Pleistocene sea-level rise on the eastern Yucatan Peninsula. Geology, 6, 713-715. 
Thom, B.G., Hall, W., 1991. Behaviour of beach profiles during accretion and erosion dominated periods. Earth Surface Processes and Landforms, 16(2), 113-127.

Toscano, M.A., Macintyre, I.G., 2003. Corrected western Atlantic sea-level curve for the last 11,000 years based on calibrated $14 \mathrm{C}$ dates from Acropora palmata framework and intertidal mangrove peat. Coral Reefs, 22(3), 257-270.

Toscano, M.A., Macintyre, I.G., 2005. Blanchon P, Comment on Toscano MA and Macintyre IG (2003): Corrected western Atlantic sea-level curve for the last 11,000 years based on calibrated dates from Acropora palmata framework and intertidal mangrove peat. Coral Reefs 22:257-270. Coral Reefs, 24(2), 187-190.

Tracey, J.I., Ladd, H.S., Hoffmeister, J.E., 1948. Reefs of Bikini, Marshall Islands. Geological Society of America Bulletin, 59(9), 861-878.

Trenberth, K.E., Jones, P.D., Ambenje, P., Bojariu, R., Easterling, D., Klein-Tank, A., Parker, D., Rahimzadeh, F., Renwick, J.A., Rusticucci, M., Soden, B., Zhai, P., 2007. Observations: Surface and Atmospheric Climate Change, Cambridge, UK and New York, USA.

Trenberth, K.E., Shea, D.J., 2006. Atlantic hurricanes and natural variability in 2005. Geophys. Res. Lett., 33(12), L12704.

Türker, U., Yagci, O., KabdaslI, M.S., 2006. Analysis of coastal damage of a beach profile under the protection of emergent vegetation. Ocean Engineering, 33(5-6), 810-828.

van Tussenbroek, B.I., Barba Santos, M.G., van Dijk, J.K., Sanabria Alcaraz, S.N.M., Téllez Calderón, M.L., 2008. Selective Elimination of Rooted Plants from a Tropical Seagrass Bed in a Back-Reef Lagoon: A Hypothesis Tested by Hurricane Wilma (2005). J. Coast. Res., 278281.

Viniegra-O, F., 1971. Age and evolution of salt basins of southeastern Mexico. American Association of Petroleum Geologists, 55(3), 478-494.

Wang, C., Lee, S.-k., 2007. Atlantic warm pool, Caribbean low-level jet, and their potential impact on Atlantic hurricanes. Geophys. Res. Lett., 34(2), L02703.

Wang, P., Horwitz, M.H., 2007. Erosional \& depositional characteristics of regional overwash deposits caused by multiple hurricanes. Sedimentology, 54(3), 545-564.

Wang, P., Kirby, J.H., Haber, J.D., Horwitz, M.H., Knorr, P.O., Krock, J.R., 2006. Morphological and sedimentological impacts of hurricane ivan and immediate poststorm beach recovery along the northwestern Florida barrier-island coasts. J. Coast. Res., 22(6), 1382-1402.

Ward, W.C., 1985. Quaternary geology of northeastern Yucatan Peninsula. In: W.C. Ward, A.E. Weidie, W. Back (Eds.), Geology and hydrogeology of the Yucatan and quaternary geology of northeastern Yucatan Peninsula. New Orleans Geological Society, New Orleans, LA, pp. 23-95.

Ward, W.C., Brady, M.J., 1979. Strandline sedimentation of carbonate grainstones, Upper Pleistocene, Yucatan Peninsula, Mexico American Association of Petroleum Geologists Bulletin, 63, 362-369.

Ward, W.C., Halley, R.B., 1985. Dolomitization in a mixing zone of near-seawater composition, late Pleistocene, northeastern Yucatan Peninsula. Journal of Sedimentary Research, 55, 407-420.

Ward, W.C., Wilson, J.L., 1976. General aspects of the northeastern coast of the Yucatan Peninsula. In: A.E. Weidie, W.C. Ward (Eds.), Carbonate rocks and hydrogeology of the Yucatan Peninsula, Mexico. New Orleans Geological Society, New Orleans, LA, pp. 35-44. 
Weaver, R.J., Slinn, D.N., 2010. Influence of bathymetric fluctuations on coastal storm surge. Coastal Engineering, 57(1), 62-70.

Webster, P.J., Holland, G.J., Curry, J.A., Chang, H.R., 2005. Changes in tropical cyclone number, duration, and intensity in a warming environment. Science, 309(5742), 1844-1846.

Weidie, A.E., 1976. Regional geology of Yucatan Peninsula. In: A.E. Weidie, W.C. Ward (Eds.), Carbonate rocks and hydrogeology of the Yucatan Peninsula, Mexico. New Orleans Geological Society, New Orleans, LA, pp. 2-17.

Weidie, A.E., 1985. Geology of Yucatan Platform. In: W.C. Ward, A.E. Weidie, W. Back (Eds.), Geology and hydrogeology of the Yucatan and quaternary geology of northeastern Yucatan Peninsula. New Orleans Geological Society, New Orleans, LA, pp. 1-19.

Whelan Iii, T., Van Tussenbroek, B.I., Barba Santos, M.G., 2011. Changes in trace metals in Thalassia testudinum after hurricane impacts. Marine Pollution Bulletin, 62(12), 2797-2802.

Whigham, D.F., Olmsted, I., Cano, E.C., Harmon, M.E., 1991. The Impact of Hurricane Gilbert on Trees, Litterfall, and Woody Debris in a Dry Tropical Forest in the Northeastern Yucatan Peninsula. Biotropica, 23(4), 434-441.

Whigham, D.F., Towle, P.Z., Cano, E.C., O'Neill, J.O., Ley, E., 1990. The effect of annual variation in precipitation on growth and litter production in a tropical dry forest in the Yucatan of Mexico. Tropical Ecology, 3, 23-34.

Wolman, M.G., Miller, J.P., 1960. Magnitude and Frequency of Forces in Geomorphic Processes. The Journal of Geology, 68(1), 54-74.

Woodroffe, C.D. (Ed.), 2002. Coasts: Form, process and evolution. Cambridge University Press, New York.

Woodroffe, C.D., 2007. Critical thresholds and the vulnerability of Australian tropical ecosystems to the impacts of climate change, Proceedings of the 9th International Coastal Symposium. Journal of Coastal Research, Gold Coast, Australia, pp. 464-468.

Wright, L.D., Swaye, F.J., Coleman, J.M., 1970. Effects of Hurricane Camille on the landscape of the Breton-Chandeleur Island Chain and the eastern portion of the Lower Mississippi Delta, Coastal Studies Institute, Louisiana State University.

Zenkovich, V.P., 1967. Processes of Coastal Development. Oliver \& Boyd, Edinburgh.

Zhang, K., Douglas, B., Leatherman, S.P., 2002. Do Storms Cause Long-Term Beach Erosion along the U.S. East Barrier Coast? The Journal of Geology, 110(4), 493-502.

Zhang, K., Douglas, B.C., Leatherman, S.P., 2001. Beach Erosion Potential for Severe Nor'easters. J. Coast. Res., 17(2), 309-321. 


\section{Appendices}




\subsection{Across-shore beach profile data and statistics}


Zone 1: Wet 'n' Wild

\begin{tabular}{|c|c|c|c|c|c|c|c|c|c|c|c|c|c|c|c|c|c|c|c|c|c|c|c|c|c|c|c|c|c|c|c|c|c|}
\hline \multirow[b]{2}{*}{ Site } & \multirow{2}{*}{ 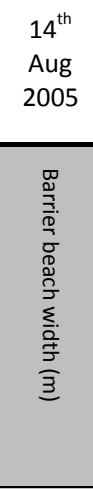 } & \multicolumn{3}{|c|}{$25^{\text {th }}$ October 2005} & \multicolumn{9}{|c|}{ June 2006 (8 months after Hurricane Wilma) } & \multicolumn{19}{|c|}{ April 2010 (54 months after Hurricane Wilma) } & \multirow[b]{2}{*}{ 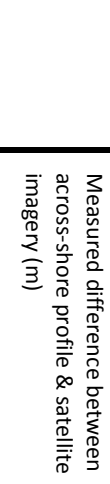 } \\
\hline & & 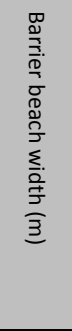 & 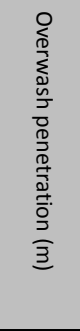 & 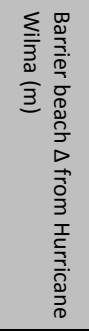 & 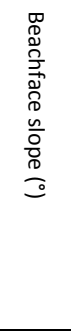 & 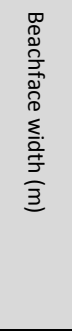 & 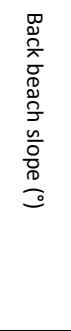 & 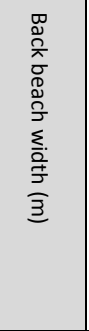 & 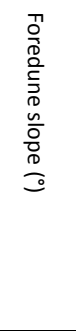 & 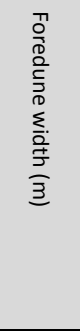 & 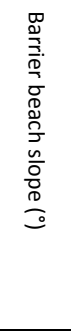 & 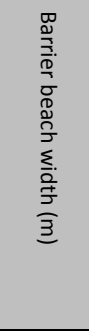 & 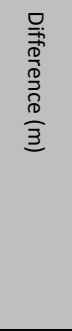 & 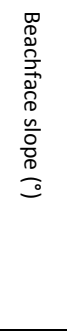 & 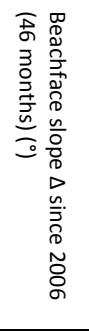 & 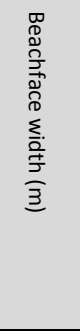 & 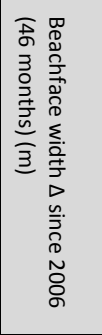 & 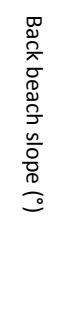 & 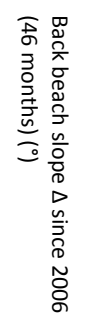 & 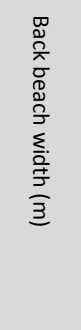 & 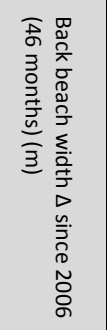 & 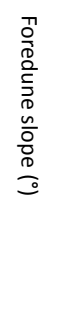 & 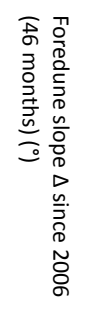 & 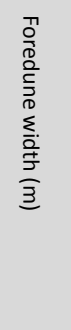 & 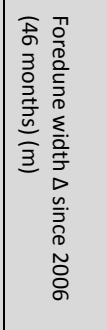 & 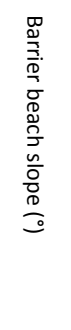 & 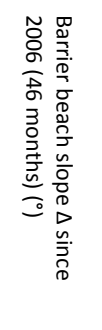 & 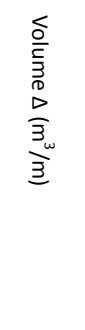 & 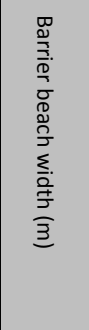 & 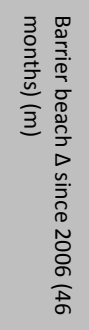 & 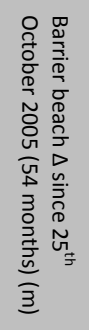 & 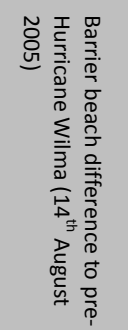 & \\
\hline WnW-1 $t^{*}$ & 31.81 & 47.82 & 62.2 & 16.01 & $\mathrm{n} / \mathrm{a}$ & $\mathrm{n} / \mathrm{a}$ & $\mathrm{n} / \mathrm{a}$ & n/a & $\mathrm{n} / \mathrm{a}$ & $\mathrm{n} / \mathrm{a}$ & $\mathrm{n} / \mathrm{a}$ & 39.18 & -8.64 & n/a & $\mathrm{n} / \mathrm{a}$ & $n / a$ & $\mathrm{n} / \mathrm{a}$ & $\mathrm{n} / \mathrm{a}$ & $\mathrm{n} / \mathrm{a}$ & n/a & $\mathrm{n} / \mathrm{a}$ & $n / a$ & $n / a$ & $\mathrm{n} / \mathrm{a}$ & $\mathrm{n} / \mathrm{a}$ & $\mathrm{n} / \mathrm{a}$ & $\mathrm{n} / \mathrm{a}$ & $\mathrm{n} / \mathrm{a}$ & 25.61 & -13.57 & -22.21 & -6.2 & $\mathrm{n} / \mathrm{a}$ \\
\hline$W_{n n W-22^{*}}$ & 26.45 & 45.05 & 63.34 & 18.60 & n/a & n/a & $\mathrm{n} / \mathrm{a}$ & n/a & n/a & n/a & $n / a$ & 39.68 & -5.37 & $\mathrm{n} / \mathrm{a}$ & $\mathrm{n} / \mathrm{a}$ & $n / a$ & $\mathrm{n} / \mathrm{a}$ & $\mathrm{n} / \mathrm{a}$ & $\mathrm{n} / \mathrm{a}$ & n/a & $\mathrm{n} / \mathrm{a}$ & n/a & n/a & n/a & $\mathrm{n} / \mathrm{a}$ & $\mathrm{n} / \mathrm{a}$ & $n / a$ & $\mathrm{n} / \mathrm{a}$ & 28.62 & -11.06 & -16.43 & 2.17 & $n / a$ \\
\hline 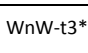 & 30.38 & 48.91 & 59.19 & 18.53 & $n / a$ & $n / a$ & n/a & n/a & $n / a$ & n/a & n/a & 40.7 & -8.21 & n/a & $\mathrm{n} / \mathrm{a}$ & $n / a$ & n/a & $\mathrm{n} / \mathrm{a}$ & $n / a$ & n/a & $n / a$ & $n / a$ & $n / a$ & $n / a$ & $n / a$ & $n / a$ & $n / a$ & n/a & 28.41 & -12.29 & -20.50 & -1.97 & $n / a$ \\
\hline WnW-4t* & 32.47 & 52.41 & 66.1 & $\begin{array}{l}9.94 \\
\end{array}$ & $n / a$ & $n / a$ & n/a & n/a & $n / a$ & n/a & n/a & 44.87 & -7.54 & n/a & $n / a$ & $n / a$ & n/a & $n / a$ & $n / a$ & n/a & $\mathrm{n} / \mathrm{a}$ & $n / a$ & $n / a$ & $\mathrm{n} / \mathrm{a}$ & $\mathrm{n} / \mathrm{a}$ & $\mathrm{n} / \mathrm{a}$ & $n / a$ & $n / a$ & 32.77 & -12.10 & $\begin{array}{l}-19.64 \\
\end{array}$ & 0.3 & $n / a$ \\
\hline$W_{n} W-5^{*}$ & 29.90 & 45.28 & 72.13 & 15.38 & $n / 2$ & $n / a$ & n/a & n/a & $n / 2$ & n/a & n/a & 41.2 & -4.08 & n/a & $n / a$ & n/a & n/a & $n / a$ & $n / a$ & n/a & $n / a$ & $n / a$ & $n / a$ & $n / a$ & $n / a$ & n/a & $n / a$ & n/a & 34.93 & -6.27 & -10.35 & 5.03 & $n / a$ \\
\hline WnW-t6 & 36.53 & 53.25 & 75.66 & 16.72 & 5.48 & 8 & -0.13 & 18 & 3.09 & 26 & 1.75 & 52 & -1.25 & 6.51 & 1.02 & 6.03 & -1.97 & 1.47 & 1.60 & 19.0 & 1.00 & 4.84 & 1.75 & 11.6 & $\begin{array}{l}-14.40 \\
\end{array}$ & 2.53 & 0.78 & -7.89 & 36.63 & -15.37 & -16.62 & 0.1 & 1.2 \\
\hline$W_{n} W-77^{*}$ & 32.58 & $\begin{array}{l}49.47 \\
\end{array}$ & 78.59 & 16.89 & $n / 2$ & $n / 2$ & n/a & $n / a$ & $n / 2$ & $n / a$ & n/a & 43.23 & -6.24 & n/a & $n / a$ & $n / a$ & $n / a$ & $n / a$ & $n / a$ & n/a & $n / a$ & $n / a$ & $n / a$ & $n / a$ & $n / a$ & $n / a$ & $n / a$ & n/a & 33.33 & -9.90 & -16.14 & 0.75 & $n / a$ \\
\hline$W_{n} W-18$ & 32.63 & 54.77 & 66.79 & 22.14 & 6.53 & 6 & -0.39 & 14 & 3.01 & 28 & 1.95 & 48 & -6.77 & 6.17 & -0.36 & 6.67 & 0.67 & -2.67 & -2.29 & 1.8 & -12.20 & 4.52 & 1.51 & 26.4 & -1.60 & 3.81 & 1.86 & 2.22 & 34.87 & -13.13 & -19.90 & 2.24 & 0.8 \\
\hline WnW-9* & 35.12 & 52.57 & 80.35 & 17.45 & $n / a$ & $n / a$ & n/a & n/a & $n / a$ & n/a & n/a & 45.85 & -6.72 & n/a & $n / a$ & $n / a$ & n/a & $n / a$ & $n / a$ & n/a & $n / a$ & $n / a$ & $n / a$ & $n / a$ & $n / a$ & $n / a$ & $\mathrm{n} / \mathrm{a}$ & n/a & 44.60 & -1.25 & -7.97 & 9.48 & $n / a$ \\
\hline$W_{n} W-110$ & 39.57 & 55.12 & 59.12 & 15.55 & 4.57 & 8 & 0.29 & 18 & 5.14 & 28 & 2.59 & 54 & -1.12 & 5.57 & 1.00 & 8.59 & 0.59 & 1.10 & 0.81 & 20.4 & 2.40 & 8.92 & 3.78 & 10.8 & $\begin{array}{l}-17.20 \\
\end{array}$ & 3.14 & 0.55 & -11.59 & 39.79 & -14.21 & -15.33 & 0.22 & 0.7 \\
\hline$W_{n} W-t 11$ & 42 & 54.25 & 66.04 & 12.25 & 7.77 & 6 & -0.54 & 12 & 3.60 & 32 & 2.47 & 50 & -4.25 & 4.77 & -3.00 & 8.54 & 2.54 & 0.34 & 0.89 & 8.0 & -4.00 & 3.65 & 0.05 & 27.2 & -4.80 & 3.06 & 0.59 & 2.08 & 43.74 & -6.26 & -10.51 & 1.74 & 1.0 \\
\hline$W_{n} W-112$ & 32.10 & 48.02 & 51.75 & 15.92 & 6.33 & 6 & -0.14 & 12 & 4.57 & 26 & 2.89 & 44 & -4.02 & 10.83 & 4.49 & 4.05 & -1.95 & 1.37 & 1.51 & 3.4 & -8.60 & 4.52 & -0.05 & 22.0 & -4.00 & 4.47 & 1.58 & 3.27 & 29.45 & -14.55 & -18.57 & -2.65 & 0.9 \\
\hline$W_{n} W-113$ & 33.20 & 44.15 & 48.60 & 10.95 & 6.56 & 6 & 0.14 & 12 & 3.60 & 26 & 2.43 & 44 & -0.15 & 5.11 & $\begin{array}{l}-1.45 \\
\end{array}$ & 6.32 & 0.32 & 3.81 & 3.66 & 9.8 & -2.20 & 3.77 & 0.17 & 21.4 & -4.60 & 3.60 & 1.17 & 3.81 & 37.52 & -6.48 & -6.63 & 4.32 & 0.5 \\
\hline WnW -124 & 32.44 & 35.57 & 36.57 & 3.13 & 8.33 & 6 & 1.49 & 8 & 4.66 & 24 & 4.35 & 38 & 2.43 & 6.17 & -2.16 & 6.01 & 0.01 & 6.52 & 5.03 & 3.4 & -4.60 & 3.75 & -0.91 & 27.0 & 3.00 & 4.14 & -0.22 & -8.45 & 36.41 & -1.59 & 0.84 & 3.97 & 0.3 \\
\hline WnW-115 & n/a & $n / a$ & $n / a$ & $n / a$ & 8.08 & 8 & 0.51 & 14 & 5.28 & 22 & 3.02 & 44 & $n / a$ & 6.75 & -1.33 & 8.26 & 0.26 & 1.81 & 1.30 & 11.8 & -2.20 & 5.01 & -0.27 & 20.0 & -2.00 & 3.55 & 0.53 & -0.13 & 40.06 & -3.94 & $n / a$ & $n / a$ & 0.7 \\
\hline$W_{n} W-116$ & 37.60 & 51.52 & 67.76 & 13.92 & 5.71 & 8 & 0.42 & 16 & 5.91 & 26 & 3.19 & 50 & $\begin{array}{l}-1.52 \\
\end{array}$ & 6.87 & 1.16 & 6.70 & $\begin{array}{l}-1.30 \\
\end{array}$ & 2.20 & 1.78 & 10.4 & -5.60 & 5.09 & $\begin{array}{l}-0.82 \\
\end{array}$ & 24.5 & -1.50 & 3.88 & 0.69 & -2.15 & 41.60 & -8.40 & -9.92 & 4.00 & 0.5 \\
\hline$W_{n} W-117$ & 46.98 & 53.95 & 61.47 & 6.97 & 7.83 & 6 & 0.49 & 24 & 5.93 & 22 & 2.67 & 52 & -1.95 & 6.87 & -0.96 & 7.43 & 1.43 & 0.84 & 0.35 & 18.4 & -5.60 & 6.02 & 0.09 & 16.4 & -5.60 & 3.25 & 0.58 & -2.72 & 42.23 & -9.77 & -11.72 & -4.75 & 1.1 \\
\hline Mean & 34.49 & 49.51 & 63.48 & 15.02 & 6.72 & 6.80 & 0.21 & 14.80 & 4.48 & 26.00 & 2.73 & 45.34 & -4.09 & 6.56 & -0.16 & 6.86 & 0.06 & 1.68 & 1.46 & 10.64 & -4.16 & 5.01 & 0.53 & 20.73 & -5.27 & 3.54 & 0.81 & -2.16 & 35.92 & -9.42 & -13.85 & 1.17 & 0.77 \\
\hline S.D. & 5.07 & 5.19 & 11.27 & 4.80 & 1.25 & 1.03 & 0.58 & 4.44 & 1.10 & 2.98 & 0.72 & 4.92 & 3.23 & 1.67 & 2.16 & 1.40 & 1.45 & 2.36 & 1.94 & 6.81 & 4.30 & 1.56 & 1.43 & 6.06 & 6.10 & 0.57 & 0.59 & 5.46 & 5.7 & 4.48 & 6.19 & 3.91 & 0.29 \\
\hline & $=$ & & & 12.51 & & & & & & & & & 5.07 & & & & & & & & & & & & & & & & & $8.66^{6 *}$ & 8.95 & 1.20 & \\
\hline & & & & & & & & & & & & & & & & & & & & & & & & & & & & & & & & & \\
\hline
\end{tabular}

*Denotes sites where only measurements of the barrier beach system as a whole were included.

**All 17 sites included when calculating the test statistics. 
Zone 2: Punta Tanchacte

\begin{tabular}{|c|c|c|c|c|c|c|c|c|c|c|c|c|c|c|c|c|c|c|c|c|c|c|c|c|c|c|c|c|c|c|c|c|c|c|}
\hline \multirow[b]{2}{*}{ Site } & \multirow{2}{*}{ 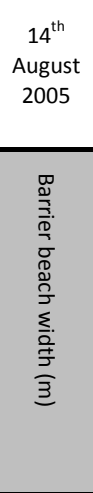 } & \multicolumn{3}{|c|}{$25^{\text {th }}$ October 2005} & \multicolumn{9}{|c|}{ June 2006 (8 months after Hurricane Wilma) } & \multicolumn{20}{|c|}{ May/June 2010 (55/56 months after Hurricane Wilma) } & \multirow[b]{2}{*}{ 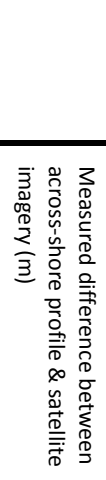 } \\
\hline & & 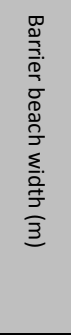 & 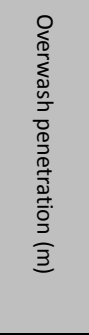 & 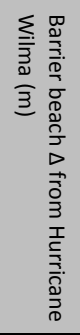 & 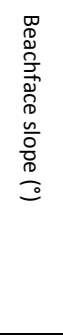 & 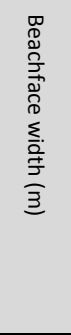 & 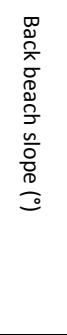 & 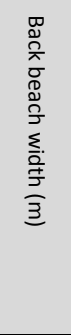 & 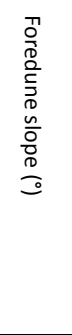 & 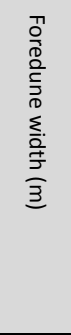 & 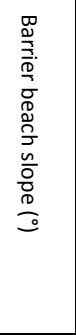 & 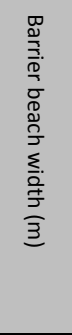 & 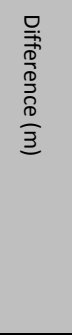 & 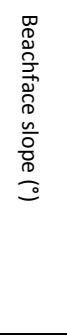 & 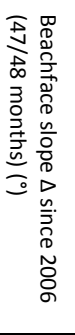 & 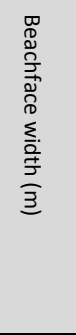 & 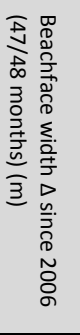 & 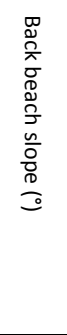 & 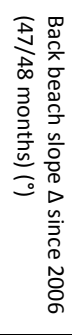 & 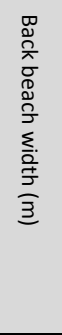 & 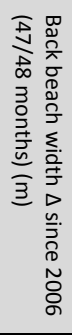 & 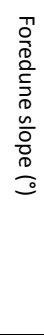 & 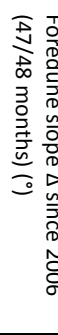 & 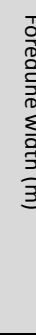 & & 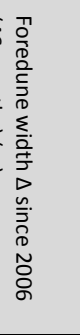 & 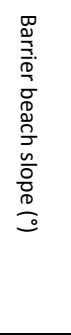 & 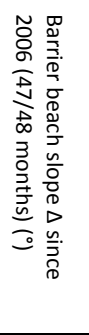 & 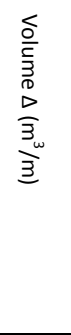 & 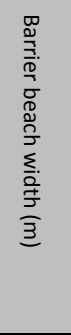 & 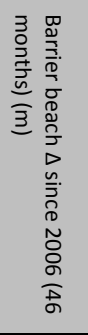 & 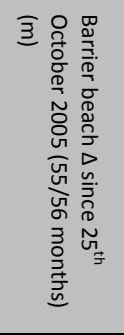 & 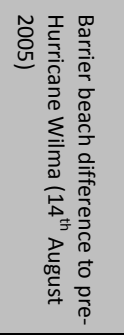 & \\
\hline Pnttrch-11 & 46.23 & 61.61 & $<61.61$ & 15.38 & 6.20 & 9.86 & 0.19 & 24.00 & 5.27 & 24.00 & 2.36 & 57.86 & -3.75 & 4.62 & -1.58 & 12.00 & 2.14 & 0.87 & 0.68 & 16.60 & -7.40 & 8.38 & 3.11 & 23. & & -1.00 & 4.37 & 2.00 & 10.93 & 51.60 & -6.26 & -10.01 & 5.37 & 1.3 \\
\hline Pnttnch +2 2 & 64.28 & 81.64 & $<81.64$ & 17.36 & 6.52 & 8.81 & 0.09 & 26.00 & 8.79 & 38.00 & 4.10 & 72.81 & -8.83 & 6.47 & -0.05 & 8.20 & -0.61 & 1.25 & 1.16 & 15.20 & -10.80 & 6.81 & -1.98 & 44. & & 6.00 & 4.66 & 0.55 & 30.55 & 67.40 & -5.41 & -14.24 & 3.12 & 1.1 \\
\hline Pnttnch - t3 & 58.14 & 71.50 & $<71.50$ & 13.36 & 7.24 & 7.05 & -0.09 & 32.00 & 8.65 & 26.00 & 2.76 & 65.05 & -6.45 & 4.83 & -2.42 & 10.80 & 3.75 & 0.89 & 0.99 & 23.60 & -8.40 & 7.87 & -0.78 & 25. & & -0.80 & 3.52 & 0.76 & 19.96 & 59.60 & -5.45 & -11.9 & 1.46 & 0.9 \\
\hline PntTnch - -t4* & 62.06 & 69.78 & 94.57 & 7.72 & $n / a$ & n/a & n/a & n/a & $\mathrm{n} / \mathrm{a}$ & n/a & $n / a$ & 72.51 & 2.73 & $n / a$ & $n / a$ & n/a & n/a & $n / a$ & $n / a$ & $n / a$ & n/a & $n / a$ & $n / a$ & $\mathrm{n} /$ & & $n / a$ & $n / a$ & n/a & $\mathrm{n} / \mathrm{a}$ & 54.40 & -18.11 & - 15.38 & -7.66 & n/a \\
\hline PntTnch - $-5 *$ & 70.50 & 88.05 & 111.52 & 17.55 & n/a & n/a & n/a & n/a & $n / a$ & $n / a$ & n/a & 79.81 & -8.24 & $n / a$ & n/a & n/a & $n / a$ & $n / a$ & n/a & $n / a$ & n/a & $n / a$ & $n / a$ & $\mathrm{n}$ & & $n / a$ & $n / a$ & $n / a$ & $\mathrm{n} / \mathrm{a}$ & 79.10 & -0.71 & -8.95 & 8.60 & n/a \\
\hline Pritnch-16 & 40.92 & 61.77 & 84.57 & 20.85 & 6.27 & 6.59 & -1.35 & 20.00 & 3.53 & 38.00 & 1.56 & 58.59 & -3.18 & 3.69 & -2.58 & 10.40 & 3.81 & -0.18 & 1.16 & 8.00 & -12.00 & 3.03 & -0.51 & 26. & & -11.80 & 2.07 & 0.51 & -23.75 & 44.60 & -13.99 & -17.17 & 3.68 & 0.8 \\
\hline Prttnch-t7 & 69.62 & 84.85 & 95.77 & 15.23 & 7.64 & 7.19 & -0.33 & 36.00 & 6.94 & 36.00 & 2.33 & 79.19 & -5.66 & 4.36 & -3.27 & 11.40 & 4.21 & 0.15 & 0.49 & 29.60 & -6.40 & 7.35 & 0.41 & 28. & & -7.60 & 2.80 & 0.47 & 14.33 & 69.40 & -9.79 & -15.45 & -0.22 & 0.9 \\
\hline Pnttnch-18 & $n / a$ & $n / a$ & $n / a$ & n/a & 7.19 & 7.16 & -0.17 & 34.00 & 5.50 & 32.00 & 1.93 & 73.16 & $n / a$ & 4.27 & -2.92 & 7.00 & -0.16 & 1.15 & 1.32 & 25.00 & -9.00 & 5.34 & -0.16 & 34. & & 2.00 & 2.89 & 0.96 & 19.63 & 66.00 & -7.16 & $n / a$ & n/a & 0.9 \\
\hline PntTnch -t9* & 62.95 & 79.21 & $<79.21$ & 16.26 & n/a & $n / a$ & n/a & n/a & $\mathrm{n} / \mathrm{a}$ & $n / a$ & $\mathrm{n} / \mathrm{a}$ & 78.94 & -0.27 & $n / a$ & $n / a$ & n/a & n/a & n/a & $n / a$ & $n / a$ & $n / a$ & $n / a$ & $n / a$ & $\mathrm{n}$ & & $\mathrm{n} / \mathrm{a}$ & $n / a$ & $n / a$ & $\mathrm{n} / \mathrm{a}$ & 61.49 & -17.45 & -17.72 & -1.46 & $\mathrm{n} / \mathrm{a}$ \\
\hline PntTnch - $110^{*}$ & 61.74 & 77.20 & $<77.20$ & 15.46 & $n / a$ & $\mathrm{n} / \mathrm{a}$ & n/a & n/a & $n / a$ & $n / a$ & $n / a$ & 76.98 & -0.22 & $n / a$ & $\mathrm{n} / \mathrm{a}$ & n/a & n/a & $n / a$ & $n / a$ & $n / a$ & n/a & $n / a$ & $n / a$ & $\mathrm{n}$ & & $n / a$ & $n / a$ & $n / a$ & n/a & 67.72 & -9.26 & -9.48 & 5.98 & $n / a$ \\
\hline PntTnch- $-111^{*}$ & 65.45 & 80.82 & $<8.82$ & 15.37 & $n / a$ & $\mathrm{n} / \mathrm{a}$ & n/a & $n / a$ & $\mathrm{n} / \mathrm{a}$ & $n / a$ & n/a & 82.35 & 1.53 & $\mathrm{n} / \mathrm{a}$ & $\mathrm{n} / \mathrm{a}$ & n/a & $n / a$ & $\mathrm{n} / \mathrm{a}$ & $n / a$ & $n / a$ & n/a & $n / a$ & $n / a$ & $\mathrm{n} /$ & & $\mathrm{n} / \mathrm{a}$ & $\mathrm{n} / \mathrm{a}$ & $\mathrm{n} / \mathrm{a}$ & $n / a$ & 66.78 & -15.57 & -14.04 & 1.33 & n/a \\
\hline PntTnch - t12* & 56.08 & 80.64 & $<80.64$ & 24.56 & $n / a$ & $n / a$ & $\mathrm{n} / \mathrm{a}$ & $n / a$ & $n / a$ & $n / a$ & $\mathrm{n} / \mathrm{a}$ & 70.90 & -9.74 & $n / a$ & $n / a$ & n/a & $n / a$ & n/a & $n / a$ & $n / a$ & $\mathrm{n} / \mathrm{a}$ & $n / a$ & $n / a$ & $\mathrm{n} /$ & & $n / a$ & $n / a$ & n/a & $n / a$ & 53.05 & -17.85 & -27.59 & -3.03 & $n / a$ \\
\hline PntTnch - $-13^{*}$ & 68.86 & 82.33 & $<82.33$ & 13.47 & $n / a$ & $\mathrm{n} / \mathrm{a}$ & n/a & n/a & $\mathrm{n} / \mathrm{a}$ & $n / a$ & n/a & 81.94 & -0.39 & $n / a$ & $n / a$ & n/a & n/a & $n / a$ & $n / a$ & $n / a$ & $n / a$ & $n / a$ & $n / a$ & n/ & & $n / a$ & $n / a$ & $n / a$ & $\mathrm{n} / \mathrm{a}$ & 65.10 & - 16.84 & -17.23 & -3.76 & $n / a$ \\
\hline PntTnch - $-11^{*}$ & 67.65 & 86.82 & $<86.82$ & 19.17 & $n / a$ & $n / a$ & n/a & $n / a$ & $n / a$ & n/a & $\mathrm{n} / \mathrm{a}$ & 79.90 & -6.92 & $n / a$ & $n / a$ & $\mathrm{n} / \mathrm{a}$ & n/a & n/a & $n / a$ & $n / a$ & $\mathrm{n} / \mathrm{a}$ & $n / a$ & n/a & $\mathrm{n} /$ & & $n / a$ & $n / a$ & $n / a$ & n/a & 66.20 & -13.7 & -20.62 & -1.45 & $n / a$ \\
\hline Prttreh - 115 & 74.61 & 88.50 & $<85.50$ & 13.89 & 3.44 & 10.67 & 0.05 & 36.00 & 6.57 & 40.00 & 2.20 & 86.67 & -1.83 & 3.29 & -0.15 & 11.00 & 0.33 & 0.42 & 0.37 & 27.50 & -8.40 & 6.15 & -0.48 & 37. & & -3.00 & 3.06 & 0.86 & 5.71 & 75.60 & -11.07 & -12.9 & 0.99 & 0.9 \\
\hline PntTnch -116* & 59.21 & 78.31 & 89.95 & 19.1 & $n / a$ & $n / a$ & n/a & $n / a$ & n/a & $n / a$ & $n / a$ & 78.01 & -0.3 & $n / a$ & n/a & $n / a$ & $n / a$ & $n / a$ & $n / a$ & $n / a$ & $n / a$ & $n / a$ & $n / a$ & $\mathrm{n} /$ & & $n / a$ & $n / a$ & $n / a$ & $n / a$ & 58.60 & - 19.41 & - -19.71 & -0.61 & $n / a$ \\
\hline Mean & 61.89 & 78.20 & 95.28 & 16.32 & 6.36 & 8.19 & -0.23 & 29.71 & 6.46 & 33.43 & 2.46 & 74.67 & -3.43 & 4.50 & -1.85 & 10.11 & 1.92 & 0.65 & 0.88 & 20.80 & -8.91 & 6.42 & -0.0 & 31. & & -2.31 & 3.34 & 0.87 & 11.05 & 62.92 & -11.75 & - 15.49 & 0.82 & 0.97 \\
\hline s.o. & 9.01 & 8.56 & 10.09 & 3.85 & 1.40 & 1.59 & 0.52 & 6.37 & 1.89 & 6.29 & 0.81 & 8.26 & 3.99 & 1.02 & 1.31 & 1.82 & 2.06 & 0.53 & 0.37 & 7.77 & 1.92 & 1.81 & 1.57 & 7.5 & & 5.92 & 0.91 & 0.53 & 17.24 & 8.99 & 5.67 & 4.88 & 4.17 & 0.17 \\
\hline Student's-test & 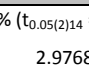 & $48 ; ; 99$ & & 16. & & & & & & & & & & & & & & & & & & & & & & & & & & & $8.30^{* *}$ & 12.29 & 0.76 & \\
\hline & $\begin{array}{l}t_{0.052} \\
3.720 \\
3\end{array}$ & & & & & & & & & & & & & & & & $n / 2$ & & $6.33 \mathrm{Z}$ & & $12.2 \mathrm{CP}$ & & & & & & & & 1.70 & & & & & \\
\hline
\end{tabular}

${ }^{*}$ Denotes sites where only measurements of the barrier beach system as a whole were included. **All 16 sites included when calculating the test statistics. 
Zone 3: Punta Petenpich

\begin{tabular}{|c|c|c|c|c|c|c|c|c|c|c|c|c|c|c|c|c|c|c|c|c|c|c|c|c|c|}
\hline Site & \multicolumn{8}{|c|}{ June 2006 (8 months after Hurricane Wilma) } & \multicolumn{16}{|c|}{ April 2010 (54 months after Hurricane Wilma) } & 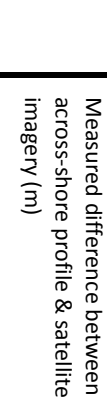 \\
\hline PntPtnpch - t3 & 5.28 & 8.00 & 0.24 & 20 & 4.72 & 6 & 1.18 & 34 & 5.69 & 0.40 & 19.26 & 11.26 & 0.00 & -0.24 & 0.00 & -20.00 & 0.00 & -4.72 & 0.00 & -6.00 & 5.69 & 4.50 & 19.26 & -14.74 & $n / a$ \\
\hline PntPtnpch - t4 & 2.69 & 12.00 & -0.80 & 18 & 4.50 & 28 & 1.95 & 58 & 4.64 & 1.95 & 11.47 & -0.53 & 1.08 & 1.88 & 10.00 & -8.00 & 1.98 & -2.52 & 36.20 & 8.20 & 2.12 & 0.17 & 57.67 & -0.33 & $n / a$ \\
\hline Mean & 5.46 & 7.50 & -0.30 & 21 & 4.16 & 22 & 1.30 & 45 & 5.27 & -0.19 & 14.50 & 7.00 & 1.30 & 1.60 & 8.00 & -13.00 & 2.43 & -1.30 & 20.00 & -1.50 & 3.67 & 2.37 & 37.50 & -7.50 & $n / a$ \\
\hline s.o. & 2.02 & 3.42 & 0.72 & 2.58 & 0.79 & 14 & 0.85 & 16.37 & 1.43 & 2.31 & 5.12 & 6.02 & 1.58 & 2.21 & 5.51 & 5.06 & 2.68 & 2.95 & 18.40 & 7.34 & 1.48 & 1.94 & 17.26 & 8.35 & $n / a$ \\
\hline
\end{tabular}

*Only post-storm barrier beach response analysed in Zone 3: Punta Petenpich due to data limitations.

Zone 4: Punta Brava

\begin{tabular}{|c|c|c|c|c|c|c|c|c|c|c|c|c|c|c|c|c|c|c|c|c|c|c|c|c|c|c|c|c|c|c|c|c|c|}
\hline \multirow[b]{2}{*}{ Site } & $\begin{array}{l}4^{\prime \prime \prime} \\
\text { September }\end{array}$ & \multicolumn{3}{|c|}{$25^{\text {th }}$ October 2005} & \multicolumn{9}{|c|}{ June 2006 (8 months after Hurricane Wilma) } & \multicolumn{20}{|c|}{ June 2010 (56 months after Hurricane Wilma) } \\
\hline & 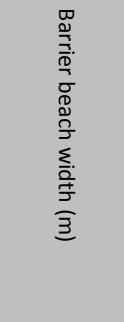 & 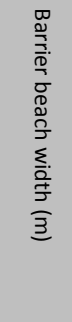 & 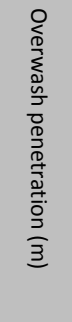 & 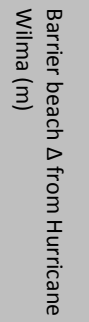 & 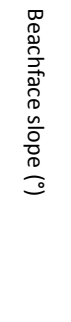 & 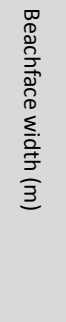 & 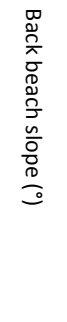 & 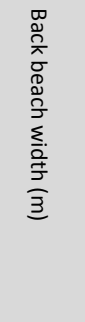 & $\begin{array}{l}\frac{1}{0} \\
\frac{0}{0} \\
\frac{0}{\overline{0}} \\
\frac{0}{0} \\
\frac{0}{0} \\
\frac{0}{3}\end{array}$ & 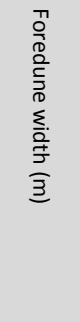 & 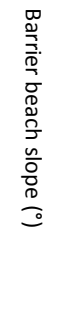 & 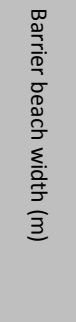 & 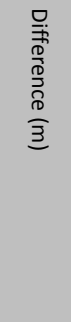 & 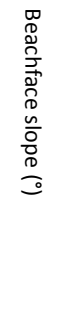 & 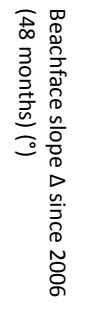 & 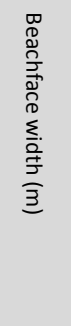 & 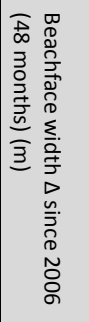 & 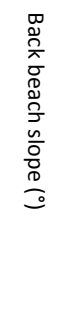 & 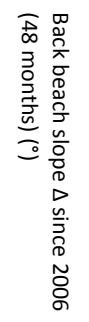 & 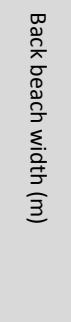 & 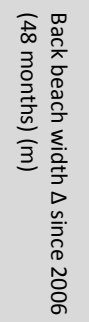 & 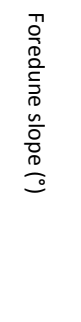 & 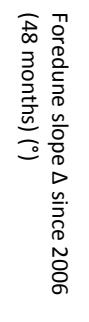 & 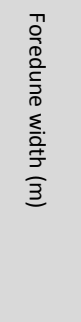 & 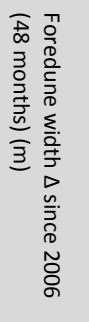 & 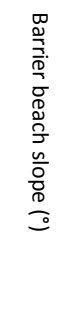 & 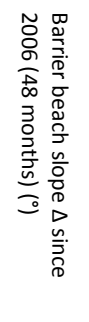 & 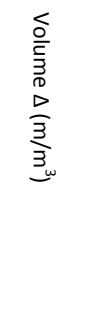 & 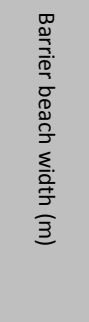 & 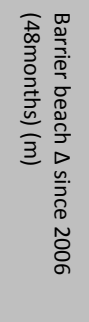 & 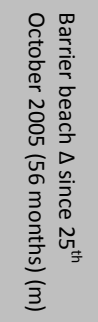 & 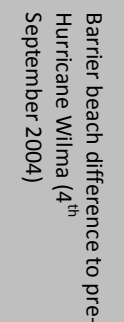 & 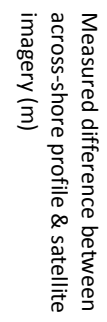 \\
\hline PntBrvt1 & 30.85 & 27.51 & 86.63 & -3.34 & 11.59 & 4.00 & -0.79 & 16.00 & 6.69 & 12.00 & 1.92 & 32.00 & 4.49 & 8.28 & -3.31 & 5.00 & 1.00 & 0.04 & 0.82 & 7.60 & -8.40 & 5.66 & -1.03 & 17.60 & 5.60 & 3.94 & 2.02 & 7.36 & 30.20 & -1.80 & -0.65 & -0.65 & 1.40 \\
\hline PntBrv t2 & 28.24 & 26.54 & 54.00 & -1.7 & 15.11 & 3.25 & -1.39 & 12.00 & 10.02 & 12.00 & 3.72 & 27.25 & 0.71 & 10.31 & -4.80 & 4.80 & 1.55 & 0.50 & 1.89 & 8.40 & -3.60 & 6.66 & -3.36 & 16.80 & 4.80 & 4.61 & 0.89 & 14.28 & 30.00 & 2.75 & 1.76 & 1.76 & 1.20 \\
\hline PntBrv t3 & 28.76 & 18.00 & 68.35 & -10.76 & 10.17 & 7.77 & -3.16 & 14.00 & 13.37 & 10.00 & 2.53 & 31.77 & 13.77 & 8.26 & -1.91 & 8.20 & 0.43 & -2.07 & 1.10 & 4.60 & -9.40 & 6.84 & -6.53 & 14.60 & 4.60 & 4.82 & 2.29 & 5.32 & 27.40 & -4.37 & -1.36 & -1.36 & 1.30 \\
\hline Mean & 29.28 & 24.02 & 69.66 & -5.27 & 12.29 & 5.01 & -1.78 & 14.00 & 10.03 & 11.33 & 2.72 & 30.34 & 6.32 & 8.95 & -3.34 & 6.00 & 0.99 & -0.51 & 1.27 & 6.87 & -7.13 & 6.39 & -3.64 & 16.33 & 5.00 & 4.46 & 1.73 & 8.99 & 29.20 & -1.14 & -0.08 & -0.08 & 1.30 \\
\hline S.D. & 1.38 & 5.23 & 16.35 & 4.83 & 2.54 & 2.42 & 1.23 & 2.00 & 3.34 & 1.15 & 0.92 & 2.68 & 6.72 & 1.18 & 1.45 & 1.91 & 0.56 & 1.37 & 0.55 & 2.00 & 3.10 & 0.64 & 2.76 & 1.55 & 0.53 & 0.46 & 0.74 & 4.70 & 1.56 & 3.61 & 1.64 & 1.64 & 0.10 \\
\hline & t: $95 \%$ & & & & & & & & & & & & 1.63 & & 4.00 & & 3.07 & & 3.96 & & 3.98 & & 2.28 & & 16.37 & & 4.04 & 3.31 & & 0.55 & 0.09 & 0.09 & \\
\hline
\end{tabular}


Zone 5: Punta Brava South

\begin{tabular}{|c|c|c|c|c|c|c|c|c|c|c|c|c|c|c|c|c|c|c|c|c|c|c|c|c|c|c|c|c|c|c|c|c|c|}
\hline \multirow[b]{2}{*}{ Site } & $\begin{array}{c}4^{4^{\text {th }}} \\
\text { September }\end{array}$ & \multicolumn{3}{|c|}{$25^{\text {th October } 2005}$} & \multicolumn{9}{|c|}{ June 2006 (8 months after Hurricane Wilma) } & \multicolumn{19}{|c|}{ June 2010 (56 months after Hurricane Wilma) } & \multirow[b]{2}{*}{ 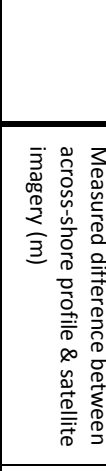 } \\
\hline & 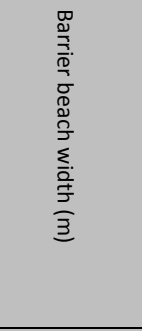 & 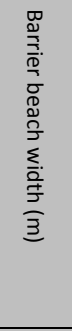 & 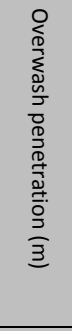 & 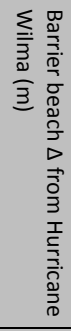 & 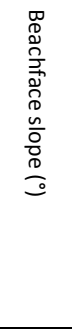 & 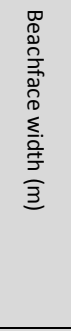 & 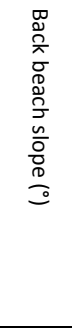 & 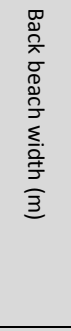 & 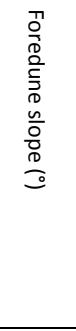 & 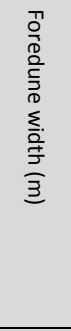 & 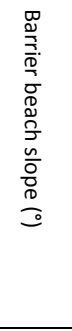 & 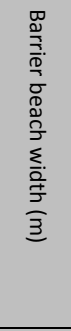 & 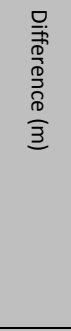 & 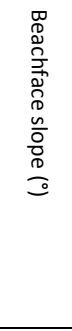 & 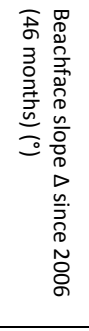 & 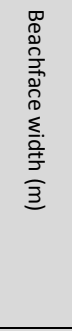 & 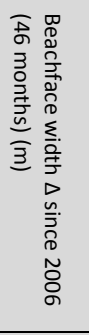 & 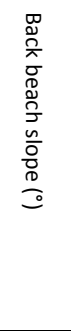 & 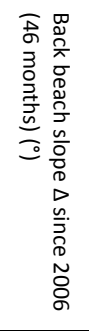 & 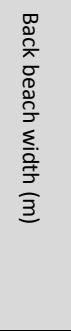 & 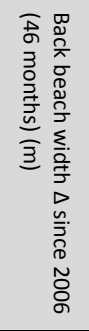 & $\begin{array}{l}\text { ग्O } \\
\overline{0} \\
\overline{0} \\
\overline{0} \\
\frac{0}{0} \\
\frac{0}{0} \\
\frac{0}{0}\end{array}$ & 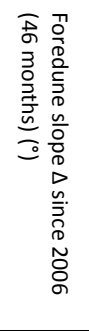 & 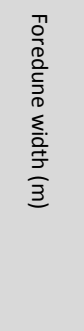 & 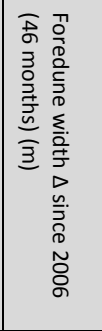 & 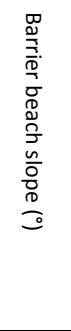 & 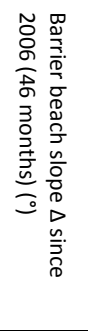 & 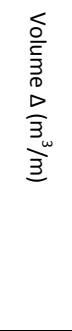 & 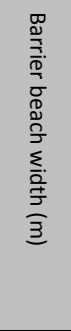 & 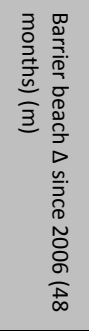 & 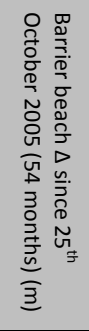 & 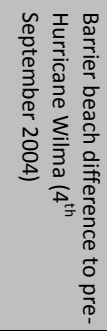 & \\
\hline Pntirnsth-11 & 32.72 & 21.47 & 68.69 & -11.25 & 8.67 & 4.00 & -0.46 & 18.00 & 5.77 & 18.00 & 2.40 & 40.00 & 18.53 & 7.40 & -1.27 & 2.80 & -1.20 & 1.44 & 1.90 & 7.40 & -10.60 & 4.82 & -0.95 & 19.20 & 1.20 & 3.79 & 1.39 & -4.39 & 29.40 & -10.60 & 7.93 & -3.32 & 1.10 \\
\hline Pntirnsth-t2 & 23.73 & 22.64 & 47.09 & -1.09 & 2.37 & 9.53 & -0.06 & 6.00 & 4.62 & 16.00 & 2.65 & 31.53 & 8.89 & 12.34 & 9.97 & 2.20 & -7.32 & 0.00 & 0.06 & 0.00 & -6.00 & 3.53 & -1.09 & 21.40 & 5.40 & 3.90 & 1.25 & 2.90 & 23.60 & -7.93 & 0.96 & -0.13 & 0.90 \\
\hline Pntirusth-3 & 27.84 & 23.93 & 66.20 & -3.91 & 13.22 & 4.00 & 0.00 & 0.00 & 7.26 & 14.00 & 7.78 & 18.00 & -5.93 & 17.45 & 4.22 & 3.40 & -0.60 & 4.72 & 4.72 & 1.60 & 1.60 & 26.77 & 19.50 & 2.40 & -11.60 & 18.64 & 10.86 & -17.80 & 7.40 & -10.60 & -16.53 & -20.44 & 0.90 \\
\hline Pntirusth-ta & 23.04 & 20.57 & 43.27 & -2.47 & 5.31 & 9.83 & 2.58 & 2.00 & 12.05 & 6.00 & 6.48 & 17.83 & -2.74 & 9.45 & 4.14 & 4.00 & -5.83 & 4.70 & 2.13 & 3.00 & 1.00 & 8.29 & -3.76 & 10.60 & 4.60 & 7.96 & 1.48 & 4.25 & 17.60 & -0.23 & -2.97 & -5.44 & 1.10 \\
\hline PntBrusth-5 & 29.70 & 22.61 & 45.64 & -7.09 & 5.31 & 6.00 & -1.15 & 4.00 & 7.18 & 10.00 & 4.52 & 20.00 & -2.61 & 10.87 & 5.55 & 2.40 & -3.60 & 3.10 & 4.24 & 1.60 & -2.40 & 5.09 & -2.09 & 11.40 & 1.40 & 5.73 & 1.21 & -0.64 & 15.40 & -4.60 & -7.21 & -14.30 & 0.90 \\
\hline Pntirnsth-t6 & 23.14 & 21.42 & 51.32 & -1.72 & 19.15 & 2.00 & 3.72 & 2.00 & 5.57 & 8.00 & 7.35 & 12.00 & -9.42 & 13.53 & -5.61 & 3.40 & 1.40 & 0.34 & -3.38 & 1.00 & -1.00 & 11.36 & 5.79 & 6.80 & -1.20 & 10.66 & 3.31 & 0.48 & 11.20 & -0.80 & -10.22 & -11.94 & 0.80 \\
\hline Pntirnsthtrt7 & 25.61 & 19.82 & 52.07 & -5.79 & 8.21 & 5.92 & -1.29 & 8.00 & 6.05 & 8.00 & 2.55 & 21.92 & 2.10 & 11.95 & 3.75 & 3.80 & -2.12 & 2.51 & 3.79 & 1.60 & -6.40 & 4.02 & -2.03 & 11.20 & 3.20 & 5.59 & 3.04 & 1.34 & 16.60 & -5.32 & -3.22 & -9.01 & 0.80 \\
\hline Pntirnsth-8 & 23.32 & 20.57 & 53.53 & -2.75 & 19.54 & 3.32 & -2.40 & 10.00 & 7.69 & 8.00 & 3.21 & 21.32 & 0.75 & 16.58 & -2.97 & 4.40 & 1.08 & 0.42 & 2.81 & 10.00 & 0.00 & 16.79 & 9.10 & 1.20 & -6.80 & 5.51 & 2.30 & -3.79 & 15.60 & -5.72 & -4.97 & -7.72 & 0.50 \\
\hline Mean & 26.14 & 21.63 & 53.48 & -4.51 & 10.22 & 5.58 & 0.12 & 6.25 & 7.02 & 11.00 & 4.62 & 22.83 & 1.20 & 12.45 & 2.22 & 3.30 & -2.27 & 2.15 & 2.03 & 3.28 & -2.98 & 10.08 & 3.06 & 10.53 & -0.48 & 7.72 & 3.11 & -2.21 & 17.10 & -5.73 & -4.53 & -9.04 & 0.88 \\
\hline S.D. & 3.62 & 1.36 & 9.31 & 3.40 & 6.46 & 2.85 & 2.05 & 5.80 & 2.27 & 4.41 & 2.27 & 8.84 & 8.90 & 3.39 & 5.09 & 0.78 & 3.13 & 1.91 & 2.65 & 3.52 & 4.29 & 8.11 & 7.99 & 7.19 & 5.91 & 4.95 & 3.24 & 6.97 & 6.85 & 3.93 & 7.30 & 6.47 & 0.19 \\
\hline & $\begin{array}{c}t_{0.05252} \\
3.49\end{array}$ & & & & & & & & & & & & 0.38 & 7 & 1.23 & & 2.05 & & 2.17 & & 1.96 & & 1.08 & & 0.23 & & 2.71 & 0.89 & & 4.12 & 1.75 & 3.95 & \\
\hline
\end{tabular}

Zone 6: Playa del Secreto

\begin{tabular}{|c|c|c|c|c|c|c|c|c|c|c|c|c|c|c|c|c|c|c|c|c|c|c|c|c|c|c|c|c|c|c|c|c|c|}
\hline \multirow[b]{2}{*}{ Site } & \multirow{2}{*}{ 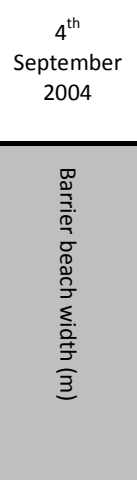 } & \multicolumn{3}{|c|}{$25^{\text {th }}$ October 2005} & \multicolumn{9}{|c|}{ June 2006 (8 months after Hurricane Wilma) } & \multicolumn{19}{|c|}{ June 2010 (56 months after Hurricane Wilma) } & \multirow[b]{2}{*}{ 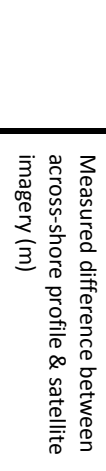 } \\
\hline & & 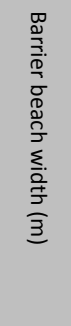 & 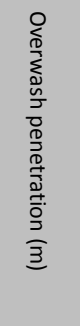 & 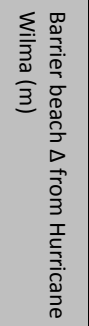 & 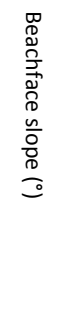 & 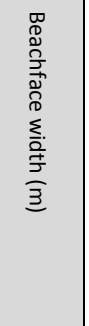 & 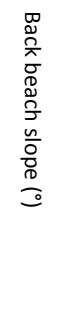 & 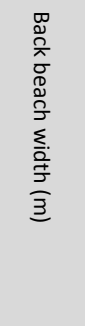 & 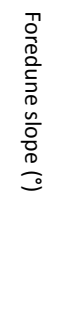 & 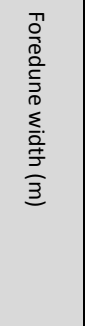 & 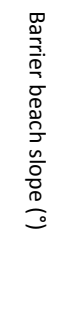 & 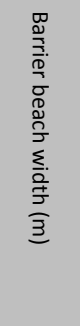 & 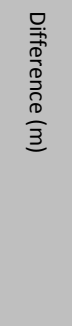 & 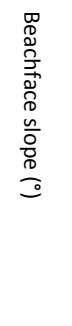 & 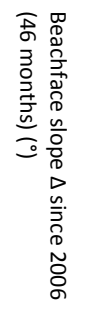 & 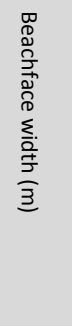 & 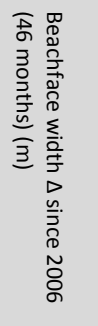 & 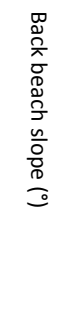 & 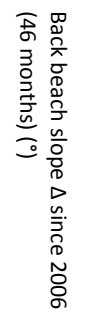 & 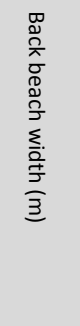 & 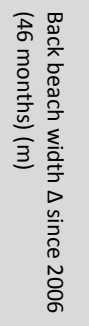 & 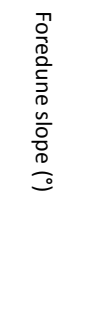 & 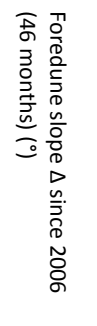 & 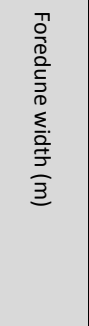 & 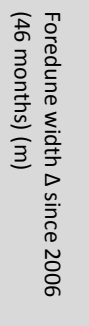 & 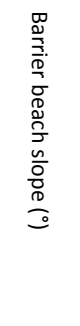 & 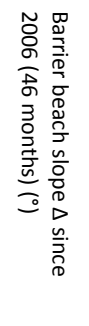 & 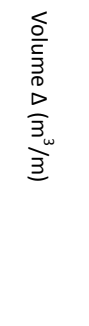 & 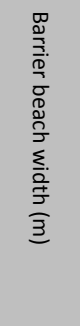 & 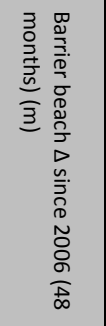 & 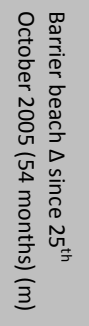 & 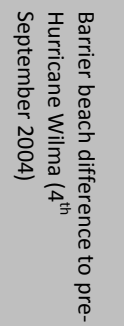 & \\
\hline Plyascrtt+11 & 36.12 & 27.55 & 53.65 & -8.57 & 4.82 & 13.18 & -3.95 & 10.00 & 10.46 & 12.00 & 2.33 & 35.18 & 7.63 & 6.45 & 1.62 & 8.40 & -4.78 & 0.64 & 4.58 & 8.60 & -1.40 & 8.93 & -1.53 & 12.00 & 0.00 & 4.66 & 2.32 & 5.43 & 29.00 & -6.18 & 1.45 & -7.12 & 1.10 \\
\hline
\end{tabular}


9.2 Across-shore beach profiles 

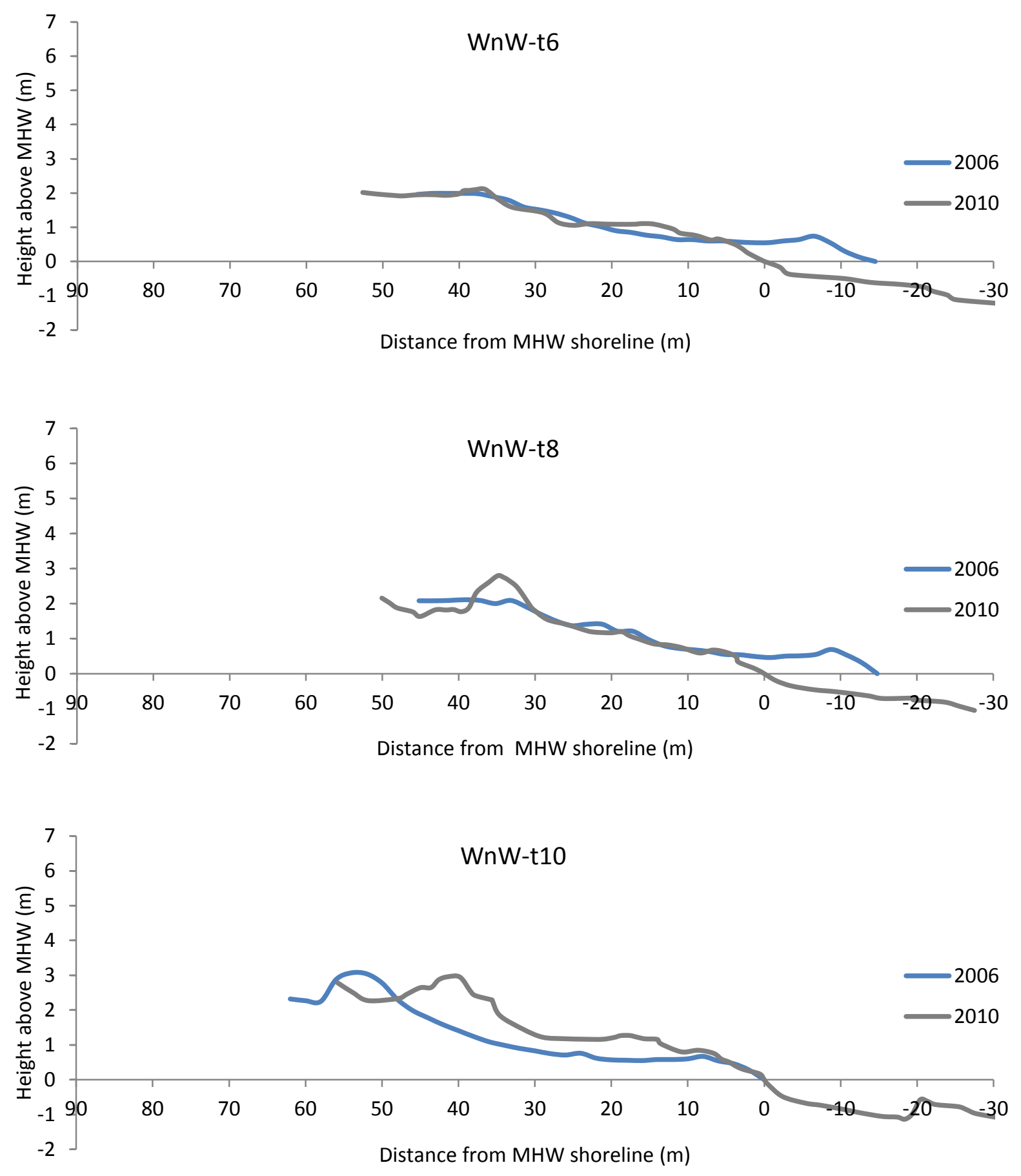

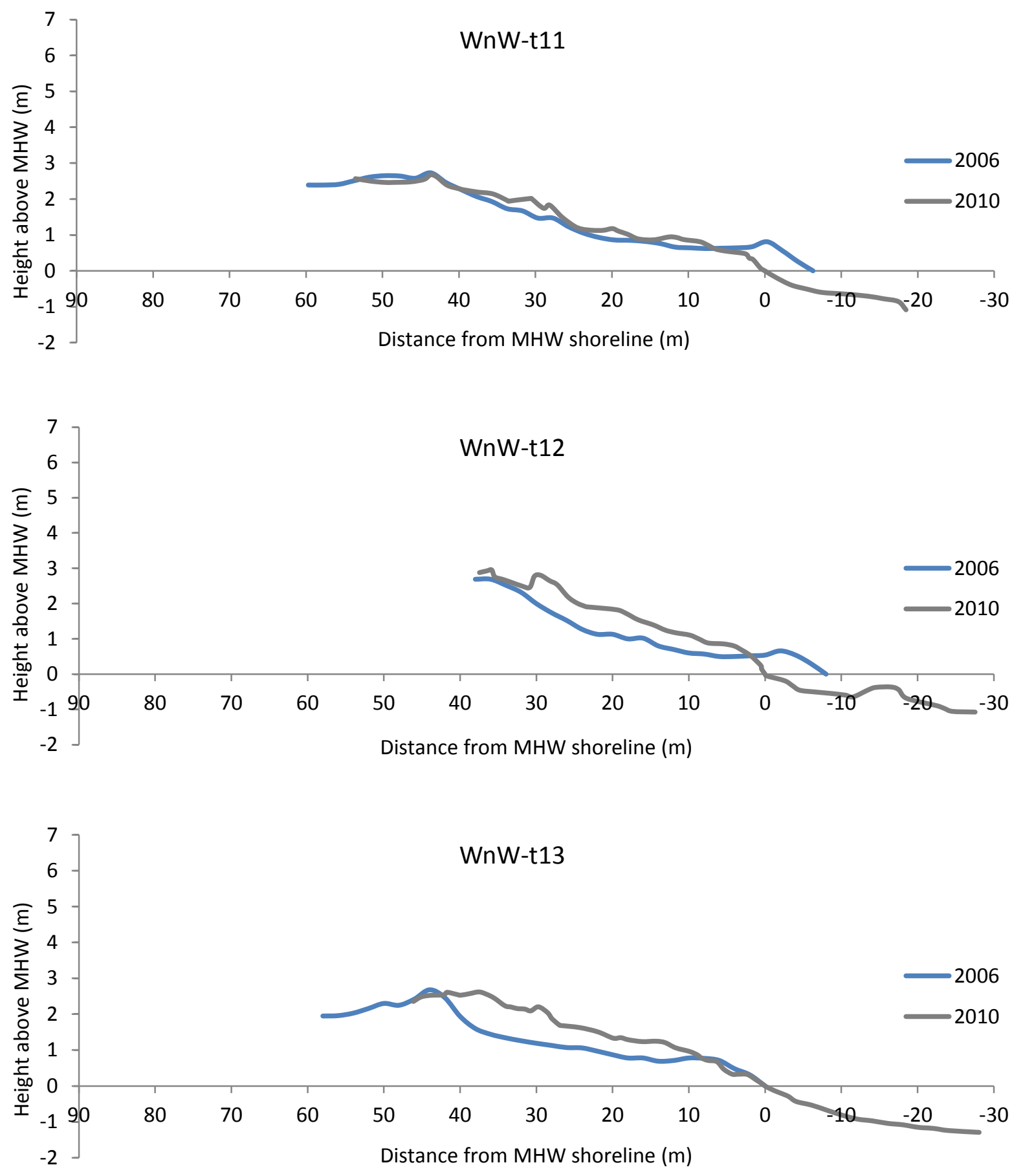

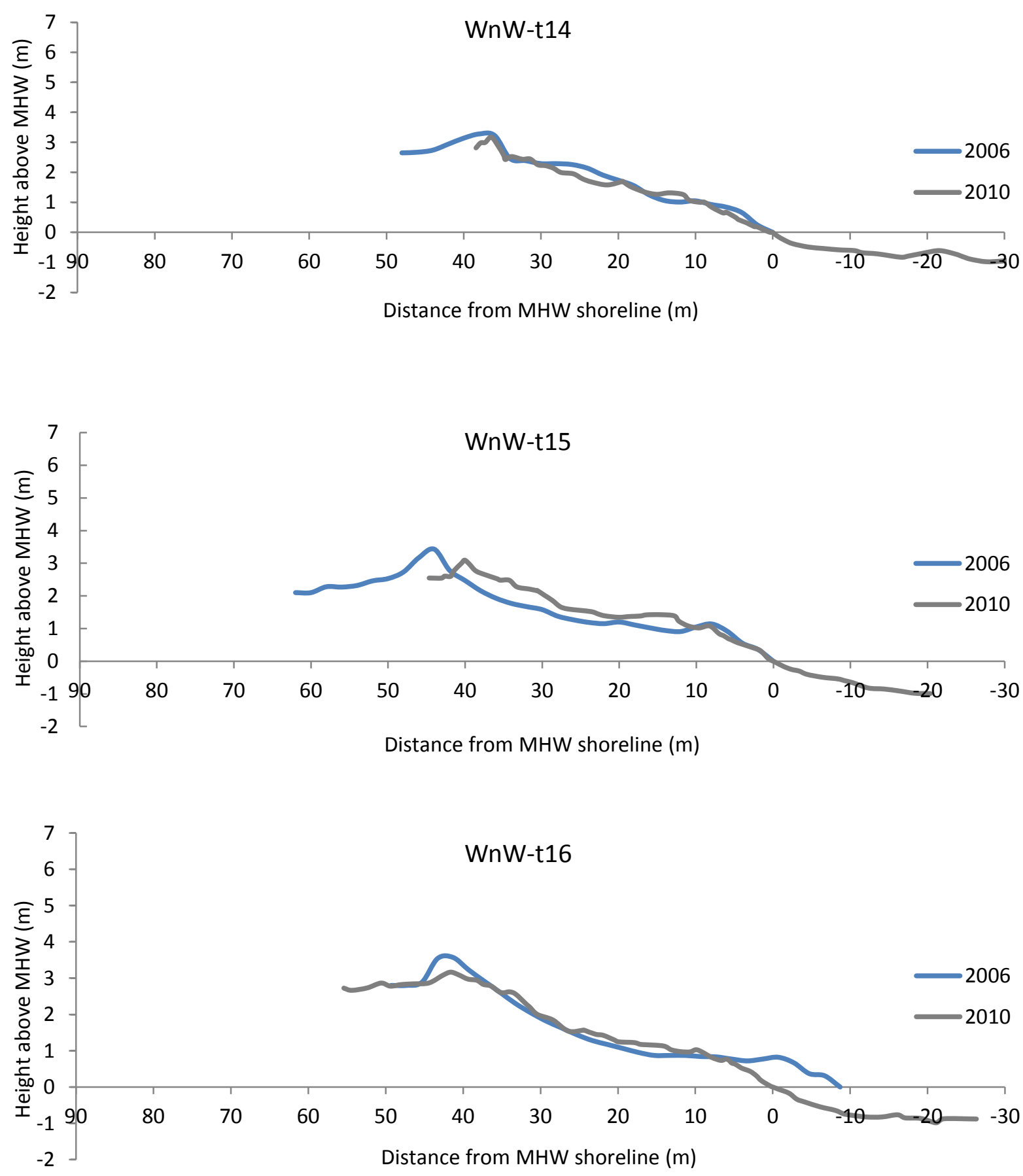

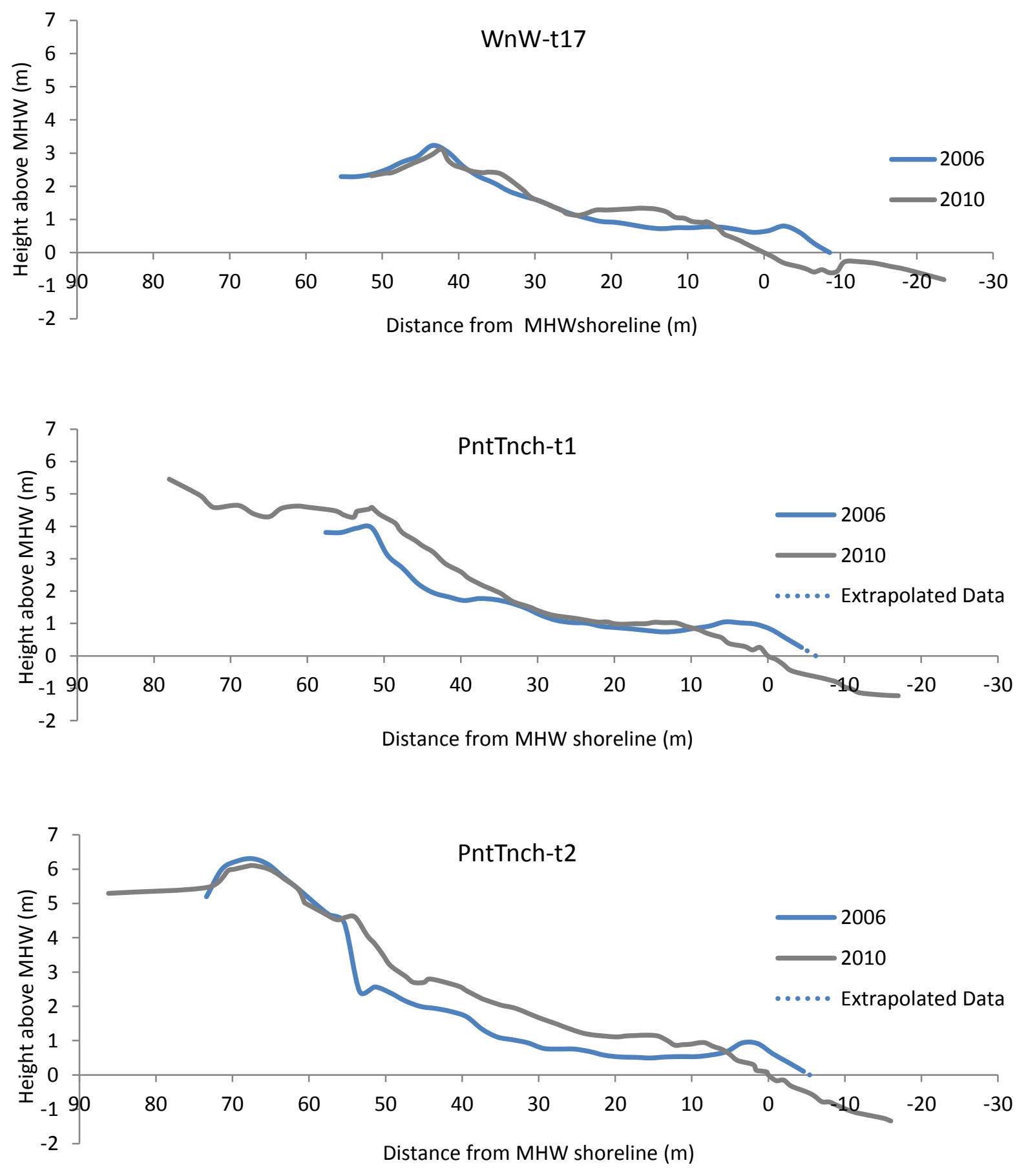

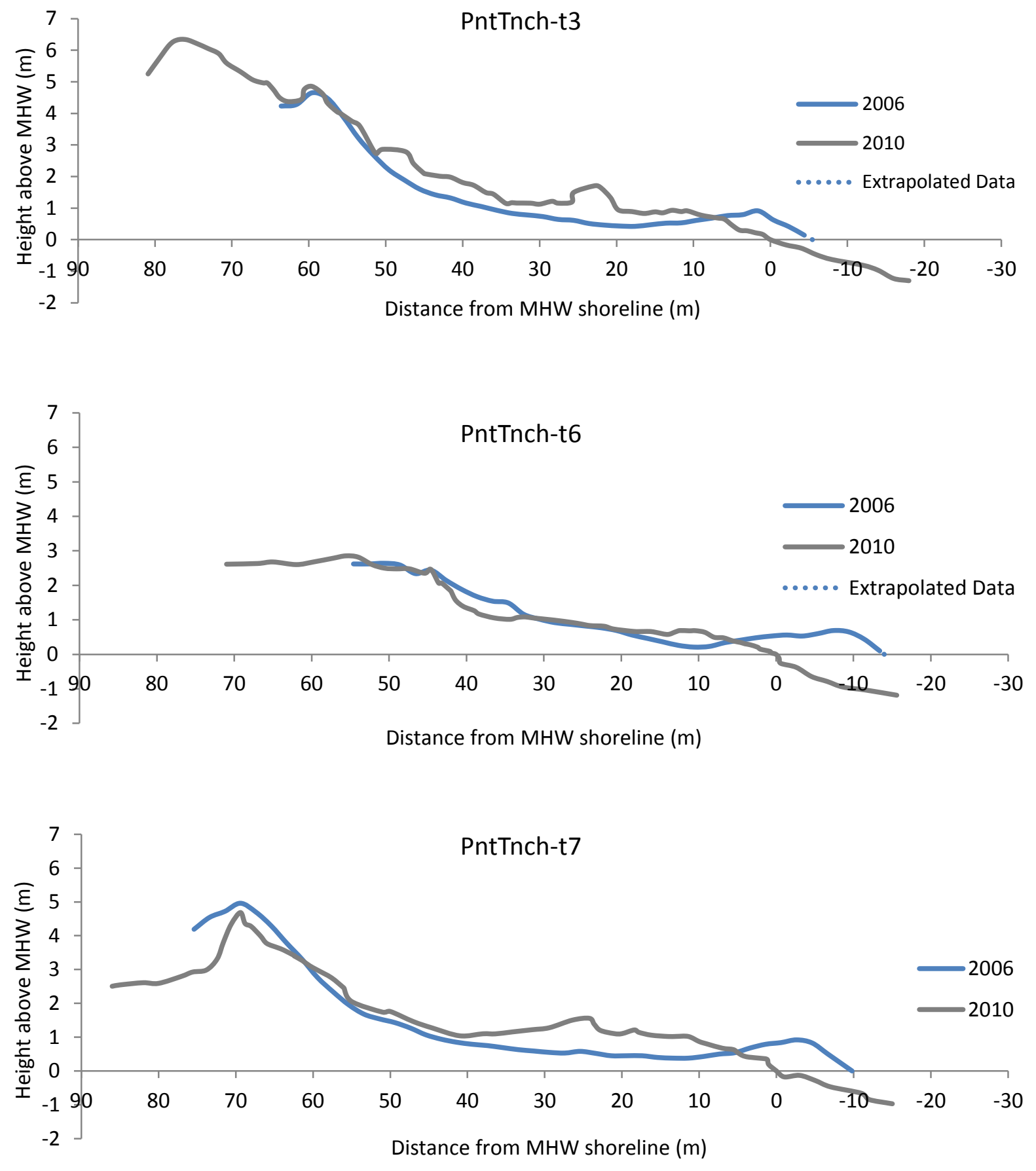

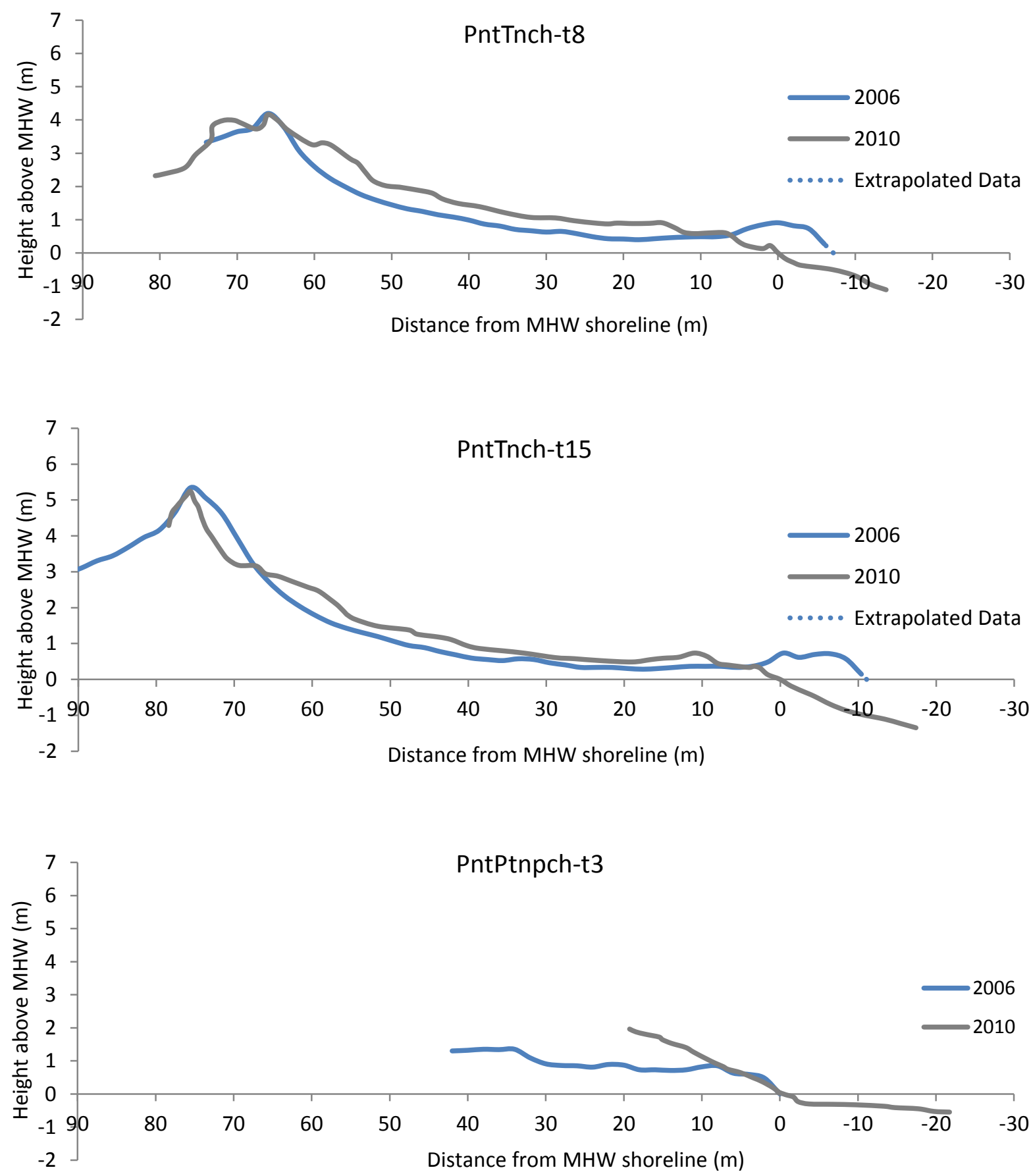

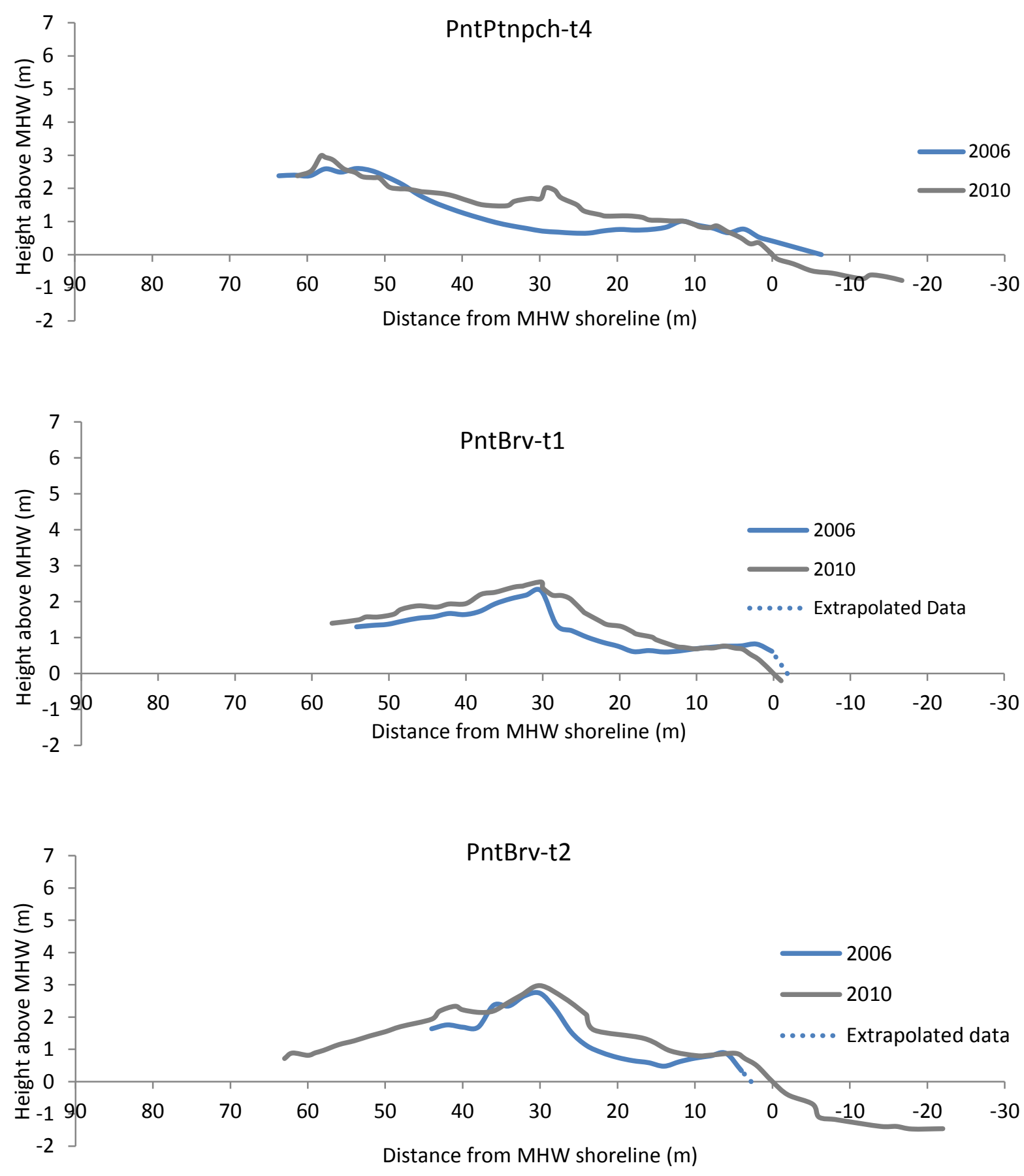

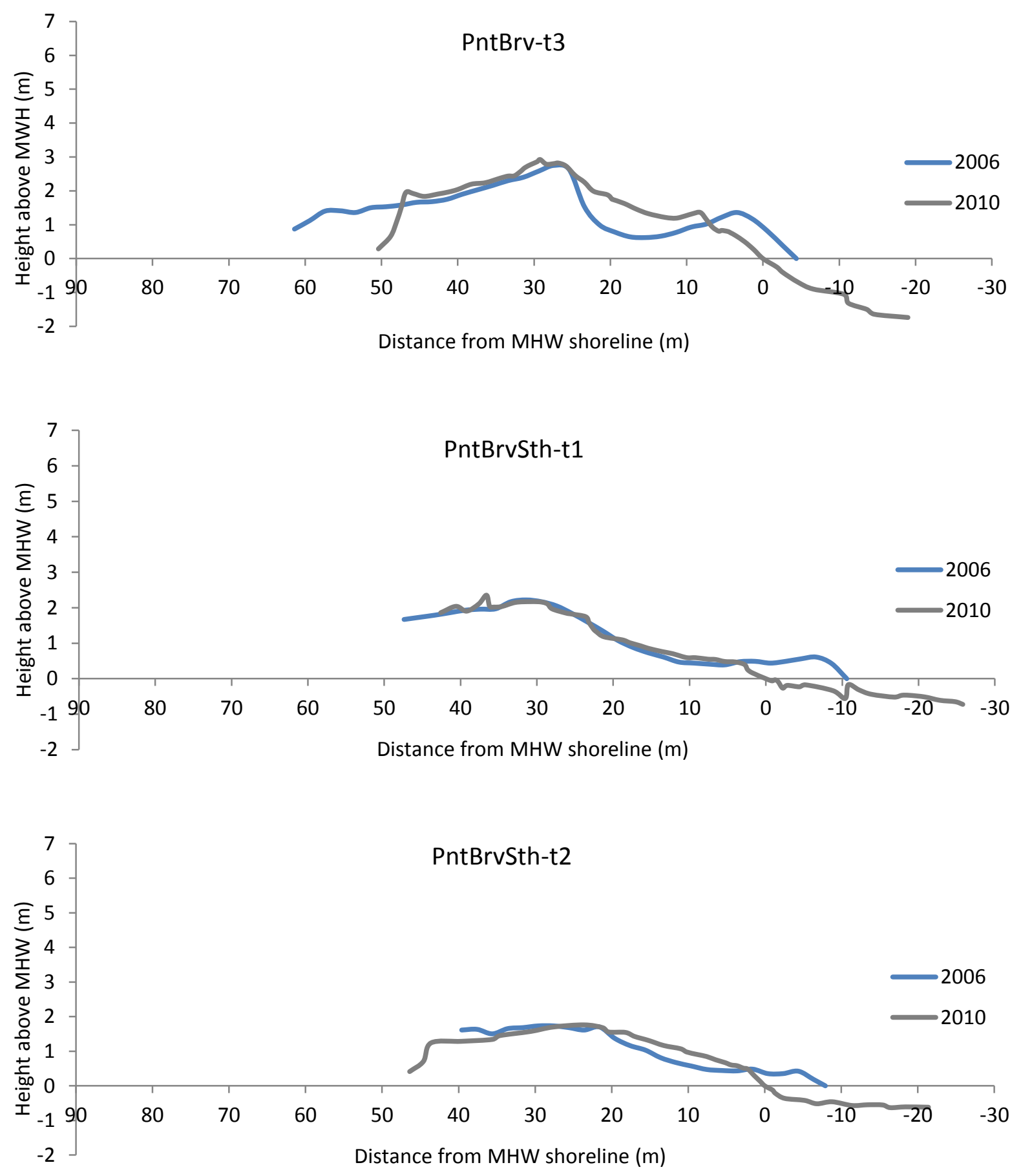

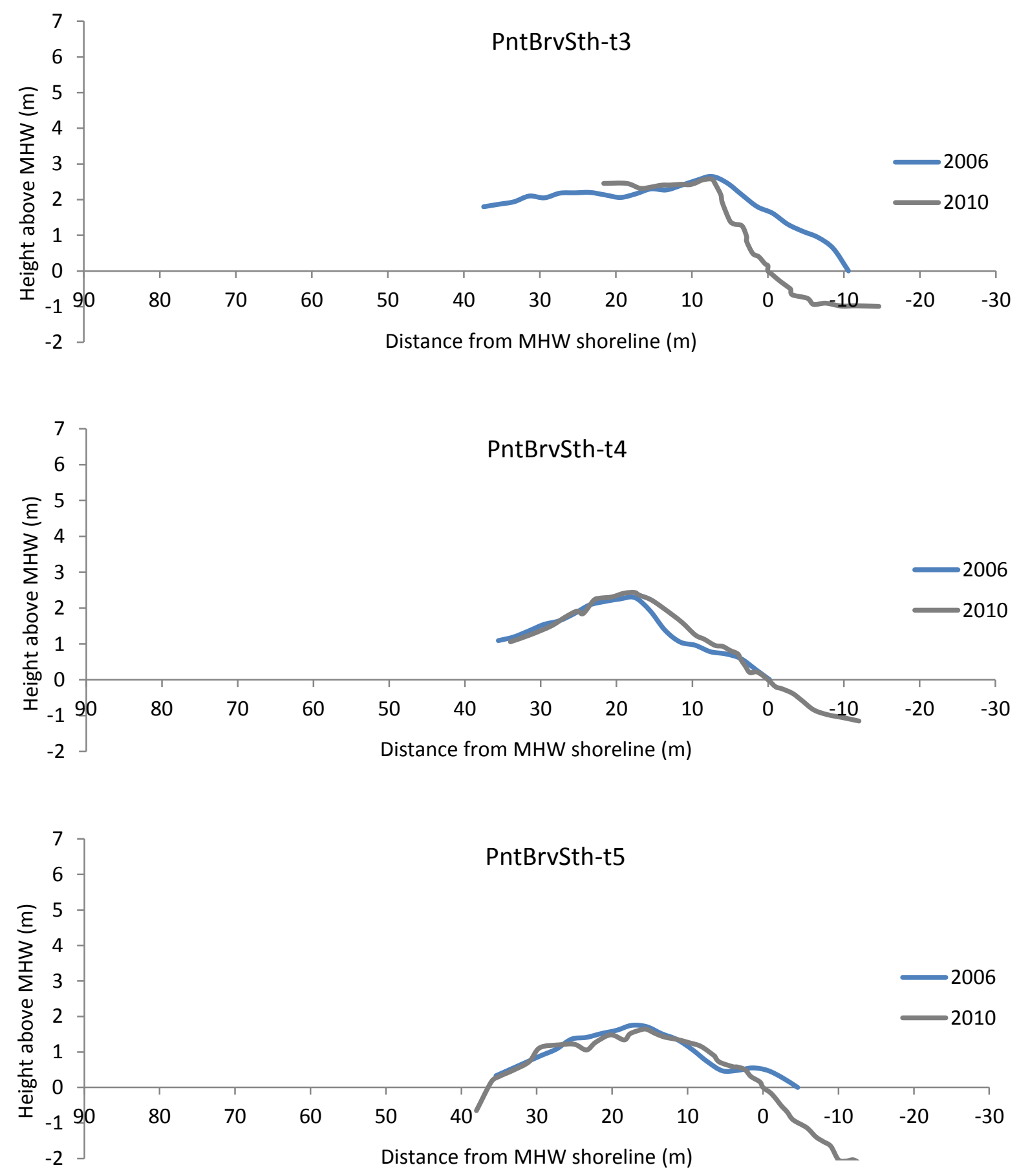

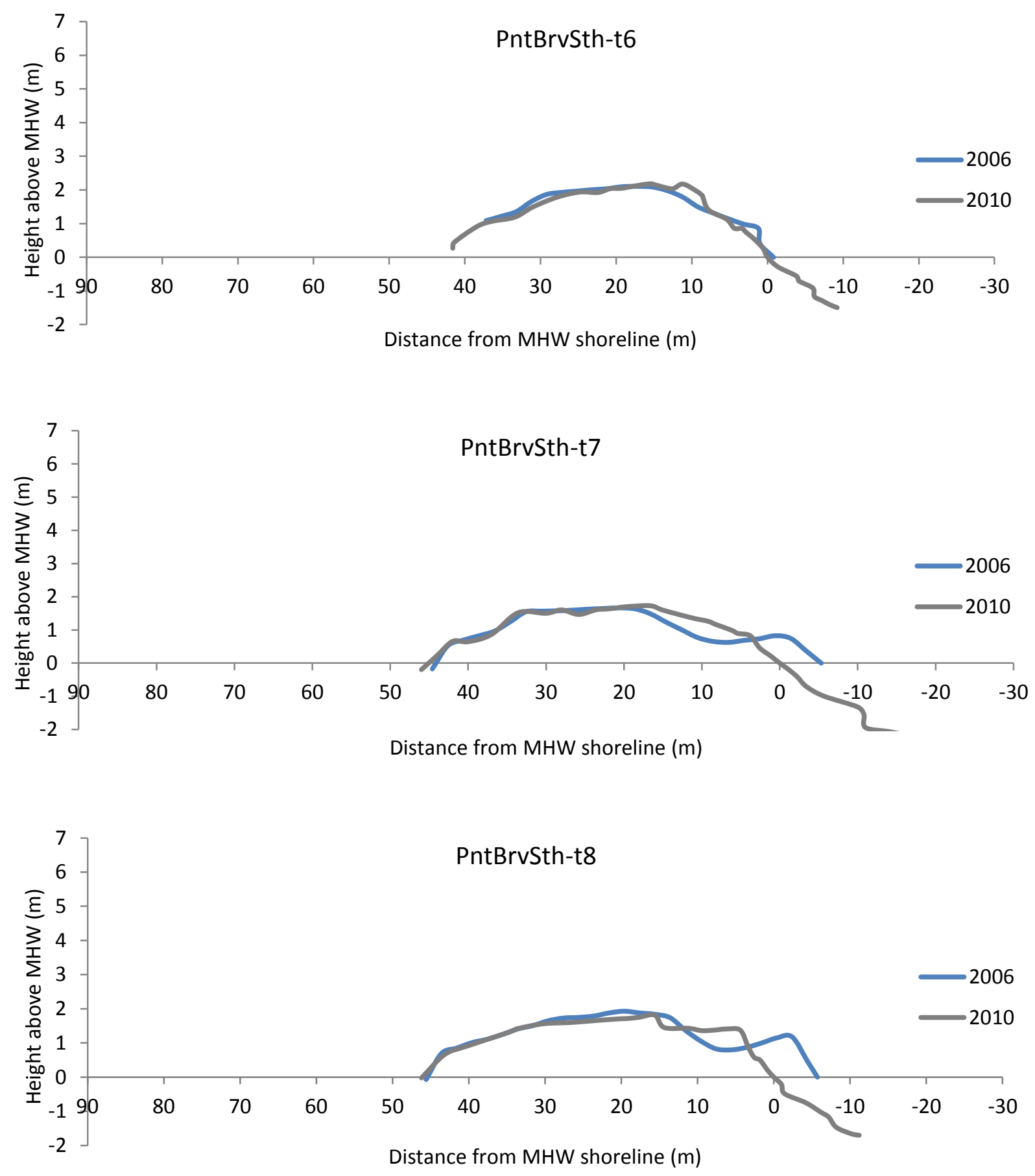


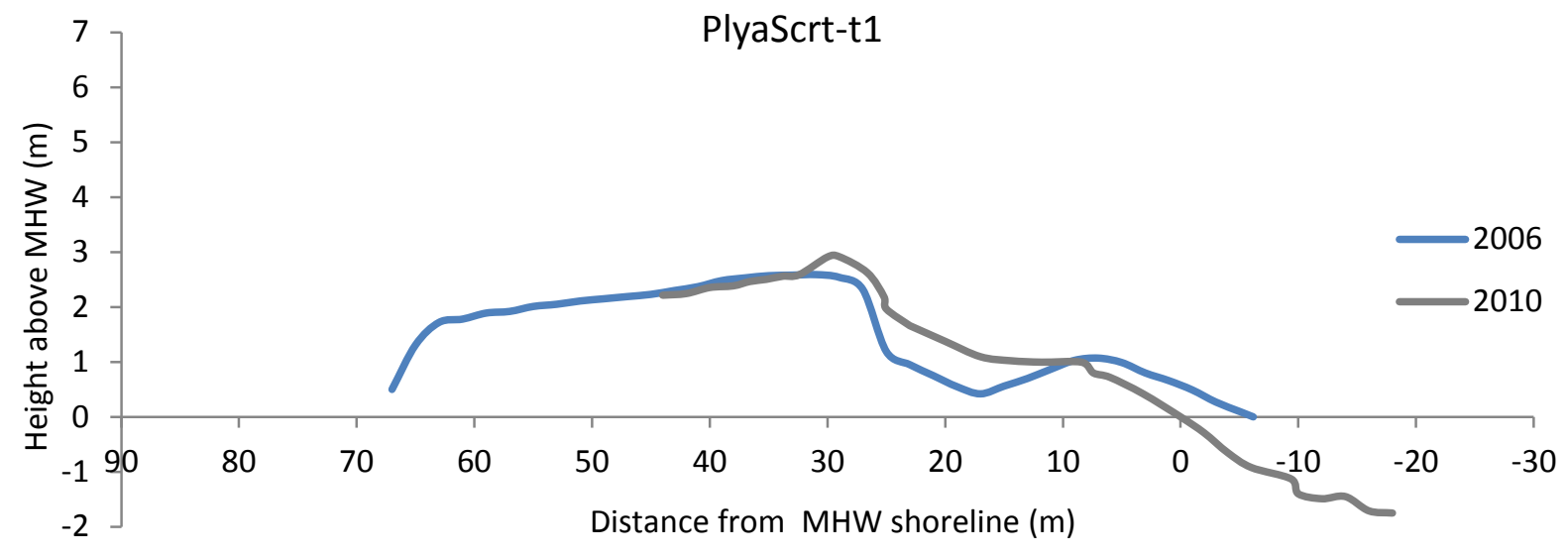




\subsection{Grain-size data}


2006 Barrier Surface

\begin{tabular}{|c|c|c|c|c|c|c|c|c|c|c|c|c|c|}
\hline & & $\begin{array}{l}\text { WnW06- } \\
\text { t1_bb-1-a }\end{array}$ & $\begin{array}{l}\text { WnW06- } \\
\text { t1_bb-2-a }\end{array}$ & $\begin{array}{l}\text { WnW06- } \\
\text { t1_fdf-1-a }\end{array}$ & $\begin{array}{l}\text { WnW06- } \\
\text { t1_fdf-2-a }\end{array}$ & $\begin{array}{l}\text { WnW06- } \\
\text { t1_bd-a }\end{array}$ & $\begin{array}{l}\text { WnW06- } \\
\text { t3_bb-1-a }\end{array}$ & $\begin{array}{l}\text { WnW06- } \\
\text { t3_bb-2-a }\end{array}$ & $\begin{array}{l}\text { WnW06- } \\
\text { t3_fdf-1-a }\end{array}$ & $\begin{array}{l}\text { WnW06- } \\
\text { t3_fdf-2-a }\end{array}$ & $\begin{array}{l}\text { WnW06- } \\
\text { t3_bd-a }\end{array}$ & $\begin{array}{l}\text { WnW06- } \\
\text { t12_bb-a }\end{array}$ & $\begin{array}{l}\text { WnW06- } \\
\text { t12_fdf-a }\end{array}$ \\
\hline & SAMPLE TYPE: & $\begin{array}{l}\text { Unimodal, } \\
\text { Moderately } \\
\text { Well Sorted }\end{array}$ & $\begin{array}{l}\text { Unimodal, } \\
\text { Moderately } \\
\text { Sorted }\end{array}$ & $\begin{array}{l}\text { Unimodal, } \\
\text { Moderately } \\
\text { Sorted }\end{array}$ & $\begin{array}{l}\text { Unimodal, } \\
\text { Moderately } \\
\text { Sorted }\end{array}$ & $\begin{array}{l}\text { Unimodal, } \\
\text { Moderately } \\
\text { Well Sorted }\end{array}$ & $\begin{array}{l}\text { Unimodal, } \\
\text { Moderately } \\
\text { Well Sorted }\end{array}$ & $\begin{array}{l}\text { Unimodal, } \\
\text { Moderately } \\
\text { Well Sorted }\end{array}$ & $\begin{array}{l}\text { Unimodal, } \\
\text { Moderately } \\
\text { Well Sorted }\end{array}$ & $\begin{array}{l}\text { Unimodal, } \\
\text { Moderately } \\
\text { Well Sorted }\end{array}$ & $\begin{array}{l}\text { Unimodal, } \\
\text { Moderately } \\
\text { Well Sorted }\end{array}$ & $\begin{array}{l}\text { Unimodal, } \\
\text { Moderately } \\
\text { Well Sorted }\end{array}$ & $\begin{array}{l}\text { Unimodal, } \\
\text { Moderately } \\
\text { Well Sorted }\end{array}$ \\
\hline & TEXTURAL GROUP: & Sand & Sand & Sand & Sand & Sand & $\begin{array}{l}\text { Slightly } \\
\text { Gravelly } \\
\text { Sand } \\
\end{array}$ & Sand & $\begin{array}{l}\text { Slightly } \\
\text { Gravelly } \\
\text { Sand } \\
\end{array}$ & $\begin{array}{l}\text { Slightly } \\
\text { Gravelly } \\
\text { Sand } \\
\end{array}$ & $\begin{array}{l}\text { Slightly } \\
\text { Gravelly } \\
\text { Sand } \\
\end{array}$ & Sand & $\begin{array}{l}\text { Slightly } \\
\text { Gravelly } \\
\text { Sand } \\
\end{array}$ \\
\hline & SEDIMENT NAME: & $\begin{array}{l}\text { Moderately } \\
\text { Well Sorted } \\
\text { Medium } \\
\text { Sand }\end{array}$ & $\begin{array}{l}\text { Moderately } \\
\text { Sorted } \\
\text { Medium } \\
\text { Sand }\end{array}$ & $\begin{array}{l}\text { Moderately } \\
\text { Sorted } \\
\text { Medium } \\
\text { Sand }\end{array}$ & $\begin{array}{l}\text { Moderately } \\
\text { Sorted } \\
\text { Medium } \\
\text { Sand }\end{array}$ & $\begin{array}{l}\text { Moderately } \\
\text { Well Sorted } \\
\text { Medium } \\
\text { Sand }\end{array}$ & $\begin{array}{l}\text { Slightly Very } \\
\text { Fine Gravelly } \\
\text { Medium } \\
\text { Sand }\end{array}$ & $\begin{array}{l}\text { Moderately } \\
\text { Well Sorted } \\
\text { Medium } \\
\text { Sand }\end{array}$ & $\begin{array}{l}\text { Slightly Very } \\
\text { Fine Gravelly } \\
\text { Medium } \\
\text { Sand }\end{array}$ & $\begin{array}{l}\text { Slightly Very } \\
\text { Fine Gravelly } \\
\text { Medium } \\
\text { Sand }\end{array}$ & $\begin{array}{l}\text { Slightly Very } \\
\text { Fine Gravelly } \\
\text { Medium } \\
\text { Sand }\end{array}$ & $\begin{array}{l}\text { Moderately } \\
\text { Well Sorted } \\
\text { Medium } \\
\text { Sand }\end{array}$ & $\begin{array}{l}\text { Slightly } \\
\text { Very Fine } \\
\text { Gravelly } \\
\text { Medium } \\
\text { Sand } \\
\end{array}$ \\
\hline \multirow{4}{*}{$\begin{array}{l}\text { FOLK AND } \\
\text { WARD } \\
\text { METHOD } \\
(\mathrm{mm}) \\
\end{array}$} & MEAN & 325.5 & 310 & 360 & 454.4 & 375 & 416.2 & 317.9 & 295.1 & 330.2 & 418.3 & 269.2 & 311 \\
\hline & SORTING & 1.466 & 1.656 & 1.633 & 1.641 & 1.551 & 1.525 & 1.499 & 1.58 & 1.547 & 1.576 & 1.47 & 1.525 \\
\hline & SKEWNESS & -0.016 & 0.183 & 0.066 & -0.013 & 0.007 & 0 & 0.064 & 0.203 & 0.043 & 0.035 & 0.161 & 0.179 \\
\hline & KURTOSIS & 0.975 & 0.997 & 0.965 & 1.021 & 0.972 & 1.03 & 0.979 & 1.075 & 0.961 & 0.984 & 1.062 & 1.038 \\
\hline \multirow{4}{*}{$\begin{array}{l}\text { FOLK AND } \\
\text { WARD } \\
\text { METHOD } \\
\text { (phi) }\end{array}$} & MEAN & 1.619 & 1.69 & 1.474 & 1.138 & 1.415 & 1.265 & 1.653 & 1.761 & 1.599 & 1.257 & 1.893 & 1.685 \\
\hline & SORTING & 0.552 & 0.728 & 0.708 & 0.715 & 0.634 & 0.608 & 0.584 & 0.66 & 0.629 & 0.656 & 0.556 & 0.609 \\
\hline & SKEWNESS & 0.016 & -0.183 & -0.066 & 0.013 & -0.007 & 0 & -0.064 & -0.203 & -0.043 & -0.035 & -0.161 & -0.179 \\
\hline & KURTOSIS & 0.975 & 0.997 & 0.965 & 1.021 & 0.972 & 1.03 & 0.979 & 1.075 & 0.961 & 0.984 & 1.062 & 1.038 \\
\hline \multirow{23}{*}{$\begin{array}{l}\text { FOLK AND } \\
\text { WARD } \\
\text { METHOD } \\
\text { (Description) }\end{array}$} & MEAN: & $\begin{array}{l}\text { Medium } \\
\text { Sand }\end{array}$ & $\begin{array}{l}\text { Medium } \\
\text { Sand }\end{array}$ & $\begin{array}{l}\text { Medium } \\
\text { Sand }\end{array}$ & $\begin{array}{l}\text { Medium } \\
\text { Sand }\end{array}$ & $\begin{array}{l}\text { Medium } \\
\text { Sand }\end{array}$ & $\begin{array}{l}\text { Medium } \\
\text { Sand }\end{array}$ & $\begin{array}{l}\text { Medium } \\
\text { Sand }\end{array}$ & $\begin{array}{l}\text { Medium } \\
\text { Sand }\end{array}$ & $\begin{array}{l}\text { Medium } \\
\text { Sand }\end{array}$ & $\begin{array}{l}\text { Medium } \\
\text { Sand }\end{array}$ & $\begin{array}{l}\text { Medium } \\
\text { Sand }\end{array}$ & $\begin{array}{l}\text { Medium } \\
\text { Sand }\end{array}$ \\
\hline & SORTING: & $\begin{array}{l}\text { Moderately } \\
\text { Well Sorted }\end{array}$ & $\begin{array}{l}\text { Moderately } \\
\text { Sorted }\end{array}$ & $\begin{array}{l}\text { Moderately } \\
\text { Sorted }\end{array}$ & $\begin{array}{l}\text { Moderately } \\
\text { Sorted }\end{array}$ & $\begin{array}{l}\text { Moderately } \\
\text { Well Sorted }\end{array}$ & $\begin{array}{l}\text { Moderately } \\
\text { Well Sorted }\end{array}$ & $\begin{array}{l}\text { Moderately } \\
\text { Well Sorted }\end{array}$ & $\begin{array}{l}\text { Moderately } \\
\text { Well Sorted }\end{array}$ & $\begin{array}{l}\text { Moderately } \\
\text { Well Sorted }\end{array}$ & $\begin{array}{l}\text { Moderately } \\
\text { Well Sorted }\end{array}$ & $\begin{array}{l}\text { Moderately } \\
\text { Well Sorted }\end{array}$ & $\begin{array}{l}\text { Moderately } \\
\text { Well Sorted }\end{array}$ \\
\hline & SKEWNESS: & Symmetrical & $\begin{array}{l}\begin{array}{l}\text { Coarse } \\
\text { Skewed }\end{array} \\
\end{array}$ & Symmetrical & Symmetrical & Symmetrical & Symmetrical & Symmetrical & $\begin{array}{l}\text { Coarse } \\
\text { Skewed } \\
\end{array}$ & Symmetrical & Symmetrical & $\begin{array}{l}\begin{array}{l}\text { Coarse } \\
\text { Skewed }\end{array} \\
\end{array}$ & $\begin{array}{l}\begin{array}{l}\text { Coarse } \\
\text { Skewed }\end{array} \\
\end{array}$ \\
\hline & KURTOSIS: & Mesokurtic & Mesokurtic & Mesokurtic & Mesokurtic & Mesokurtic & Mesokurtic & Mesokurtic & Mesokurtic & Mesokurtic & Mesokurtic & Mesokurtic & Mesokurtic \\
\hline & \% GRAVEL: & $0.0 \%$ & $0.0 \%$ & $0.0 \%$ & $0.0 \%$ & $0.0 \%$ & $0.2 \%$ & $0.0 \%$ & $0.1 \%$ & $0.1 \%$ & $0.1 \%$ & $0.0 \%$ & $0.3 \%$ \\
\hline & \% SAND: & $100.0 \%$ & $100.0 \%$ & $100.0 \%$ & 99.9\% & 99.9\% & $99.7 \%$ & $100.0 \%$ & 99.9\% & $99.9 \%$ & 99.9\% & $100.0 \%$ & $99.7 \%$ \\
\hline & \% MUD: & $0.0 \%$ & $0.0 \%$ & $0.0 \%$ & $0.1 \%$ & $0.1 \%$ & $0.1 \%$ & $0.0 \%$ & $0.0 \%$ & $0.0 \%$ & $0.0 \%$ & $0.0 \%$ & $0.0 \%$ \\
\hline & \% V COARSE GRAVEL: & $0.0 \%$ & $0.0 \%$ & $0.0 \%$ & $0.0 \%$ & $0.0 \%$ & $0.0 \%$ & $0.0 \%$ & $0.0 \%$ & $0.0 \%$ & $0.0 \%$ & $0.0 \%$ & $0.0 \%$ \\
\hline & \% COARSE GRAVEL: & $0.0 \%$ & $0.0 \%$ & $0.0 \%$ & $0.0 \%$ & $0.0 \%$ & $0.0 \%$ & $0.0 \%$ & $0.0 \%$ & $0.0 \%$ & $0.0 \%$ & $0.0 \%$ & $0.0 \%$ \\
\hline & \% MEDIUM GRAVEL: & $0.0 \%$ & $0.0 \%$ & $0.0 \%$ & $0.0 \%$ & $0.0 \%$ & $0.0 \%$ & $0.0 \%$ & $0.0 \%$ & $0.0 \%$ & $0.0 \%$ & $0.0 \%$ & $0.0 \%$ \\
\hline & \% FINE GRAVEL: & $0.0 \%$ & $0.0 \%$ & $0.0 \%$ & $0.0 \%$ & $0.0 \%$ & $0.0 \%$ & $0.0 \%$ & $0.0 \%$ & $0.0 \%$ & $0.0 \%$ & $0.0 \%$ & $0.0 \%$ \\
\hline & \% V FINE GRAVEL: & $0.0 \%$ & $0.0 \%$ & $0.0 \%$ & $0.0 \%$ & $0.0 \%$ & $0.2 \%$ & $0.0 \%$ & $0.1 \%$ & $0.1 \%$ & $0.1 \%$ & $0.0 \%$ & $0.3 \%$ \\
\hline & \% V COARSE SAND: & $0.2 \%$ & $2.6 \%$ & $2.6 \%$ & $5.7 \%$ & $1.4 \%$ & $2.3 \%$ & $0.4 \%$ & $2.0 \%$ & $0.7 \%$ & $3.3 \%$ & $0.7 \%$ & $1.5 \%$ \\
\hline & \% COARSE SAND: & $12.9 \%$ & $15.4 \%$ & $22.9 \%$ & $36.9 \%$ & $24.7 \%$ & $30.5 \%$ & $13.5 \%$ & $11.7 \%$ & $16.9 \%$ & $31.3 \%$ & $7.2 \%$ & $12.6 \%$ \\
\hline & $\%$ MEDIUM SAND: & $62.0 \%$ & $45.5 \%$ & $50.9 \%$ & $45.8 \%$ & $55.8 \%$ & $55.7 \%$ & $57.5 \%$ & $47.6 \%$ & $55.1 \%$ & $52.7 \%$ & $47.0 \%$ & $53.7 \%$ \\
\hline & \% FINE SAND: & $24.1 \%$ & $35.4 \%$ & $22.9 \%$ & $11.1 \%$ & $17.5 \%$ & $10.9 \%$ & $28.4 \%$ & $38.1 \%$ & $26.5 \%$ & $12.5 \%$ & $44.8 \%$ & $31.9 \%$ \\
\hline & \% V FINE SAND: & $0.7 \%$ & $1.0 \%$ & $0.7 \%$ & $0.4 \%$ & $0.5 \%$ & $0.3 \%$ & $0.2 \%$ & $0.5 \%$ & $0.7 \%$ & $0.2 \%$ & $0.4 \%$ & $0.1 \%$ \\
\hline & \% V COARSE SILT: & $0.0 \%$ & $0.0 \%$ & $0.0 \%$ & $0.1 \%$ & $0.1 \%$ & $0.1 \%$ & $0.0 \%$ & $0.0 \%$ & $0.0 \%$ & $0.0 \%$ & $0.0 \%$ & $0.0 \%$ \\
\hline & \% COARSE SILT: & $0.0 \%$ & $0.0 \%$ & $0.0 \%$ & $0.0 \%$ & $0.0 \%$ & $0.0 \%$ & $0.0 \%$ & $0.0 \%$ & $0.0 \%$ & $0.0 \%$ & $0.0 \%$ & $0.0 \%$ \\
\hline & \% MEDIUM SILT: & $0.0 \%$ & $0.0 \%$ & $0.0 \%$ & $0.0 \%$ & $0.0 \%$ & $0.0 \%$ & $0.0 \%$ & $0.0 \%$ & $0.0 \%$ & $0.0 \%$ & $0.0 \%$ & $0.0 \%$ \\
\hline & \% FINE SILT: & $0.0 \%$ & $0.0 \%$ & $0.0 \%$ & $0.0 \%$ & $0.0 \%$ & $0.0 \%$ & $0.0 \%$ & $0.0 \%$ & $0.0 \%$ & $0.0 \%$ & $0.0 \%$ & $0.0 \%$ \\
\hline & \% V FINE SILT: & $0.0 \%$ & $0.0 \%$ & $0.0 \%$ & $0.0 \%$ & $0.0 \%$ & $0.0 \%$ & $0.0 \%$ & $0.0 \%$ & $0.0 \%$ & $0.0 \%$ & $0.0 \%$ & $0.0 \%$ \\
\hline & \% CLAY: & $0.0 \%$ & $0.0 \%$ & $0.0 \%$ & $0.0 \%$ & $0.0 \%$ & $0.0 \%$ & $0.0 \%$ & $0.0 \%$ & $0.0 \%$ & $0.0 \%$ & $0.0 \%$ & $0.0 \%$ \\
\hline
\end{tabular}




\section{Barrier Surface}

\begin{tabular}{|c|c|c|c|c|c|c|c|c|c|c|c|c|c|}
\hline & & $\begin{array}{l}\text { WnW06- } \\
\text { t17_bb-1-a }\end{array}$ & $\begin{array}{l}\text { WnW06- } \\
\text { t17_bb-2-a }\end{array}$ & $\begin{array}{l}\text { WnW10- } \\
\text { t17_fdf-a }\end{array}$ & $\begin{array}{l}\text { WnW10- } \\
\text { t17_bd-a }\end{array}$ & $\begin{array}{l}\text { PntTnch06- } \\
\text { t3_bb-1-a }\end{array}$ & $\begin{array}{l}\text { PntTnch06- } \\
\text { t3_bb-2-a }\end{array}$ & $\begin{array}{l}\text { PntTnch06- } \\
\text { t3_fdf-a }\end{array}$ & $\begin{array}{l}\text { PntTnch06- } \\
\text { t5_bb-1-a }\end{array}$ & $\begin{array}{l}\text { PntTnch06- } \\
\text { t5_bb-2-a }\end{array}$ & $\begin{array}{l}\text { PntTnch06- } \\
\text { t5_fdf-a }\end{array}$ & $\begin{array}{l}\text { PntTnch06- } \\
\text { t15_bb-1-a }\end{array}$ & $\begin{array}{l}\text { PntTnch06- } \\
\text { t15_bb-2-a }\end{array}$ \\
\hline & SAMPLE TYPE: & $\begin{array}{l}\text { Unimodal, } \\
\text { Moderately } \\
\text { Well Sorted }\end{array}$ & $\begin{array}{l}\text { Unimodal, } \\
\text { Moderately } \\
\text { Well Sorted }\end{array}$ & $\begin{array}{l}\text { Unimodal, } \\
\text { Well Sorted }\end{array}$ & $\begin{array}{l}\text { Unimodal, } \\
\text { Moderately } \\
\text { Well Sorted }\end{array}$ & $\begin{array}{l}\text { Unimodal, } \\
\text { Well Sorted }\end{array}$ & $\begin{array}{l}\text { Unimodal, } \\
\text { Moderately } \\
\text { Well Sorted }\end{array}$ & $\begin{array}{l}\text { Unimodal, } \\
\text { Moderately } \\
\text { Well Sorted }\end{array}$ & $\begin{array}{l}\text { Unimodal, } \\
\text { Moderately } \\
\text { Well Sorted }\end{array}$ & $\begin{array}{l}\text { Unimodal, } \\
\text { Moderately } \\
\text { Well Sorted }\end{array}$ & $\begin{array}{l}\text { Unimodal, } \\
\text { Moderately } \\
\text { Sorted }\end{array}$ & $\begin{array}{l}\text { Unimodal, } \\
\text { Moderately } \\
\text { Well Sorted }\end{array}$ & $\begin{array}{l}\text { Unimodal, } \\
\text { Moderately } \\
\text { Well Sorted }\end{array}$ \\
\hline & TEXTURAL GROUP: & Sand & Sand & Sand & Sand & Sand & Sand & Sand & Sand & Sand & Sand & Sand & Sand \\
\hline & SEDIMENT NAME: & $\begin{array}{l}\text { Moderately } \\
\text { Well Sorted } \\
\text { Medium } \\
\text { Sand }\end{array}$ & $\begin{array}{l}\text { Moderately } \\
\text { Well Sorted } \\
\text { Medium } \\
\text { Sand }\end{array}$ & $\begin{array}{l}\text { Well Sorted } \\
\text { Medium } \\
\text { Sand }\end{array}$ & $\begin{array}{l}\text { Moderately } \\
\text { Well Sorted } \\
\text { Medium } \\
\text { Sand }\end{array}$ & $\begin{array}{l}\text { Well Sorted } \\
\text { Medium } \\
\text { Sand }\end{array}$ & $\begin{array}{l}\text { Moderately } \\
\text { Well Sorted } \\
\text { Medium } \\
\text { Sand }\end{array}$ & $\begin{array}{l}\text { Moderately } \\
\text { Well Sorted } \\
\text { Medium } \\
\text { Sand }\end{array}$ & $\begin{array}{l}\text { Moderately } \\
\text { Well Sorted } \\
\text { Medium } \\
\text { Sand }\end{array}$ & $\begin{array}{l}\text { Moderately } \\
\text { Well Sorted } \\
\text { Medium } \\
\text { Sand }\end{array}$ & $\begin{array}{l}\text { Moderately } \\
\text { Sorted } \\
\text { Medium } \\
\text { Sand }\end{array}$ & $\begin{array}{l}\text { Moderately } \\
\text { Well Sorted } \\
\text { Medium } \\
\text { Sand }\end{array}$ & $\begin{array}{l}\text { Moderately } \\
\text { Well Sorted } \\
\text { Medium } \\
\text { Sand }\end{array}$ \\
\hline \multirow{4}{*}{$\begin{array}{l}\text { FOLK AND } \\
\text { WARD } \\
\text { METHOD } \\
(\mathrm{mm})\end{array}$} & MEAN & 314.8 & 300.3 & 268 & 329 & 281.4 & 322.2 & 323.8 & 344.7 & 363.7 & 406.1 & 334.5 & 312.3 \\
\hline & SORTING & 1.415 & 1.501 & 1.361 & 1.442 & 1.381 & 1.458 & 1.449 & 1.506 & 1.561 & 1.657 & 1.521 & 1.423 \\
\hline & SKEWNESS & 0.013 & 0.195 & 0.112 & 0.116 & 0.105 & 0.148 & 0.112 & 0.075 & 0.059 & 0.151 & 0.15 & 0.05 \\
\hline & KURTOSIS & 0.972 & 1.069 & 1.047 & 1.007 & 1.022 & 1.043 & 0.996 & 0.939 & 0.948 & 0.952 & 0.981 & 0.963 \\
\hline \multirow{4}{*}{$\begin{array}{l}\text { FOLK AND } \\
\text { WARD } \\
\text { METHOD } \\
\text { (phi) }\end{array}$} & MEAN & 1.667 & 1.736 & 1.9 & 1.604 & 1.933 & 1.776 & 1.736 & 1.666 & 1.607 & 1.514 & 1.741 & 1.773 \\
\hline & SORTING & 0.501 & 0.586 & 0.445 & 0.529 & 0.466 & 0.544 & 0.535 & 0.59 & 0.643 & 0.729 & 0.605 & 0.509 \\
\hline & SKEWNESS & -0.013 & -0.195 & -0.112 & -0.116 & -0.105 & -0.148 & -0.112 & -0.075 & -0.059 & -0.151 & -0.15 & -0.05 \\
\hline & KURTOSIS & 0.972 & 1.069 & 1.047 & 1.007 & 1.022 & 1.043 & 0.996 & 0.939 & 0.948 & 0.952 & 0.981 & 0.963 \\
\hline \multirow{23}{*}{$\begin{array}{l}\text { FOLK AND } \\
\text { WARD } \\
\text { METHOD } \\
\text { (Description) }\end{array}$} & MEAN: & $\begin{array}{l}\text { Medium } \\
\text { Sand }\end{array}$ & $\begin{array}{l}\text { Medium } \\
\text { Sand }\end{array}$ & $\begin{array}{l}\text { Medium } \\
\text { Sand }\end{array}$ & $\begin{array}{l}\text { Medium } \\
\text { Sand }\end{array}$ & $\begin{array}{l}\text { Medium } \\
\text { Sand }\end{array}$ & $\begin{array}{l}\text { Medium } \\
\text { Sand }\end{array}$ & $\begin{array}{l}\text { Medium } \\
\text { Sand }\end{array}$ & $\begin{array}{l}\text { Medium } \\
\text { Sand }\end{array}$ & $\begin{array}{l}\text { Medium } \\
\text { Sand }\end{array}$ & $\begin{array}{l}\text { Medium } \\
\text { Sand }\end{array}$ & $\begin{array}{l}\text { Medium } \\
\text { Sand }\end{array}$ & $\begin{array}{l}\text { Medium } \\
\text { Sand }\end{array}$ \\
\hline & SORTING: & $\begin{array}{l}\text { Moderately } \\
\text { Well Sorted }\end{array}$ & $\begin{array}{l}\text { Moderately } \\
\text { Well Sorted }\end{array}$ & Well Sorted & $\begin{array}{l}\text { Moderately } \\
\text { Well Sorted }\end{array}$ & Well Sorted & $\begin{array}{l}\text { Moderately } \\
\text { Well Sorted }\end{array}$ & $\begin{array}{l}\text { Moderately } \\
\text { Well Sorted }\end{array}$ & $\begin{array}{l}\text { Moderately } \\
\text { Well Sorted }\end{array}$ & $\begin{array}{l}\text { Moderately } \\
\text { Well Sorted }\end{array}$ & $\begin{array}{l}\text { Moderately } \\
\text { Sorted }\end{array}$ & $\begin{array}{l}\text { Moderately } \\
\text { Well Sorted }\end{array}$ & $\begin{array}{l}\text { Moderately } \\
\text { Well Sorted }\end{array}$ \\
\hline & SKEWNESS: & Symmetrical & $\begin{array}{l}\text { Coarse } \\
\text { Skewed }\end{array}$ & $\begin{array}{l}\text { Coarse } \\
\text { Skewed }\end{array}$ & $\begin{array}{l}\text { Coarse } \\
\text { Skewed }\end{array}$ & $\begin{array}{l}\text { Coarse } \\
\text { Skewed }\end{array}$ & $\begin{array}{l}\text { Coarse } \\
\text { Skewed }\end{array}$ & $\begin{array}{l}\text { Coarse } \\
\text { Skewed }\end{array}$ & Symmetrical & Symmetrical & $\begin{array}{l}\text { Coarse } \\
\text { Skewed }\end{array}$ & $\begin{array}{l}\text { Coarse } \\
\text { Skewed }\end{array}$ & Symmetrical \\
\hline & KURTOSIS: & Mesokurtic & Mesokurtic & Mesokurtic & Mesokurtic & Mesokurtic & Mesokurtic & Mesokurtic & Mesokurtic & Mesokurtic & Mesokurtic & Mesokurtic & Mesokurtic \\
\hline & \% GRAVEL: & $0.0 \%$ & $0.0 \%$ & $0.0 \%$ & $0.0 \%$ & $0.0 \%$ & $0.0 \%$ & $0.0 \%$ & $0.0 \%$ & $0.0 \%$ & $0.0 \%$ & $0.0 \%$ & $0.0 \%$ \\
\hline & \% SAND: & $100.0 \%$ & $100.0 \%$ & $100.0 \%$ & $100.0 \%$ & $100.0 \%$ & $100.0 \%$ & $100.0 \%$ & $100.0 \%$ & $100.0 \%$ & $100.0 \%$ & $100.0 \%$ & $100.0 \%$ \\
\hline & \% MUD: & $0.0 \%$ & $0.0 \%$ & $0.0 \%$ & $0.0 \%$ & $0.0 \%$ & $0.0 \%$ & $0.0 \%$ & $0.0 \%$ & $0.0 \%$ & $0.0 \%$ & $0.0 \%$ & $0.0 \%$ \\
\hline & \% V COARSE GRAVEL: & $0.0 \%$ & $0.0 \%$ & $0.0 \%$ & $0.0 \%$ & $0.0 \%$ & $0.0 \%$ & $0.0 \%$ & $0.0 \%$ & $0.0 \%$ & $0.0 \%$ & $0.0 \%$ & $0.0 \%$ \\
\hline & \% COARSE GRAVEL: & $0.0 \%$ & $0.0 \%$ & $0.0 \%$ & $0.0 \%$ & $0.0 \%$ & $0.0 \%$ & $0.0 \%$ & $0.0 \%$ & $0.0 \%$ & $0.0 \%$ & $0.0 \%$ & $0.0 \%$ \\
\hline & \% MEDIUM GRAVEL: & $0.0 \%$ & $0.0 \%$ & $0.0 \%$ & $0.0 \%$ & $0.0 \%$ & $0.0 \%$ & $0.0 \%$ & $0.0 \%$ & $0.0 \%$ & $0.0 \%$ & $0.0 \%$ & $0.0 \%$ \\
\hline & \% FINE GRAVEL: & $0.0 \%$ & $0.0 \%$ & $0.0 \%$ & $0.0 \%$ & $0.0 \%$ & $0.0 \%$ & $0.0 \%$ & $0.0 \%$ & $0.0 \%$ & $0.0 \%$ & $0.0 \%$ & $0.0 \%$ \\
\hline & \% V FINE GRAVEL: & $0.0 \%$ & $0.0 \%$ & $0.0 \%$ & $0.0 \%$ & $0.0 \%$ & $0.0 \%$ & $0.0 \%$ & $0.0 \%$ & $0.0 \%$ & $0.0 \%$ & $0.0 \%$ & $0.0 \%$ \\
\hline & $\%$ V COARSE SAND: & $0.0 \%$ & $1.1 \%$ & $0.0 \%$ & $0.7 \%$ & $0.0 \%$ & $0.7 \%$ & $0.0 \%$ & $0.3 \%$ & $0.5 \%$ & $3.2 \%$ & $1.1 \%$ & $0.0 \%$ \\
\hline & $\%$ COARSE SAND: & $9.5 \%$ & $11.4 \%$ & $4.4 \%$ & $13.0 \%$ & $4.1 \%$ & $9.0 \%$ & $10.0 \%$ & $13.9 \%$ & $17.6 \%$ & $21.2 \%$ & $11.7 \%$ & $7.1 \%$ \\
\hline & \% MEDIUM SAND: & $64.7 \%$ & $52.9 \%$ & $53.1 \%$ & $63.2 \%$ & $49.9 \%$ & $54.6 \%$ & $57.3 \%$ & $55.6 \%$ & $53.5 \%$ & $48.6 \%$ & $51.3 \%$ & $58.9 \%$ \\
\hline & \% FINE SAND: & $25.4 \%$ & $34.5 \%$ & $42.5 \%$ & $23.1 \%$ & $45.9 \%$ & $35.7 \%$ & $32.3 \%$ & $30.1 \%$ & $28.0 \%$ & $26.8 \%$ & $35.8 \%$ & $33.9 \%$ \\
\hline & \% V FINE SAND: & $0.4 \%$ & $0.1 \%$ & $0.0 \%$ & $0.0 \%$ & $0.1 \%$ & $0.0 \%$ & $0.3 \%$ & $0.1 \%$ & $0.3 \%$ & $0.2 \%$ & $0.1 \%$ & $0.1 \%$ \\
\hline & $\%$ V COARSE SILT: & $0.0 \%$ & $0.0 \%$ & $0.0 \%$ & $0.0 \%$ & $0.0 \%$ & $0.0 \%$ & $0.0 \%$ & $0.0 \%$ & $0.0 \%$ & $0.0 \%$ & $0.0 \%$ & $0.0 \%$ \\
\hline & \% COARSE SILT: & $0.0 \%$ & $0.0 \%$ & $0.0 \%$ & $0.0 \%$ & $0.0 \%$ & $0.0 \%$ & $0.0 \%$ & $0.0 \%$ & $0.0 \%$ & $0.0 \%$ & $0.0 \%$ & $0.0 \%$ \\
\hline & \% MEDIUM SILT: & $0.0 \%$ & $0.0 \%$ & $0.0 \%$ & $0.0 \%$ & $0.0 \%$ & $0.0 \%$ & $0.0 \%$ & $0.0 \%$ & $0.0 \%$ & $0.0 \%$ & $0.0 \%$ & $0.0 \%$ \\
\hline & \% FINE SILT: & $0.0 \%$ & $0.0 \%$ & $0.0 \%$ & $0.0 \%$ & $0.0 \%$ & $0.0 \%$ & $0.0 \%$ & $0.0 \%$ & $0.0 \%$ & $0.0 \%$ & $0.0 \%$ & $0.0 \%$ \\
\hline & $\%$ V FINE SILT: & $0.0 \%$ & $0.0 \%$ & $0.0 \%$ & $0.0 \%$ & $0.0 \%$ & $0.0 \%$ & $0.0 \%$ & $0.0 \%$ & $0.0 \%$ & $0.0 \%$ & $0.0 \%$ & $0.0 \%$ \\
\hline & \% CLAY: & $0.0 \%$ & $0.0 \%$ & $0.0 \%$ & $0.0 \%$ & $0.0 \%$ & $0.0 \%$ & $0.0 \%$ & $0.0 \%$ & $0.0 \%$ & $0.0 \%$ & $0.0 \%$ & $0.0 \%$ \\
\hline
\end{tabular}


2006 Barrier Surface

\begin{tabular}{|c|c|c|c|c|c|c|c|c|c|c|c|c|c|}
\hline & & $\begin{array}{l}\text { PntTnch06- } \\
\text { t15_fdf-a }\end{array}$ & $\begin{array}{l}\text { PntPtnpch06 } \\
\text {-t3_bb-1-a }\end{array}$ & $\begin{array}{l}\text { PntPtnpch06 } \\
\text {-t3_bb-2-a }\end{array}$ & $\begin{array}{l}\text { PntPtnpch0 } \\
\text { 6-t3_fdf-a }\end{array}$ & $\begin{array}{l}\text { PntPtnpch06 } \\
\text {-t3_bd-a }\end{array}$ & $\begin{array}{l}\text { PntPtnpch06 } \\
\text {-t5_bb-1-a }\end{array}$ & $\begin{array}{l}\text { PntPtnpch0 } \\
\text { 6-t5_bb-2-a }\end{array}$ & $\begin{array}{l}\text { PntPtnpch06 } \\
\text {-t5_fdf-1-a }\end{array}$ & $\begin{array}{l}\text { PntPtnpch06 } \\
\text {-t5_fdf-2-a }\end{array}$ & $\begin{array}{l}\text { PntPtnpch0 } \\
\text { 6-t5_bd-a }\end{array}$ & $\begin{array}{l}\text { PntPtnpch- } \\
\text { t6_bb-1-a }\end{array}$ & $\begin{array}{l}\text { PntPtnpch- } \\
\text { t6_bb-2-a }\end{array}$ \\
\hline & SAMPLE TYPE: & $\begin{array}{l}\text { Unimodal, } \\
\text { Moderately } \\
\text { Well Sorted }\end{array}$ & $\begin{array}{l}\text { Unimodal, } \\
\text { Moderately } \\
\text { Well Sorted }\end{array}$ & $\begin{array}{l}\text { Unimodal, } \\
\text { Moderately } \\
\text { Sorted }\end{array}$ & $\begin{array}{l}\text { Unimodal, } \\
\text { Moderately } \\
\text { Well Sorted }\end{array}$ & $\begin{array}{l}\text { Unimodal, } \\
\text { Moderately } \\
\text { Sorted }\end{array}$ & $\begin{array}{l}\text { Unimodal, } \\
\text { Moderately } \\
\text { Well Sorted }\end{array}$ & $\begin{array}{l}\text { Unimodal, } \\
\text { Moderately } \\
\text { Well Sorted }\end{array}$ & $\begin{array}{l}\text { Unimodal, } \\
\text { Moderately } \\
\text { Well Sorted }\end{array}$ & $\begin{array}{l}\text { Unimodal, } \\
\text { Moderately } \\
\text { Well Sorted }\end{array}$ & $\begin{array}{l}\text { Unimodal, } \\
\text { Moderately } \\
\text { Well Sorted }\end{array}$ & $\begin{array}{l}\text { Unimodal, } \\
\text { Moderately } \\
\text { Well Sorted }\end{array}$ & $\begin{array}{l}\text { Unimodal, } \\
\text { Moderately } \\
\text { Well Sorted }\end{array}$ \\
\hline & TEXTURAL GROUP: & Sand & Sand & Sand & Sand & $\begin{array}{l}\text { Slightly } \\
\text { Gravelly } \\
\text { Sand }\end{array}$ & Sand & Sand & Sand & Sand & Sand & Sand & Sand \\
\hline & SEDIMENT NAME: & $\begin{array}{l}\text { Moderately } \\
\text { Well Sorted } \\
\text { Medium } \\
\text { Sand }\end{array}$ & $\begin{array}{l}\text { Moderately } \\
\text { Well Sorted } \\
\text { Medium } \\
\text { Sand }\end{array}$ & $\begin{array}{l}\text { Moderately } \\
\text { Sorted } \\
\text { Medium } \\
\text { Sand }\end{array}$ & $\begin{array}{l}\text { Moderately } \\
\text { Well Sorted } \\
\text { Medium } \\
\text { Sand }\end{array}$ & $\begin{array}{l}\text { Slightly Very } \\
\text { Fine Gravelly } \\
\text { Medium } \\
\text { Sand }\end{array}$ & $\begin{array}{l}\text { Moderately } \\
\text { Well Sorted } \\
\text { Medium } \\
\text { Sand }\end{array}$ & $\begin{array}{l}\text { Moderately } \\
\text { Well Sorted } \\
\text { Medium } \\
\text { Sand }\end{array}$ & $\begin{array}{l}\text { Moderately } \\
\text { Well Sorted } \\
\text { Medium } \\
\text { Sand }\end{array}$ & $\begin{array}{l}\text { Moderately } \\
\text { Well Sorted } \\
\text { Medium } \\
\text { Sand }\end{array}$ & $\begin{array}{l}\text { Moderately } \\
\text { Well Sorted } \\
\text { Medium } \\
\text { Sand }\end{array}$ & $\begin{array}{l}\text { Moderately } \\
\text { Well Sorted } \\
\text { Medium } \\
\text { Sand }\end{array}$ & $\begin{array}{l}\text { Moderately } \\
\text { Well Sorted } \\
\text { Medium } \\
\text { Sand }\end{array}$ \\
\hline \multirow{4}{*}{$\begin{array}{l}\text { FOLK AND } \\
\text { WARD } \\
\text { METHOD } \\
(\mathrm{mm})\end{array}$} & MEAN & 414.4 & 296.6 & 502.8 & 308.4 & 434.4 & 358.5 & 372.3 & 369.2 & 284 & 317.9 & 348.9 & 319.8 \\
\hline & SORTING & 1.566 & 1.56 & 1.66 & 1.568 & 1.823 & 1.481 & 1.611 & 1.57 & 1.431 & 1.516 & 1.46 & 1.472 \\
\hline & SKEWNESS & 0.045 & 0.114 & 0.012 & 0.141 & 0.068 & 0.009 & 0.067 & 0.06 & 0.066 & 0.053 & -0.025 & 0.076 \\
\hline & KURTOSIS & 0.959 & 0.966 & 1.021 & 0.973 & 0.962 & 0.969 & 0.986 & 0.995 & 0.964 & 0.97 & 0.967 & 0.983 \\
\hline \multirow{4}{*}{$\begin{array}{l}\text { FOLK AND } \\
\text { WARD } \\
\text { METHOD } \\
\text { (phi) }\end{array}$} & MEAN & 1.434 & 1.753 & 0.992 & 1.697 & 1.203 & 1.48 & 1.426 & 1.438 & 1.816 & 1.653 & 1.519 & 1.645 \\
\hline & SORTING & 0.647 & 0.641 & 0.731 & 0.649 & 0.866 & 0.566 & 0.688 & 0.651 & 0.518 & 0.6 & 0.546 & 0.558 \\
\hline & SKEWNESS & -0.045 & -0.114 & -0.012 & -0.141 & -0.068 & -0.009 & -0.067 & -0.06 & -0.066 & -0.053 & 0.025 & -0.076 \\
\hline & KURTOSIS & 0.959 & 0.966 & 1.021 & 0.973 & 0.962 & 0.969 & 0.986 & 0.995 & 0.964 & 0.97 & 0.967 & 0.983 \\
\hline \multirow{23}{*}{$\begin{array}{l}\text { FOLK AND } \\
\text { WARD } \\
\text { METHOD } \\
\text { (Description) }\end{array}$} & MEAN: & $\begin{array}{l}\text { Medium } \\
\text { Sand }\end{array}$ & $\begin{array}{l}\text { Medium } \\
\text { Sand }\end{array}$ & Coarse Sand & $\begin{array}{l}\text { Medium } \\
\text { Sand }\end{array}$ & $\begin{array}{l}\text { Medium } \\
\text { Sand }\end{array}$ & $\begin{array}{l}\text { Medium } \\
\text { Sand }\end{array}$ & $\begin{array}{l}\text { Medium } \\
\text { Sand }\end{array}$ & $\begin{array}{l}\text { Medium } \\
\text { Sand }\end{array}$ & $\begin{array}{l}\text { Medium } \\
\text { Sand }\end{array}$ & $\begin{array}{l}\text { Medium } \\
\text { Sand }\end{array}$ & $\begin{array}{l}\text { Medium } \\
\text { Sand }\end{array}$ & $\begin{array}{l}\text { Medium } \\
\text { Sand }\end{array}$ \\
\hline & SORTING: & $\begin{array}{l}\text { Moderately } \\
\text { Well Sorted }\end{array}$ & $\begin{array}{l}\text { Moderately } \\
\text { Well Sorted }\end{array}$ & $\begin{array}{l}\text { Moderately } \\
\text { Sorted }\end{array}$ & $\begin{array}{l}\text { Moderately } \\
\text { Well Sorted }\end{array}$ & $\begin{array}{l}\text { Moderately } \\
\text { Sorted }\end{array}$ & $\begin{array}{l}\text { Moderately } \\
\text { Well Sorted }\end{array}$ & $\begin{array}{l}\text { Moderately } \\
\text { Well Sorted }\end{array}$ & $\begin{array}{l}\text { Moderately } \\
\text { Well Sorted }\end{array}$ & $\begin{array}{l}\text { Moderately } \\
\text { Well Sorted }\end{array}$ & $\begin{array}{l}\text { Moderately } \\
\text { Well Sorted }\end{array}$ & $\begin{array}{l}\text { Moderately } \\
\text { Well Sorted }\end{array}$ & $\begin{array}{l}\text { Moderately } \\
\text { Well Sorted }\end{array}$ \\
\hline & SKEWNESS: & Symmetrical & $\begin{array}{l}\text { Coarse } \\
\text { Skewed }\end{array}$ & Symmetrical & $\begin{array}{l}\text { Coarse } \\
\text { Skewed }\end{array}$ & Symmetrical & Symmetrical & Symmetrical & Symmetrical & Symmetrical & Symmetrical & Symmetrical & Symmetrical \\
\hline & KURTOSIS: & Mesokurtic & Mesokurtic & Mesokurtic & Mesokurtic & Mesokurtic & Mesokurtic & Mesokurtic & Mesokurtic & Mesokurtic & Mesokurtic & Mesokurtic & Mesokurtic \\
\hline & \% GRAVEL: & $0.0 \%$ & $0.0 \%$ & $0.0 \%$ & $0.0 \%$ & $0.4 \%$ & $0.0 \%$ & $0.0 \%$ & $0.0 \%$ & $0.0 \%$ & $0.0 \%$ & $0.0 \%$ & $0.0 \%$ \\
\hline & $\%$ SAND: & $100.0 \%$ & $100.0 \%$ & $99.8 \%$ & $100.0 \%$ & $99.3 \%$ & $100.0 \%$ & $99.9 \%$ & $100.0 \%$ & $100.0 \%$ & $99.9 \%$ & $100.0 \%$ & $100.0 \%$ \\
\hline & $\%$ MUD: & $0.0 \%$ & $0.0 \%$ & $0.2 \%$ & $0.0 \%$ & $0.2 \%$ & $0.0 \%$ & $0.1 \%$ & $0.0 \%$ & $0.0 \%$ & $0.1 \%$ & $0.0 \%$ & $0.0 \%$ \\
\hline & \% V COARSE GRAVEL: & $0.0 \%$ & $0.0 \%$ & $0.0 \%$ & $0.0 \%$ & $0.0 \%$ & $0.0 \%$ & $0.0 \%$ & $0.0 \%$ & $0.0 \%$ & $0.0 \%$ & $0.0 \%$ & $0.0 \%$ \\
\hline & \% COARSE GRAVEL: & $0.0 \%$ & $0.0 \%$ & $0.0 \%$ & $0.0 \%$ & $0.0 \%$ & $0.0 \%$ & $0.0 \%$ & $0.0 \%$ & $0.0 \%$ & $0.0 \%$ & $0.0 \%$ & $0.0 \%$ \\
\hline & \% MEDIUM GRAVEL: & $0.0 \%$ & $0.0 \%$ & $0.0 \%$ & $0.0 \%$ & $0.0 \%$ & $0.0 \%$ & $0.0 \%$ & $0.0 \%$ & $0.0 \%$ & $0.0 \%$ & $0.0 \%$ & $0.0 \%$ \\
\hline & \% FINE GRAVEL: & $0.0 \%$ & $0.0 \%$ & $0.0 \%$ & $0.0 \%$ & $0.0 \%$ & $0.0 \%$ & $0.0 \%$ & $0.0 \%$ & $0.0 \%$ & $0.0 \%$ & $0.0 \%$ & $0.0 \%$ \\
\hline & \% V FINE GRAVEL: & $0.0 \%$ & $0.0 \%$ & $0.0 \%$ & $0.0 \%$ & $0.4 \%$ & $0.0 \%$ & $0.0 \%$ & $0.0 \%$ & $0.0 \%$ & $0.0 \%$ & $0.0 \%$ & $0.0 \%$ \\
\hline & $\%$ V COARSE SAND: & $1.9 \%$ & $1.1 \%$ & $9.1 \%$ & $1.4 \%$ & $9.0 \%$ & $0.3 \%$ & $3.1 \%$ & $2.3 \%$ & $0.0 \%$ & $0.6 \%$ & $0.0 \%$ & $0.3 \%$ \\
\hline & \% COARSE SAND: & $23.7 \%$ & $12.3 \%$ & $41.2 \%$ & $14.1 \%$ & $30.5 \%$ & $20.0 \%$ & $23.6 \%$ & $22.6 \%$ & $6.7 \%$ & $13.9 \%$ & $17.4 \%$ & $13.0 \%$ \\
\hline & $\%$ MEDIUM SAND: & $54.8 \%$ & $49.2 \%$ & $41.4 \%$ & $50.1 \%$ & $41.9 \%$ & $61.4 \%$ & $52.8 \%$ & $55.6 \%$ & $55.8 \%$ & $56.3 \%$ & $63.1 \%$ & $59.6 \%$ \\
\hline & \% FINE SAND: & $19.5 \%$ & $36.3 \%$ & $7.9 \%$ & $33.9 \%$ & $17.2 \%$ & $18.0 \%$ & $19.9 \%$ & $19.2 \%$ & $37.3 \%$ & $28.3 \%$ & $19.2 \%$ & $26.8 \%$ \\
\hline & \% V FINE SAND: & $0.2 \%$ & $1.1 \%$ & $0.2 \%$ & $0.4 \%$ & $0.8 \%$ & $0.3 \%$ & $0.5 \%$ & $0.3 \%$ & $0.2 \%$ & $0.7 \%$ & $0.3 \%$ & $0.3 \%$ \\
\hline & \% V COARSE SILT: & $0.0 \%$ & $0.0 \%$ & $0.1 \%$ & $0.0 \%$ & $0.1 \%$ & $0.0 \%$ & $0.1 \%$ & $0.0 \%$ & $0.0 \%$ & $0.1 \%$ & $0.0 \%$ & $0.0 \%$ \\
\hline & \% COARSE SILT: & $0.0 \%$ & $0.0 \%$ & $0.0 \%$ & $0.0 \%$ & $0.0 \%$ & $0.0 \%$ & $0.0 \%$ & $0.0 \%$ & $0.0 \%$ & $0.0 \%$ & $0.0 \%$ & $0.0 \%$ \\
\hline & \% MEDIUM SILT: & $0.0 \%$ & $0.0 \%$ & $0.0 \%$ & $0.0 \%$ & $0.0 \%$ & $0.0 \%$ & $0.0 \%$ & $0.0 \%$ & $0.0 \%$ & $0.0 \%$ & $0.0 \%$ & $0.0 \%$ \\
\hline & \% FINE SILT: & $0.0 \%$ & $0.0 \%$ & $0.0 \%$ & $0.0 \%$ & $0.0 \%$ & $0.0 \%$ & $0.0 \%$ & $0.0 \%$ & $0.0 \%$ & $0.0 \%$ & $0.0 \%$ & $0.0 \%$ \\
\hline & $\%$ V FINE SILT: & $0.0 \%$ & $0.0 \%$ & $0.0 \%$ & $0.0 \%$ & $0.0 \%$ & $0.0 \%$ & $0.0 \%$ & $0.0 \%$ & $0.0 \%$ & $0.0 \%$ & $0.0 \%$ & $0.0 \%$ \\
\hline & \% CLAY: & $0.0 \%$ & $0.0 \%$ & $0.0 \%$ & $0.0 \%$ & $0.0 \%$ & $0.0 \%$ & $0.0 \%$ & $0.0 \%$ & $0.0 \%$ & $0.0 \%$ & $0.0 \%$ & $0.0 \%$ \\
\hline
\end{tabular}


2006 Barrier Surface

\begin{tabular}{|c|c|c|c|c|c|c|c|c|c|c|c|c|c|}
\hline & & $\begin{array}{l}\text { PntPtnpch- } \\
\text { t6_fdf-1-a }\end{array}$ & $\begin{array}{l}\text { PntPtnpch- } \\
\text { t6_fdf-2-a }\end{array}$ & $\begin{array}{l}\text { PntPtnpch- } \\
\text { t6_bd-a }\end{array}$ & $\begin{array}{l}\text { PntPtnpch- } \\
\text { t7_bb-1-a }\end{array}$ & $\begin{array}{l}\text { PntPtnpch- } \\
\text { t7_bb-2-a }\end{array}$ & $\begin{array}{l}\text { PntPtnpch- } \\
\text { t7_fdf-a }\end{array}$ & $\begin{array}{l}\text { PntBrv06- } \\
\text { t1_bb-1-a }\end{array}$ & $\begin{array}{l}\text { PntBrv06- } \\
\text { t1_bb-2-a }\end{array}$ & $\begin{array}{l}\text { PntBrv06- } \\
\text { t1_fdf-1-a }\end{array}$ & $\begin{array}{l}\text { PntBrv06- } \\
\text { t1_fdf-2-a }\end{array}$ & $\begin{array}{l}\text { PntBrv06- } \\
\text { t1_bd-a }\end{array}$ & $\begin{array}{l}\text { PntBrv06- } \\
\text { t2_bb-a }\end{array}$ \\
\hline & SAMPLE TYPE: & $\begin{array}{l}\text { Unimodal, } \\
\text { Moderately } \\
\text { Well Sorted }\end{array}$ & $\begin{array}{l}\text { Unimodal, } \\
\text { Moderately } \\
\text { Well Sorted }\end{array}$ & $\begin{array}{l}\text { Unimodal, } \\
\text { Moderately } \\
\text { Well Sorted }\end{array}$ & $\begin{array}{l}\text { Unimodal, } \\
\text { Moderately } \\
\text { Well Sorted }\end{array}$ & $\begin{array}{l}\text { Unimodal, } \\
\text { Moderately } \\
\text { Well Sorted }\end{array}$ & $\begin{array}{l}\text { Unimodal, } \\
\text { Moderately } \\
\text { Well Sorted }\end{array}$ & $\begin{array}{l}\text { Unimodal, } \\
\text { Well Sorted }\end{array}$ & $\begin{array}{l}\text { Unimodal, } \\
\text { Well Sorted }\end{array}$ & $\begin{array}{l}\text { Unimodal, } \\
\text { Well Sorted }\end{array}$ & $\begin{array}{l}\text { Unimodal, } \\
\text { Moderately } \\
\text { Well Sorted }\end{array}$ & $\begin{array}{l}\text { Unimodal, } \\
\text { Moderately } \\
\text { Well Sorted }\end{array}$ & $\begin{array}{l}\text { Trimodal, } \\
\text { Moderately } \\
\text { Well Sorted }\end{array}$ \\
\hline & TEXTURAL GROUP: & Sand & Sand & Sand & Sand & $\begin{array}{l}\text { Slightly } \\
\text { Gravelly } \\
\text { Sand }\end{array}$ & Sand & $\begin{array}{l}\text { Slightly } \\
\text { Gravelly } \\
\text { Sand }\end{array}$ & Sand & Sand & Sand & Sand & Sand \\
\hline & SEDIMENT NAME: & $\begin{array}{l}\text { Moderately } \\
\text { Well Sorted } \\
\text { Medium } \\
\text { Sand }\end{array}$ & $\begin{array}{l}\text { Moderately } \\
\text { Well Sorted } \\
\text { Medium } \\
\text { Sand }\end{array}$ & $\begin{array}{l}\text { Moderately } \\
\text { Well Sorted } \\
\text { Medium } \\
\text { Sand }\end{array}$ & $\begin{array}{l}\text { Moderately } \\
\text { Well Sorted } \\
\text { Medium } \\
\text { Sand }\end{array}$ & $\begin{array}{l}\text { Slightly Very } \\
\text { Fine Gravelly } \\
\text { Medium } \\
\text { Sand }\end{array}$ & $\begin{array}{l}\text { Moderately } \\
\text { Well Sorted } \\
\text { Medium } \\
\text { Sand }\end{array}$ & $\begin{array}{l}\text { Slightly Very } \\
\text { Fine Gravelly } \\
\text { Medium } \\
\text { Sand }\end{array}$ & $\begin{array}{l}\text { Well Sorted } \\
\text { Medium } \\
\text { Sand }\end{array}$ & $\begin{array}{l}\text { Well Sorted } \\
\text { Medium } \\
\text { Sand }\end{array}$ & $\begin{array}{l}\text { Moderately } \\
\text { Well Sorted } \\
\text { Medium } \\
\text { Sand }\end{array}$ & $\begin{array}{l}\text { Moderately } \\
\text { Well Sorted } \\
\text { Medium } \\
\text { Sand }\end{array}$ & $\begin{array}{l}\text { Moderately } \\
\text { Well Sorted } \\
\text { Very Coarse } \\
\text { Sand }\end{array}$ \\
\hline \multirow{4}{*}{$\begin{array}{l}\text { FOLK AND } \\
\text { WARD } \\
\text { METHOD } \\
(\mathrm{mm})\end{array}$} & MEAN & 304.9 & 296.6 & 331.7 & 301.8 & 375.7 & 296.2 & 397.8 & 289.8 & 390.1 & 380.5 & 447 & 1003.7 \\
\hline & SORTING & 1.592 & 1.511 & 1.545 & 1.52 & 1.624 & 1.505 & 1.399 & 1.335 & 1.384 & 1.451 & 1.444 & 1.528 \\
\hline & SKEWNESS & 0.116 & 0.121 & 0.088 & 0.073 & 0.098 & 0.049 & 0.031 & 0.019 & 0.023 & 0.005 & 0.009 & 0.003 \\
\hline & KURTOSIS & 0.951 & 0.979 & 0.976 & 0.97 & 1.072 & 0.958 & 0.971 & 0.972 & 0.977 & 1.001 & 0.99 & 0.958 \\
\hline \multirow{4}{*}{$\begin{array}{l}\text { FOLK AND } \\
\text { WARD } \\
\text { METHOD } \\
\text { (phi) } \\
\end{array}$} & MEAN & 1.714 & 1.754 & 1.592 & 1.728 & 1.412 & 1.755 & 1.33 & 1.787 & 1.358 & 1.394 & 1.162 & -0.005 \\
\hline & SORTING & 0.671 & 0.595 & 0.627 & 0.604 & 0.699 & 0.59 & 0.485 & 0.416 & 0.468 & 0.537 & 0.53 & 0.611 \\
\hline & SKEWNESS & -0.116 & -0.121 & -0.088 & -0.073 & -0.098 & -0.049 & -0.031 & -0.019 & -0.023 & -0.005 & -0.009 & -0.003 \\
\hline & KURTOSIS & 0.951 & 0.979 & 0.976 & 0.97 & 1.072 & 0.958 & 0.971 & 0.972 & 0.977 & 1.001 & 0.99 & 0.958 \\
\hline \multirow{23}{*}{$\begin{array}{l}\text { FOLK AND } \\
\text { WARD } \\
\text { METHOD } \\
\text { (Description) }\end{array}$} & MEAN: & $\begin{array}{l}\text { Medium } \\
\text { Sand }\end{array}$ & $\begin{array}{l}\text { Medium } \\
\text { Sand }\end{array}$ & $\begin{array}{l}\text { Medium } \\
\text { Sand }\end{array}$ & $\begin{array}{l}\text { Medium } \\
\text { Sand }\end{array}$ & $\begin{array}{l}\text { Medium } \\
\text { Sand }\end{array}$ & $\begin{array}{l}\text { Medium } \\
\text { Sand }\end{array}$ & $\begin{array}{l}\text { Medium } \\
\text { Sand }\end{array}$ & $\begin{array}{l}\text { Medium } \\
\text { Sand }\end{array}$ & $\begin{array}{l}\text { Medium } \\
\text { Sand }\end{array}$ & $\begin{array}{l}\text { Medium } \\
\text { Sand }\end{array}$ & $\begin{array}{l}\text { Medium } \\
\text { Sand }\end{array}$ & $\begin{array}{l}\text { Very Coarse } \\
\text { Sand }\end{array}$ \\
\hline & SORTING: & $\begin{array}{l}\text { Moderately } \\
\text { Well Sorted }\end{array}$ & $\begin{array}{l}\text { Moderately } \\
\text { Well Sorted }\end{array}$ & $\begin{array}{l}\text { Moderately } \\
\text { Well Sorted }\end{array}$ & $\begin{array}{l}\text { Moderately } \\
\text { Well Sorted }\end{array}$ & $\begin{array}{l}\text { Moderately } \\
\text { Well Sorted }\end{array}$ & $\begin{array}{l}\text { Moderately } \\
\text { Well Sorted }\end{array}$ & Well Sorted & Well Sorted & Well Sorted & $\begin{array}{l}\text { Moderately } \\
\text { Well Sorted }\end{array}$ & $\begin{array}{l}\text { Moderately } \\
\text { Well Sorted }\end{array}$ & $\begin{array}{l}\text { Moderately } \\
\text { Well Sorted }\end{array}$ \\
\hline & SKEWNESS: & $\begin{array}{l}\text { Coarse } \\
\text { Skewed }\end{array}$ & $\begin{array}{l}\text { Coarse } \\
\text { Skewed }\end{array}$ & Symmetrical & Symmetrical & Symmetrical & Symmetrical & Symmetrical & Symmetrical & Symmetrical & Symmetrical & Symmetrical & Symmetrical \\
\hline & KURTOSIS: & Mesokurtic & Mesokurtic & Mesokurtic & Mesokurtic & Mesokurtic & Mesokurtic & Mesokurtic & Mesokurtic & Mesokurtic & Mesokurtic & Mesokurtic & Mesokurtic \\
\hline & \% GRAVEL: & $0.0 \%$ & $0.0 \%$ & $0.0 \%$ & $0.0 \%$ & $0.4 \%$ & $0.0 \%$ & $0.1 \%$ & $0.0 \%$ & $0.0 \%$ & $0.0 \%$ & $0.0 \%$ & $0.0 \%$ \\
\hline & \% SAND: & $100.0 \%$ & $100.0 \%$ & $100.0 \%$ & $100.0 \%$ & $99.5 \%$ & $99.9 \%$ & $99.9 \%$ & $100.0 \%$ & $100.0 \%$ & $100.0 \%$ & $99.8 \%$ & $100.0 \%$ \\
\hline & \% MUD: & $0.0 \%$ & $0.0 \%$ & $0.0 \%$ & $0.0 \%$ & $0.1 \%$ & $0.1 \%$ & $0.0 \%$ & $0.0 \%$ & $0.0 \%$ & $0.0 \%$ & $0.2 \%$ & $0.0 \%$ \\
\hline & $\%$ V COARSE GRAVEL: & $0.0 \%$ & $0.0 \%$ & $0.0 \%$ & $0.0 \%$ & $0.0 \%$ & $0.0 \%$ & $0.0 \%$ & $0.0 \%$ & $0.0 \%$ & $0.0 \%$ & $0.0 \%$ & $0.0 \%$ \\
\hline & \% COARSE GRAVEL: & $0.0 \%$ & $0.0 \%$ & $0.0 \%$ & $0.0 \%$ & $0.0 \%$ & $0.0 \%$ & $0.0 \%$ & $0.0 \%$ & $0.0 \%$ & $0.0 \%$ & $0.0 \%$ & $0.0 \%$ \\
\hline & \% MEDIUM GRAVEL: & $0.0 \%$ & $0.0 \%$ & $0.0 \%$ & $0.0 \%$ & $0.0 \%$ & $0.0 \%$ & $0.0 \%$ & $0.0 \%$ & $0.0 \%$ & $0.0 \%$ & $0.0 \%$ & $0.0 \%$ \\
\hline & \% FINE GRAVEL: & $0.0 \%$ & $0.0 \%$ & $0.0 \%$ & $0.0 \%$ & $0.0 \%$ & $0.0 \%$ & $0.0 \%$ & $0.0 \%$ & $0.0 \%$ & $0.0 \%$ & $0.0 \%$ & $0.0 \%$ \\
\hline & \% V FINE GRAVEL: & $0.0 \%$ & $0.0 \%$ & $0.0 \%$ & $0.0 \%$ & $0.4 \%$ & $0.0 \%$ & $0.1 \%$ & $0.0 \%$ & $0.0 \%$ & $0.0 \%$ & $0.0 \%$ & $0.0 \%$ \\
\hline & \% V COARSE SAND: & $1.0 \%$ & $0.8 \%$ & $1.4 \%$ & $0.6 \%$ & $4.0 \%$ & $0.0 \%$ & $0.1 \%$ & $0.0 \%$ & $0.2 \%$ & $0.5 \%$ & $1.3 \%$ & $48.8 \%$ \\
\hline & \% COARSE SAND: & $14.7 \%$ & $11.0 \%$ & $16.5 \%$ & $11.8 \%$ & $22.0 \%$ & $10.9 \%$ & $24.8 \%$ & $2.9 \%$ & $22.5 \%$ & $22.7 \%$ & $36.6 \%$ & $45.6 \%$ \\
\hline & \% MEDIUM SAND: & $48.4 \%$ & $52.2 \%$ & $55.3 \%$ & $53.6 \%$ & $54.3 \%$ & $53.9 \%$ & $66.8 \%$ & $65.9 \%$ & $69.0 \%$ & $63.8 \%$ & $56.4 \%$ & $5.4 \%$ \\
\hline & \% FINE SAND: & $35.0 \%$ & $35.7 \%$ & $26.6 \%$ & $33.2 \%$ & $18.6 \%$ & $34.1 \%$ & $7.9 \%$ & $31.0 \%$ & $8.1 \%$ & $12.6 \%$ & $5.2 \%$ & $0.1 \%$ \\
\hline & \% V FINE SAND: & $0.9 \%$ & $0.3 \%$ & $0.2 \%$ & $0.9 \%$ & $0.5 \%$ & $1.1 \%$ & $0.2 \%$ & $0.2 \%$ & $0.3 \%$ & $0.4 \%$ & $0.3 \%$ & $0.0 \%$ \\
\hline & \% V COARSE SILT: & $0.0 \%$ & $0.0 \%$ & $0.0 \%$ & $0.0 \%$ & $0.1 \%$ & $0.1 \%$ & $0.0 \%$ & $0.0 \%$ & $0.0 \%$ & $0.0 \%$ & $0.1 \%$ & $0.0 \%$ \\
\hline & \% COARSE SILT: & $0.0 \%$ & $0.0 \%$ & $0.0 \%$ & $0.0 \%$ & $0.0 \%$ & $0.0 \%$ & $0.0 \%$ & $0.0 \%$ & $0.0 \%$ & $0.0 \%$ & $0.0 \%$ & $0.0 \%$ \\
\hline & \% MEDIUM SILT: & $0.0 \%$ & $0.0 \%$ & $0.0 \%$ & $0.0 \%$ & $0.0 \%$ & $0.0 \%$ & $0.0 \%$ & $0.0 \%$ & $0.0 \%$ & $0.0 \%$ & $0.0 \%$ & $0.0 \%$ \\
\hline & \% FINE SILT: & $0.0 \%$ & $0.0 \%$ & $0.0 \%$ & $0.0 \%$ & $0.0 \%$ & $0.0 \%$ & $0.0 \%$ & $0.0 \%$ & $0.0 \%$ & $0.0 \%$ & $0.0 \%$ & $0.0 \%$ \\
\hline & \% V FINE SILT: & $0.0 \%$ & $0.0 \%$ & $0.0 \%$ & $0.0 \%$ & $0.0 \%$ & $0.0 \%$ & $0.0 \%$ & $0.0 \%$ & $0.0 \%$ & $0.0 \%$ & $0.0 \%$ & $0.0 \%$ \\
\hline & \% CLAY: & $0.0 \%$ & $0.0 \%$ & $0.0 \%$ & $0.0 \%$ & $0.0 \%$ & $0.0 \%$ & $0.0 \%$ & $0.0 \%$ & $0.0 \%$ & $0.0 \%$ & $0.0 \%$ & $0.0 \%$ \\
\hline
\end{tabular}


2006 Barrier Surface

\begin{tabular}{|c|c|c|c|c|c|c|c|}
\hline & & $\begin{array}{l}\text { PntBrv06-t2_fdf- } \\
\text { a }\end{array}$ & $\begin{array}{l}\text { PntBrv06-t2_bd- } \\
\text { a }\end{array}$ & $\begin{array}{l}\text { PlyaScrt06-t1_bf- } \\
\text { a }\end{array}$ & $\begin{array}{l}\text { PlyaScrt06- } \\
\text { t1_bb-a }\end{array}$ & $\begin{array}{l}\text { PlyaScrt06- } \\
\text { t1_fdf-a }\end{array}$ & $\begin{array}{l}\text { PlyaScrt06- } \\
\text { t1_bd-a }\end{array}$ \\
\hline & SAMPLE TYPE: & $\begin{array}{l}\text { Unimodal, } \\
\text { Moderately Well } \\
\text { Sorted }\end{array}$ & $\begin{array}{l}\text { Unimodal, } \\
\text { Moderately Well } \\
\text { Sorted }\end{array}$ & $\begin{array}{l}\text { Unimodal, } \\
\text { Moderately Well } \\
\text { Sorted }\end{array}$ & $\begin{array}{l}\text { Bimodal, Very } \\
\text { Poorly Sorted }\end{array}$ & $\begin{array}{l}\text { Unimodal, } \\
\text { Moderately Well } \\
\text { Sorted }\end{array}$ & $\begin{array}{l}\text { Unimodal, } \\
\text { Moderately Well } \\
\text { Sorted }\end{array}$ \\
\hline & TEXTURAL GROUP: & Sand & Sand & Sand & Sandy Gravel & Sand & Sand \\
\hline & SEDIMENT NAME: & $\begin{array}{l}\text { Moderately Well } \\
\text { Sorted Coarse } \\
\text { Sand }\end{array}$ & $\begin{array}{l}\text { Moderately Well } \\
\text { Sorted Coarse } \\
\text { Sand }\end{array}$ & $\begin{array}{l}\text { Moderately Well } \\
\text { Sorted Medium } \\
\text { Sand }\end{array}$ & $\begin{array}{l}\text { Sandy Very } \\
\text { Coarse Gravel }\end{array}$ & $\begin{array}{l}\text { Moderately Well } \\
\text { Sorted Coarse } \\
\text { Sand }\end{array}$ & $\begin{array}{l}\text { Moderately Well } \\
\text { Sorted Coarse } \\
\text { Sand }\end{array}$ \\
\hline \multirow{4}{*}{$\begin{array}{l}\text { FOLK AND } \\
\text { WARD } \\
\text { METHOD } \\
(\mathrm{mm})\end{array}$} & MEAN & 607.9 & 590.2 & 477.9 & 3827.7 & 516.4 & 532.2 \\
\hline & SORTING & 1.498 & 1.455 & 1.431 & 7.169 & 1.515 & 1.442 \\
\hline & SKEWNESS & 0.021 & 0.045 & 0.04 & 0.469 & 0.054 & 0.053 \\
\hline & KURTOSIS & 1.028 & 0.98 & 0.996 & 0.738 & 1.035 & 0.998 \\
\hline \multirow{4}{*}{$\begin{array}{l}\text { FOLK AND } \\
\text { WARD } \\
\text { METHOD } \\
\text { (phi) }\end{array}$} & MEAN & 0.718 & 0.761 & 1.065 & -1.936 & 0.953 & 0.91 \\
\hline & SORTING & 0.583 & 0.541 & 0.517 & 2.842 & 0.599 & 0.528 \\
\hline & SKEWNESS & -0.021 & -0.045 & -0.04 & -0.469 & -0.054 & -0.053 \\
\hline & KURTOSIS & 1.028 & 0.98 & 0.996 & 0.738 & 1.035 & 0.998 \\
\hline \multirow{23}{*}{$\begin{array}{l}\text { FOLK AND } \\
\text { WARD } \\
\text { METHOD } \\
\text { (Description) }\end{array}$} & MEAN: & Coarse Sand & Coarse Sand & Medium Sand & Very Fine Gravel & Coarse Sand & Coarse Sand \\
\hline & SORTING: & $\begin{array}{l}\text { Moderately Well } \\
\text { Sorted }\end{array}$ & $\begin{array}{l}\text { Moderately Well } \\
\text { Sorted }\end{array}$ & $\begin{array}{l}\text { Moderately Well } \\
\text { Sorted }\end{array}$ & $\begin{array}{l}\text { Very Poorly } \\
\text { Sorted }\end{array}$ & $\begin{array}{l}\text { Moderately Well } \\
\text { Sorted }\end{array}$ & $\begin{array}{l}\text { Moderately Well } \\
\text { Sorted }\end{array}$ \\
\hline & SKEWNESS: & Symmetrical & Symmetrical & Symmetrical & $\begin{array}{l}\text { Very Coarse } \\
\text { Skewed }\end{array}$ & Symmetrical & Symmetrical \\
\hline & KURTOSIS: & Mesokurtic & Mesokurtic & Mesokurtic & Platykurtic & Mesokurtic & Mesokurtic \\
\hline & \% GRAVEL: & $0.0 \%$ & $0.0 \%$ & $0.0 \%$ & $50.4 \%$ & $0.0 \%$ & $0.0 \%$ \\
\hline & \% SAND: & $99.2 \%$ & $100.0 \%$ & $100.0 \%$ & $49.6 \%$ & $99.1 \%$ & $100.0 \%$ \\
\hline & \% MUD: & $0.8 \%$ & $0.0 \%$ & $0.0 \%$ & $0.0 \%$ & $0.9 \%$ & $0.0 \%$ \\
\hline & $\%$ V COARSE GRAVEL: & $0.0 \%$ & $0.0 \%$ & $0.0 \%$ & $19.8 \%$ & $0.0 \%$ & $0.0 \%$ \\
\hline & \% COARSE GRAVEL: & $0.0 \%$ & $0.0 \%$ & $0.0 \%$ & $8.8 \%$ & $0.0 \%$ & $0.0 \%$ \\
\hline & \% MEDIUM GRAVEL: & $0.0 \%$ & $0.0 \%$ & $0.0 \%$ & $7.8 \%$ & $0.0 \%$ & $0.0 \%$ \\
\hline & \% FINE GRAVEL: & $0.0 \%$ & $0.0 \%$ & $0.0 \%$ & $6.8 \%$ & $0.0 \%$ & $0.0 \%$ \\
\hline & \% V FINE GRAVEL: & $0.0 \%$ & $0.0 \%$ & $0.0 \%$ & $7.2 \%$ & $0.0 \%$ & $0.0 \%$ \\
\hline & $\%$ V COARSE SAND: & $11.1 \%$ & $8.8 \%$ & $2.4 \%$ & $9.2 \%$ & $6.5 \%$ & $5.0 \%$ \\
\hline & \% COARSE SAND: & $57.3 \%$ & $57.3 \%$ & $41.7 \%$ & $32.7 \%$ & $45.2 \%$ & $50.6 \%$ \\
\hline & $\%$ MEDIUM SAND: & $29.3 \%$ & $32.9 \%$ & $52.9 \%$ & $7.4 \%$ & $44.2 \%$ & $42.9 \%$ \\
\hline & \% FINE SAND: & $1.3 \%$ & $1.0 \%$ & $2.9 \%$ & $0.2 \%$ & $2.7 \%$ & $1.5 \%$ \\
\hline & \% V FINE SAND: & $0.2 \%$ & $0.0 \%$ & $0.0 \%$ & $0.0 \%$ & $0.4 \%$ & $0.0 \%$ \\
\hline & $\%$ V COARSE SILT: & $0.1 \%$ & $0.0 \%$ & $0.0 \%$ & $0.0 \%$ & $0.2 \%$ & $0.0 \%$ \\
\hline & $\%$ COARSE SILT: & $0.1 \%$ & $0.0 \%$ & $0.0 \%$ & $0.0 \%$ & $0.2 \%$ & $0.0 \%$ \\
\hline & \% MEDIUM SILT: & $0.1 \%$ & $0.0 \%$ & $0.0 \%$ & $0.0 \%$ & $0.2 \%$ & $0.0 \%$ \\
\hline & \% FINE SILT: & $0.2 \%$ & $0.0 \%$ & $0.0 \%$ & $0.0 \%$ & $0.2 \%$ & $0.0 \%$ \\
\hline & \% V FINE SILT: & $0.2 \%$ & $0.0 \%$ & $0.0 \%$ & $0.0 \%$ & $0.1 \%$ & $0.0 \%$ \\
\hline & \% CLAY: & $0.1 \%$ & $0.0 \%$ & $0.0 \%$ & $0.0 \%$ & $0.1 \%$ & $0.0 \%$ \\
\hline
\end{tabular}


2010 Barrier and Lagoon

\begin{tabular}{|c|c|c|c|c|c|c|c|c|c|c|c|c|}
\hline & & $\begin{array}{l}\text { WnW10- } \\
\text { t1_bf-a }\end{array}$ & $\begin{array}{l}\text { WnW10- } \\
\text { t1_fdf-a }\end{array}$ & $\begin{array}{l}\text { WnW10- } \\
\text { t1_bd-a }\end{array}$ & $\begin{array}{l}\text { WnW10- } \\
\text { t3_bf-a }\end{array}$ & $\begin{array}{l}\text { WnW10- } \\
\text { t3_fdf-a }\end{array}$ & $\begin{array}{l}\text { WnW10- } \\
\text { t3_bd-a }\end{array}$ & $\begin{array}{l}\text { WnW10- } \\
\text { t12_bf-a }\end{array}$ & $\begin{array}{l}\text { WnW10- } \\
\text { t12_bb-a }\end{array}$ & $\begin{array}{l}\text { WnW10- } \\
\text { t12_fdf-a }\end{array}$ & $\begin{array}{l}\text { WnW10- } \\
\text { t12_bd-a }\end{array}$ & $\begin{array}{l}\text { WnW10- } \\
\text { t17_bf-a }\end{array}$ \\
\hline & SAMPLE TYPE: & $\begin{array}{l}\text { Unimodal, } \\
\text { Moderately } \\
\text { Sorted }\end{array}$ & $\begin{array}{l}\text { Unimodal, } \\
\text { Moderately } \\
\text { Well Sorted }\end{array}$ & $\begin{array}{l}\text { Unimodal, } \\
\text { Moderately } \\
\text { Well Sorted }\end{array}$ & $\begin{array}{l}\text { Unimodal, } \\
\text { Moderately } \\
\text { Well Sorted }\end{array}$ & $\begin{array}{l}\text { Unimodal, } \\
\text { Moderately } \\
\text { Sorted }\end{array}$ & $\begin{array}{l}\text { Unimodal, } \\
\text { Moderately } \\
\text { Well Sorted }\end{array}$ & $\begin{array}{l}\text { Unimodal, } \\
\text { Moderately } \\
\text { Well Sorted }\end{array}$ & $\begin{array}{l}\text { Trimodal, } \\
\text { Moderately } \\
\text { Sorted }\end{array}$ & $\begin{array}{l}\text { Unimodal, } \\
\text { Moderately } \\
\text { Well Sorted }\end{array}$ & $\begin{array}{l}\text { Unimodal, } \\
\text { Moderately } \\
\text { Well Sorted }\end{array}$ & $\begin{array}{l}\text { Unimodal, } \\
\text { Moderately } \\
\text { Well Sorted }\end{array}$ \\
\hline & TEXTURAL GROUP: & Sand & Sand & $\begin{array}{l}\text { Slightly } \\
\text { Gravelly Sand }\end{array}$ & Sand & Sand & Sand & Sand & Sand & Sand & Sand & Sand \\
\hline & SEDIMENT NAME: & $\begin{array}{l}\text { Moderately } \\
\text { Sorted } \\
\text { Medium Sand }\end{array}$ & $\begin{array}{l}\text { Moderately } \\
\text { Well Sorted } \\
\text { Coarse Sand }\end{array}$ & $\begin{array}{l}\text { Slightly Very } \\
\text { Fine Gravelly } \\
\text { Medium Sand }\end{array}$ & $\begin{array}{l}\text { Moderately } \\
\text { Well Sorted } \\
\text { Medium Sand }\end{array}$ & $\begin{array}{l}\text { Moderately } \\
\text { Sorted } \\
\text { Medium Sand }\end{array}$ & $\begin{array}{l}\text { Moderately } \\
\text { Well Sorted } \\
\text { Medium Sand }\end{array}$ & $\begin{array}{l}\text { Moderately } \\
\text { Well Sorted } \\
\text { Medium Sand }\end{array}$ & $\begin{array}{l}\text { Moderately } \\
\text { Sorted } \\
\text { Medium Sand }\end{array}$ & $\begin{array}{l}\text { Moderately } \\
\text { Well Sorted } \\
\text { Medium Sand }\end{array}$ & $\begin{array}{l}\text { Moderately } \\
\text { Well Sorted } \\
\text { Medium Sand }\end{array}$ & $\begin{array}{l}\text { Moderately } \\
\text { Well Sorted } \\
\text { Fine Sand }\end{array}$ \\
\hline \multirow{4}{*}{$\begin{array}{l}\text { FOLK AND } \\
\text { WARD } \\
\text { METHOD } \\
(\mathrm{mm}) \\
\end{array}$} & MEAN & 430.6 & 572.7 & 427.2 & 286.5 & 323.3 & 290.6 & 292.8 & 509.7 & 313.9 & 324.6 & 239.8 \\
\hline & SORTING & 1.761 & 1.59 & 1.561 & 1.476 & 1.685 & 1.504 & 1.446 & 1.945 & 1.555 & 1.552 & 1.428 \\
\hline & SKEWNESS & -0.104 & -0.064 & -0.035 & 0.126 & 0.155 & 0.085 & 0.11 & 0.009 & 0.128 & 0.201 & 0.202 \\
\hline & KURTOSIS & 0.93 & 1.035 & 1.02 & 0.99 & 0.958 & 0.999 & 0.994 & 0.76 & 1.013 & 1.049 & 1.171 \\
\hline \multirow{4}{*}{$\begin{array}{l}\text { FOLK AND } \\
\text { WARD } \\
\text { METHOD } \\
\text { (phi) } \\
\end{array}$} & MEAN & 1.216 & 0.804 & 1.227 & 1.803 & 1.629 & 1.783 & 1.772 & 0.972 & 1.672 & 1.623 & 2.06 \\
\hline & SORTING & 0.817 & 0.669 & 0.642 & 0.562 & 0.753 & 0.589 & 0.532 & 0.96 & 0.637 & 0.634 & 0.514 \\
\hline & SKEWNESS & 0.104 & 0.064 & 0.035 & -0.126 & -0.155 & -0.085 & \begin{tabular}{ll|}
-0.11 \\
\end{tabular} & -0.009 & -0.128 & -0.201 & -0.202 \\
\hline & KURTOSIS & 0.93 & 1.035 & 1.02 & 0.99 & 0.958 & 0.999 & 0.994 & 0.76 & 1.013 & 1.049 & 1.171 \\
\hline \multirow{23}{*}{$\begin{array}{l}\text { FOLK AND } \\
\text { WARD } \\
\text { METHOD } \\
\text { (Description) }\end{array}$} & MEAN: & Medium Sand & Coarse Sand & Medium Sand & Medium Sand & Medium Sand & Medium Sand & Medium Sand & Coarse Sand & Medium Sand & Medium Sand & Fine Sand \\
\hline & SORTING: & $\begin{array}{l}\text { Moderately } \\
\text { Sorted }\end{array}$ & $\begin{array}{l}\text { Moderately } \\
\text { Well Sorted }\end{array}$ & $\begin{array}{l}\text { Moderately } \\
\text { Well Sorted }\end{array}$ & $\begin{array}{l}\text { Moderately } \\
\text { Well Sorted } \\
\end{array}$ & $\begin{array}{l}\text { Moderately } \\
\text { Sorted }\end{array}$ & $\begin{array}{l}\text { Moderately } \\
\text { Well Sorted } \\
\end{array}$ & $\begin{array}{l}\text { Moderately } \\
\text { Well Sorted }\end{array}$ & $\begin{array}{l}\text { Moderately } \\
\text { Sorted }\end{array}$ & $\begin{array}{l}\text { Moderately } \\
\text { Well Sorted }\end{array}$ & $\begin{array}{l}\text { Moderately } \\
\text { Well Sorted } \\
\end{array}$ & $\begin{array}{l}\text { Moderately } \\
\text { Well Sorted }\end{array}$ \\
\hline & SKEWNESS: & Fine Skewed & Symmetrical & Symmetrical & $\begin{array}{l}\text { Coarse } \\
\text { Skewed }\end{array}$ & $\begin{array}{l}\text { Coarse } \\
\text { Skewed }\end{array}$ & Symmetrical & $\begin{array}{l}\text { Coarse } \\
\text { Skewed }\end{array}$ & Symmetrical & $\begin{array}{l}\text { Coarse } \\
\text { Skewed }\end{array}$ & $\begin{array}{l}\text { Coarse } \\
\text { Skewed }\end{array}$ & $\begin{array}{l}\text { Coarse } \\
\text { Skewed }\end{array}$ \\
\hline & KURTOSIS: & Mesokurtic & Mesokurtic & Mesokurtic & Mesokurtic & Mesokurtic & Mesokurtic & Mesokurtic & Platykurtic & Mesokurtic & Mesokurtic & Leptokurtic \\
\hline & \% GRAVEL: & $0.0 \%$ & $0.0 \%$ & $0.2 \%$ & $0.0 \%$ & $0.0 \%$ & $0.0 \%$ & $0.0 \%$ & $0.0 \%$ & $0.0 \%$ & $0.0 \%$ & $0.0 \%$ \\
\hline & \% SAND: & $100.0 \%$ & $99.9 \%$ & $99.5 \%$ & $100.0 \%$ & $100.0 \%$ & $99.7 \%$ & $100.0 \%$ & $100.0 \%$ & $100.0 \%$ & $100.0 \%$ & $100.0 \%$ \\
\hline & \% MUD: & $0.0 \%$ & $0.1 \%$ & $0.4 \%$ & $0.0 \%$ & $0.0 \%$ & $0.3 \%$ & $0.0 \%$ & $0.0 \%$ & $0.0 \%$ & $0.0 \%$ & $0.0 \%$ \\
\hline & \% V COARSE GRAVEL: & $0.0 \%$ & $0.0 \%$ & $0.0 \%$ & $0.0 \%$ & $0.0 \%$ & $0.0 \%$ & $0.0 \%$ & $0.0 \%$ & $0.0 \%$ & $0.0 \%$ & $0.0 \%$ \\
\hline & $\%$ COARSE GRAVEL: & $0.0 \%$ & $0.0 \%$ & $0.0 \%$ & $0.0 \%$ & $0.0 \%$ & $0.0 \%$ & $0.0 \%$ & $0.0 \%$ & $0.0 \%$ & $0.0 \%$ & $0.0 \%$ \\
\hline & \% MEDIUM GRAVEL: & $0.0 \%$ & $0.0 \%$ & $0.0 \%$ & $0.0 \%$ & $0.0 \%$ & $0.0 \%$ & $0.0 \%$ & $0.0 \%$ & $0.0 \%$ & $0.0 \%$ & $0.0 \%$ \\
\hline & \% FINE GRAVEL: & $0.0 \%$ & $0.0 \%$ & $0.0 \%$ & $0.0 \%$ & $0.0 \%$ & $0.0 \%$ & $0.0 \%$ & $0.0 \%$ & $0.0 \%$ & $0.0 \%$ & $0.0 \%$ \\
\hline & \% V FINE GRAVEL: & $0.0 \%$ & $0.0 \%$ & $0.2 \%$ & $0.0 \%$ & $0.0 \%$ & $0.0 \%$ & $0.0 \%$ & $0.0 \%$ & $0.0 \%$ & $0.0 \%$ & $0.0 \%$ \\
\hline & $\%$ V COARSE SAND: & $5.8 \%$ & $10.8 \%$ & $2.6 \%$ & $0.7 \%$ & $2.8 \%$ & $0.7 \%$ & $0.7 \%$ & $18.3 \%$ & $1.5 \%$ & $2.1 \%$ & $0.7 \%$ \\
\hline & \% COARSE SAND: & $36.9 \%$ & $52.1 \%$ & $33.9 \%$ & $8.6 \%$ & $18.2 \%$ & $9.7 \%$ & $8.2 \%$ & $32.5 \%$ & $14.1 \%$ & $14.8 \%$ & $4.9 \%$ \\
\hline & $\%$ MEDIUM SAND: & $38.7 \%$ & $32.1 \%$ & $51.5 \%$ & $52.0 \%$ & $45.2 \%$ & $52.5 \%$ & $56.0 \%$ & $32.7 \%$ & $52.8 \%$ & $54.3 \%$ & $35.9 \%$ \\
\hline & \% FINE SAND: & $17.6 \%$ & $4.7 \%$ & $11.1 \%$ & $38.3 \%$ & $32.5 \%$ & $35.8 \%$ & $35.1 \%$ & $16.3 \%$ & $30.7 \%$ & $28.8 \%$ & $57.8 \%$ \\
\hline & \% V FINE SAND: & $1.0 \%$ & $0.1 \%$ & $0.3 \%$ & $0.3 \%$ & $1.2 \%$ & $1.0 \%$ & $0.1 \%$ & $0.1 \%$ & $0.9 \%$ & $0.0 \%$ & $0.6 \%$ \\
\hline & \% V COARSE SILT: & $0.0 \%$ & $0.0 \%$ & $0.1 \%$ & $0.0 \%$ & $0.0 \%$ & $0.1 \%$ & $0.0 \%$ & $0.0 \%$ & $0.0 \%$ & $0.0 \%$ & $0.0 \%$ \\
\hline & \% COARSE SILT: & $0.0 \%$ & $0.0 \%$ & $0.1 \%$ & $0.0 \%$ & $0.0 \%$ & $0.1 \%$ & $0.0 \%$ & $0.0 \%$ & $0.0 \%$ & $0.0 \%$ & $0.0 \%$ \\
\hline & \% MEDIUM SILT: & $0.0 \%$ & $0.0 \%$ & $0.1 \%$ & $0.0 \%$ & $0.0 \%$ & $0.1 \%$ & $0.0 \%$ & $0.0 \%$ & $0.0 \%$ & $0.0 \%$ & $0.0 \%$ \\
\hline & \% FINE SILT: & $0.0 \%$ & $0.0 \%$ & $0.1 \%$ & $0.0 \%$ & $0.0 \%$ & $0.0 \%$ & $0.0 \%$ & $0.0 \%$ & $0.0 \%$ & $0.0 \%$ & $0.0 \%$ \\
\hline & \% V FINE SILT: & $0.0 \%$ & $0.0 \%$ & $0.0 \%$ & $0.0 \%$ & $0.0 \%$ & $0.0 \%$ & $0.0 \%$ & $0.0 \%$ & $0.0 \%$ & $0.0 \%$ & $0.0 \%$ \\
\hline & \% CLAY: & $0.0 \%$ & $0.0 \%$ & $0.0 \%$ & $0.0 \%$ & $0.0 \%$ & $0.0 \%$ & $0.0 \%$ & $0.0 \%$ & $0.0 \%$ & $0.0 \%$ & $0.0 \%$ \\
\hline
\end{tabular}




\section{Barrier and Lagoon}

\begin{tabular}{|c|c|c|c|c|c|c|c|c|c|c|c|c|}
\hline & & $\begin{array}{l}\text { WnW10- } \\
\text { t17_bb-a }\end{array}$ & $\begin{array}{l}\text { WnW10- } \\
\text { t17_bd-a }\end{array}$ & $\begin{array}{l}\text { WnW10- } \\
\text { m1_a }\end{array}$ & $\begin{array}{l}\text { WnW10- } \\
\text { m1_b }\end{array}$ & WnW10-m1_c & $\begin{array}{l}\text { WnW10- } \\
\text { m1_d }\end{array}$ & $\begin{array}{l}\text { WnW10- } \\
\text { m1_e }\end{array}$ & WnW10-m1_f & $\begin{array}{l}\text { WnW10- } \\
\text { m1_g }\end{array}$ & $\begin{array}{l}\text { WnW10- } \\
\text { m1_h }\end{array}$ & WnW10-m1_i \\
\hline & SAMPLE TYPE: & $\begin{array}{l}\text { Unimodal, } \\
\text { Moderately } \\
\text { Well Sorted }\end{array}$ & $\begin{array}{l}\text { Unimodal, } \\
\text { Moderately } \\
\text { Well Sorted }\end{array}$ & $\begin{array}{l}\text { Unimodal, } \\
\text { Poorly Sorted }\end{array}$ & $\begin{array}{l}\text { Polymodal, } \\
\text { Very Poorly } \\
\text { Sorted }\end{array}$ & $\begin{array}{l}\text { Unimodal, } \\
\text { Poorly Sorted }\end{array}$ & $\begin{array}{l}\text { Polymodal, } \\
\text { Poorly Sorted }\end{array}$ & $\begin{array}{l}\text { Unimodal, } \\
\text { Moderately } \\
\text { Sorted }\end{array}$ & $\begin{array}{l}\text { Unimodal, } \\
\text { Moderately } \\
\text { Sorted }\end{array}$ & $\begin{array}{l}\text { Unimodal, } \\
\text { Poorly Sorted }\end{array}$ & $\begin{array}{l}\text { Trimodal, } \\
\text { Very Poorly } \\
\text { Sorted }\end{array}$ & $\begin{array}{l}\text { Unimodal, } \\
\text { Moderately } \\
\text { Sorted }\end{array}$ \\
\hline & TEXTURAL GROUP: & Sand & Sand & Sand & Gravelly Sand & Sand & Sand & $\begin{array}{l}\text { Slightly } \\
\text { Gravelly Sand }\end{array}$ & $\begin{array}{l}\text { Slightly } \\
\text { Gravelly Sand }\end{array}$ & $\begin{array}{l}\text { Slightly } \\
\text { Gravelly Sand }\end{array}$ & Gravelly Sand & Sand \\
\hline & SEDIMENT NAME: & $\begin{array}{l}\text { Moderately } \\
\text { Well Sorted } \\
\text { Medium Sand }\end{array}$ & $\begin{array}{l}\text { Moderately } \\
\text { Well Sorted } \\
\text { Medium Sand }\end{array}$ & $\begin{array}{l}\text { Poorly Sorted } \\
\text { Medium Sand }\end{array}$ & $\begin{array}{l}\text { Very Fine } \\
\text { Gravelly Fine } \\
\text { Sand }\end{array}$ & $\begin{array}{l}\text { Poorly Sorted } \\
\text { Medium Sand }\end{array}$ & $\begin{array}{l}\text { Poorly Sorted } \\
\text { Medium Sand }\end{array}$ & $\begin{array}{l}\text { Slightly Very } \\
\text { Fine Gravelly } \\
\text { Medium Sand }\end{array}$ & $\begin{array}{l}\text { Slightly Very } \\
\text { Fine Gravelly } \\
\text { Coarse Sand }\end{array}$ & $\begin{array}{l}\text { Slightly Very } \\
\text { Fine Gravelly } \\
\text { Medium Sand }\end{array}$ & $\begin{array}{l}\text { Very Fine } \\
\text { Gravelly } \\
\text { Coarse Sand }\end{array}$ & $\begin{array}{l}\text { Moderately } \\
\text { Sorted Coarse } \\
\text { Sand }\end{array}$ \\
\hline \multirow{4}{*}{$\begin{array}{l}\text { FOLK AND } \\
\text { WARD } \\
\text { METHOD } \\
(\mathrm{mm}) \\
\end{array}$} & MEAN & 330.3 & 299.7 & 384.8 & 659.9 & 323.5 & 610.9 & 399.9 & 620.7 & 448.9 & 996.8 & 578.1 \\
\hline & SORTING & 1.605 & 1.547 & 2.192 & 5.316 & 2.545 & 2.226 & 1.834 & 1.906 & 2.031 & 4.513 & 1.701 \\
\hline & SKEWNESS & 0.164 & 0.106 & 0.173 & 0.373 & 0.027 & 0.23 & 0.147 & -0.06 & 0.074 & 0.5 & 0.008 \\
\hline & KURTOSIS & 0.987 & 1.099 & 1.001 & 0.796 & 1.002 & 0.833 & 0.919 & 0.958 & 1.111 & 1.201 & 1.006 \\
\hline \multirow{4}{*}{$\begin{array}{l}\text { FOLK AND } \\
\text { WARD } \\
\text { METHOD } \\
\text { (phi) }\end{array}$} & MEAN & 1.598 & 1.738 & 1.378 & 0.6 & 1.628 & 0.711 & 1.322 & 0.688 & 1.156 & 0.005 & 0.791 \\
\hline & SORTING & 0.683 & 0.629 & 1.132 & 2.41 & 1.348 & 1.155 & 0.875 & 0.93 & 1.022 & 2.174 & 0.766 \\
\hline & SKEWNESS & -0.164 & -0.106 & -0.173 & -0.373 & -0.027 & -0.23 & -0.147 & 0.06 & -0.074 & -0.5 & -0.008 \\
\hline & KURTOSIS & 0.987 & 1.099 & 1.001 & 0.796 & 1.002 & 0.833 & 0.919 & 0.958 & 1.111 & 1.201 & 1.006 \\
\hline \multirow{23}{*}{$\begin{array}{l}\text { FOLK AND } \\
\text { WARD } \\
\text { METHOD } \\
\text { (Description) }\end{array}$} & MEAN: & Medium Sand & Medium Sand & Medium Sand & Coarse Sand & Medium Sand & Coarse Sand & Medium Sand & Coarse Sand & Medium Sand & Coarse Sand & Coarse Sand \\
\hline & SORTING: & $\begin{array}{l}\text { Moderately } \\
\text { Well Sorted }\end{array}$ & $\begin{array}{l}\text { Moderately } \\
\text { Well Sorted }\end{array}$ & Poorly Sorted & $\begin{array}{l}\text { Very Poorly } \\
\text { Sorted }\end{array}$ & Poorly Sorted & Poorly Sorted & $\begin{array}{l}\text { Moderately } \\
\text { Sorted }\end{array}$ & $\begin{array}{l}\text { Moderately } \\
\text { Sorted }\end{array}$ & Poorly Sorted & $\begin{array}{l}\text { Very Poorly } \\
\text { Sorted }\end{array}$ & $\begin{array}{l}\text { Moderately } \\
\text { Sorted }\end{array}$ \\
\hline & SKEWNESS: & $\begin{array}{l}\text { Coarse } \\
\text { Skewed }\end{array}$ & $\begin{array}{l}\text { Coarse } \\
\text { Skewed }\end{array}$ & $\begin{array}{l}\text { Coarse } \\
\text { Skewed }\end{array}$ & $\begin{array}{l}\text { Very Coarse } \\
\text { Skewed }\end{array}$ & Symmetrical & $\begin{array}{l}\text { Coarse } \\
\text { Skewed }\end{array}$ & $\begin{array}{l}\text { Coarse } \\
\text { Skewed }\end{array}$ & Symmetrical & Symmetrical & $\begin{array}{l}\text { Very Coarse } \\
\text { Skewed }\end{array}$ & Symmetrical \\
\hline & KURTOSIS: & Mesokurtic & Mesokurtic & Mesokurtic & Platykurtic & Mesokurtic & Platykurtic & Mesokurtic & Mesokurtic & Leptokurtic & Leptokurtic & Mesokurtic \\
\hline & \% GRAVEL: & $0.0 \%$ & $0.0 \%$ & $0.0 \%$ & $27.4 \%$ & $0.0 \%$ & $0.0 \%$ & $0.8 \%$ & $0.4 \%$ & $4.1 \%$ & $26.9 \%$ & $0.0 \%$ \\
\hline & \% SAND: & $100.0 \%$ & $98.3 \%$ & $97.3 \%$ & $69.5 \%$ & $95.2 \%$ & $100.0 \%$ & $99.2 \%$ & $99.3 \%$ & $95.3 \%$ & $72.8 \%$ & $99.5 \%$ \\
\hline & \% MUD: & $0.0 \%$ & $1.7 \%$ & $2.7 \%$ & $3.1 \%$ & $4.8 \%$ & $0.0 \%$ & $0.0 \%$ & $0.3 \%$ & $0.6 \%$ & $0.3 \%$ & $0.5 \%$ \\
\hline & \% V COARSE GRAVEL: & $0.0 \%$ & $0.0 \%$ & $0.0 \%$ & $0.6 \%$ & $0.0 \%$ & $0.0 \%$ & $0.0 \%$ & $0.0 \%$ & $0.0 \%$ & $6.7 \%$ & $0.0 \%$ \\
\hline & \% COARSE GRAVEL: & $0.0 \%$ & $0.0 \%$ & $0.0 \%$ & $3.4 \%$ & $0.0 \%$ & $0.0 \%$ & $0.0 \%$ & $0.0 \%$ & $0.0 \%$ & $4.0 \%$ & $0.0 \%$ \\
\hline & \% MEDIUM GRAVEL: & $0.0 \%$ & $0.0 \%$ & $0.0 \%$ & $6.6 \%$ & $0.0 \%$ & $0.0 \%$ & $0.0 \%$ & $0.0 \%$ & $0.1 \%$ & $2.5 \%$ & $0.0 \%$ \\
\hline & \% FINE GRAVEL: & $0.0 \%$ & $0.0 \%$ & $0.0 \%$ & $8.1 \%$ & $0.0 \%$ & $0.0 \%$ & $0.0 \%$ & $0.0 \%$ & $0.6 \%$ & $5.3 \%$ & $0.0 \%$ \\
\hline & \% V FINE GRAVEL: & $0.0 \%$ & $0.0 \%$ & $0.0 \%$ & $8.8 \%$ & $0.0 \%$ & $0.0 \%$ & $0.8 \%$ & $0.4 \%$ & $3.4 \%$ & $8.4 \%$ & $0.0 \%$ \\
\hline & \% V COARSE SAND: & $2.3 \%$ & $1.4 \%$ & $13.4 \%$ & $6.7 \%$ & $11.8 \%$ & $24.8 \%$ & $7.6 \%$ & $23.6 \%$ & $6.8 \%$ & $7.3 \%$ & $15.3 \%$ \\
\hline & $\%$ COARSE SAND: & $17.6 \%$ & $11.3 \%$ & $20.0 \%$ & $12.4 \%$ & $19.7 \%$ & $26.0 \%$ & $26.6 \%$ & $39.7 \%$ & $32.5 \%$ & $27.5 \%$ & $45.1 \%$ \\
\hline & \% MEDIUM SAND: & $50.6 \%$ & $52.5 \%$ & $35.0 \%$ & $15.7 \%$ & $27.7 \%$ & $36.2 \%$ & $41.3 \%$ & $27.3 \%$ & $37.5 \%$ & $27.3 \%$ & $33.6 \%$ \\
\hline & \% FINE SAND: & $28.7 \%$ & $31.4 \%$ & $25.8 \%$ & $26.4 \%$ & $25.9 \%$ & $12.7 \%$ & $23.5 \%$ & $8.2 \%$ & $16.8 \%$ & $9.7 \%$ & $5.2 \%$ \\
\hline & $\%$ V FINE SAND: & $0.8 \%$ & $1.7 \%$ & $3.1 \%$ & $8.3 \%$ & $10.1 \%$ & $0.2 \%$ & $0.2 \%$ & $0.5 \%$ & $1.8 \%$ & $0.9 \%$ & $0.3 \%$ \\
\hline & $\%$ V COARSE SILT: & $0.0 \%$ & $0.7 \%$ & $1.5 \%$ & $2.6 \%$ & $2.8 \%$ & $0.0 \%$ & $0.0 \%$ & $0.1 \%$ & $0.5 \%$ & $0.2 \%$ & $0.2 \%$ \\
\hline & \% COARSE SILT: & $0.0 \%$ & $0.3 \%$ & $0.5 \%$ & $0.5 \%$ & $1.1 \%$ & $0.0 \%$ & $0.0 \%$ & $0.1 \%$ & $0.1 \%$ & $0.0 \%$ & $0.1 \%$ \\
\hline & \% MEDIUM SILT: & $0.0 \%$ & $0.3 \%$ & $0.4 \%$ & $0.0 \%$ & $0.6 \%$ & $0.0 \%$ & $0.0 \%$ & $0.1 \%$ & $0.0 \%$ & $0.0 \%$ & $0.1 \%$ \\
\hline & \% FINE SILT: & $0.0 \%$ & $0.2 \%$ & $0.2 \%$ & $0.0 \%$ & $0.3 \%$ & $0.0 \%$ & $0.0 \%$ & $0.0 \%$ & $0.0 \%$ & $0.0 \%$ & $0.1 \%$ \\
\hline & \% V FINE SILT: & $0.0 \%$ & $0.1 \%$ & $0.1 \%$ & $0.0 \%$ & $0.0 \%$ & $0.0 \%$ & $0.0 \%$ & $0.0 \%$ & $0.0 \%$ & $0.0 \%$ & $0.0 \%$ \\
\hline & $\%$ CLAY: & $0.0 \%$ & $0.0 \%$ & $0.0 \%$ & $0.0 \%$ & $0.0 \%$ & $0.0 \%$ & $0.0 \%$ & $0.0 \%$ & $0.0 \%$ & $0.0 \%$ & $0.0 \%$ \\
\hline
\end{tabular}




\section{Barrier and Lagoon}

\begin{tabular}{|c|c|c|c|c|c|c|c|c|c|c|c|c|}
\hline & & WnW10-m1_ & $\begin{array}{l}\text { PntTnch10- } \\
\text { t3_bf-a }\end{array}$ & $\begin{array}{l}\text { PntTnch10- } \\
\text { t3_bb-a }\end{array}$ & $\begin{array}{l}\text { PntTnch10- } \\
\text { t3_fdf-a }\end{array}$ & $\begin{array}{l}\text { PntTnch10- } \\
\text { t3_bd-a }\end{array}$ & $\begin{array}{l}\text { PntTnch10- } \\
\text { t5_bb-a }\end{array}$ & $\begin{array}{l}\text { PntTnch10- } \\
\text { t5_fdf-a }\end{array}$ & $\begin{array}{l}\text { PntTnch10- } \\
\text { t5_bd-a }\end{array}$ & $\begin{array}{l}\text { PntTnch10- } \\
\text { t15_bb-a }\end{array}$ & $\begin{array}{l}\text { PntTnch10- } \\
\text { t15_fdf-a }\end{array}$ & $\begin{array}{l}\text { PntTnch10- } \\
\text { t15_bd-a }\end{array}$ \\
\hline & SAMPLE TYPE: & $\begin{array}{l}\text { Unimodal, } \\
\text { Moderately } \\
\text { Well Sorted }\end{array}$ & $\begin{array}{l}\text { Bimodal, } \\
\text { Moderately } \\
\text { Sorted }\end{array}$ & $\begin{array}{l}\text { Unimodal, } \\
\text { Moderately } \\
\text { Well Sorted }\end{array}$ & $\begin{array}{l}\text { Bimodal, } \\
\text { Moderately } \\
\text { Sorted }\end{array}$ & $\begin{array}{l}\text { Unimodal, } \\
\text { Moderately } \\
\text { Well Sorted }\end{array}$ & $\begin{array}{l}\text { Polymodal, } \\
\text { Moderately } \\
\text { Sorted }\end{array}$ & $\begin{array}{l}\text { Polymodal, } \\
\text { Moderately } \\
\text { Sorted }\end{array}$ & $\begin{array}{l}\text { Unimodal, } \\
\text { Well Sorted }\end{array}$ & $\begin{array}{l}\text { Bimodal, } \\
\text { Moderately } \\
\text { Well Sorted }\end{array}$ & $\begin{array}{l}\text { Unimodal, } \\
\text { Moderately } \\
\text { Sorted }\end{array}$ & $\begin{array}{l}\text { Unimodal, } \\
\text { Moderately } \\
\text { Well Sorted }\end{array}$ \\
\hline & TEXTURAL GROUP: & $\begin{array}{l}\text { Slightly } \\
\text { Gravelly Sand }\end{array}$ & $\begin{array}{l}\text { Slightly } \\
\text { Gravelly Sand }\end{array}$ & Sand & $\begin{array}{l}\text { Slightly } \\
\text { Gravelly Sand }\end{array}$ & Sand & Sand & $\begin{array}{l}\text { Slightly } \\
\text { Gravelly Sand }\end{array}$ & Sand & $\begin{array}{l}\text { Slightly } \\
\text { Gravelly Sand }\end{array}$ & Sand & Sand \\
\hline & SEDIMENT NAME: & $\begin{array}{l}\text { Slightly Very } \\
\text { Fine Gravelly } \\
\text { Medium Sand }\end{array}$ & $\begin{array}{l}\text { Slightly Very } \\
\text { Fine Gravelly } \\
\text { Medium Sand }\end{array}$ & $\begin{array}{l}\text { Moderately } \\
\text { Well Sorted } \\
\text { Medium Sand }\end{array}$ & $\begin{array}{l}\text { Slightly Very } \\
\text { Fine Gravelly } \\
\text { Coarse Sand }\end{array}$ & $\begin{array}{l}\text { Moderately } \\
\text { Well Sorted } \\
\text { Fine Sand }\end{array}$ & $\begin{array}{l}\text { Moderately } \\
\text { Sorted Coarse } \\
\text { Sand }\end{array}$ & $\begin{array}{l}\text { Slightly Very } \\
\text { Fine Gravelly } \\
\text { Medium Sand }\end{array}$ & $\begin{array}{l}\text { Well Sorted } \\
\text { Fine Sand }\end{array}$ & $\begin{array}{l}\text { Slightly Very } \\
\text { Fine Gravelly } \\
\text { Fine Sand }\end{array}$ & $\begin{array}{l}\text { Moderately } \\
\text { Sorted Coarse } \\
\text { Sand }\end{array}$ & $\begin{array}{l}\text { Moderately } \\
\text { Well Sorted } \\
\text { Fine Sand }\end{array}$ \\
\hline \multirow{4}{*}{$\begin{array}{l}\text { FOLK AND } \\
\text { WARD } \\
\text { METHOD } \\
(\mathrm{mm}) \\
\end{array}$} & MEAN & 474.2 & 381.8 & 281.4 & 487.4 & 247.6 & 436.9 & 436.3 & 248 & 248.4 & 673.1 & 248.4 \\
\hline & SORTING & 1.485 & 1.915 & 1.511 & 1.851 & 1.427 & 1.838 & 1.984 & 1.348 & 1.551 & 1.822 & 1.548 \\
\hline & SKEWNESS & 0.042 & 0.193 & 0.156 & -0.063 & 0.153 & -0.096 & 0.05 & 0.03 & 0.298 & -0.137 & 0.151 \\
\hline & KURTOSIS & 1.053 & 0.892 & 0.985 & 0.872 & 1.096 & 0.924 & 0.828 & 0.953 & 1.171 & 1.005 & 1.098 \\
\hline \multirow{4}{*}{$\begin{array}{l}\text { FOLK AND } \\
\text { WARD } \\
\text { METHOD } \\
\text { (phi) } \\
\end{array}$} & MEAN & 1.076 & 1.389 & 1.829 & 1.037 & 2.014 & 1.195 & 1.196 & 2.012 & 2.009 & 0.571 & 2.009 \\
\hline & SORTING & 0.571 & 0.937 & 0.595 & 0.888 & 0.513 & 0.878 & 0.989 & 0.431 & 0.633 & 0.865 & 0.63 \\
\hline & SKEWNESS & -0.042 & -0.193 & -0.156 & 0.063 & -0.153 & 0.096 & -0.05 & -0.03 & -0.298 & 0.137 & -0.151 \\
\hline & KURTOSIS & 1.053 & 0.892 & 0.985 & 0.872 & 1.096 & 0.924 & 0.828 & 0.953 & 1.171 & 1.005 & 1.098 \\
\hline \multirow{23}{*}{$\begin{array}{l}\text { FOLK AND } \\
\text { WARD } \\
\text { METHOD } \\
\text { (Description) }\end{array}$} & MEAN: & Medium Sand & Medium Sand & Medium Sand & Medium Sand & Fine Sand & Medium Sand & Medium Sand & Fine Sand & Fine Sand & Coarse Sand & Fine Sand \\
\hline & SORTING: & $\begin{array}{l}\text { Moderately } \\
\text { Well Sorted }\end{array}$ & $\begin{array}{l}\text { Moderately } \\
\text { Sorted }\end{array}$ & $\begin{array}{l}\text { Moderately } \\
\text { Well Sorted }\end{array}$ & $\begin{array}{l}\text { Moderately } \\
\text { Sorted }\end{array}$ & $\begin{array}{l}\text { Moderately } \\
\text { Well Sorted }\end{array}$ & $\begin{array}{l}\text { Moderately } \\
\text { Sorted }\end{array}$ & $\begin{array}{l}\text { Moderately } \\
\text { Sorted }\end{array}$ & Well Sorted & $\begin{array}{l}\text { Moderately } \\
\text { Well Sorted }\end{array}$ & $\begin{array}{l}\text { Moderately } \\
\text { Sorted }\end{array}$ & $\begin{array}{l}\text { Moderately } \\
\text { Well Sorted }\end{array}$ \\
\hline & SKEWNESS: & Symmetrical & $\begin{array}{l}\text { Coarse } \\
\text { Skewed }\end{array}$ & $\begin{array}{l}\text { Coarse } \\
\text { Skewed }\end{array}$ & Symmetrical & $\begin{array}{l}\text { Coarse } \\
\text { Skewed } \\
\end{array}$ & Symmetrical & Symmetrical & Symmetrical & $\begin{array}{l}\text { Coarse } \\
\text { Skewed } \\
\end{array}$ & Fine Skewed & $\begin{array}{l}\text { Coarse } \\
\text { Skewed }\end{array}$ \\
\hline & KURTOSIS: & Mesokurtic & Platykurtic & Mesokurtic & Platykurtic & Mesokurtic & Mesokurtic & Platykurtic & Mesokurtic & Leptokurtic & Mesokurtic & Mesokurtic \\
\hline & \% GRAVEL: & $0.1 \%$ & $0.6 \%$ & $0.0 \%$ & $0.2 \%$ & $0.0 \%$ & $0.0 \%$ & $0.4 \%$ & $0.0 \%$ & $0.0 \%$ & $0.0 \%$ & $0.0 \%$ \\
\hline & \% SAND: & $99.6 \%$ & $99.4 \%$ & $99.9 \%$ & $99.8 \%$ & $100.0 \%$ & $100.0 \%$ & $99.5 \%$ & $100.0 \%$ & $100.0 \%$ & $100.0 \%$ & $98.4 \%$ \\
\hline & \% MUD: & $0.3 \%$ & $0.0 \%$ & $0.1 \%$ & $0.0 \%$ & $0.0 \%$ & $0.0 \%$ & $0.0 \%$ & $0.0 \%$ & $0.0 \%$ & $0.0 \%$ & $1.6 \%$ \\
\hline & \% V COARSE GRAVEL: & $0.0 \%$ & $0.0 \%$ & $0.0 \%$ & $0.0 \%$ & $0.0 \%$ & $0.0 \%$ & $0.0 \%$ & $0.0 \%$ & $0.0 \%$ & $0.0 \%$ & $0.0 \%$ \\
\hline & \% COARSE GRAVEL: & $0.0 \%$ & $0.0 \%$ & $0.0 \%$ & $0.0 \%$ & $0.0 \%$ & $0.0 \%$ & $0.0 \%$ & $0.0 \%$ & $0.0 \%$ & $0.0 \%$ & $0.0 \%$ \\
\hline & \% MEDIUM GRAVEL: & $0.0 \%$ & $0.0 \%$ & $0.0 \%$ & $0.0 \%$ & $0.0 \%$ & $0.0 \%$ & $0.0 \%$ & $0.0 \%$ & $0.0 \%$ & $0.0 \%$ & $0.0 \%$ \\
\hline & \% FINE GRAVEL: & $0.0 \%$ & $0.0 \%$ & $0.0 \%$ & $0.0 \%$ & $0.0 \%$ & $0.0 \%$ & $0.0 \%$ & $0.0 \%$ & $0.0 \%$ & $0.0 \%$ & $0.0 \%$ \\
\hline & \% V FINE GRAVEL: & $0.1 \%$ & $0.6 \%$ & $0.0 \%$ & $0.2 \%$ & $0.0 \%$ & $0.0 \%$ & $0.4 \%$ & $0.0 \%$ & $0.0 \%$ & $0.0 \%$ & $0.0 \%$ \\
\hline & $\% \vee$ COARSE SAND: & $4.2 \%$ & $8.8 \%$ & $0.9 \%$ & $12.1 \%$ & $0.7 \%$ & $8.2 \%$ & $12.2 \%$ & $0.0 \%$ & $2.0 \%$ & $26.6 \%$ & $1.1 \%$ \\
\hline & \% COARSE SAND: & $39.5 \%$ & $24.0 \%$ & $9.3 \%$ & $38.3 \%$ & $4.4 \%$ & $36.5 \%$ & $30.0 \%$ & $0.5 \%$ & $7.7 \%$ & $44.2 \%$ & $6.7 \%$ \\
\hline & \% MEDIUM SAND: & $51.3 \%$ & $36.4 \%$ & $47.5 \%$ & $33.5 \%$ & $41.0 \%$ & $35.1 \%$ & $32.6 \%$ & $47.8 \%$ & $31.9 \%$ & $22.0 \%$ & $37.6 \%$ \\
\hline & \% FINE SAND: & $4.3 \%$ & $29.7 \%$ & $41.2 \%$ & $15.7 \%$ & $53.2 \%$ & $19.5 \%$ & $23.9 \%$ & $51.4 \%$ & $57.2 \%$ & $7.1 \%$ & $50.1 \%$ \\
\hline & \% V FINE SAND: & $0.3 \%$ & $0.4 \%$ & $1.0 \%$ & $0.2 \%$ & $0.7 \%$ & $0.8 \%$ & $0.8 \%$ & $0.3 \%$ & $1.3 \%$ & $0.1 \%$ & $2.9 \%$ \\
\hline & \% V COARSE SILT: & $0.1 \%$ & $0.0 \%$ & $0.1 \%$ & $0.0 \%$ & $0.0 \%$ & $0.0 \%$ & $0.0 \%$ & $0.0 \%$ & $0.0 \%$ & $0.0 \%$ & $0.6 \%$ \\
\hline & \% COARSE SILT: & $0.1 \%$ & $0.0 \%$ & $0.0 \%$ & $0.0 \%$ & $0.0 \%$ & $0.0 \%$ & $0.0 \%$ & $0.0 \%$ & $0.0 \%$ & $0.0 \%$ & $0.3 \%$ \\
\hline & \% MEDIUM SILT: & $0.1 \%$ & $0.0 \%$ & $0.0 \%$ & $0.0 \%$ & $0.0 \%$ & $0.0 \%$ & $0.0 \%$ & $0.0 \%$ & $0.0 \%$ & $0.0 \%$ & $0.3 \%$ \\
\hline & \% FINE SILT: & $0.0 \%$ & $0.0 \%$ & $0.0 \%$ & $0.0 \%$ & $0.0 \%$ & $0.0 \%$ & $0.0 \%$ & $0.0 \%$ & $0.0 \%$ & $0.0 \%$ & $0.2 \%$ \\
\hline & \% V FINE SILT: & $0.0 \%$ & $0.0 \%$ & $0.0 \%$ & $0.0 \%$ & $0.0 \%$ & $0.0 \%$ & $0.0 \%$ & $0.0 \%$ & $0.0 \%$ & $0.0 \%$ & $0.1 \%$ \\
\hline & \% CLAY: & $0.0 \%$ & $0.0 \%$ & $0.0 \%$ & $0.0 \%$ & $0.0 \%$ & $0.0 \%$ & $0.0 \%$ & $0.0 \%$ & $0.0 \%$ & $0.0 \%$ & $0.0 \%$ \\
\hline
\end{tabular}


2010 Barrier and Lagoon

\begin{tabular}{|c|c|c|c|c|c|c|c|c|c|c|c|c|}
\hline & & $\begin{array}{l}\text { PntTnch10- } \\
\text { m1_a }\end{array}$ & $\begin{array}{l}\text { PntTnch10- } \\
\text { m1_b }\end{array}$ & $\begin{array}{l}\text { PntTnch10- } \\
\text { m1_c }\end{array}$ & $\begin{array}{l}\text { PntTnch10- } \\
\text { m1_d }\end{array}$ & $\begin{array}{l}\text { PntTnch10- } \\
\text { m1_e }\end{array}$ & $\begin{array}{l}\text { PntPtnpch10- } \\
\text { t1_bf-a }\end{array}$ & $\begin{array}{l}\text { PntPtnpch10- } \\
\text { t1_fdf-a }\end{array}$ & $\begin{array}{l}\text { PntPtnpch10- } \\
\text { t2_bf-a }\end{array}$ & $\begin{array}{l}\text { PntPtnpch10- } \\
\text { t2_fdf-a }\end{array}$ & $\begin{array}{l}\text { PntPtnpch10- } \\
\text { m1_a }\end{array}$ & $\begin{array}{l}\text { PntPtnpch10- } \\
\text { m1_b }\end{array}$ \\
\hline & SAMPLE TYPE: & $\begin{array}{l}\text { Unimodal, } \\
\text { Poorly Sorted }\end{array}$ & $\begin{array}{l}\text { Bimodal, Very } \\
\text { Poorly Sorted }\end{array}$ & $\begin{array}{l}\text { Trimodal, } \\
\text { Very Poorly } \\
\text { Sorted }\end{array}$ & $\begin{array}{l}\text { Trimodal, } \\
\text { Moderately } \\
\text { Well Sorted }\end{array}$ & $\begin{array}{l}\text { Trimodal, } \\
\text { Moderately } \\
\text { Well Sorted }\end{array}$ & $\begin{array}{l}\text { Unimodal, } \\
\text { Moderately } \\
\text { Well Sorted }\end{array}$ & $\begin{array}{l}\text { Unimodal, } \\
\text { Moderately } \\
\text { Sorted }\end{array}$ & $\begin{array}{l}\text { Unimodal, } \\
\text { Moderately } \\
\text { Sorted }\end{array}$ & $\begin{array}{l}\text { Unimodal, } \\
\text { Moderately } \\
\text { Sorted }\end{array}$ & $\begin{array}{l}\text { Polymodal, } \\
\text { Poorly Sorted }\end{array}$ & $\begin{array}{l}\text { Trimodal, } \\
\text { Very Poorly } \\
\text { Sorted }\end{array}$ \\
\hline & TEXTURAL GROUP: & $\begin{array}{l}\text { Slightly } \\
\text { Gravelly Sand }\end{array}$ & Gravelly Sand & Gravelly Sand & Sand & $\begin{array}{l}\text { Slightly } \\
\text { Gravelly Sand }\end{array}$ & Sand & $\begin{array}{l}\text { Slightly } \\
\text { Gravelly Sand }\end{array}$ & $\begin{array}{l}\text { Slightly } \\
\text { Gravelly Sand }\end{array}$ & $\begin{array}{l}\text { Slightly } \\
\text { Gravelly Sand }\end{array}$ & Muddy Sand & Sandy Gravel \\
\hline & SEDIMENT NAME: & $\begin{array}{l}\text { Slightly Very } \\
\text { Fine Gravelly } \\
\text { Medium Sand }\end{array}$ & $\begin{array}{l}\text { Very Coarse } \\
\text { Gravelly Fine } \\
\text { Sand }\end{array}$ & $\begin{array}{l}\text { Fine Gravelly } \\
\text { Fine Sand }\end{array}$ & $\begin{array}{l}\text { Moderately } \\
\text { Well Sorted } \\
\text { Coarse Sand }\end{array}$ & $\begin{array}{l}\text { Slightly Very } \\
\text { Fine Gravelly } \\
\text { Coarse Sand }\end{array}$ & $\begin{array}{l}\text { Moderately } \\
\text { Well Sorted } \\
\text { Medium Sand }\end{array}$ & $\begin{array}{l}\text { Slightly Very } \\
\text { Fine Gravelly } \\
\text { Medium Sand }\end{array}$ & $\begin{array}{l}\text { Slightly Very } \\
\text { Fine Gravelly } \\
\text { Fine Sand }\end{array}$ & $\begin{array}{l}\text { Slightly Very } \\
\text { Fine Gravelly } \\
\text { Medium Sand }\end{array}$ & $\begin{array}{l}\text { Very Coarse } \\
\text { Silty Very Fine } \\
\text { Sand }\end{array}$ & $\begin{array}{l}\text { Sandy Fine } \\
\text { Gravel }\end{array}$ \\
\hline \multirow{4}{*}{$\begin{array}{l}\text { FOLK AND } \\
\text { WARD } \\
\text { METHOD } \\
(\mathrm{mm})\end{array}$} & MEAN & 311.8 & 437.8 & 609.9 & 967.1 & 829.5 & 284.7 & 367 & 248 & 435.4 & 236.3 & 911.8 \\
\hline & SORTING & 2.26 & 6.26 & 5.167 & 1.563 & 1.492 & 1.586 & 1.797 & 1.63 & 1.869 & 3.069 & 5.99 \\
\hline & SKEWNESS & 0.073 & 0.4 & 0.53 & 0.002 & 0.156 & 0.158 & 0.105 & 0.294 & 0.04 & 0.154 & 0.354 \\
\hline & KURTOSIS & 1.038 & 2.213 & 0.823 & 0.948 & 1.174 & 0.958 & 0.913 & 1.179 & 0.9 & 0.615 & 0.891 \\
\hline \multirow{4}{*}{$\begin{array}{l}\text { FOLK AND } \\
\text { WARD } \\
\text { METHOD } \\
\text { (phi) } \\
\end{array}$} & MEAN & 1.681 & 1.192 & 0.713 & 0.048 & 0.27 & 1.812 & 1.446 & 2.012 & 1.2 & 2.081 & 0.133 \\
\hline & SORTING & 1.176 & 2.646 & 2.369 & 0.644 & 0.577 & 0.666 & 0.845 & 0.705 & 0.903 & 1.618 & 2.583 \\
\hline & SKEWNESS & -0.073 & -0.4 & -0.53 & -0.002 & -0.156 & -0.158 & -0.105 & -0.294 & -0.04 & -0.154 & -0.354 \\
\hline & KURTOSIS & 1.038 & 2.213 & 0.823 & 0.948 & 1.174 & 0.958 & 0.913 & 1.179 & 0.9 & 0.615 & 0.891 \\
\hline \multirow{23}{*}{$\begin{array}{l}\text { FOLK AND } \\
\text { WARD } \\
\text { METHOD } \\
\text { (Description) }\end{array}$} & MEAN: & Medium Sand & Medium Sand & Coarse Sand & Coarse Sand & Coarse Sand & Medium Sand & Medium Sand & Fine Sand & Medium Sand & Fine Sand & Coarse Sand \\
\hline & SORTING: & Poorly Sorted & $\begin{array}{l}\text { Very Poorly } \\
\text { Sorted }\end{array}$ & $\begin{array}{l}\text { Very Poorly } \\
\text { Sorted }\end{array}$ & $\begin{array}{l}\text { Moderately } \\
\text { Well Sorted }\end{array}$ & $\begin{array}{l}\text { Moderately } \\
\text { Well Sorted }\end{array}$ & $\begin{array}{l}\text { Moderately } \\
\text { Well Sorted }\end{array}$ & $\begin{array}{l}\text { Moderately } \\
\text { Sorted }\end{array}$ & $\begin{array}{l}\text { Moderately } \\
\text { Sorted }\end{array}$ & $\begin{array}{l}\text { Moderately } \\
\text { Sorted }\end{array}$ & Poorly Sorted & $\begin{array}{l}\text { Very Poorly } \\
\text { Sorted }\end{array}$ \\
\hline & SKEWNESS: & Symmetrical & $\begin{array}{l}\text { Very Coarse } \\
\text { Skewed }\end{array}$ & $\begin{array}{l}\text { Very Coarse } \\
\text { Skewed }\end{array}$ & Symmetrical & $\begin{array}{l}\text { Coarse } \\
\text { Skewed }\end{array}$ & $\begin{array}{l}\text { Coarse } \\
\text { Skewed }\end{array}$ & $\begin{array}{l}\text { Coarse } \\
\text { Skewed }\end{array}$ & $\begin{array}{l}\text { Coarse } \\
\text { Skewed }\end{array}$ & Symmetrical & $\begin{array}{l}\text { Coarse } \\
\text { Skewed }\end{array}$ & $\begin{array}{l}\text { Very Coarse } \\
\text { Skewed }\end{array}$ \\
\hline & KURTOSIS: & Mesokurtic & $\begin{array}{l}\text { Very } \\
\text { Leptokurtic }\end{array}$ & Platykurtic & Mesokurtic & Leptokurtic & Mesokurtic & Mesokurtic & Leptokurtic & Platykurtic & $\begin{array}{l}\text { Very } \\
\text { Platykurtic }\end{array}$ & Platykurtic \\
\hline & \% GRAVEL: & $0.5 \%$ & $14.2 \%$ & $25.8 \%$ & $0.0 \%$ & $0.4 \%$ & $0.0 \%$ & $0.1 \%$ & $1.0 \%$ & $0.3 \%$ & $0.0 \%$ & $30.4 \%$ \\
\hline & \% SAND: & $97.8 \%$ & $82.3 \%$ & $73.1 \%$ & $100.0 \%$ & $99.6 \%$ & $100.0 \%$ & $99.9 \%$ & $99.0 \%$ & $99.5 \%$ & $88.9 \%$ & $68.3 \%$ \\
\hline & \% MUD: & $1.7 \%$ & $3.5 \%$ & $1.0 \%$ & $0.0 \%$ & $0.0 \%$ & $0.0 \%$ & $0.0 \%$ & $0.0 \%$ & $0.2 \%$ & $11.1 \%$ & $1.3 \%$ \\
\hline & \% V COARSE GRAVEL: & $0.0 \%$ & $6.6 \%$ & $2.0 \%$ & $0.0 \%$ & $0.0 \%$ & $0.0 \%$ & $0.0 \%$ & $0.0 \%$ & $0.0 \%$ & $0.0 \%$ & $3.8 \%$ \\
\hline & \% COARSE GRAVEL: & $0.0 \%$ & $0.3 \%$ & $2.8 \%$ & $0.0 \%$ & $0.0 \%$ & $0.0 \%$ & $0.0 \%$ & $0.0 \%$ & $0.0 \%$ & $0.0 \%$ & $5.1 \%$ \\
\hline & \% MEDIUM GRAVEL: & $0.0 \%$ & $1.0 \%$ & $5.5 \%$ & $0.0 \%$ & $0.0 \%$ & $0.0 \%$ & $0.0 \%$ & $0.0 \%$ & $0.0 \%$ & $0.0 \%$ & $6.4 \%$ \\
\hline & \% FINE GRAVEL: & $0.0 \%$ & $2.4 \%$ & $7.9 \%$ & $0.0 \%$ & $0.0 \%$ & $0.0 \%$ & $0.0 \%$ & $0.0 \%$ & $0.0 \%$ & $0.0 \%$ & $7.6 \%$ \\
\hline & \% V FINE GRAVEL: & $0.5 \%$ & $4.0 \%$ & $7.7 \%$ & $0.0 \%$ & $0.4 \%$ & $0.0 \%$ & $0.1 \%$ & $1.0 \%$ & $0.3 \%$ & $0.0 \%$ & $7.6 \%$ \\
\hline & \% V COARSE SAND: & $8.2 \%$ & $4.9 \%$ & $5.4 \%$ & $45.7 \%$ & $25.2 \%$ & $1.4 \%$ & $5.7 \%$ & $2.4 \%$ & $9.7 \%$ & $12.4 \%$ & $8.0 \%$ \\
\hline & \% COARSE SAND: & $18.3 \%$ & $22.4 \%$ & $10.6 \%$ & $46.8 \%$ & $66.1 \%$ & $11.5 \%$ & $24.6 \%$ & $7.5 \%$ & $31.2 \%$ & $25.0 \%$ & $15.6 \%$ \\
\hline & $\%$ MEDIUM SAND: & $32.3 \%$ & $21.0 \%$ & $17.2 \%$ & $6.9 \%$ & $8.2 \%$ & $44.6 \%$ & $41.4 \%$ & $31.3 \%$ & $38.5 \%$ & $11.8 \%$ & $20.8 \%$ \\
\hline & \% FINE SAND: & $28.2 \%$ & $27.1 \%$ & $32.0 \%$ & $0.6 \%$ & $0.2 \%$ & $41.1 \%$ & $27.5 \%$ & $54.5 \%$ & $19.3 \%$ & $11.2 \%$ & $15.3 \%$ \\
\hline & \% V FINE SAND: & $10.7 \%$ & $6.9 \%$ & $7.9 \%$ & $0.0 \%$ & $0.0 \%$ & $1.3 \%$ & $0.7 \%$ & $3.3 \%$ & $0.8 \%$ & $28.6 \%$ & $8.6 \%$ \\
\hline & \% V COARSE SILT: & $1.7 \%$ & $2.9 \%$ & $0.9 \%$ & $0.0 \%$ & $0.0 \%$ & $0.0 \%$ & $0.0 \%$ & $0.0 \%$ & $0.1 \%$ & $10.9 \%$ & $1.2 \%$ \\
\hline & \% COARSE SILT: & $0.0 \%$ & $0.6 \%$ & $0.2 \%$ & $0.0 \%$ & $0.0 \%$ & $0.0 \%$ & $0.0 \%$ & $0.0 \%$ & $0.0 \%$ & $0.1 \%$ & $0.1 \%$ \\
\hline & \% MEDIUM SILT: & $0.0 \%$ & $0.0 \%$ & $0.0 \%$ & $0.0 \%$ & $0.0 \%$ & $0.0 \%$ & $0.0 \%$ & $0.0 \%$ & $0.0 \%$ & $0.0 \%$ & $0.0 \%$ \\
\hline & \% FINE SILT: & $0.0 \%$ & $0.0 \%$ & $0.0 \%$ & $0.0 \%$ & $0.0 \%$ & $0.0 \%$ & $0.0 \%$ & $0.0 \%$ & $0.0 \%$ & $0.0 \%$ & $0.0 \%$ \\
\hline & \% V FINE SILT: & $0.0 \%$ & $0.0 \%$ & $0.0 \%$ & $0.0 \%$ & $0.0 \%$ & $0.0 \%$ & $0.0 \%$ & $0.0 \%$ & $0.0 \%$ & $0.0 \%$ & $0.0 \%$ \\
\hline & \% CLAY: & $0.0 \%$ & $0.0 \%$ & $0.0 \%$ & $0.0 \%$ & $0.0 \%$ & $0.0 \%$ & $0.0 \%$ & $0.0 \%$ & $0.0 \%$ & $0.0 \%$ & $0.0 \%$ \\
\hline
\end{tabular}


2010 Barrier and Lagoon

\begin{tabular}{|c|c|c|c|c|c|c|c|c|c|c|c|c|}
\hline & & $\begin{array}{l}\text { PntPtnpch10- } \\
\text { m1_c }\end{array}$ & $\begin{array}{l}\text { PntPtnpch10- } \\
\text { m1_d }\end{array}$ & $\begin{array}{l}\text { PntPtnpch10- } \\
\text { m1_e }\end{array}$ & $\begin{array}{l}\text { PntPtnpch10- } \\
\text { m1_f }\end{array}$ & $\begin{array}{l}\text { PntBrv10- } \\
\text { t1_bb-a }\end{array}$ & $\begin{array}{l}\text { PntBrv10- } \\
\text { t1_bd-a }\end{array}$ & $\begin{array}{l}\text { PntBrv10- } \\
\text { t2_bb-a }\end{array}$ & $\begin{array}{l}\text { PntBrv10- } \\
\text { t2_bd-a }\end{array}$ & $\begin{array}{l}\text { PntBrv10- } \\
\text { m1_a }\end{array}$ & $\begin{array}{l}\text { PntBrv10- } \\
\text { m1_b }\end{array}$ & $\begin{array}{l}\text { PntBrv10- } \\
\text { m1_c }\end{array}$ \\
\hline & SAMPLE TYPE: & $\begin{array}{l}\text { Polymodal, } \\
\text { Very Poorly } \\
\text { Sorted }\end{array}$ & $\begin{array}{l}\text { Polymodal, } \\
\text { Very Poorly } \\
\text { Sorted }\end{array}$ & $\begin{array}{l}\text { Bimodal, } \\
\text { Poorly Sorted }\end{array}$ & $\begin{array}{l}\text { Unimodal, } \\
\text { Well Sorted }\end{array}$ & $\begin{array}{l}\text { Unimodal, } \\
\text { Moderately } \\
\text { Well Sorted }\end{array}$ & $\begin{array}{l}\text { Unimodal, } \\
\text { Moderately } \\
\text { Well Sorted }\end{array}$ & $\begin{array}{l}\text { Unimodal, } \\
\text { Moderately } \\
\text { Well Sorted }\end{array}$ & $\begin{array}{l}\text { Unimodal, } \\
\text { Moderately } \\
\text { Well Sorted }\end{array}$ & $\begin{array}{l}\text { Unimodal, } \\
\text { Moderately } \\
\text { Well Sorted }\end{array}$ & $\begin{array}{l}\text { Unimodal, } \\
\text { Poorly Sorted }\end{array}$ & $\begin{array}{l}\text { Unimodal, } \\
\text { Moderately } \\
\text { Well Sorted }\end{array}$ \\
\hline & TEXTURAL GROUP: & Gravelly Sand & Sandy Gravel & Sandy Gravel & Gravelly Sand & Sand & $\begin{array}{l}\text { Slightly } \\
\text { Gravelly Sand }\end{array}$ & $\begin{array}{l}\text { Slightly } \\
\text { Gravelly Sand }\end{array}$ & $\begin{array}{l}\text { Slightly } \\
\text { Gravelly Sand }\end{array}$ & $\begin{array}{l}\text { Slightly } \\
\text { Gravelly Sand }\end{array}$ & Sandy Gravel & Gravelly Sand \\
\hline & SEDIMENT NAME: & $\begin{array}{l}\text { Very Fine } \\
\text { Gravelly } \\
\text { Coarse Sand }\end{array}$ & $\begin{array}{l}\text { Sandy Very } \\
\text { Coarse Gravel }\end{array}$ & $\begin{array}{l}\text { Sandy Very } \\
\text { Fine Gravel }\end{array}$ & $\begin{array}{l}\text { Very Fine } \\
\text { Gravelly Very } \\
\text { Coarse Sand }\end{array}$ & $\begin{array}{l}\text { Moderately } \\
\text { Well Sorted } \\
\text { Coarse Sand }\end{array}$ & $\begin{array}{l}\text { Slightly Very } \\
\text { Fine Gravelly } \\
\text { Coarse Sand }\end{array}$ & $\begin{array}{l}\text { Slightly Very } \\
\text { Fine Gravelly } \\
\text { Coarse Sand }\end{array}$ & $\begin{array}{l}\text { Slightly Very } \\
\text { Fine Gravelly } \\
\text { Coarse Sand }\end{array}$ & $\begin{array}{l}\text { Slightly Very } \\
\text { Fine Gravelly } \\
\text { Medium Sand }\end{array}$ & $\begin{array}{l}\text { Sandy Very } \\
\text { Fine Gravel }\end{array}$ & $\begin{array}{l}\text { Very Fine } \\
\text { Gravelly } \\
\text { Coarse Sand }\end{array}$ \\
\hline \multirow{4}{*}{$\begin{array}{l}\text { FOLK AND } \\
\text { WARD } \\
\text { METHOD } \\
(\mathrm{mm})\end{array}$} & MEAN & 688 & 6349.8 & 2260.4 & 1258.2 & 615.4 & 605.7 & 749.5 & 619.3 & 506.3 & 1561.5 & 944.9 \\
\hline & SORTING & 6.739 & 10.71 & 3.008 & 1.393 & 1.447 & 1.574 & 1.436 & 1.458 & 1.455 & 2.036 & 1.553 \\
\hline & SKEWNESS & 0.297 & -0.252 & -0.12 & 0.15 & 0.01 & 0.021 & -0.015 & 0.04 & 0.068 & 0.346 & 0.279 \\
\hline & KURTOSIS & 1.592 & 0.622 & 0.937 & 1.053 & 1.021 & 0.969 & 0.971 & 0.985 & 1.007 & 1.096 & 1.455 \\
\hline \multirow{4}{*}{$\begin{array}{l}\text { FOLK AND } \\
\text { WARD } \\
\text { METHOD } \\
\text { (phi) } \\
\end{array}$} & MEAN & 0.54 & -2.667 & -1.177 & -0.331 & 0.7 & 0.723 & 0.416 & 0.691 & 0.982 & -0.643 & 0.082 \\
\hline & SORTING & 2.753 & 3.42 & 1.589 & 0.478 & 0.533 & 0.654 & 0.522 & 0.544 & 0.541 & 1.026 & 0.635 \\
\hline & SKEWNESS & -0.297 & 0.252 & 0.12 & -0.15 & -0.01 & -0.021 & 0.015 & -0.04 & -0.068 & -0.346 & -0.279 \\
\hline & KURTOSIS & 1.592 & 0.622 & 0.937 & 1.053 & 1.021 & 0.969 & 0.971 & 0.985 & 1.007 & 1.096 & 1.455 \\
\hline \multirow{23}{*}{$\begin{array}{l}\text { FOLK AND } \\
\text { WARD } \\
\text { METHOD } \\
\text { (Description) }\end{array}$} & MEAN: & Coarse Sand & Fine Gravel & $\begin{array}{l}\text { Very Fine } \\
\text { Gravel }\end{array}$ & $\begin{array}{l}\text { Very Coarse } \\
\text { Sand }\end{array}$ & Coarse Sand & Coarse Sand & Coarse Sand & Coarse Sand & Coarse Sand & $\begin{array}{l}\text { Very Coarse } \\
\text { Sand }\end{array}$ & Coarse Sand \\
\hline & SORTING: & $\begin{array}{l}\text { Very Poorly } \\
\text { Sorted }\end{array}$ & $\begin{array}{l}\text { Very Poorly } \\
\text { Sorted }\end{array}$ & Poorly Sorted & Well Sorted & $\begin{array}{l}\text { Moderately } \\
\text { Well Sorted }\end{array}$ & $\begin{array}{l}\text { Moderately } \\
\text { Well Sorted }\end{array}$ & $\begin{array}{l}\text { Moderately } \\
\text { Well Sorted }\end{array}$ & $\begin{array}{l}\text { Moderately } \\
\text { Well Sorted }\end{array}$ & $\begin{array}{l}\text { Moderately } \\
\text { Well Sorted }\end{array}$ & Poorly Sorted & $\begin{array}{l}\text { Moderately } \\
\text { Well Sorted }\end{array}$ \\
\hline & SKEWNESS: & $\begin{array}{l}\text { Coarse } \\
\text { Skewed }\end{array}$ & Fine Skewed & Fine Skewed & $\begin{array}{l}\text { Coarse } \\
\text { Skewed }\end{array}$ & Symmetrical & Symmetrical & Symmetrical & Symmetrical & Symmetrical & $\begin{array}{l}\text { Very Coarse } \\
\text { Skewed }\end{array}$ & $\begin{array}{l}\text { Coarse } \\
\text { Skewed }\end{array}$ \\
\hline & KURTOSIS: & $\begin{array}{l}\text { Very } \\
\text { Leptokurtic }\end{array}$ & $\begin{array}{l}\text { Very } \\
\text { Platykurtic }\end{array}$ & Mesokurtic & Mesokurtic & Mesokurtic & Mesokurtic & Mesokurtic & Mesokurtic & Mesokurtic & Mesokurtic & Leptokurtic \\
\hline & \% GRAVEL: & $22.3 \%$ & $64.4 \%$ & $58.8 \%$ & $12.1 \%$ & $0.0 \%$ & $0.1 \%$ & $0.2 \%$ & $0.4 \%$ & $0.2 \%$ & $32.6 \%$ & $7.8 \%$ \\
\hline & $\%$ SAND: & $73.9 \%$ & $34.3 \%$ & $41.2 \%$ & $87.9 \%$ & $100.0 \%$ & $99.5 \%$ & $99.8 \%$ & $99.3 \%$ & $99.8 \%$ & $67.4 \%$ & $92.2 \%$ \\
\hline & \% MUD: & $3.8 \%$ & $1.3 \%$ & $0.0 \%$ & $0.0 \%$ & $0.0 \%$ & $0.4 \%$ & $0.0 \%$ & $0.3 \%$ & $0.0 \%$ & $0.0 \%$ & $0.0 \%$ \\
\hline & $\%$ V COARSE GRAVEL: & $6.0 \%$ & $35.8 \%$ & $1.1 \%$ & $0.0 \%$ & $0.0 \%$ & $0.0 \%$ & $0.0 \%$ & $0.0 \%$ & $0.0 \%$ & $1.3 \%$ & $0.0 \%$ \\
\hline & $\%$ COARSE GRAVEL: & $0.8 \%$ & $8.6 \%$ & $3.1 \%$ & $0.0 \%$ & $0.0 \%$ & $0.0 \%$ & $0.0 \%$ & $0.0 \%$ & $0.0 \%$ & $1.2 \%$ & $0.1 \%$ \\
\hline & \% MEDIUM GRAVEL: & $2.7 \%$ & $8.0 \%$ & $7.7 \%$ & $0.1 \%$ & $0.0 \%$ & $0.0 \%$ & $0.0 \%$ & $0.0 \%$ & $0.0 \%$ & $3.0 \%$ & $0.4 \%$ \\
\hline & \% FINE GRAVEL: & $5.5 \%$ & $6.9 \%$ & $20.3 \%$ & $0.7 \%$ & $0.0 \%$ & $0.0 \%$ & $0.0 \%$ & $0.0 \%$ & $0.0 \%$ & $7.3 \%$ & $1.6 \%$ \\
\hline & \% V FINE GRAVEL: & $7.3 \%$ & $5.1 \%$ & $26.6 \%$ & $11.3 \%$ & $0.0 \%$ & $0.1 \%$ & $0.2 \%$ & $0.4 \%$ & $0.2 \%$ & $19.8 \%$ & $5.7 \%$ \\
\hline & $\%$ V COARSE SAND: & $8.5 \%$ & $4.3 \%$ & $14.8 \%$ & $63.2 \%$ & $9.8 \%$ & $13.9 \%$ & $21.7 \%$ & $10.4 \%$ & $4.3 \%$ & $36.5 \%$ & $22.7 \%$ \\
\hline & \% COARSE SAND: & $23.7 \%$ & $10.1 \%$ & $17.6 \%$ & $24.6 \%$ & $61.6 \%$ & $51.6 \%$ & $64.7 \%$ & $60.0 \%$ & $45.5 \%$ & $29.9 \%$ & $64.8 \%$ \\
\hline & \% MEDIUM SAND: & $19.3 \%$ & $9.6 \%$ & $5.9 \%$ & $0.0 \%$ & $27.4 \%$ & $31.9 \%$ & $13.1 \%$ & $28.0 \%$ & $47.8 \%$ & $0.8 \%$ & $4.5 \%$ \\
\hline & \% FINE SAND: & $14.5 \%$ & $7.2 \%$ & $1.9 \%$ & $0.0 \%$ & $1.1 \%$ & $2.0 \%$ & $0.4 \%$ & $0.8 \%$ & $2.2 \%$ & $0.1 \%$ & $0.2 \%$ \\
\hline & \% V FINE SAND: & $7.9 \%$ & $3.1 \%$ & $1.0 \%$ & $0.0 \%$ & $0.0 \%$ & $0.1 \%$ & $0.0 \%$ & $0.0 \%$ & $0.0 \%$ & $0.0 \%$ & $0.1 \%$ \\
\hline & $\%$ V COARSE SILT: & $3.2 \%$ & $1.1 \%$ & $0.0 \%$ & $0.0 \%$ & $0.0 \%$ & $0.1 \%$ & $0.0 \%$ & $0.1 \%$ & $0.0 \%$ & $0.0 \%$ & $0.0 \%$ \\
\hline & $\%$ COARSE SILT: & $0.7 \%$ & $0.2 \%$ & $0.0 \%$ & $0.0 \%$ & $0.0 \%$ & $0.1 \%$ & $0.0 \%$ & $0.1 \%$ & $0.0 \%$ & $0.0 \%$ & $0.0 \%$ \\
\hline & \% MEDIUM SILT: & $0.0 \%$ & $0.0 \%$ & $0.0 \%$ & $0.0 \%$ & $0.0 \%$ & $0.1 \%$ & $0.0 \%$ & $0.1 \%$ & $0.0 \%$ & $0.0 \%$ & $0.0 \%$ \\
\hline & \% FINE SILT: & $0.0 \%$ & $0.0 \%$ & $0.0 \%$ & $0.0 \%$ & $0.0 \%$ & $0.1 \%$ & $0.0 \%$ & $0.0 \%$ & $0.0 \%$ & $0.0 \%$ & $0.0 \%$ \\
\hline & $\%$ V FINE SILT: & $0.0 \%$ & $0.0 \%$ & $0.0 \%$ & $0.0 \%$ & $0.0 \%$ & $0.0 \%$ & $0.0 \%$ & $0.0 \%$ & $0.0 \%$ & $0.0 \%$ & $0.0 \%$ \\
\hline & \% CLAY: & $0.0 \%$ & $0.0 \%$ & $0.0 \%$ & $0.0 \%$ & $0.0 \%$ & $0.0 \%$ & $0.0 \%$ & $0.0 \%$ & $0.0 \%$ & $0.0 \%$ & $0.0 \%$ \\
\hline
\end{tabular}

Mulcahy, 2014; correspondence: nick.mulcahy@coastalresearch.org.nz 


\section{Barrier and Lagoon}

\begin{tabular}{|c|c|c|c|c|c|c|c|}
\hline & & $\begin{array}{l}\text { PlyaScrt10- } \\
\text { t1_bb-a }\end{array}$ & $\begin{array}{l}\text { PlyaScrt10- } \\
\text { t1_bd-a }\end{array}$ & $\begin{array}{l}\text { PlyaScrt10- } \\
\text { m1_a }\end{array}$ & $\begin{array}{l}\text { PlyaScrt10- } \\
\text { m1_b }\end{array}$ & $\begin{array}{l}\text { PlyaScrt10- } \\
\text { m1_c }\end{array}$ & $\begin{array}{l}\text { PlyaScrt10- } \\
\text { m1_d }\end{array}$ \\
\hline & SAMPLE TYPE: & $\begin{array}{l}\text { Unimodal, } \\
\text { Moderately } \\
\text { Well Sorted }\end{array}$ & $\begin{array}{l}\text { Unimodal, } \\
\text { Well Sorted }\end{array}$ & $\begin{array}{l}\text { Unimodal, } \\
\text { Moderately } \\
\text { Well Sorted }\end{array}$ & $\begin{array}{l}\text { Unimodal, } \\
\text { Moderately } \\
\text { Well Sorted }\end{array}$ & $\begin{array}{l}\text { Unimodal, } \\
\text { Moderately } \\
\text { Sorted }\end{array}$ & $\begin{array}{l}\text { Unimodal, } \\
\text { Poorly Sorted }\end{array}$ \\
\hline & TEXTURAL GROUP: & Sand & Sand & $\begin{array}{l}\text { Slightly } \\
\text { Gravelly Sand }\end{array}$ & $\begin{array}{l}\text { Slightly } \\
\text { Gravelly Sand }\end{array}$ & $\begin{array}{l}\text { Slightly } \\
\text { Gravelly Sand }\end{array}$ & Gravelly Sand \\
\hline & SEDIMENT NAME: & $\begin{array}{l}\text { Moderately } \\
\text { Well Sorted } \\
\text { Coarse Sand }\end{array}$ & $\begin{array}{l}\text { Well Sorted } \\
\text { Coarse Sand }\end{array}$ & $\begin{array}{l}\text { Slightly Very } \\
\text { Fine Gravelly } \\
\text { Medium Sand }\end{array}$ & $\begin{array}{l}\text { Slightly Very } \\
\text { Fine Gravelly } \\
\text { Medium Sand }\end{array}$ & $\begin{array}{l}\text { Slightly Very } \\
\text { Fine Gravelly } \\
\text { Medium Sand }\end{array}$ & $\begin{array}{l}\text { Very Fine } \\
\text { Gravelly } \\
\text { Coarse Sand }\end{array}$ \\
\hline \multirow{4}{*}{$\begin{array}{l}\text { FOLK AND } \\
\text { WARD } \\
\text { METHOD } \\
(\mathrm{mm})\end{array}$} & MEAN & 599.8 & 512.4 & 423.3 & 378.1 & 412.8 & 1108.2 \\
\hline & SORTING & 1.543 & 1.394 & 1.548 & 1.582 & 1.774 & 2.716 \\
\hline & SKEWNESS & 0.05 & 0.048 & 0.08 & 0.062 & 0.078 & 0.283 \\
\hline & KURTOSIS & 0.953 & 0.986 & 1.005 & 0.986 & 0.98 & 1.526 \\
\hline \multirow{4}{*}{$\begin{array}{l}\text { FOLK AND } \\
\text { WARD } \\
\text { METHOD } \\
\text { (phi) } \\
\end{array}$} & MEAN & 0.737 & 0.965 & 1.24 & 1.403 & 1.277 & -0.148 \\
\hline & SORTING & 0.626 & 0.479 & 0.63 & 0.661 & 0.827 & 1.441 \\
\hline & SKEWNESS & -0.05 & -0.048 & -0.08 & -0.062 & -0.078 & -0.283 \\
\hline & KURTOSIS & 0.953 & 0.986 & 1.005 & 0.986 & 0.98 & 1.526 \\
\hline \multirow{23}{*}{$\begin{array}{l}\text { FOLK AND } \\
\text { WARD } \\
\text { METHOD } \\
\text { (Description) }\end{array}$} & MEAN: & Coarse Sand & Coarse Sand & Medium Sand & Medium Sand & Medium Sand & $\begin{array}{l}\text { Very Coarse } \\
\text { Sand }\end{array}$ \\
\hline & SORTING: & $\begin{array}{l}\text { Moderately } \\
\text { Well Sorted }\end{array}$ & Well Sorted & $\begin{array}{l}\text { Moderately } \\
\text { Well Sorted } \\
\end{array}$ & $\begin{array}{l}\text { Moderately } \\
\text { Well Sorted }\end{array}$ & $\begin{array}{l}\text { Moderately } \\
\text { Sorted }\end{array}$ & Poorly Sorted \\
\hline & SKEWNESS: & Symmetrical & Symmetrical & Symmetrical & Symmetrical & Symmetrical & $\begin{array}{l}\text { Coarse } \\
\text { Skewed }\end{array}$ \\
\hline & KURTOSIS: & Mesokurtic & Mesokurtic & Mesokurtic & Mesokurtic & Mesokurtic & $\begin{array}{l}\text { Very } \\
\text { Leptokurtic }\end{array}$ \\
\hline & \% GRAVEL: & $0.0 \%$ & $0.0 \%$ & $1.0 \%$ & $0.1 \%$ & $0.1 \%$ & $23.5 \%$ \\
\hline & \% SAND: & $99.9 \%$ & $100.0 \%$ & $99.0 \%$ & $99.9 \%$ & $99.7 \%$ & $76.4 \%$ \\
\hline & \% MUD: & $0.1 \%$ & $0.0 \%$ & $0.0 \%$ & $0.0 \%$ & $0.2 \%$ & $0.1 \%$ \\
\hline & $\%$ V COARSE GRAVEL: & $0.0 \%$ & $0.0 \%$ & $0.0 \%$ & $0.0 \%$ & $0.0 \%$ & $1.1 \%$ \\
\hline & \% COARSE GRAVEL: & $0.0 \%$ & $0.0 \%$ & $0.0 \%$ & $0.0 \%$ & $0.0 \%$ & $2.3 \%$ \\
\hline & \% MEDIUM GRAVEL: & $0.0 \%$ & $0.0 \%$ & $0.0 \%$ & $0.0 \%$ & $0.0 \%$ & $3.4 \%$ \\
\hline & \% FINE GRAVEL: & $0.0 \%$ & $0.0 \%$ & $0.0 \%$ & $0.0 \%$ & $0.0 \%$ & $5.3 \%$ \\
\hline & \% V FINE GRAVEL: & $0.0 \%$ & $0.0 \%$ & $1.0 \%$ & $0.1 \%$ & $0.1 \%$ & $11.4 \%$ \\
\hline & $\%$ V COARSE SAND: & $12.9 \%$ & $2.7 \%$ & $2.8 \%$ & $2.7 \%$ & $7.2 \%$ & $21.0 \%$ \\
\hline & \% COARSE SAND: & $52.0 \%$ & $49.3 \%$ & $30.4 \%$ & $24.3 \%$ & $28.5 \%$ & $39.9 \%$ \\
\hline & $\%$ MEDIUM SAND: & $33.5 \%$ & $47.1 \%$ & $55.4 \%$ & $54.6 \%$ & $44.8 \%$ & $10.2 \%$ \\
\hline & \% FINE SAND: & $1.5 \%$ & $1.0 \%$ & $10.3 \%$ & $18.1 \%$ & $18.2 \%$ & $4.9 \%$ \\
\hline & \% V FINE SAND: & $0.1 \%$ & $0.0 \%$ & $0.1 \%$ & $0.3 \%$ & $0.9 \%$ & $0.3 \%$ \\
\hline & $\%$ V COARSE SILT: & $0.0 \%$ & $0.0 \%$ & $0.0 \%$ & $0.0 \%$ & $0.1 \%$ & $0.1 \%$ \\
\hline & \% COARSE SILT: & $0.0 \%$ & $0.0 \%$ & $0.0 \%$ & $0.0 \%$ & $0.0 \%$ & $0.0 \%$ \\
\hline & \% MEDIUM SILT: & $0.0 \%$ & $0.0 \%$ & $0.0 \%$ & $0.0 \%$ & $0.0 \%$ & $0.0 \%$ \\
\hline & \% FINE SILT: & $0.0 \%$ & $0.0 \%$ & $0.0 \%$ & $0.0 \%$ & $0.0 \%$ & $0.0 \%$ \\
\hline & \% V FINE SILT: & $0.0 \%$ & $0.0 \%$ & $0.0 \%$ & $0.0 \%$ & $0.0 \%$ & $0.0 \%$ \\
\hline & $\%$ CLAY: & $0.0 \%$ & $0.0 \%$ & $0.0 \%$ & $0.0 \%$ & $0.0 \%$ & $0.0 \%$ \\
\hline
\end{tabular}




\section{Barrier Subsurface}

\begin{tabular}{|c|c|c|c|c|c|c|c|c|c|c|c|c|c|}
\hline & & $\begin{array}{l}\text { WnW10- } \\
\text { t1_bf-a }\end{array}$ & $\begin{array}{l}\text { WnW10- } \\
\text { t1_bf-b }\end{array}$ & $\begin{array}{l}\text { WnW10- } \\
\text { t1_bf-c }\end{array}$ & $\begin{array}{l}\text { WnW10- } \\
\text { t1_bf-d }\end{array}$ & $\begin{array}{l}\text { WnW10- } \\
\text { t1_bf-e }\end{array}$ & $\begin{array}{l}\text { WnW10- } \\
\text { t1_bf-f }\end{array}$ & $\begin{array}{l}\text { WnW10- } \\
\text { t1_bf-g }\end{array}$ & $\begin{array}{l}\text { WnW10- } \\
\text { t1_fdf-a }\end{array}$ & $\begin{array}{l}\text { WnW10- } \\
\text { t1_fdf-b }\end{array}$ & $\begin{array}{l}\text { WnW10- } \\
\text { t1_fdf-c }\end{array}$ & $\begin{array}{l}\text { WnW10- } \\
\text { t1_fdf-d }\end{array}$ & $\begin{array}{l}\text { WnW10- } \\
\text { t1_fdf-e }\end{array}$ \\
\hline & SAMPLE TYPE: & $\begin{array}{l}\text { Unimodal, } \\
\text { Moderately } \\
\text { Sorted }\end{array}$ & $\begin{array}{l}\text { Bimodal, } \\
\text { Moderately } \\
\text { Sorted }\end{array}$ & $\begin{array}{l}\text { Unimodal, } \\
\text { Moderately } \\
\text { Sorted }\end{array}$ & $\begin{array}{l}\text { Bimodal, } \\
\text { Moderately } \\
\text { Sorted }\end{array}$ & $\begin{array}{l}\text { Unimodal, } \\
\text { Poorly } \\
\text { Sorted }\end{array}$ & $\begin{array}{l}\text { Unimodal, } \\
\text { Moderately } \\
\text { Well Sorted }\end{array}$ & $\begin{array}{l}\text { Unimodal, } \\
\text { Moderately } \\
\text { Sorted }\end{array}$ & $\begin{array}{l}\text { Unimodal, } \\
\text { Moderately } \\
\text { Well Sorted }\end{array}$ & $\begin{array}{l}\text { Unimodal, } \\
\text { Moderately } \\
\text { Sorted }\end{array}$ & $\begin{array}{l}\text { Unimodal, } \\
\text { Moderately } \\
\text { Sorted }\end{array}$ & $\begin{array}{l}\text { Unimodal, } \\
\text { Moderately } \\
\text { Well Sorted }\end{array}$ & $\begin{array}{l}\text { Unimodal, } \\
\text { Moderately } \\
\text { Well Sorted }\end{array}$ \\
\hline & TEXTURAL GROUP: & Sand & Sand & Sand & $\begin{array}{l}\text { Slightly } \\
\text { Gravelly } \\
\text { Sand } \\
\end{array}$ & $\begin{array}{l}\text { Slightly } \\
\text { Gravelly } \\
\text { Sand }\end{array}$ & Sand & Sand & Sand & Sand & Sand & Sand & Sand \\
\hline & SEDIMENT NAME: & $\begin{array}{l}\text { Moderately } \\
\text { Sorted } \\
\text { Medium } \\
\text { Sand } \\
\end{array}$ & $\begin{array}{l}\text { Moderately } \\
\text { Sorted } \\
\text { Medium } \\
\text { Sand } \\
\end{array}$ & $\begin{array}{l}\text { Moderately } \\
\text { Sorted } \\
\text { Medium } \\
\text { Sand }\end{array}$ & $\begin{array}{l}\text { Slightly Very } \\
\text { Fine Gravelly } \\
\text { Medium } \\
\text { Sand } \\
\end{array}$ & $\begin{array}{l}\text { Slightly Very } \\
\text { Fine Gravelly } \\
\text { Coarse Sand }\end{array}$ & $\begin{array}{l}\text { Moderately } \\
\text { Well Sorted } \\
\text { Medium } \\
\text { Sand }\end{array}$ & $\begin{array}{l}\text { Moderately } \\
\text { Sorted } \\
\text { Medium } \\
\text { Sand } \\
\end{array}$ & $\begin{array}{l}\text { Moderately } \\
\text { Well Sorted } \\
\text { Coarse Sand }\end{array}$ & $\begin{array}{l}\text { Moderately } \\
\text { Sorted } \\
\text { Medium } \\
\text { Sand } \\
\end{array}$ & $\begin{array}{l}\text { Moderately } \\
\text { Sorted } \\
\text { Medium } \\
\text { Sand }\end{array}$ & $\begin{array}{l}\text { Moderately } \\
\text { Well Sorted } \\
\text { Medium } \\
\text { Sand }\end{array}$ & $\begin{array}{l}\text { Moderately } \\
\text { Well Sorted } \\
\text { Medium } \\
\text { Sand }\end{array}$ \\
\hline \multirow{4}{*}{$\begin{array}{l}\text { FOLK AND } \\
\text { WARD } \\
\text { METHOD } \\
(\mathrm{mm}) \\
\end{array}$} & MEAN & 430.6 & 343 & 481.6 & 390.3 & 557.9 & 322.5 & 340.7 & 572.7 & 387.5 & 425.8 & 361.5 & 343.6 \\
\hline & SORTING & 1.761 & 1.729 & 1.892 & 1.787 & 2.01 & 1.541 & 1.728 & 1.59 & 1.705 & 1.706 & 1.582 & 1.517 \\
\hline & SKEWNESS & -0.104 & 0.065 & -0.016 & 0.039 & 0.038 & 0.085 & 0.073 & -0.064 & 0.05 & 0.005 & 0.019 & -0.016 \\
\hline & KURTOSIS & 0.93 & 0.934 & 0.926 & 0.943 & 0.904 & 0.964 & 0.924 & 1.035 & 0.947 & 0.949 & 0.946 & 0.971 \\
\hline \multirow{4}{*}{$\begin{array}{l}\text { FOLK AND } \\
\text { WARD } \\
\text { METHOD } \\
\text { (phi) }\end{array}$} & MEAN & 1.216 & 1.544 & 1.054 & 1.358 & 0.842 & 1.633 & 1.553 & 0.804 & 1.368 & 1.232 & 1.468 & 1.541 \\
\hline & SORTING & 0.817 & 0.79 & 0.92 & 0.837 & 1.007 & 0.624 & 0.789 & 0.669 & 0.77 & 0.77 & 0.662 & 0.601 \\
\hline & SKEWNESS & 0.104 & -0.065 & 0.016 & -0.039 & -0.038 & -0.085 & -0.073 & 0.064 & -0.05 & -0.005 & -0.019 & 0.016 \\
\hline & KURTOSIS & 0.93 & 0.934 & 0.926 & 0.943 & 0.904 & 0.964 & 0.924 & 1.035 & 0.947 & 0.949 & 0.946 & 0.971 \\
\hline \multirow{23}{*}{$\begin{array}{l}\text { FOLK AND } \\
\text { WARD } \\
\text { METHOD } \\
\text { (Description) }\end{array}$} & MEAN: & $\begin{array}{l}\text { Medium } \\
\text { Sand }\end{array}$ & $\begin{array}{l}\text { Medium } \\
\text { Sand }\end{array}$ & $\begin{array}{l}\text { Medium } \\
\text { Sand }\end{array}$ & $\begin{array}{l}\text { Medium } \\
\text { Sand }\end{array}$ & Coarse Sand & $\begin{array}{l}\text { Medium } \\
\text { Sand }\end{array}$ & $\begin{array}{l}\text { Medium } \\
\text { Sand }\end{array}$ & Coarse Sand & $\begin{array}{l}\text { Medium } \\
\text { Sand }\end{array}$ & $\begin{array}{l}\text { Medium } \\
\text { Sand }\end{array}$ & $\begin{array}{l}\text { Medium } \\
\text { Sand }\end{array}$ & $\begin{array}{l}\text { Medium } \\
\text { Sand }\end{array}$ \\
\hline & SORTING: & $\begin{array}{l}\text { Moderately } \\
\text { Sorted }\end{array}$ & $\begin{array}{l}\text { Moderately } \\
\text { Sorted }\end{array}$ & $\begin{array}{l}\text { Moderately } \\
\text { Sorted }\end{array}$ & $\begin{array}{l}\text { Moderately } \\
\text { Sorted }\end{array}$ & $\begin{array}{l}\text { Poorly } \\
\text { Sorted }\end{array}$ & $\begin{array}{l}\text { Moderately } \\
\text { Well Sorted }\end{array}$ & $\begin{array}{l}\text { Moderately } \\
\text { Sorted }\end{array}$ & $\begin{array}{l}\text { Moderately } \\
\text { Well Sorted }\end{array}$ & $\begin{array}{l}\text { Moderately } \\
\text { Sorted }\end{array}$ & $\begin{array}{l}\text { Moderately } \\
\text { Sorted }\end{array}$ & $\begin{array}{l}\text { Moderately } \\
\text { Well Sorted }\end{array}$ & $\begin{array}{l}\text { Moderately } \\
\text { Well Sorted }\end{array}$ \\
\hline & SKEWNESS: & Fine Skewed & Symmetrical & Symmetrical & Symmetrical & Symmetrical & Symmetrical & Symmetrical & Symmetrical & Symmetrical & Symmetrical & Symmetrical & Symmetrical \\
\hline & KURTOSIS: & Mesokurtic & Mesokurtic & Mesokurtic & Mesokurtic & Mesokurtic & Mesokurtic & Mesokurtic & Mesokurtic & Mesokurtic & Mesokurtic & Mesokurtic & Mesokurtic \\
\hline & \% GRAVEL: & $0.0 \%$ & $0.0 \%$ & $0.0 \%$ & $0.9 \%$ & $2.3 \%$ & $0.0 \%$ & $0.0 \%$ & $0.0 \%$ & $0.0 \%$ & $0.0 \%$ & $0.0 \%$ & $0.0 \%$ \\
\hline & \% SAND: & $100.0 \%$ & $100.0 \%$ & $99.9 \%$ & $99.0 \%$ & $97.6 \%$ & $100.0 \%$ & $99.9 \%$ & $99.9 \%$ & $100.0 \%$ & $100.0 \%$ & $100.0 \%$ & $100.0 \%$ \\
\hline & \% MUD: & $0.0 \%$ & $0.0 \%$ & $0.1 \%$ & $0.0 \%$ & $0.1 \%$ & $0.0 \%$ & $0.1 \%$ & $0.1 \%$ & $0.0 \%$ & $0.0 \%$ & $0.0 \%$ & $0.0 \%$ \\
\hline & \% V COARSE GRAVEL: & $0.0 \%$ & $0.0 \%$ & $0.0 \%$ & $0.0 \%$ & $0.0 \%$ & $0.0 \%$ & $0.0 \%$ & $0.0 \%$ & $0.0 \%$ & $0.0 \%$ & $0.0 \%$ & $0.0 \%$ \\
\hline & \% COARSE GRAVEL: & $0.0 \%$ & $0.0 \%$ & $0.0 \%$ & $0.0 \%$ & $0.0 \%$ & $0.0 \%$ & $0.0 \%$ & $0.0 \%$ & $0.0 \%$ & $0.0 \%$ & $0.0 \%$ & $0.0 \%$ \\
\hline & \% MEDIUM GRAVEL: & $0.0 \%$ & $0.0 \%$ & $0.0 \%$ & $0.0 \%$ & $0.0 \%$ & $0.0 \%$ & $0.0 \%$ & $0.0 \%$ & $0.0 \%$ & $0.0 \%$ & $0.0 \%$ & $0.0 \%$ \\
\hline & \% FINE GRAVEL: & $0.0 \%$ & $0.0 \%$ & $0.0 \%$ & $0.0 \%$ & $0.0 \%$ & $0.0 \%$ & $0.0 \%$ & $0.0 \%$ & $0.0 \%$ & $0.0 \%$ & $0.0 \%$ & $0.0 \%$ \\
\hline & $\%$ V FINE GRAVEL: & $0.0 \%$ & $0.0 \%$ & $0.0 \%$ & $0.9 \%$ & $2.3 \%$ & $0.0 \%$ & $0.0 \%$ & $0.0 \%$ & $0.0 \%$ & $0.0 \%$ & $0.0 \%$ & $0.0 \%$ \\
\hline & $\% \vee$ COARSE SAND: & $5.8 \%$ & $3.3 \%$ & $13.1 \%$ & $5.3 \%$ & $19.1 \%$ & $1.3 \%$ & $3.2 \%$ & $10.8 \%$ & $4.6 \%$ & $5.7 \%$ & $1.6 \%$ & $1.1 \%$ \\
\hline & \% COARSE SAND: & $36.9 \%$ & $22.3 \%$ & $35.3 \%$ & $28.2 \%$ & $33.7 \%$ & $15.2 \%$ & $22.2 \%$ & $52.1 \%$ & $27.4 \%$ & $33.1 \%$ & $23.2 \%$ & $17.6 \%$ \\
\hline & \% MEDIUM SAND: & $38.7 \%$ & $44.4 \%$ & $35.3 \%$ & $42.0 \%$ & $32.2 \%$ & $54.4 \%$ & $43.8 \%$ & $32.1 \%$ & $46.3 \%$ & $44.6 \%$ & $53.2 \%$ & $58.5 \%$ \\
\hline & \% FINE SAND: & $17.6 \%$ & $28.3 \%$ & $15.5 \%$ & $22.4 \%$ & $12.1 \%$ & $28.4 \%$ & $29.0 \%$ & $4.7 \%$ & $21.0 \%$ & $16.0 \%$ & $21.5 \%$ & $22.1 \%$ \\
\hline & \% V FINE SAND: & $1.0 \%$ & $1.7 \%$ & $0.8 \%$ & $1.2 \%$ & $0.5 \%$ & $0.8 \%$ & $1.6 \%$ & $0.1 \%$ & $0.6 \%$ & $0.5 \%$ & $0.5 \%$ & $0.6 \%$ \\
\hline & \% V COARSE SILT: & $0.0 \%$ & $0.0 \%$ & $0.1 \%$ & $0.0 \%$ & $0.1 \%$ & $0.0 \%$ & $0.1 \%$ & $0.0 \%$ & $0.0 \%$ & $0.0 \%$ & $0.0 \%$ & $0.0 \%$ \\
\hline & \% COARSE SILT: & $0.0 \%$ & $0.0 \%$ & $0.0 \%$ & $0.0 \%$ & $0.0 \%$ & $0.0 \%$ & $0.0 \%$ & $0.0 \%$ & $0.0 \%$ & $0.0 \%$ & $0.0 \%$ & $0.0 \%$ \\
\hline & \% MEDIUM SILT: & $0.0 \%$ & $0.0 \%$ & $0.0 \%$ & $0.0 \%$ & $0.0 \%$ & $0.0 \%$ & $0.0 \%$ & $0.0 \%$ & $0.0 \%$ & $0.0 \%$ & $0.0 \%$ & $0.0 \%$ \\
\hline & \% FINE SILT: & $0.0 \%$ & $0.0 \%$ & $0.0 \%$ & $0.0 \%$ & $0.0 \%$ & $0.0 \%$ & $0.0 \%$ & $0.0 \%$ & $0.0 \%$ & $0.0 \%$ & $0.0 \%$ & $0.0 \%$ \\
\hline & \% V FINE SILT: & $0.0 \%$ & $0.0 \%$ & $0.0 \%$ & $0.0 \%$ & $0.0 \%$ & $0.0 \%$ & $0.0 \%$ & $0.0 \%$ & $0.0 \%$ & $0.0 \%$ & $0.0 \%$ & $0.0 \%$ \\
\hline & \% CLAY: & $0.0 \%$ & $0.0 \%$ & $0.0 \%$ & $0.0 \%$ & $0.0 \%$ & $0.0 \%$ & $0.0 \%$ & $0.0 \%$ & $0.0 \%$ & $0.0 \%$ & $0.0 \%$ & $0.0 \%$ \\
\hline
\end{tabular}


2010 Barrier Subsurface

\begin{tabular}{|c|c|c|c|c|c|c|c|c|c|c|c|c|c|}
\hline & & $\begin{array}{l}\text { WnW10- } \\
\text { t1_fdf-f }\end{array}$ & $\begin{array}{l}\text { WnW10- } \\
\text { t1_bd-a }\end{array}$ & $\begin{array}{l}\text { WnW10- } \\
\text { t1_bd-b }\end{array}$ & $\begin{array}{l}\text { WnW10- } \\
\text { t1_bd-c }\end{array}$ & $\begin{array}{l}\text { WnW10- } \\
\text { t1_bd-d }\end{array}$ & $\begin{array}{l}\text { WnW10- } \\
\text { t1_bd-e }\end{array}$ & $\begin{array}{l}\text { WnW10- } \\
\text { t1_bd-f }\end{array}$ & $\begin{array}{l}\text { WnW10- } \\
\text { t1_bd-g }\end{array}$ & $\begin{array}{l}\text { WnW10- } \\
\text { t3_bf-a }\end{array}$ & $\begin{array}{l}\text { WnW10- } \\
\text { t3_bf-b }\end{array}$ & $\begin{array}{l}\text { WnW10- } \\
\text { t3_bf-c }\end{array}$ & $\begin{array}{l}\text { WnW10- } \\
\text { t3_bf-d }\end{array}$ \\
\hline & SAMPLE TYPE: & $\begin{array}{l}\text { Unimodal, } \\
\text { Moderately } \\
\text { Well Sorted }\end{array}$ & $\begin{array}{l}\text { Unimodal, } \\
\text { Moderately } \\
\text { Well Sorted }\end{array}$ & $\begin{array}{l}\text { Unimodal, } \\
\text { Moderately } \\
\text { Well Sorted }\end{array}$ & $\begin{array}{l}\text { Unimodal, } \\
\text { Moderately } \\
\text { Well Sorted }\end{array}$ & $\begin{array}{l}\text { Unimodal, } \\
\text { Moderately } \\
\text { Well Sorted }\end{array}$ & $\begin{array}{l}\text { Unimodal, } \\
\text { Moderately } \\
\text { Well Sorted }\end{array}$ & $\begin{array}{l}\text { Unimodal, } \\
\text { Moderately } \\
\text { Sorted }\end{array}$ & $\begin{array}{l}\text { Unimodal, } \\
\text { Poorly } \\
\text { Sorted }\end{array}$ & $\begin{array}{l}\text { Unimodal, } \\
\text { Moderately } \\
\text { Well Sorted }\end{array}$ & $\begin{array}{l}\text { Unimodal, } \\
\text { Moderately } \\
\text { Sorted }\end{array}$ & $\begin{array}{l}\text { Unimodal, } \\
\text { Moderately } \\
\text { Sorted }\end{array}$ & $\begin{array}{l}\text { Unimodal, } \\
\text { Moderately } \\
\text { Well Sorted }\end{array}$ \\
\hline & TEXTURAL GROUP: & Sand & $\begin{array}{l}\text { Slightly } \\
\text { Gravelly } \\
\text { Sand }\end{array}$ & $\begin{array}{l}\text { Slightly } \\
\text { Gravelly } \\
\text { Sand }\end{array}$ & Sand & Sand & Sand & Sand & Sand & Sand & Sand & Sand & Sand \\
\hline & SEDIMENT NAME: & $\begin{array}{l}\text { Moderately } \\
\text { Well Sorted } \\
\text { Medium } \\
\text { Sand }\end{array}$ & $\begin{array}{l}\text { Slightly Very } \\
\text { Fine Gravelly } \\
\text { Medium } \\
\text { Sand } \\
\end{array}$ & $\begin{array}{l}\text { Slightly Very } \\
\text { Fine Gravelly } \\
\text { Medium } \\
\text { Sand } \\
\end{array}$ & $\begin{array}{l}\text { Moderately } \\
\text { Well Sorted } \\
\text { Medium } \\
\text { Sand } \\
\end{array}$ & $\begin{array}{l}\text { Moderately } \\
\text { Well Sorted } \\
\text { Medium } \\
\text { Sand }\end{array}$ & $\begin{array}{l}\text { Moderately } \\
\text { Well Sorted } \\
\text { Medium } \\
\text { Sand }\end{array}$ & $\begin{array}{l}\text { Moderately } \\
\text { Sorted } \\
\text { Medium } \\
\text { Sand } \\
\end{array}$ & $\begin{array}{l}\text { Poorly } \\
\text { Sorted } \\
\text { Medium } \\
\text { Sand } \\
\end{array}$ & $\begin{array}{l}\text { Moderately } \\
\text { Well Sorted } \\
\text { Medium } \\
\text { Sand }\end{array}$ & $\begin{array}{l}\text { Moderately } \\
\text { Sorted } \\
\text { Medium } \\
\text { Sand } \\
\end{array}$ & $\begin{array}{l}\text { Moderately } \\
\text { Sorted } \\
\text { Medium } \\
\text { Sand } \\
\end{array}$ & $\begin{array}{l}\text { Moderately } \\
\text { Well Sorted } \\
\text { Medium } \\
\text { Sand } \\
\end{array}$ \\
\hline \multirow{4}{*}{$\begin{array}{l}\text { FOLK AND } \\
\text { WARD } \\
\text { METHOD } \\
(\mathrm{mm})\end{array}$} & MEAN & 331.3 & 427.2 & 459.9 & 417.2 & 440.1 & 426.8 & 345.6 & 391.4 & 286.5 & 366.4 & 380.6 & 317.3 \\
\hline & SORTING & 1.539 & 1.561 & 1.55 & 1.589 & 1.576 & 1.605 & 1.652 & 2.078 & 1.476 & 1.73 & 1.701 & 1.519 \\
\hline & SKEWNESS & 0.093 & -0.035 & -0.053 & -0.043 & -0.028 & -0.034 & -0.031 & -0.163 & 0.126 & 0.121 & 0.121 & 0.034 \\
\hline & KURTOSIS & 0.974 & 1.02 & 1.032 & 1.009 & 1.036 & 0.995 & 0.992 & 1.137 & 0.99 & 0.933 & 0.988 & 0.969 \\
\hline \multirow{4}{*}{$\begin{array}{l}\text { FOLK AND } \\
\text { WARD } \\
\text { METHOD } \\
\text { (phi) }\end{array}$} & MEAN & 1.594 & 1.227 & 1.121 & 1.261 & 1.184 & 1.228 & 1.533 & 1.353 & 1.803 & 1.448 & 1.394 & 1.656 \\
\hline & SORTING & 0.622 & 0.642 & 0.632 & 0.668 & 0.657 & 0.682 & 0.724 & 1.055 & 0.562 & 0.791 & 0.767 & 0.603 \\
\hline & SKEWNESS & -0.093 & 0.035 & 0.053 & 0.043 & 0.028 & 0.034 & 0.031 & 0.163 & -0.126 & -0.121 & -0.121 & -0.034 \\
\hline & KURTOSIS & 0.974 & 1.02 & 1.032 & 1.009 & 1.036 & 0.995 & 0.992 & 1.137 & 0.99 & 0.933 & 0.988 & 0.969 \\
\hline \multirow{23}{*}{$\begin{array}{l}\text { FOLK AND } \\
\text { WARD } \\
\text { METHOD } \\
\text { (Description) }\end{array}$} & MEAN: & $\begin{array}{l}\text { Medium } \\
\text { Sand }\end{array}$ & $\begin{array}{l}\text { Medium } \\
\text { Sand }\end{array}$ & $\begin{array}{l}\text { Medium } \\
\text { Sand }\end{array}$ & $\begin{array}{l}\text { Medium } \\
\text { Sand }\end{array}$ & $\begin{array}{l}\text { Medium } \\
\text { Sand }\end{array}$ & $\begin{array}{l}\text { Medium } \\
\text { Sand }\end{array}$ & $\begin{array}{l}\text { Medium } \\
\text { Sand }\end{array}$ & $\begin{array}{l}\text { Medium } \\
\text { Sand }\end{array}$ & $\begin{array}{l}\text { Medium } \\
\text { Sand }\end{array}$ & $\begin{array}{l}\text { Medium } \\
\text { Sand }\end{array}$ & $\begin{array}{l}\text { Medium } \\
\text { Sand }\end{array}$ & $\begin{array}{l}\text { Medium } \\
\text { Sand }\end{array}$ \\
\hline & SORTING: & $\begin{array}{l}\text { Moderately } \\
\text { Well Sorted }\end{array}$ & $\begin{array}{l}\text { Moderately } \\
\text { Well Sorted }\end{array}$ & $\begin{array}{l}\text { Moderately } \\
\text { Well Sorted }\end{array}$ & $\begin{array}{l}\text { Moderately } \\
\text { Well Sorted }\end{array}$ & $\begin{array}{l}\text { Moderately } \\
\text { Well Sorted }\end{array}$ & $\begin{array}{l}\text { Moderately } \\
\text { Well Sorted }\end{array}$ & $\begin{array}{l}\text { Moderately } \\
\text { Sorted }\end{array}$ & $\begin{array}{l}\text { Poorly } \\
\text { Sorted }\end{array}$ & $\begin{array}{l}\text { Moderately } \\
\text { Well Sorted }\end{array}$ & $\begin{array}{l}\text { Moderately } \\
\text { Sorted }\end{array}$ & $\begin{array}{l}\text { Moderately } \\
\text { Sorted }\end{array}$ & $\begin{array}{l}\text { Moderately } \\
\text { Well Sorted }\end{array}$ \\
\hline & SKEWNESS: & Symmetrical & Symmetrical & Symmetrical & Symmetrical & Symmetrical & Symmetrical & Symmetrical & Fine Skewed & $\begin{array}{l}\text { Coarse } \\
\text { Skewed }\end{array}$ & $\begin{array}{l}\text { Coarse } \\
\text { Skewed }\end{array}$ & $\begin{array}{l}\text { Coarse } \\
\text { Skewed } \\
\end{array}$ & Symmetrical \\
\hline & KURTOSIS: & Mesokurtic & Mesokurtic & Mesokurtic & Mesokurtic & Mesokurtic & Mesokurtic & Mesokurtic & Leptokurtic & Mesokurtic & Mesokurtic & Mesokurtic & Mesokurtic \\
\hline & \% GRAVEL: & $0.0 \%$ & $0.2 \%$ & $0.1 \%$ & $0.0 \%$ & $0.0 \%$ & $0.0 \%$ & $0.0 \%$ & $0.0 \%$ & $0.0 \%$ & $0.0 \%$ & $0.0 \%$ & $0.0 \%$ \\
\hline & \% SAND: & $100.0 \%$ & $99.5 \%$ & $99.5 \%$ & $99.7 \%$ & $99.6 \%$ & $99.7 \%$ & $98.9 \%$ & $96.1 \%$ & $100.0 \%$ & $100.0 \%$ & $100.0 \%$ & $99.9 \%$ \\
\hline & \% MUD: & $0.0 \%$ & $0.4 \%$ & $0.3 \%$ & $0.3 \%$ & $0.4 \%$ & $0.3 \%$ & $1.1 \%$ & $3.9 \%$ & $0.0 \%$ & $0.0 \%$ & $0.0 \%$ & $0.1 \%$ \\
\hline & \% V COARSE GRAVEL: & $0.0 \%$ & $0.0 \%$ & $0.0 \%$ & $0.0 \%$ & $0.0 \%$ & $0.0 \%$ & $0.0 \%$ & $0.0 \%$ & $0.0 \%$ & $0.0 \%$ & $0.0 \%$ & $0.0 \%$ \\
\hline & \% COARSE GRAVEL: & $0.0 \%$ & $0.0 \%$ & $0.0 \%$ & $0.0 \%$ & $0.0 \%$ & $0.0 \%$ & $0.0 \%$ & $0.0 \%$ & $0.0 \%$ & $0.0 \%$ & $0.0 \%$ & $0.0 \%$ \\
\hline & \% MEDIUM GRAVEL: & $0.0 \%$ & $0.0 \%$ & $0.0 \%$ & $0.0 \%$ & $0.0 \%$ & $0.0 \%$ & $0.0 \%$ & $0.0 \%$ & $0.0 \%$ & $0.0 \%$ & $0.0 \%$ & $0.0 \%$ \\
\hline & \% FINE GRAVEL: & $0.0 \%$ & $0.0 \%$ & $0.0 \%$ & $0.0 \%$ & $0.0 \%$ & $0.0 \%$ & $0.0 \%$ & $0.0 \%$ & $0.0 \%$ & $0.0 \%$ & $0.0 \%$ & $0.0 \%$ \\
\hline & \% V FINE GRAVEL: & $0.0 \%$ & $0.2 \%$ & $0.1 \%$ & $0.0 \%$ & $0.0 \%$ & $0.0 \%$ & $0.0 \%$ & $0.0 \%$ & $0.0 \%$ & $0.0 \%$ & $0.0 \%$ & $0.0 \%$ \\
\hline & \% V COARSE SAND: & $1.6 \%$ & $2.6 \%$ & $3.3 \%$ & $2.7 \%$ & $3.6 \%$ & $3.1 \%$ & $1.8 \%$ & $7.1 \%$ & $0.7 \%$ & $4.4 \%$ & $5.2 \%$ & $0.9 \%$ \\
\hline & \% COARSE SAND: & $16.1 \%$ & $33.9 \%$ & $39.9 \%$ & $32.8 \%$ & $35.7 \%$ & $34.5 \%$ & $21.6 \%$ & $30.7 \%$ & $8.6 \%$ & $24.4 \%$ & $24.5 \%$ & $13.5 \%$ \\
\hline & \% MEDIUM SAND: & $55.6 \%$ & $51.5 \%$ & $47.6 \%$ & $50.6 \%$ & $49.7 \%$ & $49.0 \%$ & $50.4 \%$ & $36.3 \%$ & $52.0 \%$ & $45.2 \%$ & $48.5 \%$ & $56.4 \%$ \\
\hline & \% FINE SAND: & $26.2 \%$ & $11.1 \%$ & $8.4 \%$ & $13.1 \%$ & $10.3 \%$ & $12.7 \%$ & $23.1 \%$ & $18.6 \%$ & $38.3 \%$ & $25.0 \%$ & $21.2 \%$ & $28.5 \%$ \\
\hline & \% V FINE SAND: & $0.5 \%$ & $0.3 \%$ & $0.3 \%$ & $0.5 \%$ & $0.4 \%$ & $0.4 \%$ & $2.0 \%$ & $3.3 \%$ & $0.3 \%$ & $1.0 \%$ & $0.7 \%$ & $0.7 \%$ \\
\hline & \% V COARSE SILT: & $0.0 \%$ & $0.1 \%$ & $0.1 \%$ & $0.1 \%$ & $0.1 \%$ & $0.1 \%$ & $0.5 \%$ & $1.6 \%$ & $0.0 \%$ & $0.0 \%$ & $0.0 \%$ & $0.1 \%$ \\
\hline & \% COARSE SILT: & $0.0 \%$ & $0.1 \%$ & $0.1 \%$ & $0.1 \%$ & $0.1 \%$ & $0.1 \%$ & $0.2 \%$ & $0.9 \%$ & $0.0 \%$ & $0.0 \%$ & $0.0 \%$ & $0.0 \%$ \\
\hline & \% MEDIUM SILT: & $0.0 \%$ & $0.1 \%$ & $0.1 \%$ & $0.1 \%$ & $0.1 \%$ & $0.1 \%$ & $0.2 \%$ & $0.7 \%$ & $0.0 \%$ & $0.0 \%$ & $0.0 \%$ & $0.0 \%$ \\
\hline & \% FINE SILT: & $0.0 \%$ & $0.1 \%$ & $0.1 \%$ & $0.1 \%$ & $0.1 \%$ & $0.0 \%$ & $0.1 \%$ & $0.4 \%$ & $0.0 \%$ & $0.0 \%$ & $0.0 \%$ & $0.0 \%$ \\
\hline & $\%$ V FINE SILT: & $0.0 \%$ & $0.0 \%$ & $0.0 \%$ & $0.0 \%$ & $0.0 \%$ & $0.0 \%$ & $0.1 \%$ & $0.3 \%$ & $0.0 \%$ & $0.0 \%$ & $0.0 \%$ & $0.0 \%$ \\
\hline & \% CLAY: & $0.0 \%$ & $0.0 \%$ & $0.0 \%$ & $0.0 \%$ & $0.0 \%$ & $0.0 \%$ & $0.0 \%$ & $0.0 \%$ & $0.0 \%$ & $0.0 \%$ & $0.0 \%$ & $0.0 \%$ \\
\hline
\end{tabular}


2010 Barrier Subsurface

\begin{tabular}{|c|c|c|c|c|c|c|c|c|c|c|c|c|c|}
\hline & & $\begin{array}{l}\text { WnW10- } \\
\text { t3_bf-e }\end{array}$ & $\begin{array}{l}\text { WnW10- } \\
\text { t3_bf-f }\end{array}$ & $\begin{array}{l}\text { WnW10- } \\
\text { t3_fdf-a }\end{array}$ & $\begin{array}{l}\text { WnW10- } \\
\text { t3_fdf-b }\end{array}$ & $\begin{array}{l}\text { WnW10- } \\
\text { t3_fdf-c }\end{array}$ & $\begin{array}{l}\text { WnW10- } \\
\text { t3_fdf-d }\end{array}$ & $\begin{array}{l}\text { WnW10- } \\
\text { t3_fdf-e }\end{array}$ & $\begin{array}{l}\text { WnW10- } \\
\text { t3_fdf-f }\end{array}$ & $\begin{array}{l}\text { WnW10- } \\
\text { t3_bd-a }\end{array}$ & $\begin{array}{l}\text { WnW10- } \\
\text { t3_bd-b }\end{array}$ & $\begin{array}{l}\text { WnW10- } \\
\text { t3_bd-c }\end{array}$ & $\begin{array}{l}\text { WnW10- } \\
\text { t3_bd-d }\end{array}$ \\
\hline & SAMPLE TYPE: & $\begin{array}{l}\text { Unimodal, } \\
\text { Moderately } \\
\text { Sorted }\end{array}$ & $\begin{array}{l}\text { Unimodal, } \\
\text { Moderately } \\
\text { Sorted }\end{array}$ & $\begin{array}{l}\text { Unimodal, } \\
\text { Moderately } \\
\text { Sorted }\end{array}$ & $\begin{array}{l}\text { Unimodal, } \\
\text { Moderately } \\
\text { Well Sorted }\end{array}$ & $\begin{array}{l}\text { Unimodal, } \\
\text { Moderately } \\
\text { Well Sorted }\end{array}$ & $\begin{array}{l}\text { Unimodal, } \\
\text { Moderately } \\
\text { Sorted }\end{array}$ & $\begin{array}{l}\text { Unimodal, } \\
\text { Moderately } \\
\text { Well Sorted }\end{array}$ & $\begin{array}{l}\text { Unimodal, } \\
\text { Moderately } \\
\text { Sorted }\end{array}$ & $\begin{array}{l}\text { Unimodal, } \\
\text { Moderately } \\
\text { Well Sorted }\end{array}$ & $\begin{array}{l}\text { Unimodal, } \\
\text { Moderately } \\
\text { Well Sorted }\end{array}$ & $\begin{array}{l}\text { Unimodal, } \\
\text { Well Sorted }\end{array}$ & $\begin{array}{l}\text { Unimodal, } \\
\text { Moderately } \\
\text { Well Sorted }\end{array}$ \\
\hline & TEXTURAL GROUP: & $\begin{array}{l}\text { Slightly } \\
\text { Gravelly } \\
\text { Sand }\end{array}$ & $\begin{array}{l}\text { Slightly } \\
\text { Gravelly } \\
\text { Sand }\end{array}$ & Sand & Sand & Sand & Sand & Sand & Sand & Sand & Sand & Sand & Sand \\
\hline & SEDIMENT NAME: & $\begin{array}{l}\text { Slightly Very } \\
\text { Fine } \\
\text { Gravelly } \\
\text { Coarse Sand }\end{array}$ & $\begin{array}{l}\text { Slightly Very } \\
\text { Fine Gravelly } \\
\text { Medium } \\
\text { Sand }\end{array}$ & $\begin{array}{l}\text { Moderately } \\
\text { Sorted } \\
\text { Medium } \\
\text { Sand }\end{array}$ & $\begin{array}{l}\text { Moderately } \\
\text { Well Sorted } \\
\text { Medium } \\
\text { Sand }\end{array}$ & $\begin{array}{l}\text { Moderately } \\
\text { Well Sorted } \\
\text { Medium } \\
\text { Sand }\end{array}$ & $\begin{array}{l}\text { Moderately } \\
\text { Sorted } \\
\text { Medium } \\
\text { Sand }\end{array}$ & $\begin{array}{l}\text { Moderately } \\
\text { Well Sorted } \\
\text { Medium } \\
\text { Sand }\end{array}$ & $\begin{array}{l}\text { Moderately } \\
\text { Sorted } \\
\text { Medium } \\
\text { Sand }\end{array}$ & $\begin{array}{l}\text { Moderately } \\
\text { Well Sorted } \\
\text { Medium } \\
\text { Sand }\end{array}$ & $\begin{array}{l}\text { Moderately } \\
\text { Well Sorted } \\
\text { Fine Sand }\end{array}$ & $\begin{array}{l}\text { Well Sorted } \\
\text { Fine Sand }\end{array}$ & $\begin{array}{l}\text { Moderately } \\
\text { Well Sorted } \\
\text { Medium } \\
\text { Sand }\end{array}$ \\
\hline \multirow{4}{*}{$\begin{array}{l}\text { FOLK AND } \\
\text { WARD } \\
\text { METHOD } \\
(\mathrm{mm})\end{array}$} & MEAN & 519.5 & 389.4 & 323.3 & 315.9 & 309.8 & 359.5 & 305.4 & 345.6 & 290.6 & 259.6 & 253.9 & 330.6 \\
\hline & SORTING & 1.813 & 1.72 & 1.685 & 1.62 & 1.539 & 1.625 & 1.581 & 1.69 & 1.504 & 1.442 & 1.408 & 1.499 \\
\hline & SKEWNESS & -0.105 & -0.044 & 0.155 & 0.146 & 0.099 & 0.102 & 0.141 & 0.122 & 0.085 & 0.128 & 0.097 & 0.065 \\
\hline & KURTOSIS & 0.996 & 0.953 & 0.958 & 0.988 & 0.972 & 0.995 & 0.999 & 0.989 & 0.999 & 1.034 & 1.011 & 0.973 \\
\hline \multirow{4}{*}{$\begin{array}{l}\text { FOLK AND } \\
\text { WARD } \\
\text { METHOD } \\
\text { (phi) } \\
\end{array}$} & MEAN & 0.945 & 1.361 & 1.629 & 1.662 & 1.69 & 1.476 & 1.711 & 1.533 & 1.783 & 1.946 & 1.978 & 1.597 \\
\hline & SORTING & 0.858 & 0.782 & 0.753 & 0.696 & 0.622 & 0.701 & 0.66 & 0.757 & 0.589 & 0.528 & 0.494 & 0.584 \\
\hline & SKEWNESS & 0.105 & 0.044 & -0.155 & -0.146 & -0.099 & -0.102 & -0.141 & -0.122 & -0.085 & -0.128 & -0.097 & -0.065 \\
\hline & KURTOSIS & 0.996 & 0.953 & 0.958 & 0.988 & 0.972 & 0.995 & 0.999 & 0.989 & 0.999 & 1.034 & 1.011 & 0.973 \\
\hline \multirow{23}{*}{$\begin{array}{l}\text { FOLK AND } \\
\text { WARD } \\
\text { METHOD } \\
\text { (Description) }\end{array}$} & MEAN: & Coarse Sand & $\begin{array}{l}\text { Medium } \\
\text { Sand }\end{array}$ & $\begin{array}{l}\text { Medium } \\
\text { Sand }\end{array}$ & $\begin{array}{l}\text { Medium } \\
\text { Sand }\end{array}$ & $\begin{array}{l}\text { Medium } \\
\text { Sand }\end{array}$ & $\begin{array}{l}\text { Medium } \\
\text { Sand }\end{array}$ & $\begin{array}{l}\text { Medium } \\
\text { Sand }\end{array}$ & $\begin{array}{l}\text { Medium } \\
\text { Sand }\end{array}$ & $\begin{array}{l}\text { Medium } \\
\text { Sand }\end{array}$ & $\begin{array}{l}\text { Medium } \\
\text { Sand }\end{array}$ & $\begin{array}{l}\text { Medium } \\
\text { Sand }\end{array}$ & $\begin{array}{l}\text { Medium } \\
\text { Sand }\end{array}$ \\
\hline & SORTING: & $\begin{array}{l}\text { Moderately } \\
\text { Sorted }\end{array}$ & $\begin{array}{l}\text { Moderately } \\
\text { Sorted }\end{array}$ & $\begin{array}{l}\text { Moderately } \\
\text { Sorted }\end{array}$ & $\begin{array}{l}\text { Moderately } \\
\text { Well Sorted }\end{array}$ & $\begin{array}{l}\text { Moderately } \\
\text { Well Sorted }\end{array}$ & $\begin{array}{l}\text { Moderately } \\
\text { Sorted }\end{array}$ & $\begin{array}{l}\text { Moderately } \\
\text { Well Sorted }\end{array}$ & $\begin{array}{l}\text { Moderately } \\
\text { Sorted }\end{array}$ & $\begin{array}{l}\text { Moderately } \\
\text { Well Sorted }\end{array}$ & $\begin{array}{l}\text { Moderately } \\
\text { Well Sorted }\end{array}$ & Well Sorted & $\begin{array}{l}\text { Moderately } \\
\text { Well Sorted }\end{array}$ \\
\hline & SKEWNESS: & Fine Skewed & Symmetrical & $\begin{array}{l}\text { Coarse } \\
\text { Skewed }\end{array}$ & $\begin{array}{l}\text { Coarse } \\
\text { Skewed }\end{array}$ & Symmetrical & $\begin{array}{l}\text { Coarse } \\
\text { Skewed }\end{array}$ & $\begin{array}{l}\text { Coarse } \\
\text { Skewed }\end{array}$ & $\begin{array}{l}\text { Coarse } \\
\text { Skewed }\end{array}$ & Symmetrical & $\begin{array}{l}\text { Coarse } \\
\text { Skewed }\end{array}$ & Symmetrical & Symmetrical \\
\hline & KURTOSIS: & Mesokurtic & Mesokurtic & Mesokurtic & Mesokurtic & Mesokurtic & Mesokurtic & Mesokurtic & Mesokurtic & Mesokurtic & Mesokurtic & Mesokurtic & Mesokurtic \\
\hline & \% GRAVEL: & $0.1 \%$ & $0.0 \%$ & $0.0 \%$ & $0.0 \%$ & $0.0 \%$ & $0.0 \%$ & $0.0 \%$ & $0.0 \%$ & $0.0 \%$ & $0.0 \%$ & $0.0 \%$ & $0.0 \%$ \\
\hline & \% SAND: & $99.6 \%$ & $99.9 \%$ & $100.0 \%$ & $100.0 \%$ & $100.0 \%$ & $100.0 \%$ & $100.0 \%$ & $100.0 \%$ & $99.7 \%$ & $100.0 \%$ & $100.0 \%$ & $100.0 \%$ \\
\hline & $\%$ MUD: & $0.3 \%$ & $0.0 \%$ & $0.0 \%$ & $0.0 \%$ & $0.0 \%$ & $0.0 \%$ & $0.0 \%$ & $0.0 \%$ & $0.3 \%$ & $0.0 \%$ & $0.0 \%$ & $0.0 \%$ \\
\hline & $\%$ V COARSE GRAVEL: & $0.0 \%$ & $0.0 \%$ & $0.0 \%$ & $0.0 \%$ & $0.0 \%$ & $0.0 \%$ & $0.0 \%$ & $0.0 \%$ & $0.0 \%$ & $0.0 \%$ & $0.0 \%$ & $0.0 \%$ \\
\hline & $\%$ COARSE GRAVEL: & $0.0 \%$ & $0.0 \%$ & $0.0 \%$ & $0.0 \%$ & $0.0 \%$ & $0.0 \%$ & $0.0 \%$ & $0.0 \%$ & $0.0 \%$ & $0.0 \%$ & $0.0 \%$ & $0.0 \%$ \\
\hline & \% MEDIUM GRAVEL: & $0.0 \%$ & $0.0 \%$ & $0.0 \%$ & $0.0 \%$ & $0.0 \%$ & $0.0 \%$ & $0.0 \%$ & $0.0 \%$ & $0.0 \%$ & $0.0 \%$ & $0.0 \%$ & $0.0 \%$ \\
\hline & \% FINE GRAVEL: & $0.0 \%$ & $0.0 \%$ & $0.0 \%$ & $0.0 \%$ & $0.0 \%$ & $0.0 \%$ & $0.0 \%$ & $0.0 \%$ & $0.0 \%$ & $0.0 \%$ & $0.0 \%$ & $0.0 \%$ \\
\hline & \% V FINE GRAVEL: & $0.1 \%$ & $0.0 \%$ & $0.0 \%$ & $0.0 \%$ & $0.0 \%$ & $0.0 \%$ & $0.0 \%$ & $0.0 \%$ & $0.0 \%$ & $0.0 \%$ & $0.0 \%$ & $0.0 \%$ \\
\hline & \% V COARSE SAND: & $12.8 \%$ & $4.0 \%$ & $2.8 \%$ & $2.4 \%$ & $1.0 \%$ & $3.2 \%$ & $1.9 \%$ & $4.0 \%$ & $0.7 \%$ & $0.0 \%$ & $0.0 \%$ & $0.9 \%$ \\
\hline & \% COARSE SAND: & $42.4 \%$ & $29.5 \%$ & $18.2 \%$ & $15.5 \%$ & $13.4 \%$ & $21.5 \%$ & $13.2 \%$ & $20.1 \%$ & $9.7 \%$ & $5.7 \%$ & $3.7 \%$ & $15.2 \%$ \\
\hline & $\%$ MEDIUM SAND: & $32.2 \%$ & $44.7 \%$ & $45.2 \%$ & $48.7 \%$ & $53.0 \%$ & $52.1 \%$ & $49.6 \%$ & $47.7 \%$ & $52.5 \%$ & $46.0 \%$ & $46.3 \%$ & $58.7 \%$ \\
\hline & \% FINE SAND: & $11.6 \%$ & $20.9 \%$ & $32.5 \%$ & $32.5 \%$ & $31.7 \%$ & $22.9 \%$ & $34.2 \%$ & $27.2 \%$ & $35.8 \%$ & $47.7 \%$ & $49.5 \%$ & $25.1 \%$ \\
\hline & \% V FINE SAND: & $0.7 \%$ & $0.9 \%$ & $1.2 \%$ & $0.9 \%$ & $0.8 \%$ & $0.3 \%$ & $1.0 \%$ & $0.9 \%$ & $1.0 \%$ & $0.6 \%$ & $0.5 \%$ & $0.2 \%$ \\
\hline & $\%$ V COARSE SILT: & $0.1 \%$ & $0.0 \%$ & $0.0 \%$ & $0.0 \%$ & $0.0 \%$ & $0.0 \%$ & $0.0 \%$ & $0.0 \%$ & $0.1 \%$ & $0.0 \%$ & $0.0 \%$ & $0.0 \%$ \\
\hline & $\%$ COARSE SILT: & $0.1 \%$ & $0.0 \%$ & $0.0 \%$ & $0.0 \%$ & $0.0 \%$ & $0.0 \%$ & $0.0 \%$ & $0.0 \%$ & $0.1 \%$ & $0.0 \%$ & $0.0 \%$ & $0.0 \%$ \\
\hline & \% MEDIUM SILT: & $0.1 \%$ & $0.0 \%$ & $0.0 \%$ & $0.0 \%$ & $0.0 \%$ & $0.0 \%$ & $0.0 \%$ & $0.0 \%$ & $0.1 \%$ & $0.0 \%$ & $0.0 \%$ & $0.0 \%$ \\
\hline & \% FINE SILT: & $0.0 \%$ & $0.0 \%$ & $0.0 \%$ & $0.0 \%$ & $0.0 \%$ & $0.0 \%$ & $0.0 \%$ & $0.0 \%$ & $0.0 \%$ & $0.0 \%$ & $0.0 \%$ & $0.0 \%$ \\
\hline & \% V FINE SILT: & $0.0 \%$ & $0.0 \%$ & $0.0 \%$ & $0.0 \%$ & $0.0 \%$ & $0.0 \%$ & $0.0 \%$ & $0.0 \%$ & $0.0 \%$ & $0.0 \%$ & $0.0 \%$ & $0.0 \%$ \\
\hline & \% CLAY: & $0.0 \%$ & $0.0 \%$ & $0.0 \%$ & $0.0 \%$ & $0.0 \%$ & $0.0 \%$ & $0.0 \%$ & $0.0 \%$ & $0.0 \%$ & $0.0 \%$ & $0.0 \%$ & $0.0 \%$ \\
\hline
\end{tabular}

Mulcahy, 2014; correspondence: nick.mulcahy@coastalresearch.org.nz 


\section{Barrier Subsurface}

\begin{tabular}{|c|c|c|c|c|c|c|c|c|c|c|c|c|c|}
\hline & & $\begin{array}{l}\text { WnW10- } \\
\text { t3_bd-e }\end{array}$ & $\begin{array}{l}\text { WnW10- } \\
\text { t3_bd-f }\end{array}$ & $\begin{array}{l}\text { WnW10- } \\
\text { t12_bf-a }\end{array}$ & $\begin{array}{l}\text { WnW10- } \\
\text { t12_bf-b }\end{array}$ & $\begin{array}{l}\text { WnW10- } \\
\text { t12_bf-c }\end{array}$ & $\begin{array}{l}\text { WnW10- } \\
\text { t12_bf-d }\end{array}$ & $\begin{array}{l}\text { WnW10- } \\
\text { t12_bf-e }\end{array}$ & $\begin{array}{l}\text { WnW10- } \\
\text { t12_bf-f }\end{array}$ & $\begin{array}{l}\text { WnW10- } \\
\text { t12_bf-g }\end{array}$ & $\begin{array}{l}\text { WnW10- } \\
\text { t12_bb-a }\end{array}$ & $\begin{array}{l}\text { WnW10- } \\
\text { t12_bb-b }\end{array}$ & $\begin{array}{l}\text { WnW10- } \\
\text { t12_bb-c }\end{array}$ \\
\hline & SAMPLE TYPE: & $\begin{array}{l}\text { Unimodal, } \\
\text { Moderately } \\
\text { Sorted }\end{array}$ & $\begin{array}{l}\text { Unimodal, } \\
\text { Moderately } \\
\text { Sorted }\end{array}$ & $\begin{array}{l}\text { Unimodal, } \\
\text { Moderately } \\
\text { Well Sorted }\end{array}$ & $\begin{array}{l}\text { Unimodal, } \\
\text { Moderately } \\
\text { Well Sorted }\end{array}$ & $\begin{array}{l}\text { Unimodal, } \\
\text { Moderately } \\
\text { Sorted }\end{array}$ & $\begin{array}{l}\text { Trimodal, } \\
\text { Poorly } \\
\text { Sorted }\end{array}$ & $\begin{array}{l}\text { Unimodal, } \\
\text { Moderately } \\
\text { Well Sorted }\end{array}$ & $\begin{array}{l}\text { Unimodal, } \\
\text { Moderately } \\
\text { Well Sorted }\end{array}$ & $\begin{array}{l}\text { Unimodal, } \\
\text { Moderately } \\
\text { Sorted }\end{array}$ & $\begin{array}{l}\text { Trimodal, } \\
\text { Moderately } \\
\text { Sorted }\end{array}$ & $\begin{array}{l}\text { Unimodal, } \\
\text { Moderately } \\
\text { Well Sorted }\end{array}$ & $\begin{array}{l}\text { Unimodal, } \\
\text { Moderately } \\
\text { Well Sorted }\end{array}$ \\
\hline & TEXTURAL GROUP: & Sand & Sand & Sand & $\begin{array}{l}\text { Slightly } \\
\text { Gravelly } \\
\text { Sand }\end{array}$ & Sand & $\begin{array}{l}\text { Gravelly } \\
\text { Sand }\end{array}$ & Sand & Sand & Sand & Sand & $\begin{array}{l}\text { Slightly } \\
\text { Gravelly } \\
\text { Sand }\end{array}$ & Sand \\
\hline & SEDIMENT NAME: & $\begin{array}{l}\text { Moderately } \\
\text { Sorted } \\
\text { Medium } \\
\text { Sand }\end{array}$ & $\begin{array}{l}\text { Moderately } \\
\text { Sorted } \\
\text { Medium } \\
\text { Sand }\end{array}$ & $\begin{array}{l}\text { Moderately } \\
\text { Well Sorted } \\
\text { Medium } \\
\text { Sand }\end{array}$ & $\begin{array}{l}\text { Slightly Very } \\
\text { Fine Gravelly } \\
\text { Medium } \\
\text { Sand }\end{array}$ & $\begin{array}{l}\text { Moderately } \\
\text { Sorted } \\
\text { Medium } \\
\text { Sand }\end{array}$ & $\begin{array}{l}\text { Very Fine } \\
\text { Gravelly } \\
\text { Medium } \\
\text { Sand }\end{array}$ & $\begin{array}{l}\text { Moderately } \\
\text { Well Sorted } \\
\text { Medium } \\
\text { Sand }\end{array}$ & $\begin{array}{l}\text { Moderately } \\
\text { Well Sorted } \\
\text { Medium } \\
\text { Sand }\end{array}$ & $\begin{array}{l}\text { Moderately } \\
\text { Sorted } \\
\text { Medium } \\
\text { Sand }\end{array}$ & $\begin{array}{l}\text { Moderately } \\
\text { Sorted } \\
\text { Medium } \\
\text { Sand }\end{array}$ & $\begin{array}{l}\text { Slightly Very } \\
\text { Fine Gravelly } \\
\text { Medium } \\
\text { Sand }\end{array}$ & $\begin{array}{l}\text { Moderately } \\
\text { Well Sorted } \\
\text { Medium } \\
\text { Sand }\end{array}$ \\
\hline \multirow{4}{*}{$\begin{array}{l}\text { FOLK AND } \\
\text { WARD } \\
\text { METHOD } \\
(\mathrm{mm}) \\
\end{array}$} & MEAN & 374.9 & 290 & 292.8 & 347.7 & 357.6 & 456.8 & 324.6 & 297.5 & 405.8 & 509.7 & 312.2 & 267.2 \\
\hline & SORTING & 1.636 & 1.918 & 1.446 & 1.605 & 1.703 & 2.344 & 1.465 & 1.433 & 1.674 & 1.945 & 1.536 & 1.459 \\
\hline & SKEWNESS & 0.123 & -0.072 & 0.11 & 0.161 & 0.039 & 0.303 & 0.098 & 0.133 & -0.003 & 0.009 & 0.2 & 0.155 \\
\hline & KURTOSIS & 1.017 & 1.365 & 0.994 & 0.998 & 0.968 & 1.192 & 0.974 & 1.022 & 0.979 & 0.76 & 1.026 & 1.077 \\
\hline \multirow{4}{*}{$\begin{array}{l}\text { FOLK AND } \\
\text { WARD } \\
\text { METHOD } \\
\text { (phi) }\end{array}$} & MEAN & 1.415 & 1.786 & 1.772 & 1.524 & 1.483 & 1.13 & 1.623 & 1.749 & 1.301 & 0.972 & 1.68 & 1.904 \\
\hline & SORTING & 0.71 & 0.94 & 0.532 & 0.683 & 0.768 & 1.229 & 0.55 & 0.519 & 0.744 & 0.96 & 0.619 & 0.545 \\
\hline & SKEWNESS & -0.123 & 0.072 & -0.11 & -0.161 & -0.039 & -0.303 & -0.098 & -0.133 & 0.003 & -0.009 & -0.2 & -0.155 \\
\hline & KURTOSIS & 1.017 & 1.365 & 0.994 & 0.998 & 0.968 & 1.192 & 0.974 & 1.022 & 0.979 & 0.76 & 1.026 & 1.077 \\
\hline \multirow{23}{*}{$\begin{array}{l}\text { FOLK AND } \\
\text { WARD } \\
\text { METHOD } \\
\text { (Description) }\end{array}$} & MEAN: & $\begin{array}{l}\text { Medium } \\
\text { Sand }\end{array}$ & $\begin{array}{l}\text { Medium } \\
\text { Sand }\end{array}$ & $\begin{array}{l}\text { Medium } \\
\text { Sand }\end{array}$ & $\begin{array}{l}\text { Medium } \\
\text { Sand }\end{array}$ & $\begin{array}{l}\text { Medium } \\
\text { Sand }\end{array}$ & $\begin{array}{l}\text { Medium } \\
\text { Sand }\end{array}$ & $\begin{array}{l}\text { Medium } \\
\text { Sand }\end{array}$ & $\begin{array}{l}\text { Medium } \\
\text { Sand }\end{array}$ & $\begin{array}{l}\text { Medium } \\
\text { Sand }\end{array}$ & Coarse Sand & $\begin{array}{l}\text { Medium } \\
\text { Sand }\end{array}$ & $\begin{array}{l}\text { Medium } \\
\text { Sand }\end{array}$ \\
\hline & SORTING: & $\begin{array}{l}\text { Moderately } \\
\text { Sorted }\end{array}$ & $\begin{array}{l}\text { Moderately } \\
\text { Sorted }\end{array}$ & $\begin{array}{l}\text { Moderately } \\
\text { Well Sorted }\end{array}$ & $\begin{array}{l}\text { Moderately } \\
\text { Well Sorted }\end{array}$ & $\begin{array}{l}\text { Moderately } \\
\text { Sorted }\end{array}$ & $\begin{array}{l}\text { Poorly } \\
\text { Sorted }\end{array}$ & $\begin{array}{l}\text { Moderately } \\
\text { Well Sorted }\end{array}$ & $\begin{array}{l}\text { Moderately } \\
\text { Well Sorted }\end{array}$ & $\begin{array}{l}\text { Moderately } \\
\text { Sorted }\end{array}$ & $\begin{array}{l}\text { Moderately } \\
\text { Sorted }\end{array}$ & $\begin{array}{l}\text { Moderately } \\
\text { Well Sorted }\end{array}$ & $\begin{array}{l}\text { Moderately } \\
\text { Well Sorted }\end{array}$ \\
\hline & SKEWNESS: & $\begin{array}{l}\text { Coarse } \\
\text { Skewed }\end{array}$ & Symmetrical & $\begin{array}{l}\text { Coarse } \\
\text { Skewed }\end{array}$ & $\begin{array}{l}\text { Coarse } \\
\text { Skewed }\end{array}$ & Symmetrical & $\begin{array}{l}\text { Very Coarse } \\
\text { Skewed }\end{array}$ & Symmetrical & $\begin{array}{l}\text { Coarse } \\
\text { Skewed }\end{array}$ & Symmetrical & Symmetrical & $\begin{array}{l}\text { Coarse } \\
\text { Skewed }\end{array}$ & $\begin{array}{l}\text { Coarse } \\
\text { Skewed }\end{array}$ \\
\hline & KURTOSIS: & Mesokurtic & Leptokurtic & Mesokurtic & Mesokurtic & Mesokurtic & Leptokurtic & Mesokurtic & Mesokurtic & Mesokurtic & Platykurtic & Mesokurtic & Mesokurtic \\
\hline & \% GRAVEL: & $0.0 \%$ & $0.0 \%$ & $0.0 \%$ & $0.1 \%$ & $0.0 \%$ & $9.9 \%$ & $0.0 \%$ & $0.0 \%$ & $0.0 \%$ & $0.0 \%$ & $0.1 \%$ & $0.0 \%$ \\
\hline & \% SAND: & $99.4 \%$ & $95.2 \%$ & $100.0 \%$ & $99.9 \%$ & $100.0 \%$ & $90.1 \%$ & $100.0 \%$ & $100.0 \%$ & $99.5 \%$ & $100.0 \%$ & $99.9 \%$ & $100.0 \%$ \\
\hline & \% MUD: & $0.6 \%$ & $4.8 \%$ & $0.0 \%$ & $0.0 \%$ & $0.0 \%$ & $0.0 \%$ & $0.0 \%$ & $0.0 \%$ & $0.5 \%$ & $0.0 \%$ & $0.0 \%$ & $0.0 \%$ \\
\hline & \% V COARSE GRAVEL: & $0.0 \%$ & $0.0 \%$ & $0.0 \%$ & $0.0 \%$ & $0.0 \%$ & $0.0 \%$ & $0.0 \%$ & $0.0 \%$ & $0.0 \%$ & $0.0 \%$ & $0.0 \%$ & $0.0 \%$ \\
\hline & \% COARSE GRAVEL: & $0.0 \%$ & $0.0 \%$ & $0.0 \%$ & $0.0 \%$ & $0.0 \%$ & $0.3 \%$ & $0.0 \%$ & $0.0 \%$ & $0.0 \%$ & $0.0 \%$ & $0.0 \%$ & $0.0 \%$ \\
\hline & \% MEDIUM GRAVEL: & $0.0 \%$ & $0.0 \%$ & $0.0 \%$ & $0.0 \%$ & $0.0 \%$ & $1.5 \%$ & $0.0 \%$ & $0.0 \%$ & $0.0 \%$ & $0.0 \%$ & $0.0 \%$ & $0.0 \%$ \\
\hline & \% FINE GRAVEL: & $0.0 \%$ & $0.0 \%$ & $0.0 \%$ & $0.0 \%$ & $0.0 \%$ & $3.0 \%$ & $0.0 \%$ & $0.0 \%$ & $0.0 \%$ & $0.0 \%$ & $0.0 \%$ & $0.0 \%$ \\
\hline & $\%$ V FINE GRAVEL: & $0.0 \%$ & $0.0 \%$ & $0.0 \%$ & $0.1 \%$ & $0.0 \%$ & $5.1 \%$ & $0.0 \%$ & $0.0 \%$ & $0.0 \%$ & $0.0 \%$ & $0.1 \%$ & $0.0 \%$ \\
\hline & \% V COARSE SAND: & $3.9 \%$ & $2.5 \%$ & $0.7 \%$ & $3.2 \%$ & $3.4 \%$ & $6.2 \%$ & $0.5 \%$ & $0.4 \%$ & $4.2 \%$ & $18.3 \%$ & $1.7 \%$ & $1.0 \%$ \\
\hline & \% COARSE SAND: & $23.0 \%$ & $14.4 \%$ & $8.2 \%$ & $18.9 \%$ & $23.4 \%$ & $25.7 \%$ & $13.5 \%$ & $8.8 \%$ & $30.5 \%$ & $32.5 \%$ & $13.4 \%$ & $6.3 \%$ \\
\hline & \% MEDIUM SAND: & $52.8 \%$ & $43.2 \%$ & $56.0 \%$ & $52.7 \%$ & $47.1 \%$ & $36.9 \%$ & $60.4 \%$ & $57.7 \%$ & $47.5 \%$ & $32.7 \%$ & $52.4 \%$ & $46.8 \%$ \\
\hline & \% FINE SAND: & $19.1 \%$ & $31.0 \%$ & $35.1 \%$ & $25.0 \%$ & $24.6 \%$ & $20.8 \%$ & $25.4 \%$ & $32.9 \%$ & $16.7 \%$ & $16.3 \%$ & $32.4 \%$ & $44.9 \%$ \\
\hline & \% V FINE SAND: & $0.6 \%$ & $4.2 \%$ & $0.1 \%$ & $0.1 \%$ & $1.4 \%$ & $0.5 \%$ & $0.2 \%$ & $0.2 \%$ & $0.6 \%$ & $0.1 \%$ & $0.1 \%$ & $0.9 \%$ \\
\hline & \% V COARSE SILT: & $0.2 \%$ & $2.6 \%$ & $0.0 \%$ & $0.0 \%$ & $0.0 \%$ & $0.0 \%$ & $0.0 \%$ & $0.0 \%$ & $0.1 \%$ & $0.0 \%$ & $0.0 \%$ & $0.0 \%$ \\
\hline & \% COARSE SILT: & $0.1 \%$ & $1.0 \%$ & $0.0 \%$ & $0.0 \%$ & $0.0 \%$ & $0.0 \%$ & $0.0 \%$ & $0.0 \%$ & $0.1 \%$ & $0.0 \%$ & $0.0 \%$ & $0.0 \%$ \\
\hline & \% MEDIUM SILT: & $0.1 \%$ & $0.6 \%$ & $0.0 \%$ & $0.0 \%$ & $0.0 \%$ & $0.0 \%$ & $0.0 \%$ & $0.0 \%$ & $0.1 \%$ & $0.0 \%$ & $0.0 \%$ & $0.0 \%$ \\
\hline & \% FINE SILT: & $0.1 \%$ & $0.3 \%$ & $0.0 \%$ & $0.0 \%$ & $0.0 \%$ & $0.0 \%$ & $0.0 \%$ & $0.0 \%$ & $0.1 \%$ & $0.0 \%$ & $0.0 \%$ & $0.0 \%$ \\
\hline & \% V FINE SILT: & $0.0 \%$ & $0.2 \%$ & $0.0 \%$ & $0.0 \%$ & $0.0 \%$ & $0.0 \%$ & $0.0 \%$ & $0.0 \%$ & $0.1 \%$ & $0.0 \%$ & $0.0 \%$ & $0.0 \%$ \\
\hline & \% CLAY: & $0.0 \%$ & $0.0 \%$ & $0.0 \%$ & $0.0 \%$ & $0.0 \%$ & $0.0 \%$ & $0.0 \%$ & $0.0 \%$ & $0.0 \%$ & $0.0 \%$ & $0.0 \%$ & $0.0 \%$ \\
\hline
\end{tabular}




\section{Barrier Subsurface}

\begin{tabular}{|c|c|c|c|c|c|c|c|c|c|c|c|c|c|}
\hline & & $\begin{array}{l}\text { WnW10- } \\
\text { t12_fdf-a }\end{array}$ & $\begin{array}{l}\text { WnW10- } \\
\text { t12_fdf-b }\end{array}$ & $\begin{array}{l}\text { WnW10- } \\
\mathrm{t} 12 \text { _fdf-c }\end{array}$ & $\begin{array}{l}\text { WnW10- } \\
\text { t12_fdf-d }\end{array}$ & $\begin{array}{l}\text { WnW10- } \\
\text { t12_fdf-e }\end{array}$ & $\begin{array}{l}\text { WnW10- } \\
\text { t12_fdf-f }\end{array}$ & $\begin{array}{l}\text { WnW10- } \\
\text { t12_fdf-g }\end{array}$ & $\begin{array}{l}\text { WnW10- } \\
\text { t12_bd-a }\end{array}$ & $\begin{array}{l}\text { WnW10- } \\
\text { t12_bd-b }\end{array}$ & $\begin{array}{l}\text { WnW10- } \\
\text { t12_bd-c }\end{array}$ & $\begin{array}{l}\text { WnW10- } \\
\text { t12_bd-d }\end{array}$ & $\begin{array}{l}\text { WnW10- } \\
\text { t12_bd-e }\end{array}$ \\
\hline & SAMPLE TYPE: & $\begin{array}{l}\text { Unimodal, } \\
\text { Moderately } \\
\text { Well Sorted }\end{array}$ & $\begin{array}{l}\text { Unimodal, } \\
\text { Moderately } \\
\text { Well Sorted }\end{array}$ & $\begin{array}{l}\text { Unimodal, } \\
\text { Moderately } \\
\text { Well Sorted }\end{array}$ & $\begin{array}{l}\text { Unimodal, } \\
\text { Moderately } \\
\text { Well Sorted }\end{array}$ & $\begin{array}{l}\text { Unimodal, } \\
\text { Moderately } \\
\text { Well Sorted }\end{array}$ & $\begin{array}{l}\text { Unimodal, } \\
\text { Well Sorted }\end{array}$ & $\begin{array}{l}\text { Unimodal, } \\
\text { Well Sorted }\end{array}$ & $\begin{array}{l}\text { Unimodal, } \\
\text { Moderately } \\
\text { Well Sorted }\end{array}$ & $\begin{array}{l}\text { Unimodal, } \\
\text { Moderately } \\
\text { Well Sorted }\end{array}$ & $\begin{array}{l}\text { Unimodal, } \\
\text { Moderately } \\
\text { Well Sorted }\end{array}$ & $\begin{array}{l}\text { Unimodal, } \\
\text { Moderately } \\
\text { Well Sorted }\end{array}$ & $\begin{array}{l}\text { Unimodal, } \\
\text { Moderately } \\
\text { Well Sorted }\end{array}$ \\
\hline & TEXTURAL GROUP: & Sand & $\begin{array}{l}\text { Slightly } \\
\text { Gravelly } \\
\text { Sand } \\
\end{array}$ & Sand & Sand & Sand & Sand & Sand & Sand & Sand & Sand & Sand & Sand \\
\hline & SEDIMENT NAME: & $\begin{array}{l}\text { Moderately } \\
\text { Well Sorted } \\
\text { Medium } \\
\text { Sand }\end{array}$ & $\begin{array}{l}\text { Slightly Very } \\
\text { Fine Gravelly } \\
\text { Medium } \\
\text { Sand } \\
\end{array}$ & $\begin{array}{l}\text { Moderately } \\
\text { Well Sorted } \\
\text { Medium } \\
\text { Sand }\end{array}$ & $\begin{array}{l}\text { Moderately } \\
\text { Well Sorted } \\
\text { Medium } \\
\text { Sand }\end{array}$ & $\begin{array}{l}\text { Moderately } \\
\text { Well Sorted } \\
\text { Medium } \\
\text { Sand }\end{array}$ & $\begin{array}{l}\text { Well Sorted } \\
\text { Medium } \\
\text { Sand }\end{array}$ & $\begin{array}{l}\text { Well Sorted } \\
\text { Fine Sand }\end{array}$ & $\begin{array}{l}\text { Moderately } \\
\text { Well Sorted } \\
\text { Medium } \\
\text { Sand }\end{array}$ & $\begin{array}{l}\text { Moderately } \\
\text { Well Sorted } \\
\text { Medium } \\
\text { Sand }\end{array}$ & $\begin{array}{l}\text { Moderately } \\
\text { Well Sorted } \\
\text { Medium } \\
\text { Sand }\end{array}$ & $\begin{array}{l}\text { Moderately } \\
\text { Well Sorted } \\
\text { Medium } \\
\text { Sand }\end{array}$ & $\begin{array}{l}\text { Moderately } \\
\text { Well Sorted } \\
\text { Medium } \\
\text { Sand }\end{array}$ \\
\hline \multirow{4}{*}{$\begin{array}{l}\text { FOLK AND } \\
\text { WARD } \\
\text { METHOD } \\
(\mathrm{mm})\end{array}$} & MEAN & 313.9 & 316.5 & 285.8 & 318.1 & 302.9 & 259.6 & 239.8 & 324.6 & 313 & 278.3 & 307.3 & 284.4 \\
\hline & SORTING & 1.555 & 1.516 & 1.476 & 1.49 & 1.464 & 1.361 & 1.367 & 1.552 & 1.528 & 1.467 & 1.542 & 1.524 \\
\hline & SKEWNESS & 0.128 & 0.16 & 0.158 & 0.117 & 0.114 & 0.097 & 0.13 & 0.201 & 0.188 & 0.192 & 0.186 & 0.129 \\
\hline & KURTOSIS & 1.013 & 1.029 & 1.02 & 0.999 & 0.996 & 1.046 & 1.102 & 1.049 & 1.03 & 1.07 & 0.996 & 1.047 \\
\hline \multirow{4}{*}{$\begin{array}{l}\text { FOLK AND } \\
\text { WARD } \\
\text { METHOD } \\
\text { (phi) }\end{array}$} & MEAN & 1.672 & 1.66 & 1.807 & 1.653 & 1.723 & 1.946 & 2.06 & 1.623 & 1.676 & 1.845 & 1.702 & 1.814 \\
\hline & SORTING & 0.637 & 0.6 & 0.562 & 0.575 & 0.549 & 0.444 & 0.451 & 0.634 & 0.612 & 0.553 & 0.625 & 0.608 \\
\hline & SKEWNESS & -0.128 & -0.16 & -0.158 & -0.117 & -0.114 & -0.097 & -0.13 & -0.201 & -0.188 & -0.192 & -0.186 & -0.129 \\
\hline & KURTOSIS & 1.013 & 1.029 & 1.02 & 0.999 & 0.996 & 1.046 & 1.102 & 1.049 & 1.03 & 1.07 & 0.996 & 1.047 \\
\hline \multirow{23}{*}{$\begin{array}{l}\text { FOLK AND } \\
\text { WARD } \\
\text { METHOD } \\
\text { (Description) }\end{array}$} & MEAN: & $\begin{array}{l}\text { Medium } \\
\text { Sand }\end{array}$ & $\begin{array}{l}\text { Medium } \\
\text { Sand }\end{array}$ & $\begin{array}{l}\text { Medium } \\
\text { Sand }\end{array}$ & $\begin{array}{l}\text { Medium } \\
\text { Sand }\end{array}$ & $\begin{array}{l}\text { Medium } \\
\text { Sand }\end{array}$ & $\begin{array}{l}\text { Medium } \\
\text { Sand }\end{array}$ & Fine Sand & $\begin{array}{l}\text { Medium } \\
\text { Sand }\end{array}$ & $\begin{array}{l}\text { Medium } \\
\text { Sand }\end{array}$ & $\begin{array}{l}\text { Medium } \\
\text { Sand }\end{array}$ & $\begin{array}{l}\text { Medium } \\
\text { Sand }\end{array}$ & $\begin{array}{l}\text { Medium } \\
\text { Sand }\end{array}$ \\
\hline & SORTING: & $\begin{array}{l}\text { Moderately } \\
\text { Well Sorted }\end{array}$ & $\begin{array}{l}\text { Moderately } \\
\text { Well Sorted }\end{array}$ & $\begin{array}{l}\text { Moderately } \\
\text { Well Sorted }\end{array}$ & $\begin{array}{l}\text { Moderately } \\
\text { Well Sorted }\end{array}$ & $\begin{array}{l}\text { Moderately } \\
\text { Well Sorted }\end{array}$ & Well Sorted & Well Sorted & $\begin{array}{l}\text { Moderately } \\
\text { Well Sorted }\end{array}$ & $\begin{array}{l}\text { Moderately } \\
\text { Well Sorted }\end{array}$ & $\begin{array}{l}\text { Moderately } \\
\text { Well Sorted }\end{array}$ & $\begin{array}{l}\text { Moderately } \\
\text { Well Sorted }\end{array}$ & $\begin{array}{l}\text { Moderately } \\
\text { Well Sorted }\end{array}$ \\
\hline & SKEWNESS: & $\begin{array}{l}\text { Coarse } \\
\text { Skewed } \\
\end{array}$ & $\begin{array}{l}\text { Coarse } \\
\text { Skewed } \\
\end{array}$ & $\begin{array}{l}\text { Coarse } \\
\text { Skewed } \\
\end{array}$ & $\begin{array}{l}\text { Coarse } \\
\text { Skewed } \\
\end{array}$ & $\begin{array}{l}\text { Coarse } \\
\text { Skewed } \\
\end{array}$ & Symmetrical & $\begin{array}{l}\text { Coarse } \\
\text { Skewed } \\
\end{array}$ & $\begin{array}{l}\text { Coarse } \\
\text { Skewed } \\
\end{array}$ & $\begin{array}{l}\text { Coarse } \\
\text { Skewed } \\
\end{array}$ & $\begin{array}{l}\text { Coarse } \\
\text { Skewed } \\
\end{array}$ & $\begin{array}{l}\text { Coarse } \\
\text { Skewed } \\
\end{array}$ & $\begin{array}{l}\text { Coarse } \\
\text { Skewed }\end{array}$ \\
\hline & KURTOSIS: & Mesokurtic & Mesokurtic & Mesokurtic & Mesokurtic & Mesokurtic & Mesokurtic & Mesokurtic & Mesokurtic & Mesokurtic & Mesokurtic & Mesokurtic & Mesokurtic \\
\hline & \% GRAVEL: & $0.0 \%$ & $0.1 \%$ & $0.0 \%$ & $0.0 \%$ & $0.0 \%$ & $0.0 \%$ & $0.0 \%$ & $0.0 \%$ & $0.0 \%$ & $0.0 \%$ & $0.0 \%$ & $0.0 \%$ \\
\hline & \% SAND: & $100.0 \%$ & $99.9 \%$ & $100.0 \%$ & $100.0 \%$ & $100.0 \%$ & $100.0 \%$ & $100.0 \%$ & $100.0 \%$ & $100.0 \%$ & $100.0 \%$ & $100.0 \%$ & $98.1 \%$ \\
\hline & \% MUD: & $0.0 \%$ & $0.0 \%$ & $0.0 \%$ & $0.0 \%$ & $0.0 \%$ & $0.0 \%$ & $0.0 \%$ & $0.0 \%$ & $0.0 \%$ & $0.0 \%$ & $0.0 \%$ & $1.9 \%$ \\
\hline & \% V COARSE GRAVEL: & $0.0 \%$ & $0.0 \%$ & $0.0 \%$ & $0.0 \%$ & $0.0 \%$ & $0.0 \%$ & $0.0 \%$ & $0.0 \%$ & $0.0 \%$ & $0.0 \%$ & $0.0 \%$ & $0.0 \%$ \\
\hline & \% COARSE GRAVEL: & $0.0 \%$ & $0.0 \%$ & $0.0 \%$ & $0.0 \%$ & $0.0 \%$ & $0.0 \%$ & $0.0 \%$ & $0.0 \%$ & $0.0 \%$ & $0.0 \%$ & $0.0 \%$ & $0.0 \%$ \\
\hline & \% MEDIUM GRAVEL: & $0.0 \%$ & $0.0 \%$ & $0.0 \%$ & $0.0 \%$ & $0.0 \%$ & $0.0 \%$ & $0.0 \%$ & $0.0 \%$ & $0.0 \%$ & $0.0 \%$ & $0.0 \%$ & $0.0 \%$ \\
\hline & \% FINE GRAVEL: & $0.0 \%$ & $0.0 \%$ & $0.0 \%$ & $0.0 \%$ & $0.0 \%$ & $0.0 \%$ & $0.0 \%$ & $0.0 \%$ & $0.0 \%$ & $0.0 \%$ & $0.0 \%$ & $0.0 \%$ \\
\hline & $\%$ V FINE GRAVEL: & $0.0 \%$ & $0.1 \%$ & $0.0 \%$ & $0.0 \%$ & $0.0 \%$ & $0.0 \%$ & $0.0 \%$ & $0.0 \%$ & $0.0 \%$ & $0.0 \%$ & $0.0 \%$ & $0.0 \%$ \\
\hline & \% V COARSE SAND: & $1.5 \%$ & $2.0 \%$ & $0.7 \%$ & $1.1 \%$ & $0.8 \%$ & $0.0 \%$ & $0.0 \%$ & $2.1 \%$ & $2.1 \%$ & $0.7 \%$ & $1.4 \%$ & $0.9 \%$ \\
\hline & \% COARSE SAND: & $14.1 \%$ & $12.6 \%$ & $8.9 \%$ & $12.8 \%$ & $10.1 \%$ & $3.4 \%$ & $3.2 \%$ & $14.8 \%$ & $12.8 \%$ & $8.5 \%$ & $13.4 \%$ & $9.7 \%$ \\
\hline & \% MEDIUM SAND: & $52.8 \%$ & $55.5 \%$ & $51.1 \%$ & $57.7 \%$ & $56.8 \%$ & $49.9 \%$ & $39.3 \%$ & $54.3 \%$ & $53.4 \%$ & $48.6 \%$ & $50.8 \%$ & $48.8 \%$ \\
\hline & $\%$ FINE SAND: & $30.7 \%$ & $29.7 \%$ & $39.0 \%$ & $28.3 \%$ & $32.0 \%$ & $46.5 \%$ & $57.2 \%$ & $28.8 \%$ & $31.7 \%$ & $42.1 \%$ & $34.2 \%$ & $37.5 \%$ \\
\hline & \% V FINE SAND: & $0.9 \%$ & $0.1 \%$ & $0.2 \%$ & $0.1 \%$ & $0.3 \%$ & $0.1 \%$ & $0.3 \%$ & $0.0 \%$ & $0.1 \%$ & $0.1 \%$ & $0.2 \%$ & $1.2 \%$ \\
\hline & \% V COARSE SILT: & $0.0 \%$ & $0.0 \%$ & $0.0 \%$ & $0.0 \%$ & $0.0 \%$ & $0.0 \%$ & $0.0 \%$ & $0.0 \%$ & $0.0 \%$ & $0.0 \%$ & $0.0 \%$ & $0.5 \%$ \\
\hline & \% COARSE SILT: & $0.0 \%$ & $0.0 \%$ & $0.0 \%$ & $0.0 \%$ & $0.0 \%$ & $0.0 \%$ & $0.0 \%$ & $0.0 \%$ & $0.0 \%$ & $0.0 \%$ & $0.0 \%$ & $0.4 \%$ \\
\hline & \% MEDIUM SILT: & $0.0 \%$ & $0.0 \%$ & $0.0 \%$ & $0.0 \%$ & $0.0 \%$ & $0.0 \%$ & $0.0 \%$ & $0.0 \%$ & $0.0 \%$ & $0.0 \%$ & $0.0 \%$ & $0.4 \%$ \\
\hline & \% FINE SILT: & $0.0 \%$ & $0.0 \%$ & $0.0 \%$ & $0.0 \%$ & $0.0 \%$ & $0.0 \%$ & $0.0 \%$ & $0.0 \%$ & $0.0 \%$ & $0.0 \%$ & $0.0 \%$ & $0.3 \%$ \\
\hline & \% V FINE SILT: & $0.0 \%$ & $0.0 \%$ & $0.0 \%$ & $0.0 \%$ & $0.0 \%$ & $0.0 \%$ & $0.0 \%$ & $0.0 \%$ & $0.0 \%$ & $0.0 \%$ & $0.0 \%$ & $0.2 \%$ \\
\hline & \% CLAY: & $0.0 \%$ & $0.0 \%$ & $0.0 \%$ & $0.0 \%$ & $0.0 \%$ & $0.0 \%$ & $0.0 \%$ & $0.0 \%$ & $0.0 \%$ & $0.0 \%$ & $0.0 \%$ & $0.0 \%$ \\
\hline
\end{tabular}




\section{Barrier Subsurface}

\begin{tabular}{|c|c|c|c|c|c|c|c|c|c|c|c|c|c|}
\hline & & $\begin{array}{l}\text { WnW10- } \\
\text { t12_bd-f }\end{array}$ & $\begin{array}{l}\text { WnW10- } \\
\text { t17_bf-a }\end{array}$ & $\begin{array}{l}\text { WnW10- } \\
\text { t17_bf-b }\end{array}$ & $\begin{array}{l}\text { WnW10- } \\
\text { t17_bf-c }\end{array}$ & $\begin{array}{l}\text { WnW10- } \\
\text { t17_bf-d }\end{array}$ & $\begin{array}{l}\text { WnW10- } \\
\text { t17_bf-e }\end{array}$ & $\begin{array}{l}\text { WnW10- } \\
\text { t17_bf-f }\end{array}$ & $\begin{array}{l}\text { WnW10- } \\
\text { t17_bb-a }\end{array}$ & $\begin{array}{l}\text { WnW10- } \\
\text { t17_bb-b }\end{array}$ & $\begin{array}{l}\text { WnW10- } \\
\text { t17_bb-c }\end{array}$ & $\begin{array}{l}\text { WnW10- } \\
\text { t17_bb-d }\end{array}$ & $\begin{array}{l}\text { WnW10- } \\
\text { t17_bb-e }\end{array}$ \\
\hline & SAMPLE TYPE: & $\begin{array}{l}\text { Unimodal, } \\
\text { Moderately } \\
\text { Well Sorted }\end{array}$ & $\begin{array}{l}\text { Unimodal, } \\
\text { Moderately } \\
\text { Well Sorted }\end{array}$ & $\begin{array}{l}\text { Unimodal, } \\
\text { Moderately } \\
\text { Well Sorted }\end{array}$ & $\begin{array}{l}\text { Unimodal, } \\
\text { Moderately } \\
\text { Well Sorted }\end{array}$ & $\begin{array}{l}\text { Unimodal, } \\
\text { Moderately } \\
\text { Sorted }\end{array}$ & $\begin{array}{l}\text { Unimodal, } \\
\text { Moderately } \\
\text { Well Sorted }\end{array}$ & $\begin{array}{l}\text { Unimodal, } \\
\text { Moderately } \\
\text { Sorted }\end{array}$ & $\begin{array}{l}\text { Unimodal, } \\
\text { Moderately } \\
\text { Well Sorted }\end{array}$ & $\begin{array}{l}\text { Unimodal, } \\
\text { Moderately } \\
\text { Well Sorted }\end{array}$ & $\begin{array}{l}\text { Unimodal, } \\
\text { Moderately } \\
\text { Well Sorted }\end{array}$ & $\begin{array}{l}\text { Unimodal, } \\
\text { Moderately } \\
\text { Well Sorted }\end{array}$ & $\begin{array}{l}\text { Unimodal, } \\
\text { Moderately } \\
\text { Well Sorted }\end{array}$ \\
\hline & TEXTURAL GROUP: & Sand & Sand & $\begin{array}{l}\text { Slightly } \\
\text { Gravelly } \\
\text { Sand } \\
\end{array}$ & $\begin{array}{l}\text { Slightly } \\
\text { Gravelly } \\
\text { Sand } \\
\end{array}$ & $\begin{array}{l}\text { Slightly } \\
\text { Gravelly } \\
\text { Sand }\end{array}$ & $\begin{array}{l}\text { Slightly } \\
\text { Gravelly } \\
\text { Sand }\end{array}$ & $\begin{array}{l}\text { Slightly } \\
\text { Gravelly } \\
\text { Sand } \\
\end{array}$ & Sand & Sand & $\begin{array}{l}\text { Slightly } \\
\text { Gravelly } \\
\text { Sand }\end{array}$ & $\begin{array}{l}\text { Slightly } \\
\text { Gravelly } \\
\text { Sand }\end{array}$ & $\begin{array}{l}\text { Slightly } \\
\text { Gravelly } \\
\text { Sand }\end{array}$ \\
\hline & SEDIMENT NAME: & $\begin{array}{l}\text { Moderately } \\
\text { Well Sorted } \\
\text { Medium } \\
\text { Sand }\end{array}$ & $\begin{array}{l}\text { Moderately } \\
\text { Well Sorted } \\
\text { Fine Sand }\end{array}$ & $\begin{array}{l}\text { Slightly Very } \\
\text { Fine Gravelly } \\
\text { Medium } \\
\text { Sand } \\
\end{array}$ & $\begin{array}{l}\text { Slightly Very } \\
\text { Fine Gravelly } \\
\text { Fine Sand }\end{array}$ & $\begin{array}{l}\text { Slightly Very } \\
\text { Fine Gravelly } \\
\text { Medium } \\
\text { Sand } \\
\end{array}$ & $\begin{array}{l}\text { Slightly Very } \\
\text { Fine Gravelly } \\
\text { Medium } \\
\text { Sand }\end{array}$ & $\begin{array}{l}\text { Slightly Very } \\
\text { Fine Gravelly } \\
\text { Medium } \\
\text { Sand } \\
\end{array}$ & $\begin{array}{l}\text { Moderately } \\
\text { Well Sorted } \\
\text { Medium } \\
\text { Sand }\end{array}$ & $\begin{array}{l}\text { Moderately } \\
\text { Well Sorted } \\
\text { Medium } \\
\text { Sand }\end{array}$ & $\begin{array}{l}\text { Slightly Very } \\
\text { Fine Gravelly } \\
\text { Medium } \\
\text { Sand }\end{array}$ & $\begin{array}{l}\text { Slightly Very } \\
\text { Fine Gravelly } \\
\text { Medium } \\
\text { Sand }\end{array}$ & $\begin{array}{l}\text { Slightly Very } \\
\text { Fine Gravelly } \\
\text { Medium } \\
\text { Sand }\end{array}$ \\
\hline \multirow{4}{*}{$\begin{array}{l}\text { FOLK AND } \\
\text { WARD } \\
\text { METHOD } \\
(\mathrm{mm})\end{array}$} & MEAN & 259.1 & 239.8 & 294.8 & 258 & 391.8 & 287.7 & 391.8 & 330.3 & 306.9 & 308.8 & 278.9 & 271.2 \\
\hline & SORTING & 1.441 & 1.428 & 1.561 & 1.514 & 1.866 & 1.462 & 1.729 & 1.605 & 1.594 & 1.581 & 1.563 & 1.518 \\
\hline & SKEWNESS & 0.064 & 0.202 & 0.244 & 0.237 & 0.179 & 0.194 & 0.186 & 0.164 & 0.188 & 0.2 & 0.198 & 0.174 \\
\hline & KURTOSIS & 1.093 & 1.171 & 1.08 & 1.182 & 0.909 & 1.133 & 0.947 & 0.987 & 1.016 & 1.061 & 1.096 & 1.075 \\
\hline \multirow{4}{*}{$\begin{array}{l}\text { FOLK AND } \\
\text { WARD } \\
\text { METHOD } \\
\text { (phi) }\end{array}$} & MEAN & 1.948 & 2.06 & 1.762 & 1.955 & 1.352 & 1.797 & 1.352 & 1.598 & 1.704 & 1.695 & 1.842 & 1.883 \\
\hline & SORTING & 0.527 & 0.514 & 0.642 & 0.598 & 0.9 & 0.548 & 0.79 & 0.683 & 0.673 & 0.661 & 0.644 & 0.602 \\
\hline & SKEWNESS & -0.064 & -0.202 & -0.244 & -0.237 & -0.179 & -0.194 & -0.186 & -0.164 & -0.188 & -0.2 & -0.198 & -0.174 \\
\hline & KURTOSIS & 1.093 & 1.171 & 1.08 & 1.182 & 0.909 & 1.133 & 0.947 & 0.987 & 1.016 & 1.061 & 1.096 & 1.075 \\
\hline \multirow{23}{*}{$\begin{array}{l}\text { FOLK AND } \\
\text { WARD } \\
\text { METHOD } \\
\text { (Description) }\end{array}$} & MEAN: & $\begin{array}{l}\text { Medium } \\
\text { Sand }\end{array}$ & Fine Sand & $\begin{array}{l}\text { Medium } \\
\text { Sand }\end{array}$ & $\begin{array}{l}\text { Medium } \\
\text { Sand }\end{array}$ & $\begin{array}{l}\text { Medium } \\
\text { Sand }\end{array}$ & $\begin{array}{l}\text { Medium } \\
\text { Sand }\end{array}$ & $\begin{array}{l}\text { Medium } \\
\text { Sand }\end{array}$ & $\begin{array}{l}\text { Medium } \\
\text { Sand }\end{array}$ & $\begin{array}{l}\text { Medium } \\
\text { Sand }\end{array}$ & $\begin{array}{l}\text { Medium } \\
\text { Sand }\end{array}$ & $\begin{array}{l}\text { Medium } \\
\text { Sand }\end{array}$ & $\begin{array}{l}\text { Medium } \\
\text { Sand }\end{array}$ \\
\hline & SORTING: & $\begin{array}{l}\text { Moderately } \\
\text { Well Sorted }\end{array}$ & $\begin{array}{l}\text { Moderately } \\
\text { Well Sorted }\end{array}$ & $\begin{array}{l}\text { Moderately } \\
\text { Well Sorted }\end{array}$ & $\begin{array}{l}\text { Moderately } \\
\text { Well Sorted }\end{array}$ & $\begin{array}{l}\text { Moderately } \\
\text { Sorted }\end{array}$ & $\begin{array}{l}\text { Moderately } \\
\text { Well Sorted }\end{array}$ & $\begin{array}{l}\text { Moderately } \\
\text { Sorted }\end{array}$ & $\begin{array}{l}\text { Moderately } \\
\text { Well Sorted }\end{array}$ & $\begin{array}{l}\text { Moderately } \\
\text { Well Sorted }\end{array}$ & $\begin{array}{l}\text { Moderately } \\
\text { Well Sorted }\end{array}$ & $\begin{array}{l}\text { Moderately } \\
\text { Well Sorted }\end{array}$ & $\begin{array}{l}\text { Moderately } \\
\text { Well Sorted }\end{array}$ \\
\hline & SKEWNESS: & Symmetrical & $\begin{array}{l}\text { Coarse } \\
\text { Skewed } \\
\end{array}$ & $\begin{array}{l}\text { Coarse } \\
\text { Skewed } \\
\end{array}$ & $\begin{array}{l}\text { Coarse } \\
\text { Skewed } \\
\end{array}$ & $\begin{array}{l}\text { Coarse } \\
\text { Skewed }\end{array}$ & $\begin{array}{l}\text { Coarse } \\
\text { Skewed } \\
\end{array}$ & $\begin{array}{l}\text { Coarse } \\
\text { Skewed } \\
\end{array}$ & $\begin{array}{l}\text { Coarse } \\
\text { Skewed } \\
\end{array}$ & $\begin{array}{l}\text { Coarse } \\
\text { Skewed } \\
\end{array}$ & $\begin{array}{l}\text { Coarse } \\
\text { Skewed } \\
\end{array}$ & $\begin{array}{l}\text { Coarse } \\
\text { Skewed } \\
\end{array}$ & $\begin{array}{l}\text { Coarse } \\
\text { Skewed } \\
\end{array}$ \\
\hline & KURTOSIS: & Mesokurtic & Leptokurtic & Mesokurtic & Leptokurtic & Mesokurtic & Leptokurtic & Mesokurtic & Mesokurtic & Mesokurtic & Mesokurtic & Mesokurtic & Mesokurtic \\
\hline & \% GRAVEL: & $0.0 \%$ & $0.0 \%$ & $0.1 \%$ & $0.1 \%$ & $0.2 \%$ & $0.0 \%$ & $0.3 \%$ & $0.0 \%$ & $0.0 \%$ & $0.3 \%$ & $0.0 \%$ & $0.0 \%$ \\
\hline & \% SAND: & $98.2 \%$ & $100.0 \%$ & $99.9 \%$ & $99.9 \%$ & $99.8 \%$ & $100.0 \%$ & $99.7 \%$ & $100.0 \%$ & $100.0 \%$ & $99.6 \%$ & $99.7 \%$ & $99.7 \%$ \\
\hline & \% MUD: & $1.8 \%$ & $0.0 \%$ & $0.0 \%$ & $0.0 \%$ & $0.0 \%$ & $0.0 \%$ & $0.0 \%$ & $0.0 \%$ & $0.0 \%$ & $0.1 \%$ & $0.3 \%$ & $0.3 \%$ \\
\hline & \% V COARSE GRAVEL: & $0.0 \%$ & $0.0 \%$ & $0.0 \%$ & $0.0 \%$ & $0.0 \%$ & $0.0 \%$ & $0.0 \%$ & $0.0 \%$ & $0.0 \%$ & $0.0 \%$ & $0.0 \%$ & $0.0 \%$ \\
\hline & \% COARSE GRAVEL: & $0.0 \%$ & $0.0 \%$ & $0.0 \%$ & $0.0 \%$ & $0.0 \%$ & $0.0 \%$ & $0.0 \%$ & $0.0 \%$ & $0.0 \%$ & $0.0 \%$ & $0.0 \%$ & $0.0 \%$ \\
\hline & \% MEDIUM GRAVEL: & $0.0 \%$ & $0.0 \%$ & $0.0 \%$ & $0.0 \%$ & $0.0 \%$ & $0.0 \%$ & $0.0 \%$ & $0.0 \%$ & $0.0 \%$ & $0.0 \%$ & $0.0 \%$ & $0.0 \%$ \\
\hline & \% FINE GRAVEL: & $0.0 \%$ & $0.0 \%$ & $0.0 \%$ & $0.0 \%$ & $0.0 \%$ & $0.0 \%$ & $0.0 \%$ & $0.0 \%$ & $0.0 \%$ & $0.0 \%$ & $0.0 \%$ & $0.0 \%$ \\
\hline & $\%$ V FINE GRAVEL: & $0.0 \%$ & $0.0 \%$ & $0.1 \%$ & $0.1 \%$ & $0.2 \%$ & $0.0 \%$ & $0.3 \%$ & $0.0 \%$ & $0.0 \%$ & $0.3 \%$ & $0.0 \%$ & $0.0 \%$ \\
\hline & $\%$ V COARSE SAND: & $0.0 \%$ & $0.7 \%$ & $2.2 \%$ & $1.6 \%$ & $8.5 \%$ & $1.7 \%$ & $6.2 \%$ & $2.3 \%$ & $1.8 \%$ & $2.3 \%$ & $1.6 \%$ & $1.0 \%$ \\
\hline & \% COARSE SAND: & $5.0 \%$ & $4.9 \%$ & $11.3 \%$ & $7.5 \%$ & $25.3 \%$ & $8.0 \%$ & $25.0 \%$ & $17.6 \%$ & $14.2 \%$ & $13.0 \%$ & $10.0 \%$ & $8.5 \%$ \\
\hline & \% MEDIUM SAND: & $47.7 \%$ & $35.9 \%$ & $47.3 \%$ & $39.4 \%$ & $40.1 \%$ & $53.1 \%$ & $47.2 \%$ & $50.6 \%$ & $48.2 \%$ & $50.0 \%$ & $44.6 \%$ & $45.0 \%$ \\
\hline & $\%$ FINE SAND: & $44.0 \%$ & $57.8 \%$ & $38.9 \%$ & $50.7 \%$ & $25.0 \%$ & $37.1 \%$ & $21.2 \%$ & $28.7 \%$ & $34.5 \%$ & $33.4 \%$ & $42.0 \%$ & $43.9 \%$ \\
\hline & \% V FINE SAND: & $1.5 \%$ & $0.6 \%$ & $0.2 \%$ & $0.7 \%$ & $0.9 \%$ & $0.1 \%$ & $0.0 \%$ & $0.8 \%$ & $1.2 \%$ & $0.8 \%$ & $1.4 \%$ & $1.2 \%$ \\
\hline & \% V COARSE SILT: & $0.5 \%$ & $0.0 \%$ & $0.0 \%$ & $0.0 \%$ & $0.0 \%$ & $0.0 \%$ & $0.0 \%$ & $0.0 \%$ & $0.0 \%$ & $0.1 \%$ & $0.2 \%$ & $0.2 \%$ \\
\hline & \% COARSE SILT: & $0.4 \%$ & $0.0 \%$ & $0.0 \%$ & $0.0 \%$ & $0.0 \%$ & $0.0 \%$ & $0.0 \%$ & $0.0 \%$ & $0.0 \%$ & $0.0 \%$ & $0.1 \%$ & $0.1 \%$ \\
\hline & \% MEDIUM SILT: & $0.4 \%$ & $0.0 \%$ & $0.0 \%$ & $0.0 \%$ & $0.0 \%$ & $0.0 \%$ & $0.0 \%$ & $0.0 \%$ & $0.0 \%$ & $0.0 \%$ & $0.0 \%$ & $0.0 \%$ \\
\hline & \% FINE SILT: & $0.3 \%$ & $0.0 \%$ & $0.0 \%$ & $0.0 \%$ & $0.0 \%$ & $0.0 \%$ & $0.0 \%$ & $0.0 \%$ & $0.0 \%$ & $0.0 \%$ & $0.0 \%$ & $0.0 \%$ \\
\hline & \% V FINE SILT: & $0.2 \%$ & $0.0 \%$ & $0.0 \%$ & $0.0 \%$ & $0.0 \%$ & $0.0 \%$ & $0.0 \%$ & $0.0 \%$ & $0.0 \%$ & $0.0 \%$ & $0.0 \%$ & $0.0 \%$ \\
\hline & \% CLAY: & $0.1 \%$ & $0.0 \%$ & $0.0 \%$ & $0.0 \%$ & $0.0 \%$ & $0.0 \%$ & $0.0 \%$ & $0.0 \%$ & $0.0 \%$ & $0.0 \%$ & $0.0 \%$ & $0.0 \%$ \\
\hline
\end{tabular}


2010 Barrier Subsurface

\begin{tabular}{|c|c|c|c|c|c|c|c|c|c|c|c|c|c|}
\hline & & $\begin{array}{l}\text { WnW10- } \\
\text { t17_bb-f }\end{array}$ & $\begin{array}{l}\text { WnW10- } \\
\text { t17_bb-g }\end{array}$ & $\begin{array}{l}\text { WnW10- } \\
\text { t17_bb-h }\end{array}$ & $\begin{array}{l}\text { WnW10- } \\
\text { t17_bb-i }\end{array}$ & $\begin{array}{l}\text { WnW10- } \\
\text { t17_bb-a }\end{array}$ & $\begin{array}{l}\text { WnW10- } \\
\text { t17_bb-b }\end{array}$ & $\begin{array}{l}\text { WnW10- } \\
\text { t17_bb-c }\end{array}$ & $\begin{array}{l}\text { WnW10- } \\
\text { t17_bb-d }\end{array}$ & $\begin{array}{l}\text { WnW10- } \\
\text { t17_bb-e }\end{array}$ & $\begin{array}{l}\text { WnW10- } \\
\text { t17_bb-f }\end{array}$ & $\begin{array}{l}\text { WnW10- } \\
\text { t17_bb-g }\end{array}$ & $\begin{array}{l}\text { WnW10- } \\
\text { t17_bb-h }\end{array}$ \\
\hline & SAMPLE TYPE: & $\begin{array}{l}\text { Unimodal, } \\
\text { Moderately } \\
\text { Well Sorted }\end{array}$ & $\begin{array}{l}\text { Unimodal, } \\
\text { Moderately } \\
\text { Well Sorted }\end{array}$ & $\begin{array}{l}\text { Unimodal, } \\
\text { Well Sorted }\end{array}$ & $\begin{array}{l}\text { Unimodal, } \\
\text { Well Sorted }\end{array}$ & $\begin{array}{l}\text { Unimodal, } \\
\text { Moderately } \\
\text { Well Sorted }\end{array}$ & $\begin{array}{l}\text { Unimodal, } \\
\text { Moderately } \\
\text { Well Sorted }\end{array}$ & $\begin{array}{l}\text { Unimodal, } \\
\text { Moderately } \\
\text { Well Sorted }\end{array}$ & $\begin{array}{l}\text { Unimodal, } \\
\text { Moderately } \\
\text { Well Sorted }\end{array}$ & $\begin{array}{l}\text { Unimodal, } \\
\text { Moderately } \\
\text { Well Sorted }\end{array}$ & $\begin{array}{l}\text { Unimodal, } \\
\text { Moderately } \\
\text { Well Sorted }\end{array}$ & $\begin{array}{l}\text { Unimodal, } \\
\text { Moderately } \\
\text { Well Sorted }\end{array}$ & $\begin{array}{l}\text { Unimodal, } \\
\text { Well Sorted }\end{array}$ \\
\hline & TEXTURAL GROUP: & $\begin{array}{l}\text { Slightly } \\
\text { Gravelly } \\
\text { Sand }\end{array}$ & $\begin{array}{l}\text { Slightly } \\
\text { Gravelly } \\
\text { Sand }\end{array}$ & Sand & $\begin{array}{l}\text { Slightly } \\
\text { Gravelly } \\
\text { Sand }\end{array}$ & Sand & Sand & $\begin{array}{l}\text { Slightly } \\
\text { Gravelly } \\
\text { Sand }\end{array}$ & $\begin{array}{l}\text { Slightly } \\
\text { Gravelly } \\
\text { Sand }\end{array}$ & $\begin{array}{l}\text { Slightly } \\
\text { Gravelly } \\
\text { Sand }\end{array}$ & $\begin{array}{l}\text { Slightly } \\
\text { Gravelly } \\
\text { Sand }\end{array}$ & $\begin{array}{l}\text { Slightly } \\
\text { Gravelly } \\
\text { Sand }\end{array}$ & Sand \\
\hline & SEDIMENT NAME: & $\begin{array}{l}\text { Slightly Very } \\
\text { Fine } \\
\text { Gravelly } \\
\text { Medium } \\
\text { Sand } \\
\end{array}$ & $\begin{array}{l}\text { Slightly Very } \\
\text { Fine Gravelly } \\
\text { Medium } \\
\text { Sand }\end{array}$ & $\begin{array}{l}\text { Well Sorted } \\
\text { Medium } \\
\text { Sand }\end{array}$ & $\begin{array}{l}\text { Slightly Very } \\
\text { Fine Gravelly } \\
\text { Medium } \\
\text { Sand }\end{array}$ & $\begin{array}{l}\text { Moderately } \\
\text { Well Sorted } \\
\text { Medium } \\
\text { Sand }\end{array}$ & $\begin{array}{l}\text { Moderately } \\
\text { Well Sorted } \\
\text { Medium } \\
\text { Sand }\end{array}$ & $\begin{array}{l}\text { Slightly Very } \\
\text { Fine Gravelly } \\
\text { Medium } \\
\text { Sand }\end{array}$ & $\begin{array}{l}\text { Slightly Very } \\
\text { Fine Gravelly } \\
\text { Medium } \\
\text { Sand }\end{array}$ & $\begin{array}{l}\text { Slightly Very } \\
\text { Fine Gravelly } \\
\text { Medium } \\
\text { Sand }\end{array}$ & $\begin{array}{l}\text { Slightly Very } \\
\text { Fine Gravelly } \\
\text { Medium } \\
\text { Sand }\end{array}$ & $\begin{array}{l}\text { Slightly Very } \\
\text { Fine Gravelly } \\
\text { Medium } \\
\text { Sand }\end{array}$ & $\begin{array}{l}\text { Well Sorted } \\
\text { Medium } \\
\text { Sand }\end{array}$ \\
\hline \multirow{4}{*}{$\begin{array}{l}\text { FOLK AND } \\
\text { WARD } \\
\text { METHOD } \\
(\mathrm{mm})\end{array}$} & MEAN & 316.2 & 271.9 & 277.7 & 263.2 & 330.3 & 306.9 & 308.8 & 278.9 & 271.2 & 316.2 & 271.9 & 277.7 \\
\hline & SORTING & 1.578 & 1.445 & 1.361 & 1.374 & 1.605 & 1.594 & 1.581 & 1.563 & 1.518 & 1.578 & 1.445 & 1.361 \\
\hline & SKEWNESS & 0.211 & 0.213 & 0.12 & 0.145 & 0.164 & 0.188 & 0.2 & 0.198 & 0.174 & 0.211 & 0.213 & 0.12 \\
\hline & KURTOSIS & 1.087 & 1.172 & 1.049 & 1.12 & 0.987 & 1.016 & 1.061 & 1.096 & 1.075 & 1.087 & 1.172 & 1.049 \\
\hline \multirow{4}{*}{$\begin{array}{l}\text { FOLK AND } \\
\text { WARD } \\
\text { METHOD } \\
\text { (phi) }\end{array}$} & MEAN & 1.661 & 1.879 & 1.849 & 1.926 & 1.598 & 1.704 & 1.695 & 1.842 & 1.883 & 1.661 & 1.879 & 1.849 \\
\hline & SORTING & 0.658 & 0.531 & 0.445 & 0.458 & 0.683 & 0.673 & 0.661 & 0.644 & 0.602 & 0.658 & 0.531 & 0.445 \\
\hline & SKEWNESS & -0.211 & -0.213 & -0.12 & -0.145 & -0.164 & -0.188 & -0.2 & -0.198 & -0.174 & -0.211 & -0.213 & -0.12 \\
\hline & KURTOSIS & 1.087 & 1.172 & 1.049 & 1.12 & 0.987 & 1.016 & 1.061 & 1.096 & 1.075 & 1.087 & 1.172 & 1.049 \\
\hline \multirow{23}{*}{$\begin{array}{l}\text { FOLK AND } \\
\text { WARD } \\
\text { METHOD } \\
\text { (Description) }\end{array}$} & MEAN: & $\begin{array}{l}\text { Medium } \\
\text { Sand }\end{array}$ & $\begin{array}{l}\text { Medium } \\
\text { Sand }\end{array}$ & $\begin{array}{l}\text { Medium } \\
\text { Sand }\end{array}$ & $\begin{array}{l}\text { Medium } \\
\text { Sand }\end{array}$ & $\begin{array}{l}\text { Medium } \\
\text { Sand }\end{array}$ & $\begin{array}{l}\text { Medium } \\
\text { Sand }\end{array}$ & $\begin{array}{l}\text { Medium } \\
\text { Sand }\end{array}$ & $\begin{array}{l}\text { Medium } \\
\text { Sand }\end{array}$ & $\begin{array}{l}\text { Medium } \\
\text { Sand }\end{array}$ & $\begin{array}{l}\text { Medium } \\
\text { Sand }\end{array}$ & $\begin{array}{l}\text { Medium } \\
\text { Sand }\end{array}$ & $\begin{array}{l}\text { Medium } \\
\text { Sand }\end{array}$ \\
\hline & SORTING: & $\begin{array}{l}\text { Moderately } \\
\text { Well Sorted }\end{array}$ & $\begin{array}{l}\text { Moderately } \\
\text { Well Sorted }\end{array}$ & Well Sorted & Well Sorted & $\begin{array}{l}\text { Moderately } \\
\text { Well Sorted }\end{array}$ & $\begin{array}{l}\text { Moderately } \\
\text { Well Sorted }\end{array}$ & $\begin{array}{l}\text { Moderately } \\
\text { Well Sorted }\end{array}$ & $\begin{array}{l}\text { Moderately } \\
\text { Well Sorted }\end{array}$ & $\begin{array}{l}\text { Moderately } \\
\text { Well Sorted }\end{array}$ & $\begin{array}{l}\text { Moderately } \\
\text { Well Sorted }\end{array}$ & $\begin{array}{l}\text { Moderately } \\
\text { Well Sorted }\end{array}$ & Well Sorted \\
\hline & SKEWNESS: & $\begin{array}{l}\text { Coarse } \\
\text { Skewed }\end{array}$ & $\begin{array}{l}\text { Coarse } \\
\text { Skewed }\end{array}$ & $\begin{array}{l}\text { Coarse } \\
\text { Skewed }\end{array}$ & $\begin{array}{l}\text { Coarse } \\
\text { Skewed }\end{array}$ & $\begin{array}{l}\text { Coarse } \\
\text { Skewed }\end{array}$ & $\begin{array}{l}\text { Coarse } \\
\text { Skewed }\end{array}$ & $\begin{array}{l}\text { Coarse } \\
\text { Skewed }\end{array}$ & $\begin{array}{l}\text { Coarse } \\
\text { Skewed }\end{array}$ & $\begin{array}{l}\text { Coarse } \\
\text { Skewed }\end{array}$ & $\begin{array}{l}\text { Coarse } \\
\text { Skewed }\end{array}$ & $\begin{array}{l}\text { Coarse } \\
\text { Skewed }\end{array}$ & $\begin{array}{l}\text { Coarse } \\
\text { Skewed }\end{array}$ \\
\hline & KURTOSIS: & Mesokurtic & Leptokurtic & Mesokurtic & Leptokurtic & Mesokurtic & Mesokurtic & Mesokurtic & Mesokurtic & Mesokurtic & Mesokurtic & Leptokurtic & Mesokurtic \\
\hline & \% GRAVEL: & $0.1 \%$ & $0.1 \%$ & $0.0 \%$ & $0.0 \%$ & $0.0 \%$ & $0.0 \%$ & $0.3 \%$ & $0.0 \%$ & $0.0 \%$ & $0.1 \%$ & $0.1 \%$ & $0.0 \%$ \\
\hline & \% SAND: & $99.9 \%$ & $99.9 \%$ & $100.0 \%$ & $100.0 \%$ & $100.0 \%$ & $100.0 \%$ & $99.6 \%$ & $99.7 \%$ & $99.7 \%$ & $99.9 \%$ & $99.9 \%$ & $100.0 \%$ \\
\hline & \% MUD: & $0.0 \%$ & $0.0 \%$ & $0.0 \%$ & $0.0 \%$ & $0.0 \%$ & $0.0 \%$ & $0.1 \%$ & $0.3 \%$ & $0.3 \%$ & $0.0 \%$ & $0.0 \%$ & $0.0 \%$ \\
\hline & \% V COARSE GRAVEL: & $0.0 \%$ & $0.0 \%$ & $0.0 \%$ & $0.0 \%$ & $0.0 \%$ & $0.0 \%$ & $0.0 \%$ & $0.0 \%$ & $0.0 \%$ & $0.0 \%$ & $0.0 \%$ & $0.0 \%$ \\
\hline & \% COARSE GRAVEL: & $0.0 \%$ & $0.0 \%$ & $0.0 \%$ & $0.0 \%$ & $0.0 \%$ & $0.0 \%$ & $0.0 \%$ & $0.0 \%$ & $0.0 \%$ & $0.0 \%$ & $0.0 \%$ & $0.0 \%$ \\
\hline & \% MEDIUM GRAVEL: & $0.0 \%$ & $0.0 \%$ & $0.0 \%$ & $0.0 \%$ & $0.0 \%$ & $0.0 \%$ & $0.0 \%$ & $0.0 \%$ & $0.0 \%$ & $0.0 \%$ & $0.0 \%$ & $0.0 \%$ \\
\hline & \% FINE GRAVEL: & $0.0 \%$ & $0.0 \%$ & $0.0 \%$ & $0.0 \%$ & $0.0 \%$ & $0.0 \%$ & $0.0 \%$ & $0.0 \%$ & $0.0 \%$ & $0.0 \%$ & $0.0 \%$ & $0.0 \%$ \\
\hline & $\%$ V FINE GRAVEL: & $0.1 \%$ & $0.1 \%$ & $0.0 \%$ & $0.0 \%$ & $0.0 \%$ & $0.0 \%$ & $0.3 \%$ & $0.0 \%$ & $0.0 \%$ & $0.1 \%$ & $0.1 \%$ & $0.0 \%$ \\
\hline & \% V COARSE SAND: & $2.6 \%$ & $1.6 \%$ & $0.0 \%$ & $0.9 \%$ & $2.3 \%$ & $1.8 \%$ & $2.3 \%$ & $1.6 \%$ & $1.0 \%$ & $2.6 \%$ & $1.6 \%$ & $0.0 \%$ \\
\hline & \% COARSE SAND: & $13.6 \%$ & $6.6 \%$ & $5.0 \%$ & $4.1 \%$ & $17.6 \%$ & $14.2 \%$ & $13.0 \%$ & $10.0 \%$ & $8.5 \%$ & $13.6 \%$ & $6.6 \%$ & $5.0 \%$ \\
\hline & \% MEDIUM SAND: & $51.8 \%$ & $47.8 \%$ & $56.9 \%$ & $49.6 \%$ & $50.6 \%$ & $48.2 \%$ & $50.0 \%$ & $44.6 \%$ & $45.0 \%$ & $51.8 \%$ & $47.8 \%$ & $56.9 \%$ \\
\hline & \% FINE SAND: & $31.3 \%$ & $43.8 \%$ & $38.0 \%$ & $45.3 \%$ & $28.7 \%$ & $34.5 \%$ & $33.4 \%$ & $42.0 \%$ & $43.9 \%$ & $31.3 \%$ & $43.8 \%$ & $38.0 \%$ \\
\hline & \% V FINE SAND: & $0.5 \%$ & $0.1 \%$ & $0.0 \%$ & $0.0 \%$ & $0.8 \%$ & $1.2 \%$ & $0.8 \%$ & $1.4 \%$ & $1.2 \%$ & $0.5 \%$ & $0.1 \%$ & $0.0 \%$ \\
\hline & \% V COARSE SILT: & $0.0 \%$ & $0.0 \%$ & $0.0 \%$ & $0.0 \%$ & $0.0 \%$ & $0.0 \%$ & $0.1 \%$ & $0.2 \%$ & $0.2 \%$ & $0.0 \%$ & $0.0 \%$ & $0.0 \%$ \\
\hline & \% COARSE SILT: & $0.0 \%$ & $0.0 \%$ & $0.0 \%$ & $0.0 \%$ & $0.0 \%$ & $0.0 \%$ & $0.0 \%$ & $0.1 \%$ & $0.1 \%$ & $0.0 \%$ & $0.0 \%$ & $0.0 \%$ \\
\hline & \% MEDIUM SILT: & $0.0 \%$ & $0.0 \%$ & $0.0 \%$ & $0.0 \%$ & $0.0 \%$ & $0.0 \%$ & $0.0 \%$ & $0.0 \%$ & $0.0 \%$ & $0.0 \%$ & $0.0 \%$ & $0.0 \%$ \\
\hline & \% FINE SILT: & $0.0 \%$ & $0.0 \%$ & $0.0 \%$ & $0.0 \%$ & $0.0 \%$ & $0.0 \%$ & $0.0 \%$ & $0.0 \%$ & $0.0 \%$ & $0.0 \%$ & $0.0 \%$ & $0.0 \%$ \\
\hline & \% V FINE SILT: & $0.0 \%$ & $0.0 \%$ & $0.0 \%$ & $0.0 \%$ & $0.0 \%$ & $0.0 \%$ & $0.0 \%$ & $0.0 \%$ & $0.0 \%$ & $0.0 \%$ & $0.0 \%$ & $0.0 \%$ \\
\hline & \% CLAY: & $0.0 \%$ & $0.0 \%$ & $0.0 \%$ & $0.0 \%$ & $0.0 \%$ & $0.0 \%$ & $0.0 \%$ & $0.0 \%$ & $0.0 \%$ & $0.0 \%$ & $0.0 \%$ & $0.0 \%$ \\
\hline
\end{tabular}

Mulcahy, 2014; correspondence: nick.mulcahy@coastalresearch.org.nz 
2010 Barrier Subsurface

\begin{tabular}{|c|c|c|c|c|c|c|c|c|c|c|c|c|c|}
\hline & & $\begin{array}{l}\text { WnW10- } \\
\text { t17_bb-i }\end{array}$ & $\begin{array}{l}\text { WnW10- } \\
\text { t17_bd-a }\end{array}$ & $\begin{array}{l}\text { WnW10- } \\
\text { t17_bd-b }\end{array}$ & $\begin{array}{l}\text { WnW10- } \\
\text { t17_bd-c }\end{array}$ & $\begin{array}{l}\text { WnW10- } \\
\text { t17_bd-d }\end{array}$ & $\begin{array}{l}\text { WnW10- } \\
\text { t17_bd-e }\end{array}$ & $\begin{array}{l}\text { PntTnch10- } \\
\text { t3_bb-a }\end{array}$ & $\begin{array}{l}\text { PntTnch10- } \\
\text { t3_bb-b }\end{array}$ & $\begin{array}{l}\text { PntTnch10- } \\
\text { t3_bb-c }\end{array}$ & $\begin{array}{l}\text { PntTnch10- } \\
\text { t3_bb-d }\end{array}$ & $\begin{array}{l}\text { PntTnch10- } \\
\text { t3_fdf-a }\end{array}$ & $\begin{array}{l}\text { PntTnch10- } \\
\text { t3_fdf-b }\end{array}$ \\
\hline & SAMPLE TYPE: & $\begin{array}{l}\text { Unimodal, } \\
\text { Well Sorted }\end{array}$ & $\begin{array}{l}\text { Unimodal, } \\
\text { Moderately } \\
\text { Well Sorted }\end{array}$ & $\begin{array}{l}\text { Unimodal, } \\
\text { Moderately } \\
\text { Well Sorted }\end{array}$ & $\begin{array}{l}\text { Unimodal, } \\
\text { Moderately } \\
\text { Well Sorted }\end{array}$ & $\begin{array}{l}\text { Unimodal, } \\
\text { Moderately } \\
\text { Well Sorted }\end{array}$ & $\begin{array}{l}\text { Unimodal, } \\
\text { Moderately } \\
\text { Well Sorted }\end{array}$ & $\begin{array}{l}\text { Unimodal, } \\
\text { Moderately } \\
\text { Well Sorted }\end{array}$ & $\begin{array}{l}\text { Unimodal, } \\
\text { Moderately } \\
\text { Well Sorted }\end{array}$ & $\begin{array}{l}\text { Unimodal, } \\
\text { Moderately } \\
\text { Well Sorted }\end{array}$ & $\begin{array}{l}\text { Unimodal, } \\
\text { Moderately } \\
\text { Well Sorted }\end{array}$ & $\begin{array}{l}\text { Bimodal, } \\
\text { Moderately } \\
\text { Sorted }\end{array}$ & $\begin{array}{l}\text { Unimodal, } \\
\text { Moderately } \\
\text { Well Sorted }\end{array}$ \\
\hline & TEXTURAL GROUP: & $\begin{array}{l}\text { Slightly } \\
\text { Gravelly } \\
\text { Sand } \\
\end{array}$ & Sand & Sand & Sand & Sand & Sand & Sand & Sand & Sand & Sand & $\begin{array}{l}\text { Slightly } \\
\text { Gravelly } \\
\text { Sand } \\
\end{array}$ & Sand \\
\hline & SEDIMENT NAME: & $\begin{array}{l}\text { Slightly Very } \\
\text { Fine } \\
\text { Gravelly } \\
\text { Medium } \\
\text { Sand } \\
\end{array}$ & $\begin{array}{l}\text { Moderately } \\
\text { Well Sorted } \\
\text { Medium } \\
\text { Sand }\end{array}$ & $\begin{array}{l}\text { Moderately } \\
\text { Well Sorted } \\
\text { Medium } \\
\text { Sand }\end{array}$ & $\begin{array}{l}\text { Moderately } \\
\text { Well Sorted } \\
\text { Medium } \\
\text { Sand }\end{array}$ & $\begin{array}{l}\text { Moderately } \\
\text { Well Sorted } \\
\text { Medium } \\
\text { Sand }\end{array}$ & $\begin{array}{l}\text { Moderately } \\
\text { Well Sorted } \\
\text { Medium } \\
\text { Sand }\end{array}$ & $\begin{array}{l}\text { Moderately } \\
\text { Well Sorted } \\
\text { Medium } \\
\text { Sand }\end{array}$ & $\begin{array}{l}\text { Moderately } \\
\text { Well Sorted } \\
\text { Medium } \\
\text { Sand }\end{array}$ & $\begin{array}{l}\text { Moderately } \\
\text { Well Sorted } \\
\text { Medium } \\
\text { Sand }\end{array}$ & $\begin{array}{l}\text { Moderately } \\
\text { Well Sorted } \\
\text { Medium } \\
\text { Sand }\end{array}$ & $\begin{array}{l}\text { Slightly Very } \\
\text { Fine Gravelly } \\
\text { Coarse Sand }\end{array}$ & $\begin{array}{l}\text { Moderately } \\
\text { Well Sorted } \\
\text { Medium } \\
\text { Sand }\end{array}$ \\
\hline \multirow{4}{*}{$\begin{array}{l}\text { FOLK AND } \\
\text { WARD } \\
\text { METHOD } \\
(\mathrm{mm})\end{array}$} & MEAN & 263.2 & 299.7 & 303.7 & 314.4 & 324.6 & 317.2 & 281.4 & 302.2 & 318.2 & 332.8 & 487.4 & 283.4 \\
\hline & SORTING & 1.374 & 1.547 & 1.485 & 1.534 & 1.587 & 1.581 & 1.511 & 1.48 & 1.494 & 1.518 & 1.851 & 1.534 \\
\hline & SKEWNESS & 0.145 & 0.106 & 0.121 & 0.107 & 0.101 & -0.111 & 0.156 & 0.138 & 0.122 & 0.078 & -0.063 & 0.179 \\
\hline & KURTOSIS & 1.12 & 1.099 & 1.049 & 1.037 & 1.021 & 1.263 & 0.985 & 0.961 & 0.94 & 0.934 & 0.872 & 1 \\
\hline \multirow{4}{*}{$\begin{array}{l}\text { FOLK AND } \\
\text { WARD } \\
\text { METHOD } \\
\text { (phi) }\end{array}$} & MEAN & 1.926 & 1.738 & 1.719 & 1.669 & 1.623 & 1.657 & 1.829 & 1.727 & 1.652 & 1.587 & 1.037 & 1.819 \\
\hline & SORTING & 0.458 & 0.629 & 0.571 & 0.618 & 0.666 & 0.661 & 0.595 & 0.566 & 0.579 & 0.603 & 0.888 & 0.618 \\
\hline & SKEWNESS & -0.145 & -0.106 & -0.121 & -0.107 & -0.101 & 0.111 & -0.156 & -0.138 & -0.122 & -0.078 & 0.063 & -0.179 \\
\hline & KURTOSIS & 1.12 & 1.099 & 1.049 & 1.037 & 1.021 & 1.263 & 0.985 & 0.961 & 0.94 & 0.934 & 0.872 & 1 \\
\hline \multirow{23}{*}{$\begin{array}{l}\text { FOLK AND } \\
\text { WARD } \\
\text { METHOD } \\
\text { (Description) }\end{array}$} & MEAN: & $\begin{array}{l}\text { Medium } \\
\text { Sand }\end{array}$ & $\begin{array}{l}\text { Medium } \\
\text { Sand }\end{array}$ & $\begin{array}{l}\text { Medium } \\
\text { Sand }\end{array}$ & $\begin{array}{l}\text { Medium } \\
\text { Sand }\end{array}$ & $\begin{array}{l}\text { Medium } \\
\text { Sand }\end{array}$ & $\begin{array}{l}\text { Medium } \\
\text { Sand }\end{array}$ & $\begin{array}{l}\text { Medium } \\
\text { Sand }\end{array}$ & $\begin{array}{l}\text { Medium } \\
\text { Sand }\end{array}$ & $\begin{array}{l}\text { Medium } \\
\text { Sand }\end{array}$ & $\begin{array}{l}\text { Medium } \\
\text { Sand }\end{array}$ & $\begin{array}{l}\text { Medium } \\
\text { Sand }\end{array}$ & $\begin{array}{l}\text { Medium } \\
\text { Sand }\end{array}$ \\
\hline & SORTING: & Well Sorted & $\begin{array}{l}\text { Moderately } \\
\text { Well Sorted }\end{array}$ & $\begin{array}{l}\text { Moderately } \\
\text { Well Sorted }\end{array}$ & $\begin{array}{l}\text { Moderately } \\
\text { Well Sorted }\end{array}$ & $\begin{array}{l}\text { Moderately } \\
\text { Well Sorted }\end{array}$ & $\begin{array}{l}\text { Moderately } \\
\text { Well Sorted }\end{array}$ & $\begin{array}{l}\text { Moderately } \\
\text { Well Sorted }\end{array}$ & $\begin{array}{l}\text { Moderately } \\
\text { Well Sorted }\end{array}$ & $\begin{array}{l}\text { Moderately } \\
\text { Well Sorted }\end{array}$ & $\begin{array}{l}\text { Moderately } \\
\text { Well Sorted }\end{array}$ & $\begin{array}{l}\text { Moderately } \\
\text { Sorted }\end{array}$ & $\begin{array}{l}\text { Moderately } \\
\text { Well Sorted }\end{array}$ \\
\hline & SKEWNESS: & $\begin{array}{l}\text { Coarse } \\
\text { Skewed }\end{array}$ & $\begin{array}{l}\text { Coarse } \\
\text { Skewed }\end{array}$ & $\begin{array}{l}\text { Coarse } \\
\text { Skewed }\end{array}$ & $\begin{array}{l}\text { Coarse } \\
\text { Skewed }\end{array}$ & $\begin{array}{l}\text { Coarse } \\
\text { Skewed }\end{array}$ & Fine Skewed & $\begin{array}{l}\text { Coarse } \\
\text { Skewed }\end{array}$ & $\begin{array}{l}\text { Coarse } \\
\text { Skewed }\end{array}$ & $\begin{array}{l}\text { Coarse } \\
\text { Skewed }\end{array}$ & Symmetrical & Symmetrical & $\begin{array}{l}\text { Coarse } \\
\text { Skewed }\end{array}$ \\
\hline & KURTOSIS: & Leptokurtic & Mesokurtic & Mesokurtic & Mesokurtic & Mesokurtic & Leptokurtic & Mesokurtic & Mesokurtic & Mesokurtic & Mesokurtic & Platykurtic & Mesokurtic \\
\hline & \% GRAVEL: & $0.0 \%$ & $0.0 \%$ & $0.0 \%$ & $0.0 \%$ & $0.0 \%$ & $0.0 \%$ & $0.0 \%$ & $0.0 \%$ & $0.0 \%$ & $0.0 \%$ & $0.2 \%$ & $0.0 \%$ \\
\hline & \% SAND: & $100.0 \%$ & $98.3 \%$ & $98.9 \%$ & $98.5 \%$ & $98.4 \%$ & $96.3 \%$ & $99.9 \%$ & $100.0 \%$ & $100.0 \%$ & $100.0 \%$ & $99.8 \%$ & $100.0 \%$ \\
\hline & \% MUD: & $0.0 \%$ & $1.7 \%$ & $1.1 \%$ & $1.5 \%$ & $1.6 \%$ & $3.7 \%$ & $0.1 \%$ & $0.0 \%$ & $0.0 \%$ & $0.0 \%$ & $0.0 \%$ & $0.0 \%$ \\
\hline & \% V COARSE GRAVEL: & $0.0 \%$ & $0.0 \%$ & $0.0 \%$ & $0.0 \%$ & $0.0 \%$ & $0.0 \%$ & $0.0 \%$ & $0.0 \%$ & $0.0 \%$ & $0.0 \%$ & $0.0 \%$ & $0.0 \%$ \\
\hline & \% COARSE GRAVEL: & $0.0 \%$ & $0.0 \%$ & $0.0 \%$ & $0.0 \%$ & $0.0 \%$ & $0.0 \%$ & $0.0 \%$ & $0.0 \%$ & $0.0 \%$ & $0.0 \%$ & $0.0 \%$ & $0.0 \%$ \\
\hline & \% MEDIUM GRAVEL: & $0.0 \%$ & $0.0 \%$ & $0.0 \%$ & $0.0 \%$ & $0.0 \%$ & $0.0 \%$ & $0.0 \%$ & $0.0 \%$ & $0.0 \%$ & $0.0 \%$ & $0.0 \%$ & $0.0 \%$ \\
\hline & \% FINE GRAVEL: & $0.0 \%$ & $0.0 \%$ & $0.0 \%$ & $0.0 \%$ & $0.0 \%$ & $0.0 \%$ & $0.0 \%$ & $0.0 \%$ & $0.0 \%$ & $0.0 \%$ & $0.0 \%$ & $0.0 \%$ \\
\hline & \% V FINE GRAVEL: & $0.0 \%$ & $0.0 \%$ & $0.0 \%$ & $0.0 \%$ & $0.0 \%$ & $0.0 \%$ & $0.0 \%$ & $0.0 \%$ & $0.0 \%$ & $0.0 \%$ & $0.2 \%$ & $0.0 \%$ \\
\hline & \% V COARSE SAND: & $0.9 \%$ & $1.4 \%$ & $0.8 \%$ & $1.3 \%$ & $1.9 \%$ & $1.9 \%$ & $0.9 \%$ & $0.9 \%$ & $1.2 \%$ & $1.3 \%$ & $12.1 \%$ & $1.5 \%$ \\
\hline & \% COARSE SAND: & $4.1 \%$ & $11.3 \%$ & $11.0 \%$ & $13.4 \%$ & $15.9 \%$ & $11.0 \%$ & $9.3 \%$ & $10.8 \%$ & $13.3 \%$ & $16.2 \%$ & $38.3 \%$ & $10.0 \%$ \\
\hline & \% MEDIUM SAND: & $49.6 \%$ & $52.5 \%$ & $56.1 \%$ & $54.8 \%$ & $52.7 \%$ & $59.7 \%$ & $47.5 \%$ & $54.4 \%$ & $56.1 \%$ & $56.3 \%$ & $33.5 \%$ & $46.4 \%$ \\
\hline & \% FINE SAND: & $45.3 \%$ & $31.4 \%$ & $30.4 \%$ & $28.0 \%$ & $26.9 \%$ & $22.2 \%$ & $41.2 \%$ & $33.7 \%$ & $29.2 \%$ & $25.9 \%$ & $15.7 \%$ & $41.6 \%$ \\
\hline & \% V FINE SAND: & $0.0 \%$ & $1.7 \%$ & $0.7 \%$ & $1.0 \%$ & $1.0 \%$ & $1.6 \%$ & $1.0 \%$ & $0.2 \%$ & $0.1 \%$ & $0.1 \%$ & $0.2 \%$ & $0.5 \%$ \\
\hline & $\%$ V COARSE SILT: & $0.0 \%$ & $0.7 \%$ & $0.4 \%$ & $0.5 \%$ & $0.4 \%$ & $0.9 \%$ & $0.1 \%$ & $0.0 \%$ & $0.0 \%$ & $0.0 \%$ & $0.0 \%$ & $0.0 \%$ \\
\hline & \% COARSE SILT: & $0.0 \%$ & $0.3 \%$ & $0.2 \%$ & $0.3 \%$ & $0.3 \%$ & $0.7 \%$ & $0.0 \%$ & $0.0 \%$ & $0.0 \%$ & $0.0 \%$ & $0.0 \%$ & $0.0 \%$ \\
\hline & \% MEDIUM SILT: & $0.0 \%$ & $0.3 \%$ & $0.2 \%$ & $0.3 \%$ & $0.3 \%$ & $0.7 \%$ & $0.0 \%$ & $0.0 \%$ & $0.0 \%$ & $0.0 \%$ & $0.0 \%$ & $0.0 \%$ \\
\hline & \% FINE SILT: & $0.0 \%$ & $0.2 \%$ & $0.1 \%$ & $0.2 \%$ & $0.2 \%$ & $0.6 \%$ & $0.0 \%$ & $0.0 \%$ & $0.0 \%$ & $0.0 \%$ & $0.0 \%$ & $0.0 \%$ \\
\hline & \% V FINE SILT: & $0.0 \%$ & $0.1 \%$ & $0.1 \%$ & $0.2 \%$ & $0.2 \%$ & $0.5 \%$ & $0.0 \%$ & $0.0 \%$ & $0.0 \%$ & $0.0 \%$ & $0.0 \%$ & $0.0 \%$ \\
\hline & \% CLAY: & $0.0 \%$ & $0.0 \%$ & $0.0 \%$ & $0.1 \%$ & $0.1 \%$ & $0.3 \%$ & $0.0 \%$ & $0.0 \%$ & $0.0 \%$ & $0.0 \%$ & $0.0 \%$ & $0.0 \%$ \\
\hline
\end{tabular}

Mulcahy, 2014; correspondence: nick.mulcahy@coastalresearch.org.nz 
2010 Barrier Subsurface

\begin{tabular}{|c|c|c|c|c|c|c|c|c|c|c|c|c|c|}
\hline & & $\begin{array}{l}\text { PntTnch10- } \\
\text { t3_fdf-c }\end{array}$ & $\begin{array}{l}\text { PntTnch10- } \\
\text { t3_fdf-d }\end{array}$ & $\begin{array}{l}\text { PntTnch10- } \\
\text { t3_fdf-e }\end{array}$ & $\begin{array}{l}\text { PntTnch10- } \\
\text { t3_fdf-f }\end{array}$ & $\begin{array}{l}\text { PntTnch10- } \\
\text { t3_bd-a }\end{array}$ & $\begin{array}{l}\text { PntTnch10- } \\
\text { t3_bd-b }\end{array}$ & $\begin{array}{l}\text { PntTnch10- } \\
\text { t3_bd-c }\end{array}$ & $\begin{array}{l}\text { PntTnch10- } \\
\text { t3_bd-d }\end{array}$ & $\begin{array}{l}\text { PntTnch10- } \\
\text { t3_bd-e }\end{array}$ & $\begin{array}{l}\text { PntTnch10- } \\
\text { t5_bb-a }\end{array}$ & $\begin{array}{l}\text { PntTnch10- } \\
\text { t5_bb-b }\end{array}$ & $\begin{array}{l}\text { PntTnch10- } \\
\text { t5_bb-c }\end{array}$ \\
\hline & SAMPLE TYPE: & $\begin{array}{l}\text { Unimodal, } \\
\text { Moderately } \\
\text { Well Sorted }\end{array}$ & $\begin{array}{l}\text { Unimodal, } \\
\text { Moderately } \\
\text { Well Sorted }\end{array}$ & $\begin{array}{l}\text { Unimodal, } \\
\text { Moderately } \\
\text { Well Sorted }\end{array}$ & $\begin{array}{l}\text { Unimodal, } \\
\text { Moderately } \\
\text { Well Sorted }\end{array}$ & $\begin{array}{l}\text { Unimodal, } \\
\text { Moderately } \\
\text { Well Sorted }\end{array}$ & $\begin{array}{l}\text { Unimodal, } \\
\text { Moderately } \\
\text { Well Sorted }\end{array}$ & $\begin{array}{l}\text { Unimodal, } \\
\text { Moderately } \\
\text { Well Sorted }\end{array}$ & $\begin{array}{l}\text { Unimodal, } \\
\text { Moderately } \\
\text { Well Sorted }\end{array}$ & $\begin{array}{l}\text { Unimodal, } \\
\text { Moderately } \\
\text { Well Sorted }\end{array}$ & $\begin{array}{l}\text { Polymodal, } \\
\text { Moderately } \\
\text { Sorted }\end{array}$ & $\begin{array}{l}\text { Unimodal, } \\
\text { Moderately } \\
\text { Well Sorted }\end{array}$ & $\begin{array}{l}\text { Unimodal, } \\
\text { Moderately } \\
\text { Well Sorted }\end{array}$ \\
\hline & TEXTURAL GROUP: & Sand & Sand & Sand & Sand & Sand & Sand & Sand & Sand & Sand & Sand & Sand & Sand \\
\hline & SEDIMENT NAME: & $\begin{array}{l}\text { Moderately } \\
\text { Well Sorted } \\
\text { Medium } \\
\text { Sand }\end{array}$ & $\begin{array}{l}\text { Moderately } \\
\text { Well Sorted } \\
\text { Medium } \\
\text { Sand }\end{array}$ & $\begin{array}{l}\text { Moderately } \\
\text { Well Sorted } \\
\text { Fine Sand }\end{array}$ & $\begin{array}{l}\text { Moderately } \\
\text { Well Sorted } \\
\text { Fine Sand }\end{array}$ & $\begin{array}{l}\text { Moderately } \\
\text { Well Sorted } \\
\text { Fine Sand }\end{array}$ & $\begin{array}{l}\text { Moderately } \\
\text { Well Sorted } \\
\text { Fine Sand }\end{array}$ & $\begin{array}{l}\text { Moderately } \\
\text { Well Sorted } \\
\text { Fine Sand }\end{array}$ & $\begin{array}{l}\text { Moderately } \\
\text { Well Sorted } \\
\text { Medium } \\
\text { Sand }\end{array}$ & $\begin{array}{l}\text { Moderately } \\
\text { Well Sorted } \\
\text { Medium } \\
\text { Sand }\end{array}$ & $\begin{array}{l}\text { Moderately } \\
\text { Sorted } \\
\text { Coarse Sand }\end{array}$ & $\begin{array}{l}\text { Moderately } \\
\text { Well Sorted } \\
\text { Medium } \\
\text { Sand }\end{array}$ & $\begin{array}{l}\text { Moderately } \\
\text { Well Sorted } \\
\text { Medium } \\
\text { Sand }\end{array}$ \\
\hline \multirow{4}{*}{$\begin{array}{l}\text { FOLK AND } \\
\text { WARD } \\
\text { METHOD } \\
(\mathrm{mm})\end{array}$} & MEAN & 291.7 & 315.8 & 236.3 & 266.7 & 247.6 & 244.7 & 261.8 & 271.4 & 279.9 & 436.9 & 284.1 & 327.5 \\
\hline & SORTING & 1.522 & 1.609 & 1.499 & 1.533 & 1.427 & 1.427 & 1.477 & 1.485 & 1.53 & 1.838 & 1.504 & 1.552 \\
\hline & SKEWNESS & 0.199 & 0.16 & 0.241 & 0.28 & 0.153 & 0.166 & 0.174 & 0.149 & 0.16 & -0.096 & 0.141 & 0.064 \\
\hline & KURTOSIS & 0.97 & 0.902 & 1.216 & 1.159 & 1.096 & 1.087 & 1.044 & 1.005 & 0.987 & 0.924 & 0.952 & 0.916 \\
\hline \multirow{4}{*}{$\begin{array}{l}\text { FOLK AND } \\
\text { WARD } \\
\text { METHOD } \\
\text { (phi) }\end{array}$} & MEAN & 1.777 & 1.663 & 2.081 & 1.907 & 2.014 & 2.031 & 1.933 & 1.881 & 1.837 & 1.195 & 1.815 & 1.61 \\
\hline & SORTING & 0.606 & 0.686 & 0.584 & 0.616 & 0.513 & 0.513 & 0.563 & 0.571 & 0.614 & 0.878 & 0.588 & 0.634 \\
\hline & SKEWNESS & -0.199 & -0.16 & -0.241 & -0.28 & -0.153 & -0.166 & -0.174 & -0.149 & -0.16 & 0.096 & -0.141 & -0.064 \\
\hline & KURTOSIS & 0.97 & 0.902 & 1.216 & 1.159 & 1.096 & 1.087 & 1.044 & 1.005 & 0.987 & 0.924 & 0.952 & 0.916 \\
\hline \multirow{23}{*}{$\begin{array}{l}\text { FOLK AND } \\
\text { WARD } \\
\text { METHOD } \\
\text { (Description) }\end{array}$} & MEAN: & $\begin{array}{l}\text { Medium } \\
\text { Sand }\end{array}$ & $\begin{array}{l}\text { Medium } \\
\text { Sand }\end{array}$ & Fine Sand & $\begin{array}{l}\text { Medium } \\
\text { Sand }\end{array}$ & Fine Sand & Fine Sand & $\begin{array}{l}\text { Medium } \\
\text { Sand }\end{array}$ & $\begin{array}{l}\text { Medium } \\
\text { Sand }\end{array}$ & $\begin{array}{l}\text { Medium } \\
\text { Sand }\end{array}$ & $\begin{array}{l}\text { Medium } \\
\text { Sand }\end{array}$ & $\begin{array}{l}\text { Medium } \\
\text { Sand }\end{array}$ & $\begin{array}{l}\text { Medium } \\
\text { Sand }\end{array}$ \\
\hline & SORTING: & $\begin{array}{l}\text { Moderately } \\
\text { Well Sorted }\end{array}$ & $\begin{array}{l}\text { Moderately } \\
\text { Well Sorted }\end{array}$ & $\begin{array}{l}\text { Moderately } \\
\text { Well Sorted }\end{array}$ & $\begin{array}{l}\text { Moderately } \\
\text { Well Sorted }\end{array}$ & $\begin{array}{l}\text { Moderately } \\
\text { Well Sorted }\end{array}$ & $\begin{array}{l}\text { Moderately } \\
\text { Well Sorted }\end{array}$ & $\begin{array}{l}\text { Moderately } \\
\text { Well Sorted }\end{array}$ & $\begin{array}{l}\text { Moderately } \\
\text { Well Sorted }\end{array}$ & $\begin{array}{l}\text { Moderately } \\
\text { Well Sorted }\end{array}$ & $\begin{array}{l}\text { Moderately } \\
\text { Sorted }\end{array}$ & $\begin{array}{l}\text { Moderately } \\
\text { Well Sorted }\end{array}$ & $\begin{array}{l}\text { Moderately } \\
\text { Well Sorted }\end{array}$ \\
\hline & SKEWNESS: & $\begin{array}{l}\text { Coarse } \\
\text { Skewed }\end{array}$ & $\begin{array}{l}\text { Coarse } \\
\text { Skewed }\end{array}$ & $\begin{array}{l}\text { Coarse } \\
\text { Skewed }\end{array}$ & $\begin{array}{l}\text { Coarse } \\
\text { Skewed }\end{array}$ & $\begin{array}{l}\text { Coarse } \\
\text { Skewed }\end{array}$ & $\begin{array}{l}\text { Coarse } \\
\text { Skewed }\end{array}$ & $\begin{array}{l}\text { Coarse } \\
\text { Skewed }\end{array}$ & $\begin{array}{l}\text { Coarse } \\
\text { Skewed }\end{array}$ & $\begin{array}{l}\text { Coarse } \\
\text { Skewed }\end{array}$ & Symmetrical & $\begin{array}{l}\text { Coarse } \\
\text { Skewed }\end{array}$ & Symmetrical \\
\hline & KURTOSIS: & Mesokurtic & Mesokurtic & Leptokurtic & Leptokurtic & Mesokurtic & Mesokurtic & Mesokurtic & Mesokurtic & Mesokurtic & Mesokurtic & Mesokurtic & Mesokurtic \\
\hline & \% GRAVEL: & $0.0 \%$ & $0.0 \%$ & $0.0 \%$ & $0.0 \%$ & $0.0 \%$ & $0.0 \%$ & $0.0 \%$ & $0.0 \%$ & $0.0 \%$ & $0.0 \%$ & $0.0 \%$ & $0.0 \%$ \\
\hline & \% SAND: & $100.0 \%$ & $100.0 \%$ & $100.0 \%$ & $100.0 \%$ & $100.0 \%$ & $100.0 \%$ & $100.0 \%$ & $100.0 \%$ & $100.0 \%$ & $100.0 \%$ & $100.0 \%$ & $100.0 \%$ \\
\hline & \% MUD: & $0.0 \%$ & $0.0 \%$ & $0.0 \%$ & $0.0 \%$ & $0.0 \%$ & $0.0 \%$ & $0.0 \%$ & $0.0 \%$ & $0.0 \%$ & $0.0 \%$ & $0.0 \%$ & $0.0 \%$ \\
\hline & $\%$ V COARSE GRAVEL: & $0.0 \%$ & $0.0 \%$ & $0.0 \%$ & $0.0 \%$ & $0.0 \%$ & $0.0 \%$ & $0.0 \%$ & $0.0 \%$ & $0.0 \%$ & $0.0 \%$ & $0.0 \%$ & $0.0 \%$ \\
\hline & \% COARSE GRAVEL: & $0.0 \%$ & $0.0 \%$ & $0.0 \%$ & $0.0 \%$ & $0.0 \%$ & $0.0 \%$ & $0.0 \%$ & $0.0 \%$ & $0.0 \%$ & $0.0 \%$ & $0.0 \%$ & $0.0 \%$ \\
\hline & \% MEDIUM GRAVEL: & $0.0 \%$ & $0.0 \%$ & $0.0 \%$ & $0.0 \%$ & $0.0 \%$ & $0.0 \%$ & $0.0 \%$ & $0.0 \%$ & $0.0 \%$ & $0.0 \%$ & $0.0 \%$ & $0.0 \%$ \\
\hline & \% FINE GRAVEL: & $0.0 \%$ & $0.0 \%$ & $0.0 \%$ & $0.0 \%$ & $0.0 \%$ & $0.0 \%$ & $0.0 \%$ & $0.0 \%$ & $0.0 \%$ & $0.0 \%$ & $0.0 \%$ & $0.0 \%$ \\
\hline & \% V FINE GRAVEL: & $0.0 \%$ & $0.0 \%$ & $0.0 \%$ & $0.0 \%$ & $0.0 \%$ & $0.0 \%$ & $0.0 \%$ & $0.0 \%$ & $0.0 \%$ & $0.0 \%$ & $0.0 \%$ & $0.0 \%$ \\
\hline & \% V COARSE SAND: & $1.4 \%$ & $1.5 \%$ & $1.5 \%$ & $2.1 \%$ & $0.7 \%$ & $0.4 \%$ & $0.8 \%$ & $0.7 \%$ & $0.6 \%$ & $8.2 \%$ & $0.8 \%$ & $0.0 \%$ \\
\hline & \% COARSE SAND: & $10.9 \%$ & $17.2 \%$ & $6.1 \%$ & $8.6 \%$ & $4.4 \%$ & $4.4 \%$ & $6.6 \%$ & $7.5 \%$ & $10.1 \%$ & $36.5 \%$ & $9.3 \%$ & $18.1 \%$ \\
\hline & \% MEDIUM SAND: & $48.0 \%$ & $46.6 \%$ & $31.9 \%$ & $39.6 \%$ & $41.0 \%$ & $39.5 \%$ & $43.7 \%$ & $46.9 \%$ & $46.3 \%$ & $35.1 \%$ & $48.9 \%$ & $53.0 \%$ \\
\hline & \% FINE SAND: & $39.4 \%$ & $34.2 \%$ & $59.0 \%$ & $49.4 \%$ & $53.2 \%$ & $54.9 \%$ & $48.3 \%$ & $44.3 \%$ & $42.2 \%$ & $19.5 \%$ & $40.6 \%$ & $28.5 \%$ \\
\hline & \% V FINE SAND: & $0.3 \%$ & $0.4 \%$ & $1.6 \%$ & $0.3 \%$ & $0.7 \%$ & $0.7 \%$ & $0.6 \%$ & $0.5 \%$ & $0.7 \%$ & $0.8 \%$ & $0.5 \%$ & $0.4 \%$ \\
\hline & \% V COARSE SILT: & $0.0 \%$ & $0.0 \%$ & $0.0 \%$ & $0.0 \%$ & $0.0 \%$ & $0.0 \%$ & $0.0 \%$ & $0.0 \%$ & $0.0 \%$ & $0.0 \%$ & $0.0 \%$ & $0.0 \%$ \\
\hline & \% COARSE SILT: & $0.0 \%$ & $0.0 \%$ & $0.0 \%$ & $0.0 \%$ & $0.0 \%$ & $0.0 \%$ & $0.0 \%$ & $0.0 \%$ & $0.0 \%$ & $0.0 \%$ & $0.0 \%$ & $0.0 \%$ \\
\hline & \% MEDIUM SILT: & $0.0 \%$ & $0.0 \%$ & $0.0 \%$ & $0.0 \%$ & $0.0 \%$ & $0.0 \%$ & $0.0 \%$ & $0.0 \%$ & $0.0 \%$ & $0.0 \%$ & $0.0 \%$ & $0.0 \%$ \\
\hline & \% FINE SILT: & $0.0 \%$ & $0.0 \%$ & $0.0 \%$ & $0.0 \%$ & $0.0 \%$ & $0.0 \%$ & $0.0 \%$ & $0.0 \%$ & $0.0 \%$ & $0.0 \%$ & $0.0 \%$ & $0.0 \%$ \\
\hline & \% V FINE SILT: & $0.0 \%$ & $0.0 \%$ & $0.0 \%$ & $0.0 \%$ & $0.0 \%$ & $0.0 \%$ & $0.0 \%$ & $0.0 \%$ & $0.0 \%$ & $0.0 \%$ & $0.0 \%$ & $0.0 \%$ \\
\hline & \% CLAY: & $0.0 \%$ & $0.0 \%$ & $0.0 \%$ & $0.0 \%$ & $0.0 \%$ & $0.0 \%$ & $0.0 \%$ & $0.0 \%$ & $0.0 \%$ & $0.0 \%$ & $0.0 \%$ & $0.0 \%$ \\
\hline
\end{tabular}


2010 Barrier Subsurface

\begin{tabular}{|c|c|c|c|c|c|c|c|c|c|c|c|c|c|}
\hline & & $\begin{array}{l}\text { PntTnch10- } \\
\text { t5_bb-d }\end{array}$ & $\begin{array}{l}\text { PntTnch10- } \\
\text { t5_fdf-a }\end{array}$ & $\begin{array}{l}\text { PntTnch10- } \\
\text { t5_fdf-b }\end{array}$ & $\begin{array}{l}\text { PntTnch10- } \\
\text { t5_fdf-c }\end{array}$ & $\begin{array}{l}\text { PntTnch10- } \\
\text { t5_fdf-d }\end{array}$ & $\begin{array}{l}\text { PntTnch10- } \\
\text { t5_fdf-e }\end{array}$ & $\begin{array}{l}\text { PntTnch10- } \\
\text { t5_bd-a }\end{array}$ & $\begin{array}{l}\text { PntTnch10- } \\
\text { t5_bd-b }\end{array}$ & $\begin{array}{l}\text { PntTnch10- } \\
\text { t5_bd-c }\end{array}$ & $\begin{array}{l}\text { PntTnch10- } \\
\text { t5_bd-d }\end{array}$ & $\begin{array}{l}\text { PntTnch10- } \\
\text { t15_bb-a }\end{array}$ & $\begin{array}{l}\text { PntTnch10- } \\
\text { t15_bb-b }\end{array}$ \\
\hline & SAMPLE TYPE: & $\begin{array}{l}\text { Unimodal, } \\
\text { Moderately } \\
\text { Well Sorted }\end{array}$ & $\begin{array}{l}\text { Polymodal, } \\
\text { Moderately } \\
\text { Sorted }\end{array}$ & $\begin{array}{l}\text { Unimodal, } \\
\text { Moderately } \\
\text { Well Sorted }\end{array}$ & $\begin{array}{l}\text { Unimodal, } \\
\text { Moderately } \\
\text { Well Sorted }\end{array}$ & $\begin{array}{l}\text { Unimodal, } \\
\text { Moderately } \\
\text { Well Sorted }\end{array}$ & $\begin{array}{l}\text { Unimodal, } \\
\text { Moderately } \\
\text { Sorted }\end{array}$ & $\begin{array}{l}\text { Unimodal, } \\
\text { Well Sorted }\end{array}$ & $\begin{array}{l}\text { Unimodal, } \\
\text { Moderately } \\
\text { Well Sorted }\end{array}$ & $\begin{array}{l}\text { Unimodal, } \\
\text { Moderately } \\
\text { Well Sorted }\end{array}$ & $\begin{array}{l}\text { Unimodal, } \\
\text { Moderately } \\
\text { Well Sorted }\end{array}$ & $\begin{array}{l}\text { Bimodal, } \\
\text { Moderately } \\
\text { Well Sorted }\end{array}$ & $\begin{array}{l}\text { Bimodal, } \\
\text { Moderately } \\
\text { Sorted }\end{array}$ \\
\hline & TEXTURAL GROUP: & Sand & $\begin{array}{l}\text { Slightly } \\
\text { Gravelly } \\
\text { Sand }\end{array}$ & Sand & Sand & Sand & $\begin{array}{l}\text { Slightly } \\
\text { Gravelly } \\
\text { Sand } \\
\end{array}$ & Sand & Sand & Sand & Sand & $\begin{array}{l}\text { Slightly } \\
\text { Gravelly } \\
\text { Sand }\end{array}$ & $\begin{array}{l}\text { Slightly } \\
\text { Gravelly } \\
\text { Sand } \\
\end{array}$ \\
\hline & SEDIMENT NAME: & $\begin{array}{l}\text { Moderately } \\
\text { Well Sorted } \\
\text { Medium } \\
\text { Sand }\end{array}$ & $\begin{array}{l}\text { Slightly Very } \\
\text { Fine Gravelly } \\
\text { Medium } \\
\text { Sand }\end{array}$ & $\begin{array}{l}\text { Moderately } \\
\text { Well Sorted } \\
\text { Medium } \\
\text { Sand }\end{array}$ & $\begin{array}{l}\text { Moderately } \\
\text { Well Sorted } \\
\text { Medium } \\
\text { Sand }\end{array}$ & $\begin{array}{l}\text { Moderately } \\
\text { Well Sorted } \\
\text { Medium } \\
\text { Sand }\end{array}$ & $\begin{array}{l}\text { Slightly Very } \\
\text { Fine Gravelly } \\
\text { Medium } \\
\text { Sand }\end{array}$ & $\begin{array}{l}\text { Well Sorted } \\
\text { Fine Sand }\end{array}$ & $\begin{array}{l}\text { Moderately } \\
\text { Well Sorted } \\
\text { Medium } \\
\text { Sand }\end{array}$ & $\begin{array}{l}\text { Moderately } \\
\text { Well Sorted } \\
\text { Medium } \\
\text { Sand }\end{array}$ & $\begin{array}{l}\text { Moderately } \\
\text { Well Sorted } \\
\text { Medium } \\
\text { Sand }\end{array}$ & $\begin{array}{l}\text { Slightly Very } \\
\text { Fine Gravelly } \\
\text { Fine Sand }\end{array}$ & $\begin{array}{l}\text { Slightly Very } \\
\text { Fine Gravelly } \\
\text { Medium } \\
\text { Sand }\end{array}$ \\
\hline \multirow{4}{*}{$\begin{array}{l}\text { FOLK AND } \\
\text { WARD } \\
\text { METHOD } \\
(\mathrm{mm})\end{array}$} & MEAN & 330.9 & 436.3 & 278.9 & 372.7 & 320.9 & 399.3 & 248 & 302.1 & 285.1 & 295.4 & 248.4 & 421.9 \\
\hline & SORTING & 1.562 & 1.984 & 1.534 & 1.563 & 1.537 & 1.703 & 1.348 & 1.475 & 1.462 & 1.523 & 1.551 & 1.885 \\
\hline & SKEWNESS & -0.117 & 0.05 & 0.168 & 0.06 & 0.068 & 0.102 & 0.03 & 0.104 & 0.123 & 0.122 & 0.298 & 0.034 \\
\hline & KURTOSIS & 0.932 & 0.828 & 0.953 & 1.022 & 0.902 & 0.977 & 0.953 & 0.971 & 0.991 & 0.946 & 1.171 & 0.892 \\
\hline \multirow{4}{*}{$\begin{array}{l}\text { FOLK AND } \\
\text { WARD } \\
\text { METHOD } \\
\text { (phi) } \\
\end{array}$} & MEAN & 1.595 & 1.196 & 1.842 & 1.424 & 1.64 & 1.324 & 2.012 & 1.727 & 1.81 & 1.759 & 2.009 & 1.245 \\
\hline & SORTING & 0.644 & 0.989 & 0.617 & 0.645 & 0.62 & 0.768 & 0.431 & 0.561 & 0.548 & 0.607 & 0.633 & 0.915 \\
\hline & SKEWNESS & 0.117 & -0.05 & -0.168 & -0.06 & -0.068 & -0.102 & -0.03 & -0.104 & -0.123 & -0.122 & -0.298 & -0.034 \\
\hline & KURTOSIS & 0.932 & 0.828 & 0.953 & 1.022 & 0.902 & 0.977 & 0.953 & 0.971 & 0.991 & 0.946 & 1.171 & 0.892 \\
\hline \multirow{23}{*}{$\begin{array}{l}\text { FOLK AND } \\
\text { WARD } \\
\text { METHOD } \\
\text { (Description) }\end{array}$} & MEAN: & $\begin{array}{l}\text { Medium } \\
\text { Sand }\end{array}$ & $\begin{array}{l}\text { Medium } \\
\text { Sand }\end{array}$ & $\begin{array}{l}\text { Medium } \\
\text { Sand }\end{array}$ & $\begin{array}{l}\text { Medium } \\
\text { Sand }\end{array}$ & $\begin{array}{l}\text { Medium } \\
\text { Sand }\end{array}$ & $\begin{array}{l}\text { Medium } \\
\text { Sand }\end{array}$ & Fine Sand & $\begin{array}{l}\text { Medium } \\
\text { Sand }\end{array}$ & $\begin{array}{l}\text { Medium } \\
\text { Sand }\end{array}$ & $\begin{array}{l}\text { Medium } \\
\text { Sand }\end{array}$ & Fine Sand & $\begin{array}{l}\text { Medium } \\
\text { Sand }\end{array}$ \\
\hline & SORTING: & $\begin{array}{l}\text { Moderately } \\
\text { Well Sorted }\end{array}$ & $\begin{array}{l}\text { Moderately } \\
\text { Sorted }\end{array}$ & $\begin{array}{l}\text { Moderately } \\
\text { Well Sorted }\end{array}$ & $\begin{array}{l}\text { Moderately } \\
\text { Well Sorted }\end{array}$ & $\begin{array}{l}\text { Moderately } \\
\text { Well Sorted }\end{array}$ & $\begin{array}{l}\text { Moderately } \\
\text { Sorted }\end{array}$ & Well Sorted & $\begin{array}{l}\text { Moderately } \\
\text { Well Sorted }\end{array}$ & $\begin{array}{l}\text { Moderately } \\
\text { Well Sorted }\end{array}$ & $\begin{array}{l}\text { Moderately } \\
\text { Well Sorted }\end{array}$ & $\begin{array}{l}\text { Moderately } \\
\text { Well Sorted }\end{array}$ & $\begin{array}{l}\text { Moderately } \\
\text { Sorted }\end{array}$ \\
\hline & SKEWNESS: & Fine Skewed & Symmetrical & $\begin{array}{l}\text { Coarse } \\
\text { Skewed }\end{array}$ & Symmetrical & Symmetrical & $\begin{array}{l}\text { Coarse } \\
\text { Skewed }\end{array}$ & Symmetrical & $\begin{array}{l}\text { Coarse } \\
\text { Skewed }\end{array}$ & $\begin{array}{l}\text { Coarse } \\
\text { Skewed }\end{array}$ & $\begin{array}{l}\text { Coarse } \\
\text { Skewed }\end{array}$ & $\begin{array}{l}\text { Coarse } \\
\text { Skewed }\end{array}$ & Symmetrical \\
\hline & KURTOSIS: & Mesokurtic & Platykurtic & Mesokurtic & Mesokurtic & Mesokurtic & Mesokurtic & Mesokurtic & Mesokurtic & Mesokurtic & Mesokurtic & Leptokurtic & Platykurtic \\
\hline & \% GRAVEL: & $0.0 \%$ & $0.4 \%$ & $0.0 \%$ & $0.0 \%$ & $0.0 \%$ & $0.0 \%$ & $0.0 \%$ & $0.0 \%$ & $0.0 \%$ & $0.0 \%$ & $0.0 \%$ & $0.4 \%$ \\
\hline & \% SAND: & $99.9 \%$ & $99.5 \%$ & $100.0 \%$ & $99.8 \%$ & $100.0 \%$ & $100.0 \%$ & $100.0 \%$ & $100.0 \%$ & $100.0 \%$ & $100.0 \%$ & $100.0 \%$ & $99.5 \%$ \\
\hline & \% MUD: & $0.1 \%$ & $0.0 \%$ & $0.0 \%$ & $0.2 \%$ & $0.0 \%$ & $0.0 \%$ & $0.0 \%$ & $0.0 \%$ & $0.0 \%$ & $0.0 \%$ & $0.0 \%$ & $0.1 \%$ \\
\hline & \% V COARSE GRAVEL: & $0.0 \%$ & $0.0 \%$ & $0.0 \%$ & $0.0 \%$ & $0.0 \%$ & $0.0 \%$ & $0.0 \%$ & $0.0 \%$ & $0.0 \%$ & $0.0 \%$ & $0.0 \%$ & $0.0 \%$ \\
\hline & $\%$ COARSE GRAVEL: & $0.0 \%$ & $0.0 \%$ & $0.0 \%$ & $0.0 \%$ & $0.0 \%$ & $0.0 \%$ & $0.0 \%$ & $0.0 \%$ & $0.0 \%$ & $0.0 \%$ & $0.0 \%$ & $0.0 \%$ \\
\hline & \% MEDIUM GRAVEL: & $0.0 \%$ & $0.0 \%$ & $0.0 \%$ & $0.0 \%$ & $0.0 \%$ & $0.0 \%$ & $0.0 \%$ & $0.0 \%$ & $0.0 \%$ & $0.0 \%$ & $0.0 \%$ & $0.0 \%$ \\
\hline & \% FINE GRAVEL: & $0.0 \%$ & $0.0 \%$ & $0.0 \%$ & $0.0 \%$ & $0.0 \%$ & $0.0 \%$ & $0.0 \%$ & $0.0 \%$ & $0.0 \%$ & $0.0 \%$ & $0.0 \%$ & $0.0 \%$ \\
\hline & \% V FINE GRAVEL: & $0.0 \%$ & $0.4 \%$ & $0.0 \%$ & $0.0 \%$ & $0.0 \%$ & $0.0 \%$ & $0.0 \%$ & $0.0 \%$ & $0.0 \%$ & $0.0 \%$ & $0.0 \%$ & $0.4 \%$ \\
\hline & \% V COARSE SAND: & $0.0 \%$ & $12.2 \%$ & $0.0 \%$ & $2.8 \%$ & $0.0 \%$ & $5.7 \%$ & $0.0 \%$ & $0.5 \%$ & $0.4 \%$ & $0.5 \%$ & $2.0 \%$ & $9.3 \%$ \\
\hline & \% COARSE SAND: & $17.8 \%$ & $30.0 \%$ & $10.7 \%$ & $22.3 \%$ & $16.6 \%$ & $26.9 \%$ & $0.5 \%$ & $10.7 \%$ & $8.2 \%$ & $11.6 \%$ & $7.7 \%$ & $30.3 \%$ \\
\hline & $\%$ MEDIUM SAND: & $55.3 \%$ & $32.6 \%$ & $45.1 \%$ & $56.6 \%$ & $53.2 \%$ & $48.2 \%$ & $47.8 \%$ & $55.7 \%$ & $52.6 \%$ & $50.6 \%$ & $31.9 \%$ & $37.2 \%$ \\
\hline & \% FINE SAND: & $25.3 \%$ & $23.9 \%$ & $42.9 \%$ & $17.7 \%$ & $29.9 \%$ & $19.0 \%$ & $51.4 \%$ & $33.0 \%$ & $38.5 \%$ & $36.9 \%$ & $57.2 \%$ & $21.9 \%$ \\
\hline & \% V FINE SAND: & $1.5 \%$ & $0.8 \%$ & $1.3 \%$ & $0.3 \%$ & $0.3 \%$ & $0.1 \%$ & $0.3 \%$ & $0.1 \%$ & $0.2 \%$ & $0.4 \%$ & $1.3 \%$ & $0.9 \%$ \\
\hline & $\%$ V COARSE SILT: & $0.1 \%$ & $0.0 \%$ & $0.0 \%$ & $0.1 \%$ & $0.0 \%$ & $0.0 \%$ & $0.0 \%$ & $0.0 \%$ & $0.0 \%$ & $0.0 \%$ & $0.0 \%$ & $0.1 \%$ \\
\hline & \% COARSE SILT: & $0.0 \%$ & $0.0 \%$ & $0.0 \%$ & $0.0 \%$ & $0.0 \%$ & $0.0 \%$ & $0.0 \%$ & $0.0 \%$ & $0.0 \%$ & $0.0 \%$ & $0.0 \%$ & $0.0 \%$ \\
\hline & \% MEDIUM SILT: & $0.0 \%$ & $0.0 \%$ & $0.0 \%$ & $0.1 \%$ & $0.0 \%$ & $0.0 \%$ & $0.0 \%$ & $0.0 \%$ & $0.0 \%$ & $0.0 \%$ & $0.0 \%$ & $0.0 \%$ \\
\hline & \% FINE SILT: & $0.0 \%$ & $0.0 \%$ & $0.0 \%$ & $0.1 \%$ & $0.0 \%$ & $0.0 \%$ & $0.0 \%$ & $0.0 \%$ & $0.0 \%$ & $0.0 \%$ & $0.0 \%$ & $0.0 \%$ \\
\hline & \% V FINE SILT: & $0.0 \%$ & $0.0 \%$ & $0.0 \%$ & $0.0 \%$ & $0.0 \%$ & $0.0 \%$ & $0.0 \%$ & $0.0 \%$ & $0.0 \%$ & $0.0 \%$ & $0.0 \%$ & $0.0 \%$ \\
\hline & \% CLAY: & $0.0 \%$ & $0.0 \%$ & $0.0 \%$ & $0.0 \%$ & $0.0 \%$ & $0.0 \%$ & $0.0 \%$ & $0.0 \%$ & $0.0 \%$ & $0.0 \%$ & $0.0 \%$ & $0.0 \%$ \\
\hline
\end{tabular}


2010 Barrier Subsurface

\begin{tabular}{|c|c|c|c|c|c|c|c|c|c|c|c|c|c|}
\hline & & $\begin{array}{l}\text { PntTnch10- } \\
\text { t15_bb-c }\end{array}$ & $\begin{array}{l}\text { PntTnch10- } \\
\text { t15_bb-d }\end{array}$ & $\begin{array}{l}\text { PntTnch10- } \\
\text { t15_bb-e }\end{array}$ & $\begin{array}{l}\text { PntTnch10- } \\
\text { t15_bb-f }\end{array}$ & $\begin{array}{l}\text { PntTnch10- } \\
\text { t15_fdf-a }\end{array}$ & $\begin{array}{l}\text { PntTnch10- } \\
\text { t15_fdf-b }\end{array}$ & $\begin{array}{l}\text { PntTnch10- } \\
\text { t15_fdf-c }\end{array}$ & $\begin{array}{l}\text { PntTnch10- } \\
\text { t15_fdf-d }\end{array}$ & $\begin{array}{l}\text { PntTnch10- } \\
\text { t15_fdf-e }\end{array}$ & $\begin{array}{l}\text { PntTnch10- } \\
\text { t15_fdf-f }\end{array}$ & $\begin{array}{l}\text { PntTnch10- } \\
\text { t15_fdf-g }\end{array}$ & $\begin{array}{l}\text { PntTnch10- } \\
\text { t15_fdf-h }\end{array}$ \\
\hline & SAMPLE TYPE: & $\begin{array}{l}\text { Unimodal, } \\
\text { Moderately } \\
\text { Sorted }\end{array}$ & $\begin{array}{l}\text { Unimodal, } \\
\text { Moderately } \\
\text { Well Sorted }\end{array}$ & $\begin{array}{l}\text { Unimodal, } \\
\text { Moderately } \\
\text { Well Sorted }\end{array}$ & $\begin{array}{l}\text { Unimodal, } \\
\text { Moderately } \\
\text { Well Sorted }\end{array}$ & $\begin{array}{l}\text { Unimodal, } \\
\text { Moderately } \\
\text { Sorted }\end{array}$ & $\begin{array}{l}\text { Bimodal, } \\
\text { Moderately } \\
\text { Sorted }\end{array}$ & $\begin{array}{l}\text { Bimodal, } \\
\text { Moderately } \\
\text { Sorted }\end{array}$ & $\begin{array}{l}\text { Unimodal, } \\
\text { Moderately } \\
\text { Well Sorted }\end{array}$ & $\begin{array}{l}\text { Unimodal, } \\
\text { Moderately } \\
\text { Well Sorted }\end{array}$ & $\begin{array}{l}\text { Bimodal, } \\
\text { Moderately } \\
\text { Sorted }\end{array}$ & $\begin{array}{l}\text { Trimodal, } \\
\text { Moderately } \\
\text { Sorted }\end{array}$ & $\begin{array}{l}\text { Bimodal, } \\
\text { Moderately } \\
\text { Sorted }\end{array}$ \\
\hline & TEXTURAL GROUP: & $\begin{array}{l}\text { Slightly } \\
\text { Gravelly } \\
\text { Sand } \\
\end{array}$ & Sand & Sand & Sand & Sand & Sand & $\begin{array}{l}\text { Slightly } \\
\text { Gravelly } \\
\text { Sand } \\
\end{array}$ & $\begin{array}{l}\text { Slightly } \\
\text { Gravelly } \\
\text { Sand } \\
\end{array}$ & Sand & Sand & $\begin{array}{l}\text { Slightly } \\
\text { Gravelly } \\
\text { Sand } \\
\end{array}$ & $\begin{array}{l}\text { Slightly } \\
\text { Gravelly } \\
\text { Sand } \\
\end{array}$ \\
\hline & SEDIMENT NAME: & $\begin{array}{l}\text { Slightly Very } \\
\text { Fine } \\
\text { Gravelly } \\
\text { Medium } \\
\text { Sand } \\
\end{array}$ & $\begin{array}{l}\text { Moderately } \\
\text { Well Sorted } \\
\text { Medium } \\
\text { Sand }\end{array}$ & $\begin{array}{l}\text { Moderately } \\
\text { Well Sorted } \\
\text { Medium } \\
\text { Sand }\end{array}$ & $\begin{array}{l}\text { Moderately } \\
\text { Well Sorted } \\
\text { Medium } \\
\text { Sand }\end{array}$ & $\begin{array}{l}\text { Moderately } \\
\text { Sorted } \\
\text { Coarse Sand }\end{array}$ & $\begin{array}{l}\text { Moderately } \\
\text { Sorted Fine } \\
\text { Sand }\end{array}$ & $\begin{array}{l}\text { Slightly Very } \\
\text { Fine Gravelly } \\
\text { Coarse Sand }\end{array}$ & $\begin{array}{l}\text { Slightly Very } \\
\text { Fine Gravelly } \\
\text { Medium } \\
\text { Sand }\end{array}$ & $\begin{array}{l}\text { Moderately } \\
\text { Well Sorted } \\
\text { Medium } \\
\text { Sand }\end{array}$ & $\begin{array}{l}\text { Moderately } \\
\text { Sorted Fine } \\
\text { Sand }\end{array}$ & $\begin{array}{l}\text { Slightly Very } \\
\text { Fine Gravelly } \\
\text { Fine Sand }\end{array}$ & $\begin{array}{l}\text { Slightly Very } \\
\text { Fine Gravelly } \\
\text { Medium } \\
\text { Sand }\end{array}$ \\
\hline \multirow{4}{*}{$\begin{array}{l}\text { FOLK AND } \\
\text { WARD } \\
\text { METHOD } \\
(\mathrm{mm})\end{array}$} & MEAN & 315 & 368 & 348.1 & 364.5 & 673.1 & 314.6 & 507.5 & 305.3 & 303.8 & 271.9 & 284.7 & 341.8 \\
\hline & SORTING & 1.686 & 1.617 & 1.573 & 1.605 & 1.822 & 1.762 & 1.925 & 1.536 & 1.534 & 1.857 & 1.816 & 1.876 \\
\hline & SKEWNESS & 0.226 & 0.064 & 0.106 & 0.067 & -0.137 & 0.26 & -0.133 & 0.17 & 0.119 & 0.237 & 0.311 & 0.207 \\
\hline & KURTOSIS & 0.99 & 0.953 & 0.929 & 0.937 & 1.005 & 0.906 & 0.845 & 0.96 & 0.957 & 0.914 & 0.956 & 0.885 \\
\hline \multirow{4}{*}{$\begin{array}{l}\text { FOLK AND } \\
\text { WARD } \\
\text { METHOD } \\
\text { (phi) }\end{array}$} & MEAN & 1.666 & 1.442 & 1.522 & 1.456 & 0.571 & 1.668 & 0.979 & 1.712 & 1.719 & 1.879 & 1.812 & 1.549 \\
\hline & SORTING & 0.754 & 0.693 & 0.653 & 0.682 & 0.865 & 0.817 & 0.945 & 0.619 & 0.617 & 0.893 & 0.861 & 0.908 \\
\hline & SKEWNESS & -0.226 & -0.064 & -0.106 & -0.067 & 0.137 & -0.26 & 0.133 & -0.17 & -0.119 & -0.237 & -0.311 & -0.207 \\
\hline & KURTOSIS & 0.99 & 0.953 & 0.929 & 0.937 & 1.005 & 0.906 & 0.845 & 0.96 & 0.957 & 0.914 & 0.956 & 0.885 \\
\hline \multirow{23}{*}{$\begin{array}{l}\text { FOLK AND } \\
\text { WARD } \\
\text { METHOD } \\
\text { (Description) }\end{array}$} & MEAN: & $\begin{array}{l}\text { Medium } \\
\text { Sand }\end{array}$ & $\begin{array}{l}\text { Medium } \\
\text { Sand }\end{array}$ & $\begin{array}{l}\text { Medium } \\
\text { Sand }\end{array}$ & $\begin{array}{l}\text { Medium } \\
\text { Sand }\end{array}$ & Coarse Sand & $\begin{array}{l}\text { Medium } \\
\text { Sand }\end{array}$ & Coarse Sand & $\begin{array}{l}\text { Medium } \\
\text { Sand }\end{array}$ & $\begin{array}{l}\text { Medium } \\
\text { Sand }\end{array}$ & $\begin{array}{l}\text { Medium } \\
\text { Sand }\end{array}$ & $\begin{array}{l}\text { Medium } \\
\text { Sand }\end{array}$ & $\begin{array}{l}\text { Medium } \\
\text { Sand }\end{array}$ \\
\hline & SORTING: & $\begin{array}{l}\text { Moderately } \\
\text { Sorted }\end{array}$ & $\begin{array}{l}\text { Moderately } \\
\text { Well Sorted }\end{array}$ & $\begin{array}{l}\text { Moderately } \\
\text { Well Sorted }\end{array}$ & $\begin{array}{l}\text { Moderately } \\
\text { Well Sorted }\end{array}$ & $\begin{array}{l}\text { Moderately } \\
\text { Sorted }\end{array}$ & $\begin{array}{l}\text { Moderately } \\
\text { Sorted }\end{array}$ & $\begin{array}{l}\text { Moderately } \\
\text { Sorted }\end{array}$ & $\begin{array}{l}\text { Moderately } \\
\text { Well Sorted }\end{array}$ & $\begin{array}{l}\text { Moderately } \\
\text { Well Sorted }\end{array}$ & $\begin{array}{l}\text { Moderately } \\
\text { Sorted }\end{array}$ & $\begin{array}{l}\text { Moderately } \\
\text { Sorted }\end{array}$ & $\begin{array}{l}\text { Moderately } \\
\text { Sorted }\end{array}$ \\
\hline & SKEWNESS: & $\begin{array}{l}\text { Coarse } \\
\text { Skewed }\end{array}$ & Symmetrical & $\begin{array}{l}\text { Coarse } \\
\text { Skewed }\end{array}$ & Symmetrical & Fine Skewed & $\begin{array}{l}\text { Coarse } \\
\text { Skewed } \\
\end{array}$ & Fine Skewed & $\begin{array}{l}\text { Coarse } \\
\text { Skewed } \\
\end{array}$ & $\begin{array}{l}\text { Coarse } \\
\text { Skewed } \\
\end{array}$ & $\begin{array}{l}\text { Coarse } \\
\text { Skewed } \\
\end{array}$ & $\begin{array}{l}\text { Very Coarse } \\
\text { Skewed }\end{array}$ & $\begin{array}{l}\text { Coarse } \\
\text { Skewed } \\
\end{array}$ \\
\hline & KURTOSIS: & Mesokurtic & Mesokurtic & Mesokurtic & Mesokurtic & Mesokurtic & Mesokurtic & Platykurtic & Mesokurtic & Mesokurtic & Mesokurtic & Mesokurtic & Platykurtic \\
\hline & \% GRAVEL: & $0.0 \%$ & $0.0 \%$ & $0.0 \%$ & $0.0 \%$ & $0.0 \%$ & $0.0 \%$ & $0.1 \%$ & $0.0 \%$ & $0.0 \%$ & $0.0 \%$ & $0.3 \%$ & $0.1 \%$ \\
\hline & \% SAND: & $99.9 \%$ & $99.9 \%$ & $100.0 \%$ & $99.9 \%$ & $100.0 \%$ & $100.0 \%$ & $99.9 \%$ & $100.0 \%$ & $100.0 \%$ & $99.9 \%$ & $99.6 \%$ & $99.9 \%$ \\
\hline & \% MUD: & $0.0 \%$ & $0.1 \%$ & $0.0 \%$ & $0.1 \%$ & $0.0 \%$ & $0.0 \%$ & $0.0 \%$ & $0.0 \%$ & $0.0 \%$ & $0.1 \%$ & $0.0 \%$ & $0.0 \%$ \\
\hline & \% V COARSE GRAVEL: & $0.0 \%$ & $0.0 \%$ & $0.0 \%$ & $0.0 \%$ & $0.0 \%$ & $0.0 \%$ & $0.0 \%$ & $0.0 \%$ & $0.0 \%$ & $0.0 \%$ & $0.0 \%$ & $0.0 \%$ \\
\hline & \% COARSE GRAVEL: & $0.0 \%$ & $0.0 \%$ & $0.0 \%$ & $0.0 \%$ & $0.0 \%$ & $0.0 \%$ & $0.0 \%$ & $0.0 \%$ & $0.0 \%$ & $0.0 \%$ & $0.0 \%$ & $0.0 \%$ \\
\hline & \% MEDIUM GRAVEL: & $0.0 \%$ & $0.0 \%$ & $0.0 \%$ & $0.0 \%$ & $0.0 \%$ & $0.0 \%$ & $0.0 \%$ & $0.0 \%$ & $0.0 \%$ & $0.0 \%$ & $0.0 \%$ & $0.0 \%$ \\
\hline & \% FINE GRAVEL: & $0.0 \%$ & $0.0 \%$ & $0.0 \%$ & $0.0 \%$ & $0.0 \%$ & $0.0 \%$ & $0.0 \%$ & $0.0 \%$ & $0.0 \%$ & $0.0 \%$ & $0.0 \%$ & $0.0 \%$ \\
\hline & \% V FINE GRAVEL: & $0.0 \%$ & $0.0 \%$ & $0.0 \%$ & $0.0 \%$ & $0.0 \%$ & $0.0 \%$ & $0.1 \%$ & $0.0 \%$ & $0.0 \%$ & $0.0 \%$ & $0.3 \%$ & $0.1 \%$ \\
\hline & $\%$ V COARSE SAND: & $3.6 \%$ & $2.8 \%$ & $1.9 \%$ & $2.4 \%$ & $26.6 \%$ & $3.7 \%$ & $15.1 \%$ & $1.8 \%$ & $1.6 \%$ & $3.1 \%$ & $4.3 \%$ & $6.5 \%$ \\
\hline & \% COARSE SAND: & $16.2 \%$ & $24.0 \%$ & $20.5 \%$ & $23.8 \%$ & $44.2 \%$ & $19.1 \%$ & $39.5 \%$ & $12.5 \%$ & $12.1 \%$ & $15.7 \%$ & $14.8 \%$ & $21.9 \%$ \\
\hline & \% MEDIUM SAND: & $43.7 \%$ & $51.2 \%$ & $53.0 \%$ & $51.5 \%$ & $22.0 \%$ & $37.4 \%$ & $28.4 \%$ & $50.7 \%$ & $51.6 \%$ & $30.5 \%$ & $32.2 \%$ & $35.4 \%$ \\
\hline & \% FINE SAND: & $35.4 \%$ & $21.4 \%$ & $24.5 \%$ & $21.8 \%$ & $7.1 \%$ & $38.5 \%$ & $16.2 \%$ & $34.8 \%$ & $33.9 \%$ & $43.7 \%$ & $45.3 \%$ & $34.4 \%$ \\
\hline & \% V FINE SAND: & $0.9 \%$ & $0.4 \%$ & $0.1 \%$ & $0.4 \%$ & $0.1 \%$ & $1.3 \%$ & $0.6 \%$ & $0.2 \%$ & $0.8 \%$ & $6.9 \%$ & $3.0 \%$ & $1.7 \%$ \\
\hline & \% V COARSE SILT: & $0.0 \%$ & $0.1 \%$ & $0.0 \%$ & $0.1 \%$ & $0.0 \%$ & $0.0 \%$ & $0.0 \%$ & $0.0 \%$ & $0.0 \%$ & $0.1 \%$ & $0.0 \%$ & $0.0 \%$ \\
\hline & \% COARSE SILT: & $0.0 \%$ & $0.0 \%$ & $0.0 \%$ & $0.0 \%$ & $0.0 \%$ & $0.0 \%$ & $0.0 \%$ & $0.0 \%$ & $0.0 \%$ & $0.0 \%$ & $0.0 \%$ & $0.0 \%$ \\
\hline & \% MEDIUM SILT: & $0.0 \%$ & $0.0 \%$ & $0.0 \%$ & $0.0 \%$ & $0.0 \%$ & $0.0 \%$ & $0.0 \%$ & $0.0 \%$ & $0.0 \%$ & $0.0 \%$ & $0.0 \%$ & $0.0 \%$ \\
\hline & \% FINE SILT: & $0.0 \%$ & $0.0 \%$ & $0.0 \%$ & $0.0 \%$ & $0.0 \%$ & $0.0 \%$ & $0.0 \%$ & $0.0 \%$ & $0.0 \%$ & $0.0 \%$ & $0.0 \%$ & $0.0 \%$ \\
\hline & \% V FINE SILT: & $0.0 \%$ & $0.0 \%$ & $0.0 \%$ & $0.0 \%$ & $0.0 \%$ & $0.0 \%$ & $0.0 \%$ & $0.0 \%$ & $0.0 \%$ & $0.0 \%$ & $0.0 \%$ & $0.0 \%$ \\
\hline & \% CLAY: & $0.0 \%$ & $0.0 \%$ & $0.0 \%$ & $0.0 \%$ & $0.0 \%$ & $0.0 \%$ & $0.0 \%$ & $0.0 \%$ & $0.0 \%$ & $0.0 \%$ & $0.0 \%$ & $0.0 \%$ \\
\hline
\end{tabular}

Mulcahy, 2014; correspondence: nick.mulcahy@coastalresearch.org.nz 


\section{Barrier Subsurface}

\begin{tabular}{|c|c|c|c|c|c|c|c|c|c|c|c|c|c|}
\hline & & $\begin{array}{l}\text { PntTnch10- } \\
\text { t15_bd-a }\end{array}$ & $\begin{array}{l}\text { PntTnch10- } \\
\text { t15_bd-b }\end{array}$ & $\begin{array}{l}\text { PntTnch10- } \\
\text { t15_bd-c }\end{array}$ & $\begin{array}{l}\text { PntTnch10- } \\
\text { t15_bd-d }\end{array}$ & $\begin{array}{l}\text { PntTnch10- } \\
\text { t15_bd-e }\end{array}$ & $\begin{array}{l}\text { PntTnch10- } \\
\text { t15_bd-f }\end{array}$ & $\begin{array}{l}\text { PntTnch10- } \\
\text { t15_bd-g }\end{array}$ & $\begin{array}{l}\text { PntTnch10- } \\
\text { t15_bd-h }\end{array}$ & $\begin{array}{l}\text { PntPtnpch10- } \\
\text { t1_bf-a }\end{array}$ & $\begin{array}{l}\text { PntPtnpch10- } \\
\text { t1_bf-b }\end{array}$ & $\begin{array}{l}\text { PntPtnpch10- } \\
\text { t1_bf-cc }\end{array}$ & $\begin{array}{l}\text { PntPtnpch10- } \\
\text { t1_fdf-d }\end{array}$ \\
\hline & SAMPLE TYPE: & $\begin{array}{l}\text { Unimodal, } \\
\text { Moderately } \\
\text { Well Sorted }\end{array}$ & $\begin{array}{l}\text { Bimodal, } \\
\text { Moderately } \\
\text { Sorted }\end{array}$ & $\begin{array}{l}\text { Unimodal, } \\
\text { Moderately } \\
\text { Sorted }\end{array}$ & $\begin{array}{l}\text { Unimodal, } \\
\text { Moderately } \\
\text { Sorted }\end{array}$ & $\begin{array}{l}\text { Unimodal, } \\
\text { Moderately } \\
\text { Well Sorted }\end{array}$ & $\begin{array}{l}\text { Unimodal, } \\
\text { Moderately } \\
\text { Sorted }\end{array}$ & $\begin{array}{l}\text { Unimodal, } \\
\text { Moderately } \\
\text { Well Sorted }\end{array}$ & $\begin{array}{l}\text { Unimodal, } \\
\text { Moderately } \\
\text { Well Sorted }\end{array}$ & $\begin{array}{l}\text { Unimodal, } \\
\text { Moderately } \\
\text { Well Sorted }\end{array}$ & $\begin{array}{l}\text { Unimodal, } \\
\text { Moderately } \\
\text { Sorted }\end{array}$ & $\begin{array}{l}\text { Unimodal, } \\
\text { Moderately } \\
\text { Sorted }\end{array}$ & $\begin{array}{l}\text { Unimodal, } \\
\text { Moderately } \\
\text { Sorted }\end{array}$ \\
\hline & TEXTURAL GROUP: & Sand & Sand & Sand & $\begin{array}{l}\text { Slightly } \\
\text { Gravelly } \\
\text { Sand }\end{array}$ & Sand & $\begin{array}{l}\text { Slightly } \\
\text { Gravelly } \\
\text { Sand }\end{array}$ & Sand & Sand & Sand & Sand & Sand & $\begin{array}{l}\text { Slightly } \\
\text { Gravelly Sand }\end{array}$ \\
\hline & SEDIMENT NAME: & $\begin{array}{l}\text { Moderately } \\
\text { Well Sorted } \\
\text { Fine Sand }\end{array}$ & $\begin{array}{l}\text { Moderately } \\
\text { Sorted Fine } \\
\text { Sand }\end{array}$ & $\begin{array}{l}\text { Moderately } \\
\text { Sorted Fine } \\
\text { Sand }\end{array}$ & $\begin{array}{l}\text { Slightly Very } \\
\text { Fine } \\
\text { Gravelly } \\
\text { Fine Sand }\end{array}$ & $\begin{array}{l}\text { Moderately } \\
\text { Well Sorted } \\
\text { Fine Sand }\end{array}$ & $\begin{array}{l}\text { Slightly Very } \\
\text { Fine } \\
\text { Gravelly } \\
\text { Medium } \\
\text { Sand } \\
\end{array}$ & $\begin{array}{l}\text { Moderately } \\
\text { Well Sorted } \\
\text { Medium } \\
\text { Sand }\end{array}$ & $\begin{array}{l}\text { Moderately } \\
\text { Well Sorted } \\
\text { Medium } \\
\text { Sand }\end{array}$ & $\begin{array}{l}\text { Moderately } \\
\text { Well Sorted } \\
\text { Medium } \\
\text { Sand }\end{array}$ & $\begin{array}{l}\text { Moderately } \\
\text { Sorted } \\
\text { Coarse Sand }\end{array}$ & $\begin{array}{l}\text { Moderately } \\
\text { Sorted } \\
\text { Medium } \\
\text { Sand }\end{array}$ & $\begin{array}{l}\text { Slightly Very } \\
\text { Fine Gravelly } \\
\text { Medium } \\
\text { Sand }\end{array}$ \\
\hline \multirow{4}{*}{$\begin{array}{l}\text { FOLK AND } \\
\text { WARD } \\
\text { METHOD } \\
(\mathrm{mm})\end{array}$} & MEAN & 248.4 & 248.8 & 240.8 & 273.5 & 263.4 & 372.7 & 296.1 & 290.1 & 284.7 & 632.3 & 300.4 & 365.8 \\
\hline & SORTING & 1.548 & 1.756 & 1.903 & 1.656 & 1.56 & 1.792 & 1.62 & 1.58 & 1.586 & 1.967 & 1.715 & 1.699 \\
\hline & SKEWNESS & 0.151 & 0.022 & -0.147 & 0.179 & 0.181 & 0.126 & 0.168 & 0.154 & 0.158 & -0.122 & 0.106 & 0.097 \\
\hline & KURTOSIS & 1.098 & 1.309 & 1.737 & 1.015 & 0.991 & 0.932 & 0.944 & 0.968 & 0.958 & 0.932 & 1.005 & 0.94 \\
\hline \multirow{4}{*}{$\begin{array}{l}\text { FOLK AND } \\
\text { WARD } \\
\text { METHOD } \\
\text { (phi) }\end{array}$} & MEAN & 2.009 & 2.007 & 2.054 & 1.87 & 1.925 & 1.424 & 1.756 & 1.785 & 1.812 & 0.661 & 1.735 & 1.451 \\
\hline & SORTING & 0.63 & 0.813 & 0.928 & 0.728 & 0.641 & 0.842 & 0.696 & 0.66 & 0.666 & 0.976 & 0.778 & 0.765 \\
\hline & SKEWNESS & -0.151 & -0.022 & 0.147 & -0.179 & -0.181 & -0.126 & -0.168 & -0.154 & -0.158 & 0.122 & -0.106 & -0.097 \\
\hline & KURTOSIS & 1.098 & 1.309 & 1.737 & 1.015 & 0.991 & 0.932 & 0.944 & 0.968 & 0.958 & 0.932 & 1.005 & 0.94 \\
\hline \multirow{23}{*}{$\begin{array}{l}\text { FOLK AND } \\
\text { WARD } \\
\text { METHOD } \\
\text { (Description) }\end{array}$} & MEAN: & Fine Sand & Fine Sand & Fine Sand & $\begin{array}{l}\text { Medium } \\
\text { Sand }\end{array}$ & $\begin{array}{l}\text { Medium } \\
\text { Sand }\end{array}$ & $\begin{array}{l}\text { Medium } \\
\text { Sand }\end{array}$ & $\begin{array}{l}\text { Medium } \\
\text { Sand }\end{array}$ & $\begin{array}{l}\text { Medium } \\
\text { Sand }\end{array}$ & $\begin{array}{l}\text { Medium } \\
\text { Sand }\end{array}$ & Coarse Sand & $\begin{array}{l}\text { Medium } \\
\text { Sand }\end{array}$ & $\begin{array}{l}\text { Medium } \\
\text { Sand }\end{array}$ \\
\hline & SORTING: & $\begin{array}{l}\text { Moderately } \\
\text { Well Sorted }\end{array}$ & $\begin{array}{l}\text { Moderately } \\
\text { Sorted }\end{array}$ & $\begin{array}{l}\text { Moderately } \\
\text { Sorted }\end{array}$ & $\begin{array}{l}\text { Moderately } \\
\text { Sorted }\end{array}$ & $\begin{array}{l}\text { Moderately } \\
\text { Well Sorted }\end{array}$ & $\begin{array}{l}\text { Moderately } \\
\text { Sorted }\end{array}$ & $\begin{array}{l}\text { Moderately } \\
\text { Well Sorted }\end{array}$ & $\begin{array}{l}\text { Moderately } \\
\text { Well Sorted }\end{array}$ & $\begin{array}{l}\text { Moderately } \\
\text { Well Sorted }\end{array}$ & $\begin{array}{l}\text { Moderately } \\
\text { Sorted }\end{array}$ & $\begin{array}{l}\text { Moderately } \\
\text { Sorted }\end{array}$ & $\begin{array}{l}\text { Moderately } \\
\text { Sorted }\end{array}$ \\
\hline & SKEWNESS: & $\begin{array}{l}\text { Coarse } \\
\text { Skewed } \\
\end{array}$ & Symmetrical & Fine Skewed & $\begin{array}{l}\text { Coarse } \\
\text { Skewed } \\
\end{array}$ & $\begin{array}{l}\text { Coarse } \\
\text { Skewed } \\
\end{array}$ & $\begin{array}{l}\text { Coarse } \\
\text { Skewed } \\
\end{array}$ & $\begin{array}{l}\text { Coarse } \\
\text { Skewed } \\
\end{array}$ & $\begin{array}{l}\text { Coarse } \\
\text { Skewed } \\
\end{array}$ & $\begin{array}{l}\text { Coarse } \\
\text { Skewed } \\
\end{array}$ & Fine Skewed & $\begin{array}{l}\text { Coarse } \\
\text { Skewed } \\
\end{array}$ & Symmetrical \\
\hline & KURTOSIS: & Mesokurtic & Leptokurtic & $\begin{array}{l}\text { Very } \\
\text { Leptokurtic }\end{array}$ & Mesokurtic & Mesokurtic & Mesokurtic & Mesokurtic & Mesokurtic & Mesokurtic & Mesokurtic & Mesokurtic & Mesokurtic \\
\hline & \% GRAVEL: & $0.0 \%$ & $0.0 \%$ & $0.0 \%$ & $0.0 \%$ & $0.0 \%$ & $0.1 \%$ & $0.0 \%$ & $0.0 \%$ & $0.0 \%$ & $0.0 \%$ & $0.0 \%$ & $0.1 \%$ \\
\hline & \% SAND: & $98.4 \%$ & $95.9 \%$ & $93.8 \%$ & $98.1 \%$ & $99.9 \%$ & $99.8 \%$ & $100.0 \%$ & $99.8 \%$ & $100.0 \%$ & $99.8 \%$ & $98.3 \%$ & $99.9 \%$ \\
\hline & \% MUD: & $1.6 \%$ & $4.1 \%$ & $6.2 \%$ & $1.8 \%$ & $0.1 \%$ & $0.1 \%$ & $0.0 \%$ & $0.2 \%$ & $0.0 \%$ & $0.2 \%$ & $1.7 \%$ & $0.0 \%$ \\
\hline & \% V COARSE GRAVEL: & $0.0 \%$ & $0.0 \%$ & $0.0 \%$ & $0.0 \%$ & $0.0 \%$ & $0.0 \%$ & $0.0 \%$ & $0.0 \%$ & $0.0 \%$ & $0.0 \%$ & $0.0 \%$ & $0.0 \%$ \\
\hline & \% COARSE GRAVEL: & $0.0 \%$ & $0.0 \%$ & $0.0 \%$ & $0.0 \%$ & $0.0 \%$ & $0.0 \%$ & $0.0 \%$ & $0.0 \%$ & $0.0 \%$ & $0.0 \%$ & $0.0 \%$ & $0.0 \%$ \\
\hline & \% MEDIUM GRAVEL: & $0.0 \%$ & $0.0 \%$ & $0.0 \%$ & $0.0 \%$ & $0.0 \%$ & $0.0 \%$ & $0.0 \%$ & $0.0 \%$ & $0.0 \%$ & $0.0 \%$ & $0.0 \%$ & $0.0 \%$ \\
\hline & \% FINE GRAVEL: & $0.0 \%$ & $0.0 \%$ & $0.0 \%$ & $0.0 \%$ & $0.0 \%$ & $0.0 \%$ & $0.0 \%$ & $0.0 \%$ & $0.0 \%$ & $0.0 \%$ & $0.0 \%$ & $0.0 \%$ \\
\hline & \% V FINE GRAVEL: & $0.0 \%$ & $0.0 \%$ & $0.0 \%$ & $0.0 \%$ & $0.0 \%$ & $0.1 \%$ & $0.0 \%$ & $0.0 \%$ & $0.0 \%$ & $0.0 \%$ & $0.0 \%$ & $0.1 \%$ \\
\hline & \% V COARSE SAND: & $1.1 \%$ & $1.5 \%$ & $0.4 \%$ & $1.6 \%$ & $1.2 \%$ & $6.1 \%$ & $1.2 \%$ & $1.4 \%$ & $1.4 \%$ & $26.7 \%$ & $2.4 \%$ & $3.9 \%$ \\
\hline & \% COARSE SAND: & $6.7 \%$ & $8.5 \%$ & $7.3 \%$ & $11.7 \%$ & $8.6 \%$ & $24.5 \%$ & $14.4 \%$ & $12.0 \%$ & $11.5 \%$ & $38.5 \%$ & $15.4 \%$ & $24.1 \%$ \\
\hline & \% MEDIUM SAND: & $37.6 \%$ & $35.3 \%$ & $37.0 \%$ & $39.3 \%$ & $40.1 \%$ & $42.5 \%$ & $44.6 \%$ & $46.1 \%$ & $44.6 \%$ & $24.3 \%$ & $43.2 \%$ & $46.7 \%$ \\
\hline & \% FINE SAND: & $50.1 \%$ & $46.0 \%$ & $44.9 \%$ & $43.1 \%$ & $47.8 \%$ & $25.8 \%$ & $38.3 \%$ & $38.8 \%$ & $41.1 \%$ & $9.7 \%$ & $34.4 \%$ & $24.8 \%$ \\
\hline & \% V FINE SAND: & $2.9 \%$ & $4.6 \%$ & $4.2 \%$ & $2.5 \%$ & $2.3 \%$ & $1.0 \%$ & $1.5 \%$ & $1.5 \%$ & $1.3 \%$ & $0.5 \%$ & $2.8 \%$ & $0.4 \%$ \\
\hline & \% V COARSE SILT: & $0.6 \%$ & $1.4 \%$ & $1.8 \%$ & $0.6 \%$ & $0.1 \%$ & $0.1 \%$ & $0.0 \%$ & $0.2 \%$ & $0.0 \%$ & $0.1 \%$ & $0.9 \%$ & $0.0 \%$ \\
\hline & \% COARSE SILT: & $0.3 \%$ & $0.8 \%$ & $1.2 \%$ & $0.3 \%$ & $0.0 \%$ & $0.0 \%$ & $0.0 \%$ & $0.0 \%$ & $0.0 \%$ & $0.1 \%$ & $0.3 \%$ & $0.0 \%$ \\
\hline & \% MEDIUM SILT: & $0.3 \%$ & $0.8 \%$ & $1.2 \%$ & $0.4 \%$ & $0.0 \%$ & $0.0 \%$ & $0.0 \%$ & $0.0 \%$ & $0.0 \%$ & $0.0 \%$ & $0.3 \%$ & $0.0 \%$ \\
\hline & \% FINE SILT: & $0.2 \%$ & $0.6 \%$ & $1.0 \%$ & $0.3 \%$ & $0.0 \%$ & $0.0 \%$ & $0.0 \%$ & $0.0 \%$ & $0.0 \%$ & $0.0 \%$ & $0.2 \%$ & $0.0 \%$ \\
\hline & \% V FINE SILT: & $0.1 \%$ & $0.5 \%$ & $0.8 \%$ & $0.2 \%$ & $0.0 \%$ & $0.0 \%$ & $0.0 \%$ & $0.0 \%$ & $0.0 \%$ & $0.0 \%$ & $0.0 \%$ & $0.0 \%$ \\
\hline & \% CLAY: & $0.0 \%$ & $0.1 \%$ & $0.1 \%$ & $0.0 \%$ & $0.0 \%$ & $0.0 \%$ & $0.0 \%$ & $0.0 \%$ & $0.0 \%$ & $0.0 \%$ & $0.0 \%$ & $0.0 \%$ \\
\hline
\end{tabular}

Mulcahy, 2014; correspondence: nick.mulcahy@coastalresearch.org.nz 


\section{Barrier Subsurface}

\begin{tabular}{|c|c|c|c|c|c|c|c|c|c|c|c|c|c|}
\hline & & $\begin{array}{l}\text { PntPtnpch1 } \\
\text { 0-t1_fdf-a }\end{array}$ & $\begin{array}{l}\text { PntPtnpch1 } \\
\text { 0-t1_fdf-b }\end{array}$ & $\begin{array}{l}\text { PntPtnpch1 } \\
\text { 0-t1_fdf-c }\end{array}$ & $\begin{array}{l}\text { PntPtnpch1 } \\
\text { 0-t1_fdf-d }\end{array}$ & $\begin{array}{l}\text { PntPtnpch1 } \\
\text { 0-t2_bf-a }\end{array}$ & $\begin{array}{l}\text { PntPtnpch1 } \\
\text { 0-t2_bf-b }\end{array}$ & $\begin{array}{l}\text { PntPtnpch1 } \\
\text { 0-t2_bf-c }\end{array}$ & $\begin{array}{l}\text { PntPtnpch1 } \\
\text { 0-t2_bf-d }\end{array}$ & $\begin{array}{l}\text { PntPtnpch1 } \\
\text { 0-t2_bf-e }\end{array}$ & $\begin{array}{l}\text { PntPtnpch1 } \\
\text { 0-t2_bf-f }\end{array}$ & $\begin{array}{l}\text { PntPtnpch1 } \\
\text { 0-t2_fdf-a }\end{array}$ & $\begin{array}{l}\text { PntPtnpch1 } \\
\text { 0-t2_fdf-b }\end{array}$ \\
\hline & SAMPLE TYPE: & $\begin{array}{l}\text { Unimodal, } \\
\text { Moderately } \\
\text { Sorted }\end{array}$ & $\begin{array}{l}\text { Unimodal, } \\
\text { Moderately } \\
\text { Sorted }\end{array}$ & $\begin{array}{l}\text { Unimodal, } \\
\text { Moderately } \\
\text { Sorted }\end{array}$ & $\begin{array}{l}\text { Unimodal, } \\
\text { Moderately } \\
\text { Sorted }\end{array}$ & $\begin{array}{l}\text { Unimodal, } \\
\text { Moderately } \\
\text { Sorted }\end{array}$ & $\begin{array}{l}\text { Unimodal, } \\
\text { Moderately } \\
\text { Well Sorted }\end{array}$ & $\begin{array}{l}\text { Unimodal, } \\
\text { Moderately } \\
\text { Well Sorted }\end{array}$ & $\begin{array}{l}\text { Unimodal, } \\
\text { Poorly } \\
\text { Sorted }\end{array}$ & $\begin{array}{l}\text { Unimodal, } \\
\text { Poorly } \\
\text { Sorted }\end{array}$ & $\begin{array}{l}\text { Bimodal, } \\
\text { Poorly } \\
\text { Sorted }\end{array}$ & $\begin{array}{l}\text { Unimodal, } \\
\text { Moderately } \\
\text { Sorted }\end{array}$ & $\begin{array}{l}\text { Unimodal, } \\
\text { Moderately } \\
\text { Sorted }\end{array}$ \\
\hline & TEXTURAL GROUP: & $\begin{array}{l}\text { Slightly } \\
\text { Gravelly } \\
\text { Sand } \\
\end{array}$ & Sand & $\begin{array}{l}\text { Slightly } \\
\text { Gravelly } \\
\text { Sand } \\
\end{array}$ & $\begin{array}{l}\text { Slightly } \\
\text { Gravelly } \\
\text { Sand } \\
\end{array}$ & $\begin{array}{l}\text { Slightly } \\
\text { Gravelly } \\
\text { Sand } \\
\end{array}$ & Sand & $\begin{array}{l}\text { Slightly } \\
\text { Gravelly } \\
\text { Sand } \\
\end{array}$ & $\begin{array}{l}\text { Gravelly } \\
\text { Sand }\end{array}$ & $\begin{array}{l}\text { Slightly } \\
\text { Gravelly } \\
\text { Sand } \\
\end{array}$ & Sand & $\begin{array}{l}\text { Slightly } \\
\text { Gravelly } \\
\text { Sand } \\
\end{array}$ & $\begin{array}{l}\text { Slightly } \\
\text { Gravelly } \\
\text { Sand } \\
\end{array}$ \\
\hline & SEDIMENT NAME: & $\begin{array}{l}\text { Slightly Very } \\
\text { Fine Gravelly } \\
\text { Medium } \\
\text { Sand } \\
\end{array}$ & $\begin{array}{l}\text { Moderately } \\
\text { Sorted } \\
\text { Medium } \\
\text { Sand } \\
\end{array}$ & $\begin{array}{l}\text { Slightly Very } \\
\text { Fine Gravelly } \\
\text { Medium } \\
\text { Sand } \\
\end{array}$ & $\begin{array}{l}\text { Slightly Very } \\
\text { Fine Gravelly } \\
\text { Medium } \\
\text { Sand } \\
\end{array}$ & $\begin{array}{l}\text { Slightly Very } \\
\text { Fine Gravelly } \\
\text { Fine Sand }\end{array}$ & $\begin{array}{l}\text { Moderately } \\
\text { Well Sorted } \\
\text { Fine Sand }\end{array}$ & $\begin{array}{l}\text { Slightly Very } \\
\text { Fine Gravelly } \\
\text { Fine Sand }\end{array}$ & $\begin{array}{l}\text { Very Fine } \\
\text { Gravelly } \\
\text { Coarse Sand }\end{array}$ & $\begin{array}{l}\text { Slightly Very } \\
\text { Fine Gravelly } \\
\text { Medium } \\
\text { Sand } \\
\end{array}$ & $\begin{array}{l}\text { Poorly } \\
\text { Sorted Fine } \\
\text { Sand }\end{array}$ & $\begin{array}{l}\text { Slightly Very } \\
\text { Fine Gravelly } \\
\text { Medium } \\
\text { Sand } \\
\end{array}$ & $\begin{array}{l}\text { Slightly Very } \\
\text { Fine Gravelly } \\
\text { Medium } \\
\text { Sand } \\
\end{array}$ \\
\hline \multirow{4}{*}{$\begin{array}{l}\text { FOLK AND } \\
\text { WARD } \\
\text { METHOD } \\
(\mathrm{mm}) \\
\end{array}$} & MEAN & 367.0 & 376.9 & 304.6 & 365.8 & 248 & 258.4 & 240 & 866.4 & 360.7 & 284.2 & 435.4 & 458.8 \\
\hline & SORTING & 1.797 & 1.660 & 1.633 & 1.699 & 1.63 & 1.58 & 1.581 & 3.49 & 2.078 & 2.064 & 1.869 & 1.814 \\
\hline & SKEWNESS & 0.105 & 0.036 & 0.179 & 0.097 & 0.294 & 0.223 & 0.227 & 0.213 & 0.229 & 0.046 & 0.04 & 0.02 \\
\hline & KURTOSIS & 0.913 & 0.953 & 0.965 & 0.940 & 1.179 & 1.056 & 1.182 & 1.081 & 0.924 & 1.112 & 0.9 & 0.928 \\
\hline \multirow{4}{*}{$\begin{array}{l}\text { FOLK AND } \\
\text { WARD } \\
\text { METHOD } \\
\text { (phi) } \\
\end{array}$} & MEAN & 1.446 & 1.408 & 1.715 & 1.451 & 2.012 & 1.953 & 2.059 & 0.207 & 1.471 & 1.815 & 1.2 & 1.124 \\
\hline & SORTING & 0.845 & 0.731 & 0.708 & 0.765 & 0.705 & 0.66 & 0.661 & 1.803 & 1.055 & 1.045 & 0.903 & 0.859 \\
\hline & SKEWNESS & -0.105 & -0.036 & -0.179 & -0.097 & -0.294 & -0.223 & -0.227 & -0.213 & -0.229 & -0.046 & -0.04 & -0.02 \\
\hline & KURTOSIS & 0.913 & 0.953 & 0.965 & 0.94 & 1.179 & 1.056 & 1.182 & 1.081 & 0.924 & 1.112 & 0.9 & 0.928 \\
\hline \multirow{23}{*}{$\begin{array}{l}\text { FOLK AND } \\
\text { WARD } \\
\text { METHOD } \\
\text { (Description) }\end{array}$} & MEAN: & $\begin{array}{l}\text { Medium } \\
\text { Sand }\end{array}$ & $\begin{array}{l}\text { Medium } \\
\text { Sand } \\
\end{array}$ & $\begin{array}{l}\text { Medium } \\
\text { Sand }\end{array}$ & $\begin{array}{l}\text { Medium } \\
\text { Sand } \\
\end{array}$ & Fine Sand & $\begin{array}{l}\text { Medium } \\
\text { Sand }\end{array}$ & Fine Sand & Coarse Sand & $\begin{array}{l}\text { Medium } \\
\text { Sand }\end{array}$ & $\begin{array}{l}\text { Medium } \\
\text { Sand }\end{array}$ & $\begin{array}{l}\text { Medium } \\
\text { Sand }\end{array}$ & $\begin{array}{l}\text { Medium } \\
\text { Sand } \\
\end{array}$ \\
\hline & SORTING: & $\begin{array}{l}\text { Moderately } \\
\text { Sorted }\end{array}$ & $\begin{array}{l}\text { Moderately } \\
\text { Sorted }\end{array}$ & $\begin{array}{l}\text { Moderately } \\
\text { Sorted }\end{array}$ & $\begin{array}{l}\text { Moderately } \\
\text { Sorted }\end{array}$ & $\begin{array}{l}\text { Moderately } \\
\text { Sorted }\end{array}$ & $\begin{array}{l}\text { Moderately } \\
\text { Well Sorted }\end{array}$ & $\begin{array}{l}\text { Moderately } \\
\text { Well Sorted }\end{array}$ & $\begin{array}{l}\text { Poorly } \\
\text { Sorted }\end{array}$ & \begin{tabular}{|l} 
Poorly \\
Sorted
\end{tabular} & $\begin{array}{l}\text { Poorly } \\
\text { Sorted }\end{array}$ & $\begin{array}{l}\text { Moderately } \\
\text { Sorted }\end{array}$ & $\begin{array}{l}\text { Moderately } \\
\text { Sorted }\end{array}$ \\
\hline & SKEWNESS: & $\begin{array}{l}\text { Coarse } \\
\text { Skewed } \\
\end{array}$ & Symmetrical & $\begin{array}{l}\text { Coarse } \\
\text { Skewed } \\
\end{array}$ & Symmetrical & $\begin{array}{l}\text { Coarse } \\
\text { Skewed } \\
\end{array}$ & $\begin{array}{l}\text { Coarse } \\
\text { Skewed } \\
\end{array}$ & $\begin{array}{l}\text { Coarse } \\
\text { Skewed } \\
\end{array}$ & $\begin{array}{l}\text { Coarse } \\
\text { Skewed } \\
\end{array}$ & $\begin{array}{l}\text { Coarse } \\
\text { Skewed } \\
\end{array}$ & Symmetrical & Symmetrical & Symmetrical \\
\hline & KURTOSIS: & Mesokurtic & Mesokurtic & Mesokurtic & Mesokurtic & Leptokurtic & Mesokurtic & Leptokurtic & Mesokurtic & Mesokurtic & Leptokurtic & Platykurtic & Mesokurtic \\
\hline & \% GRAVEL: & $0.1 \%$ & $0.0 \%$ & $0.1 \%$ & $0.1 \%$ & $1.0 \%$ & $0.0 \%$ & $0.1 \%$ & $23.9 \%$ & $0.9 \%$ & $0.0 \%$ & $0.3 \%$ & $0.3 \%$ \\
\hline & \% SAND: & $99.9 \%$ & $100.0 \%$ & $99.9 \%$ & $99.9 \%$ & $99.0 \%$ & $99.9 \%$ & $99.4 \%$ & $76.1 \%$ & $98.9 \%$ & $95.8 \%$ & $99.5 \%$ & $99.6 \%$ \\
\hline & \% MUD: & $0.0 \%$ & $0.0 \%$ & $0.0 \%$ & $0.0 \%$ & $0.0 \%$ & $0.1 \%$ & $0.5 \%$ & $0.0 \%$ & $0.2 \%$ & $4.2 \%$ & $0.2 \%$ & $0.1 \%$ \\
\hline & \% V COARSE GRAVEL: & $0.0 \%$ & $0.0 \%$ & $0.0 \%$ & $0.0 \%$ & $0.0 \%$ & $0.0 \%$ & $0.0 \%$ & $1.4 \%$ & $0.0 \%$ & $0.0 \%$ & $0.0 \%$ & $0.0 \%$ \\
\hline & \% COARSE GRAVEL: & $0.0 \%$ & $0.0 \%$ & $0.0 \%$ & $0.0 \%$ & $0.0 \%$ & $0.0 \%$ & $0.0 \%$ & $2.6 \%$ & $0.0 \%$ & $0.0 \%$ & $0.0 \%$ & $0.0 \%$ \\
\hline & \% MEDIUM GRAVEL: & $0.0 \%$ & $0.0 \%$ & $0.0 \%$ & $0.0 \%$ & $0.0 \%$ & $0.0 \%$ & $0.0 \%$ & $2.8 \%$ & $0.0 \%$ & $0.0 \%$ & $0.0 \%$ & $0.0 \%$ \\
\hline & \% FINE GRAVEL: & $0.0 \%$ & $0.0 \%$ & $0.0 \%$ & $0.0 \%$ & $0.0 \%$ & $0.0 \%$ & $0.0 \%$ & $5.8 \%$ & $0.0 \%$ & $0.0 \%$ & $0.0 \%$ & $0.0 \%$ \\
\hline & \% V FINE GRAVEL: & $0.1 \%$ & $0.0 \%$ & $0.1 \%$ & $0.1 \%$ & $1.0 \%$ & $0.0 \%$ & $0.1 \%$ & $11.3 \%$ & $0.9 \%$ & $0.0 \%$ & $0.3 \%$ & $0.3 \%$ \\
\hline & \% V COARSE SAND: & $5.7 \%$ & $3.2 \%$ & $2.2 \%$ & $3.9 \%$ & $2.4 \%$ & $1.3 \%$ & $2.1 \%$ & $13.3 \%$ & $10.4 \%$ & $3.5 \%$ & $9.7 \%$ & $9.9 \%$ \\
\hline & $\%$ COARSE SAND: & $24.6 \%$ & $26.1 \%$ & $14.8 \%$ & $24.1 \%$ & $7.5 \%$ & $9.0 \%$ & $6.8 \%$ & $29.1 \%$ & $19.9 \%$ & $18.1 \%$ & $31.2 \%$ & $34.1 \%$ \\
\hline & \% MEDIUM SAND: & $41.4 \%$ & $48.9 \%$ & $45.2 \%$ & $46.7 \%$ & $31.3 \%$ & $37.1 \%$ & $32.1 \%$ & $20.3 \%$ & $32.9 \%$ & $32.7 \%$ & $38.5 \%$ & $39.5 \%$ \\
\hline & \% FINE SAND: & $27.5 \%$ & $21.5 \%$ & $37.0 \%$ & $24.8 \%$ & $54.5 \%$ & $50.1 \%$ & $54.7 \%$ & $12.7 \%$ & $32.2 \%$ & $34.7 \%$ & $19.3 \%$ & $15.5 \%$ \\
\hline & \% V FINE SAND: & $0.7 \%$ & $0.3 \%$ & $0.8 \%$ & $0.4 \%$ & $3.3 \%$ & $2.4 \%$ & $3.7 \%$ & $0.7 \%$ & $3.5 \%$ & $6.8 \%$ & $0.8 \%$ & $0.5 \%$ \\
\hline & \% V COARSE SILT: & $0.0 \%$ & $0.0 \%$ & $0.0 \%$ & $0.0 \%$ & $0.0 \%$ & $0.1 \%$ & $0.3 \%$ & $0.0 \%$ & $0.2 \%$ & $2.6 \%$ & $0.1 \%$ & $0.1 \%$ \\
\hline & \% COARSE SILT: & $0.0 \%$ & $0.0 \%$ & $0.0 \%$ & $0.0 \%$ & $0.0 \%$ & $0.0 \%$ & $0.1 \%$ & $0.0 \%$ & $0.0 \%$ & $0.8 \%$ & $0.0 \%$ & $0.0 \%$ \\
\hline & \% MEDIUM SILT: & $0.0 \%$ & $0.0 \%$ & $0.0 \%$ & $0.0 \%$ & $0.0 \%$ & $0.0 \%$ & $0.1 \%$ & $0.0 \%$ & $0.0 \%$ & $0.5 \%$ & $0.0 \%$ & $0.0 \%$ \\
\hline & \% FINE SILT: & $0.0 \%$ & $0.0 \%$ & $0.0 \%$ & $0.0 \%$ & $0.0 \%$ & $0.0 \%$ & $0.0 \%$ & $0.0 \%$ & $0.0 \%$ & $0.3 \%$ & $0.0 \%$ & $0.0 \%$ \\
\hline & \% V FINE SILT: & $0.0 \%$ & $0.0 \%$ & $0.0 \%$ & $0.0 \%$ & $0.0 \%$ & $0.0 \%$ & $0.0 \%$ & $0.0 \%$ & $0.0 \%$ & $0.0 \%$ & $0.0 \%$ & $0.0 \%$ \\
\hline & \% CLAY: & $0.0 \%$ & $0.0 \%$ & $0.0 \%$ & $0.0 \%$ & $0.0 \%$ & $0.0 \%$ & $0.0 \%$ & $0.0 \%$ & $0.0 \%$ & $0.0 \%$ & $0.0 \%$ & $0.0 \%$ \\
\hline
\end{tabular}


2010 Barrier Subsurface

\begin{tabular}{|c|c|c|c|c|c|c|c|c|c|c|c|c|c|}
\hline & & $\begin{array}{l}\text { PntPtnpch10- } \\
\text { t2_fdf-c }\end{array}$ & $\begin{array}{l}\text { PntPtnpch10- } \\
\text { t2_fdf-d }\end{array}$ & $\begin{array}{l}\text { PntPtnpch10- } \\
\text { t2_fdf-e }\end{array}$ & $\begin{array}{l}\text { PntBrv10- } \\
\text { t1_bb-a }\end{array}$ & $\begin{array}{l}\text { PntBrv10- } \\
\text { t1_bb-b }\end{array}$ & $\begin{array}{l}\text { PntBrv10- } \\
\text { t1_bb-c }\end{array}$ & $\begin{array}{l}\text { PntBrv10- } \\
\text { t1_bb-d }\end{array}$ & $\begin{array}{l}\text { PntBrv10- } \\
\text { t1_bb-e }\end{array}$ & $\begin{array}{l}\text { PntBrv10- } \\
\text { t1_bb-f }\end{array}$ & $\begin{array}{l}\text { PntBrv10- } \\
\text { t1_bb-g }\end{array}$ & $\begin{array}{l}\text { PntBrv10- } \\
\text { t1_bb-h }\end{array}$ & $\begin{array}{l}\text { PntBrv10- } \\
\text { t1_bb-i }\end{array}$ \\
\hline & SAMPLE TYPE: & $\begin{array}{l}\text { Bimodal, } \\
\text { Moderately } \\
\text { Sorted }\end{array}$ & $\begin{array}{l}\text { Unimodal, } \\
\text { Moderately } \\
\text { Sorted }\end{array}$ & $\begin{array}{l}\text { Unimodal, } \\
\text { Moderately } \\
\text { Sorted }\end{array}$ & $\begin{array}{l}\text { Unimodal, } \\
\text { Moderately } \\
\text { Well Sorted }\end{array}$ & $\begin{array}{l}\text { Unimodal, } \\
\text { Well Sorted }\end{array}$ & $\begin{array}{l}\text { Polymodal, } \\
\text { Moderately } \\
\text { Sorted }\end{array}$ & $\begin{array}{l}\text { Unimodal, } \\
\text { Moderately } \\
\text { Sorted }\end{array}$ & $\begin{array}{l}\text { Unimodal, } \\
\text { Moderately } \\
\text { Sorted }\end{array}$ & $\begin{array}{l}\text { Unimodal, } \\
\text { Moderately } \\
\text { Well Sorted }\end{array}$ & $\begin{array}{l}\text { Unimodal, } \\
\text { Moderately } \\
\text { Well Sorted }\end{array}$ & $\begin{array}{l}\text { Unimodal, } \\
\text { Poorly } \\
\text { Sorted }\end{array}$ & $\begin{array}{l}\text { Unimodal, } \\
\text { Moderately } \\
\text { Well Sorted }\end{array}$ \\
\hline & TEXTURAL GROUP: & $\begin{array}{l}\text { Slightly } \\
\text { Gravelly Sand }\end{array}$ & $\begin{array}{l}\text { Slightly } \\
\text { Gravelly Sand }\end{array}$ & $\begin{array}{l}\text { Slightly } \\
\text { Gravelly Sand }\end{array}$ & Sand & Sand & Sand & Sand & Sand & Sand & $\begin{array}{l}\text { Gravelly } \\
\text { Sand }\end{array}$ & $\begin{array}{l}\text { Gravelly } \\
\text { Sand }\end{array}$ & Sand \\
\hline & SEDIMENT NAME: & $\begin{array}{l}\text { Slightly Very } \\
\text { Fine Gravelly } \\
\text { Medium } \\
\text { Sand }\end{array}$ & $\begin{array}{l}\text { Slightly Very } \\
\text { Fine Gravelly } \\
\text { Medium } \\
\text { Sand }\end{array}$ & $\begin{array}{l}\text { Slightly Very } \\
\text { Fine Gravelly } \\
\text { Medium } \\
\text { Sand }\end{array}$ & $\begin{array}{l}\text { Moderately } \\
\text { Well Sorted } \\
\text { Coarse Sand }\end{array}$ & $\begin{array}{l}\text { Well Sorted } \\
\text { Medium } \\
\text { Sand }\end{array}$ & $\begin{array}{l}\text { Moderately } \\
\text { Sorted } \\
\text { Coarse Sand }\end{array}$ & $\begin{array}{l}\text { Moderately } \\
\text { Sorted } \\
\text { Medium } \\
\text { Sand }\end{array}$ & $\begin{array}{l}\text { Moderately } \\
\text { Sorted } \\
\text { Coarse Sand }\end{array}$ & $\begin{array}{l}\text { Moderately } \\
\text { Well Sorted } \\
\text { Coarse Sand }\end{array}$ & $\begin{array}{l}\text { Very Fine } \\
\text { Gravelly } \\
\text { Coarse Sand }\end{array}$ & $\begin{array}{l}\text { Very Fine } \\
\text { Gravelly } \\
\text { Coarse Sand }\end{array}$ & $\begin{array}{l}\text { Moderately } \\
\text { Well Sorted } \\
\text { Coarse Sand }\end{array}$ \\
\hline \multirow{4}{*}{$\begin{array}{l}\text { FOLK AND } \\
\text { WARD } \\
\text { METHOD } \\
(\mathrm{mm})\end{array}$} & MEAN & 435 & 381.3 & 425 & 615.4 & 372.9 & 685.7 & 474.3 & 560.9 & 517.7 & 1055.7 & 1149.3 & 613.2 \\
\hline & SORTING & 1.892 & 1.753 & 1.936 & 1.447 & 1.355 & 1.705 & 1.626 & 1.648 & 1.53 & 1.586 & 2.532 & 1.417 \\
\hline & SKEWNESS & -0.013 & 0.099 & 0.114 & 0.01 & 0.007 & -0.144 & 0.115 & -0.043 & -0.034 & 0.351 & 0.477 & 0.008 \\
\hline & KURTOSIS & 0.85 & 0.947 & 0.902 & 1.021 & 1.006 & 1.03 & 0.929 & 0.878 & 0.965 & 1.238 & 1.568 & 1.002 \\
\hline \multirow{4}{*}{$\begin{array}{l}\text { FOLK AND } \\
\text { WARD } \\
\text { METHOD } \\
\text { (phi) }\end{array}$} & MEAN & 1.201 & 1.391 & 1.235 & 0.7 & 1.423 & 0.544 & 1.076 & 0.834 & 0.95 & -0.078 & -0.201 & 0.706 \\
\hline & SORTING & 0.92 & 0.809 & 0.953 & 0.533 & 0.438 & 0.77 & 0.701 & 0.721 & 0.613 & 0.666 & 1.34 & 0.503 \\
\hline & SKEWNESS & 0.013 & -0.099 & -0.114 & -0.01 & -0.007 & 0.144 & -0.115 & 0.043 & 0.034 & -0.351 & -0.477 & -0.008 \\
\hline & KURTOSIS & 0.85 & 0.947 & 0.902 & 1.021 & 1.006 & 1.03 & 0.929 & 0.878 & 0.965 & 1.238 & 1.568 & 1.002 \\
\hline \multirow{23}{*}{$\begin{array}{l}\text { FOLK AND } \\
\text { WARD } \\
\text { METHOD } \\
\text { (Description) }\end{array}$} & MEAN: & $\begin{array}{l}\text { Medium } \\
\text { Sand }\end{array}$ & $\begin{array}{l}\text { Medium } \\
\text { Sand }\end{array}$ & $\begin{array}{l}\text { Medium } \\
\text { Sand }\end{array}$ & Coarse Sand & $\begin{array}{l}\text { Medium } \\
\text { Sand }\end{array}$ & Coarse Sand & $\begin{array}{l}\text { Medium } \\
\text { Sand }\end{array}$ & Coarse Sand & Coarse Sand & $\begin{array}{l}\text { Very Coarse } \\
\text { Sand }\end{array}$ & $\begin{array}{l}\text { Very Coarse } \\
\text { Sand }\end{array}$ & Coarse Sand \\
\hline & SORTING: & $\begin{array}{l}\text { Moderately } \\
\text { Sorted }\end{array}$ & $\begin{array}{l}\text { Moderately } \\
\text { Sorted }\end{array}$ & $\begin{array}{l}\text { Moderately } \\
\text { Sorted }\end{array}$ & $\begin{array}{l}\text { Moderately } \\
\text { Well Sorted }\end{array}$ & Well Sorted & $\begin{array}{l}\text { Moderately } \\
\text { Sorted }\end{array}$ & $\begin{array}{l}\text { Moderately } \\
\text { Sorted }\end{array}$ & $\begin{array}{l}\text { Moderately } \\
\text { Sorted }\end{array}$ & $\begin{array}{l}\text { Moderately } \\
\text { Well Sorted }\end{array}$ & $\begin{array}{l}\text { Moderately } \\
\text { Well Sorted }\end{array}$ & $\begin{array}{l}\text { Poorly } \\
\text { Sorted }\end{array}$ & $\begin{array}{l}\text { Moderately } \\
\text { Well Sorted }\end{array}$ \\
\hline & SKEWNESS: & Symmetrical & Symmetrical & $\begin{array}{l}\text { Coarse } \\
\text { Skewed }\end{array}$ & Symmetrical & Symmetrical & Fine Skewed & $\begin{array}{l}\text { Coarse } \\
\text { Skewed }\end{array}$ & Symmetrical & Symmetrical & $\begin{array}{l}\text { Very Coarse } \\
\text { Skewed }\end{array}$ & $\begin{array}{l}\text { Very Coarse } \\
\text { Skewed }\end{array}$ & Symmetrical \\
\hline & KURTOSIS: & Platykurtic & Mesokurtic & Mesokurtic & Mesokurtic & Mesokurtic & Mesokurtic & Mesokurtic & Platykurtic & Mesokurtic & Leptokurtic & $\begin{array}{l}\text { Very } \\
\text { Leptokurtic }\end{array}$ & Mesokurtic \\
\hline & \% GRAVEL: & $0.2 \%$ & $0.3 \%$ & $0.8 \%$ & $0.0 \%$ & $0.0 \%$ & $0.0 \%$ & $0.0 \%$ & $0.0 \%$ & $0.0 \%$ & $12.6 \%$ & $22.2 \%$ & $0.0 \%$ \\
\hline & \% SAND: & $99.8 \%$ & $99.7 \%$ & $99.0 \%$ & $100.0 \%$ & $100.0 \%$ & $100.0 \%$ & $100.0 \%$ & $100.0 \%$ & $100.0 \%$ & $87.4 \%$ & $77.8 \%$ & $100.0 \%$ \\
\hline & \% MUD: & $0.0 \%$ & $0.0 \%$ & $0.1 \%$ & $0.0 \%$ & $0.0 \%$ & $0.0 \%$ & $0.0 \%$ & $0.0 \%$ & $0.0 \%$ & $0.0 \%$ & $0.0 \%$ & $0.0 \%$ \\
\hline & \% V COARSE GRAVEL: & $0.0 \%$ & $0.0 \%$ & $0.0 \%$ & $0.0 \%$ & $0.0 \%$ & $0.0 \%$ & $0.0 \%$ & $0.0 \%$ & $0.0 \%$ & $0.6 \%$ & $2.1 \%$ & $0.0 \%$ \\
\hline & \% COARSE GRAVEL: & $0.0 \%$ & $0.0 \%$ & $0.0 \%$ & $0.0 \%$ & $0.0 \%$ & $0.0 \%$ & $0.0 \%$ & $0.0 \%$ & $0.0 \%$ & $0.7 \%$ & $2.0 \%$ & $0.0 \%$ \\
\hline & $\%$ MEDIUM GRAVEL: & $0.0 \%$ & $0.0 \%$ & $0.0 \%$ & $0.0 \%$ & $0.0 \%$ & $0.0 \%$ & $0.0 \%$ & $0.0 \%$ & $0.0 \%$ & $0.4 \%$ & $3.5 \%$ & $0.0 \%$ \\
\hline & \% FINE GRAVEL: & $0.0 \%$ & $0.0 \%$ & $0.0 \%$ & $0.0 \%$ & $0.0 \%$ & $0.0 \%$ & $0.0 \%$ & $0.0 \%$ & $0.0 \%$ & $1.6 \%$ & $5.0 \%$ & $0.0 \%$ \\
\hline & \% V FINE GRAVEL: & $0.2 \%$ & $0.3 \%$ & $0.8 \%$ & $0.0 \%$ & $0.0 \%$ & $0.0 \%$ & $0.0 \%$ & $0.0 \%$ & $0.0 \%$ & $9.3 \%$ & $9.5 \%$ & $0.0 \%$ \\
\hline & \% V COARSE SAND: & $9.7 \%$ & $5.4 \%$ & $10.8 \%$ & $9.8 \%$ & $0.3 \%$ & $24.4 \%$ & $7.6 \%$ & $12.6 \%$ & $5.7 \%$ & $29.9 \%$ & $18.8 \%$ & $8.3 \%$ \\
\hline & \% COARSE SAND: & $33.0 \%$ & $25.6 \%$ & $27.3 \%$ & $61.6 \%$ & $16.4 \%$ & $49.1 \%$ & $35.8 \%$ & $46.4 \%$ & $48.4 \%$ & $53.9 \%$ & $48.1 \%$ & $63.8 \%$ \\
\hline & \% MEDIUM SAND: & $35.2 \%$ & $44.8 \%$ & $38.2 \%$ & $27.4 \%$ & $74.0 \%$ & $23.5 \%$ & $48.9 \%$ & $36.1 \%$ & $41.4 \%$ & $3.4 \%$ & $10.5 \%$ & $27.1 \%$ \\
\hline & \% FINE SAND: & $20.8 \%$ & $23.2 \%$ & $21.8 \%$ & $1.1 \%$ & $9.1 \%$ & $3.0 \%$ & $7.6 \%$ & $4.9 \%$ & $4.4 \%$ & $0.1 \%$ & $0.4 \%$ & $0.9 \%$ \\
\hline & $\%$ V FINE SAND: & $1.0 \%$ & $0.7 \%$ & $1.0 \%$ & $0.0 \%$ & $0.2 \%$ & $0.0 \%$ & $0.1 \%$ & $0.0 \%$ & $0.1 \%$ & $0.0 \%$ & $0.0 \%$ & $0.0 \%$ \\
\hline & $\%$ V COARSE SILT: & $0.0 \%$ & $0.0 \%$ & $0.1 \%$ & $0.0 \%$ & $0.0 \%$ & $0.0 \%$ & $0.0 \%$ & $0.0 \%$ & $0.0 \%$ & $0.0 \%$ & $0.0 \%$ & $0.0 \%$ \\
\hline & \% COARSE SILT: & $0.0 \%$ & $0.0 \%$ & $0.0 \%$ & $0.0 \%$ & $0.0 \%$ & $0.0 \%$ & $0.0 \%$ & $0.0 \%$ & $0.0 \%$ & $0.0 \%$ & $0.0 \%$ & $0.0 \%$ \\
\hline & \% MEDIUM SILT: & $0.0 \%$ & $0.0 \%$ & $0.0 \%$ & $0.0 \%$ & $0.0 \%$ & $0.0 \%$ & $0.0 \%$ & $0.0 \%$ & $0.0 \%$ & $0.0 \%$ & $0.0 \%$ & $0.0 \%$ \\
\hline & \% FINE SILT: & $0.0 \%$ & $0.0 \%$ & $0.0 \%$ & $0.0 \%$ & $0.0 \%$ & $0.0 \%$ & $0.0 \%$ & $0.0 \%$ & $0.0 \%$ & $0.0 \%$ & $0.0 \%$ & $0.0 \%$ \\
\hline & $\%$ V FINE SILT: & $0.0 \%$ & $0.0 \%$ & $0.0 \%$ & $0.0 \%$ & $0.0 \%$ & $0.0 \%$ & $0.0 \%$ & $0.0 \%$ & $0.0 \%$ & $0.0 \%$ & $0.0 \%$ & $0.0 \%$ \\
\hline & \% CLAY: & $0.0 \%$ & $0.0 \%$ & $0.0 \%$ & $0.0 \%$ & $0.0 \%$ & $0.0 \%$ & $0.0 \%$ & $0.0 \%$ & $0.0 \%$ & $0.0 \%$ & $0.0 \%$ & $0.0 \%$ \\
\hline
\end{tabular}

Mulcahy, 2014; correspondence: nick.mulcahy@coastalresearch.org.nz 
2010 Barrier Subsurface

\begin{tabular}{|c|c|c|c|c|c|c|c|c|c|c|c|c|c|}
\hline & & $\begin{array}{l}\text { PntBrv10- } \\
\text { t1_bd-a }\end{array}$ & $\begin{array}{l}\text { PntBrv10- } \\
\text { t1_bd-b }\end{array}$ & $\begin{array}{l}\text { PntBrv10- } \\
\text { t1_bd-c }\end{array}$ & $\begin{array}{l}\text { PntBrv10- } \\
\text { t1_bd-d }\end{array}$ & $\begin{array}{l}\text { PntBrv10- } \\
\text { t1_bd-e }\end{array}$ & $\begin{array}{l}\text { PntBrv10- } \\
\text { t1_bd-f }\end{array}$ & $\begin{array}{l}\text { PntBrv10- } \\
\text { t2_bb-a }\end{array}$ & $\begin{array}{l}\text { PntBrv10- } \\
\text { t2_bb-b }\end{array}$ & $\begin{array}{l}\text { PntBrv10- } \\
\text { t2_bb-c }\end{array}$ & $\begin{array}{l}\text { PntBrv10- } \\
\text { t2_bb-d }\end{array}$ & $\begin{array}{l}\text { PntBrv10- } \\
\text { t2_bb-e }\end{array}$ & $\begin{array}{l}\text { PntBrv10- } \\
\text { t2_bd-a }\end{array}$ \\
\hline & SAMPLE TYPE: & $\begin{array}{l}\text { Unimodal, } \\
\text { Moderately } \\
\text { Well Sorted }\end{array}$ & $\begin{array}{l}\text { Unimodal, } \\
\text { Moderately } \\
\text { Well Sorted }\end{array}$ & $\begin{array}{l}\text { Unimodal, } \\
\text { Moderately } \\
\text { Well Sorted }\end{array}$ & $\begin{array}{l}\text { Unimodal, } \\
\text { Poorly } \\
\text { Sorted }\end{array}$ & $\begin{array}{l}\text { Unimodal, } \\
\text { Poorly } \\
\text { Sorted }\end{array}$ & $\begin{array}{l}\text { Bimodal, } \\
\text { Poorly } \\
\text { Sorted }\end{array}$ & $\begin{array}{l}\text { Unimodal, } \\
\text { Moderately } \\
\text { Well Sorted }\end{array}$ & $\begin{array}{l}\text { Unimodal, } \\
\text { Well Sorted }\end{array}$ & $\begin{array}{l}\text { Unimodal, } \\
\text { Moderately } \\
\text { Well Sorted }\end{array}$ & $\begin{array}{l}\text { Unimodal, } \\
\text { Moderately } \\
\text { Well Sorted }\end{array}$ & $\begin{array}{l}\text { Trimodal, } \\
\text { Moderately } \\
\text { Well Sorted }\end{array}$ & $\begin{array}{l}\text { Unimodal, } \\
\text { Moderately } \\
\text { Well Sorted }\end{array}$ \\
\hline & TEXTURAL GROUP: & $\begin{array}{l}\text { Slightly } \\
\text { Gravelly } \\
\text { Sand } \\
\end{array}$ & Sand & $\begin{array}{l}\text { Slightly } \\
\text { Gravelly } \\
\text { Sand } \\
\end{array}$ & Sand & Muddy Sand & Sand & $\begin{array}{l}\text { Slightly } \\
\text { Gravelly } \\
\text { Sand } \\
\end{array}$ & Sand & Sand & $\begin{array}{l}\text { Slightly } \\
\text { Gravelly } \\
\text { Sand } \\
\end{array}$ & Sand & $\begin{array}{l}\text { Slightly } \\
\text { Gravelly } \\
\text { Sand } \\
\end{array}$ \\
\hline & SEDIMENT NAME: & $\begin{array}{l}\text { Slightly Very } \\
\text { Fine } \\
\text { Gravelly } \\
\text { Coarse Sand }\end{array}$ & $\begin{array}{l}\text { Moderately } \\
\text { Well Sorted } \\
\text { Coarse Sand }\end{array}$ & $\begin{array}{l}\text { Slightly Very } \\
\text { Fine Gravelly } \\
\text { Coarse Sand }\end{array}$ & $\begin{array}{l}\text { Poorly } \\
\text { Sorted } \\
\text { Medium } \\
\text { Sand } \\
\end{array}$ & $\begin{array}{l}\text { Very Fine } \\
\text { Silty } \\
\text { Medium } \\
\text { Sand } \\
\end{array}$ & $\begin{array}{l}\text { Poorly } \\
\text { Sorted } \\
\text { Coarse Sand }\end{array}$ & $\begin{array}{l}\text { Slightly Very } \\
\text { Fine Gravelly } \\
\text { Coarse Sand }\end{array}$ & $\begin{array}{l}\text { Well Sorted } \\
\text { Coarse Sand }\end{array}$ & $\begin{array}{l}\text { Moderately } \\
\text { Well Sorted } \\
\text { Coarse Sand }\end{array}$ & $\begin{array}{l}\text { Slightly Very } \\
\text { Fine Gravelly } \\
\text { Coarse Sand }\end{array}$ & $\begin{array}{l}\text { Moderately } \\
\text { Well Sorted } \\
\text { Coarse Sand }\end{array}$ & $\begin{array}{l}\text { Slightly Very } \\
\text { Fine Gravelly } \\
\text { Coarse Sand }\end{array}$ \\
\hline \multirow{4}{*}{$\begin{array}{l}\text { FOLK AND } \\
\text { WARD } \\
\text { METHOD } \\
(\mathrm{mm})\end{array}$} & MEAN & 605.7 & 564 & 546.5 & 452.7 & 400.2 & 486.5 & 749.5 & 599.4 & 731.1 & 749.3 & 789.1 & 619.3 \\
\hline & SORTING & 1.574 & 1.56 & 1.56 & 2.314 & 3.051 & 2.542 & 1.436 & 1.39 & 1.487 & 1.438 & 1.461 & 1.458 \\
\hline & SKEWNESS & 0.021 & 0.063 & 0.145 & -0.338 & -0.47 & -0.327 & -0.015 & -0.01 & 0.019 & -0.013 & -0.041 & 0.04 \\
\hline & KURTOSIS & 0.969 & 0.995 & 1.062 & 2.879 & 3.125 & 2.452 & 0.971 & 0.992 & 0.968 & 0.98 & 0.957 & 0.985 \\
\hline \multirow{4}{*}{$\begin{array}{l}\text { FOLK AND } \\
\text { WARD } \\
\text { METHOD } \\
\text { (phi) }\end{array}$} & MEAN & 0.723 & 0.826 & 0.872 & 1.143 & 1.321 & 1.039 & 0.416 & 0.738 & 0.452 & 0.416 & 0.342 & 0.691 \\
\hline & SORTING & 0.654 & 0.642 & 0.642 & 1.21 & 1.609 & 1.346 & 0.522 & 0.476 & 0.573 & 0.524 & 0.547 & 0.544 \\
\hline & SKEWNESS & -0.021 & -0.063 & -0.145 & 0.338 & 0.47 & 0.327 & 0.015 & 0.01 & -0.019 & 0.013 & 0.041 & -0.04 \\
\hline & KURTOSIS & 0.969 & 0.995 & 1.062 & 2.879 & 3.125 & 2.452 & 0.971 & 0.992 & 0.968 & 0.98 & 0.957 & 0.985 \\
\hline \multirow{23}{*}{$\begin{array}{l}\text { FOLK AND } \\
\text { WARD } \\
\text { METHOD } \\
\text { (Description) }\end{array}$} & MEAN: & Coarse Sand & Coarse Sand & Coarse Sand & $\begin{array}{l}\text { Medium } \\
\text { Sand }\end{array}$ & $\begin{array}{l}\text { Medium } \\
\text { Sand }\end{array}$ & $\begin{array}{l}\text { Medium } \\
\text { Sand }\end{array}$ & Coarse Sand & Coarse Sand & Coarse Sand & Coarse Sand & Coarse Sand & Coarse Sand \\
\hline & SORTING: & $\begin{array}{l}\text { Moderately } \\
\text { Well Sorted }\end{array}$ & $\begin{array}{l}\text { Moderately } \\
\text { Well Sorted }\end{array}$ & $\begin{array}{l}\text { Moderately } \\
\text { Well Sorted }\end{array}$ & $\begin{array}{l}\text { Poorly } \\
\text { Sorted }\end{array}$ & $\begin{array}{l}\text { Poorly } \\
\text { Sorted }\end{array}$ & $\begin{array}{l}\text { Poorly } \\
\text { Sorted }\end{array}$ & $\begin{array}{l}\text { Moderately } \\
\text { Well Sorted }\end{array}$ & Well Sorted & $\begin{array}{l}\text { Moderately } \\
\text { Well Sorted }\end{array}$ & $\begin{array}{l}\text { Moderately } \\
\text { Well Sorted }\end{array}$ & $\begin{array}{l}\text { Moderately } \\
\text { Well Sorted }\end{array}$ & $\begin{array}{l}\text { Moderately } \\
\text { Well Sorted }\end{array}$ \\
\hline & SKEWNESS: & Symmetrical & Symmetrical & $\begin{array}{l}\text { Coarse } \\
\text { Skewed }\end{array}$ & $\begin{array}{l}\text { Very Fine } \\
\text { Skewed }\end{array}$ & $\begin{array}{l}\text { Very Fine } \\
\text { Skewed }\end{array}$ & $\begin{array}{l}\text { Very Fine } \\
\text { Skewed }\end{array}$ & Symmetrical & Symmetrical & Symmetrical & Symmetrical & Symmetrical & Symmetrical \\
\hline & KURTOSIS: & Mesokurtic & Mesokurtic & Mesokurtic & $\begin{array}{l}\text { Very } \\
\text { Leptokurtic }\end{array}$ & $\begin{array}{l}\text { Extremely } \\
\text { Leptokurtic }\end{array}$ & $\begin{array}{l}\text { Very } \\
\text { Leptokurtic }\end{array}$ & Mesokurtic & Mesokurtic & Mesokurtic & Mesokurtic & Mesokurtic & Mesokurtic \\
\hline & \% GRAVEL: & $0.1 \%$ & $0.0 \%$ & $1.0 \%$ & $0.0 \%$ & $0.0 \%$ & $0.0 \%$ & $0.2 \%$ & $0.0 \%$ & $0.0 \%$ & $0.2 \%$ & $0.0 \%$ & $0.4 \%$ \\
\hline & \% SAND: & $99.5 \%$ & $99.4 \%$ & $98.6 \%$ & $93.4 \%$ & $87.4 \%$ & $92.1 \%$ & $99.8 \%$ & $100.0 \%$ & $100.0 \%$ & $99.8 \%$ & $100.0 \%$ & $99.3 \%$ \\
\hline & \% MUD: & $0.4 \%$ & $0.6 \%$ & $0.4 \%$ & $6.6 \%$ & $12.6 \%$ & $7.9 \%$ & $0.0 \%$ & $0.0 \%$ & $0.0 \%$ & $0.0 \%$ & $0.0 \%$ & $0.3 \%$ \\
\hline & \% V COARSE GRAVEL: & $0.0 \%$ & $0.0 \%$ & $0.0 \%$ & $0.0 \%$ & $0.0 \%$ & $0.0 \%$ & $0.0 \%$ & $0.0 \%$ & $0.0 \%$ & $0.0 \%$ & $0.0 \%$ & $0.0 \%$ \\
\hline & \% COARSE GRAVEL: & $0.0 \%$ & $0.0 \%$ & $0.0 \%$ & $0.0 \%$ & $0.0 \%$ & $0.0 \%$ & $0.0 \%$ & $0.0 \%$ & $0.0 \%$ & $0.0 \%$ & $0.0 \%$ & $0.0 \%$ \\
\hline & \% MEDIUM GRAVEL: & $0.0 \%$ & $0.0 \%$ & $0.0 \%$ & $0.0 \%$ & $0.0 \%$ & $0.0 \%$ & $0.0 \%$ & $0.0 \%$ & $0.0 \%$ & $0.0 \%$ & $0.0 \%$ & $0.0 \%$ \\
\hline & \% FINE GRAVEL: & $0.0 \%$ & $0.0 \%$ & $0.0 \%$ & $0.0 \%$ & $0.0 \%$ & $0.0 \%$ & $0.0 \%$ & $0.0 \%$ & $0.0 \%$ & $0.0 \%$ & $0.0 \%$ & $0.0 \%$ \\
\hline & \% V FINE GRAVEL: & $0.1 \%$ & $0.0 \%$ & $1.0 \%$ & $0.0 \%$ & $0.0 \%$ & $0.0 \%$ & $0.2 \%$ & $0.0 \%$ & $0.0 \%$ & $0.2 \%$ & $0.0 \%$ & $0.4 \%$ \\
\hline & $\%$ V COARSE SAND: & $13.9 \%$ & $10.9 \%$ & $9.7 \%$ & $4.7 \%$ & $3.9 \%$ & $10.1 \%$ & $21.7 \%$ & $5.8 \%$ & $22.1 \%$ & $21.6 \%$ & $27.8 \%$ & $10.4 \%$ \\
\hline & \% COARSE SAND: & $51.6 \%$ & $48.3 \%$ & $44.7 \%$ & $37.2 \%$ & $35.5 \%$ & $39.6 \%$ & $64.7 \%$ & $65.1 \%$ & $60.8 \%$ & $64.7 \%$ & $60.1 \%$ & $60.0 \%$ \\
\hline & \% MEDIUM SAND: & $31.9 \%$ & $37.7 \%$ & $42.2 \%$ & $46.2 \%$ & $41.7 \%$ & $35.8 \%$ & $13.1 \%$ & $28.2 \%$ & $16.6 \%$ & $13.1 \%$ & $11.7 \%$ & $28.0 \%$ \\
\hline & \% FINE SAND: & $2.0 \%$ & $2.2 \%$ & $1.9 \%$ & $4.6 \%$ & $4.7 \%$ & $4.5 \%$ & $0.4 \%$ & $0.9 \%$ & $0.6 \%$ & $0.4 \%$ & $0.4 \%$ & $0.8 \%$ \\
\hline & \% V FINE SAND: & $0.1 \%$ & $0.3 \%$ & $0.2 \%$ & $0.7 \%$ & $1.6 \%$ & $2.0 \%$ & $0.0 \%$ & $0.0 \%$ & $0.0 \%$ & $0.0 \%$ & $0.0 \%$ & $0.0 \%$ \\
\hline & \% V COARSE SILT: & $0.1 \%$ & $0.2 \%$ & $0.1 \%$ & $0.8 \%$ & $1.6 \%$ & $1.7 \%$ & $0.0 \%$ & $0.0 \%$ & $0.0 \%$ & $0.0 \%$ & $0.0 \%$ & $0.1 \%$ \\
\hline & \% COARSE SILT: & $0.1 \%$ & $0.1 \%$ & $0.1 \%$ & $0.9 \%$ & $1.7 \%$ & $1.4 \%$ & $0.0 \%$ & $0.0 \%$ & $0.0 \%$ & $0.0 \%$ & $0.0 \%$ & $0.1 \%$ \\
\hline & \% MEDIUM SILT: & $0.1 \%$ & $0.1 \%$ & $0.1 \%$ & $1.1 \%$ & $2.5 \%$ & $1.6 \%$ & $0.0 \%$ & $0.0 \%$ & $0.0 \%$ & $0.0 \%$ & $0.0 \%$ & $0.1 \%$ \\
\hline & \% FINE SILT: & $0.1 \%$ & $0.1 \%$ & $0.1 \%$ & $1.1 \%$ & $2.6 \%$ & $1.4 \%$ & $0.0 \%$ & $0.0 \%$ & $0.0 \%$ & $0.0 \%$ & $0.0 \%$ & $0.0 \%$ \\
\hline & \% V FINE SILT: & $0.0 \%$ & $0.1 \%$ & $0.1 \%$ & $1.4 \%$ & $2.9 \%$ & $1.4 \%$ & $0.0 \%$ & $0.0 \%$ & $0.0 \%$ & $0.0 \%$ & $0.0 \%$ & $0.0 \%$ \\
\hline & \% CLAY: & $0.0 \%$ & $0.0 \%$ & $0.0 \%$ & $1.2 \%$ & $1.3 \%$ & $0.4 \%$ & $0.0 \%$ & $0.0 \%$ & $0.0 \%$ & $0.0 \%$ & $0.0 \%$ & $0.0 \%$ \\
\hline
\end{tabular}

Mulcahy, 2014; correspondence: nick.mulcahy@coastalresearch.org.nz 
2010 Barrier Subsurface

\begin{tabular}{|c|c|c|c|c|c|c|c|c|c|c|c|c|c|}
\hline & & $\begin{array}{l}\text { PntBrv10- } \\
\text { t2_bd-b }\end{array}$ & $\begin{array}{l}\text { PntBrv10- } \\
\text { t2_bd-c }\end{array}$ & $\begin{array}{l}\text { PntBrv10- } \\
\text { t2_bd-d }\end{array}$ & $\begin{array}{l}\text { PlyaScrt10- } \\
\text { t1_bb-a }\end{array}$ & $\begin{array}{l}\text { PlyaScrt10- } \\
\text { t1_bb-b }\end{array}$ & $\begin{array}{l}\text { PlyaScrt10- } \\
\text { t1_bb-c }\end{array}$ & $\begin{array}{l}\text { PlyaScrt10- } \\
\text { t1_bb-d }\end{array}$ & $\begin{array}{l}\text { PlyaScrt10- } \\
\text { t1_bb-e }\end{array}$ & $\begin{array}{l}\text { PlyaScrt10- } \\
\text { t1_bb-f }\end{array}$ & $\begin{array}{l}\text { PlyaScrt10- } \\
\text { t1_bb-g }\end{array}$ & $\begin{array}{l}\text { PlyaScrt10- } \\
\text { t1_bb-h }\end{array}$ & $\begin{array}{l}\text { PlyaScrt10- } \\
\text { t1_bd-a }\end{array}$ \\
\hline & SAMPLE TYPE: & $\begin{array}{l}\text { Unimodal, } \\
\text { Moderately } \\
\text { Well Sorted }\end{array}$ & $\begin{array}{l}\text { Unimodal, } \\
\text { Moderately } \\
\text { Well Sorted }\end{array}$ & $\begin{array}{l}\text { Bimodal, } \\
\text { Poorly } \\
\text { Sorted }\end{array}$ & $\begin{array}{l}\text { Unimodal, } \\
\text { Moderately } \\
\text { Well Sorted }\end{array}$ & $\begin{array}{l}\text { Unimodal, } \\
\text { Well Sorted }\end{array}$ & $\begin{array}{l}\text { Unimodal, } \\
\text { Moderately } \\
\text { Well Sorted }\end{array}$ & $\begin{array}{l}\text { Unimodal, } \\
\text { Moderately } \\
\text { Well Sorted }\end{array}$ & $\begin{array}{l}\text { Unimodal, } \\
\text { Moderately } \\
\text { Well Sorted }\end{array}$ & $\begin{array}{l}\text { Unimodal, } \\
\text { Moderately } \\
\text { Well Sorted }\end{array}$ & $\begin{array}{l}\text { Unimodal, } \\
\text { Very Poorly } \\
\text { Sorted }\end{array}$ & $\begin{array}{l}\text { Bimodal, } \\
\text { Very Poorly } \\
\text { Sorted }\end{array}$ & $\begin{array}{l}\text { Unimodal, } \\
\text { Well Sorted }\end{array}$ \\
\hline & TEXTURAL GROUP: & $\begin{array}{l}\text { Slightly } \\
\text { Gravelly } \\
\text { Sand } \\
\end{array}$ & Sand & Sand & Sand & Sand & Sand & Sand & $\begin{array}{l}\text { Slightly } \\
\text { Gravelly } \\
\text { Sand } \\
\end{array}$ & Sand & $\begin{array}{l}\text { Gravelly } \\
\text { Sand }\end{array}$ & Sandy Gravel & Sand \\
\hline & SEDIMENT NAME: & $\begin{array}{l}\text { Slightly Very } \\
\text { Fine Gravelly } \\
\text { Coarse Sand }\end{array}$ & $\begin{array}{l}\text { Moderately } \\
\text { Well Sorted } \\
\text { Coarse Sand }\end{array}$ & $\begin{array}{l}\text { Poorly } \\
\text { Sorted } \\
\text { Coarse Sand }\end{array}$ & $\begin{array}{l}\text { Moderately } \\
\text { Well Sorted } \\
\text { Coarse Sand }\end{array}$ & $\begin{array}{l}\text { Well Sorted } \\
\text { Medium } \\
\text { Sand }\end{array}$ & $\begin{array}{l}\text { Moderately } \\
\text { Well Sorted } \\
\text { Coarse Sand }\end{array}$ & $\begin{array}{l}\text { Moderately } \\
\text { Well Sorted } \\
\text { Medium } \\
\text { Sand } \\
\end{array}$ & $\begin{array}{l}\text { Slightly Very } \\
\text { Fine Gravelly } \\
\text { Coarse Sand }\end{array}$ & $\begin{array}{l}\text { Moderately } \\
\text { Well Sorted } \\
\text { Coarse Sand }\end{array}$ & $\begin{array}{l}\text { Very Coarse } \\
\text { Gravelly } \\
\text { Coarse Sand }\end{array}$ & $\begin{array}{l}\text { Sandy Very } \\
\text { Coarse } \\
\text { Gravel }\end{array}$ & $\begin{array}{l}\text { Well Sorted } \\
\text { Coarse Sand }\end{array}$ \\
\hline \multirow{4}{*}{$\begin{array}{l}\text { FOLK AND } \\
\text { WARD } \\
\text { METHOD } \\
(\mathrm{mm}) \\
\end{array}$} & MEAN & 683.3 & 669 & 655.9 & 599.8 & 491.8 & 605.5 & 453.8 & 541.8 & 505.1 & 1108.5 & 8025.2 & 512.4 \\
\hline & SORTING & 1.501 & 1.513 & 2.705 & 1.543 & 1.407 & 1.454 & 1.439 & 1.48 & 1.475 & 4.932 & 8.928 & 1.394 \\
\hline & SKEWNESS & 0.05 & 0.044 & -0.452 & 0.05 & -0.002 & 0.053 & 0.052 & 0.037 & 0.022 & 0.75 & -0.237 & 0.048 \\
\hline & KURTOSIS & 0.974 & 0.986 & 7.32 & 0.953 & 0.982 & 0.967 & 0.997 & 1.017 & 0.997 & 3.93 & 0.545 & 0.986 \\
\hline \multirow{4}{*}{$\begin{array}{l}\text { FOLK AND } \\
\text { WARD } \\
\text { METHOD } \\
\text { (phi) }\end{array}$} & MEAN & 0.549 & 0.58 & 0.608 & 0.737 & 1.024 & 0.724 & 1.14 & 0.884 & 0.985 & -0.149 & -3.005 & 0.965 \\
\hline & SORTING & 0.585 & 0.597 & 1.436 & 0.626 & 0.493 & 0.54 & 0.525 & 0.565 & 0.561 & 2.302 & 3.158 & 0.479 \\
\hline & SKEWNESS & -0.05 & -0.044 & 0.452 & -0.05 & 0.002 & -0.053 & -0.052 & -0.037 & -0.022 & -0.75 & 0.237 & -0.048 \\
\hline & KURTOSIS & 0.974 & 0.986 & 7.32 & 0.953 & 0.982 & 0.967 & $\begin{array}{ll}0.997 \\
\end{array}$ & 1.017 & 0.997 & 3.93 & 0.545 & 0.986 \\
\hline \multirow{23}{*}{$\begin{array}{l}\text { FOLK AND } \\
\text { WARD } \\
\text { METHOD } \\
\text { (Description) }\end{array}$} & MEAN: & Coarse Sand & Coarse Sand & Coarse Sand & Coarse Sand & $\begin{array}{l}\text { Medium } \\
\text { Sand }\end{array}$ & Coarse Sand & $\begin{array}{l}\text { Medium } \\
\text { Sand }\end{array}$ & Coarse Sand & Coarse Sand & $\begin{array}{l}\text { Very Coarse } \\
\text { Sand }\end{array}$ & $\begin{array}{l}\text { Medium } \\
\text { Gravel }\end{array}$ & Coarse Sand \\
\hline & SORTING: & $\begin{array}{l}\text { Moderately } \\
\text { Well Sorted }\end{array}$ & $\begin{array}{l}\text { Moderately } \\
\text { Well Sorted }\end{array}$ & $\begin{array}{l}\text { Poorly } \\
\text { Sorted }\end{array}$ & $\begin{array}{l}\text { Moderately } \\
\text { Well Sorted }\end{array}$ & Well Sorted & $\begin{array}{l}\text { Moderately } \\
\text { Well Sorted }\end{array}$ & $\begin{array}{l}\text { Moderately } \\
\text { Well Sorted }\end{array}$ & $\begin{array}{l}\text { Moderately } \\
\text { Well Sorted }\end{array}$ & $\begin{array}{l}\text { Moderately } \\
\text { Well Sorted }\end{array}$ & $\begin{array}{l}\text { Very Poorly } \\
\text { Sorted }\end{array}$ & $\begin{array}{l}\text { Very Poorly } \\
\text { Sorted }\end{array}$ & Well Sorted \\
\hline & SKEWNESS: & Symmetrical & Symmetrical & $\begin{array}{l}\text { Very Fine } \\
\text { Skewed }\end{array}$ & Symmetrical & Symmetrical & Symmetrical & Symmetrical & Symmetrical & Symmetrical & $\begin{array}{l}\text { Very Coarse } \\
\text { Skewed }\end{array}$ & Fine Skewed & Symmetrical \\
\hline & KURTOSIS: & Mesokurtic & Mesokurtic & $\begin{array}{l}\text { Extremely } \\
\text { Leptokurtic }\end{array}$ & Mesokurtic & Mesokurtic & Mesokurtic & Mesokurtic & Mesokurtic & Mesokurtic & $\begin{array}{l}\text { Extremely } \\
\text { Leptokurtic }\end{array}$ & $\begin{array}{l}\text { Very } \\
\text { Platykurtic }\end{array}$ & Mesokurtic \\
\hline & \% GRAVEL: & $1.0 \%$ & $0.0 \%$ & $0.0 \%$ & $0.0 \%$ & $0.0 \%$ & $0.0 \%$ & $0.0 \%$ & $0.5 \%$ & $0.0 \%$ & $18.3 \%$ & $57.6 \%$ & $0.0 \%$ \\
\hline & \% SAND: & $98.7 \%$ & $98.9 \%$ & $90.0 \%$ & $99.9 \%$ & $100.0 \%$ & $100.0 \%$ & $100.0 \%$ & $99.4 \%$ & $99.7 \%$ & $81.7 \%$ & $42.4 \%$ & $100.0 \%$ \\
\hline & \% MUD: & $0.3 \%$ & $1.1 \%$ & $10.0 \%$ & $0.1 \%$ & $0.0 \%$ & $0.0 \%$ & $0.0 \%$ & $0.2 \%$ & $0.3 \%$ & $0.1 \%$ & $0.0 \%$ & $0.0 \%$ \\
\hline & \% V COARSE GRAVEL: & $0.0 \%$ & $0.0 \%$ & $0.0 \%$ & $0.0 \%$ & $0.0 \%$ & $0.0 \%$ & $0.0 \%$ & $0.0 \%$ & $0.0 \%$ & $8.3 \%$ & $37.6 \%$ & $0.0 \%$ \\
\hline & \% COARSE GRAVEL: & $0.0 \%$ & $0.0 \%$ & $0.0 \%$ & $0.0 \%$ & $0.0 \%$ & $0.0 \%$ & $0.0 \%$ & $0.0 \%$ & $0.0 \%$ & $2.6 \%$ & $10.7 \%$ & $0.0 \%$ \\
\hline & \% MEDIUM GRAVEL: & $0.0 \%$ & $0.0 \%$ & $0.0 \%$ & $0.0 \%$ & $0.0 \%$ & $0.0 \%$ & $0.0 \%$ & $0.0 \%$ & $0.0 \%$ & $3.8 \%$ & $4.3 \%$ & $0.0 \%$ \\
\hline & \% FINE GRAVEL: & $0.0 \%$ & $0.0 \%$ & $0.0 \%$ & $0.0 \%$ & $0.0 \%$ & $0.0 \%$ & $0.0 \%$ & $0.0 \%$ & $0.0 \%$ & $2.8 \%$ & $2.8 \%$ & $0.0 \%$ \\
\hline & \% V FINE GRAVEL: & $1.0 \%$ & $0.0 \%$ & $0.0 \%$ & $0.0 \%$ & $0.0 \%$ & $0.0 \%$ & $0.0 \%$ & $0.5 \%$ & $0.0 \%$ & $0.8 \%$ & $2.1 \%$ & $0.0 \%$ \\
\hline & \% V COARSE SAND: & $17.1 \%$ & $17.1 \%$ & $9.7 \%$ & $12.9 \%$ & $1.7 \%$ & $9.9 \%$ & $2.2 \%$ & $6.1 \%$ & $4.1 \%$ & $1.0 \%$ & $1.0 \%$ & $2.7 \%$ \\
\hline & \% COARSE SAND: & $59.4 \%$ & $58.3 \%$ & $75.4 \%$ & $52.0 \%$ & $46.4 \%$ & $58.5 \%$ & $36.6 \%$ & $50.9 \%$ & $46.3 \%$ & $42.3 \%$ & $24.8 \%$ & $49.3 \%$ \\
\hline & \% MEDIUM SAND: & $21.8 \%$ & $22.8 \%$ & $4.9 \%$ & $33.5 \%$ & $49.4 \%$ & $31.0 \%$ & $56.9 \%$ & $40.2 \%$ & $46.2 \%$ & $35.9 \%$ & $15.9 \%$ & $47.1 \%$ \\
\hline & \% FINE SAND: & $0.4 \%$ & $0.5 \%$ & $0.0 \%$ & $1.5 \%$ & $2.5 \%$ & $0.6 \%$ & $4.3 \%$ & $2.1 \%$ & $3.1 \%$ & $2.4 \%$ & $0.6 \%$ & $1.0 \%$ \\
\hline & \% V FINE SAND: & $0.0 \%$ & $0.1 \%$ & $0.0 \%$ & $0.1 \%$ & $0.0 \%$ & $0.0 \%$ & $0.0 \%$ & $0.1 \%$ & $0.2 \%$ & $0.0 \%$ & $0.0 \%$ & $0.0 \%$ \\
\hline & $\%$ V COARSE SILT: & $0.1 \%$ & $0.2 \%$ & $0.3 \%$ & $0.0 \%$ & $0.0 \%$ & $0.0 \%$ & $0.0 \%$ & $0.1 \%$ & $0.1 \%$ & $0.0 \%$ & $0.0 \%$ & $0.0 \%$ \\
\hline & \% COARSE SILT: & $0.1 \%$ & $0.2 \%$ & $1.6 \%$ & $0.0 \%$ & $0.0 \%$ & $0.0 \%$ & $0.0 \%$ & $0.0 \%$ & $0.1 \%$ & $0.0 \%$ & $0.0 \%$ & $0.0 \%$ \\
\hline & \% MEDIUM SILT: & $0.1 \%$ & $0.2 \%$ & $1.8 \%$ & $0.0 \%$ & $0.0 \%$ & $0.0 \%$ & $0.0 \%$ & $0.0 \%$ & $0.0 \%$ & $0.0 \%$ & $0.0 \%$ & $0.0 \%$ \\
\hline & \% FINE SILT: & $0.0 \%$ & $0.2 \%$ & $1.7 \%$ & $0.0 \%$ & $0.0 \%$ & $0.0 \%$ & $0.0 \%$ & $0.0 \%$ & $0.0 \%$ & $0.0 \%$ & $0.0 \%$ & $0.0 \%$ \\
\hline & \% V FINE SILT: & $0.0 \%$ & $0.2 \%$ & $2.4 \%$ & $0.0 \%$ & $0.0 \%$ & $0.0 \%$ & $0.0 \%$ & $0.0 \%$ & $0.0 \%$ & $0.0 \%$ & $0.0 \%$ & $0.0 \%$ \\
\hline & \% CLAY: & $0.0 \%$ & $0.1 \%$ & $2.2 \%$ & $0.0 \%$ & $0.0 \%$ & $0.0 \%$ & $0.0 \%$ & $0.0 \%$ & $0.0 \%$ & $0.0 \%$ & $0.0 \%$ & $0.0 \%$ \\
\hline
\end{tabular}

Mulcahy, 2014; correspondence: nick.mulcahy@coastalresearch.org.nz 


\section{Barrier Subsurface}

\begin{tabular}{|c|c|c|c|c|c|c|c|c|c|}
\hline & & $\begin{array}{l}\text { PlyaScrt10- } \\
\text { t1_bd-b }\end{array}$ & $\begin{array}{l}\text { PlyaScrt10- } \\
\text { t1_bd-c }\end{array}$ & $\begin{array}{l}\text { PlyaScrt10- } \\
\text { t1_bd-d }\end{array}$ & $\begin{array}{l}\text { PlyaScrt10- } \\
\text { t1_bd-e }\end{array}$ & $\begin{array}{l}\text { PlyaScrt10- } \\
\text { t1_bd-f }\end{array}$ & $\begin{array}{l}\text { PlyaScrt10- } \\
\text { t1_bd-g }\end{array}$ & $\begin{array}{l}\text { PlyaScrt10- } \\
\text { t1_bd-h }\end{array}$ & $\begin{array}{l}\text { PlyaScrt10- } \\
\text { t1_bd-i }\end{array}$ \\
\hline & SAMPLE TYPE: & $\begin{array}{l}\text { Unimodal, } \\
\text { Moderately } \\
\text { Well Sorted }\end{array}$ & $\begin{array}{l}\text { Unimodal, } \\
\text { Moderately } \\
\text { Well Sorted }\end{array}$ & $\begin{array}{l}\text { Unimodal, } \\
\text { Poorly } \\
\text { Sorted }\end{array}$ & $\begin{array}{l}\text { Unimodal, } \\
\text { Moderately } \\
\text { Well Sorted }\end{array}$ & $\begin{array}{l}\text { Unimodal, } \\
\text { Moderately } \\
\text { Well Sorted }\end{array}$ & $\begin{array}{l}\text { Unimodal, } \\
\text { Moderately } \\
\text { Well Sorted }\end{array}$ & $\begin{array}{l}\text { Unimodal, } \\
\text { Moderately } \\
\text { Well Sorted }\end{array}$ & $\begin{array}{l}\text { Unimodal, } \\
\text { Moderately } \\
\text { Well Sorted }\end{array}$ \\
\hline & TEXTURAL GROUP: & Sand & Sand & $\begin{array}{l}\text { Gravelly } \\
\text { Sand }\end{array}$ & Sand & Sand & Sand & Sand & $\begin{array}{l}\text { Slightly } \\
\text { Gravelly } \\
\text { Sand } \\
\end{array}$ \\
\hline & SEDIMENT NAME: & $\begin{array}{l}\text { Moderately } \\
\text { Well Sorted } \\
\text { Coarse Sand }\end{array}$ & $\begin{array}{l}\text { Moderately } \\
\text { Well Sorted } \\
\text { Medium } \\
\text { Sand }\end{array}$ & $\begin{array}{l}\text { Very Fine } \\
\text { Gravelly } \\
\text { Coarse Sand }\end{array}$ & $\begin{array}{l}\text { Moderately } \\
\text { Well Sorted } \\
\text { Coarse Sand }\end{array}$ & $\begin{array}{l}\text { Moderately } \\
\text { Well Sorted } \\
\text { Coarse Sand }\end{array}$ & $\begin{array}{l}\text { Moderately } \\
\text { Well Sorted } \\
\text { Coarse Sand }\end{array}$ & $\begin{array}{l}\text { Moderately } \\
\text { Well Sorted } \\
\text { Coarse Sand }\end{array}$ & $\begin{array}{l}\text { Slightly Very } \\
\text { Fine Gravelly } \\
\text { Coarse Sand }\end{array}$ \\
\hline \multirow{4}{*}{$\begin{array}{l}\text { FOLK AND } \\
\text { WARD } \\
\text { METHOD } \\
(\mathrm{mm})\end{array}$} & MEAN & 551.5 & 472.2 & 763.1 & 576.9 & 521 & 534.8 & 523.7 & 551.2 \\
\hline & SORTING & 1.443 & 1.415 & 2.271 & 1.513 & 1.451 & 1.508 & 1.474 & 1.452 \\
\hline & SKEWNESS & 0.05 & 0.03 & 0.612 & 0.065 & 0.032 & 0.045 & 0.031 & 0.068 \\
\hline & KURTOSIS & 0.982 & 1.021 & 2.599 & 1.032 & 1.024 & 1.032 & 1.005 & 1.001 \\
\hline \multirow{4}{*}{$\begin{array}{l}\text { FOLK AND } \\
\text { WARD } \\
\text { METHOD } \\
\text { (phi) }\end{array}$} & MEAN & 0.859 & 1.083 & 0.39 & 0.794 & 0.941 & 0.903 & 0.933 & 0.859 \\
\hline & SORTING & 0.529 & 0.5 & 1.183 & 0.598 & 0.537 & 0.592 & 0.56 & 0.538 \\
\hline & SKEWNESS & -0.05 & -0.03 & -0.612 & -0.065 & -0.032 & -0.045 & -0.031 & -0.068 \\
\hline & KURTOSIS & 0.982 & 1.021 & 2.599 & 1.032 & 1.024 & 1.032 & 1.005 & 1.001 \\
\hline \multirow{23}{*}{$\begin{array}{l}\text { FOLK AND } \\
\text { WARD } \\
\text { METHOD } \\
\text { (Description) }\end{array}$} & MEAN: & Coarse Sand & $\begin{array}{l}\text { Medium } \\
\text { Sand }\end{array}$ & Coarse Sand & Coarse Sand & Coarse Sand & Coarse Sand & Coarse Sand & Coarse Sand \\
\hline & SORTING: & $\begin{array}{l}\text { Moderately } \\
\text { Well Sorted }\end{array}$ & $\begin{array}{l}\text { Moderately } \\
\text { Well Sorted }\end{array}$ & $\begin{array}{l}\text { Poorly } \\
\text { Sorted }\end{array}$ & $\begin{array}{l}\text { Moderately } \\
\text { Well Sorted }\end{array}$ & $\begin{array}{l}\text { Moderately } \\
\text { Well Sorted }\end{array}$ & $\begin{array}{l}\text { Moderately } \\
\text { Well Sorted }\end{array}$ & $\begin{array}{l}\text { Moderately } \\
\text { Well Sorted }\end{array}$ & $\begin{array}{l}\text { Moderately } \\
\text { Well Sorted }\end{array}$ \\
\hline & SKEWNESS: & Symmetrical & Symmetrical & $\begin{array}{l}\text { Very Coarse } \\
\text { Skewed }\end{array}$ & Symmetrical & Symmetrical & Symmetrical & Symmetrical & Symmetrical \\
\hline & KURTOSIS: & Mesokurtic & Mesokurtic & $\begin{array}{l}\text { Very } \\
\text { Leptokurtic }\end{array}$ & Mesokurtic & Mesokurtic & Mesokurtic & Mesokurtic & Mesokurtic \\
\hline & \% GRAVEL: & $0.0 \%$ & $0.0 \%$ & $14.7 \%$ & $0.0 \%$ & $0.0 \%$ & $0.0 \%$ & $0.0 \%$ & $0.8 \%$ \\
\hline & \% SAND: & $100.0 \%$ & $99.6 \%$ & $85.3 \%$ & $99.4 \%$ & $99.6 \%$ & $99.1 \%$ & $99.5 \%$ & $99.2 \%$ \\
\hline & $\%$ MUD: & $0.0 \%$ & $0.4 \%$ & $0.0 \%$ & $0.6 \%$ & $0.4 \%$ & $0.9 \%$ & $0.5 \%$ & $0.0 \%$ \\
\hline & \% V COARSE GRAVEL: & $0.0 \%$ & $0.0 \%$ & $0.0 \%$ & $0.0 \%$ & $0.0 \%$ & $0.0 \%$ & $0.0 \%$ & $0.0 \%$ \\
\hline & \% COARSE GRAVEL: & $0.0 \%$ & $0.0 \%$ & $1.8 \%$ & $0.0 \%$ & $0.0 \%$ & $0.0 \%$ & $0.0 \%$ & $0.0 \%$ \\
\hline & \% MEDIUM GRAVEL: & $0.0 \%$ & $0.0 \%$ & $4.0 \%$ & $0.0 \%$ & $0.0 \%$ & $0.0 \%$ & $0.0 \%$ & $0.0 \%$ \\
\hline & \% FINE GRAVEL: & $0.0 \%$ & $0.0 \%$ & $4.4 \%$ & $0.0 \%$ & $0.0 \%$ & $0.0 \%$ & $0.0 \%$ & $0.0 \%$ \\
\hline & $\%$ V FINE GRAVEL: & $0.0 \%$ & $0.0 \%$ & $4.5 \%$ & $0.0 \%$ & $0.0 \%$ & $0.0 \%$ & $0.0 \%$ & $0.8 \%$ \\
\hline & $\%$ V COARSE SAND: & $6.0 \%$ & $2.1 \%$ & $4.5 \%$ & $10.1 \%$ & $4.6 \%$ & $7.1 \%$ & $5.2 \%$ & $5.8 \%$ \\
\hline & \% COARSE SAND: & $53.5 \%$ & $40.6 \%$ & $52.8 \%$ & $52.4 \%$ & $49.2 \%$ & $48.4 \%$ & $48.7 \%$ & $52.5 \%$ \\
\hline & $\%$ MEDIUM SAND: & $39.3 \%$ & $54.0 \%$ & $27.5 \%$ & $34.9 \%$ & $43.6 \%$ & $41.0 \%$ & $43.0 \%$ & $39.7 \%$ \\
\hline & \% FINE SAND: & $1.3 \%$ & $2.7 \%$ & $0.5 \%$ & $1.6 \%$ & $2.1 \%$ & $2.2 \%$ & $2.2 \%$ & $1.2 \%$ \\
\hline & \% V FINE SAND: & $0.0 \%$ & $0.2 \%$ & $0.0 \%$ & $0.3 \%$ & $0.1 \%$ & $0.5 \%$ & $0.2 \%$ & $0.0 \%$ \\
\hline & \% V COARSE SILT: & $0.0 \%$ & $0.1 \%$ & $0.0 \%$ & $0.2 \%$ & $0.1 \%$ & $0.3 \%$ & $0.2 \%$ & $0.0 \%$ \\
\hline & \% COARSE SILT: & $0.0 \%$ & $0.1 \%$ & $0.0 \%$ & $0.1 \%$ & $0.1 \%$ & $0.2 \%$ & $0.1 \%$ & $0.0 \%$ \\
\hline & \% MEDIUM SILT: & $0.0 \%$ & $0.1 \%$ & $0.0 \%$ & $0.1 \%$ & $0.1 \%$ & $0.1 \%$ & $0.1 \%$ & $0.0 \%$ \\
\hline & \% FINE SILT: & $0.0 \%$ & $0.1 \%$ & $0.0 \%$ & $0.1 \%$ & $0.1 \%$ & $0.1 \%$ & $0.1 \%$ & $0.0 \%$ \\
\hline & \% V FINE SILT: & $0.0 \%$ & $0.1 \%$ & $0.0 \%$ & $0.1 \%$ & $0.1 \%$ & $0.1 \%$ & $0.1 \%$ & $0.0 \%$ \\
\hline & \% CLAY: & $0.0 \%$ & $0.0 \%$ & $0.0 \%$ & $0.0 \%$ & $0.0 \%$ & $0.1 \%$ & $0.0 \%$ & $0.0 \%$ \\
\hline
\end{tabular}




\subsection{Petrology data}


2006 Barrier Subsurface

\begin{tabular}{|c|c|c|c|c|c|c|c|c|c|c|c|c|c|c|c|c|c|c|}
\hline Sample & Depth $(m)$ & Coral & $\%$ & $\begin{array}{c}\text { Coralline } \\
\text { algae }\end{array}$ & $\%$ & Mollusc & $\%$ & Halimeda & $\%$ & Echinoid & $\%$ & Micrite & $\%$ & Miscellaneous & $\%$ & Foraminifera & $\%$ & Total count \\
\hline WnW06-t1_bb-1-b & $<0 \mathrm{~m}$ & 50 & 12.1951 & 30 & 7.317073 & 26 & 6.341463 & 164 & 40 & 6 & 1.463415 & 98 & 23.90244 & 8 & 1.95122 & 28 & 6.829268 & 410 \\
\hline WnW06-t1_bb-2-b & $<0 \mathrm{~m}$ & 46 & 12.1693 & 46 & 12.16931 & 16 & 4.232804 & 148 & 39.15344 & 2 & 0.529101 & 88 & 23.28042 & 2 & 0.529101 & 30 & 7.936508 & 378 \\
\hline WnW06-t1_fdf-1-b & $<0 \mathrm{~m}$ & 25 & 6.51042 & 32 & 8.333333 & 40 & 10.41667 & 171 & 44.53125 & 4 & 1.041667 & 52 & 13.54167 & 12 & 3.125 & 48 & 12.5 & 384 \\
\hline PntTnch06-t15_bb-1-b & $<0 \mathrm{~m}$ & 48 & 12.56545 & 32 & 8.376963 & 14 & 3.664921 & 171 & 44.7644 & 4 & 1.04712 & 64 & 16.75393 & 5 & 1.308901 & 44 & 11.67109 & 382 \\
\hline PntBrv06-t2_bb-1-b & $<0 \mathrm{~m}$ & 129 & 36.85714 & 31 & 8.857143 & 26 & 7.428571 & 132 & 37.71429 & 2 & 0.571429 & 23 & 6.571429 & 2 & 0.571429 & 5 & 1.428571 & 350 \\
\hline PntBrv06_t2_fdf-1-b & $<0 \mathrm{~m}$ & 142 & 35.23573 & 22 & 5.459057 & 24 & 5.955335 & 181 & 44.91315 & 4 & 0.992556 & 14 & 3.473945 & 4 & 0.992556 & 12 & 2.977667 & 403 \\
\hline
\end{tabular}

2006 Barrier Surface

\begin{tabular}{|c|c|c|c|c|c|c|c|c|c|c|c|c|c|c|c|c|c|c|}
\hline Sample & $\begin{array}{c}\text { Distance from } \\
\text { MHW shoreline } \\
\text { (m) } \\
\end{array}$ & Coral & $\%$ & $\begin{array}{c}\text { Coralline } \\
\text { algae }\end{array}$ & $\%$ & Mollusc & $\%$ & Halimeda & $\%$ & Echinoid & $\%$ & Micrite & $\%$ & Miscellaneous & $\%$ & Foraminifera & $\%$ & Total count \\
\hline WnW06-t1_bb-1-a & -12 & 42 & 9.98 & 52 & 12.35 & 28 & 6.65 & 202 & 47.98 & 2 & 0.48 & 52 & 12.35 & 15 & 3.56 & 28 & 6.65 & 421 \\
\hline WnW06-t1_bb-2-a & -20 & 38 & 10.67 & 37 & 10.39 & 30 & 8.43 & 148 & 41.57 & 6 & 1.69 & 57 & 16.01 & 12 & 3.37 & 28 & 7.87 & 356 \\
\hline WnW06-t1 fdf-1-a & -25 & 30 & 7.50 & 36 & 9.00 & 34 & 8.50 & 160 & 40.00 & 4 & 1.00 & 84 & 21.00 & 10 & 2.50 & 42 & 10.50 & 400 \\
\hline WnW06-t1_fdf-2-a & -35 & 45 & 11.60 & 28 & 7.22 & 24 & 6.19 & 145 & 37.37 & 2 & 0.52 & 90 & 23.20 & 6 & 1.55 & 48 & 12.37 & 388 \\
\hline WnW06-t1_bd-a & -45 & 52 & 12.97 & 54 & 13.47 & 20 & 4.99 & 142 & 35.41 & 0 & 0.00 & 95 & 23.69 & 14 & 3.49 & 24 & 5.99 & 401 \\
\hline PntTnch06-t15_bb-1-a & -12 & 42 & 10.82 & 30 & 7.73 & 16 & 4.12 & 187 & 48.20 & 4 & 1.03 & 57 & 14.69 & 0 & 0.00 & 52 & 13.40 & 388 \\
\hline PntTnch06-t15_bb-2-a & -32 & 46 & 12.71 & 32 & 8.84 & 8 & 2.21 & 153 & 42.27 & 0 & 0.00 & 75 & 20.72 & 0 & 0.00 & 48 & 13.26 & 362 \\
\hline PntTnch06-t15_fdf-a & -48 & 52 & 15.52 & 32 & 9.55 & 10 & 2.99 & 148 & 44.18 & 0 & 0.00 & 63 & 18.81 & 4 & 1.19 & 26 & 7.76 & 335 \\
\hline PntBrv06-t2 bb-1-a & -10 & 134 & 31.83 & 65 & 15.44 & 22 & 5.23 & 157 & 37.29 & 5 & 1.19 & 22 & 5.23 & 7 & 1.66 & 9 & 2.14 & 421 \\
\hline PntBrv06-t2_bb-2-a & -15 & 130 & 32.42 & 18 & 4.49 & 13 & 3.24 & 231 & 57.61 & 0 & 0.00 & 3 & 0.75 & 0 & 0.00 & 6 & 1.50 & 401 \\
\hline PntBrv06-t2_fdf-1-a & -22 & 142 & 34.55 & 20 & 4.87 & 12 & 2.92 & 214 & 52.07 & 1 & 0.24 & 16 & 3.89 & 3 & 0.73 & 3 & 0.73 & 411 \\
\hline PntBrv06-t2_fdf-2-a & -28 & 134 & 32.92 & 25 & 6.14 & 40 & 9.83 & 184 & 45.21 & 0 & 0.00 & 17 & 4.18 & 0 & 0.00 & 7 & 1.72 & 407 \\
\hline PntBrv06-t2_bd-a & -40 & 141 & 34.73 & 35 & 8.62 & 19 & 4.68 & 177 & 43.60 & 1 & 0.25 & 20 & 4.93 & 3 & 0.74 & 10 & 2.46 & 406 \\
\hline
\end{tabular}


2010 Barrier and Lagoon Surface

\begin{tabular}{|c|c|c|c|c|c|c|c|c|c|c|c|c|c|c|c|c|c|c|}
\hline Sample & $\begin{array}{c}\text { Distance from } \\
\text { MHW shoreline } \\
\text { (m) } \\
\end{array}$ & Coral & $\%$ & $\begin{array}{l}\text { Coralline } \\
\text { algae }\end{array}$ & $\%$ & Mollusc & $\%$ & Halimeda & $\%$ & Echinoid & $\%$ & Micrite & $\%$ & Miscellaneous & $\%$ & Foraminifera & $\%$ & Total count \\
\hline WnW10-t1_bf-a & -4.5 & 0 & 7.94 & 34 & 8.44 & 44 & 10.92 & 195 & 48.39 & 9 & 2.23 & 37 & 9.18 & 15 & 3.72 & 37 & 9.18 & 403 \\
\hline WnW10-t1_fdf-a & -15 & 27 & 6.65 & 49 & 12.07 & 62 & 15.27 & 170 & 41.87 & 5 & 1.23 & 45 & 11.08 & 12 & 2.96 & 36 & 8.87 & 406 \\
\hline WnW10-t1_bd-a & -34 & 44 & 11.43 & 46 & 11.95 & 32 & 8.31 & 160 & 41.56 & 4 & 1.04 & 77 & 20.00 & 12 & 3.12 & 10 & 2.60 & 385 \\
\hline WnW10-m1_a & 50 & 18 & 4.50 & 46 & 11.50 & 76 & 19.00 & 164 & 41.00 & 0 & 0.00 & 65 & 16.25 & 19 & 4.75 & 12 & 3.00 & 400 \\
\hline WnW10-m1_b & 400 & 8 & 2.01 & 8 & 2.01 & 44 & 11.06 & 270 & 67.84 & 2 & 0.50 & 54 & 13.57 & 8 & 2.01 & 4 & 1.01 & 398 \\
\hline WnW10-m1_c & 750 & 28 & 7.00 & 58 & 14.50 & 64 & 16.00 & 182 & 45.50 & 4 & 1.00 & 24 & 6.00 & 20 & 5.00 & 20 & 5.00 & 400 \\
\hline WnW10-m1_d & 1100 & 34 & 8.50 & 48 & 12.00 & 80 & 20.00 & 150 & 37.50 & 0 & 0.00 & 34 & 8.50 & 26 & 6.50 & 28 & 7.00 & 400 \\
\hline WnW10-m1_e & 1450 & 22 & 5.50 & 100 & 25.00 & 58 & 14.50 & 152 & 38.00 & 6 & 1.50 & 34 & 8.50 & 20 & 5.00 & 8 & 2.00 & 400 \\
\hline WnW10-m1_f & 1800 & 46 & 11.44 & 58 & 14.43 & 54 & 13.43 & 192 & 47.76 & 0 & 0.00 & 14 & 3.48 & 22 & 5.47 & 16 & 3.98 & 402 \\
\hline WnW10-m1_g & 2150 & 50 & 12.50 & 42 & 10.50 & 66 & 16.50 & 160 & 40.00 & 10 & 2.50 & 10 & 2.50 & 32 & 8.00 & 30 & 7.50 & 400 \\
\hline WnW10-m1_h & 2500 & 98 & 24.50 & 68 & 17.00 & 46 & 11.50 & 146 & 36.50 & 10 & 2.50 & 4 & 1.00 & 16 & 4.00 & 12 & 3.00 & 400 \\
\hline WnW10-m1_i & 2850 & 106 & 26.50 & 46 & 11.50 & 58 & 14.50 & 140 & 35.00 & 0 & 0.00 & 4 & 1.00 & 28 & 7.00 & 18 & 4.50 & 400 \\
\hline WnW10-m1_j & 3200 & 134 & 33.50 & 62 & 15.50 & 34 & 8.50 & 108 & 27.00 & 0 & 0.00 & 30 & 7.50 & 14 & 3.50 & 18 & 4.50 & 400 \\
\hline PntTnch10-bf-a & -22 & 42 & 10.50 & 26 & 6.50 & 30 & 7.50 & 180 & 45.00 & 4 & 1.00 & 80 & 20.00 & 6 & 1.50 & 32 & 8.00 & 400 \\
\hline PntTnch10-fdf-a & -46 & 34 & 8.46 & 42 & 10.45 & 70 & 17.41 & 158 & 39.30 & 2 & 0.50 & 52 & 12.94 & 18 & 4.48 & 26 & 6.47 & 402 \\
\hline PntTnch10-m1_a & 50 & 46 & 12.71 & 58 & 16.02 & 50 & 13.81 & 138 & 38.12 & 2 & 0.55 & 16 & 4.42 & 38 & 10.50 & 14 & 3.87 & 362 \\
\hline PntTnch10-m1_b & 400 & 26 & 6.50 & 28 & 7.00 & 64 & 16.00 & 218 & 54.50 & 8 & 2.00 & 20 & 5.00 & 10 & 2.50 & 26 & 6.50 & 400 \\
\hline PntTnch10-m1_c & 750 & 36 & 9.00 & 30 & 7.50 & 72 & 18.00 & 158 & 39.50 & 16 & 4.00 & 20 & 5.00 & 24 & 6.00 & 44 & 11.00 & 400 \\
\hline PntTnch10-m1_d & 1100 & 60 & 14.49 & 18 & 4.35 & 100 & 24.15 & 138 & 33.33 & 4 & 0.97 & 40 & 9.66 & 36 & 8.70 & 18 & 4.35 & 414 \\
\hline PntTnch10-m1_e & 1450 & 80 & 20.00 & 94 & 23.50 & 44 & 11.00 & 148 & 37.00 & 2 & 0.50 & 2 & 0.50 & 16 & 4.00 & 14 & 3.50 & 400 \\
\hline PntBrv10-t2_bb-a & -13.5 & 89 & 22.14 & 30 & 7.46 & 54 & 13.43 & 175 & 43.53 & 5 & 1.24 & 24 & 5.97 & 5 & 1.24 & 20 & 4.98 & 402 \\
\hline PntBrv10-t2_bd-a & -37 & 72 & 18.00 & 60 & 15.00 & 44 & 11.00 & 140 & 35.00 & 4 & 1.00 & 44 & 11.00 & 10 & 2.50 & 26 & 6.50 & 400 \\
\hline PntBrv10-m1_a & 50 & 64 & 16.00 & 64 & 16.00 & 36 & 9.00 & 158 & 39.50 & 4 & 1.00 & 8 & 2.00 & 24 & 6.00 & 42 & 10.50 & 400 \\
\hline PntBrv10-m1_b & 300 & 48 & 12.00 & 54 & 13.50 & 46 & 11.50 & 184 & 46.00 & 0 & 0.00 & 2 & 0.50 & 64 & 16.00 & 2 & 0.50 & 400 \\
\hline PntBrv10-m1_c & 550 & 70 & 17.50 & 116 & 29.00 & 34 & 8.50 & 138 & 34.50 & 0 & 0.00 & 16 & 4.00 & 20 & 5.00 & 6 & 1.50 & 400 \\
\hline
\end{tabular}




\section{Barrier Subsurface}

\begin{tabular}{|c|c|c|c|c|c|c|c|c|c|c|c|c|c|c|c|c|c|c|}
\hline Sample & Depth (m) & Coral & $\%$ & $\begin{array}{c}\text { Coralline } \\
\text { algae }\end{array}$ & $\%$ & Mollusc & $\%$ & Halimeda & $\%$ & Echinoid & $\%$ & Micrite & $\%$ & Miscellaneous & $\%$ & Foraminifera & $\%$ & Total count \\
\hline WnW10-t1_bf-a & 0 & 0 & 7.94 & 34 & 8.44 & 44 & 10.92 & 195 & 48.39 & 9 & 2.23 & 37 & 9.18 & 15 & 3.72 & 37 & 9.18 & 403 \\
\hline WnW10-t1_bf-b & 0.05 & 32 & 7.73 & 48 & 11.59 & 62 & 14.98 & 172 & 41.55 & 8 & 1.93 & 62 & 14.98 & 10 & 2.42 & 20 & 4.83 & 414 \\
\hline WnW10-t1_bf-c & 0.09 & 25 & 6.05 & 45 & 10.90 & 80 & 19.37 & 192 & 46.49 & 0 & 0.00 & 32 & 7.75 & 14 & 3.39 & 25 & 6.05 & 413 \\
\hline WnW10-t1_bf-d & 0.11 & 34 & 8.25 & 73 & 17.72 & 54 & 13.11 & 166 & 40.29 & 0 & 0.00 & 40 & 9.71 & 17 & 4.13 & 28 & 6.80 & 412 \\
\hline WnW10-t1_bf-e & 0.13 & 39 & 9.75 & 48 & 12.00 & 40 & 10.00 & 179 & 44.75 & 4 & 1.00 & 45 & 11.25 & 15 & 3.75 & 30 & 7.50 & 400 \\
\hline WnW10-t1_bf-f & 0.24 & 52 & 12.71 & 92 & 22.49 & 38 & 9.29 & 154 & 37.65 & 0 & 0.00 & 47 & 11.49 & 14 & 3.42 & 12 & 2.93 & 409 \\
\hline WnW10-t1_bf-g & 0.44 & 62 & 15.74 & 74 & 18.78 & 32 & 8.12 & 150 & 38.07 & 0 & 0.00 & 36 & 9.14 & 22 & 5.58 & 18 & 4.57 & 394 \\
\hline WnW10-t1_fdf-a & 0 & 27 & 6.65 & 49 & 12.07 & 62 & 15.27 & 170 & 41.87 & 5 & 1.23 & 45 & 11.08 & 12 & 2.96 & 36 & 8.87 & 406 \\
\hline WnW10-t1_fdf-b & 0.07 & 45 & 10.92 & 51 & 12.38 & 47 & 11.41 & 210 & 50.97 & 1 & 0.24 & 29 & 7.04 & 8 & 1.94 & 21 & 5.10 & 412 \\
\hline WnW10-t1_fdf-c & 0.135 & 32 & 7.44 & 61 & 14.19 & 48 & 11.16 & 185 & 43.02 & 2 & 0.47 & 57 & 13.26 & 2 & 0.47 & 43 & 10.00 & 430 \\
\hline WnW10-t1_fdf-d & 0.26 & 50 & 11.96 & 90 & 21.53 & 32 & 7.66 & 170 & 40.67 & 2 & 0.48 & 38 & 9.09 & 16 & 3.83 & 20 & 4.78 & 418 \\
\hline WnW10-t1_fdf-e & 0.39 & 58 & 17.26 & 38 & 11.31 & 18 & 5.36 & 147 & 43.75 & 2 & 0.60 & 45 & 13.39 & 4 & 1.19 & 24 & 7.14 & 336 \\
\hline WnW10-t1_fdf-f & 0.455 & 40 & 11.08 & 25 & 6.93 & 22 & 6.09 & 145 & 40.17 & 2 & 0.55 & 79 & 21.88 & 6 & 1.66 & 42 & 11.63 & 361 \\
\hline WnW10-t1_bd-a & 0 & 44 & 11.43 & 46 & 11.95 & 32 & 8.31 & 160 & 41.56 & 4 & 1.04 & 77 & 20.00 & 12 & 3.12 & 10 & 2.60 & 385 \\
\hline WnW10-t1_bd-b & 0.1 & 56 & 14.00 & 50 & 12.50 & 38 & 9.50 & 144 & 36.00 & 0 & 0.00 & 70 & 17.50 & 24 & 6.00 & 18 & 4.50 & 400 \\
\hline WnW10-t1_bd-c & 0.2 & 60 & 15.00 & 52 & 13.00 & 18 & 4.50 & 148 & 37.00 & 4 & 1.00 & 78 & 19.50 & 22 & 5.50 & 18 & 4.50 & 400 \\
\hline WnW10-t1_bd-d & 0.3 & 52 & 13.00 & 80 & 20.00 & 18 & 4.50 & 152 & 38.00 & 4 & 1.00 & 36 & 9.00 & 42 & 10.50 & 16 & 4.00 & 400 \\
\hline WnW10-t1_bd-e & 0.4 & 48 & 12.12 & 58 & 14.65 & 46 & 11.62 & 146 & 36.87 & 4 & 1.01 & 58 & 14.65 & 24 & 6.06 & 12 & 3.03 & 396 \\
\hline WnW10-t1_bd-f & 0.49 & 48 & 11.85 & 72 & 17.78 & 24 & 5.93 & 145 & 35.80 & 0 & 0.00 & 68 & 16.79 & 40 & 9.88 & 8 & 1.98 & 405 \\
\hline WnW10-t1_bd-g & 0.5 & 38 & 9.50 & 50 & 12.50 & 54 & 13.50 & 164 & 41.00 & 6 & 1.50 & 34 & 8.50 & 40 & 10.00 & 14 & 3.50 & 400 \\
\hline PntTnch10-bf-a & 0 & 42 & 10.50 & 26 & 6.50 & 30 & 7.50 & 180 & 45.00 & 4 & 1.00 & 80 & 20.00 & 6 & 1.50 & 32 & 8.00 & 400 \\
\hline PntTnch10-bf-b & 0.15 & 62 & 15.50 & 22 & 5.50 & 52 & 13.00 & 138 & 34.50 & 2 & 0.50 & 66 & 16.50 & 10 & 2.50 & 48 & 12.00 & 400 \\
\hline PntTnch10-bf-c & 0.3 & 50 & 12.38 & 22 & 5.45 & 34 & 8.42 & 149 & 36.88 & 6 & 1.49 & 94 & 23.27 & 3 & 0.74 & 46 & 11.39 & 404 \\
\hline PntTnch10-bf-d & 0.45 & 54 & 13.50 & 22 & 5.50 & 22 & 5.50 & 156 & 39.00 & 2 & 0.50 & 100 & 25.00 & 2 & 0.50 & 42 & 10.50 & 400 \\
\hline PntTnch10-bf-e & 0.6 & 48 & 12.06 & 28 & 7.04 & 22 & 5.53 & 124 & 31.16 & 0 & 0.00 & 140 & 35.18 & 0 & 0.00 & 36 & 9.05 & 398 \\
\hline PntTnch10-bf-f & 0.75 & 44 & 11.00 & 28 & 7.00 & 36 & 9.00 & 160 & 40.00 & 4 & 1.00 & 88 & 22.00 & 6 & 1.50 & 34 & 8.50 & 400 \\
\hline PntTnch10-fdf-a & 0 & 34 & 8.46 & 42 & 10.45 & 70 & 17.41 & 158 & 39.30 & 2 & 0.50 & 52 & 12.94 & 18 & 4.48 & 26 & 6.47 & 402 \\
\hline PntTnch10-fdf-b & 0.15 & 58 & 14.50 & 46 & 11.50 & 32 & 8.00 & 154 & 38.50 & 2 & 0.50 & 76 & 19.00 & 2 & 0.50 & 30 & 7.50 & 400 \\
\hline PntTnch10-fdf-c & 0.22 & 46 & 11.50 & 28 & 7.00 & 38 & 9.50 & 168 & 42.00 & 4 & 1.00 & 94 & 23.50 & 2 & 0.50 & 20 & 5.00 & 400 \\
\hline PntTnch10-fdf-d & 0.3 & 54 & 13.50 & 12 & 3.00 & 32 & 8.00 & 140 & 35.00 & 4 & 1.00 & 126 & 31.50 & 0 & 0.00 & 32 & 8.00 & 400 \\
\hline PntTnch10-fdf-e & 0.4 & 56 & 14.00 & 32 & 8.00 & 14 & 3.50 & 146 & 36.50 & 2 & 0.50 & 102 & 25.50 & 8 & 2.00 & 40 & 10.00 & 400 \\
\hline PntTnch10-fdf-f & 0.5 & 38 & 9.50 & 32 & 8.00 & 36 & 9.00 & 184 & 46.00 & 4 & 1.00 & 58 & 14.50 & 8 & 2.00 & 40 & 10.00 & 400 \\
\hline PntTnch10-fdf-g & 0.6 & 50 & 12.50 & 26 & 6.50 & 40 & 10.00 & 158 & 39.50 & 4 & 1.00 & 84 & 21.00 & 10 & 2.50 & 28 & 7.00 & 400 \\
\hline PntTnch10-fdf-h & 0.7 & 56 & 14.00 & 54 & 13.50 & 12 & 3.00 & 124 & 31.00 & 2 & 0.50 & 114 & 28.50 & 14 & 3.50 & 24 & 6.00 & 400 \\
\hline
\end{tabular}


2010 Barrier Subsurface

\begin{tabular}{|c|c|c|c|c|c|c|c|c|c|c|c|c|c|c|c|c|c|c|}
\hline Sample & Depth $(m)$ & Coral & $\%$ & $\begin{array}{c}\text { Coralline } \\
\text { algae }\end{array}$ & $\%$ & Mollusc & $\%$ & Halimeda & $\%$ & Echinoid & $\%$ & Micrite & $\%$ & Miscellaneous & $\%$ & Foraminifera & $\%$ & $\begin{array}{l}\text { Total } \\
\text { count }\end{array}$ \\
\hline PntBrv10-t2_bb-a & 0 & 89 & 22.14 & 30 & 7.46 & 54 & 13.43 & 175 & 43.53 & 5 & 1.24 & 24 & 5.97 & 5 & 1.24 & 20 & 4.98 & 402 \\
\hline PntBrv10-t2_bb-b & 0.11 & 117 & 29.18 & 48 & 11.97 & 38 & 9.48 & 160 & 39.90 & 0 & 0.00 & 11 & 2.74 & 14 & 3.49 & 13 & 3.24 & 401 \\
\hline PntBrv10-t2_bb-c & 0.22 & 70 & 18.52 & 22 & 5.82 & 53 & 14.02 & 166 & 43.92 & 7 & 1.85 & 26 & 6.88 & 11 & 2.91 & 23 & 6.08 & 378 \\
\hline PntBrv10-t2_bb-d & 0.25 & 79 & 20.47 & 31 & 8.03 & 36 & 9.33 & 203 & 52.59 & 3 & 0.78 & 13 & 3.37 & 10 & 2.59 & 11 & 2.85 & 386 \\
\hline PntBrv10-t2_bb-e & 0.27 & 81 & 19.85 & 61 & 14.95 & 38 & 9.31 & 168 & 41.18 & 10 & 2.45 & 17 & 4.17 & 7 & 1.72 & 26 & 6.37 & 408 \\
\hline PntBrv10-t2_bb-f & 0.36 & 118 & 29.50 & 43 & 10.75 & 36 & 9.00 & 135 & 33.75 & 3 & 0.75 & 35 & 8.75 & 5 & 1.25 & 25 & 6.25 & 400 \\
\hline PntBrv10-t2_bb-g & 0.46 & 111 & 27.75 & 25 & 6.25 & 42 & 10.50 & 165 & 41.25 & 2 & 0.50 & 26 & 6.50 & 9 & 2.25 & 20 & 5.00 & 400 \\
\hline PntBrv10-t2_bb-h & 0.56 & 83 & 20.75 & 69 & 17.25 & 62 & 15.50 & 133 & 33.25 & 4 & 1.00 & 23 & 5.75 & 13 & 3.25 & 13 & 3.25 & 400 \\
\hline PntBrv10-t2_bb-i & 0.71 & 93 & 23.25 & 61 & 15.25 & 52 & 13.00 & 141 & 35.25 & 0 & 0.00 & 23 & 5.75 & 7 & 1.75 & 23 & 5.75 & 400 \\
\hline PntBrv10-t2_bd-a & 0 & 72 & 18.00 & 60 & 15.00 & 44 & 11.00 & 140 & 35.00 & 4 & 1.00 & 44 & 11.00 & 10 & 2.50 & 26 & 6.50 & 400 \\
\hline PntBrv10-t2_bd-b & 0.05 & 120 & 30.00 & 54 & 13.50 & 60 & 15.00 & 106 & 26.50 & 2 & 0.50 & 32 & 8.00 & 12 & 3.00 & 14 & 3.50 & 400 \\
\hline PntBrv10-t2_bd-c & 0.15 & 100 & 25.00 & 52 & 13.00 & 48 & 12.00 & 148 & 37.00 & 4 & 1.00 & 24 & 6.00 & 2 & 0.50 & 22 & 5.50 & 400 \\
\hline PntBrv10-t2_bd-d & 0.25 & 108 & 27.00 & 58 & 14.50 & 46 & 11.50 & 130 & 32.50 & 6 & 1.50 & 18 & 4.50 & 18 & 4.50 & 16 & 4.00 & 400 \\
\hline PntBrv10-t2_bd-e & 0.4 & 82 & 20.50 & 66 & 16.50 & 60 & 15.00 & 136 & 34.00 & 0 & 0.00 & 34 & 8.50 & 2 & 0.50 & 20 & 5.00 & 400 \\
\hline PntBrv10-t2_bd-f & 0.55 & 126 & 31.50 & 68 & 17.00 & 32 & 8.00 & 130 & 32.50 & 2 & 0.50 & 22 & 5.50 & 4 & 1.00 & 16 & 4.00 & 400 \\
\hline
\end{tabular}




\subsection{Sediment component identification}




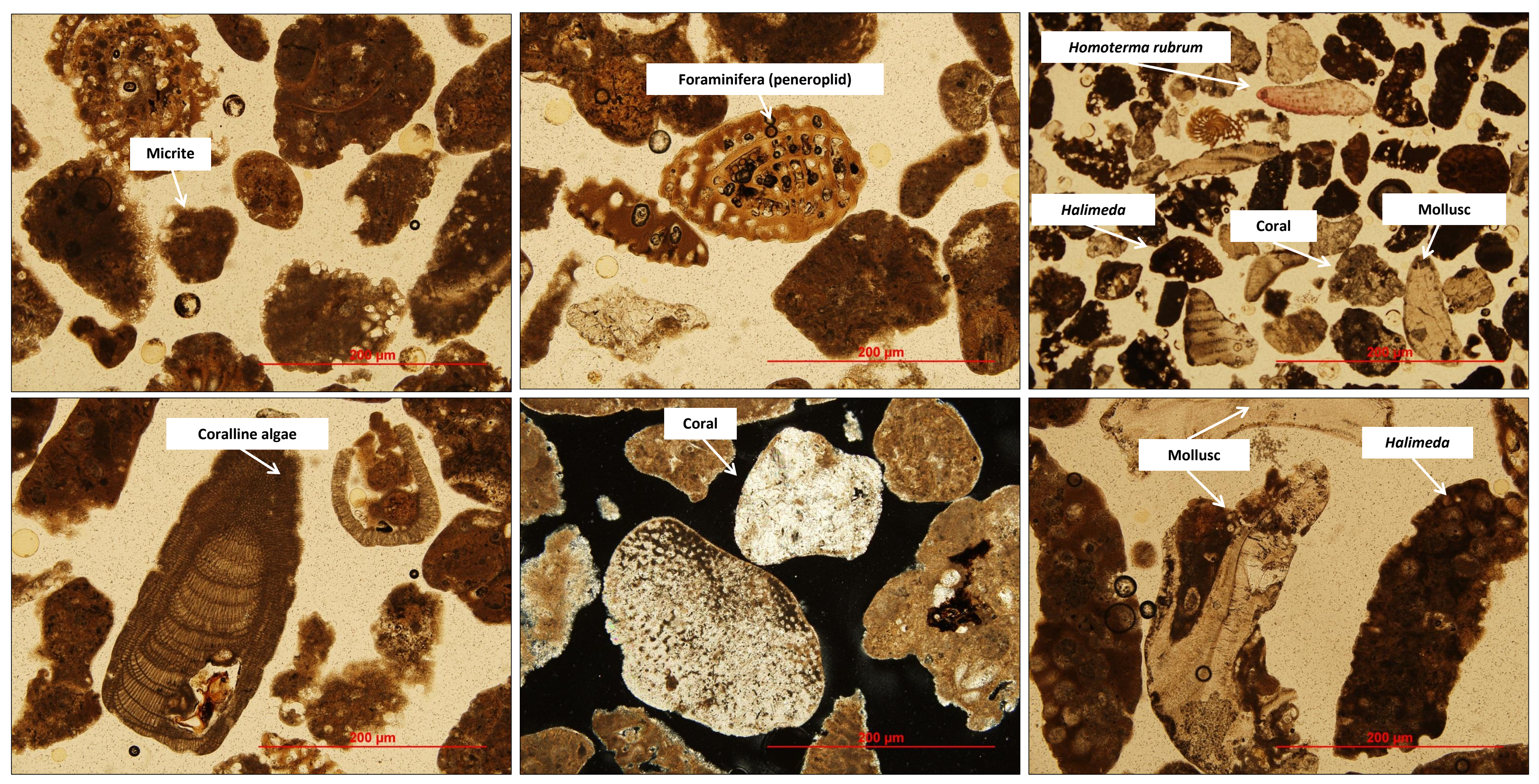

